
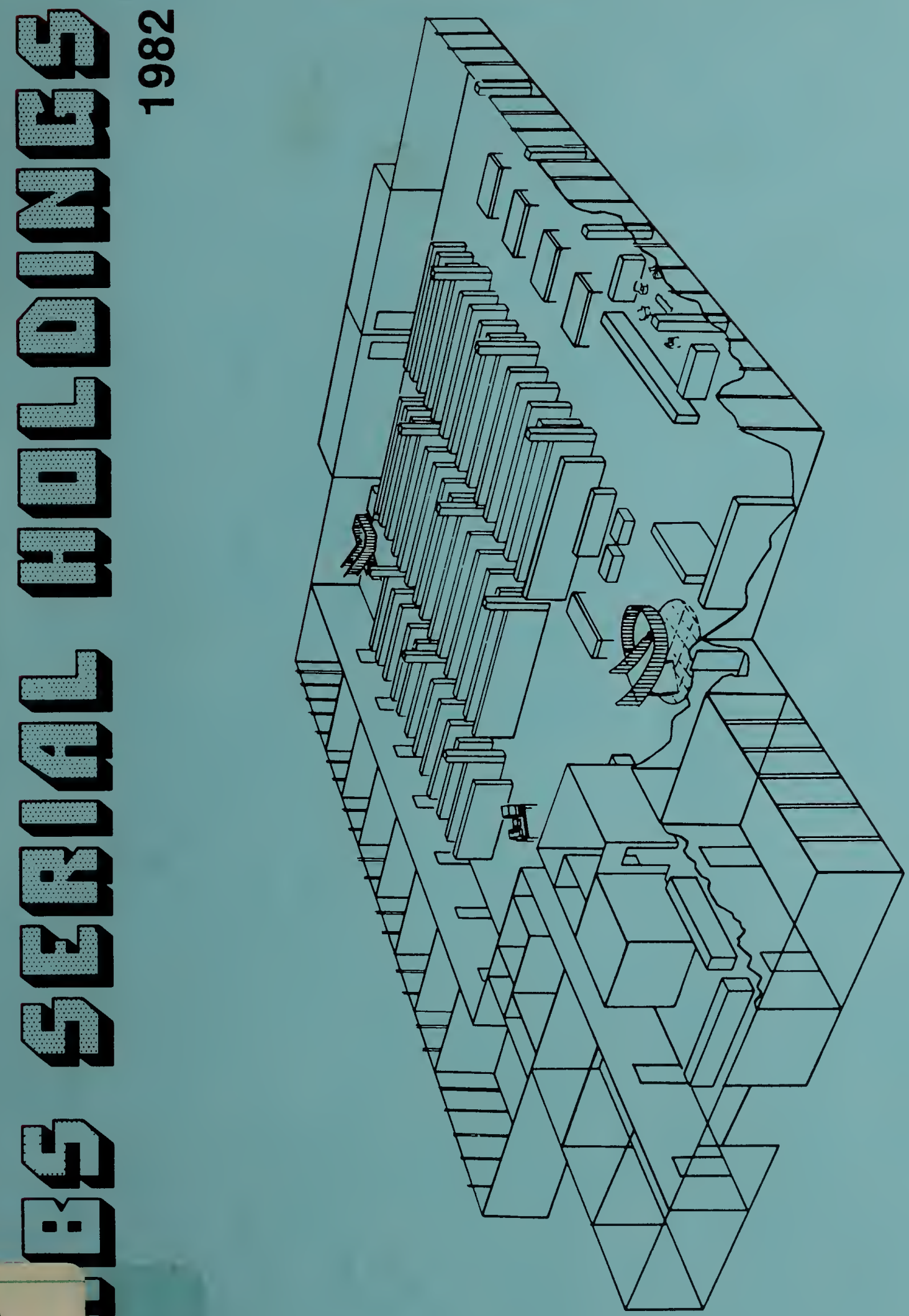

$\infty$
0
$\frac{1}{2}$
$\frac{1}{2}$
$\frac{1}{2}$
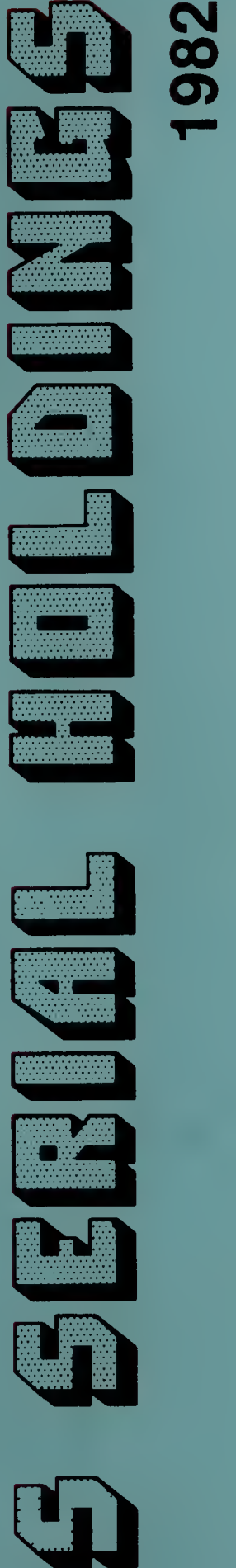

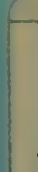

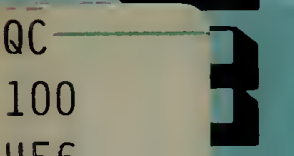

.456

82-2575 


\section{NBS SERIAL HOLDINGS 1982}

Mary Lynn Kingston

Chief Editor

Library Division

National Bureau of Standards

Washington, DC 20234

September 1982

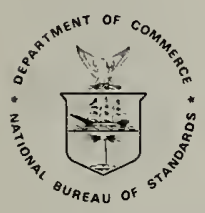

\section{U.S. DEPARTMENT OF COMMERCE}

NATIONAL BUREAU OF STANDARDS, Ernest Ambler 


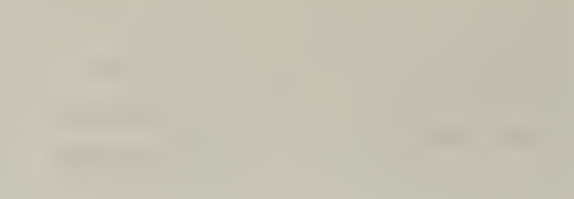




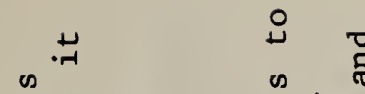

동요

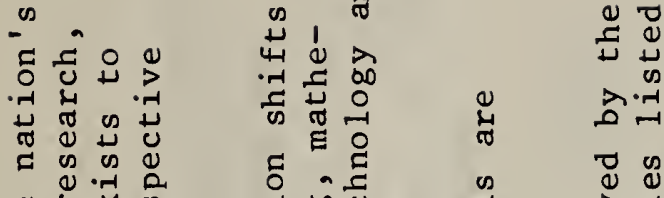

\& $x$ क

- I d D U

I ar

บ.

भु.

$\sum_{0}^{\infty}$

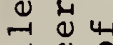

न1 0

ว

ช. $\overbrace{00}^{-10}$

के 요

㫕选

유 न्त है

岂

का

羿造

\& $\rightarrow-1$

को

ف

0.7

击愳嵒

पू 0 ठ

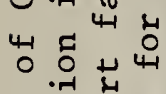

๑

岃岕号

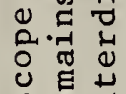

ष

तू के

का

离 ธี

ถิ․ㄷㄷำ

उप

봃

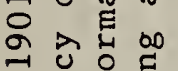

$00=-1$

.

- ${ }_{-1}^{1}$ O

व

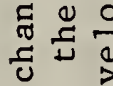

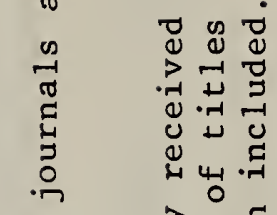

8 至

क्ष

N

$\overbrace{}^{2}$

元 点

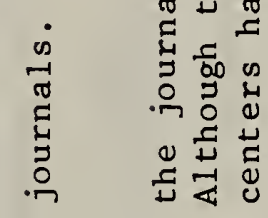

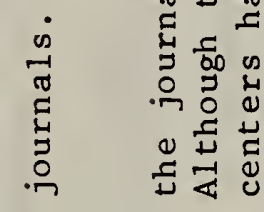

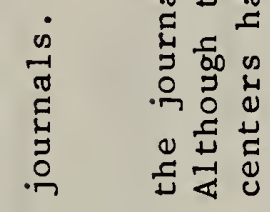

ป 용

可

4 ⿹

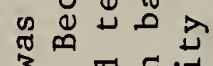

3 .

क

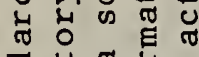

艺

तี

के

4

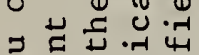

赵

记苋苍

氙艺过

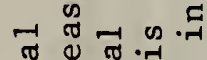

药

.-

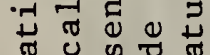

z

$0>0$

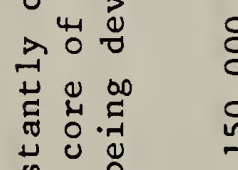

os

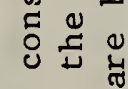

米 章

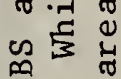

孚

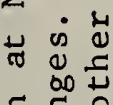

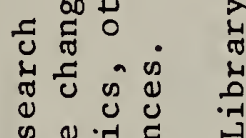

of 010

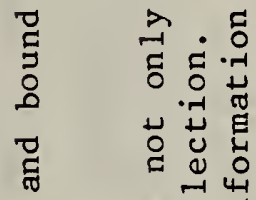

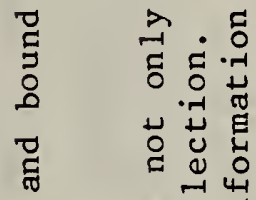

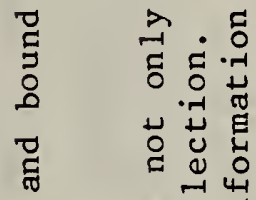

क స્-

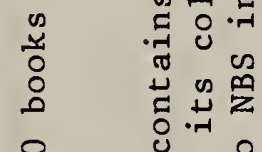

8 ग

每

क्त.

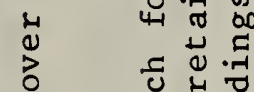

$4 \stackrel{2}{2}$

药

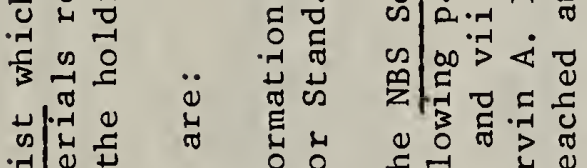

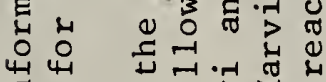

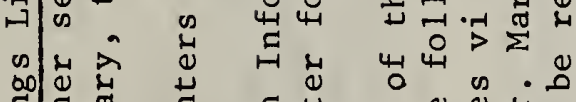

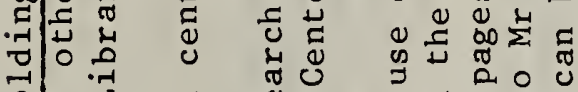

원에

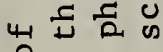

の

बี

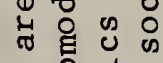

i

శ్

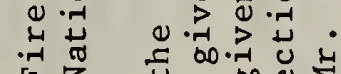

死茫

串

कात्र

(2)

乙悉

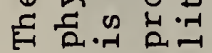

导 㫕

0

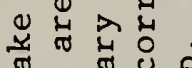

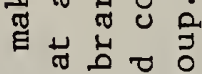

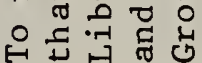

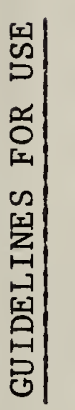

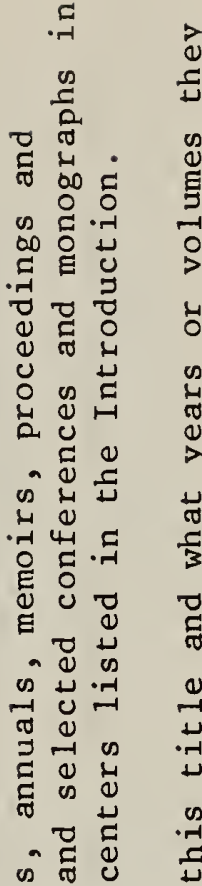

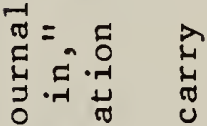

$\therefore$ क

की क⿱ 口)

का

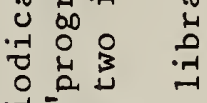

$\cdot=$

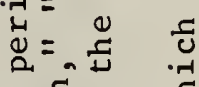

क. 告

चैं का

خे

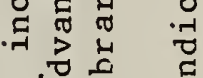

战告

武

-

$-10$

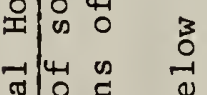

-

क गु क

点

留

元苛 


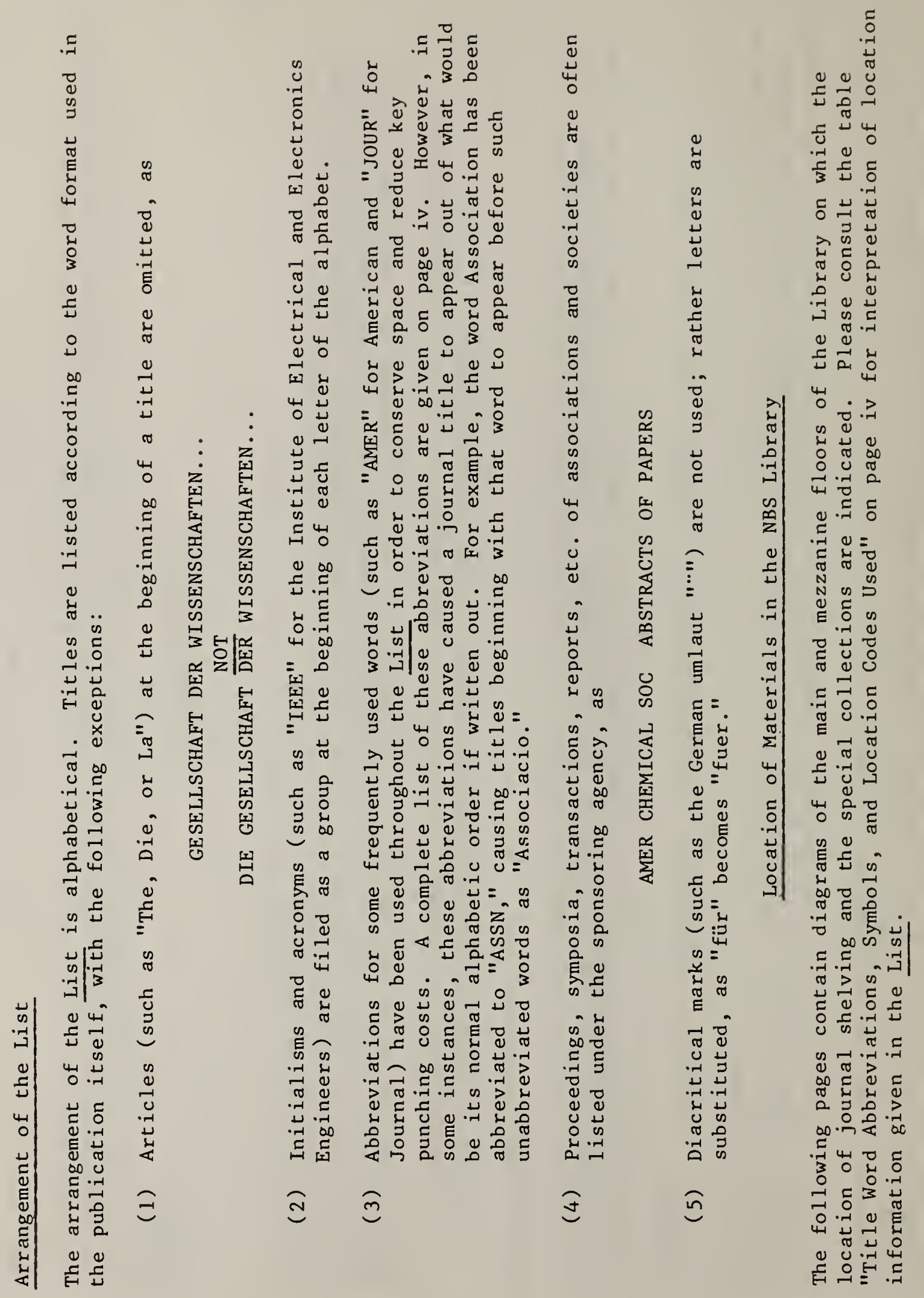




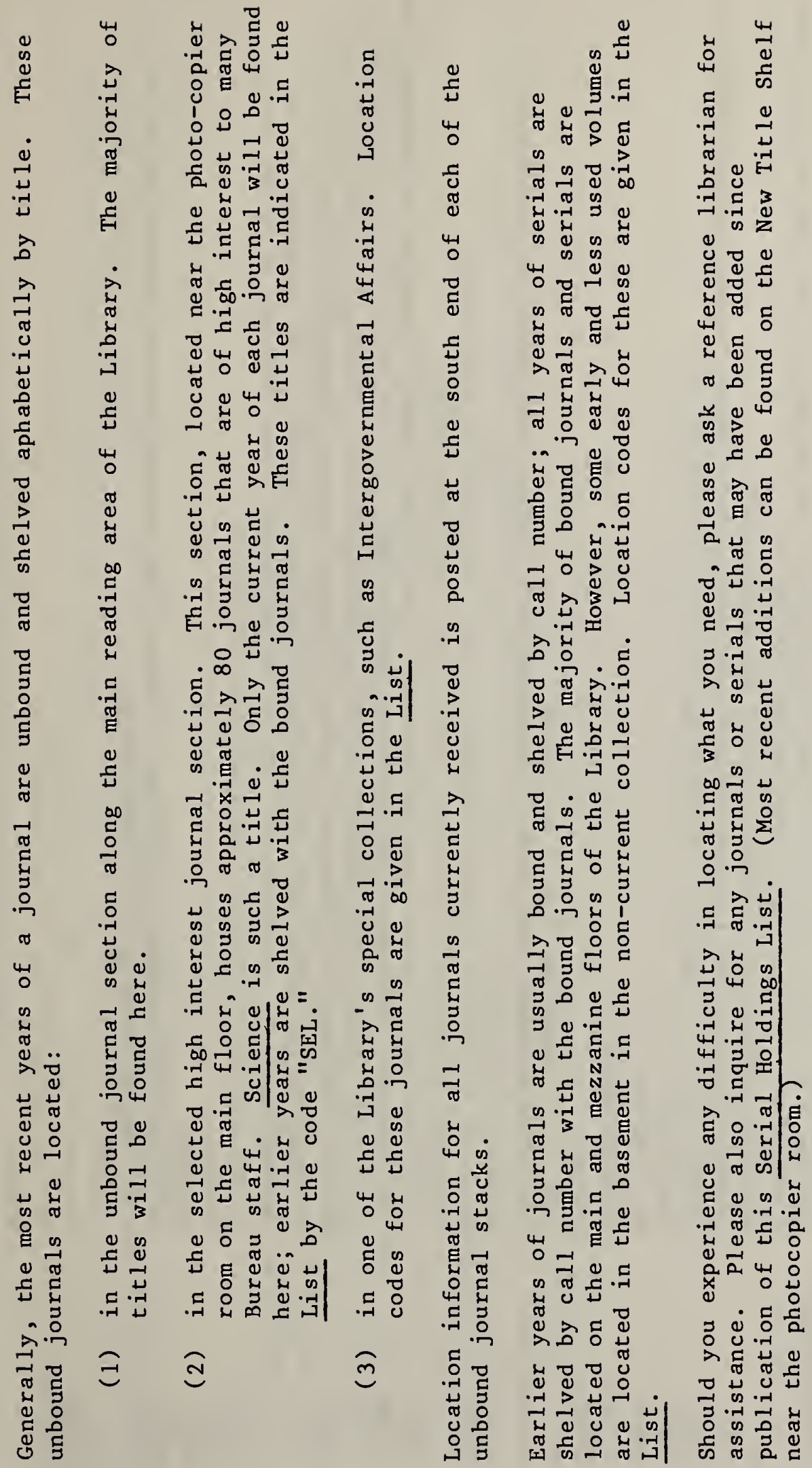




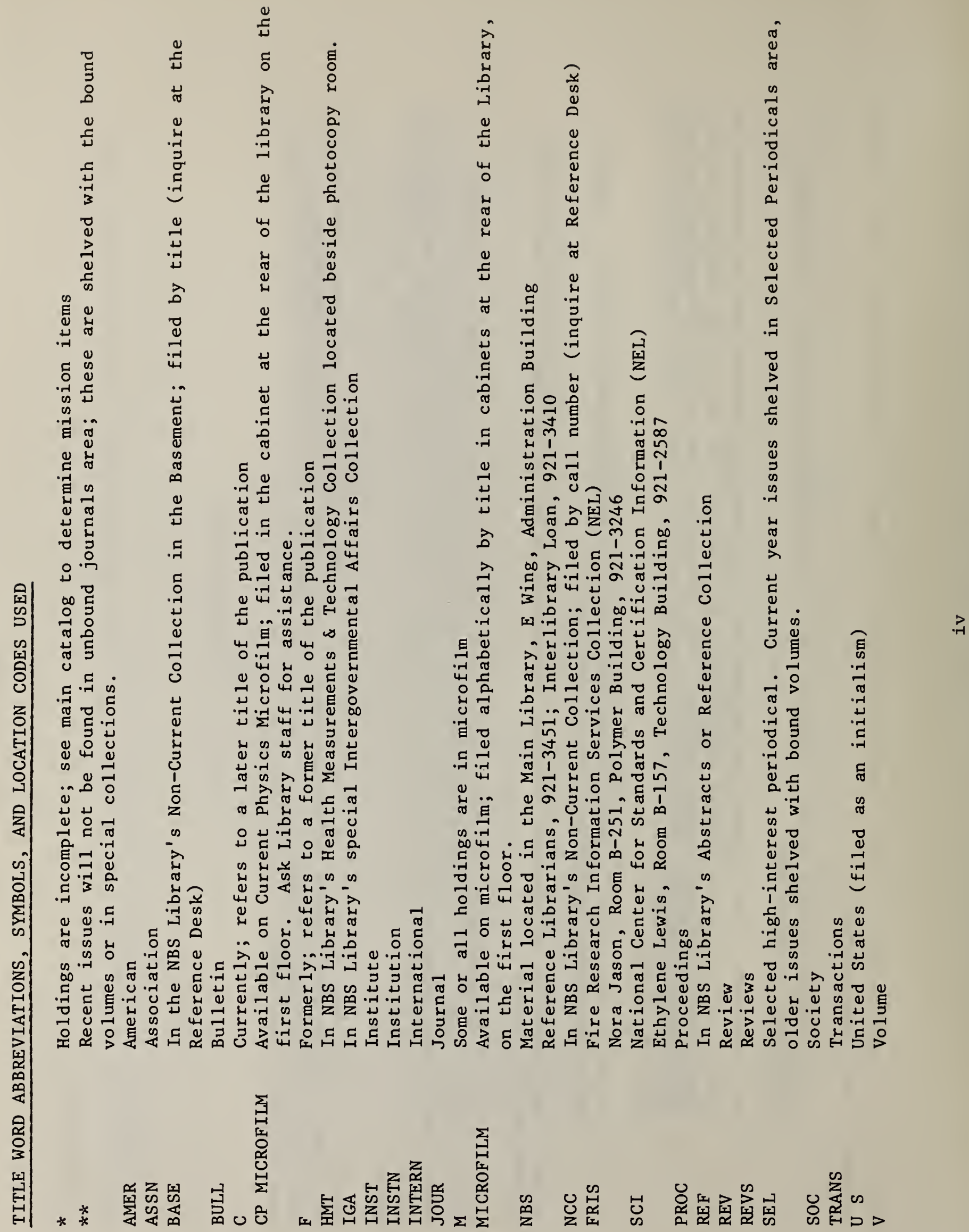




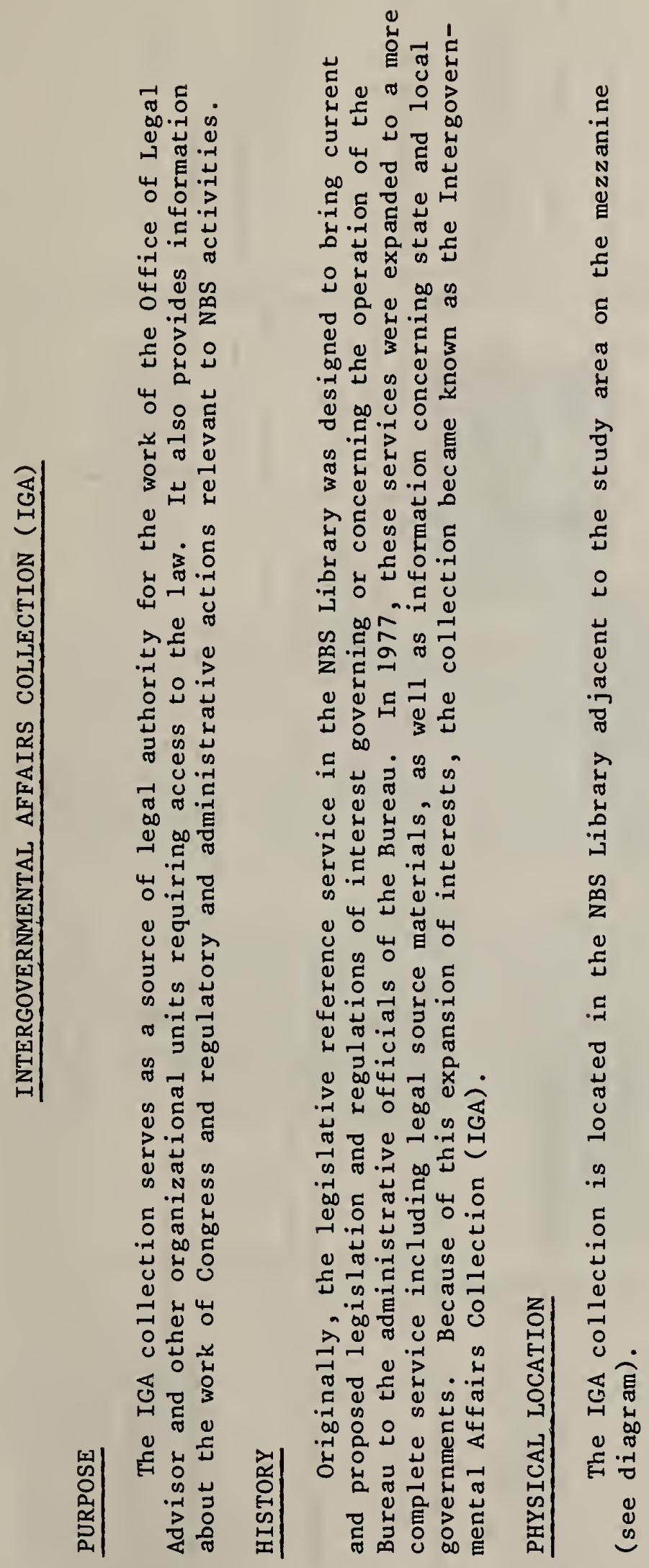




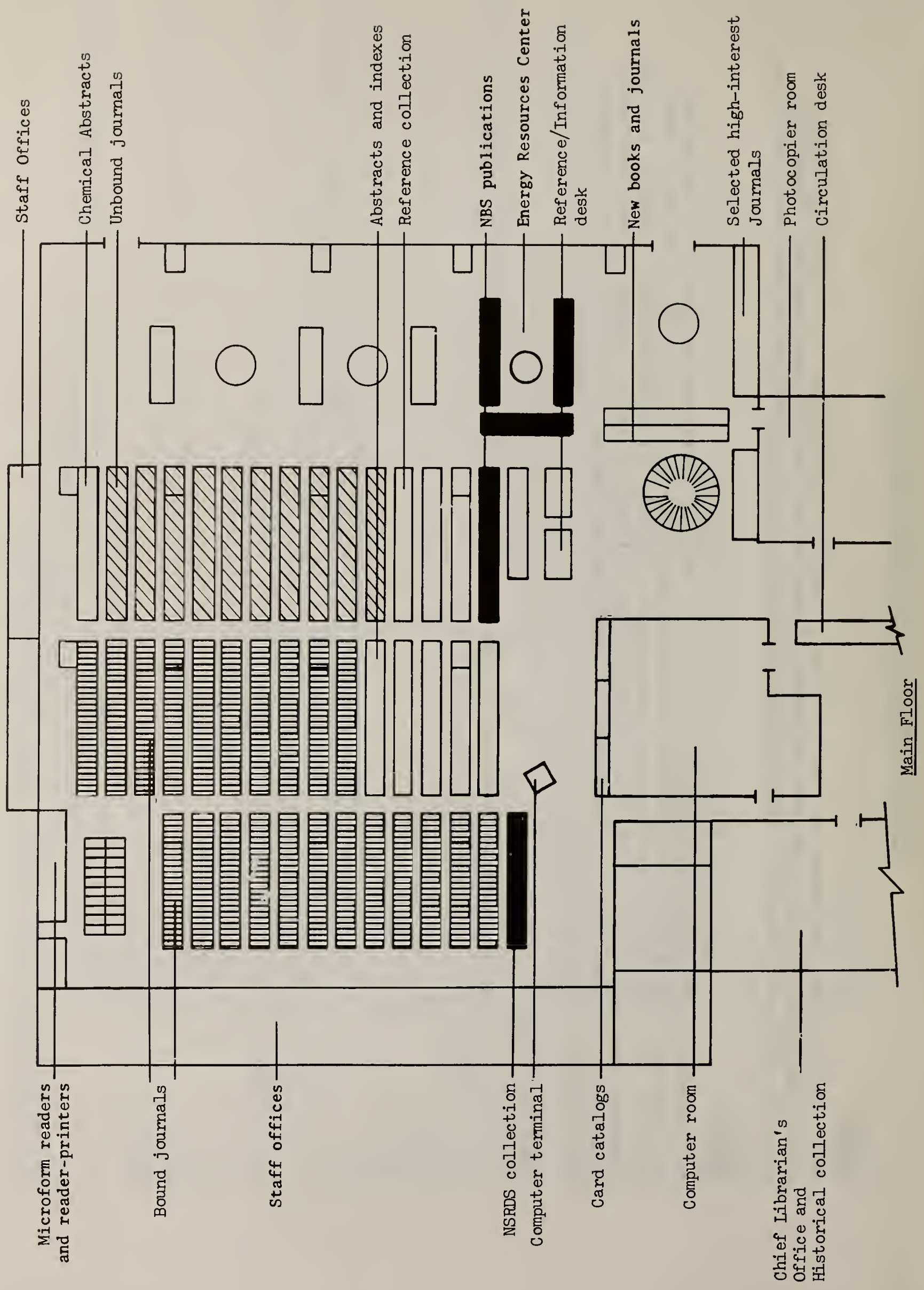




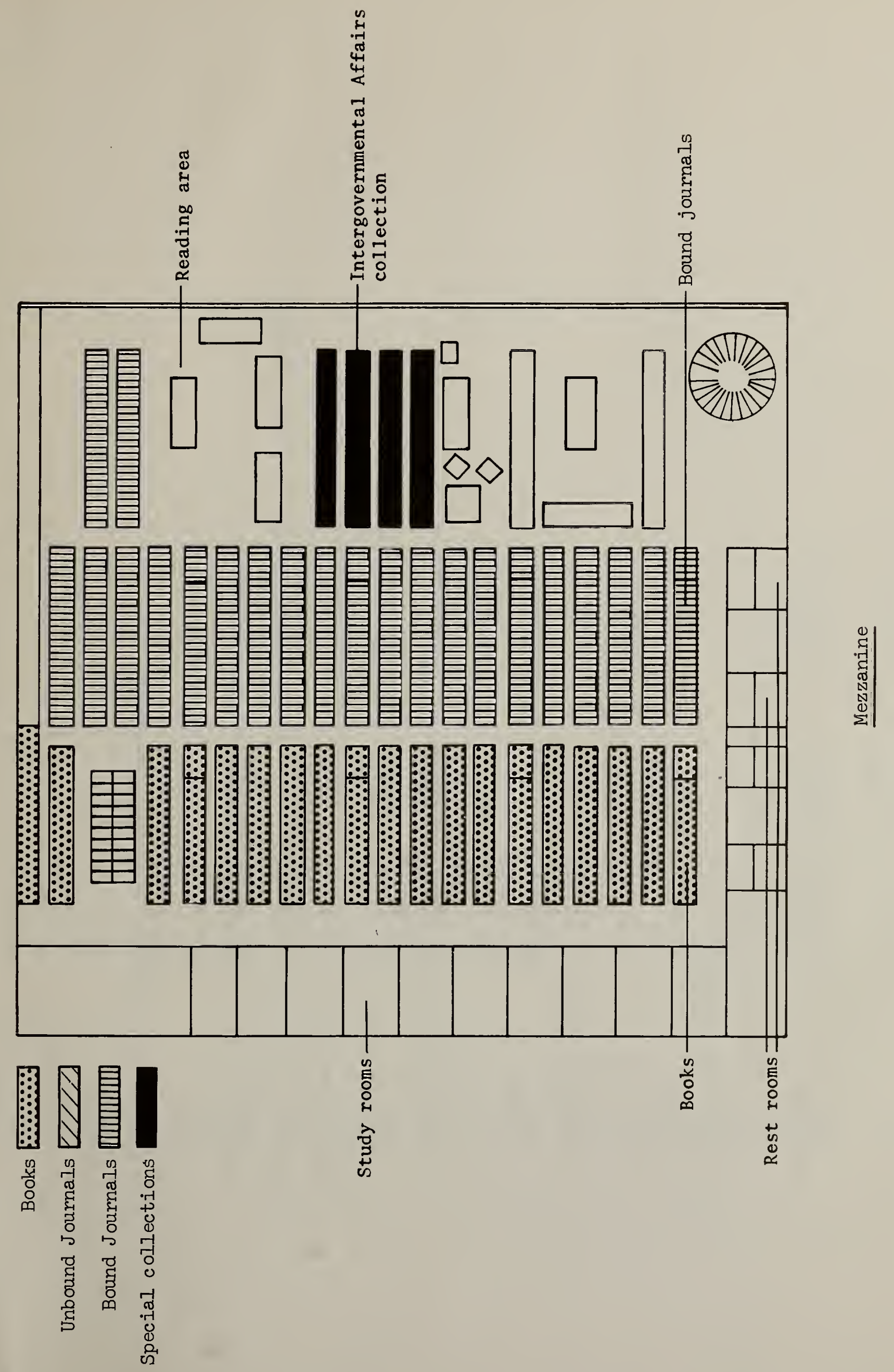





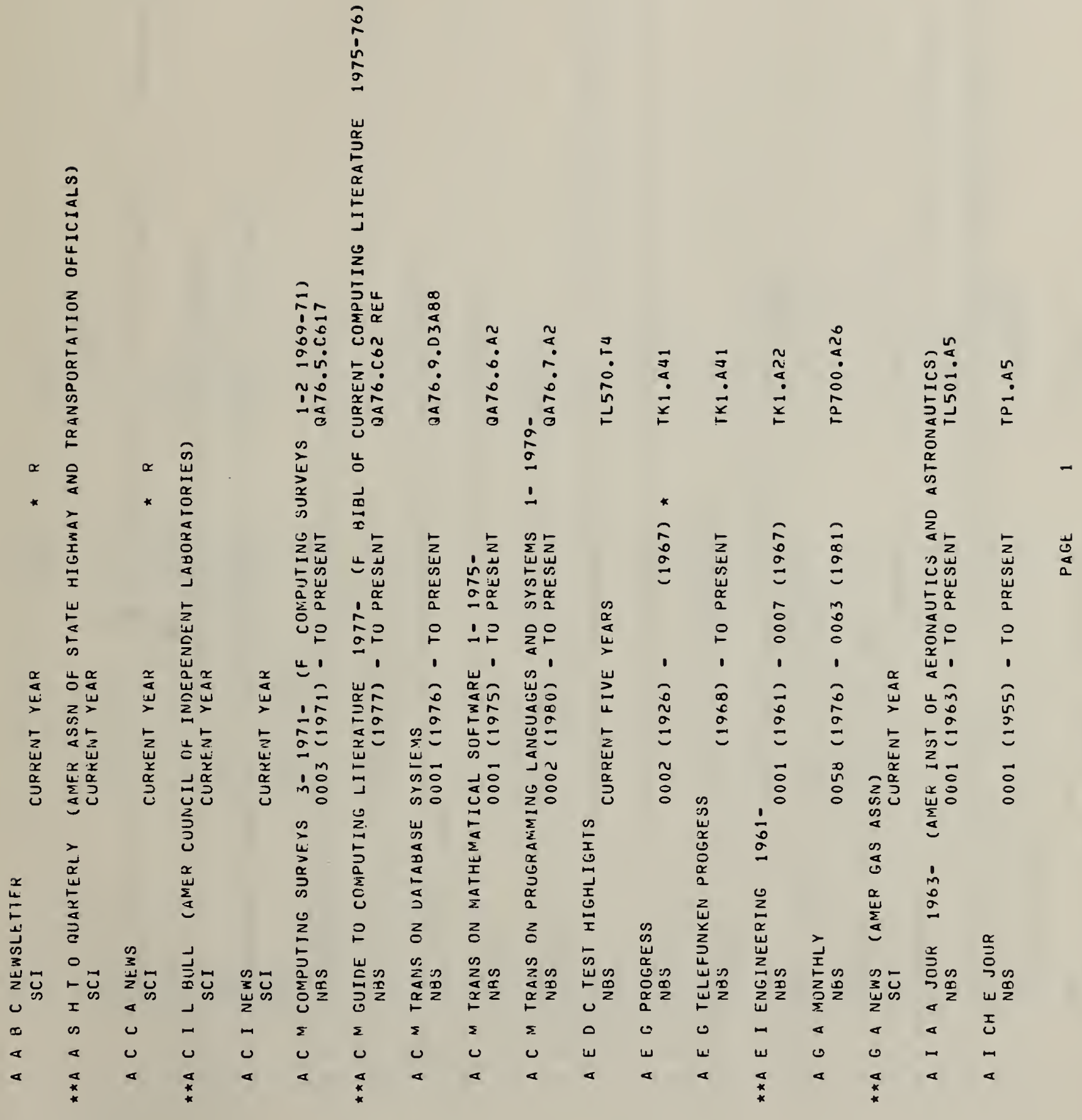




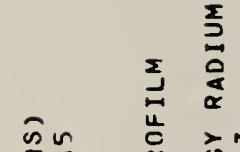

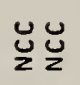

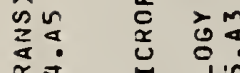

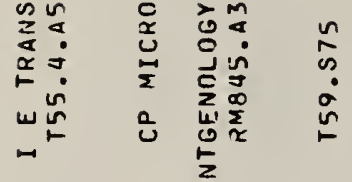

$\sim \quad \Sigma \sum_{\alpha}^{\infty}$

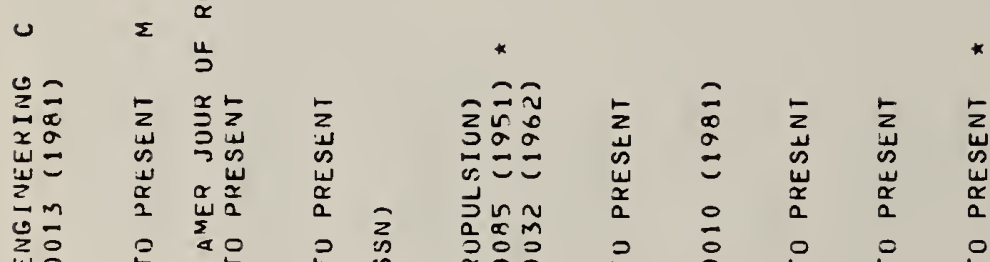

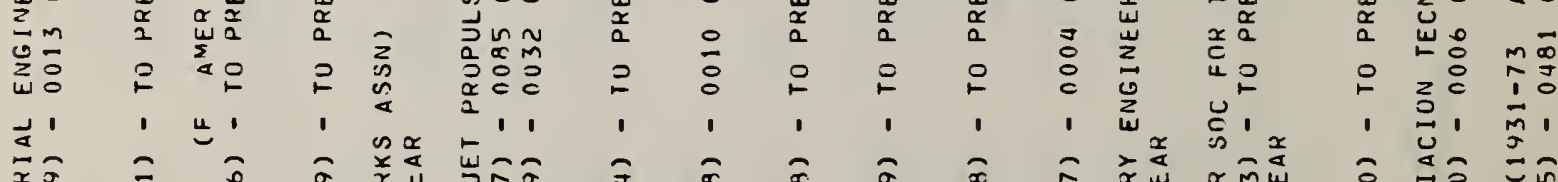

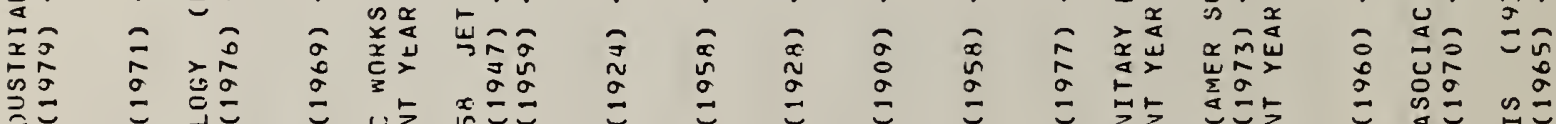

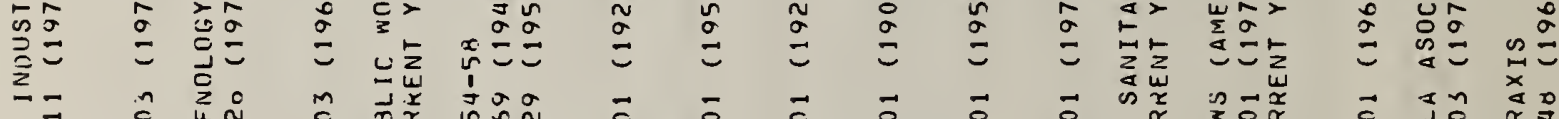

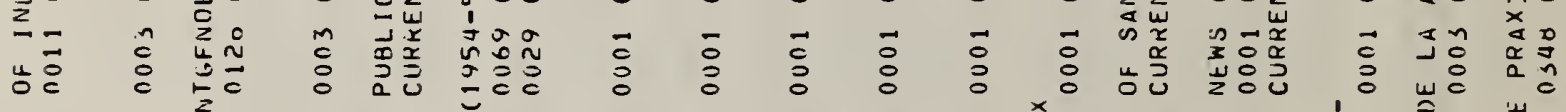

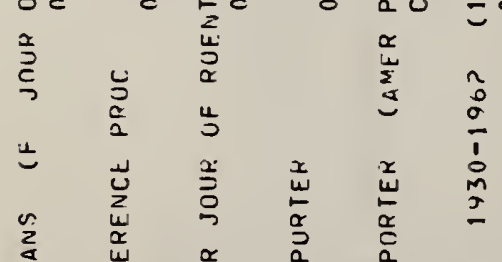

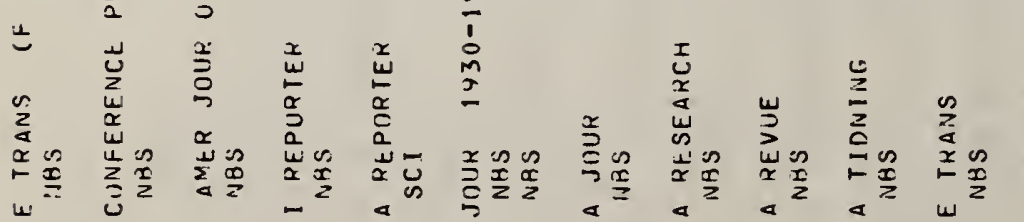

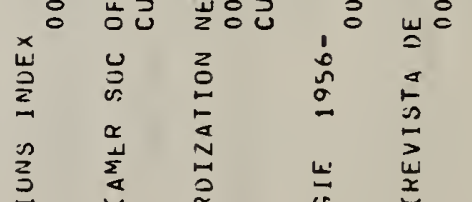

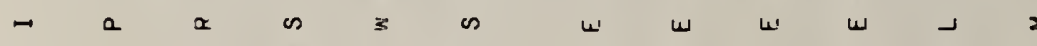

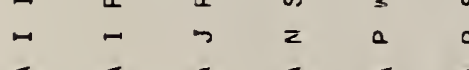

$4 \quad a \quad 4 \quad \frac{\pi}{*}$ 


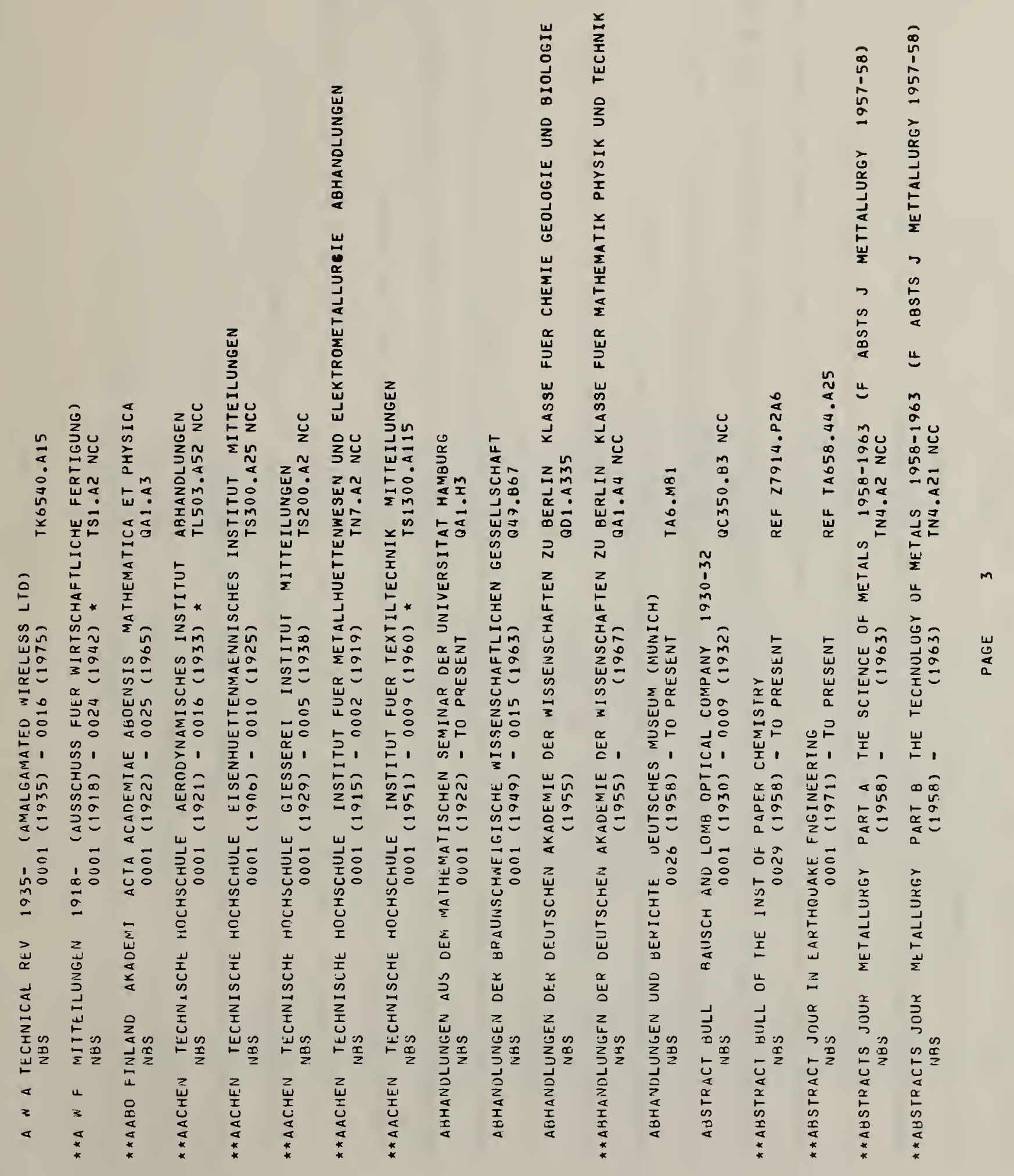




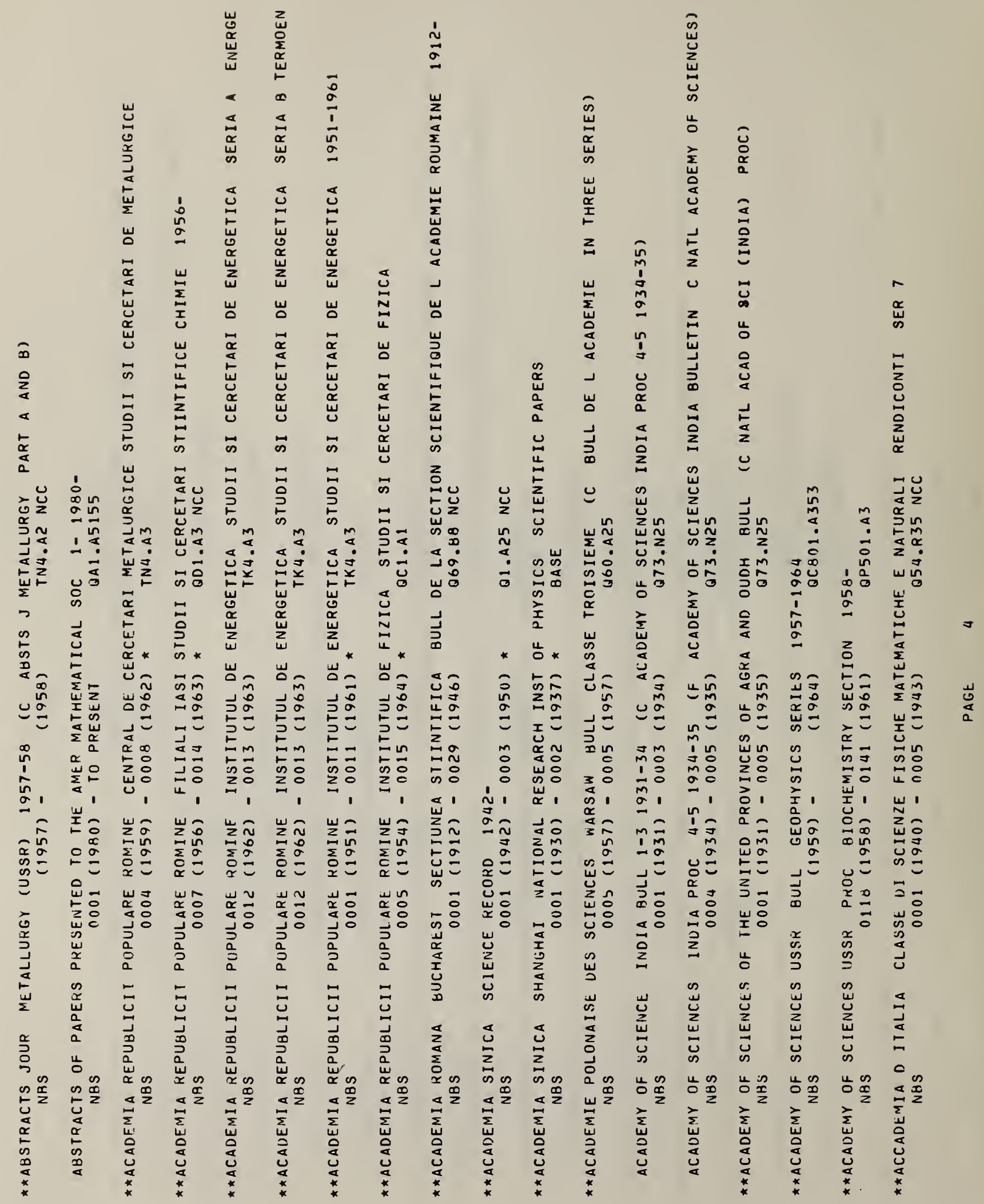




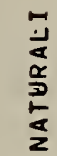

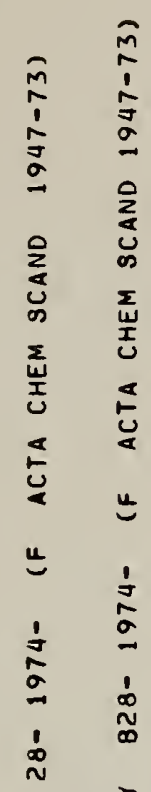

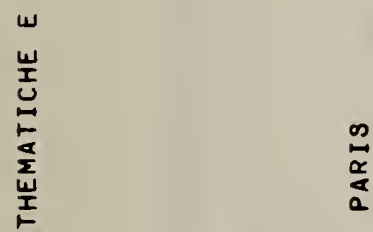

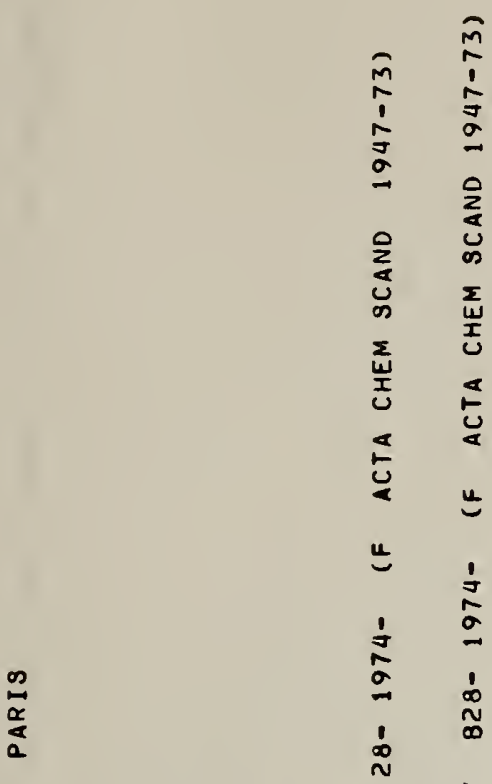

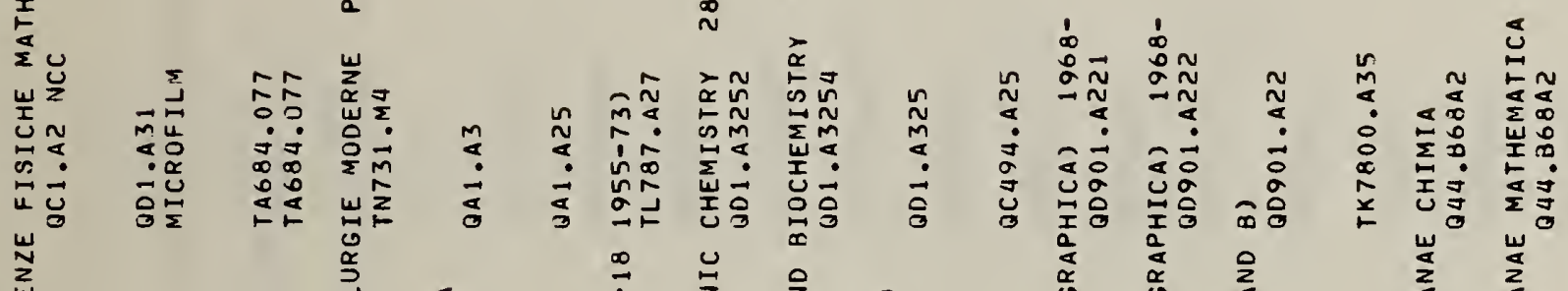

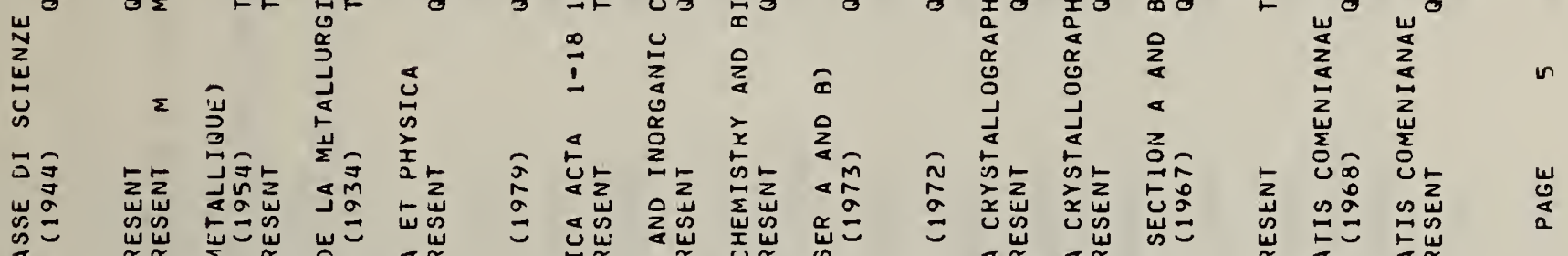

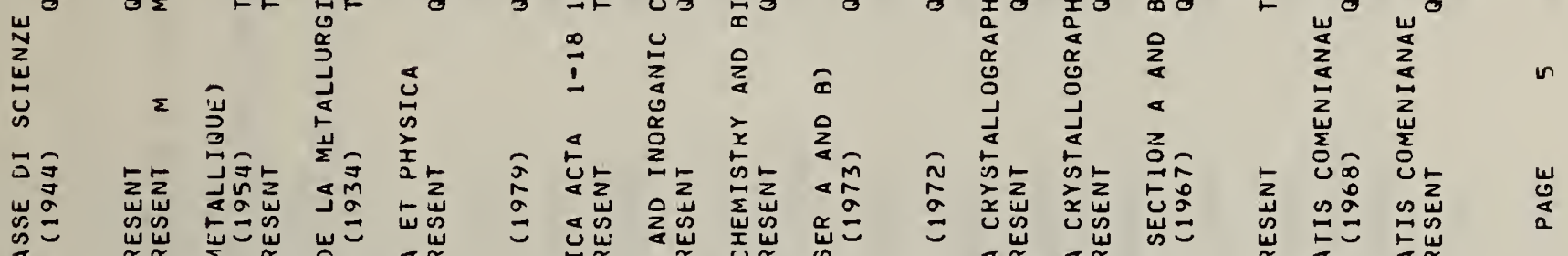

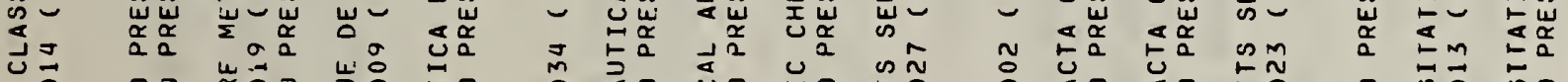

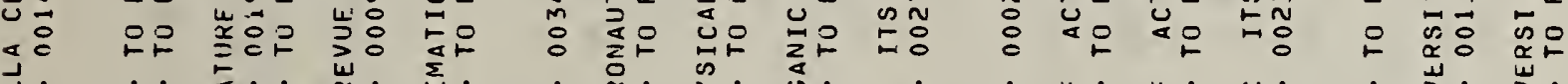

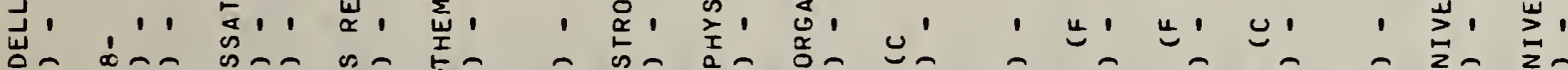

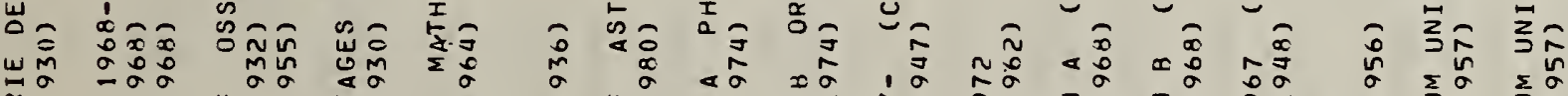

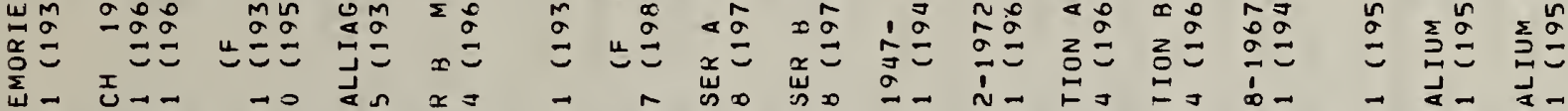

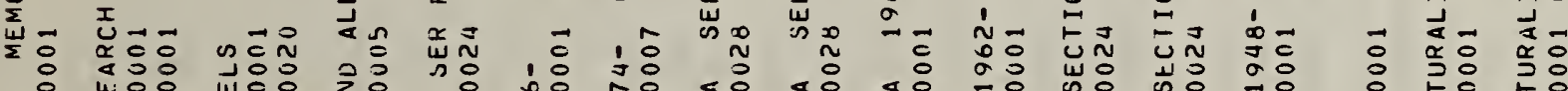

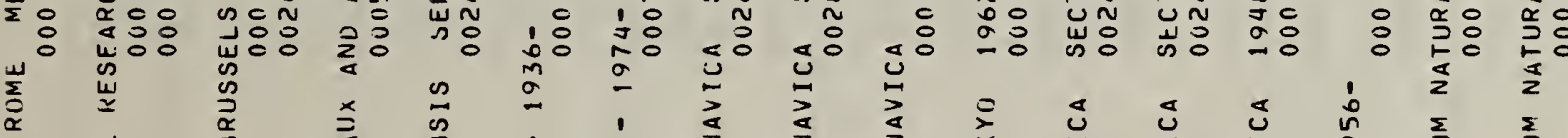

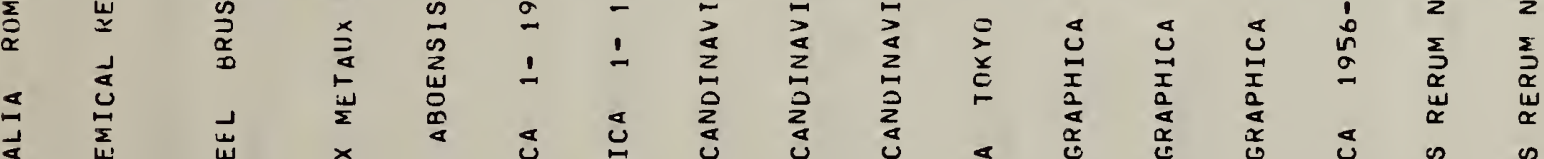

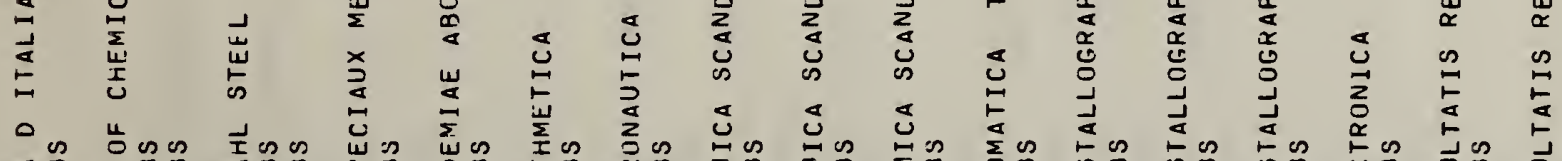

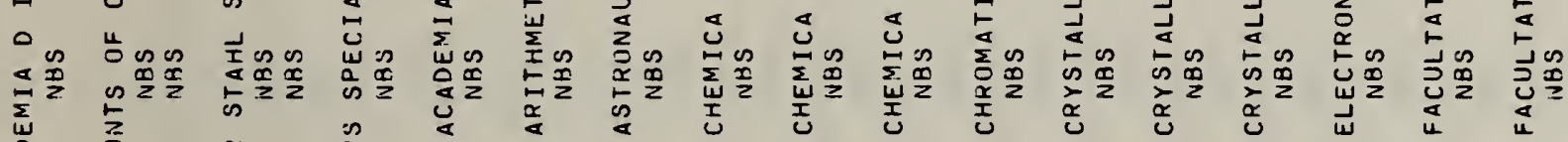

.

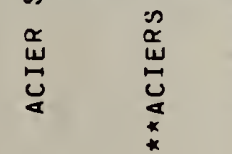

$\stackrel{5}{\leftrightarrows}$

๕๕ 


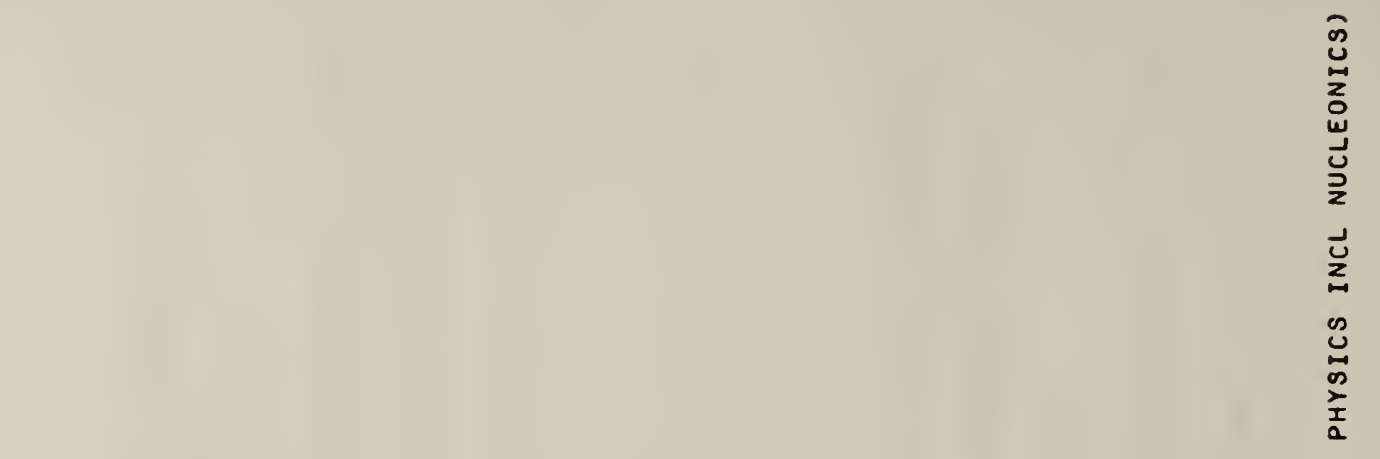

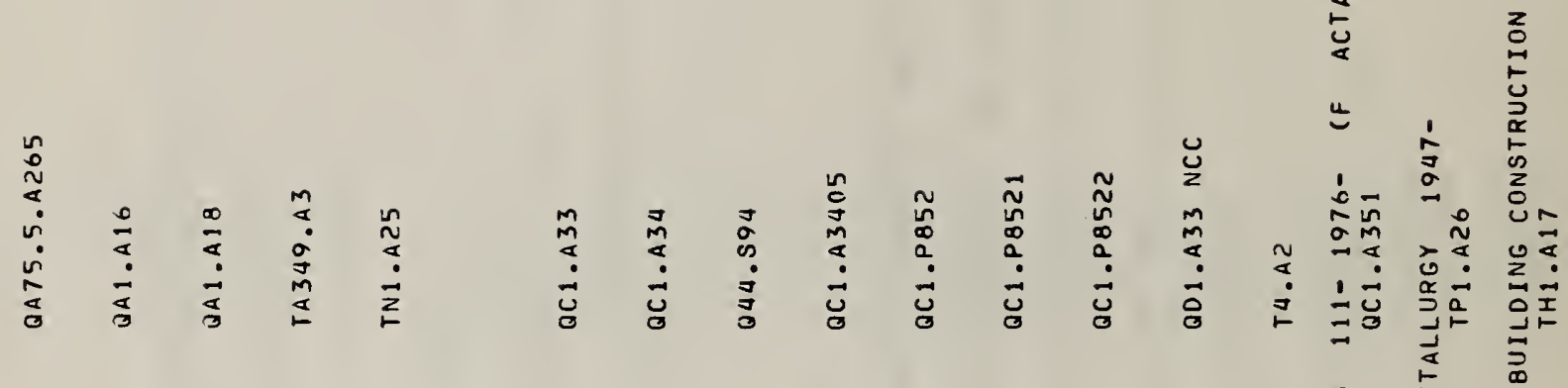

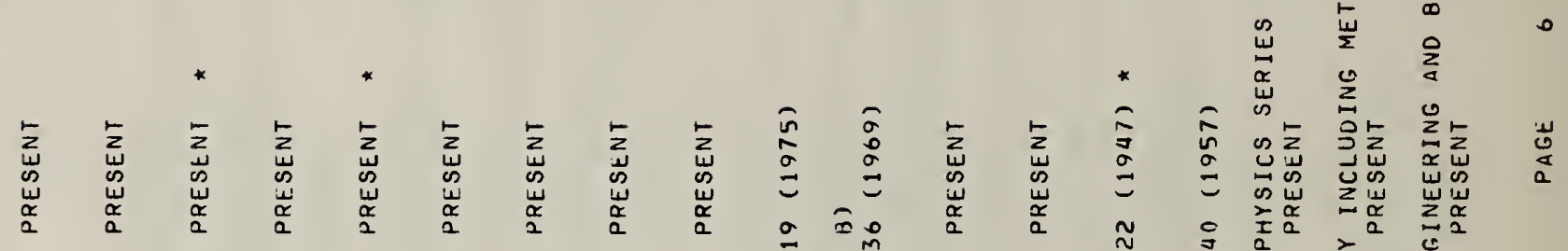

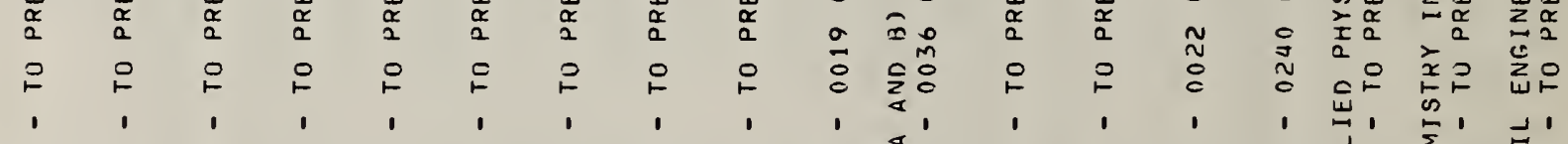

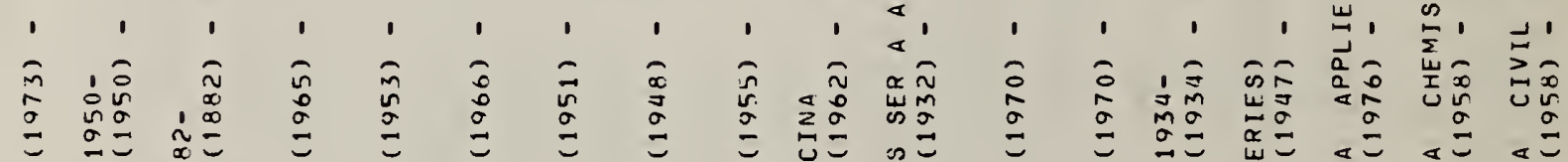

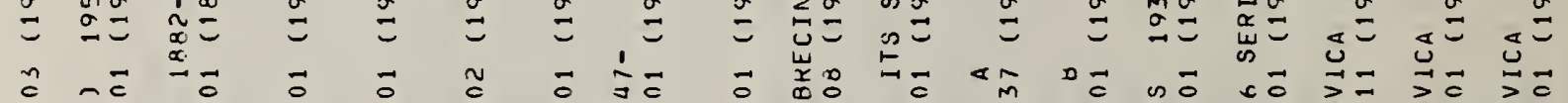

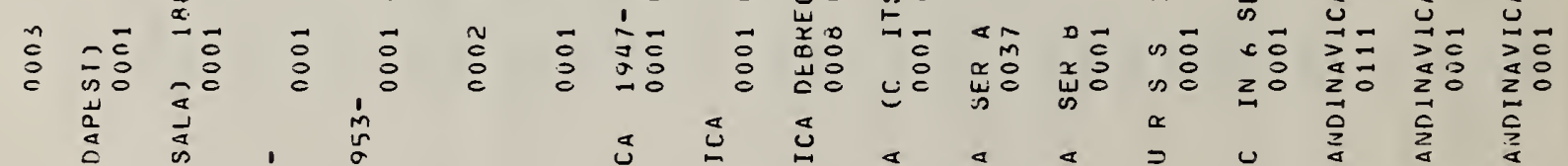

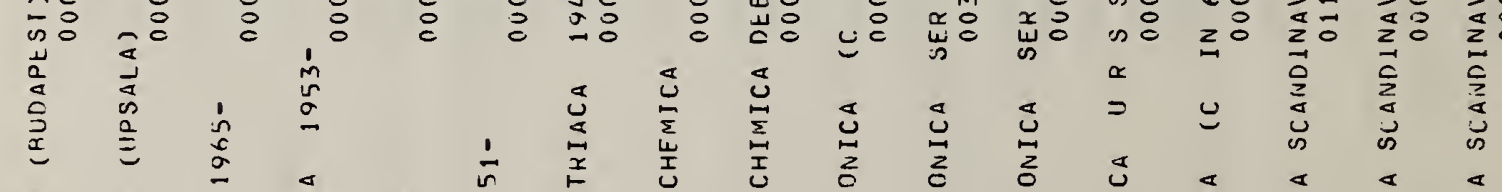

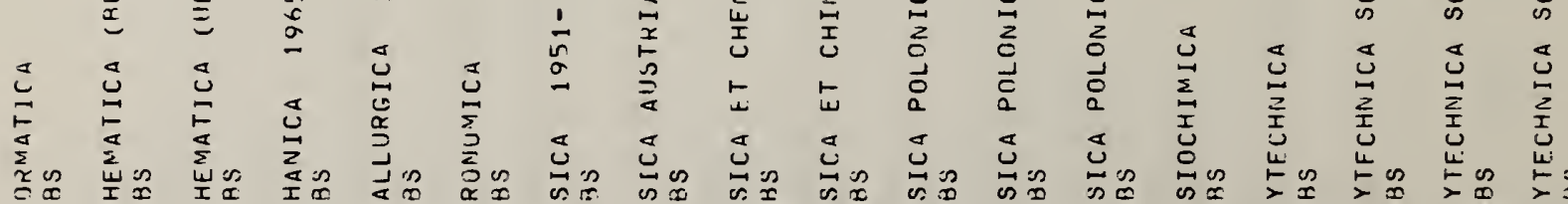

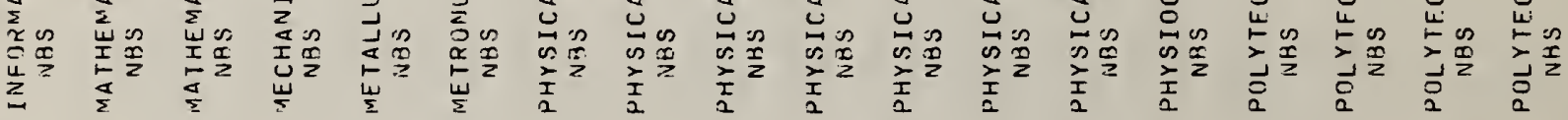

$$
\begin{aligned}
& \text { 若 }
\end{aligned}
$$




\section{嵪 \\ $\stackrel{\frac{0}{2}}{\frac{5}{a}}$ \\ $\frac{1}{a}$ \\ 总

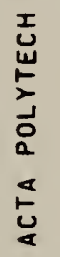 \\ צ \\ 紊}

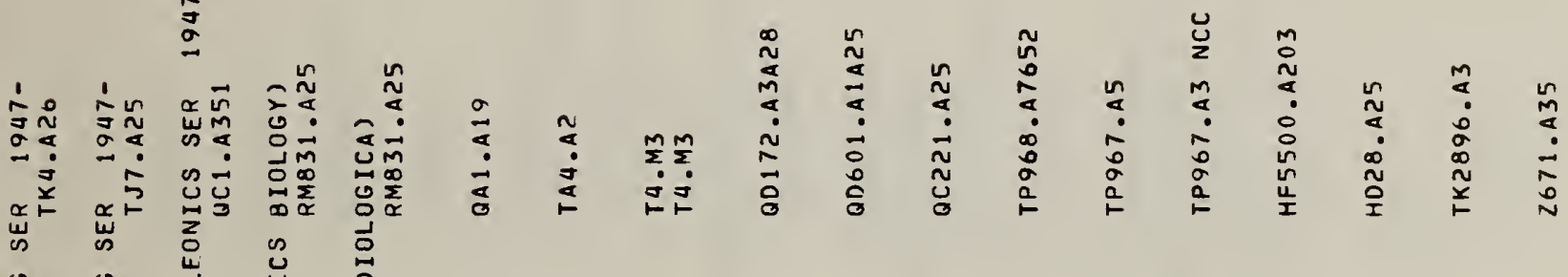

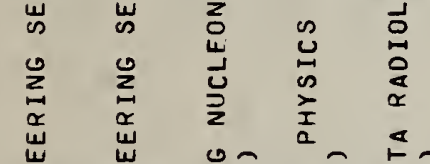

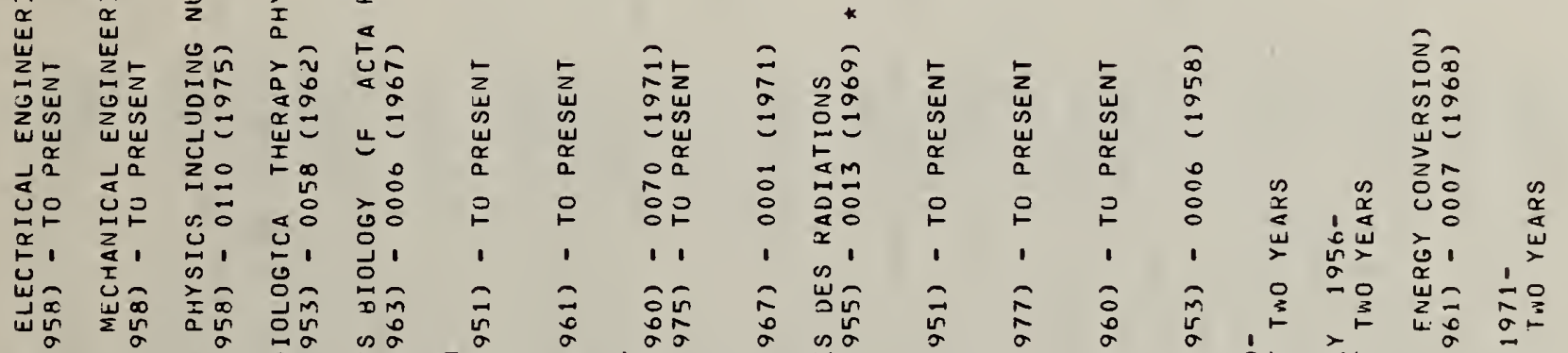

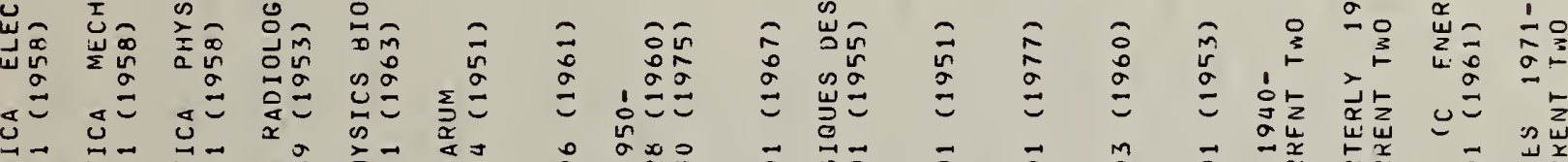

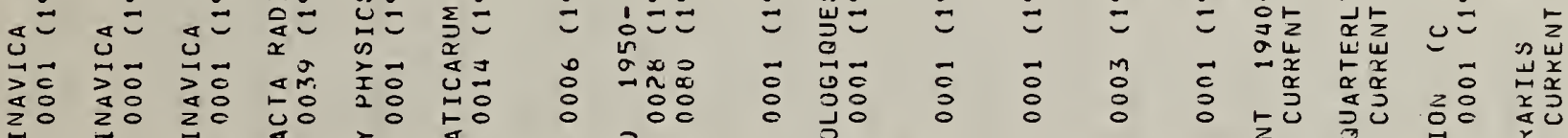

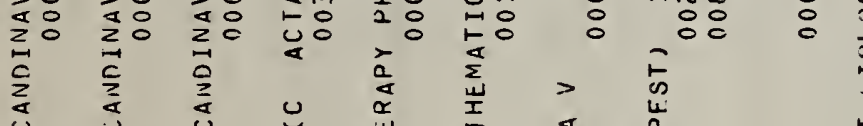

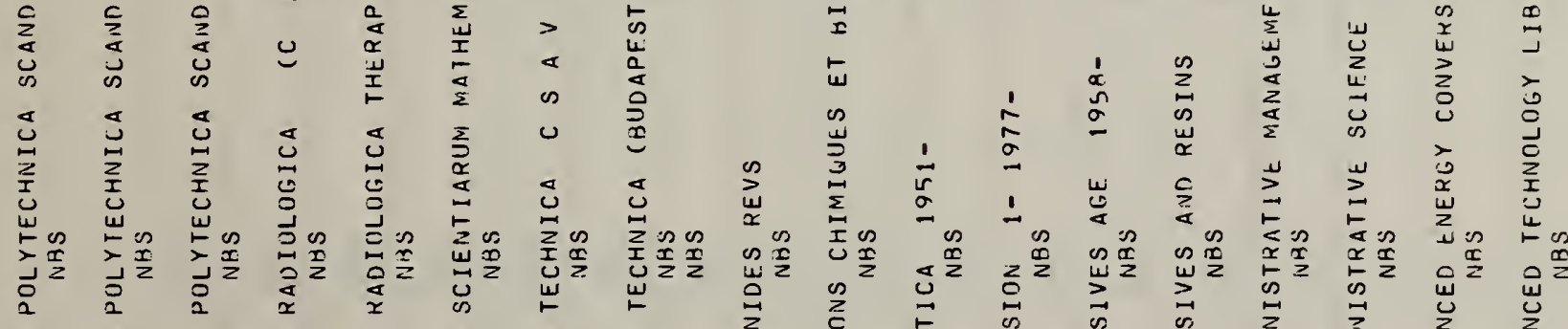

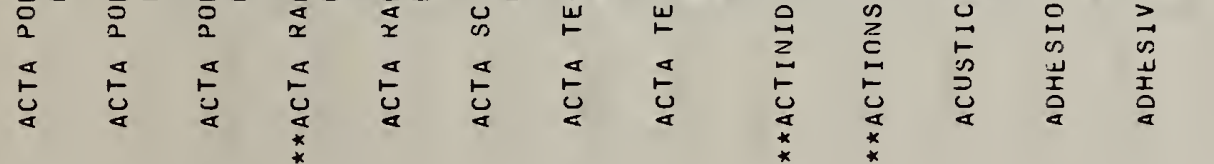




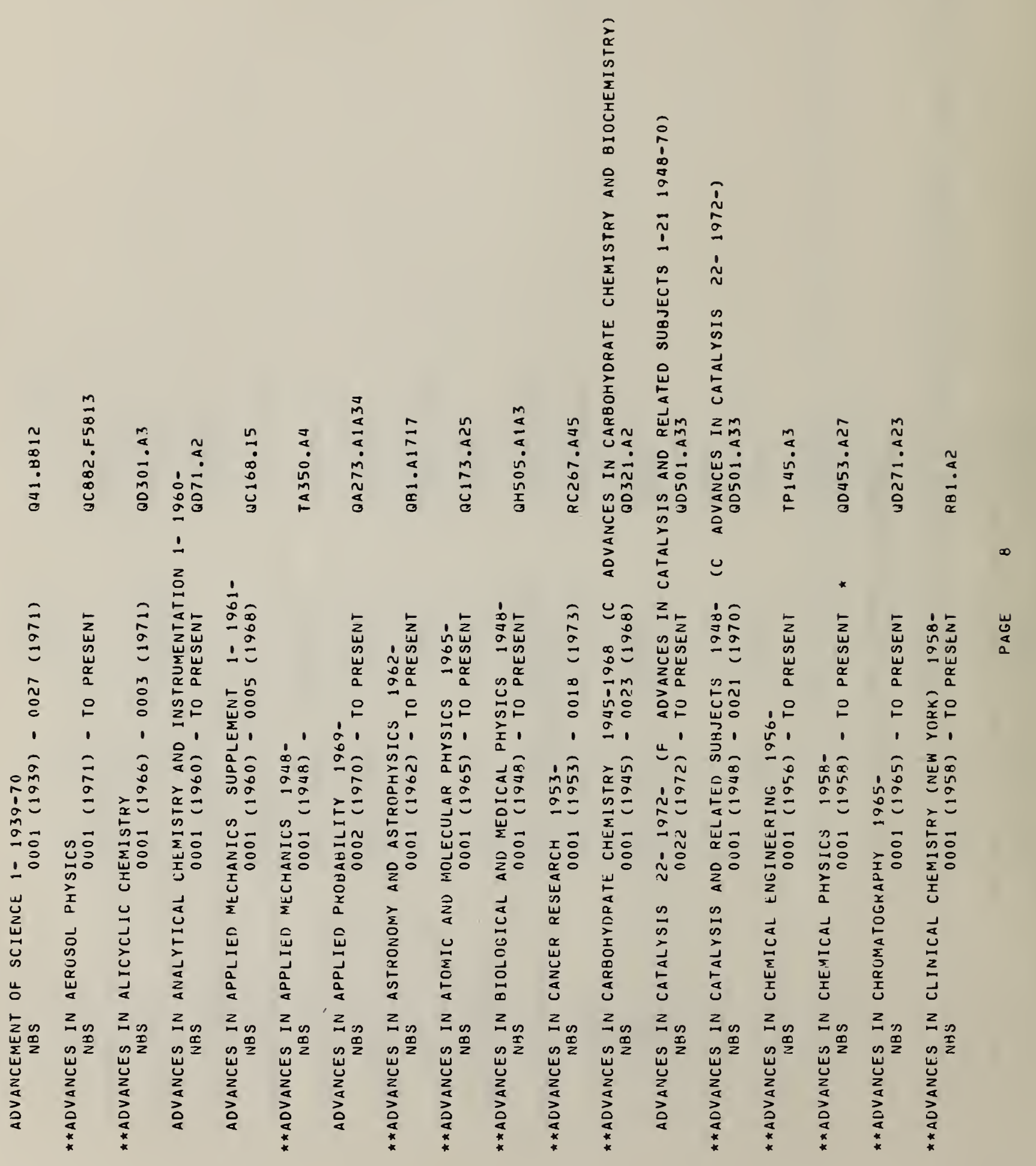




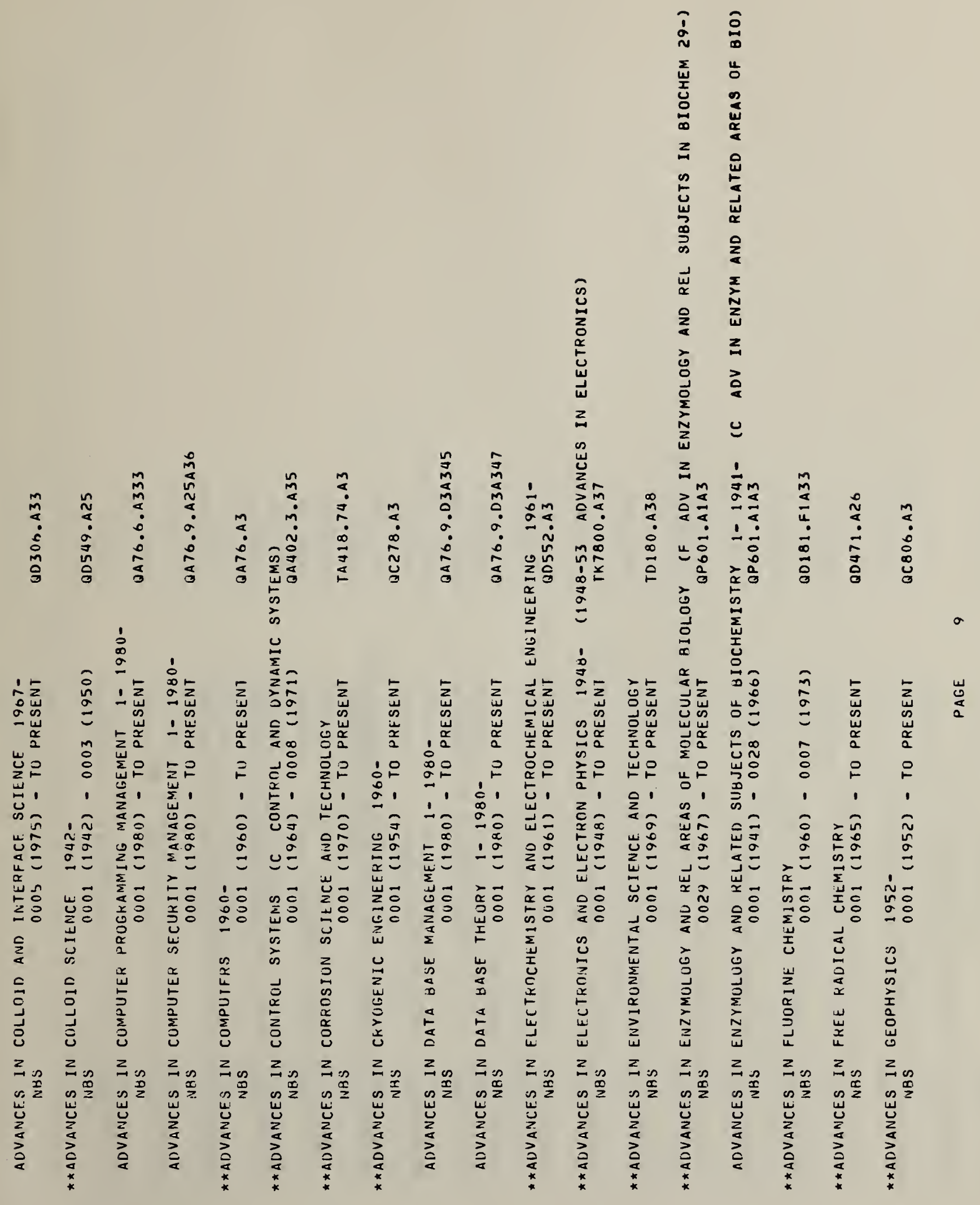




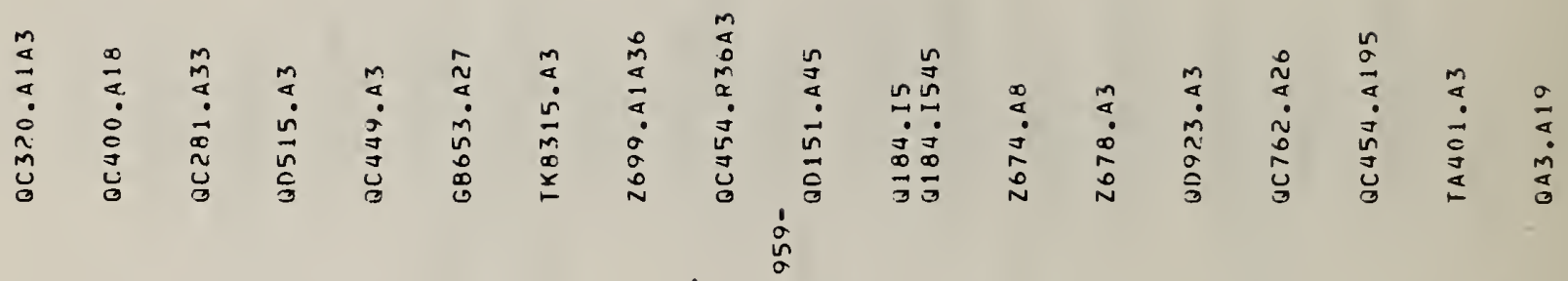

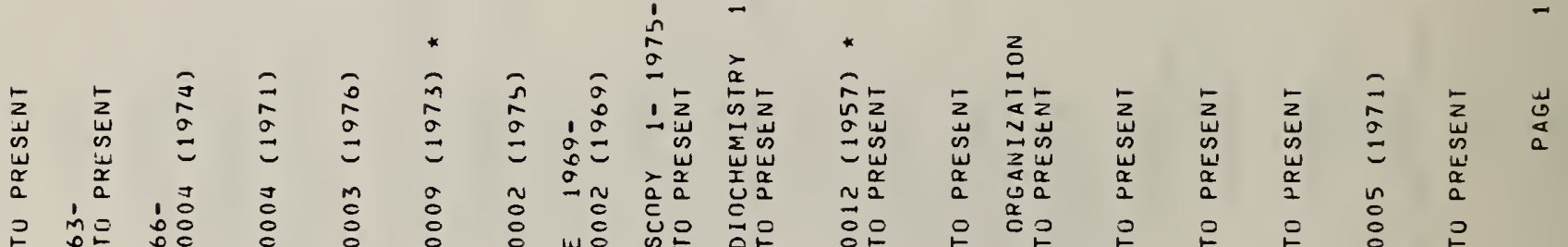

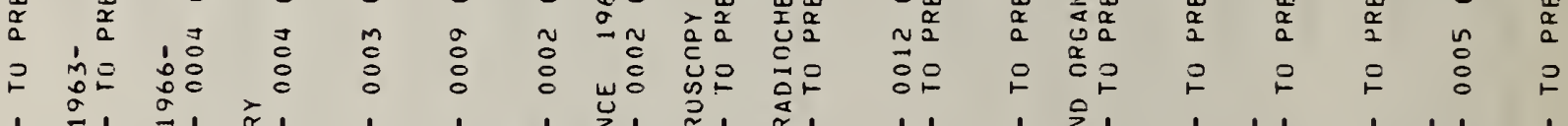

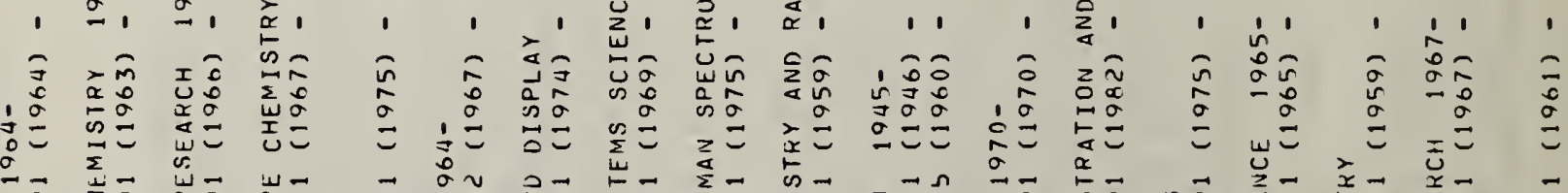

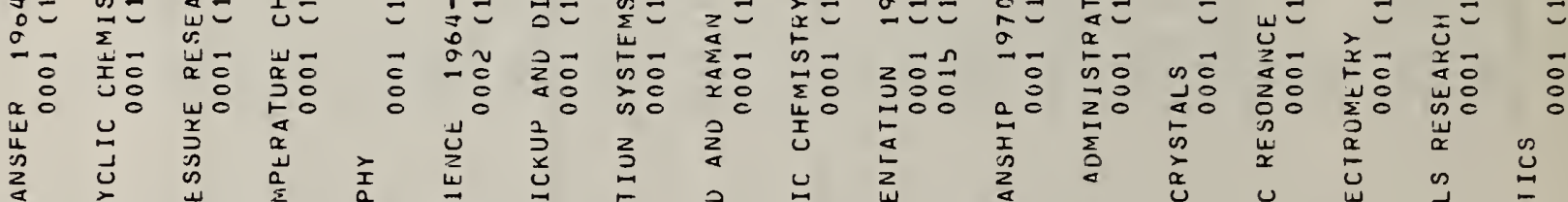
in en

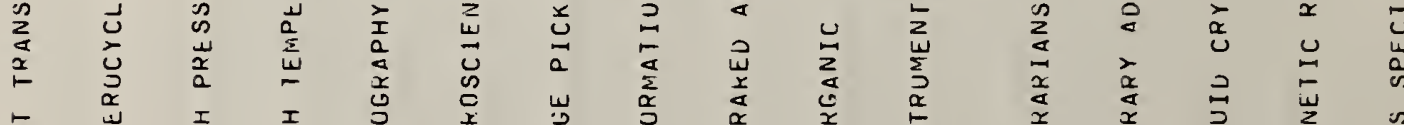

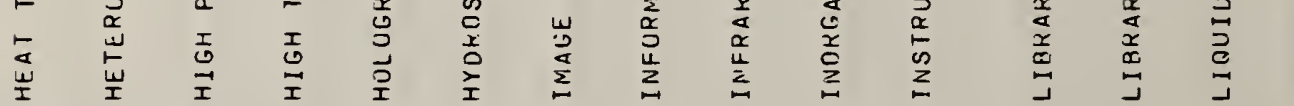

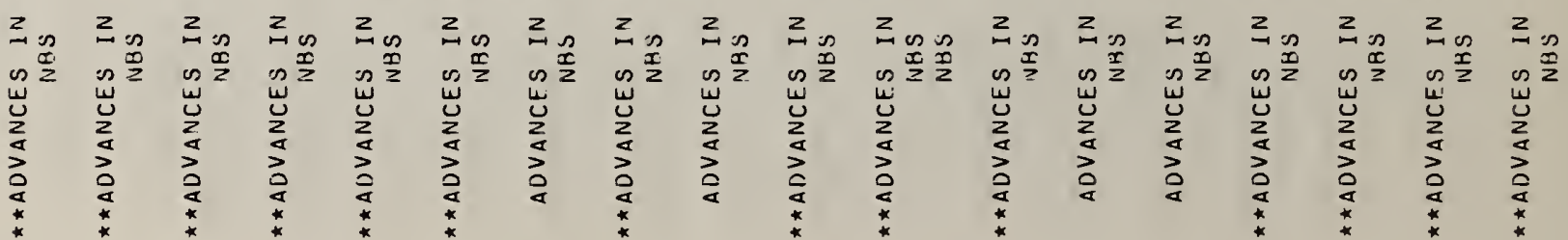



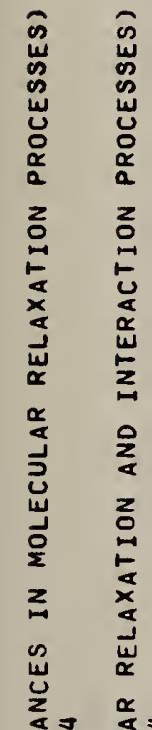

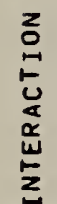

$\sum_{3}^{\infty}$

zo

軲

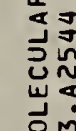

un

i $\sum_{i=1}$

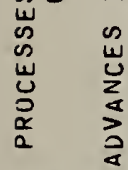

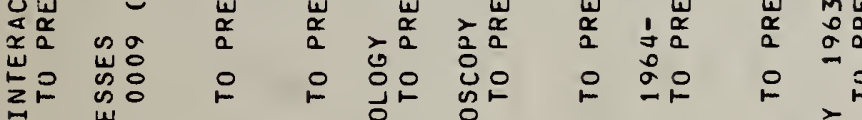

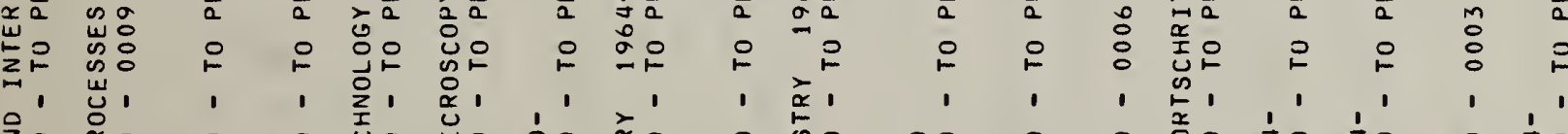

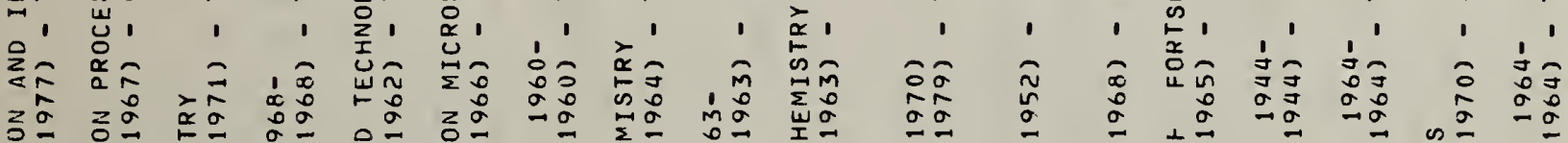

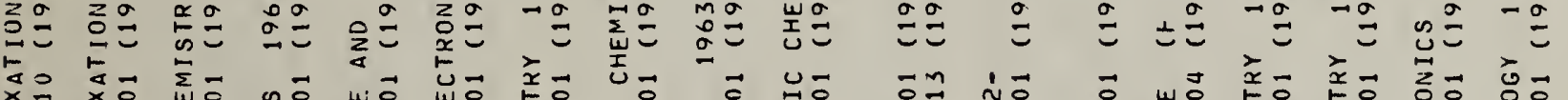

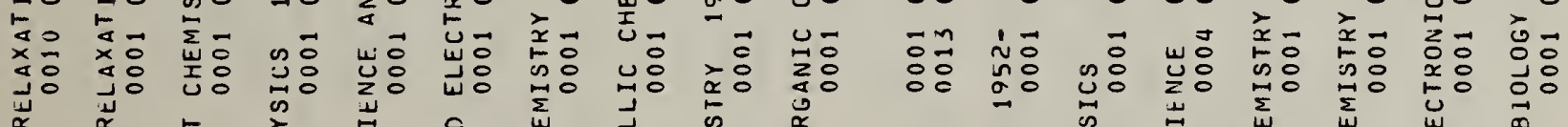

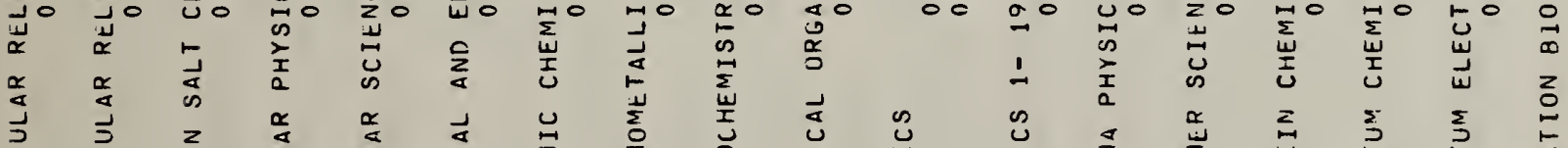

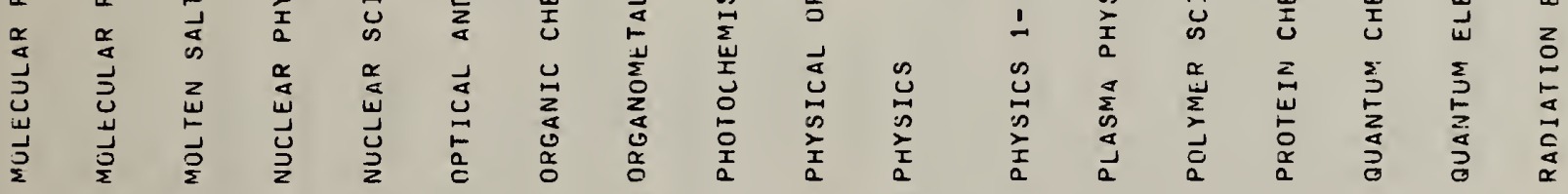

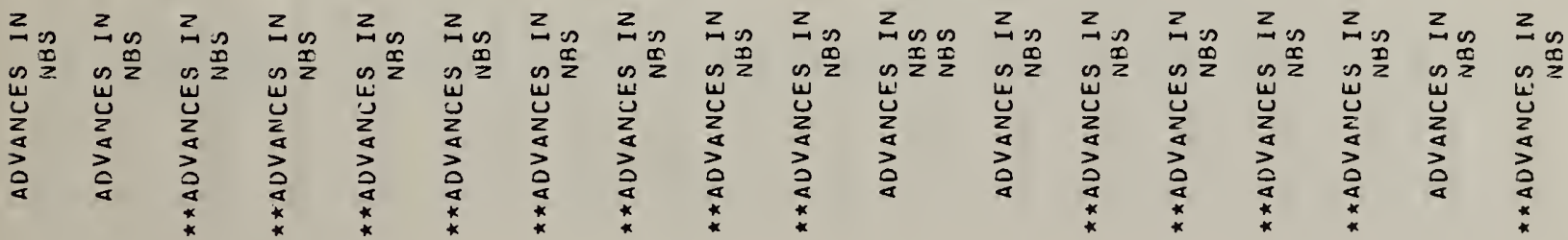


岕

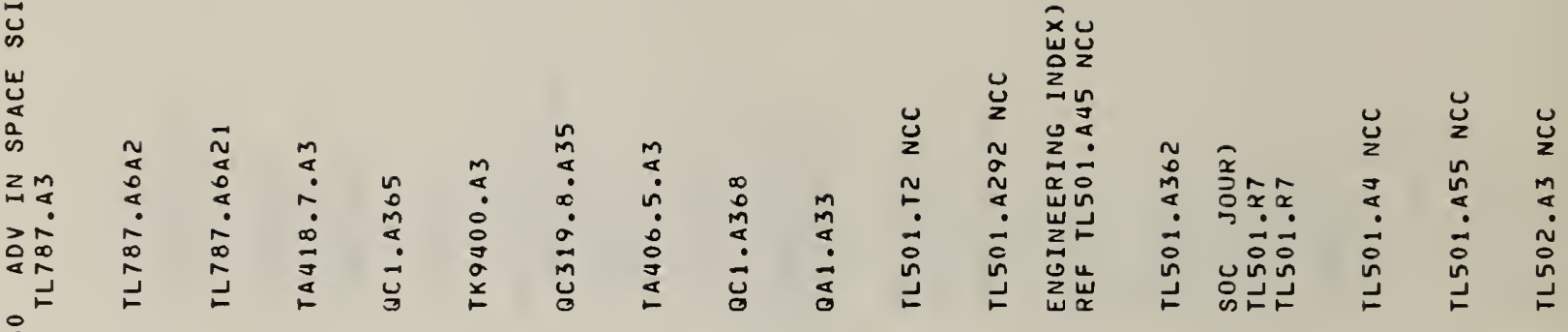

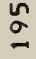

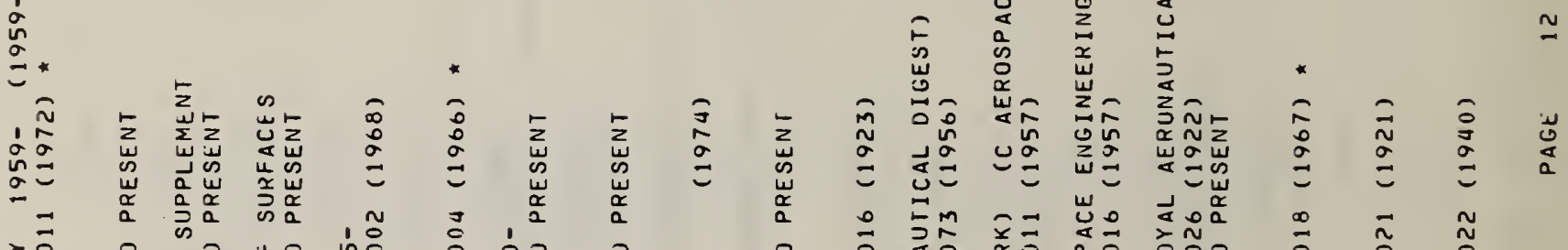

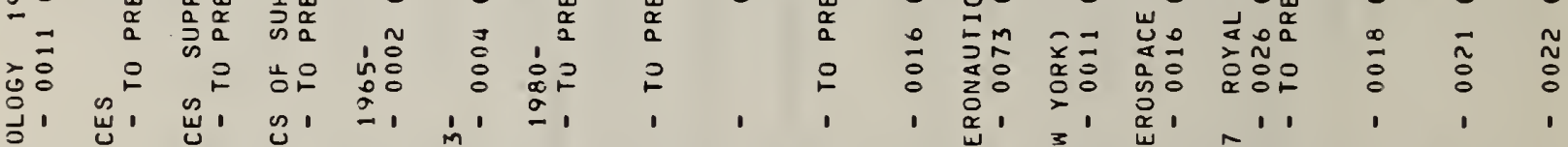

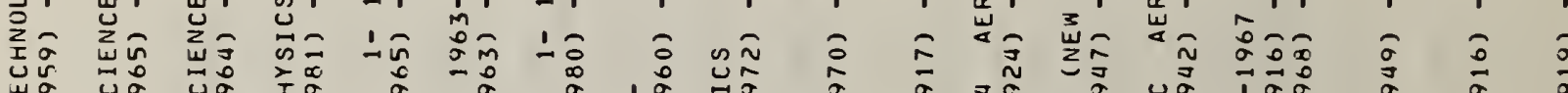

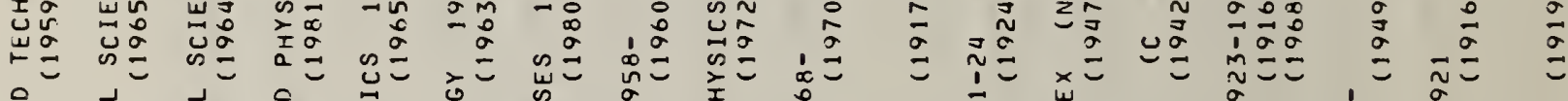

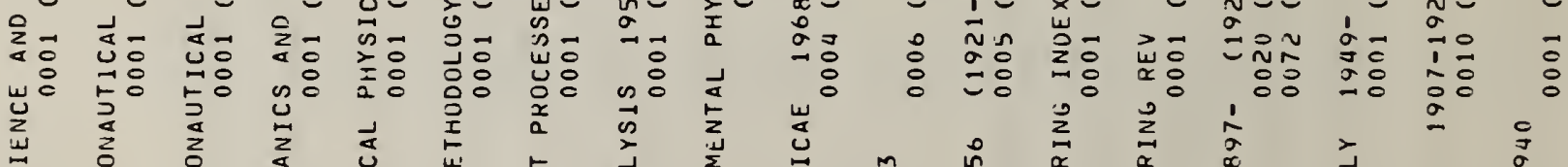

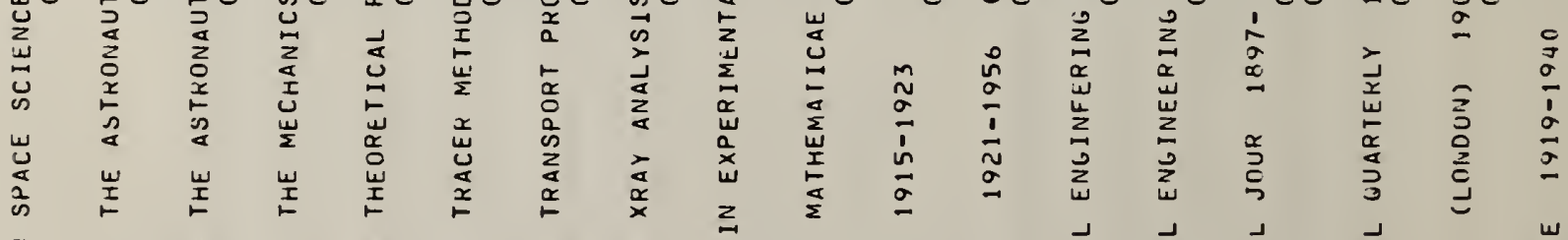

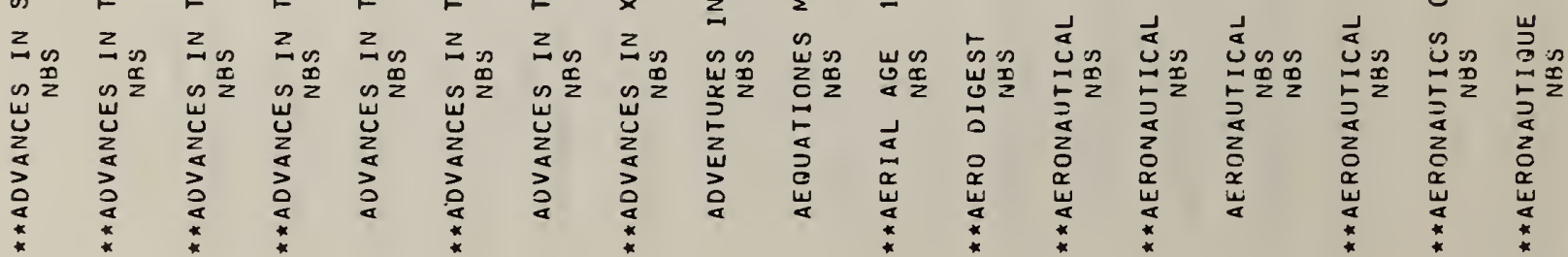




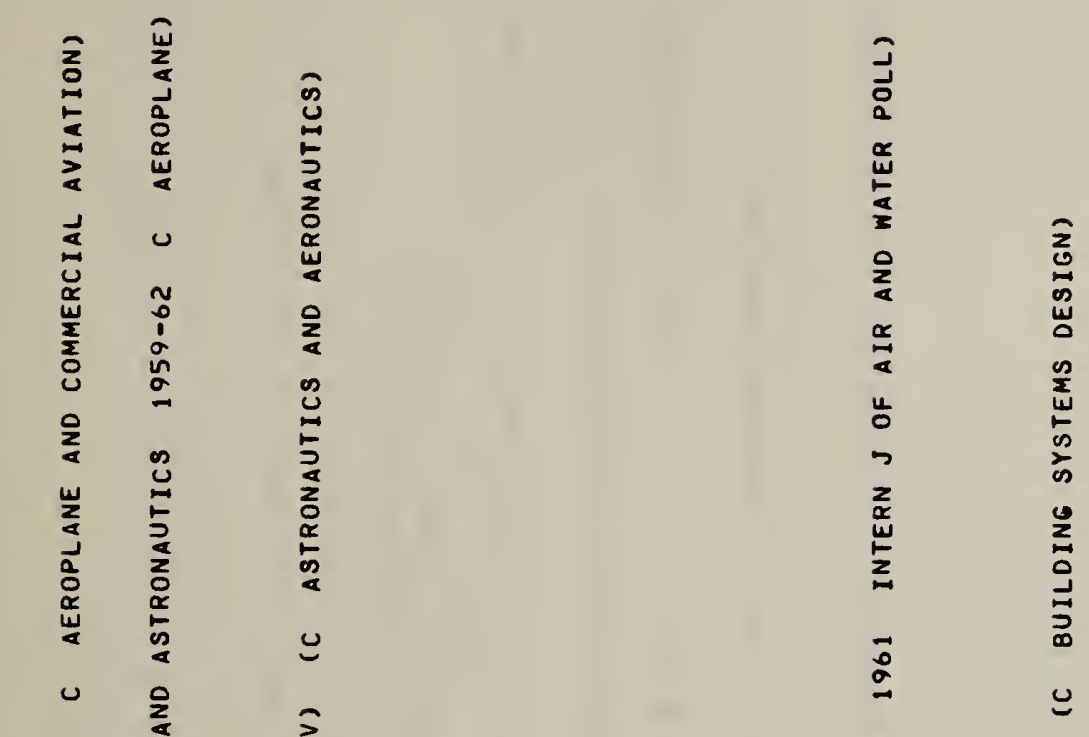

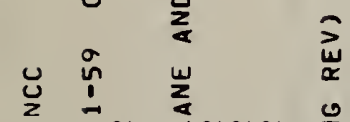

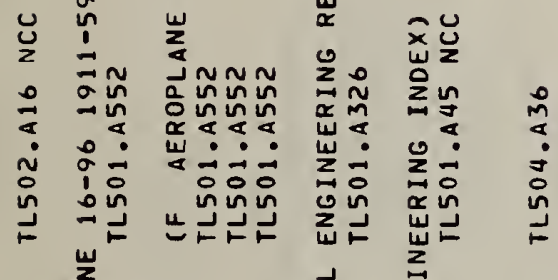

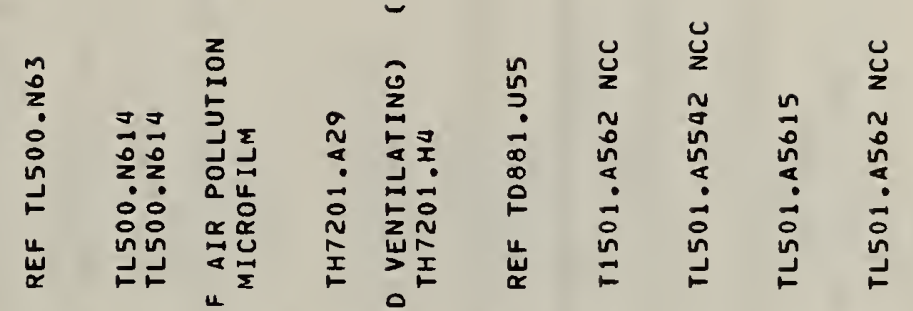

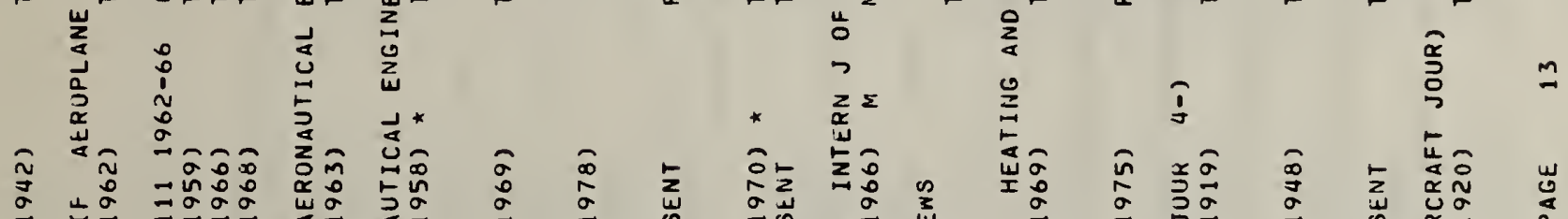

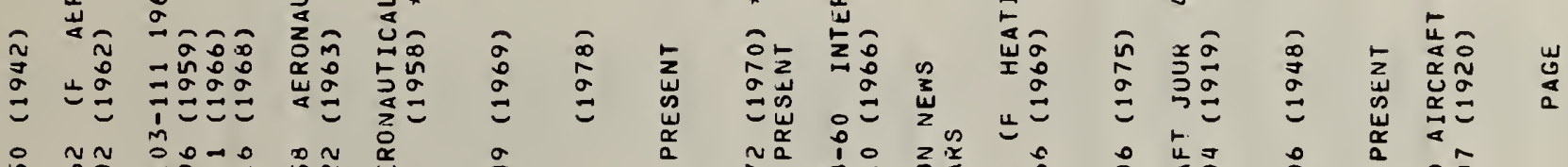

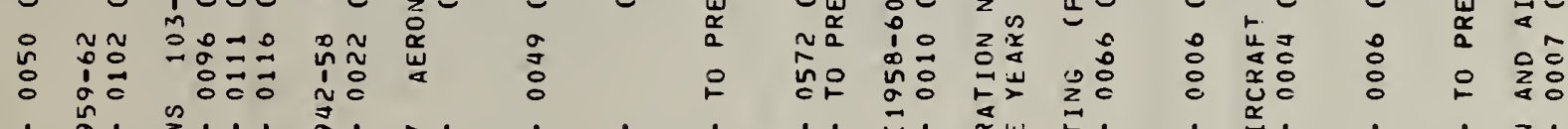

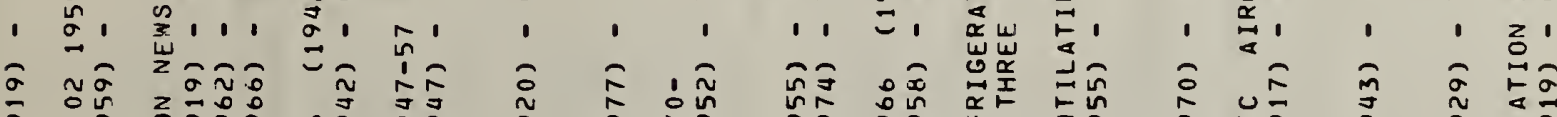

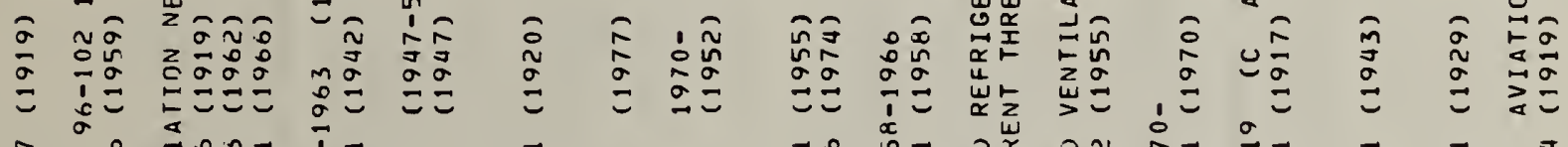

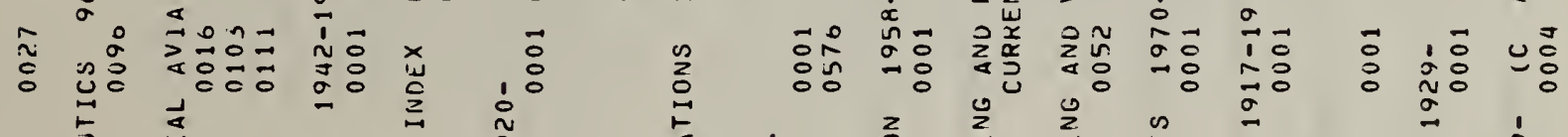

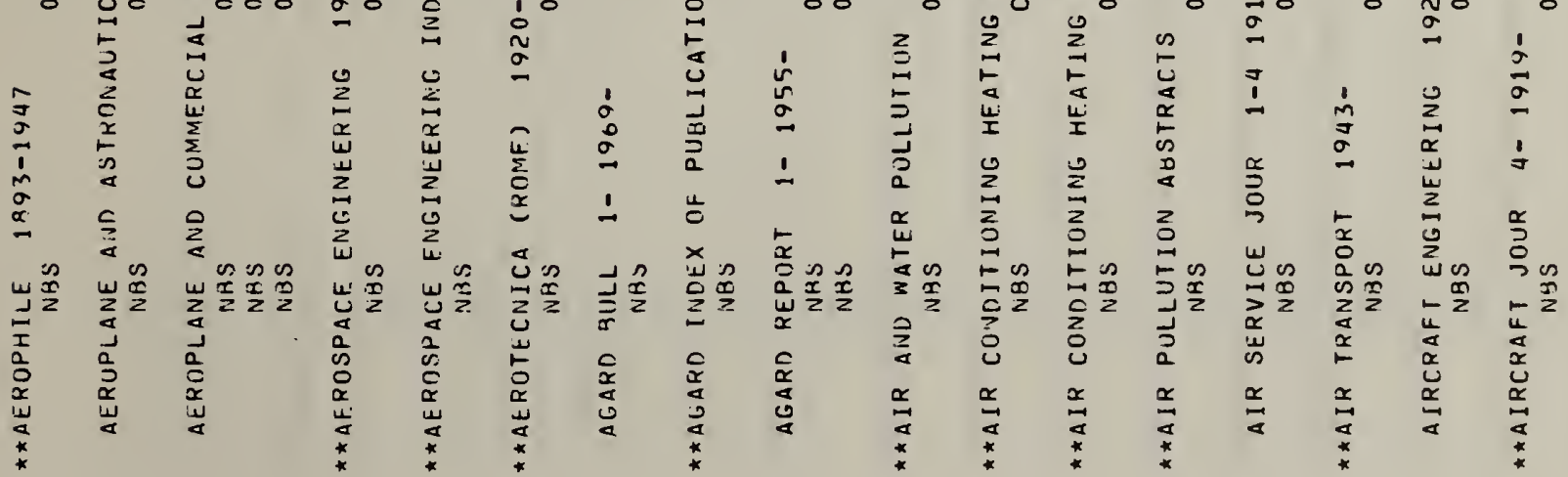




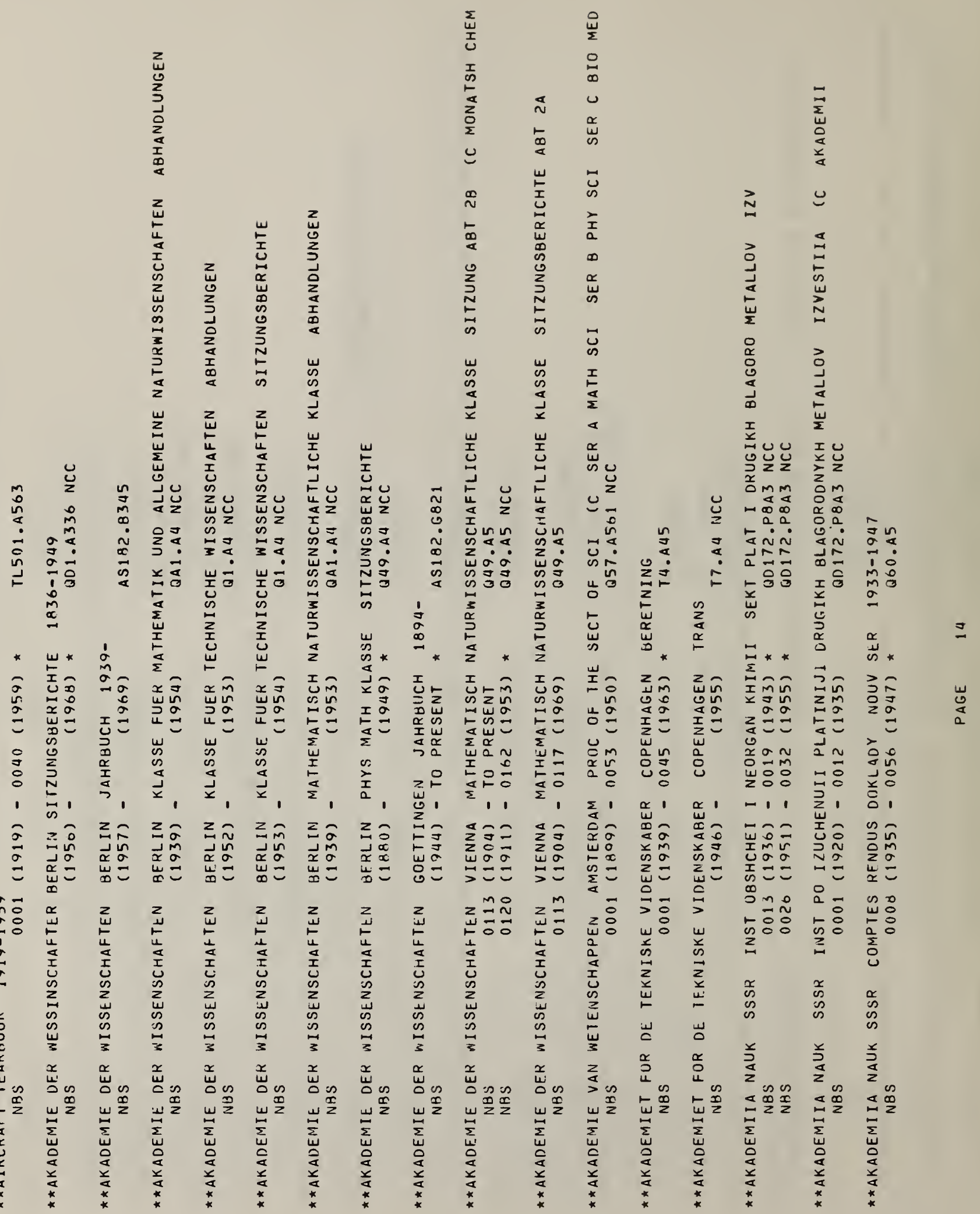




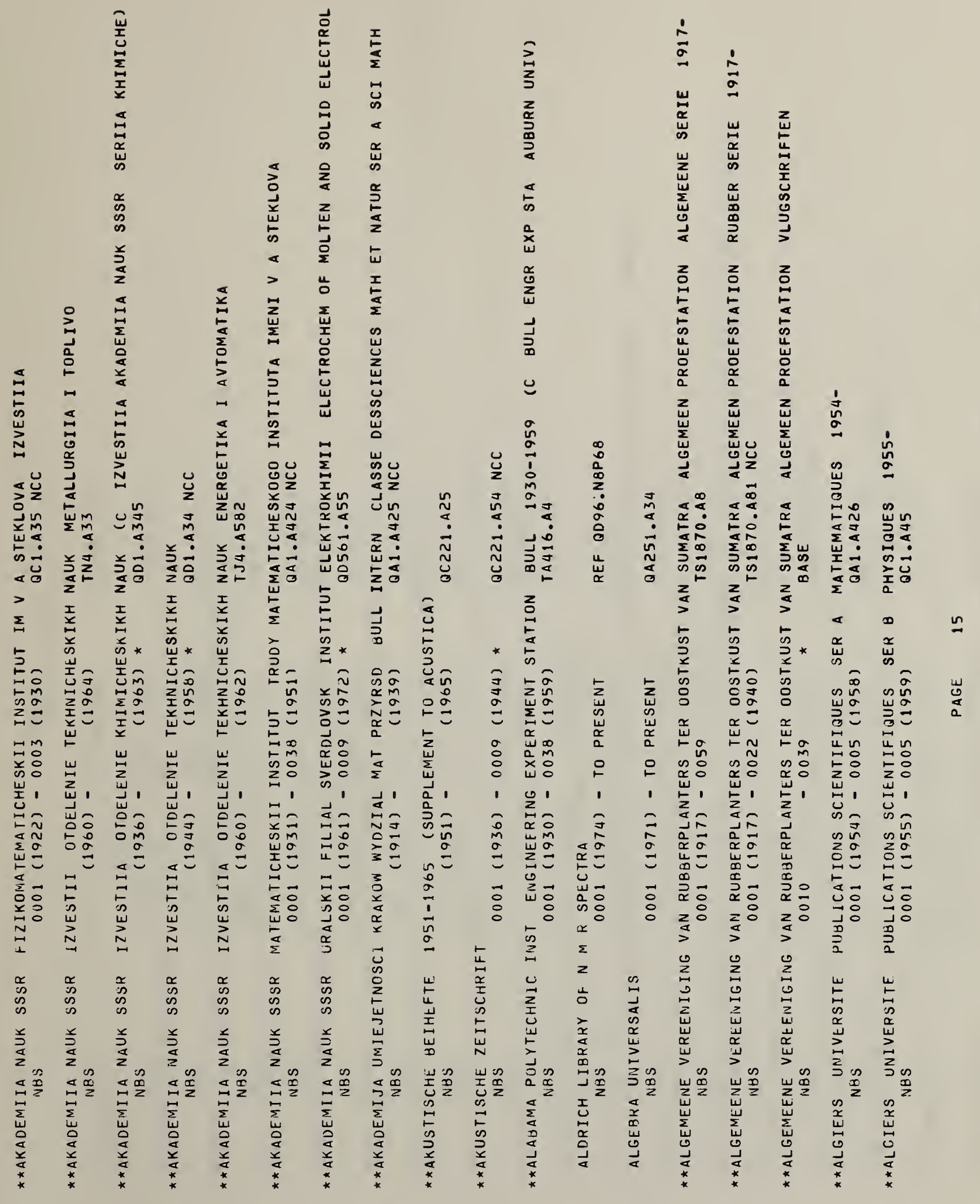




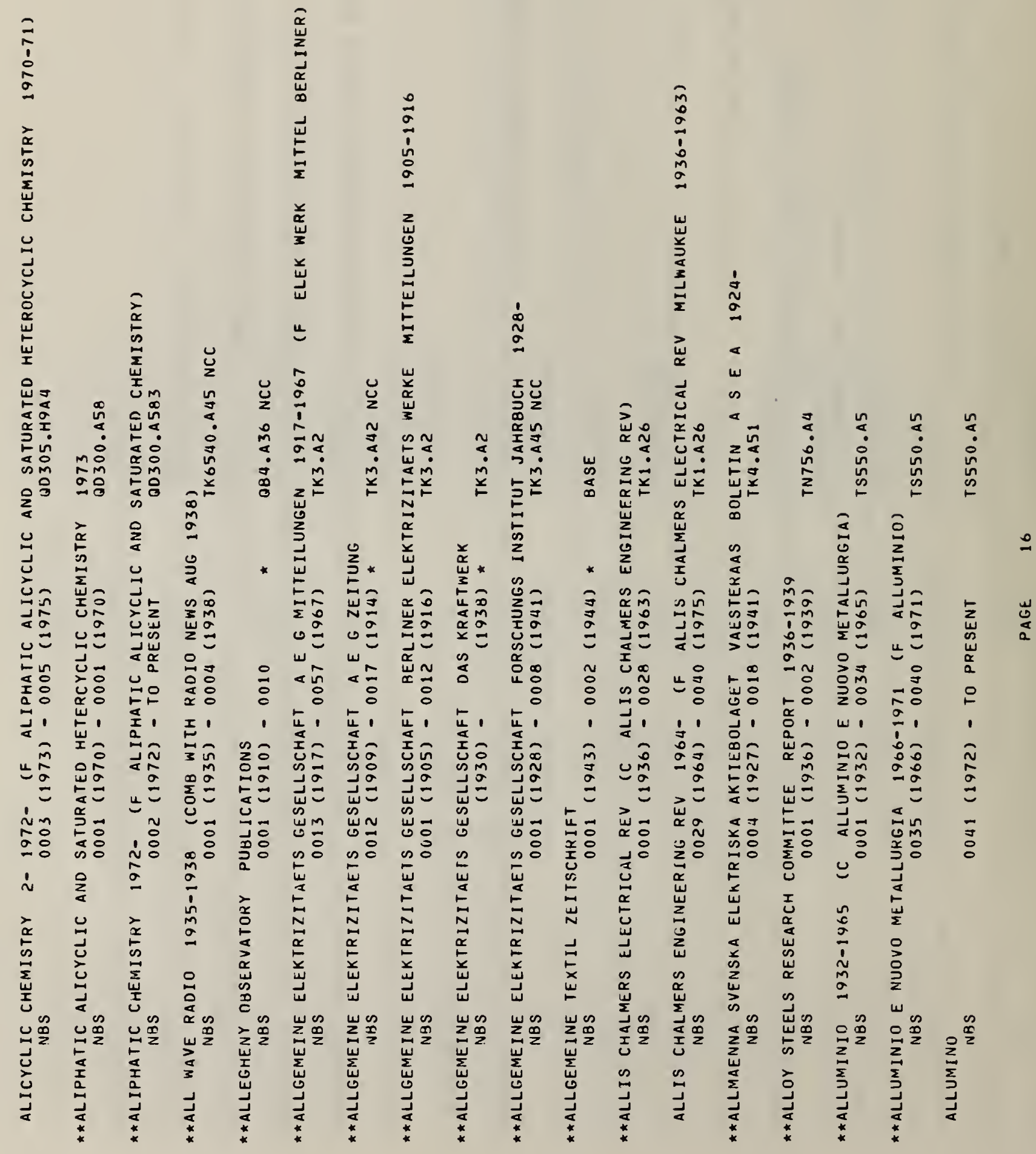




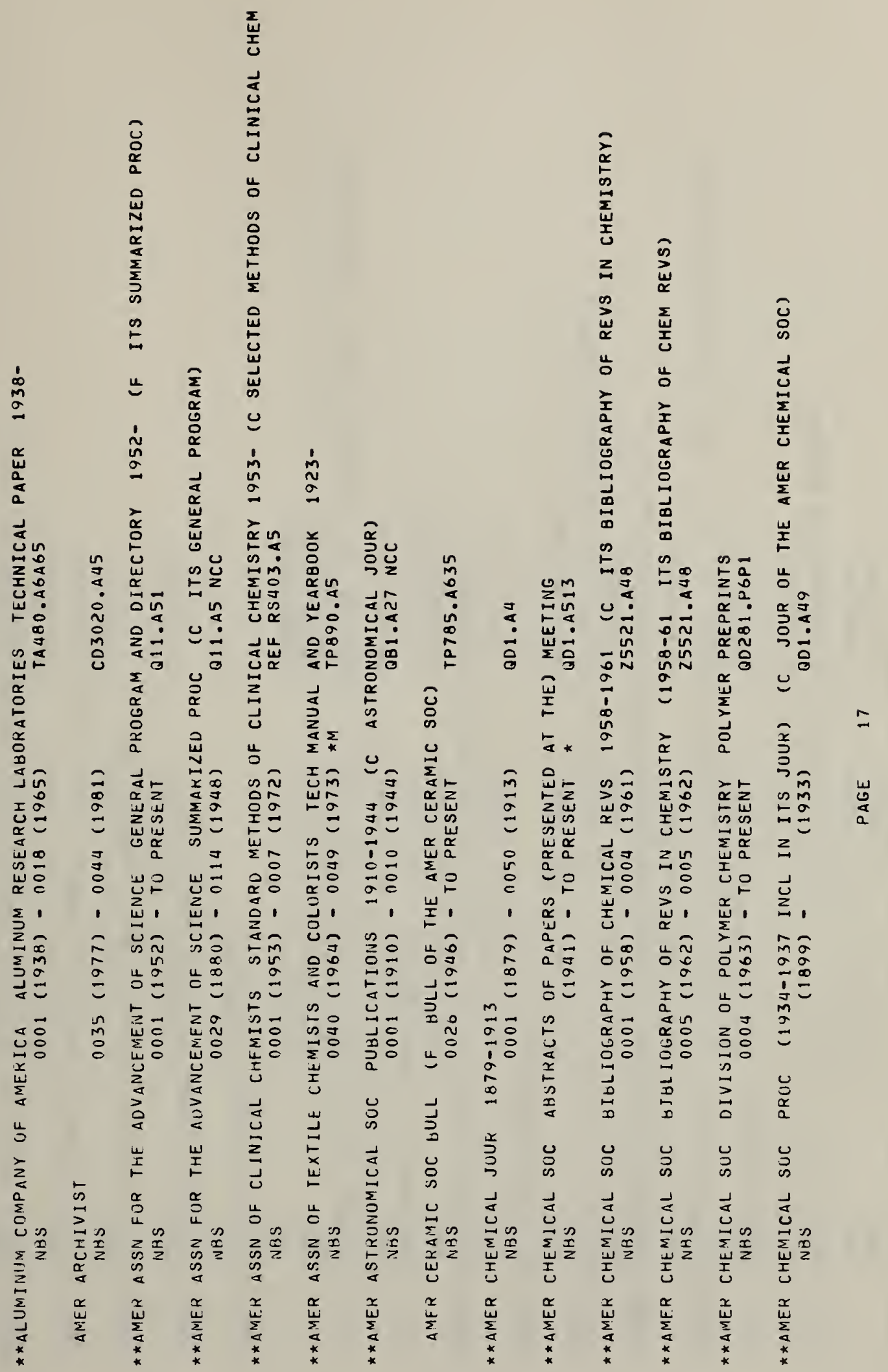





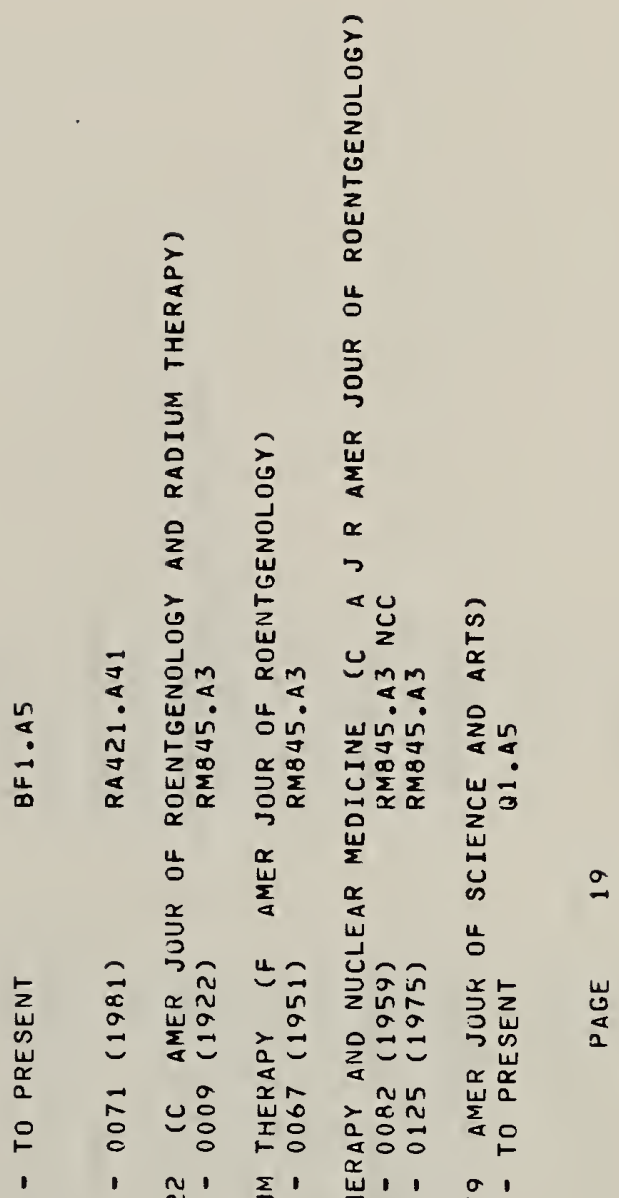

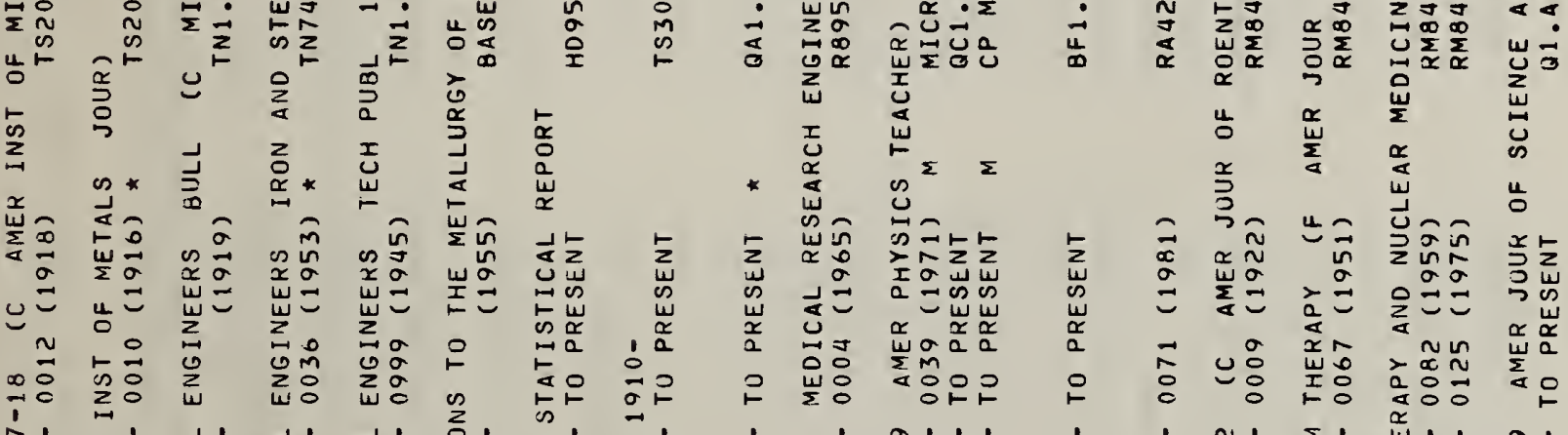

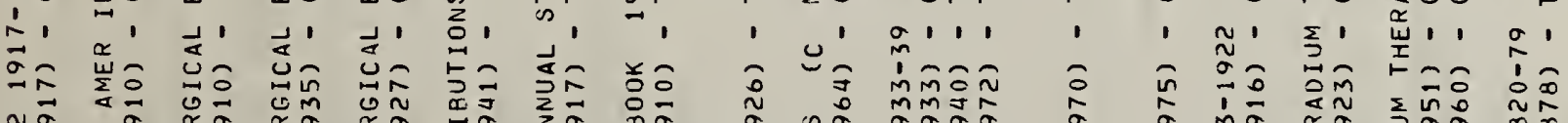

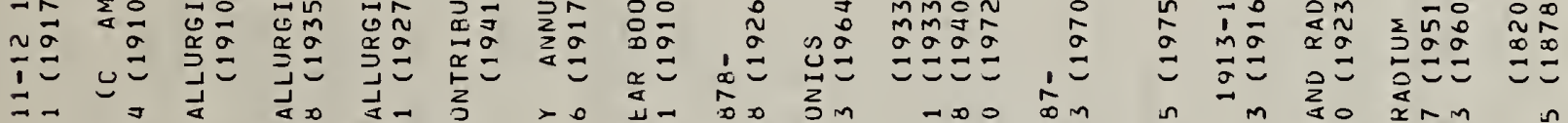

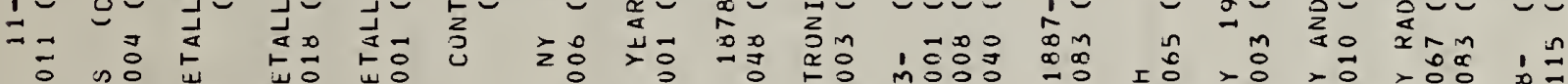

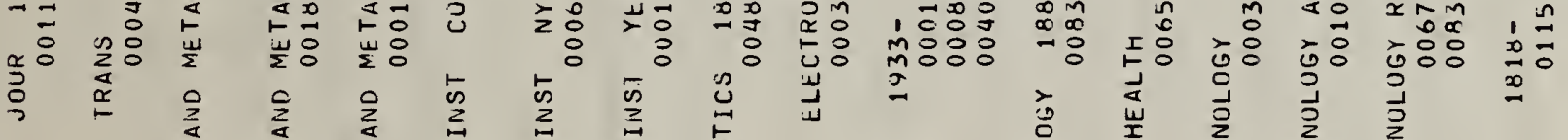

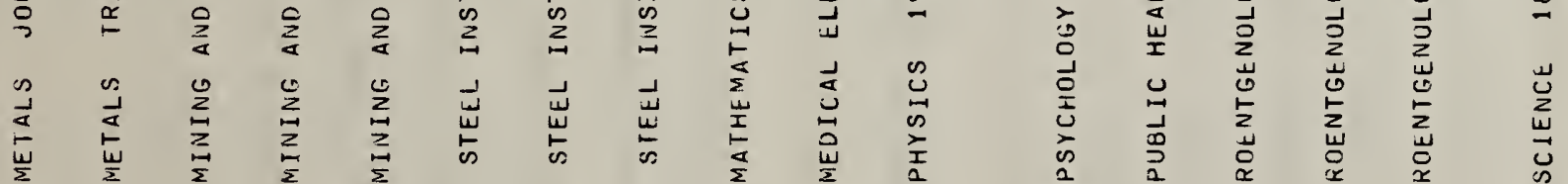

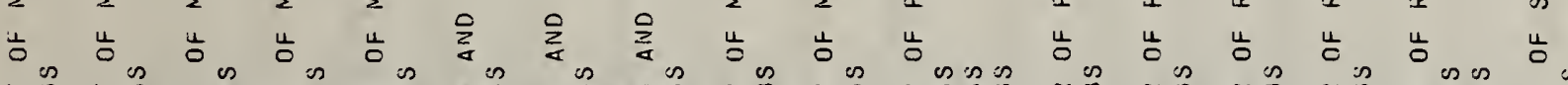

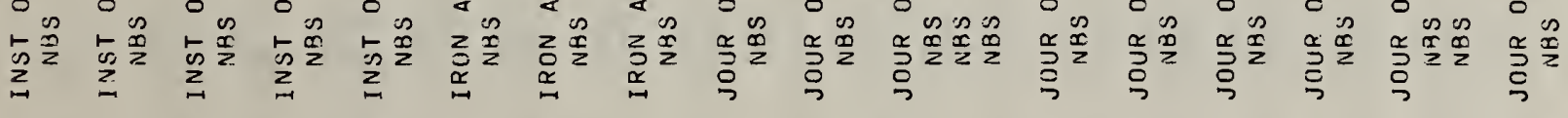

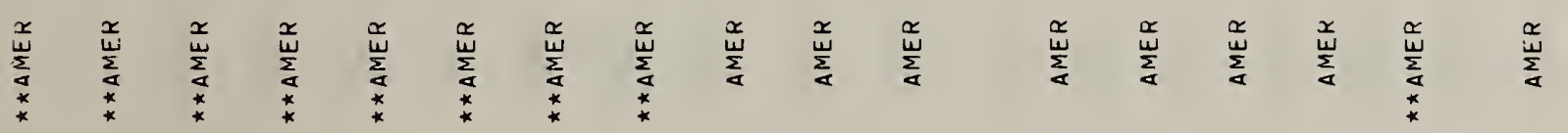




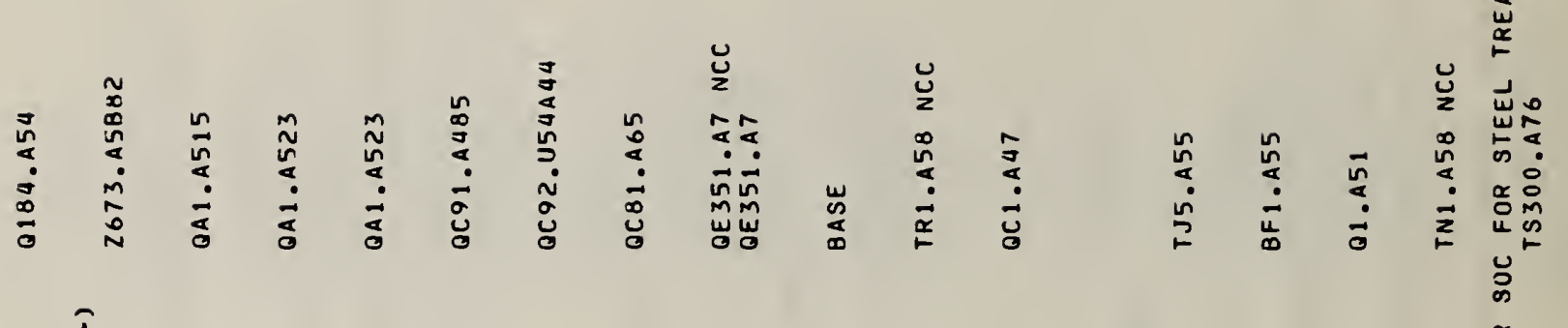

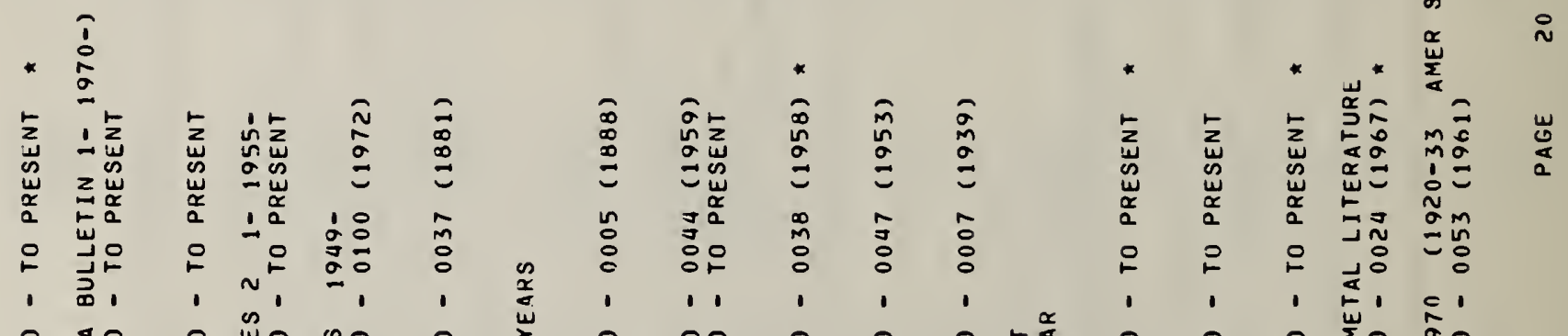

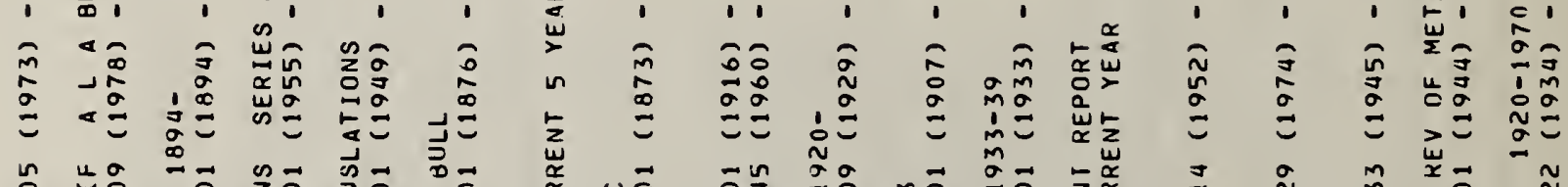

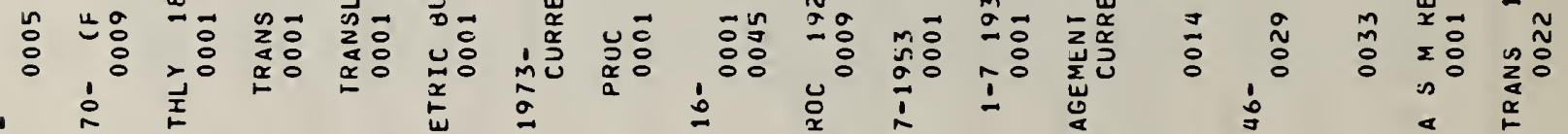

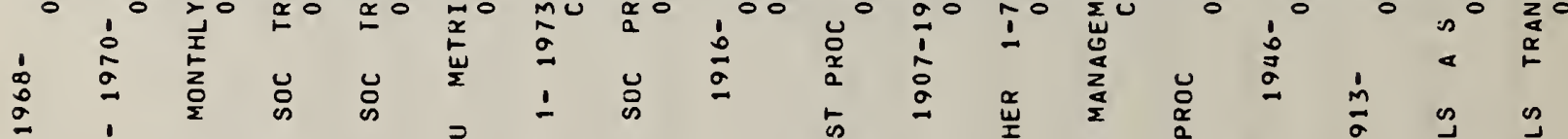

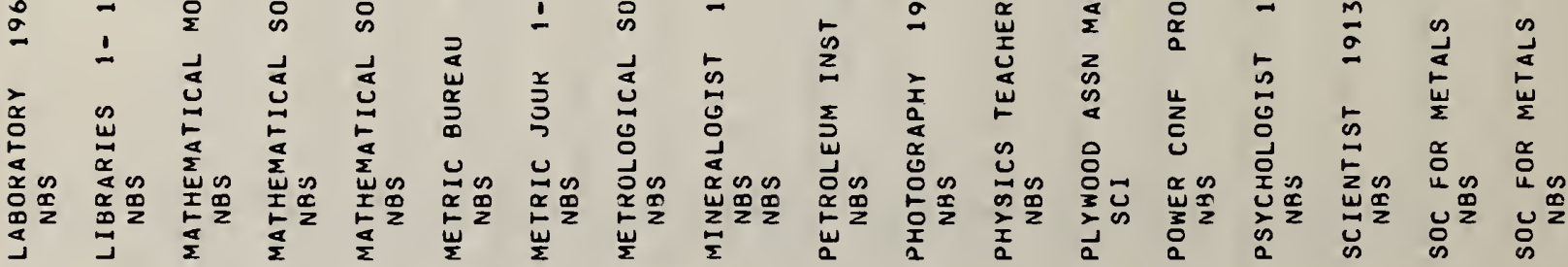

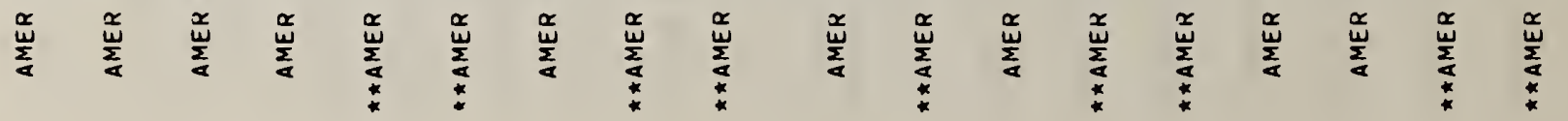




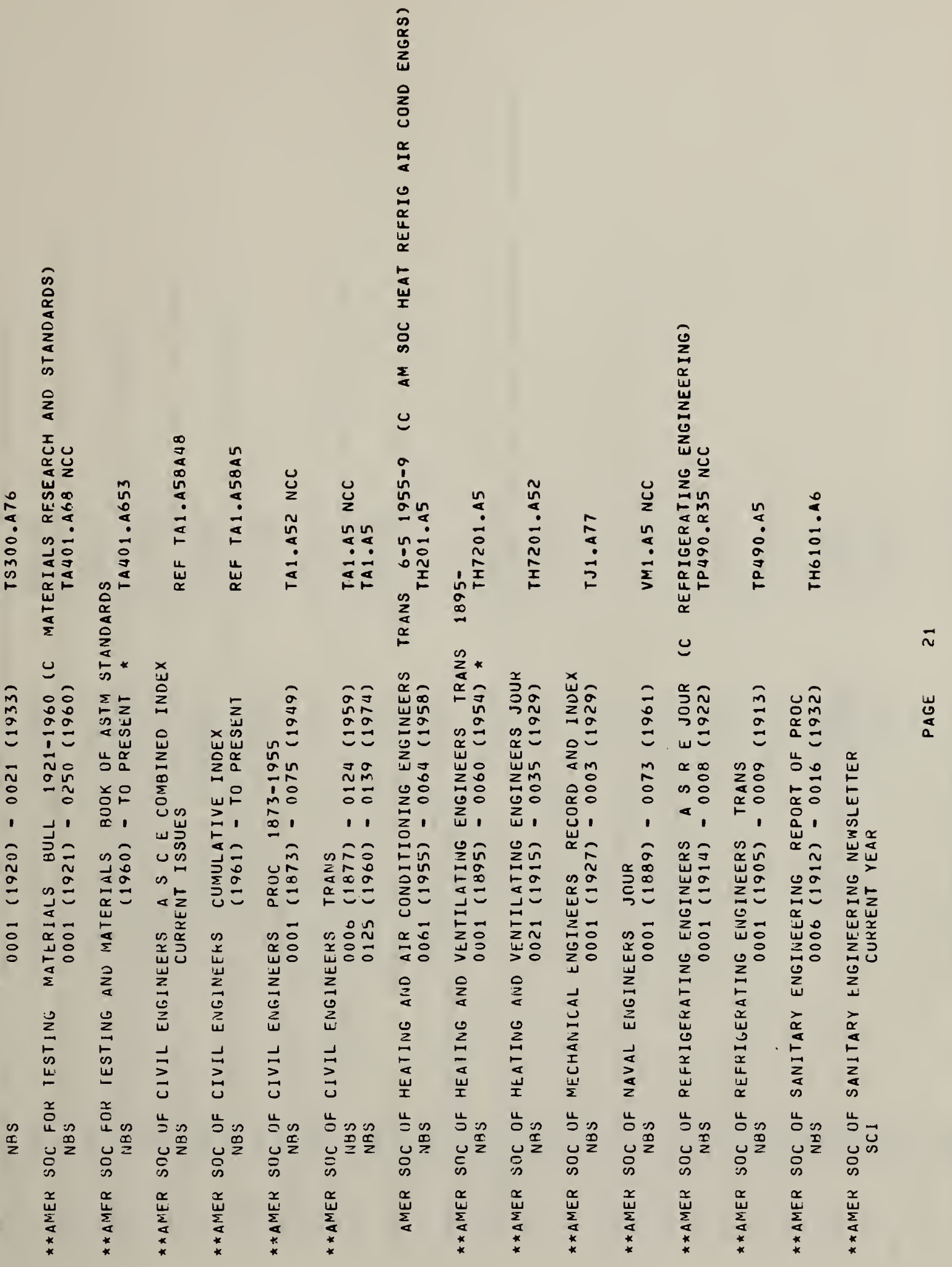




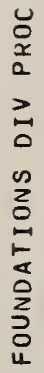

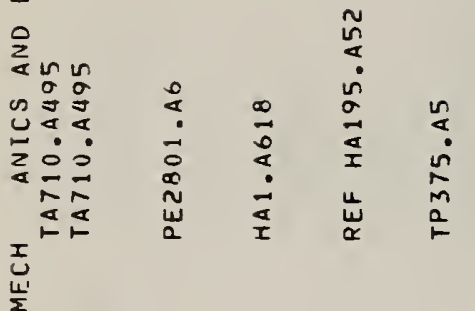

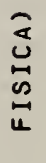

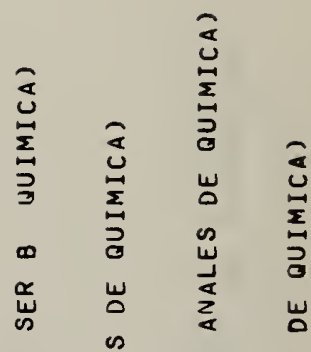

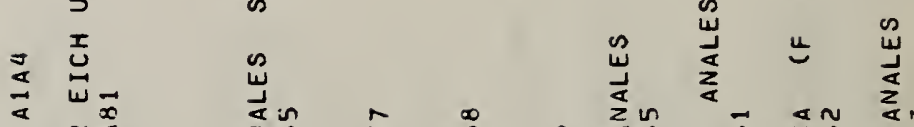

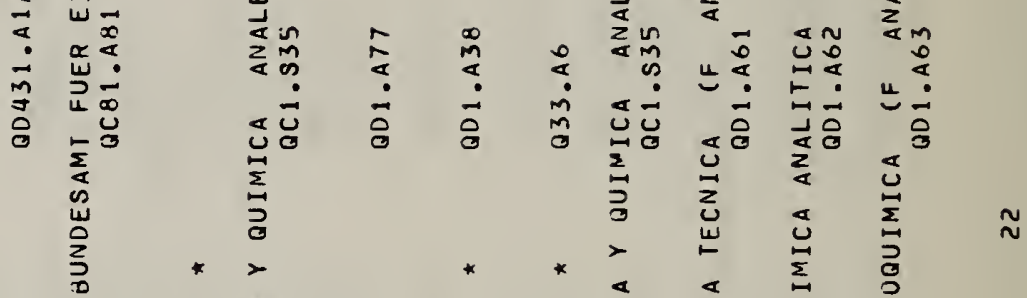

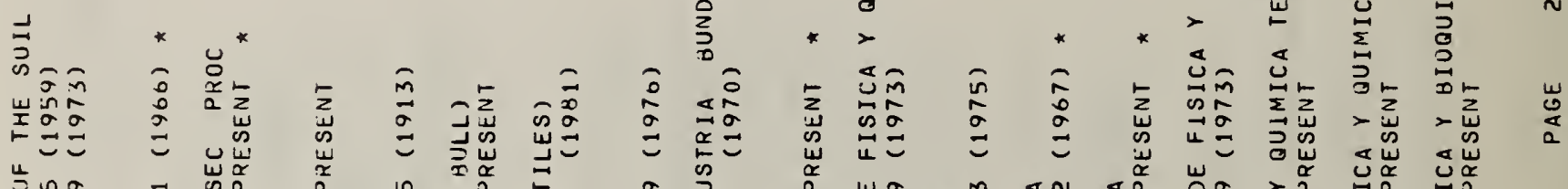

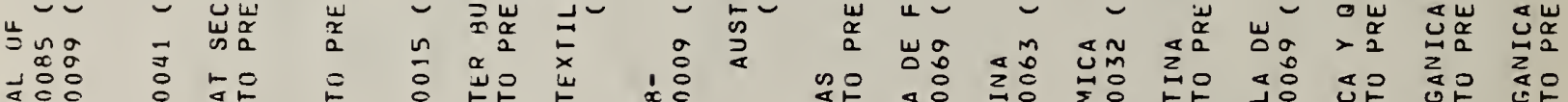
还品 :

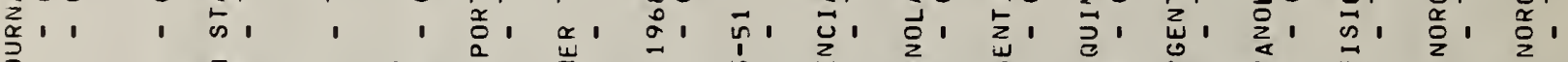

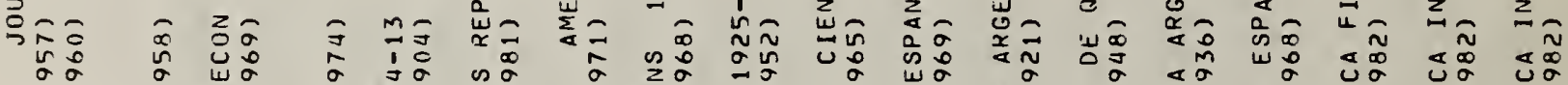

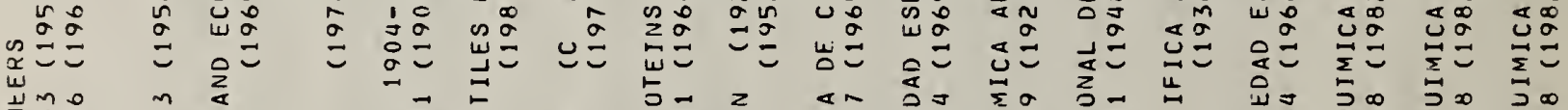

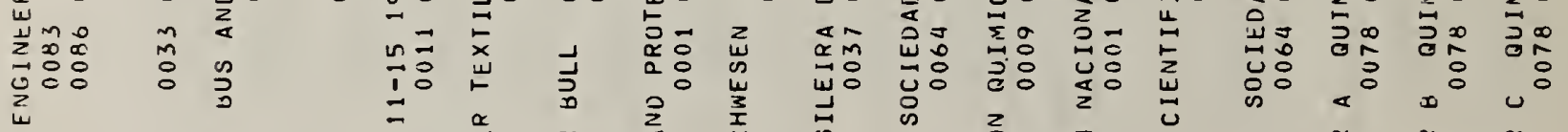

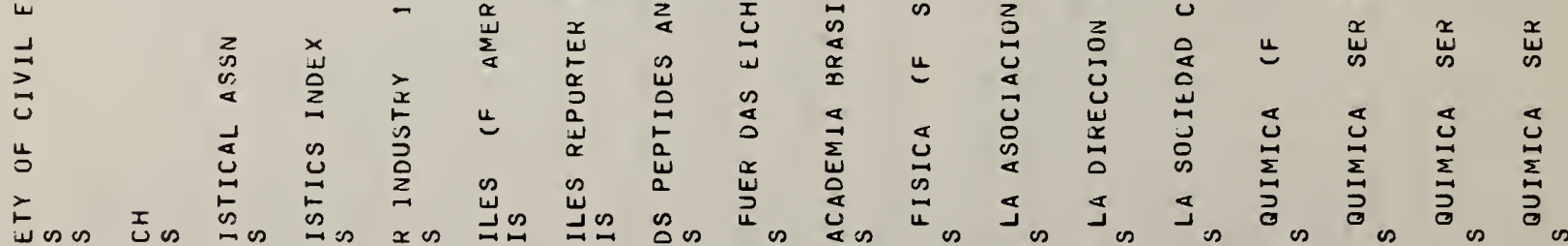

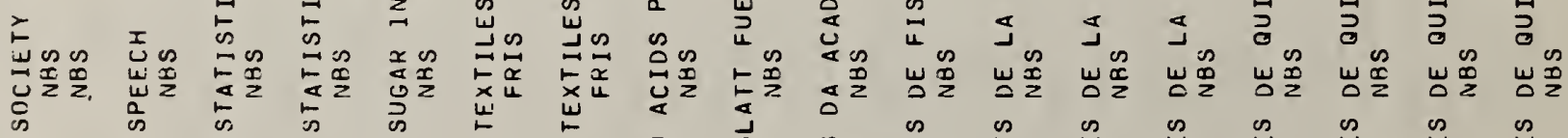

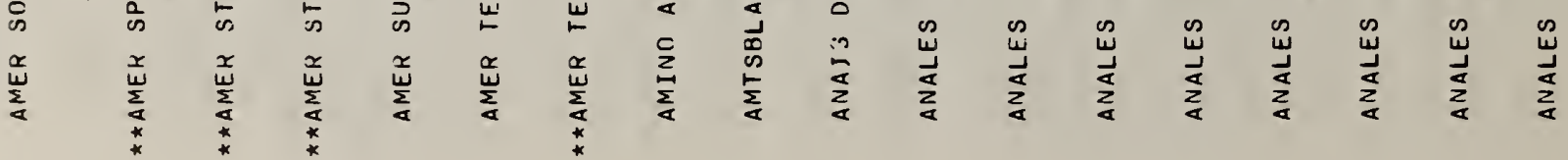




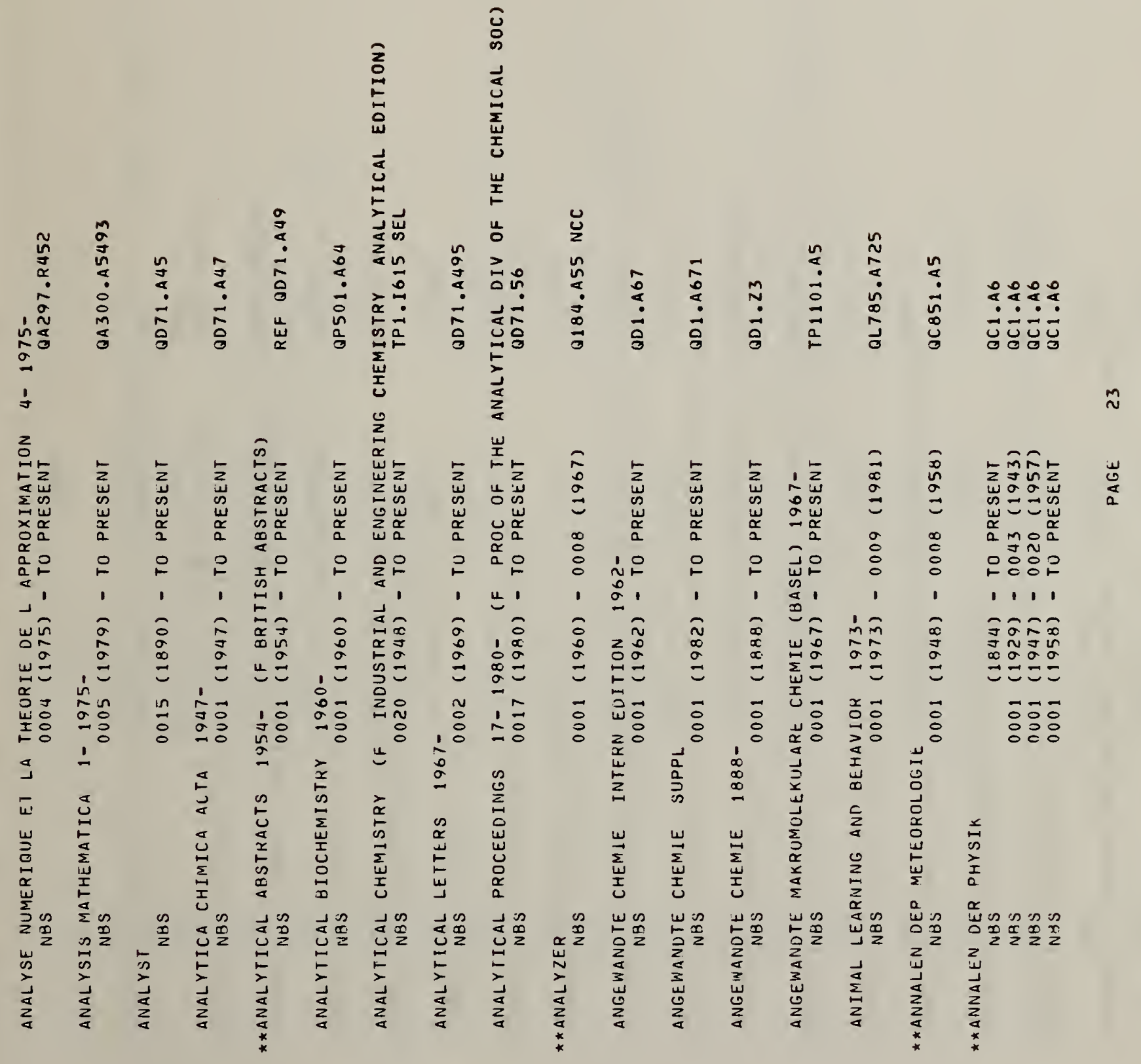




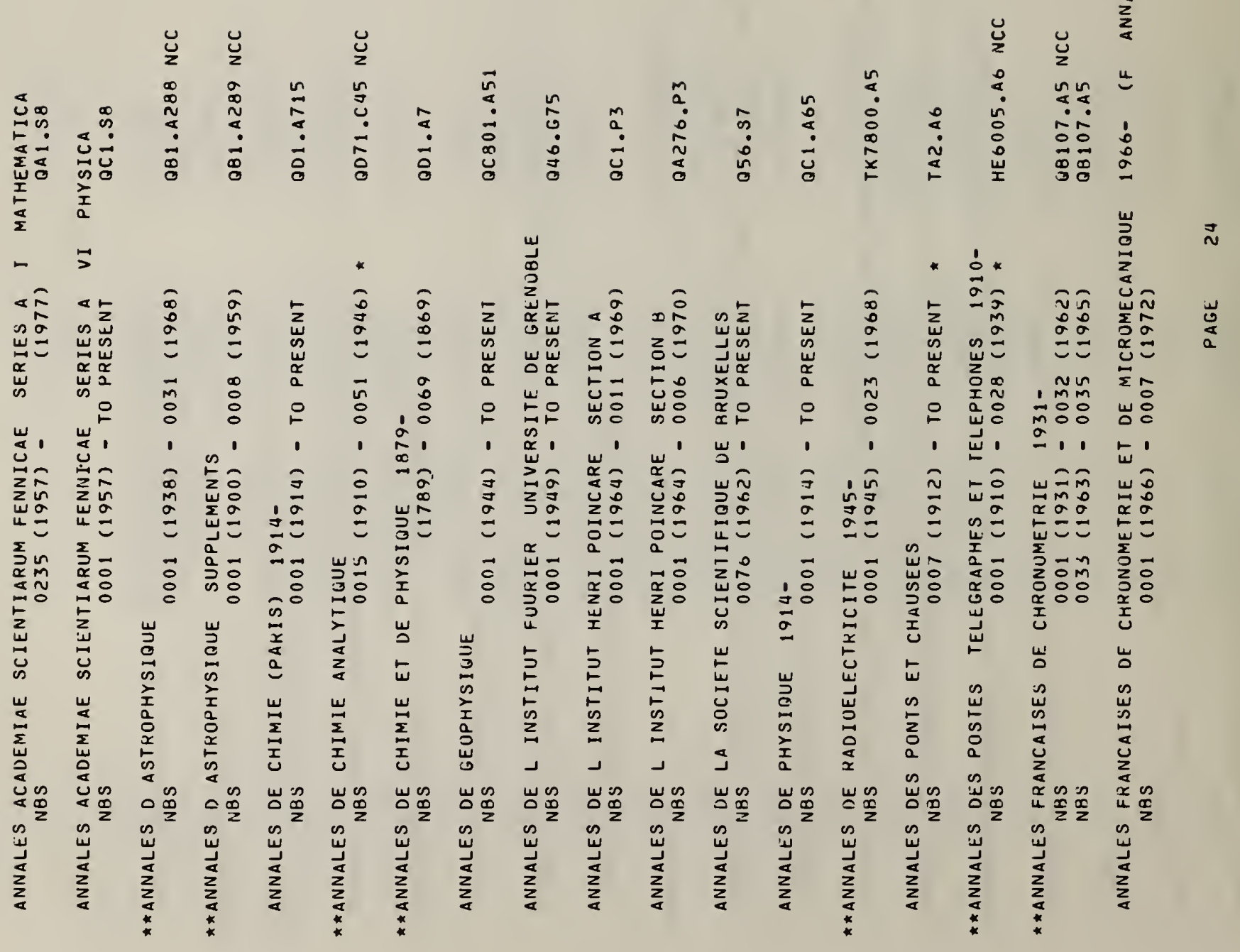




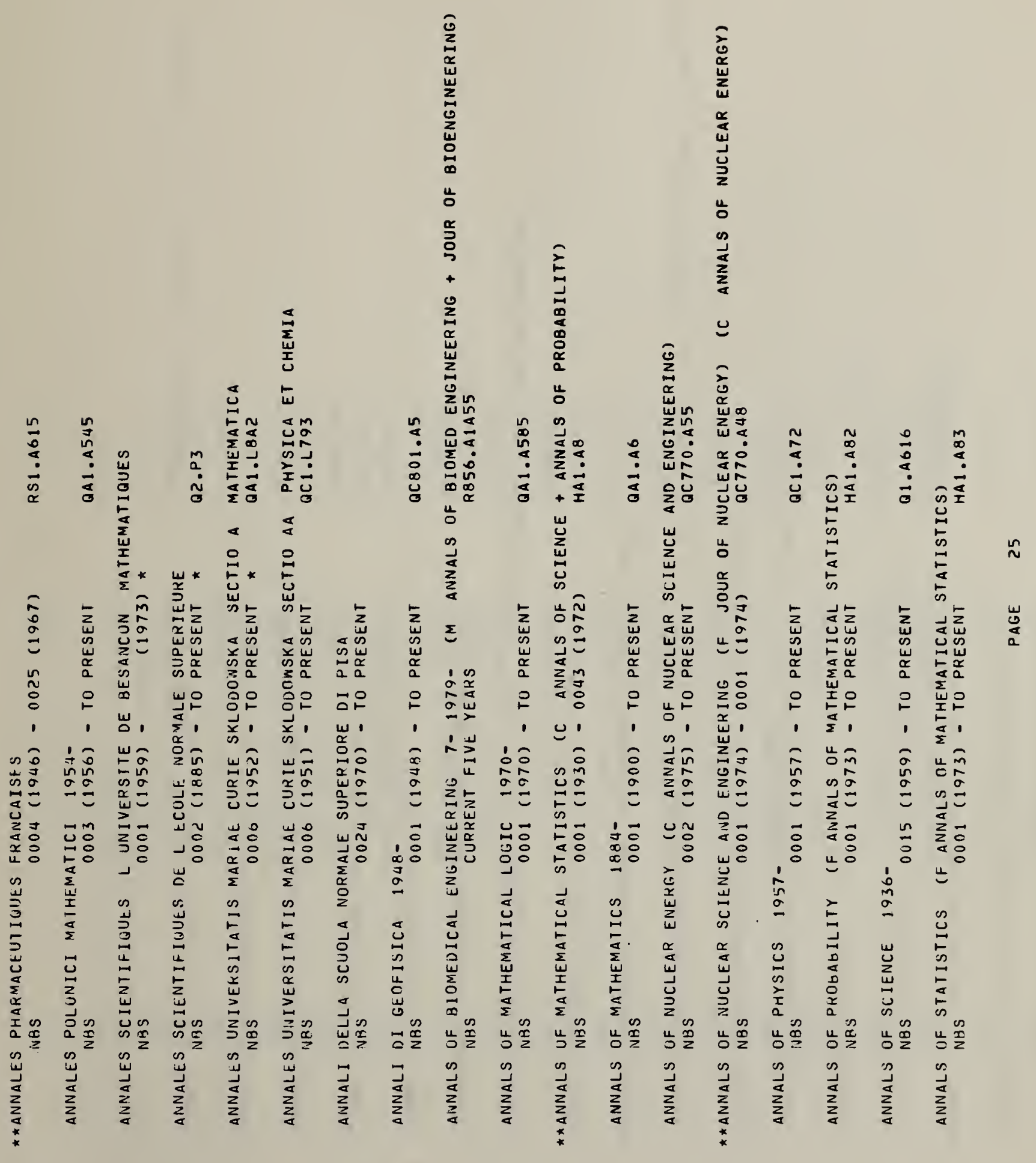




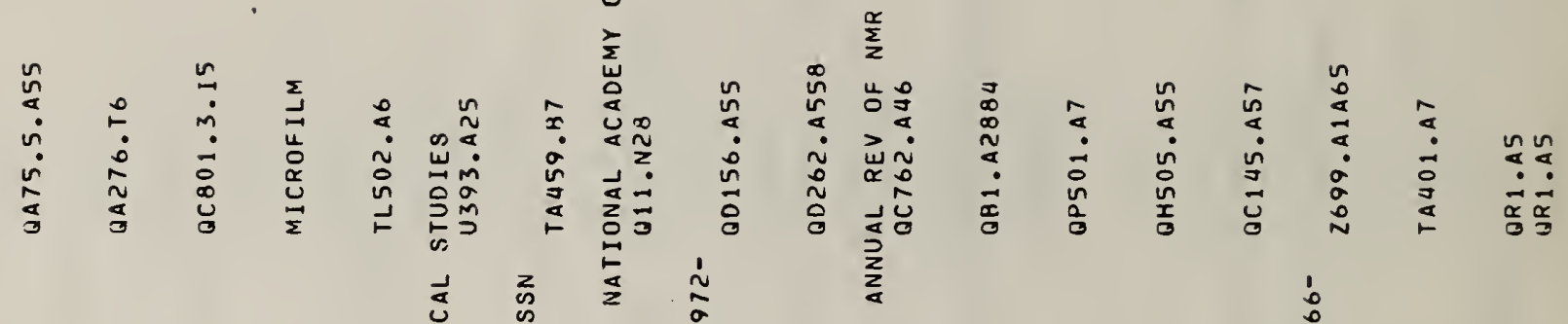

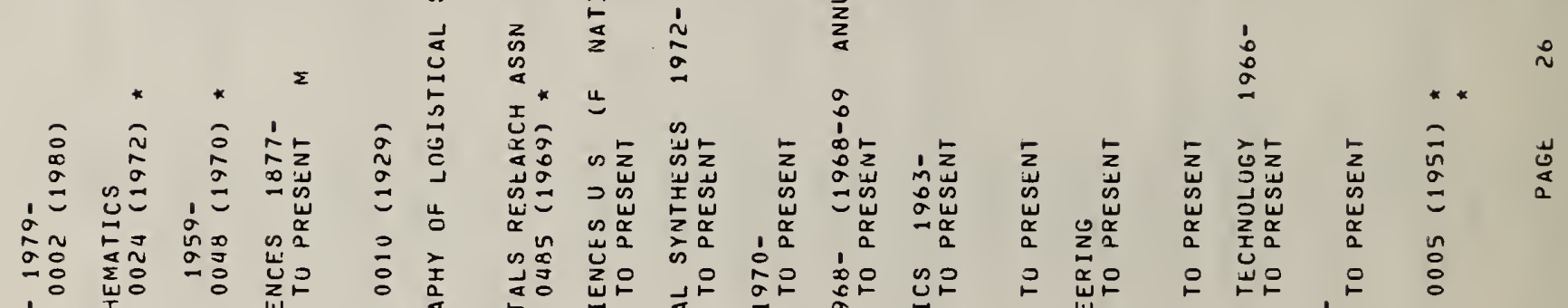

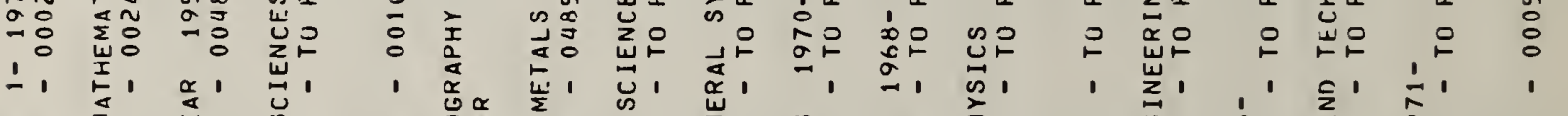

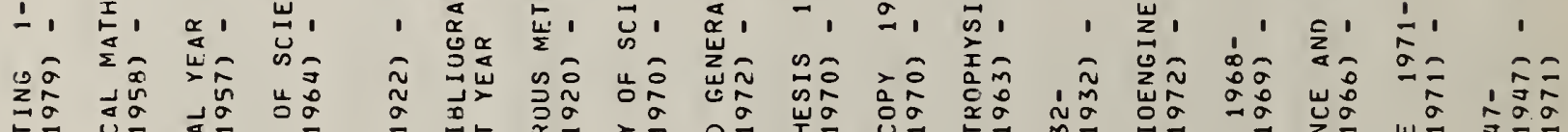

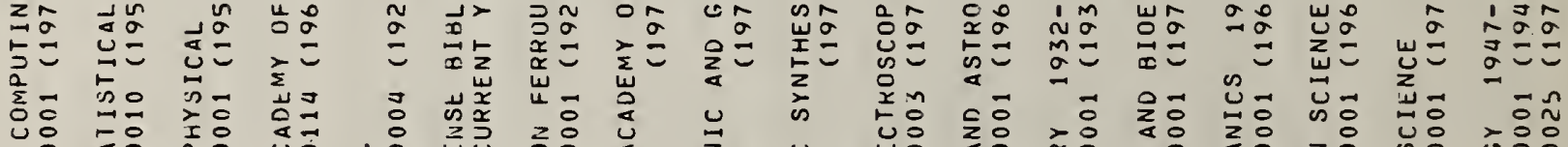

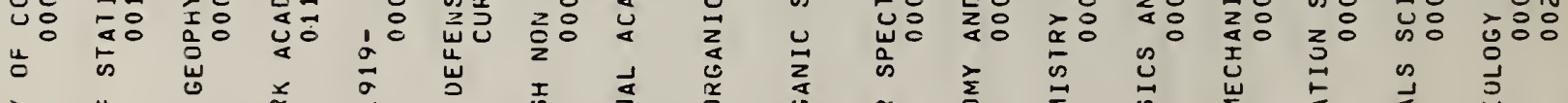

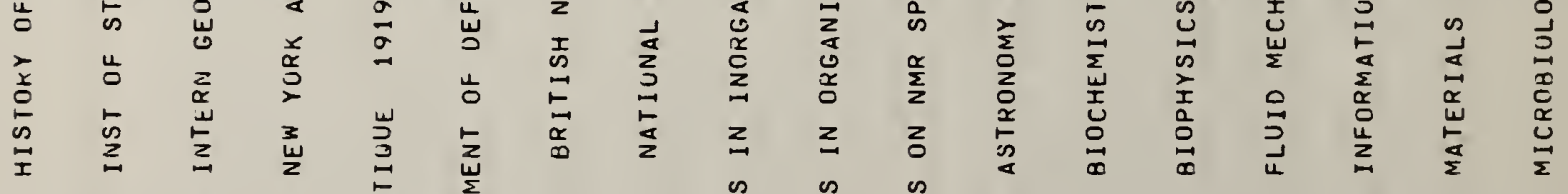

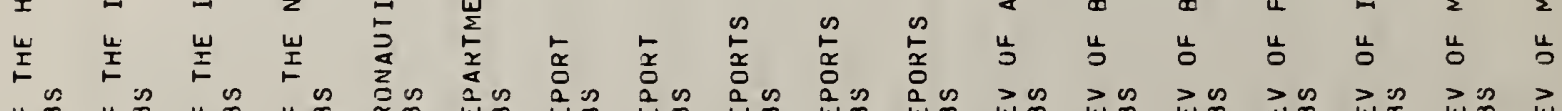

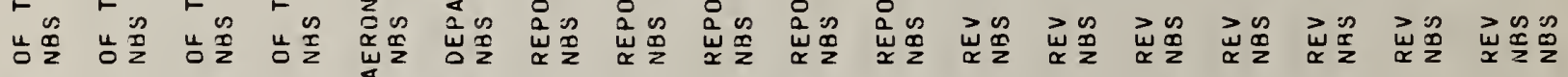

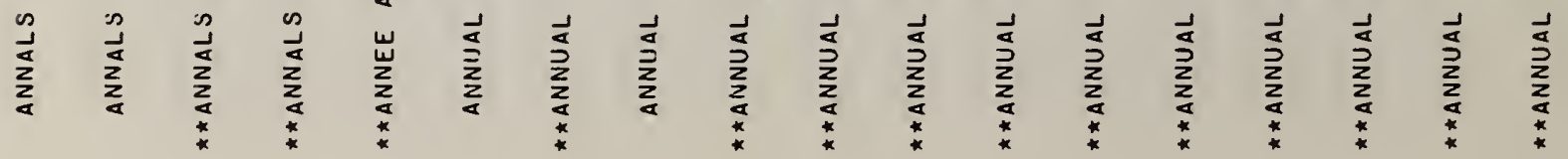




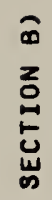

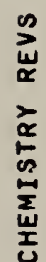

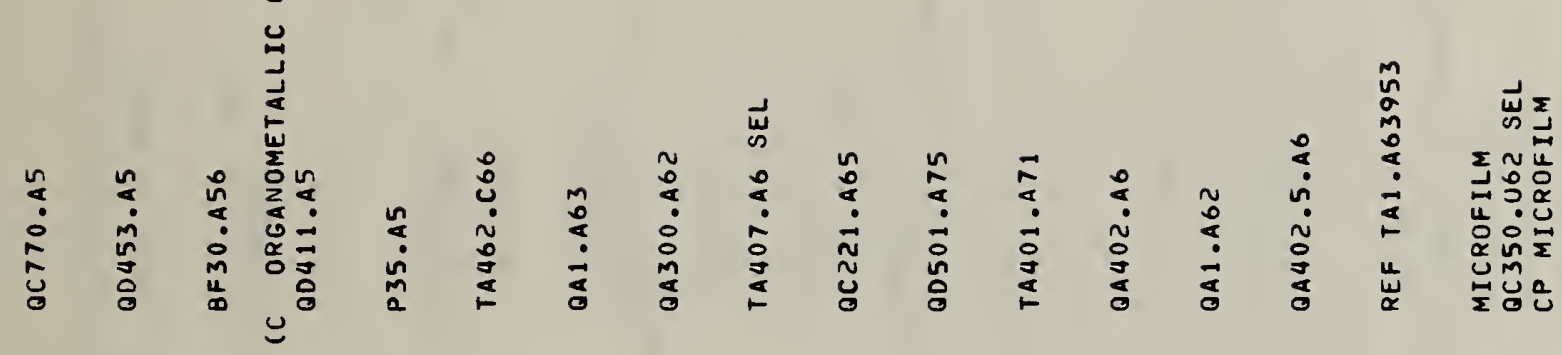

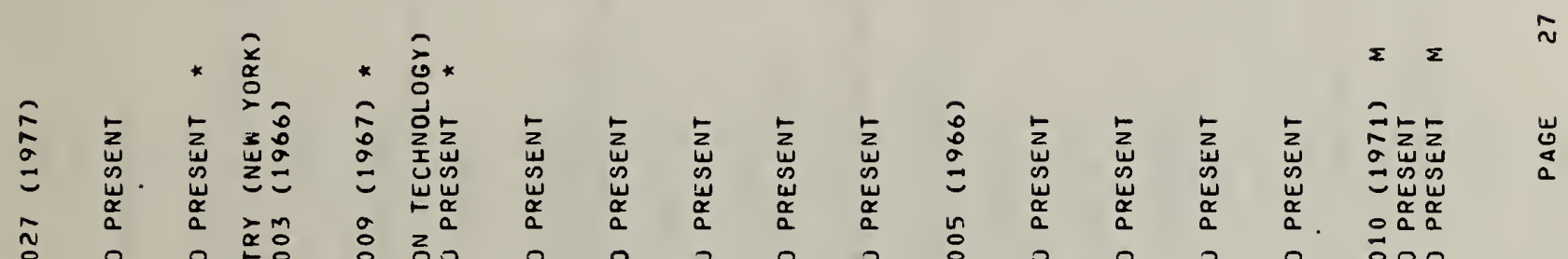

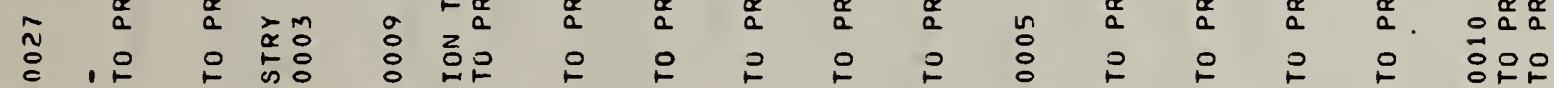

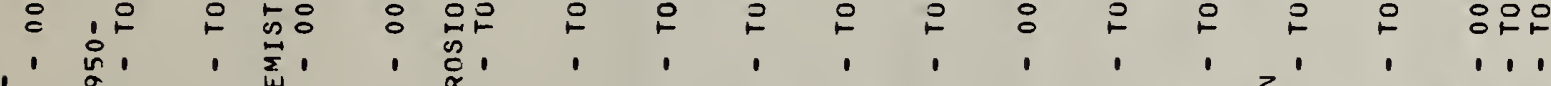

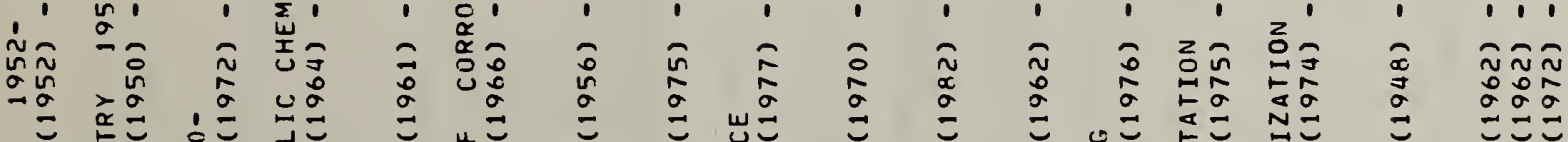
放

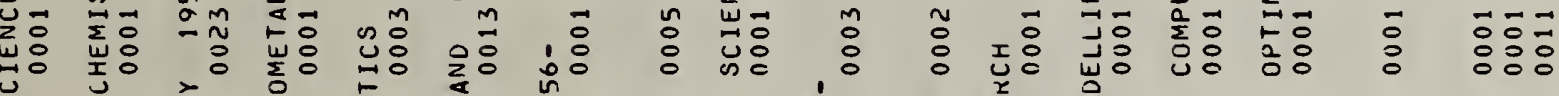

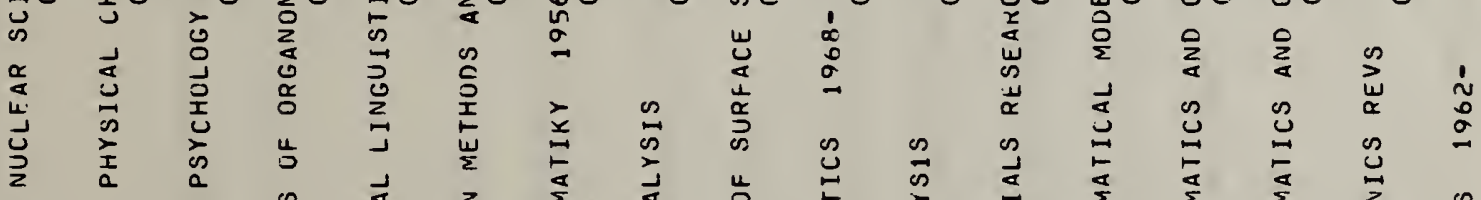

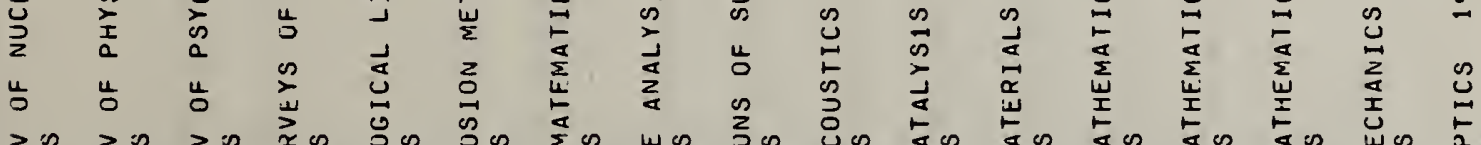

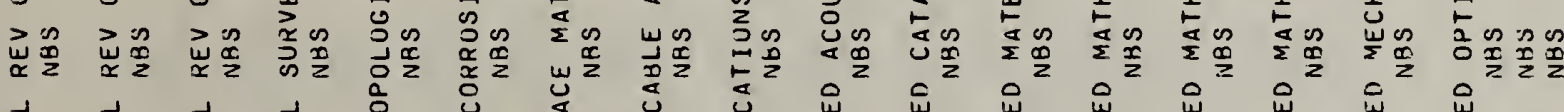

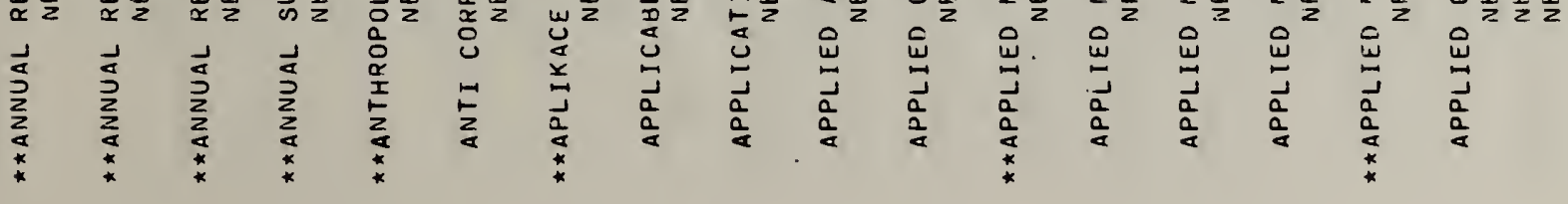




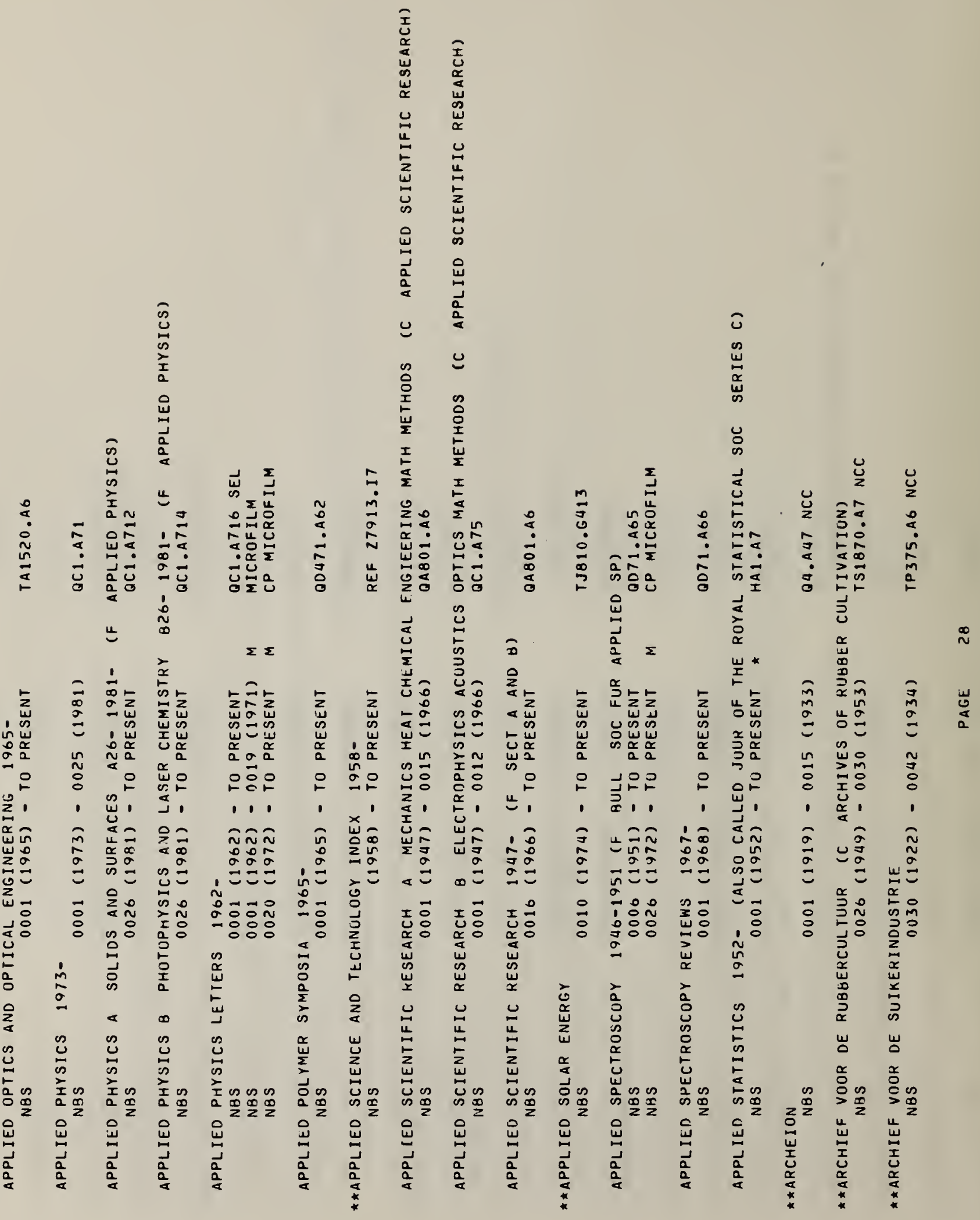




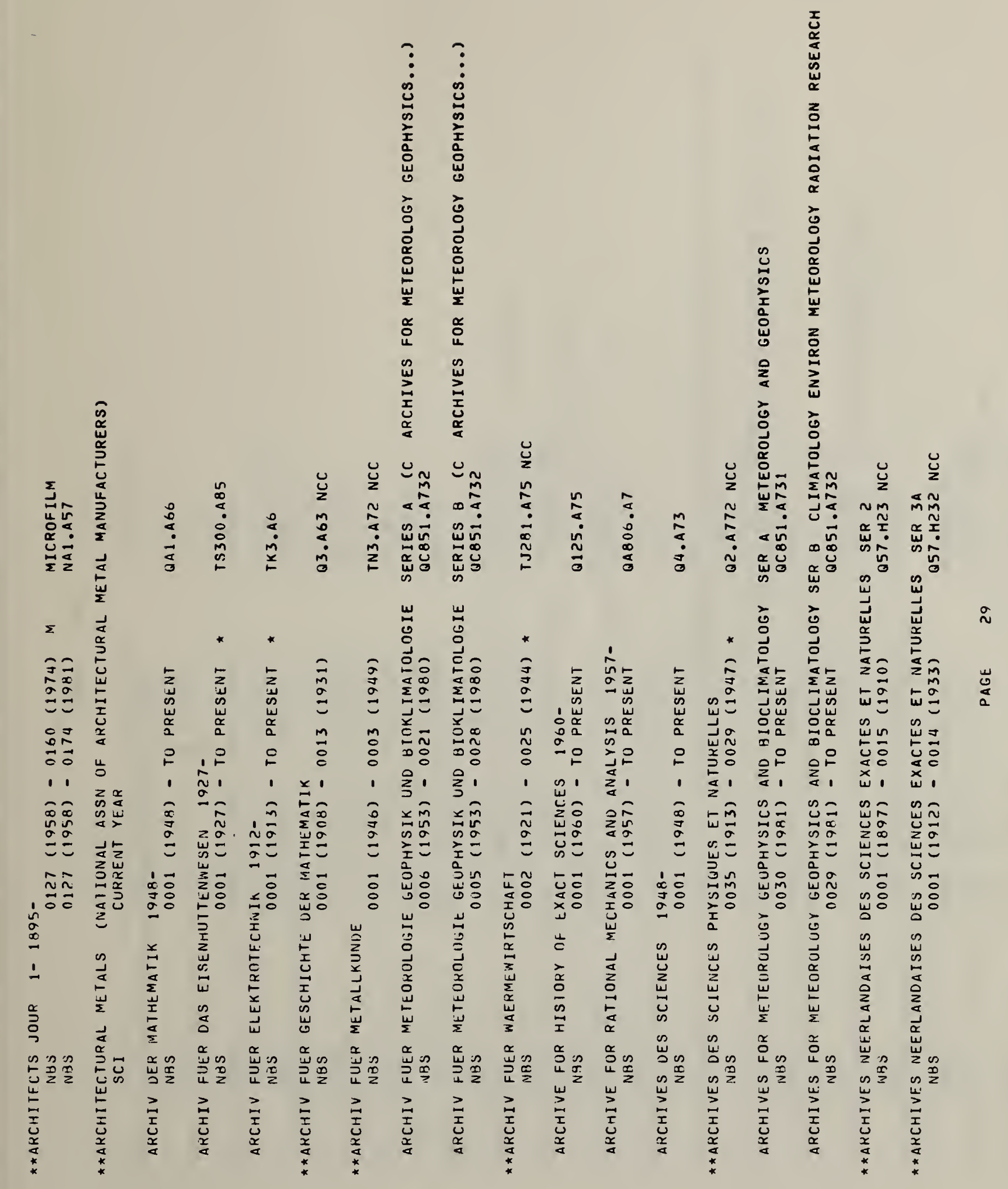




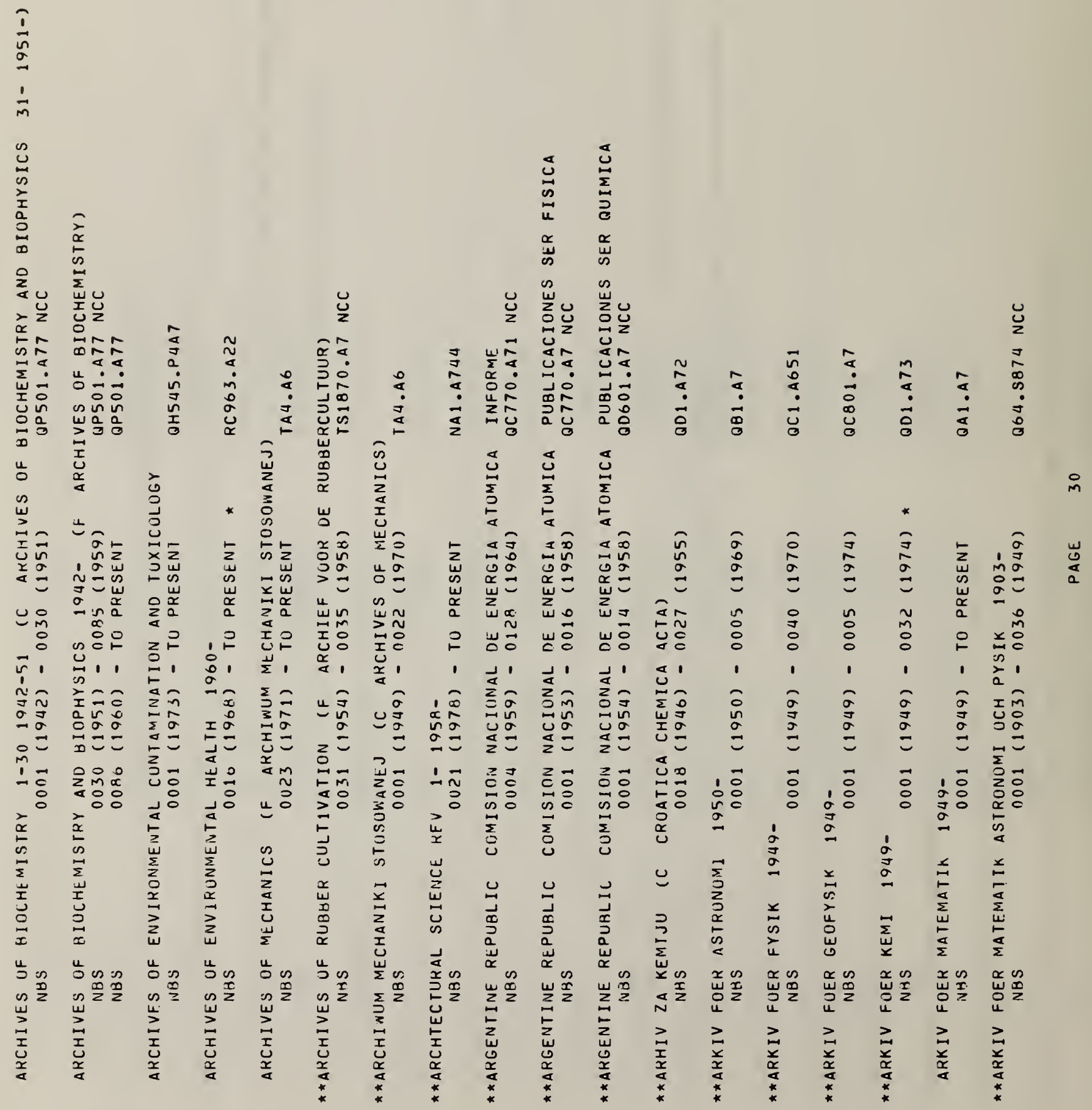




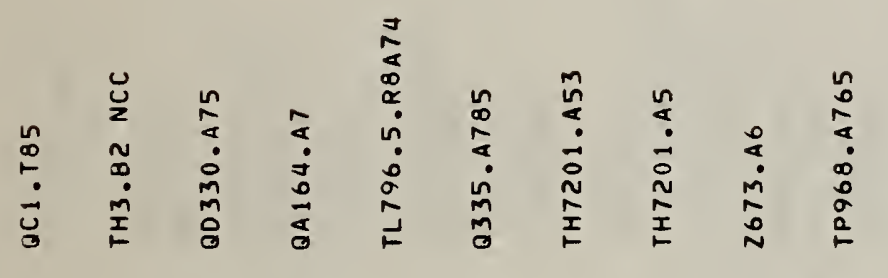

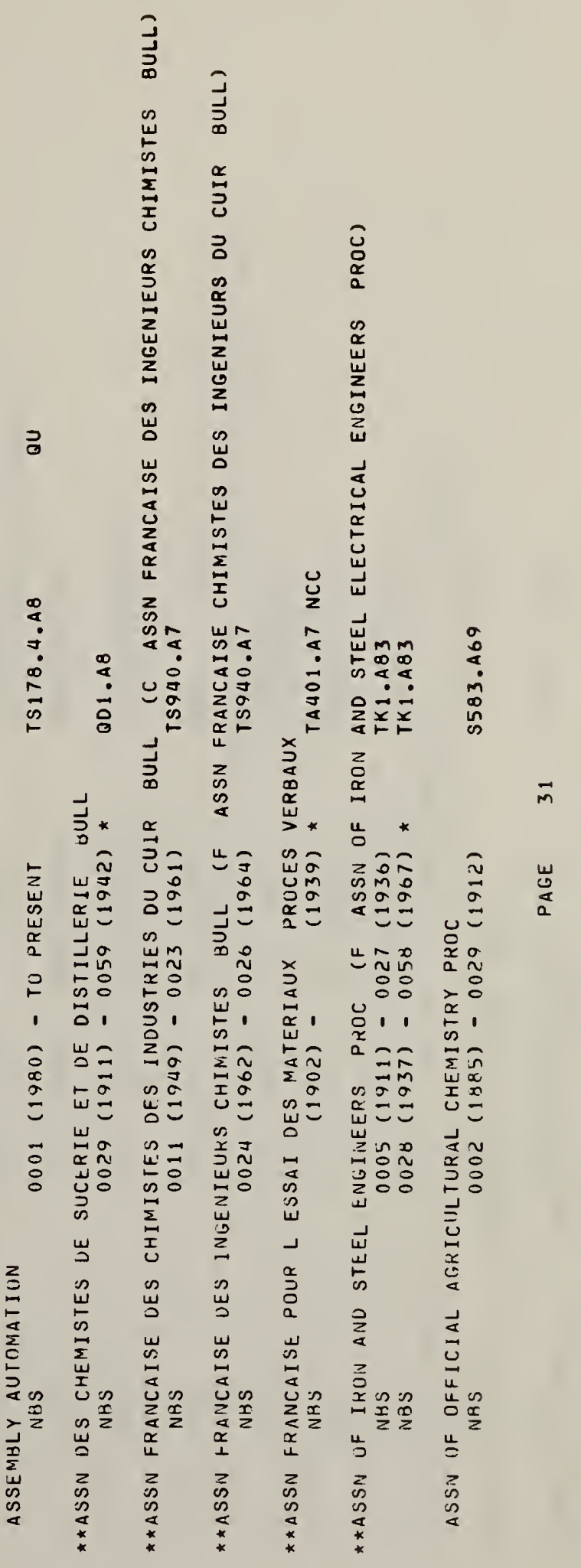




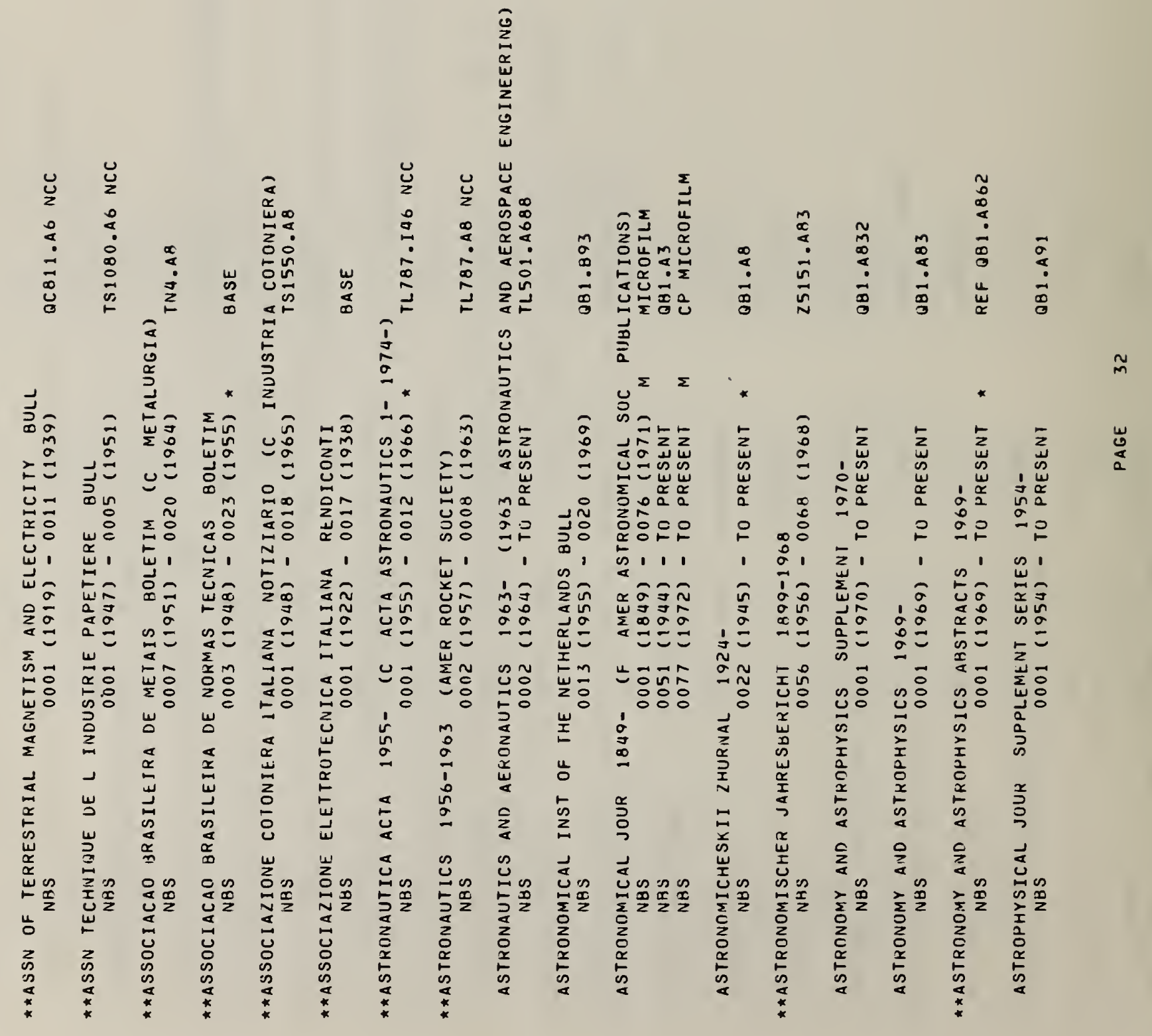




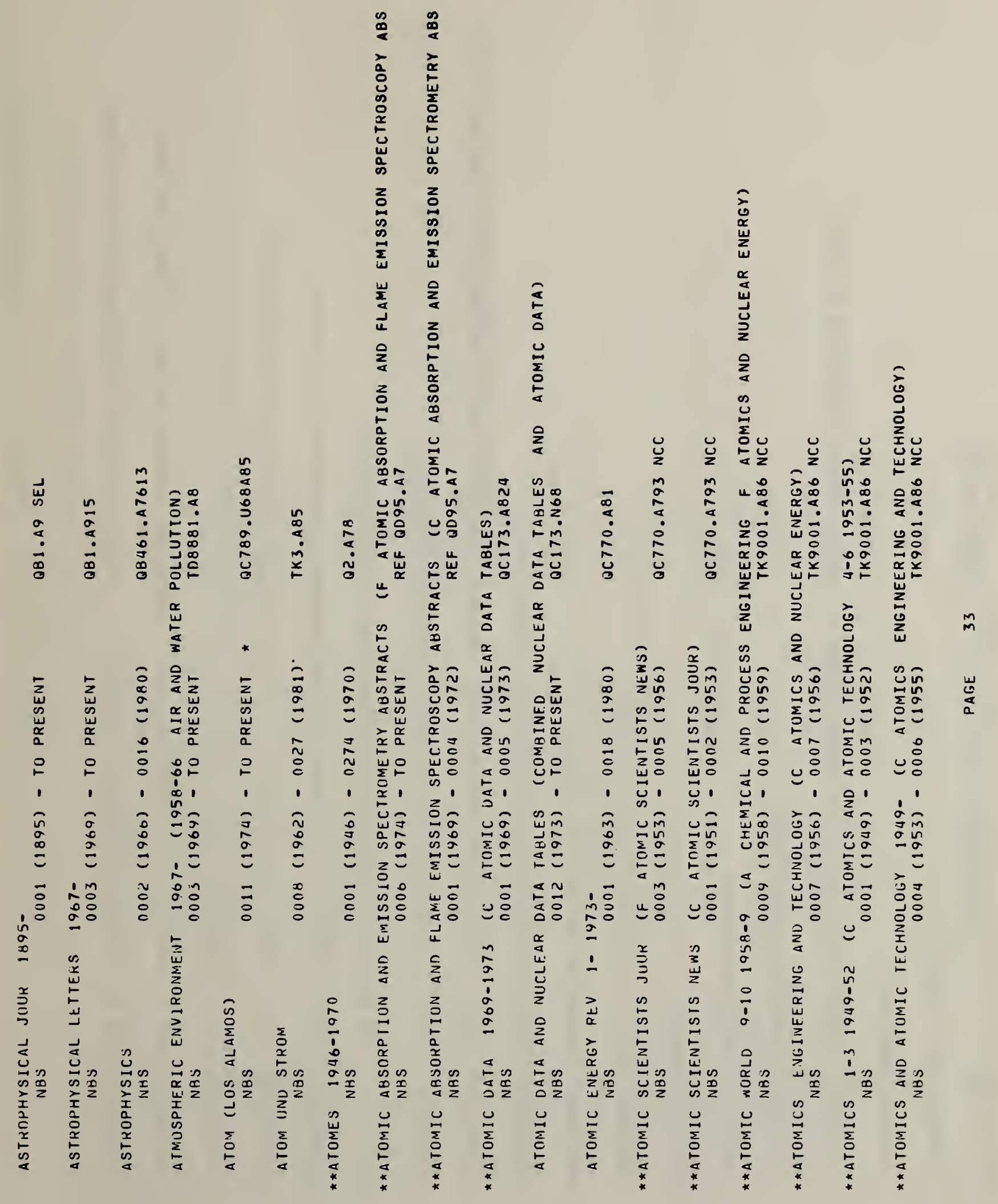




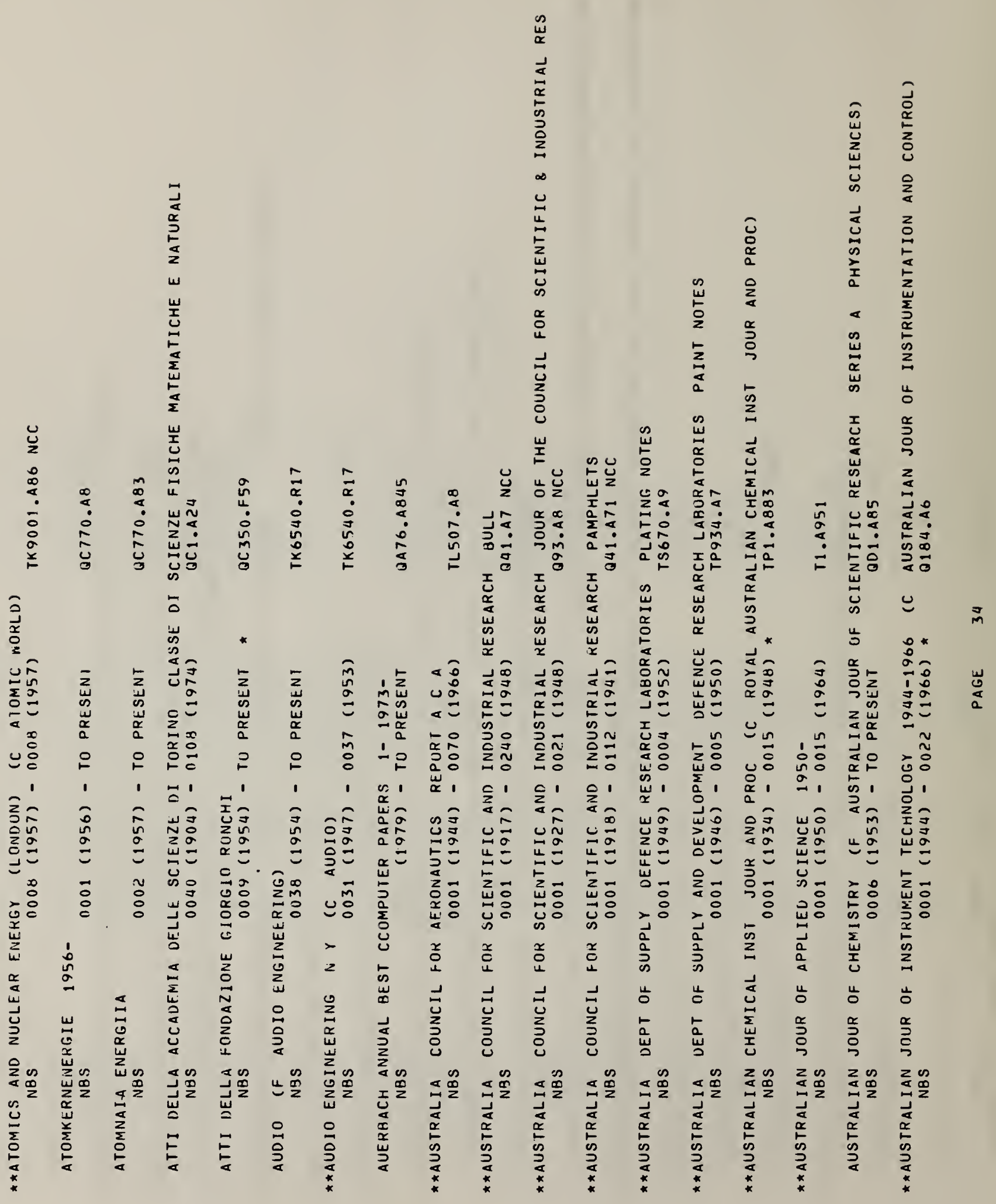




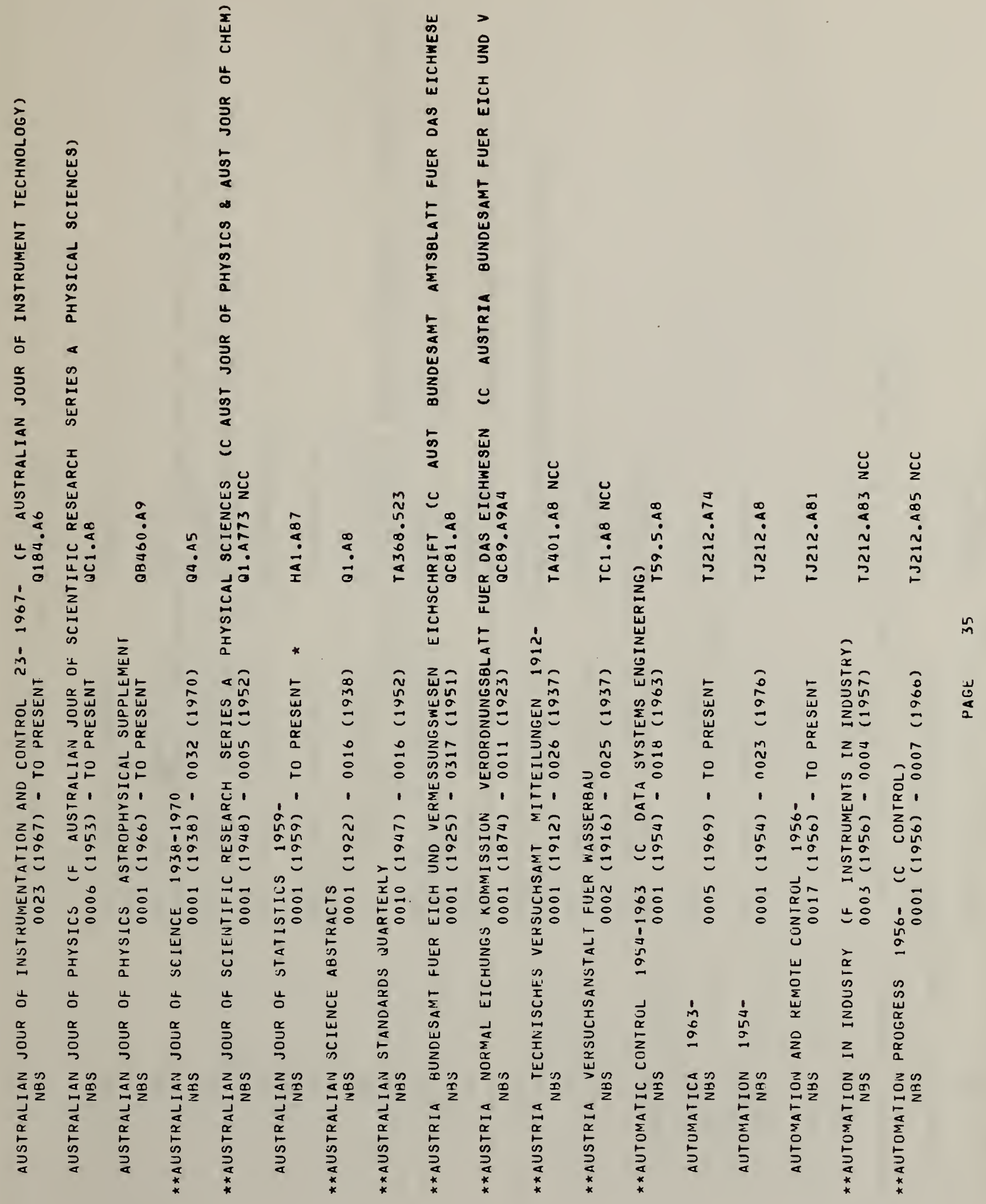




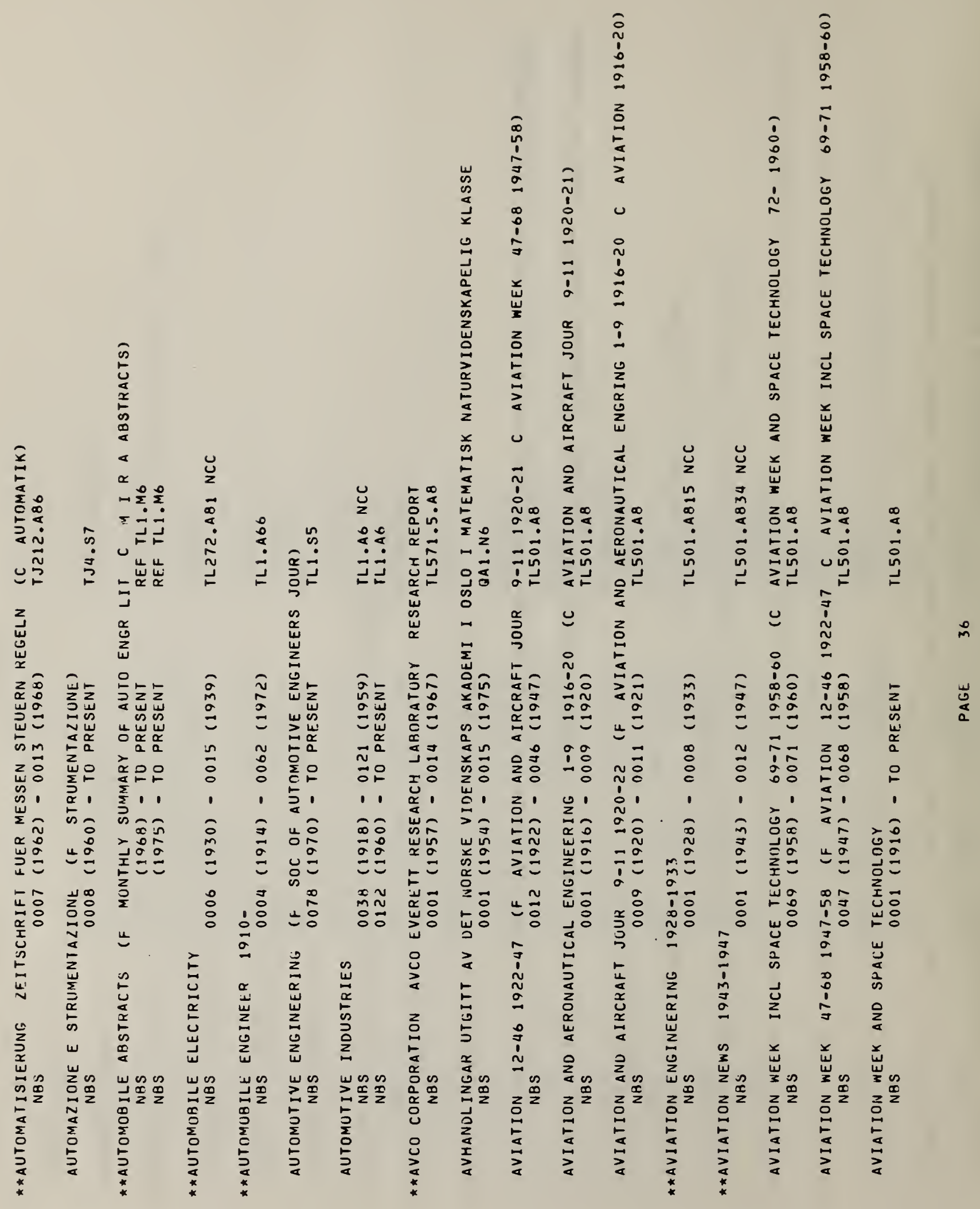




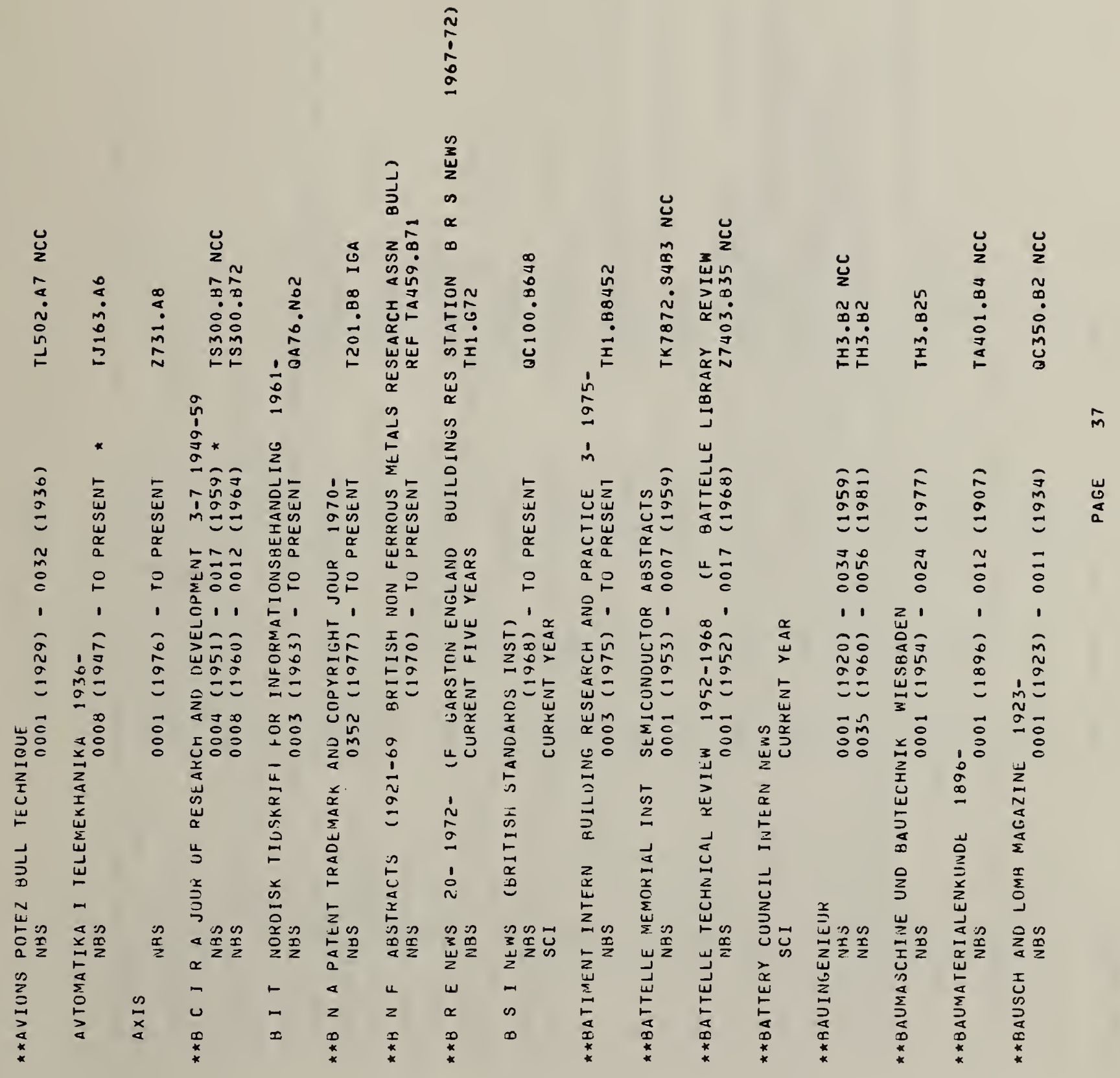




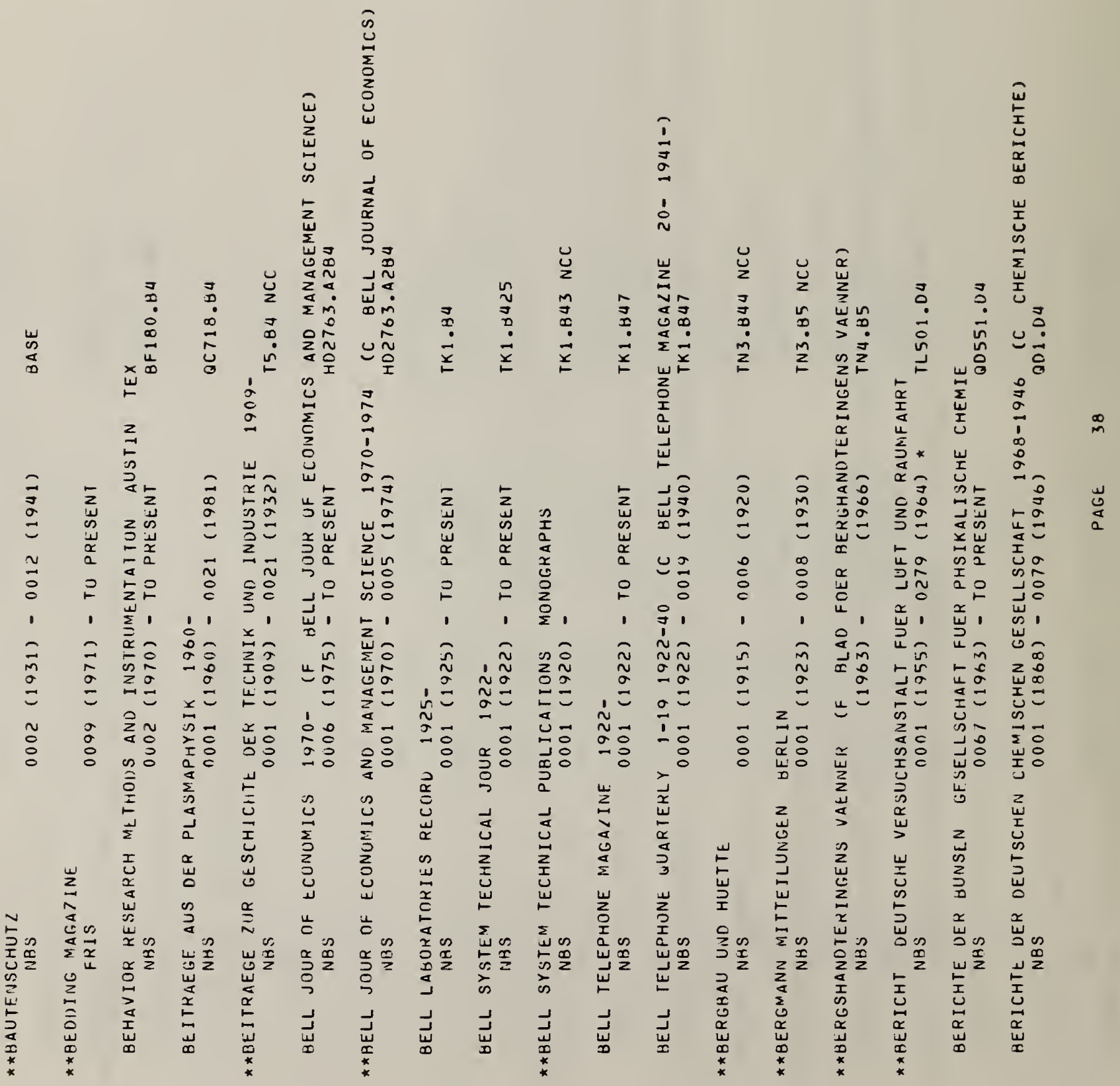




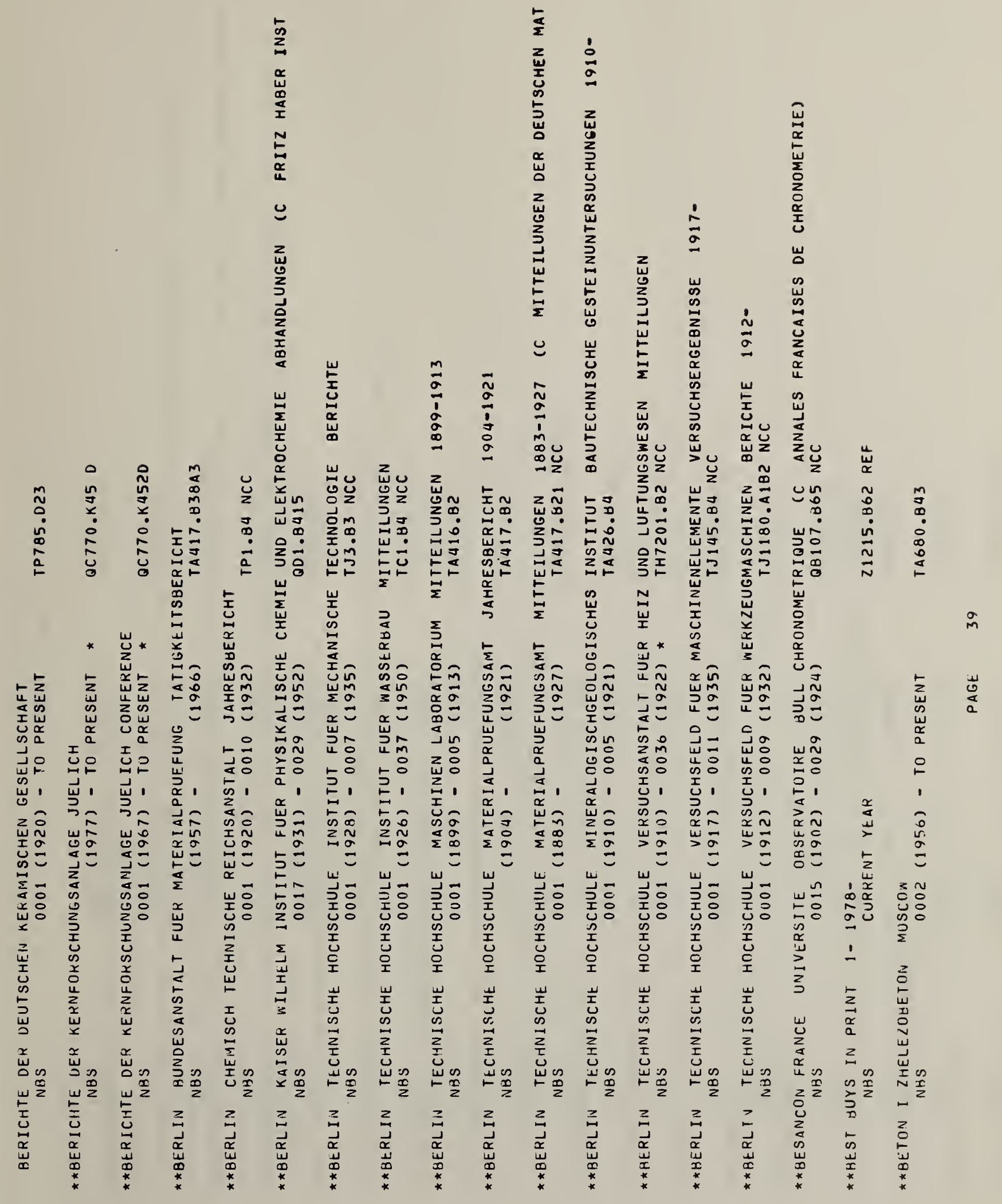




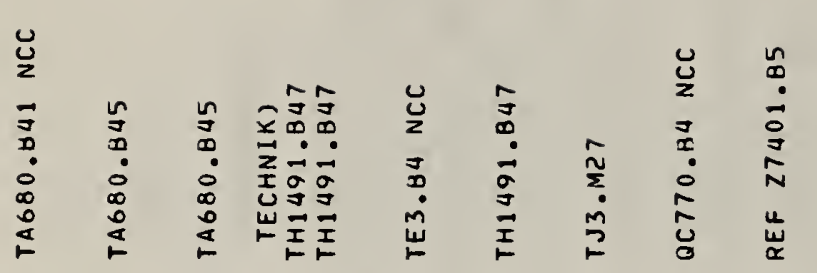

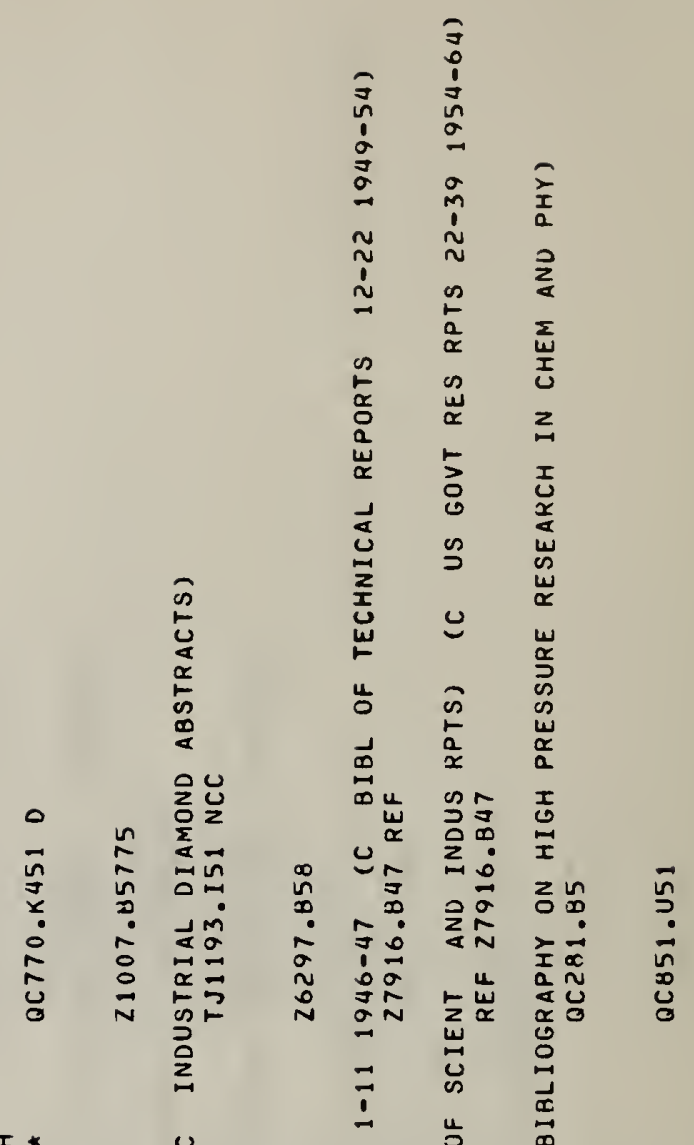

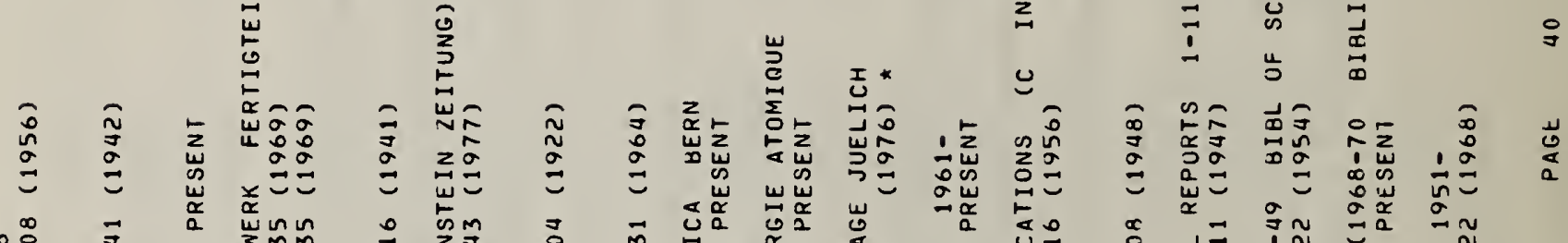

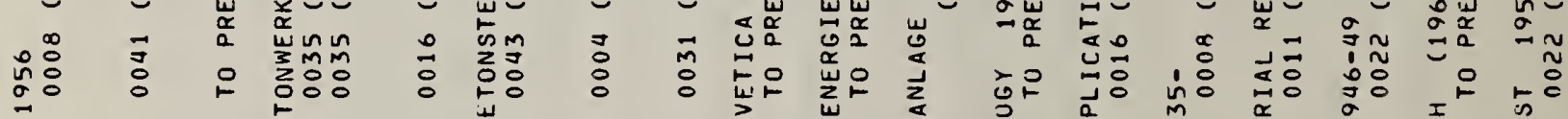

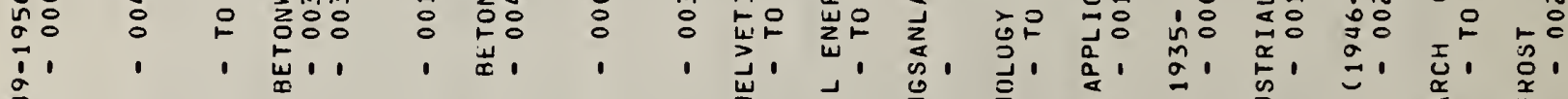

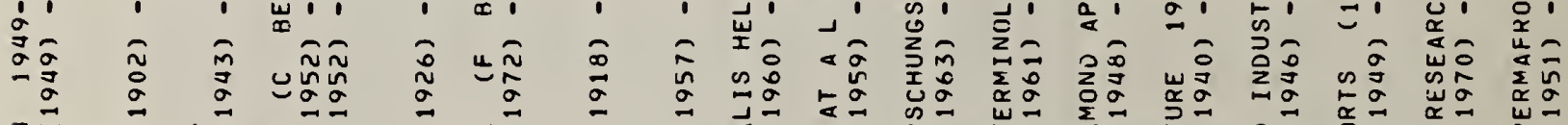

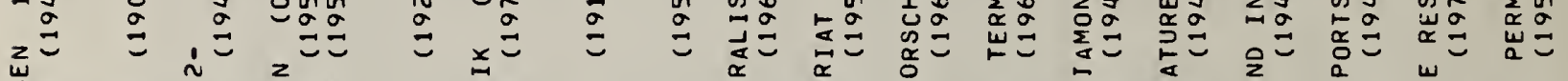

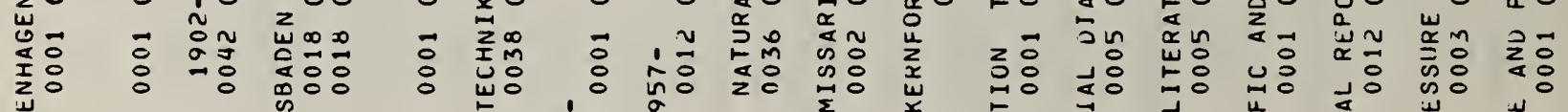

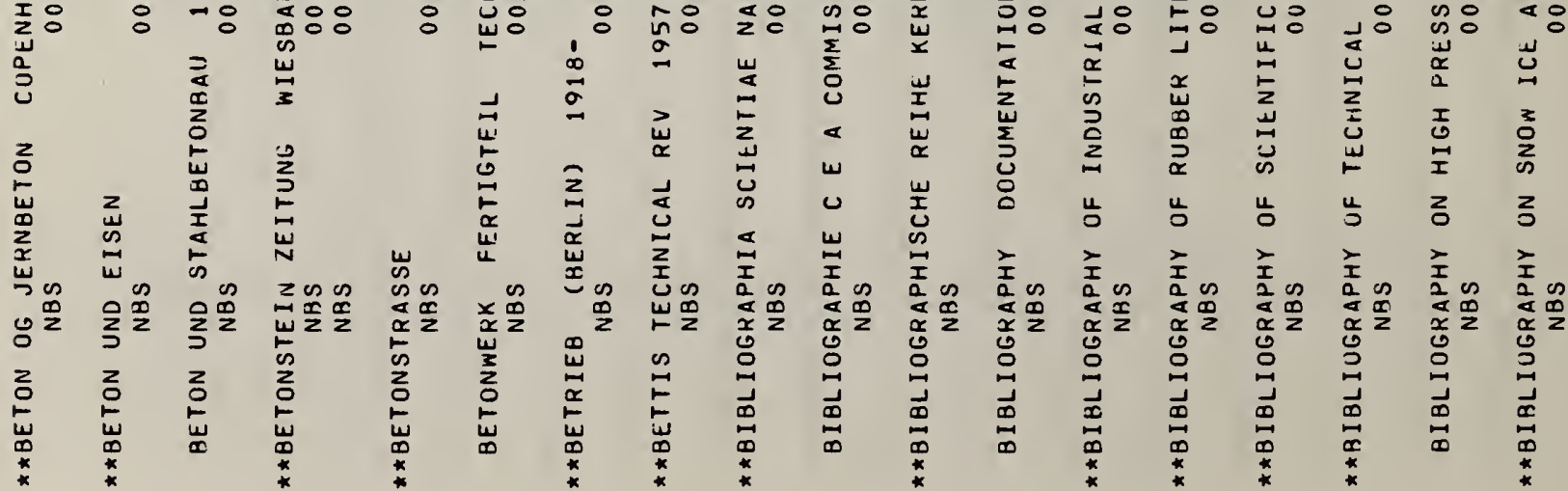




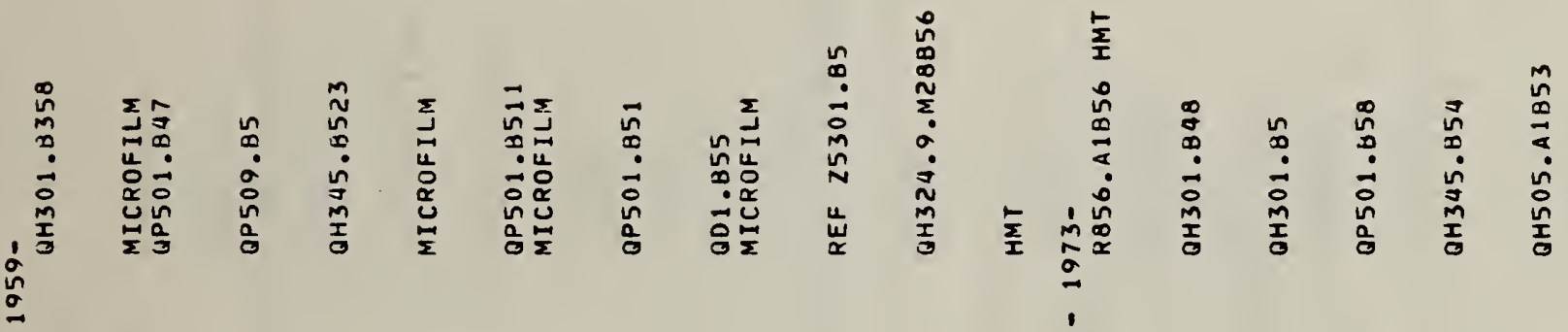

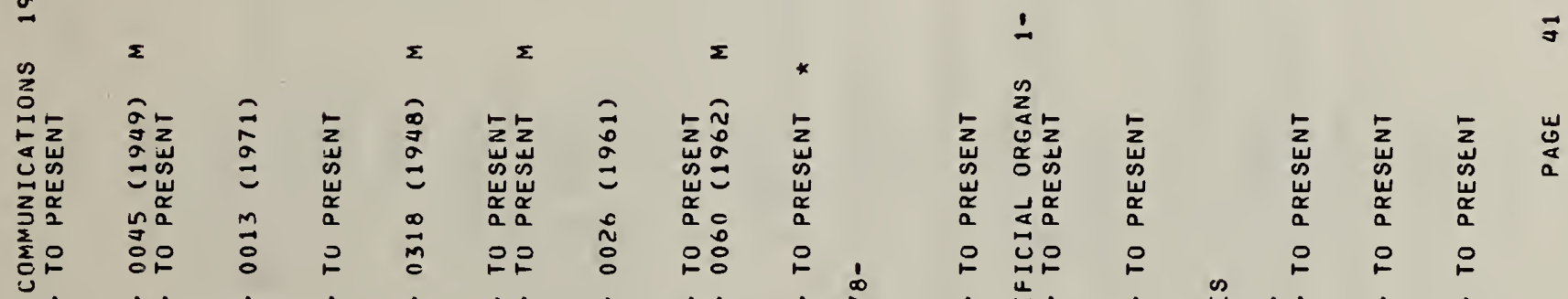

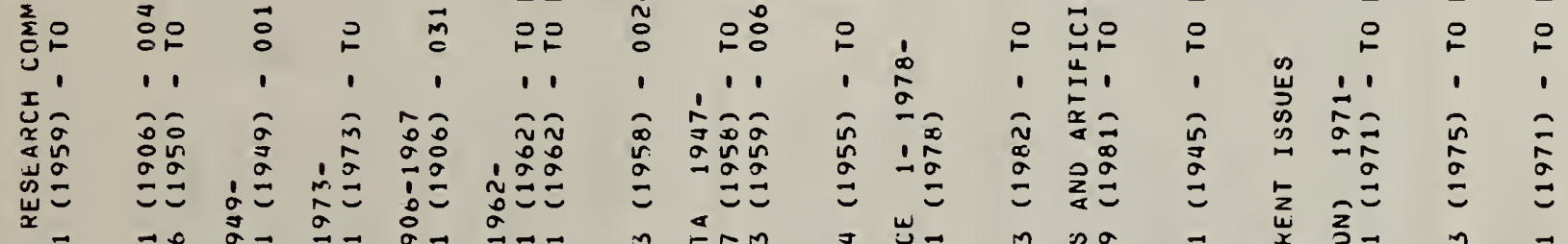

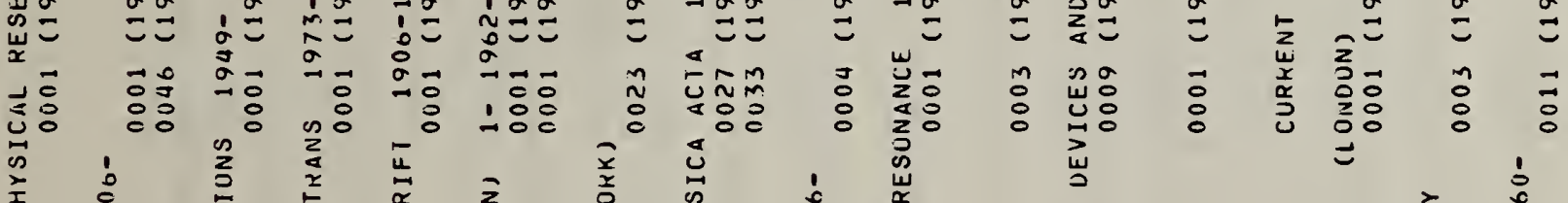

$$
\begin{aligned}
& \begin{array}{lllllllllll} 
& & & \\
0
\end{array}
\end{aligned}
$$

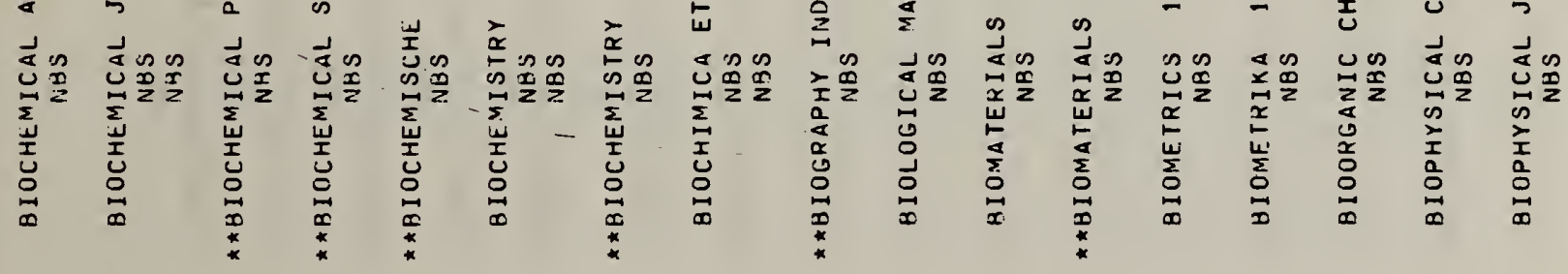




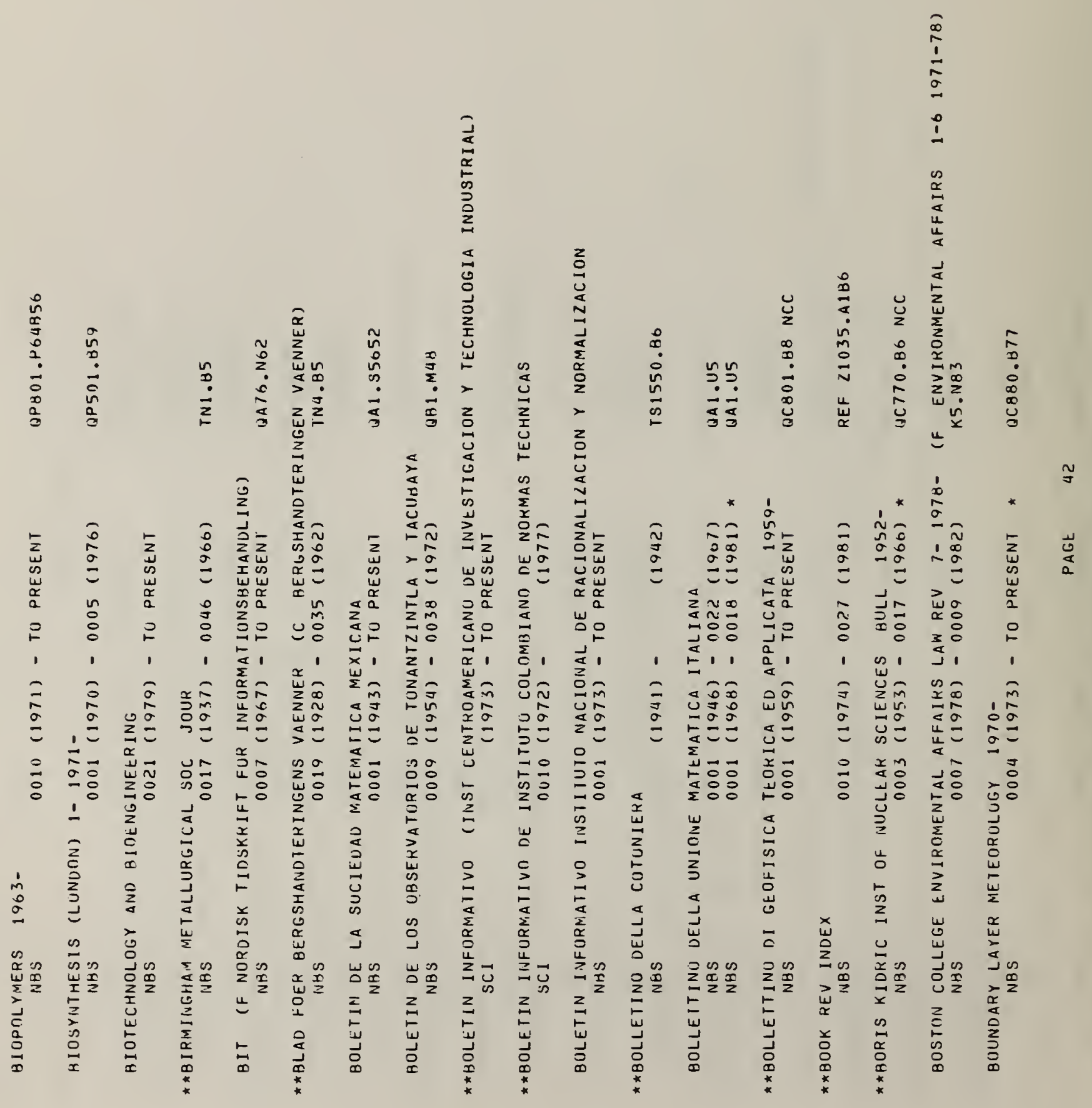




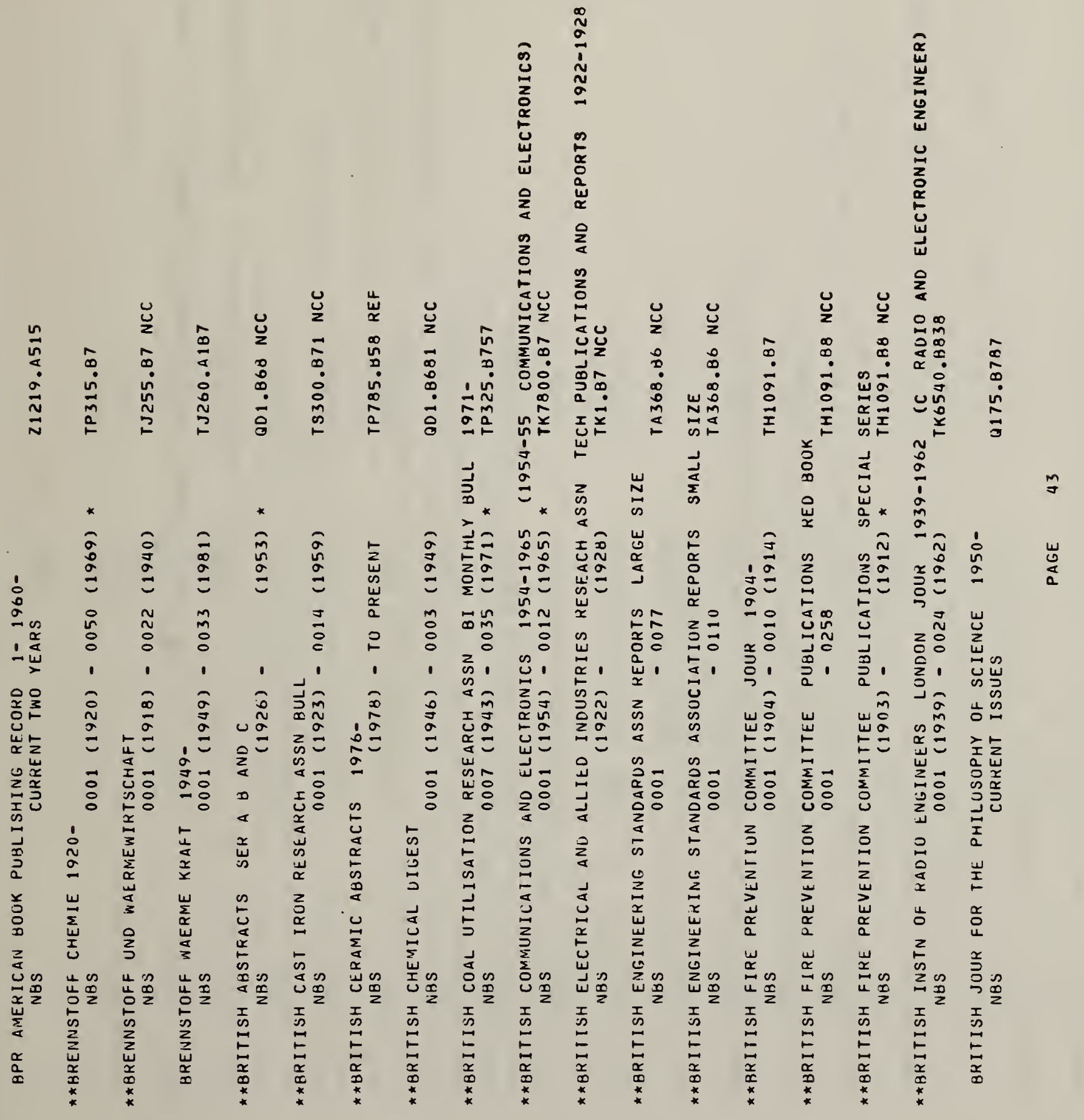




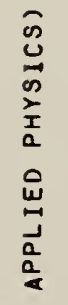

$\frac{1}{0}$
$\frac{1}{7}$

$\circ$

总

告

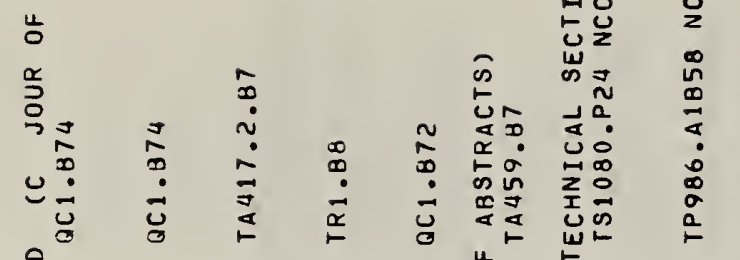

$\circ$

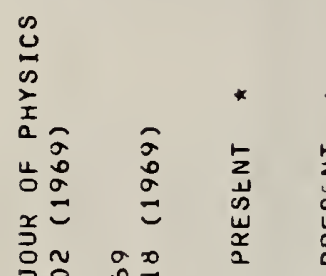

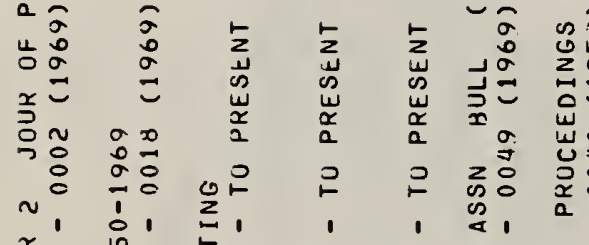

ข.

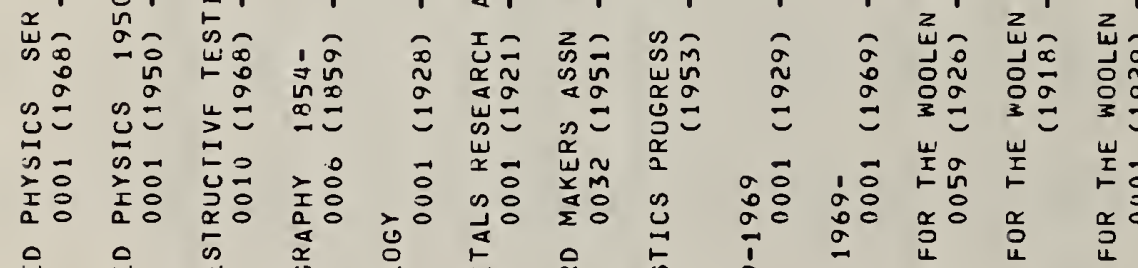

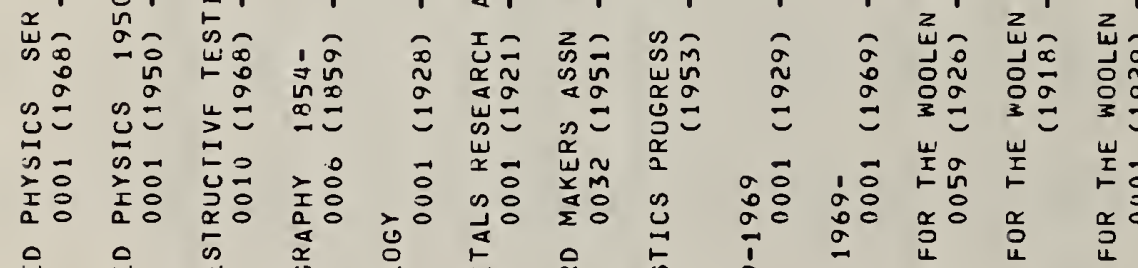

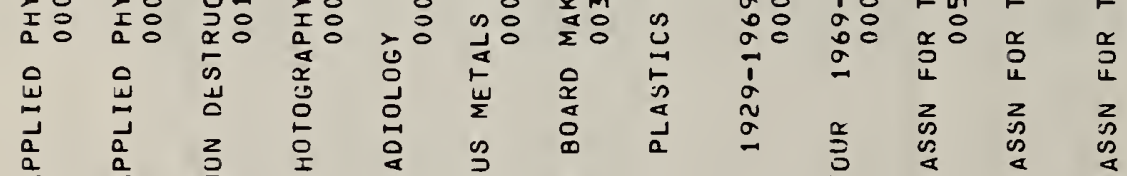

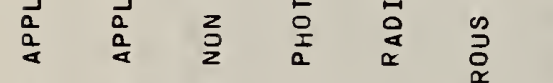

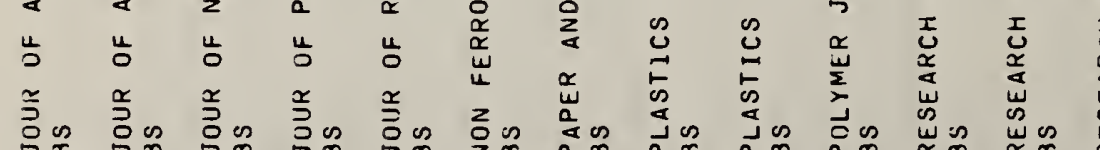

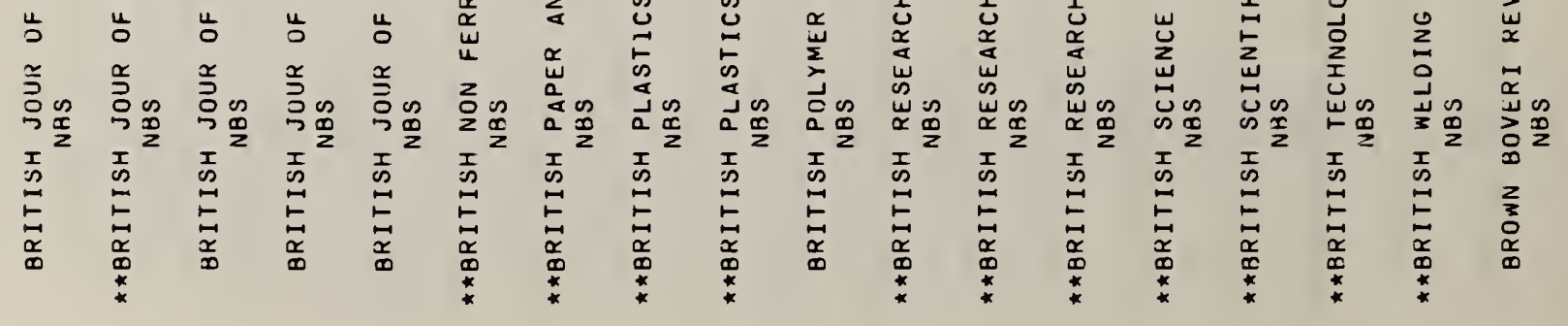




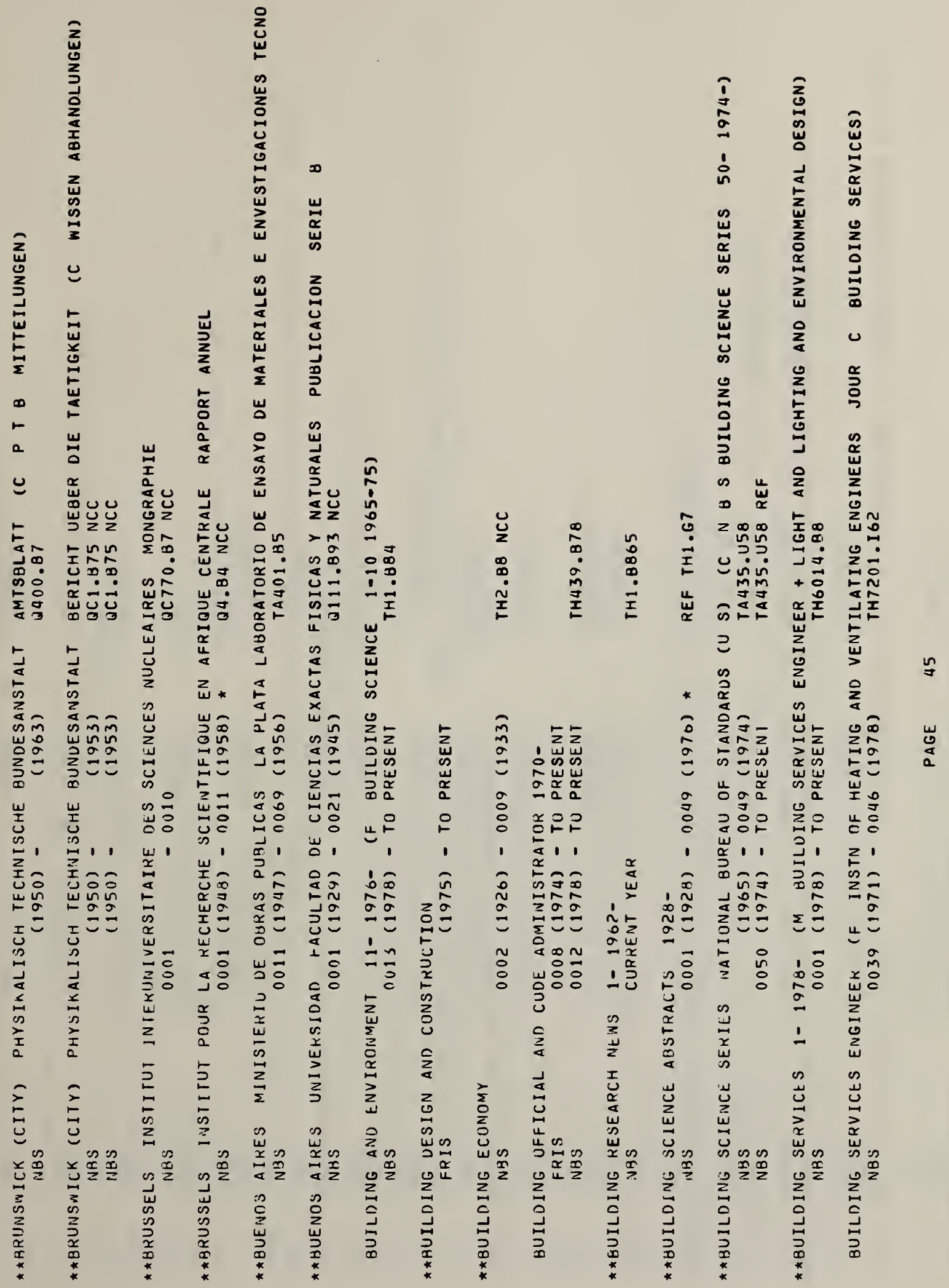




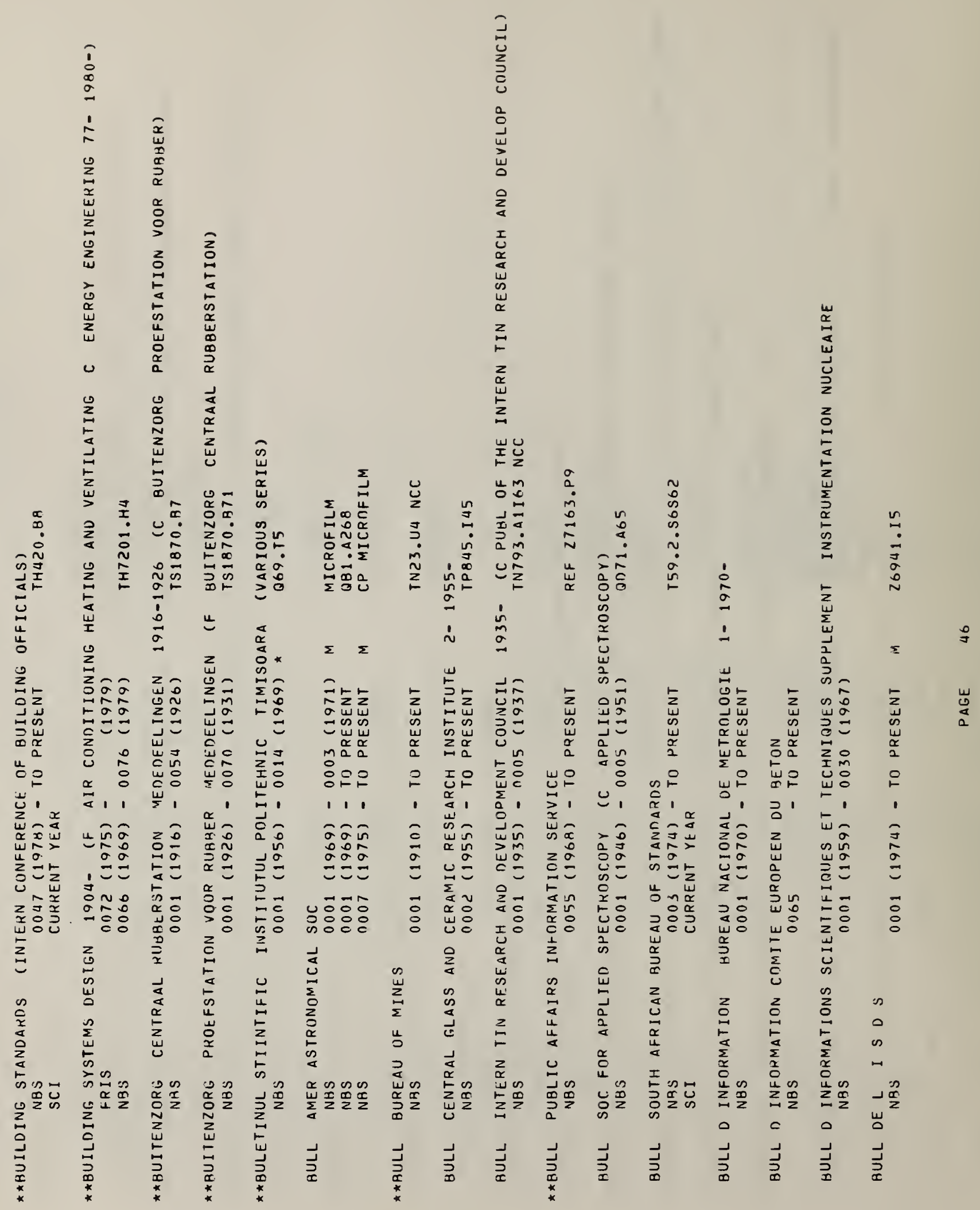




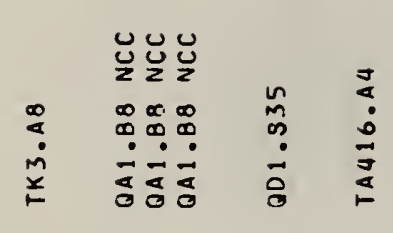

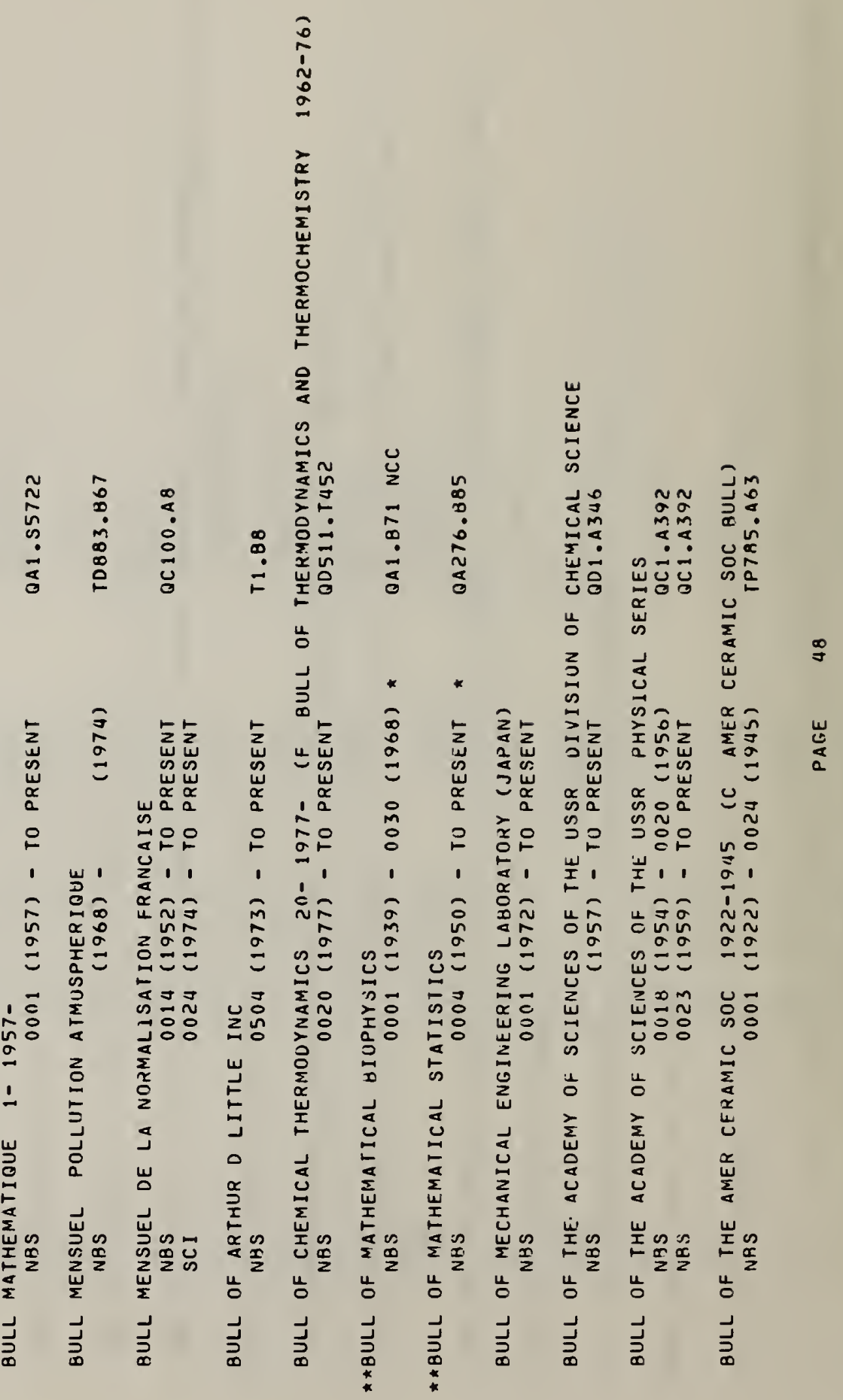




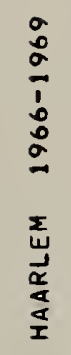

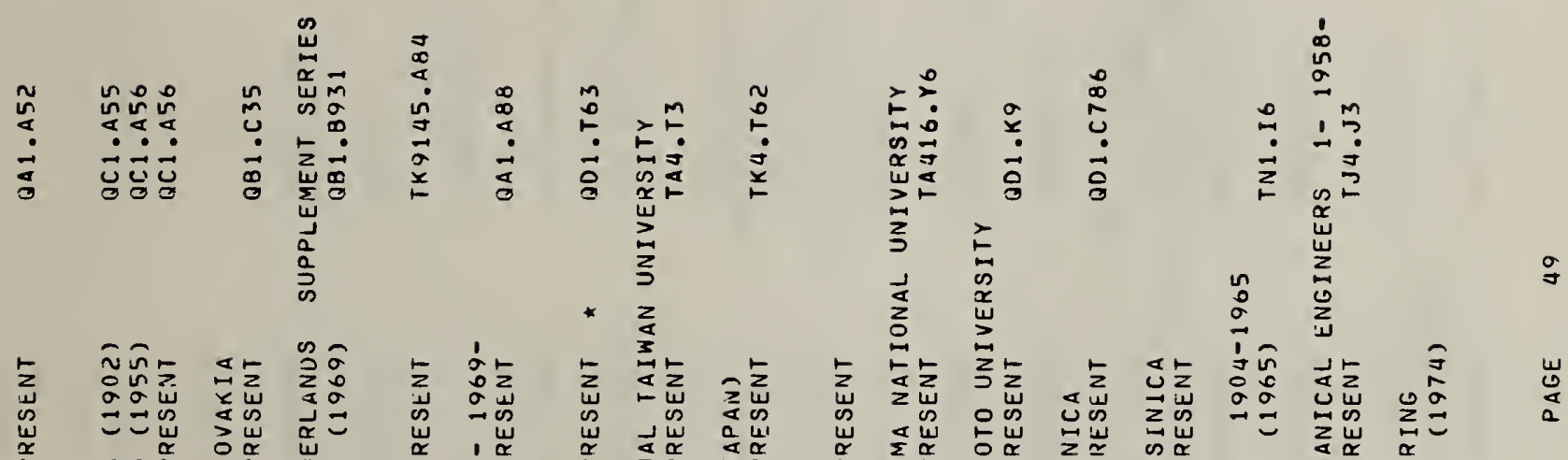

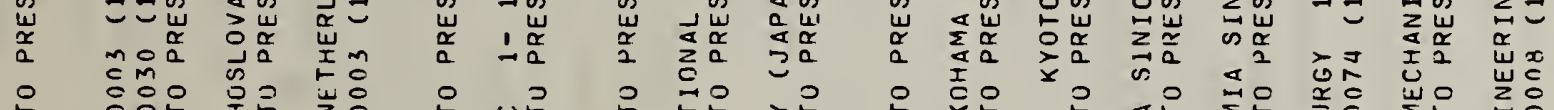

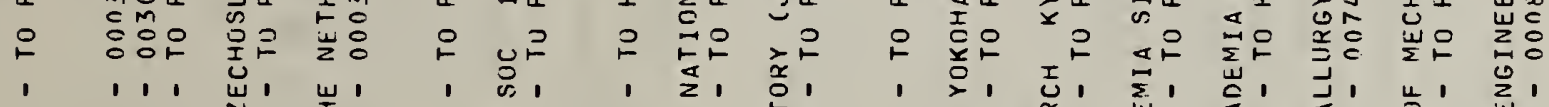

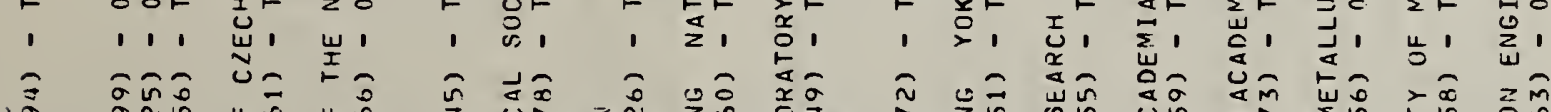

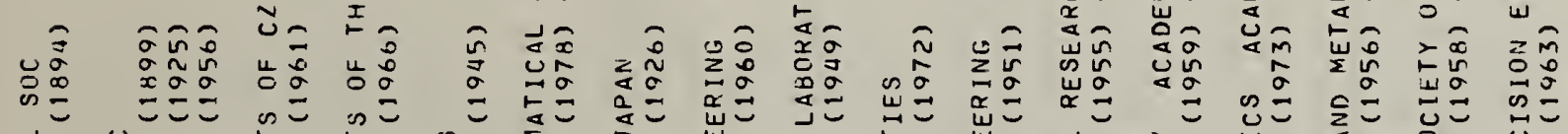

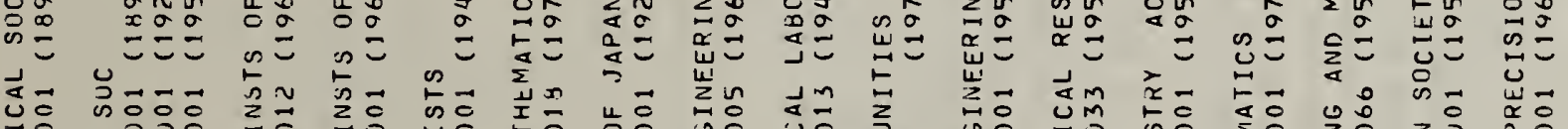
녕

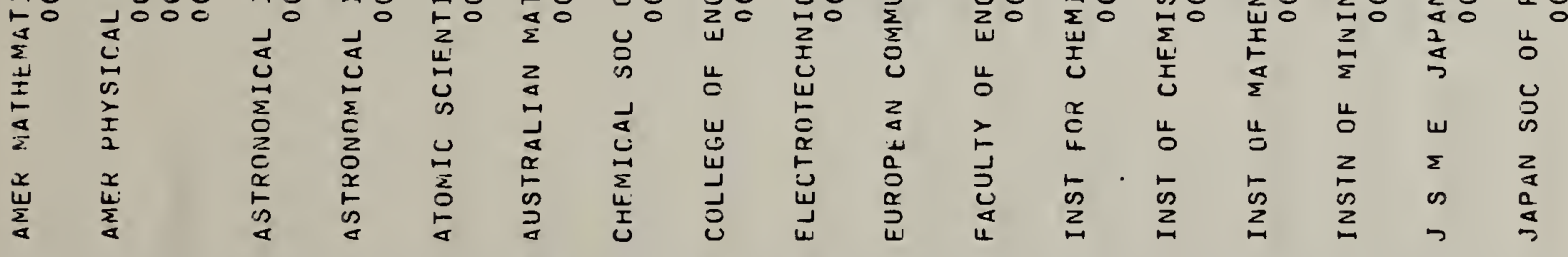

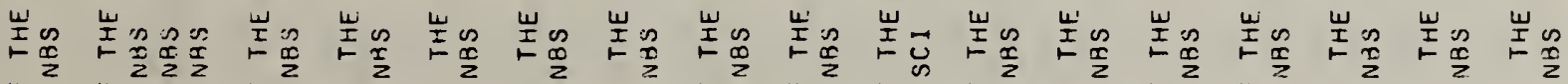

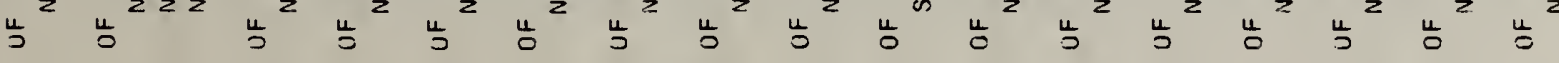

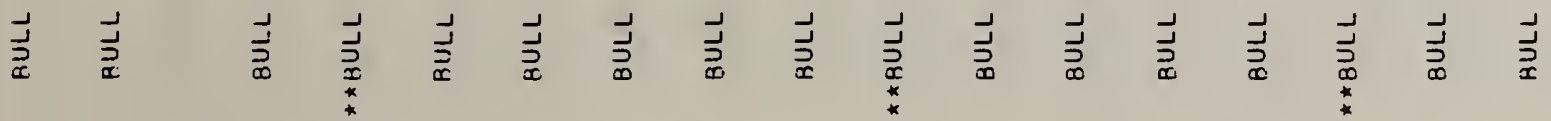




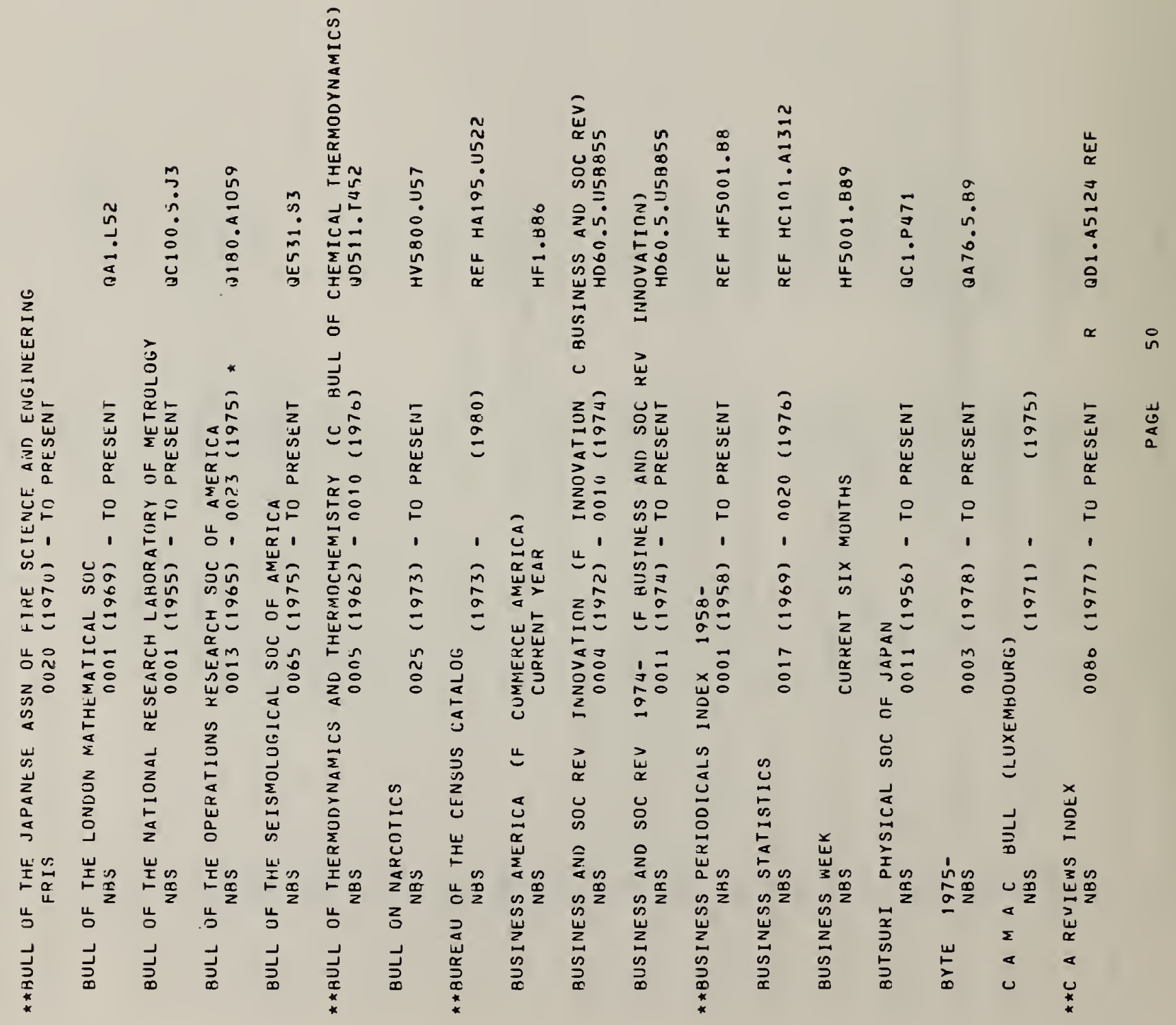


운

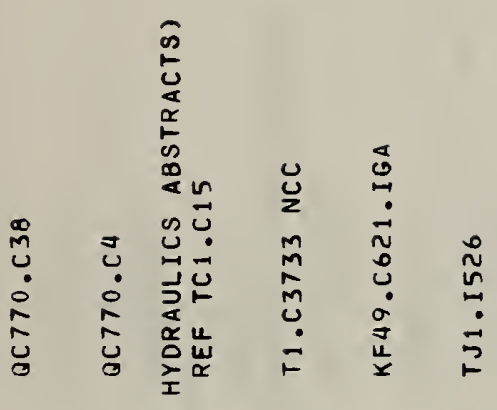

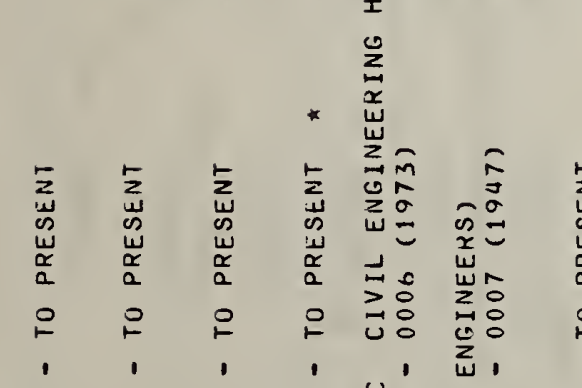

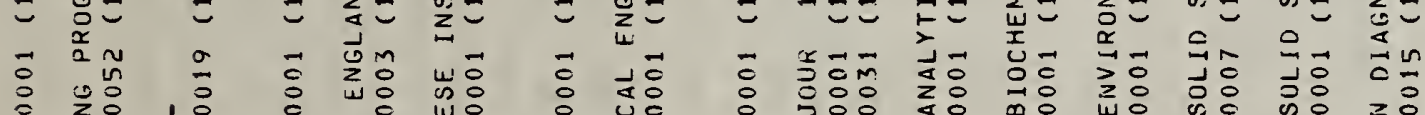

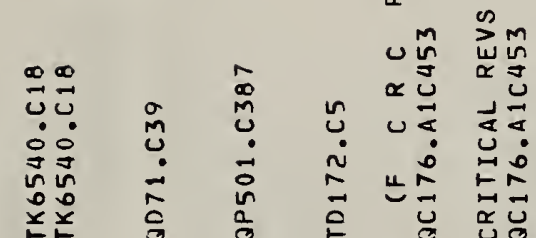

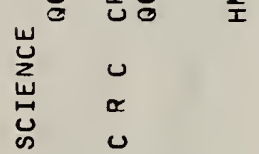

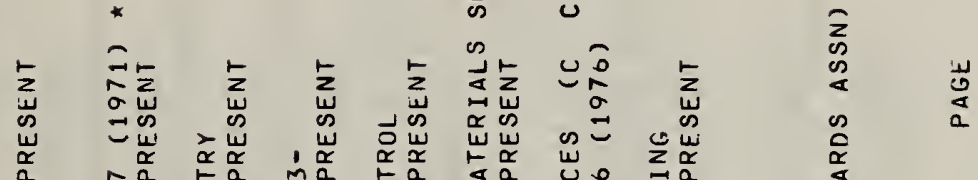

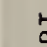

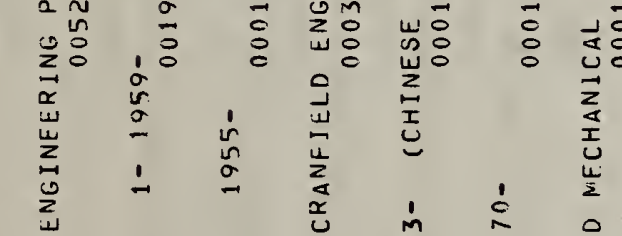
童 


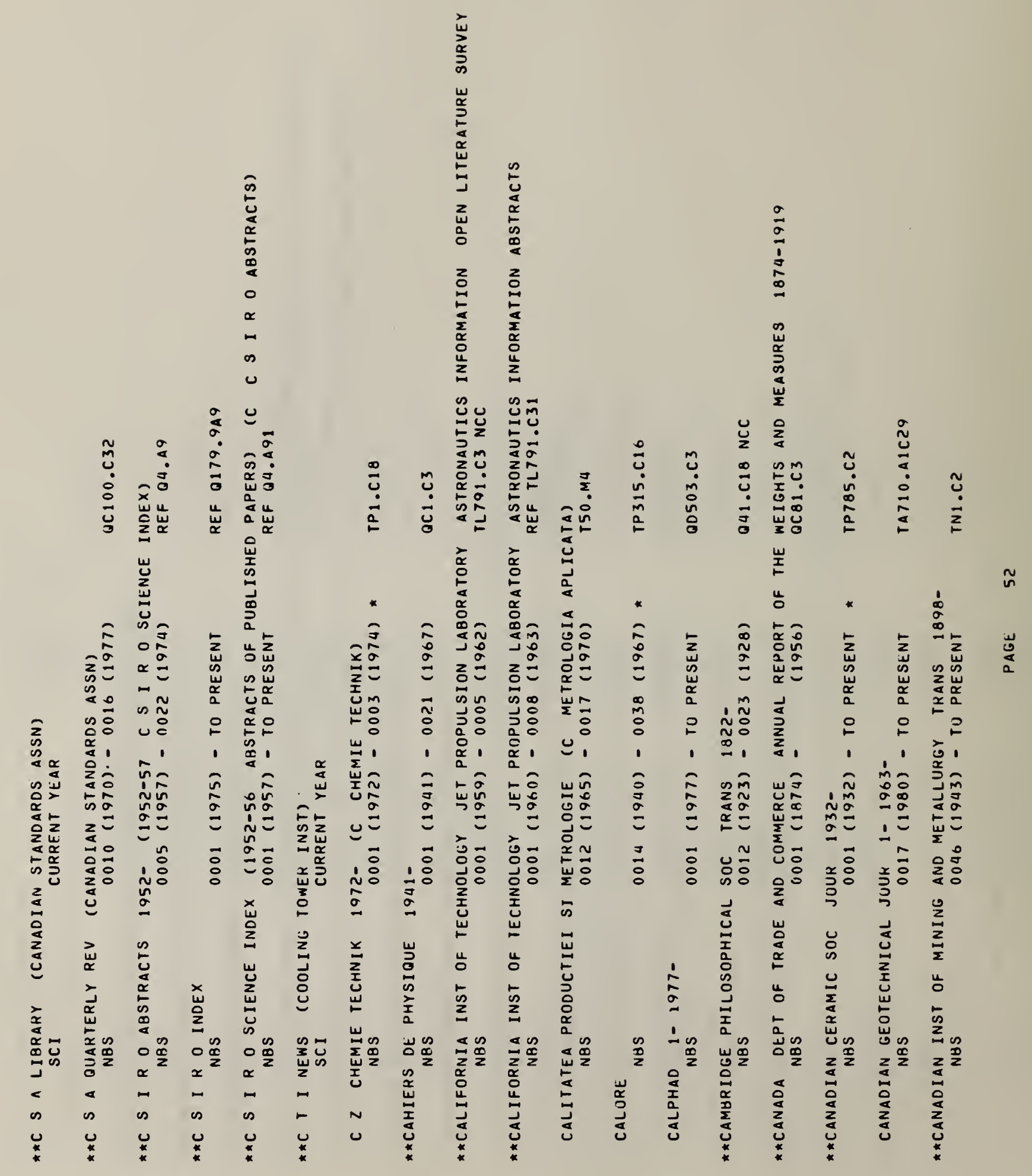




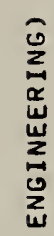

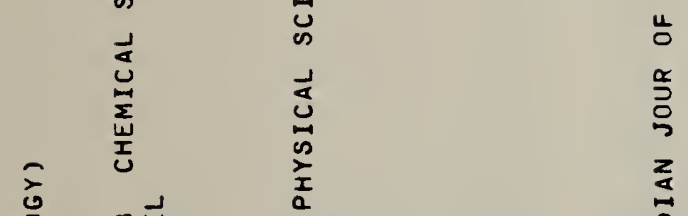

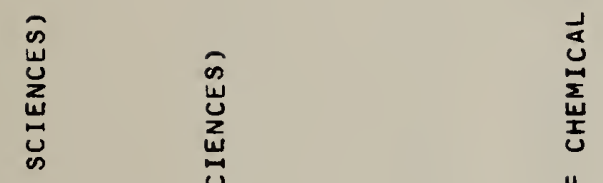

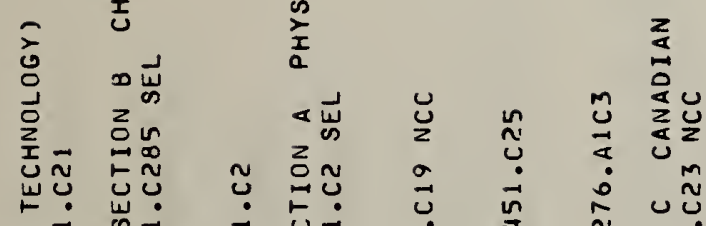

में

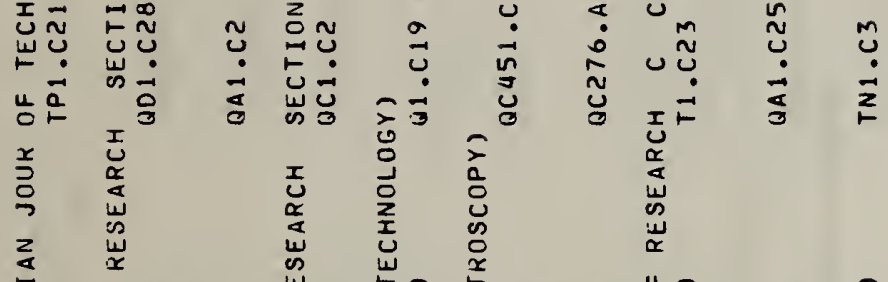

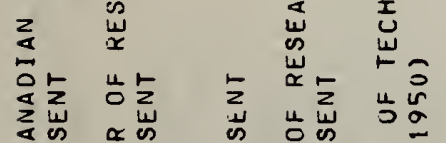

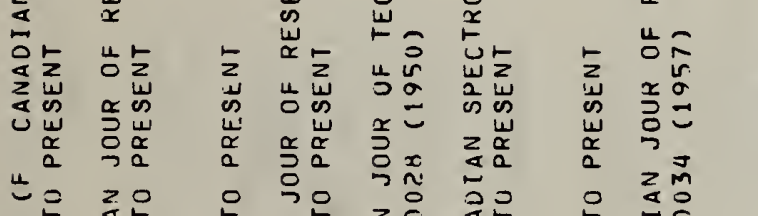

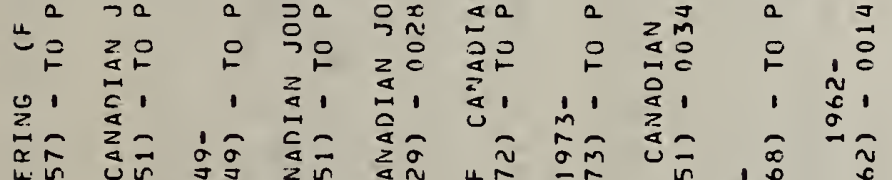

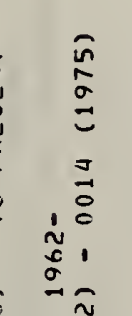

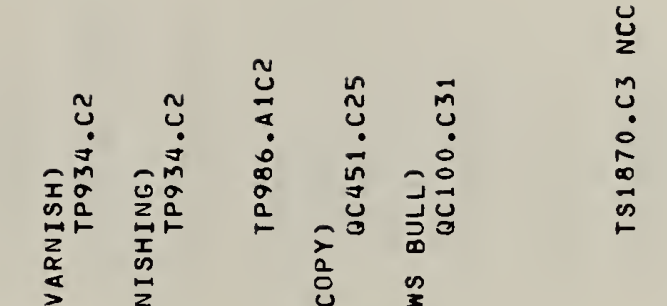

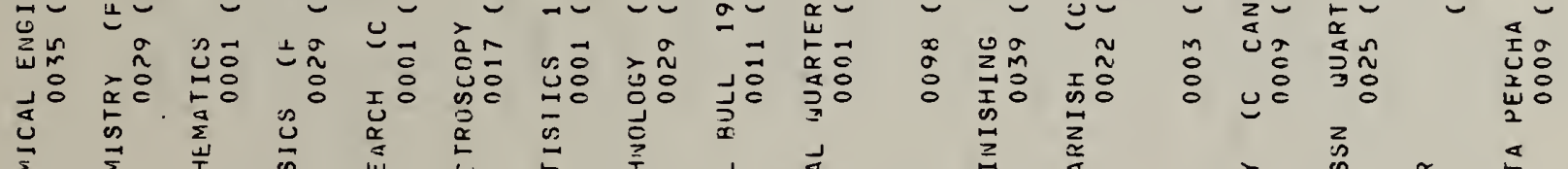

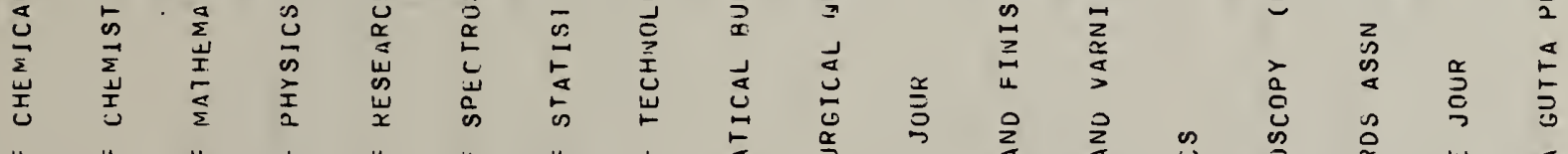

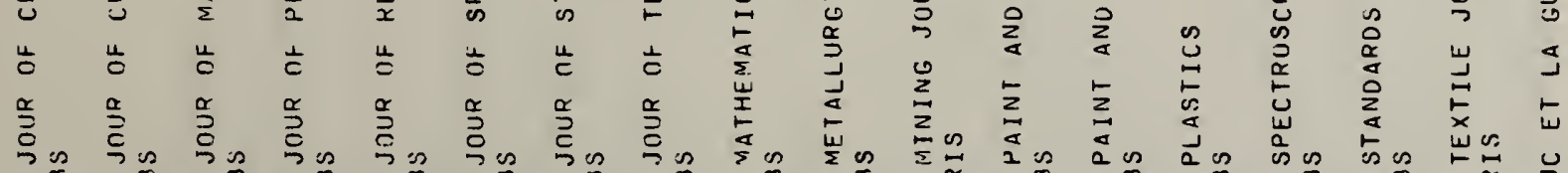

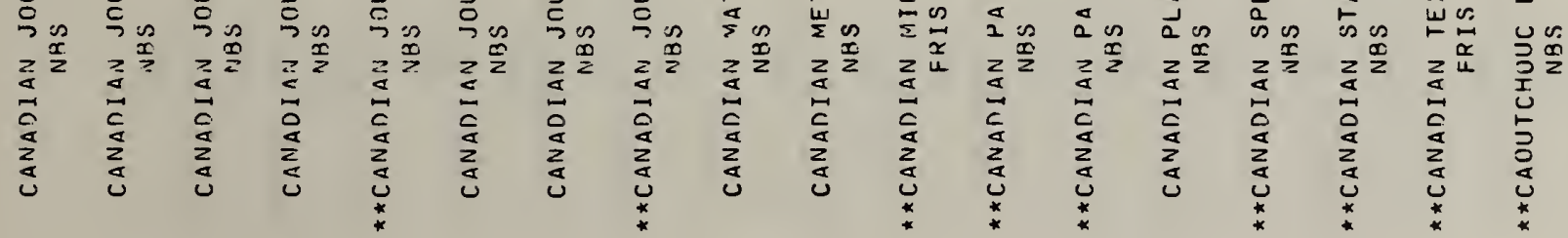




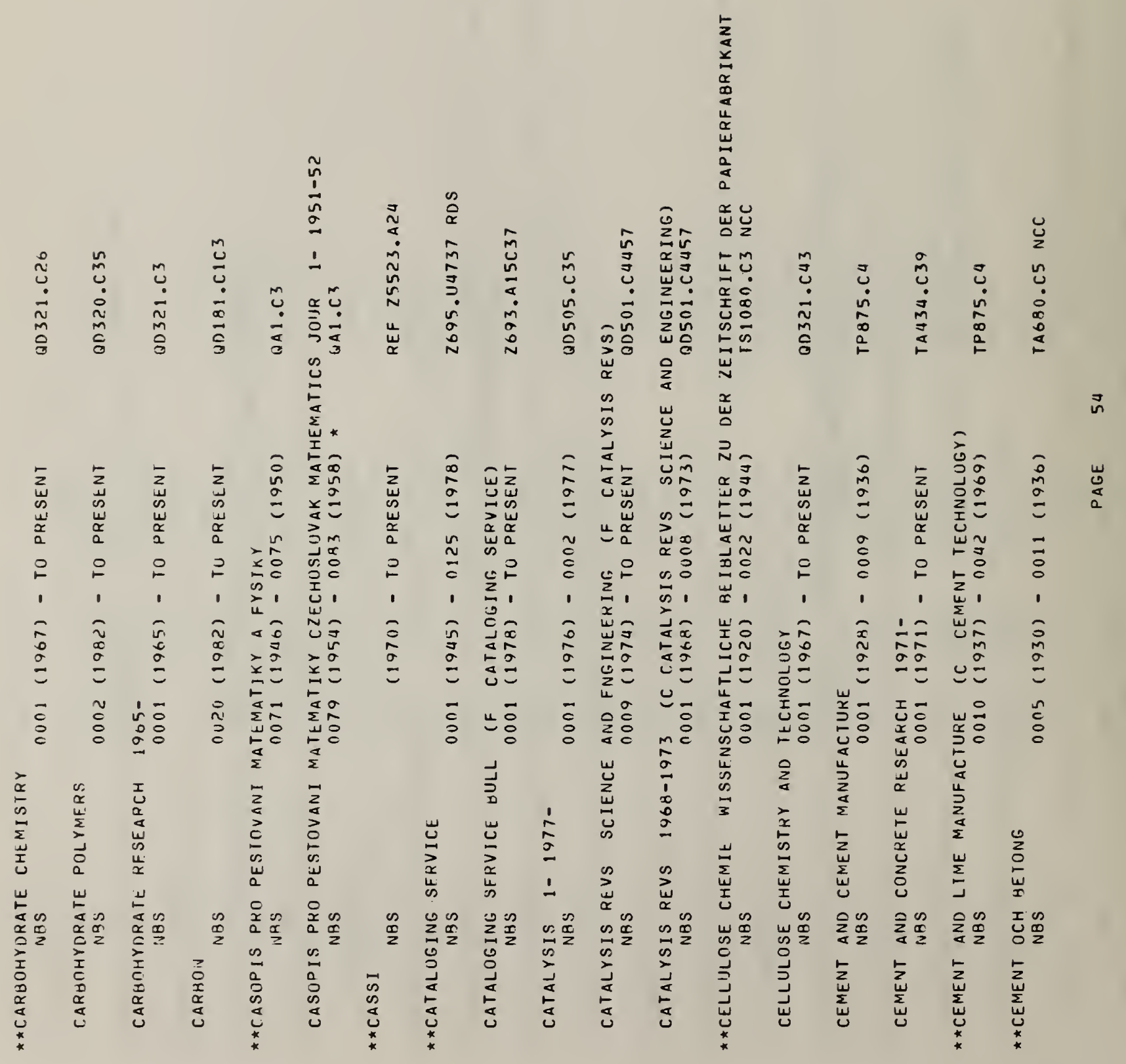




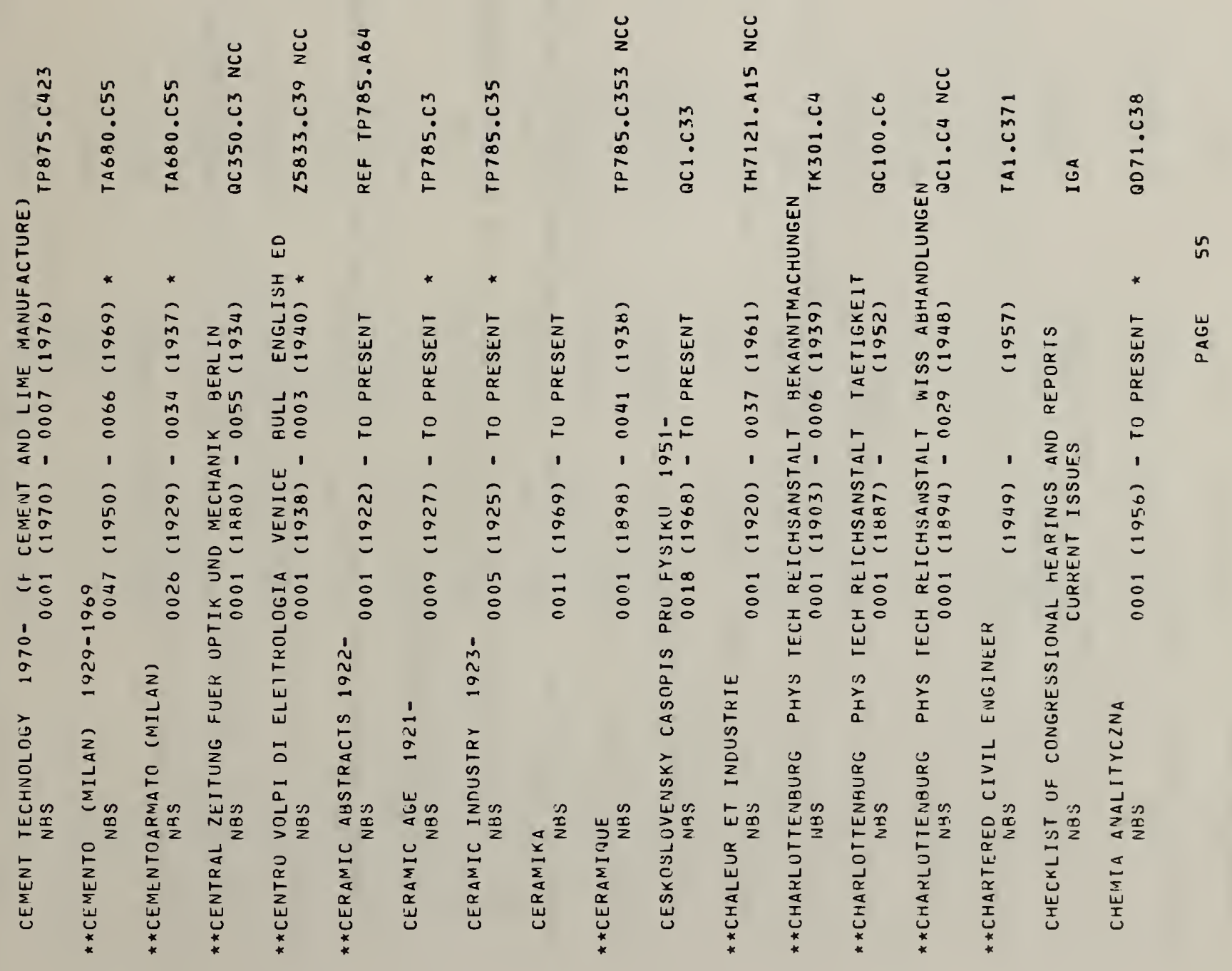




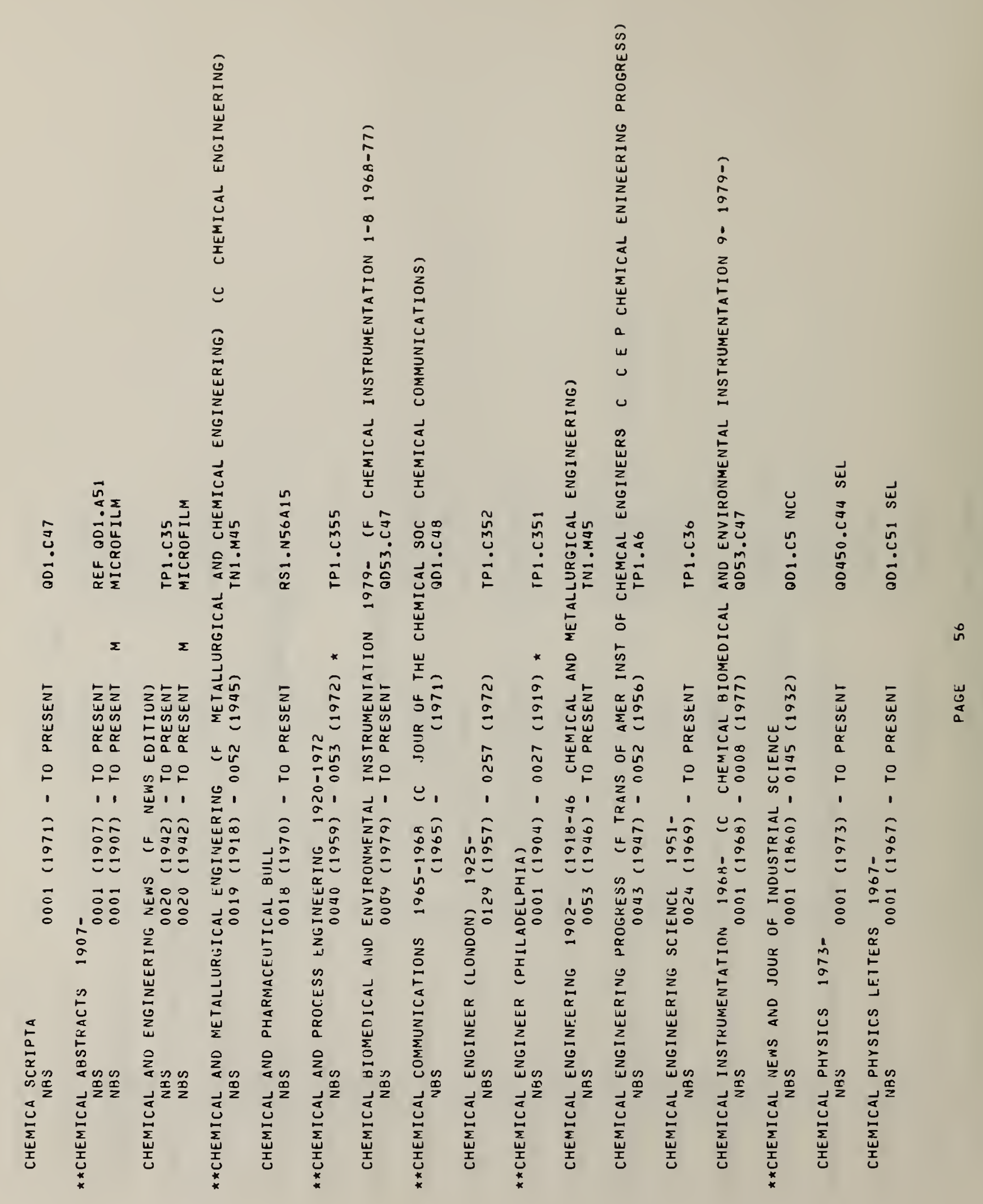




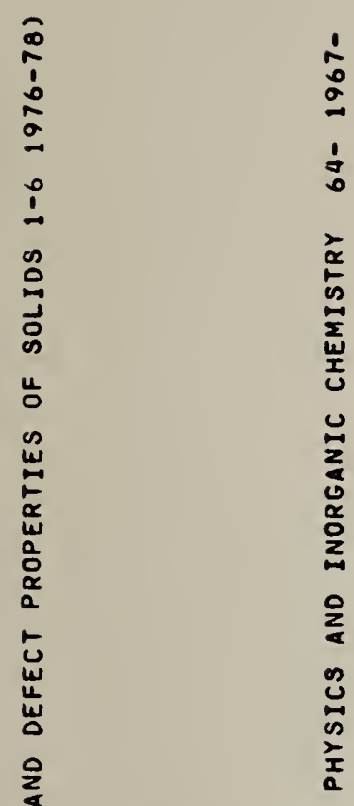

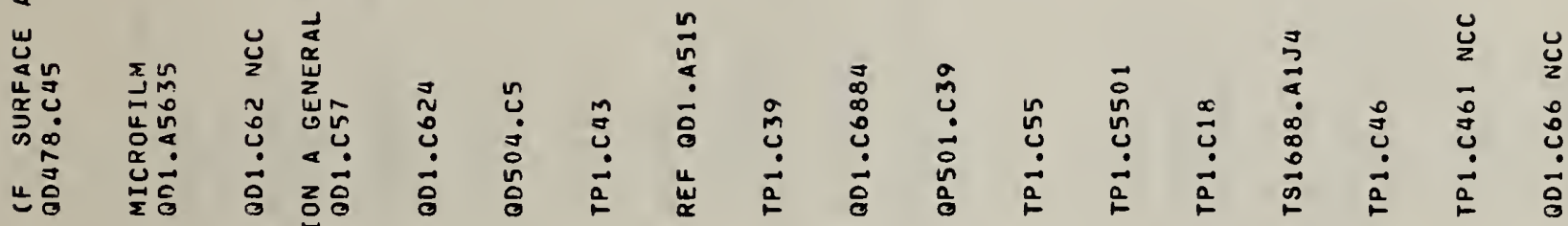

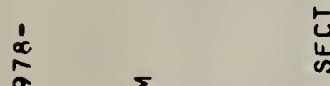

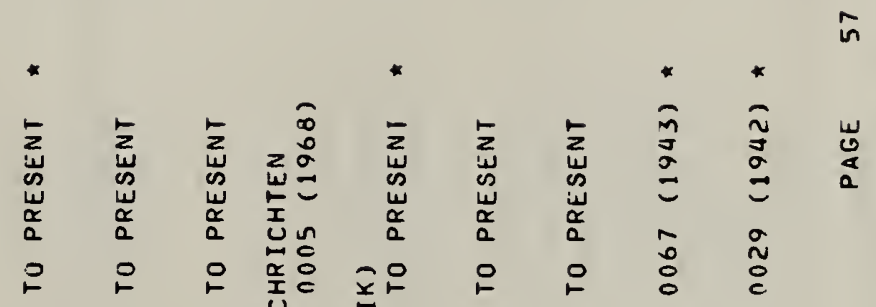
í

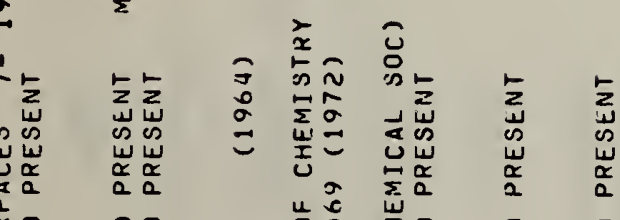

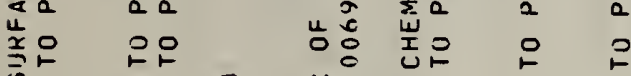

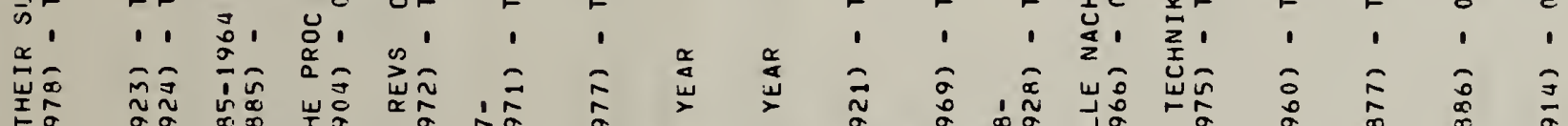

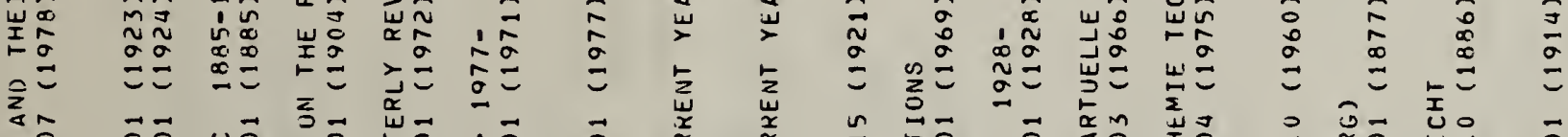

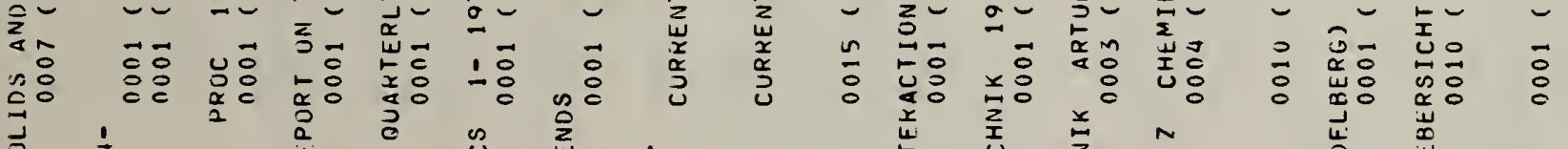

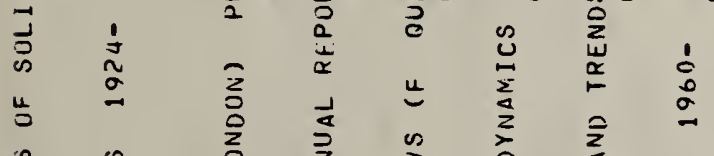




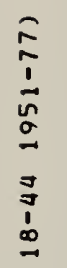

总

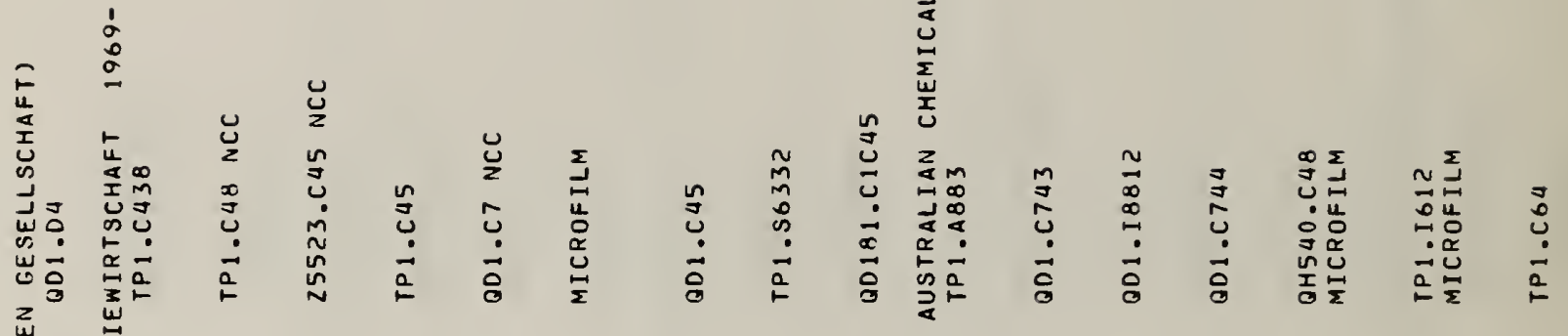

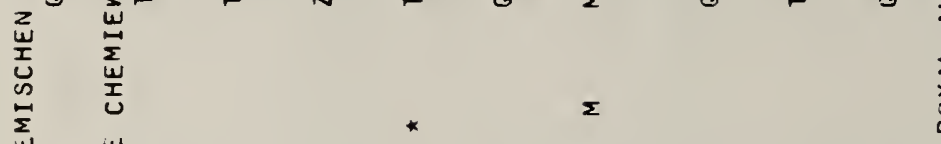

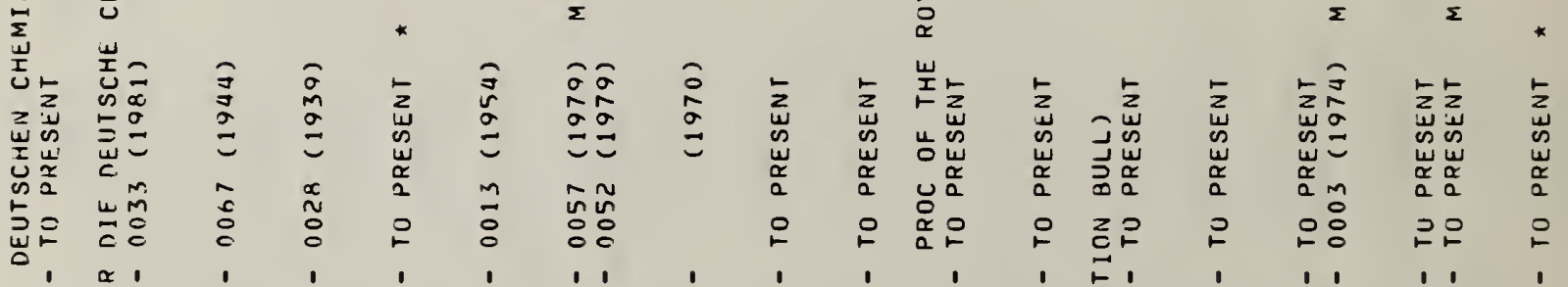

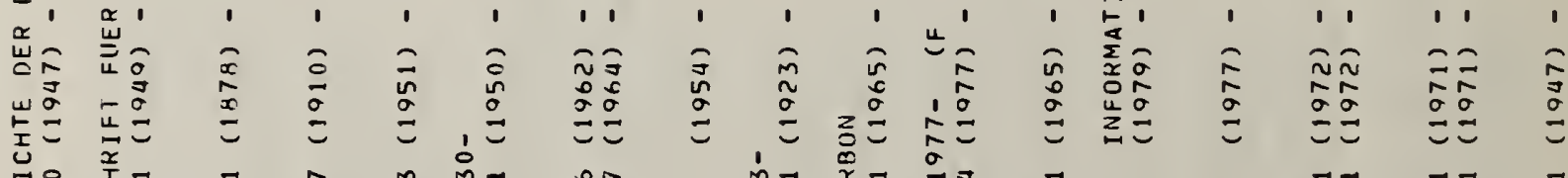

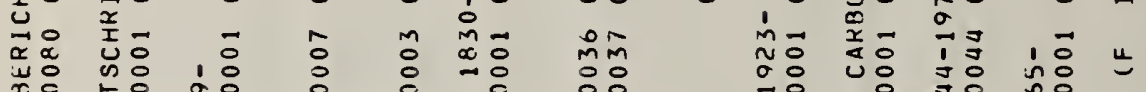

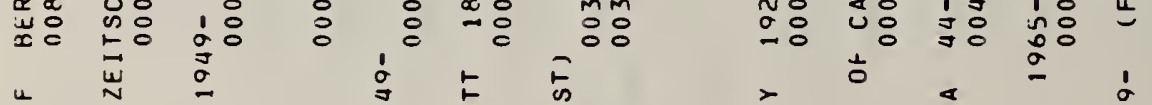

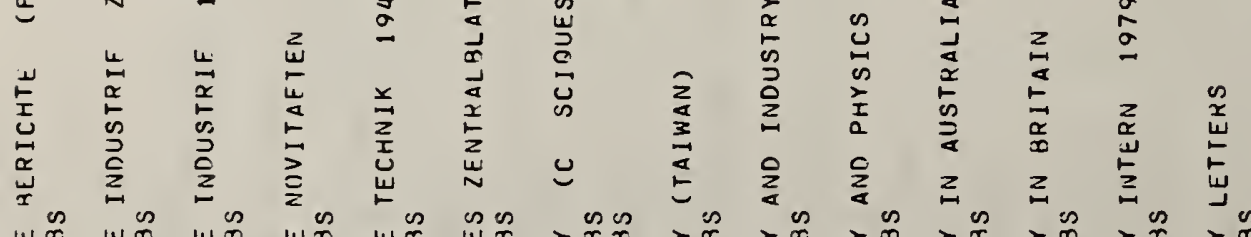

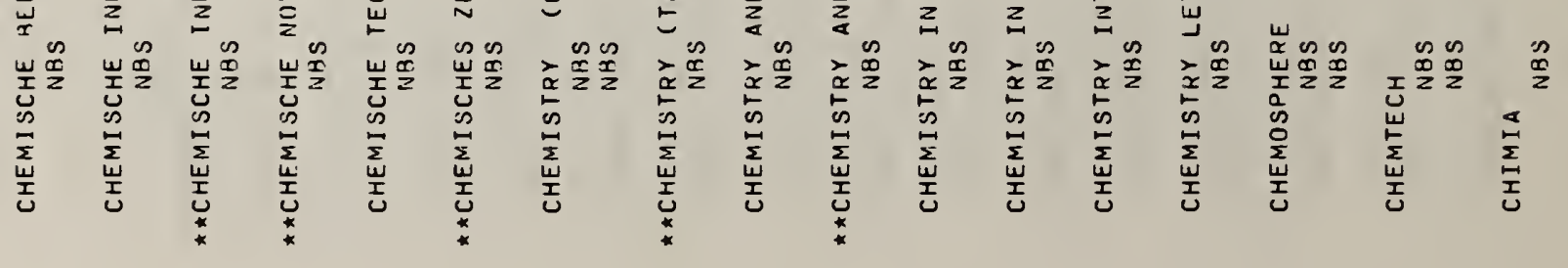




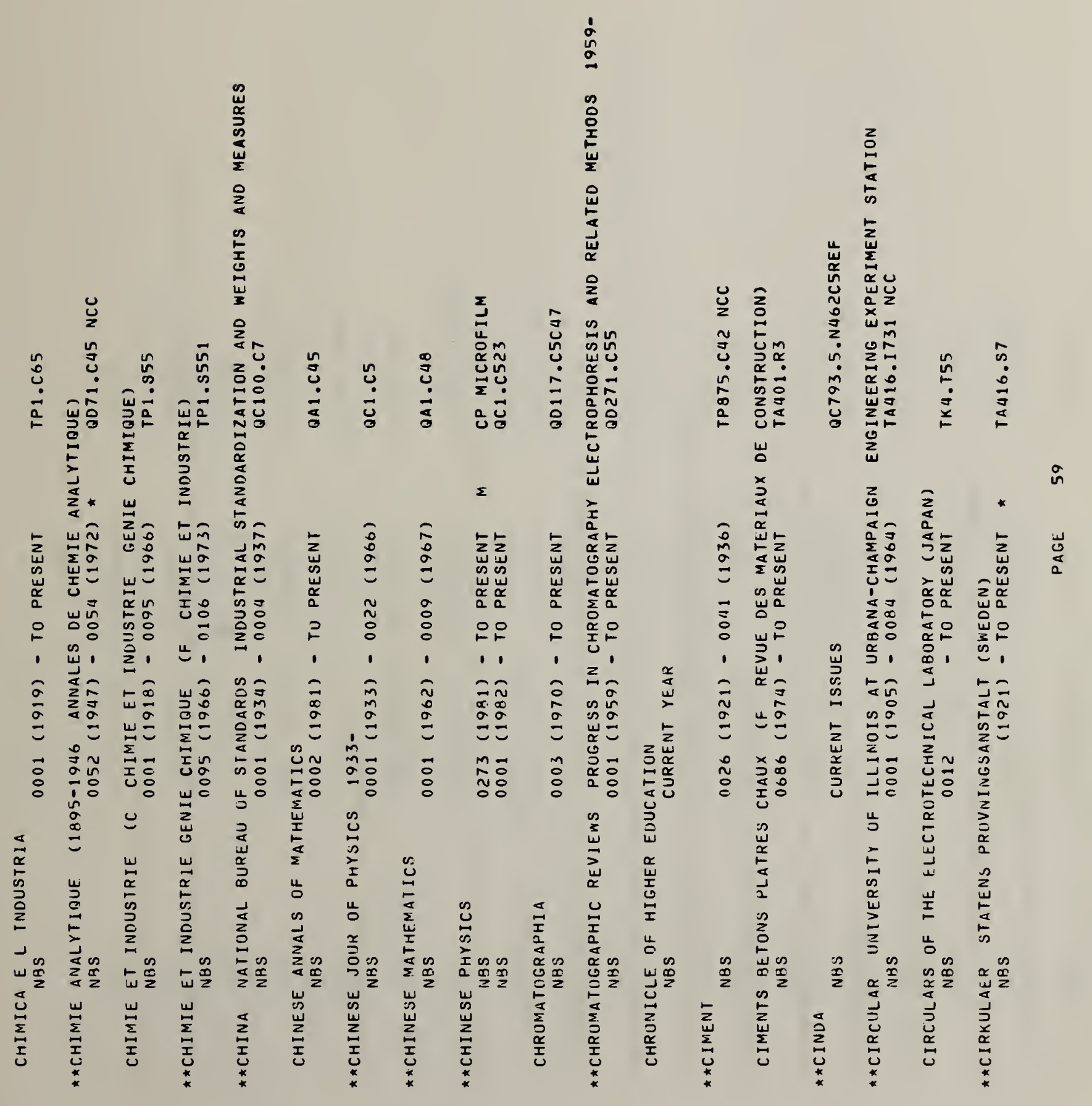




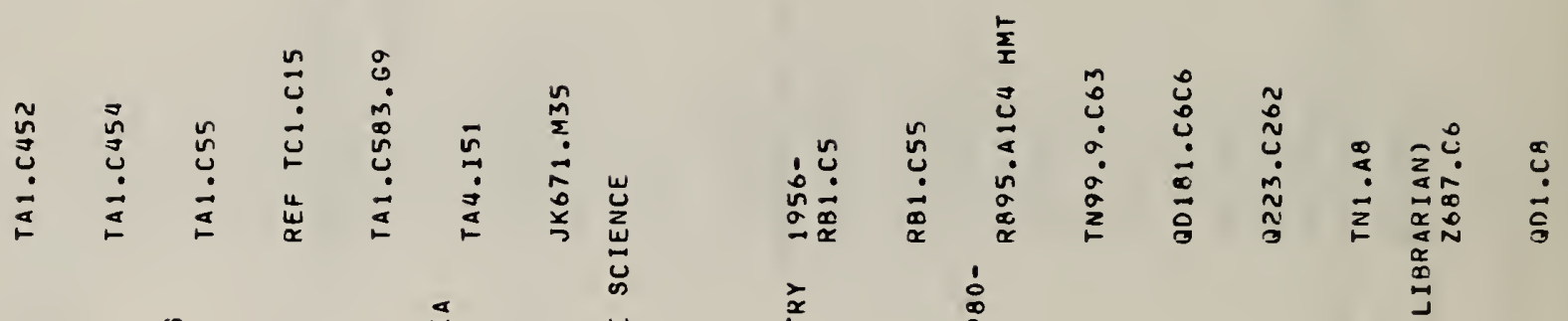

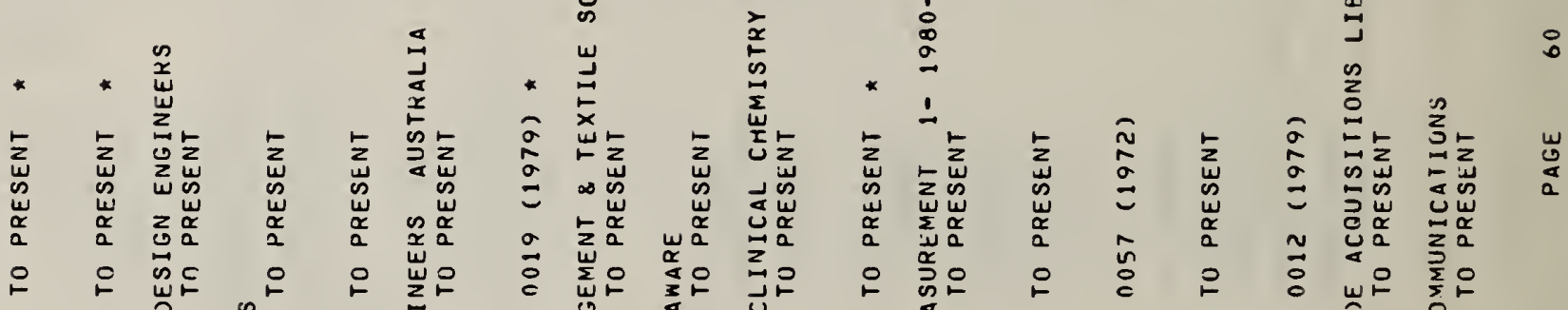

1 1

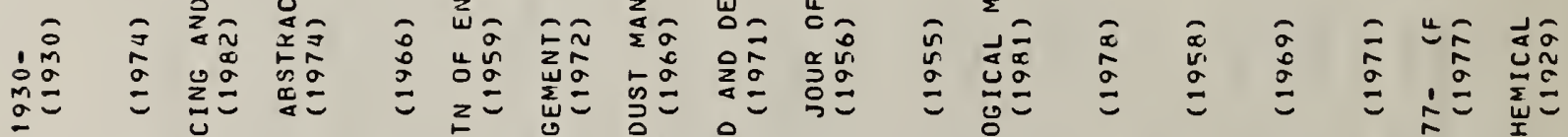

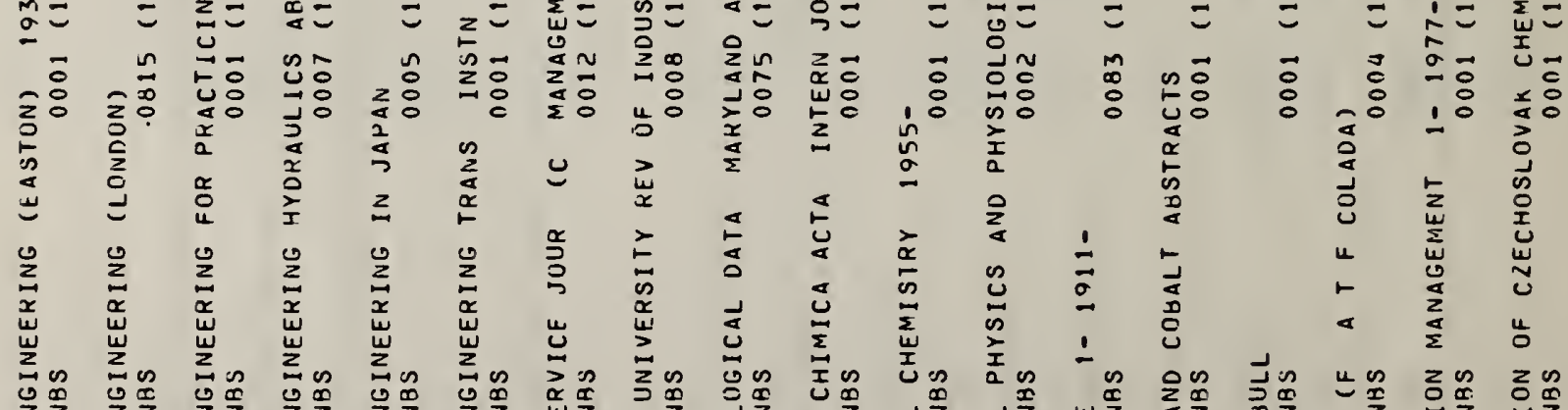

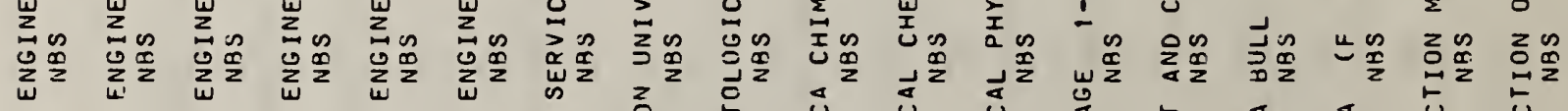

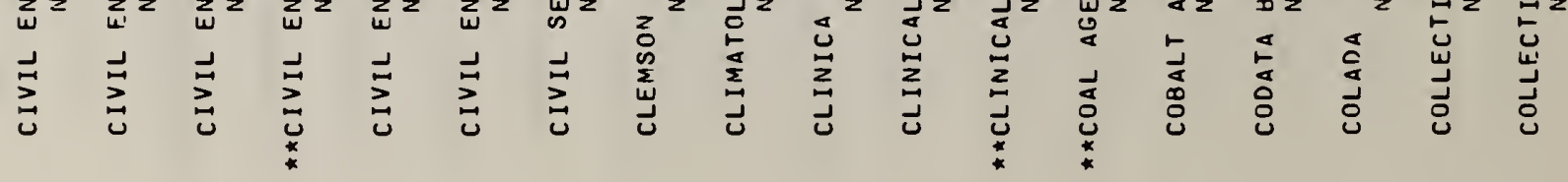




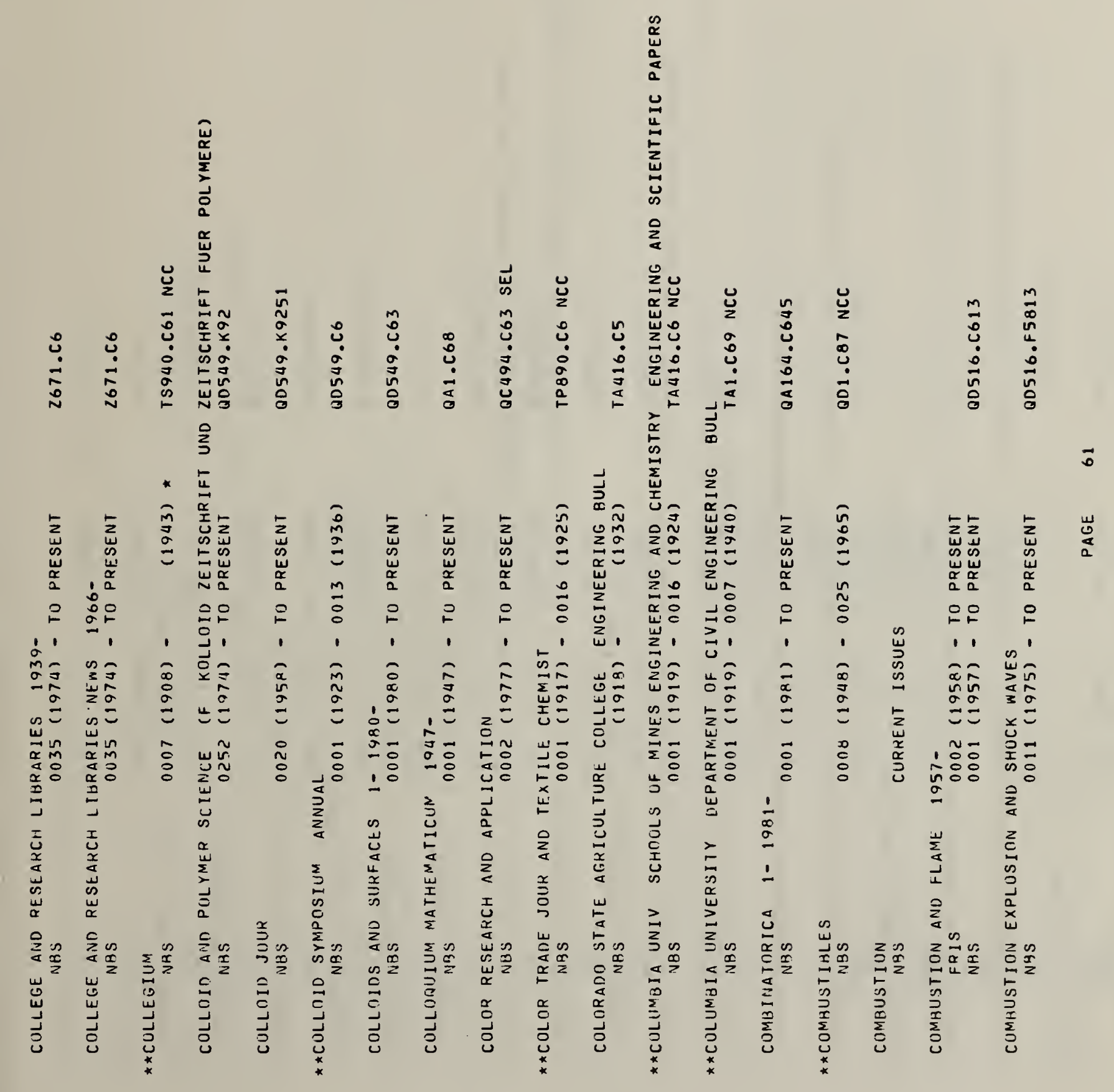




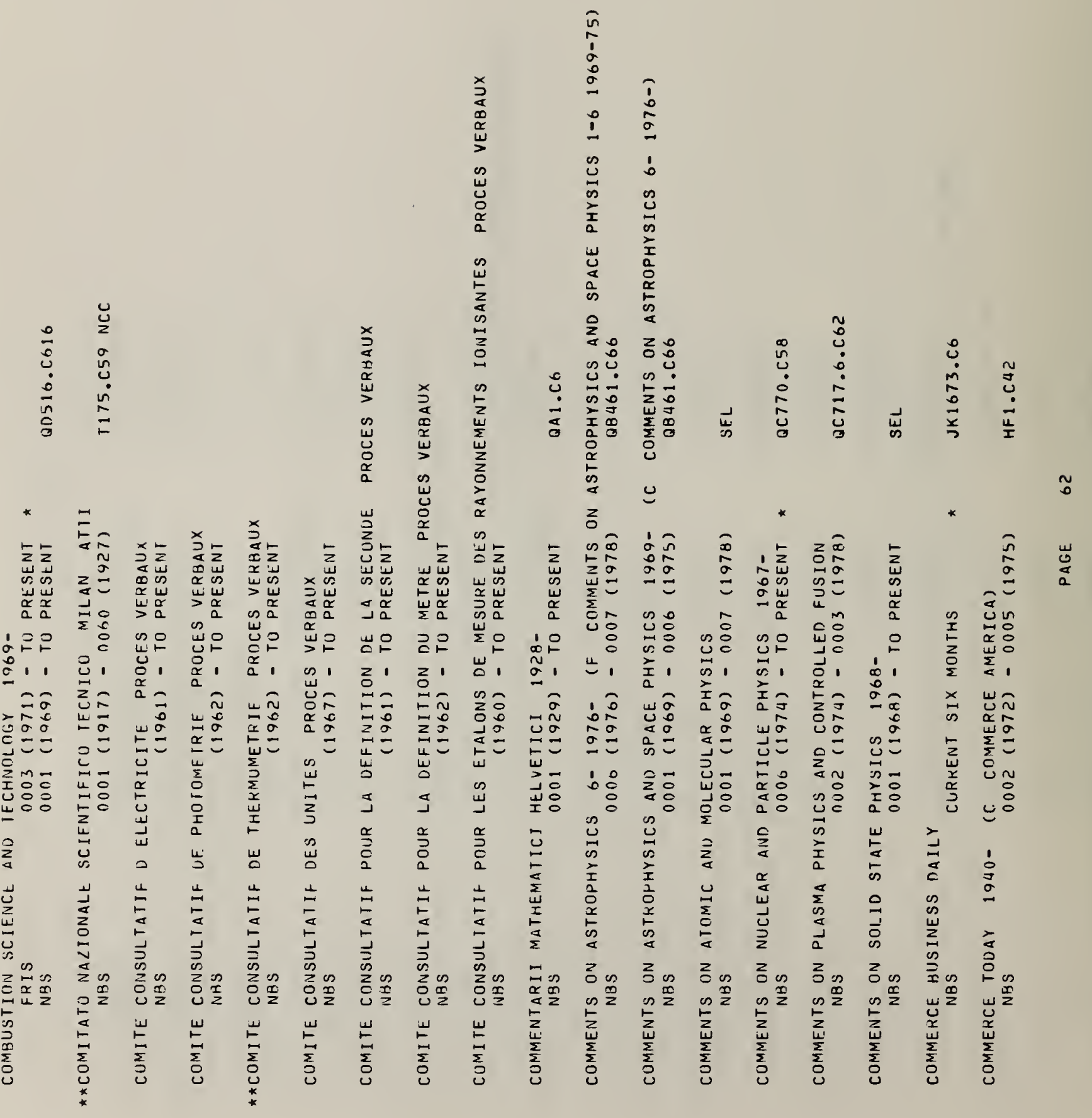




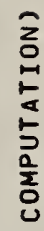

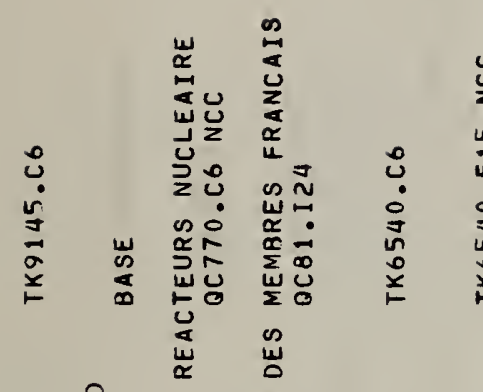

\&

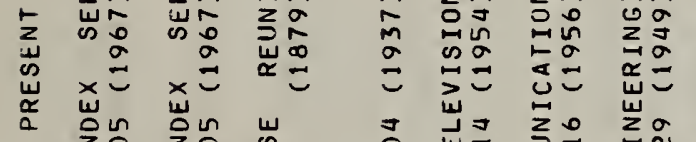

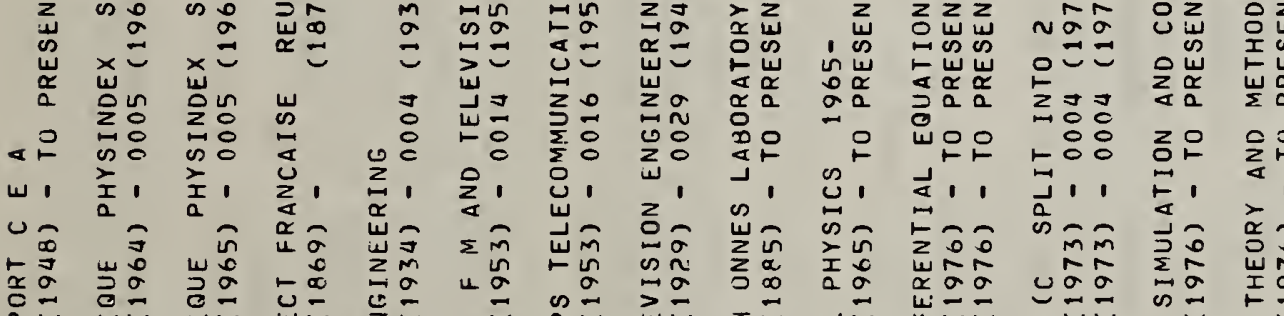

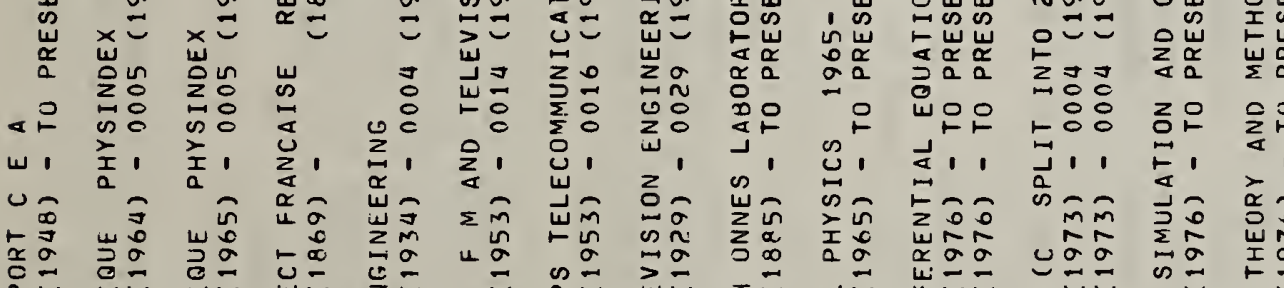

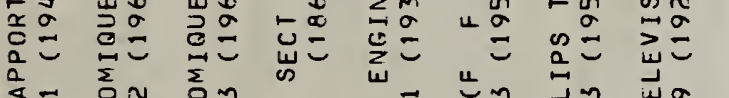

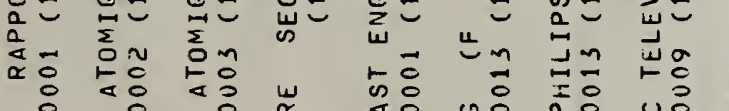

$\mu$ 品

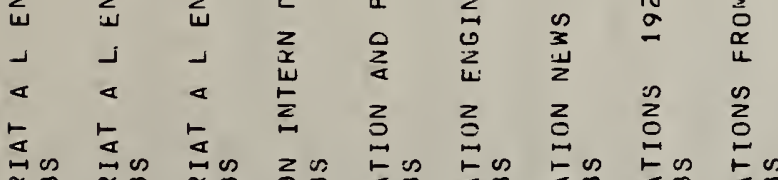

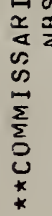




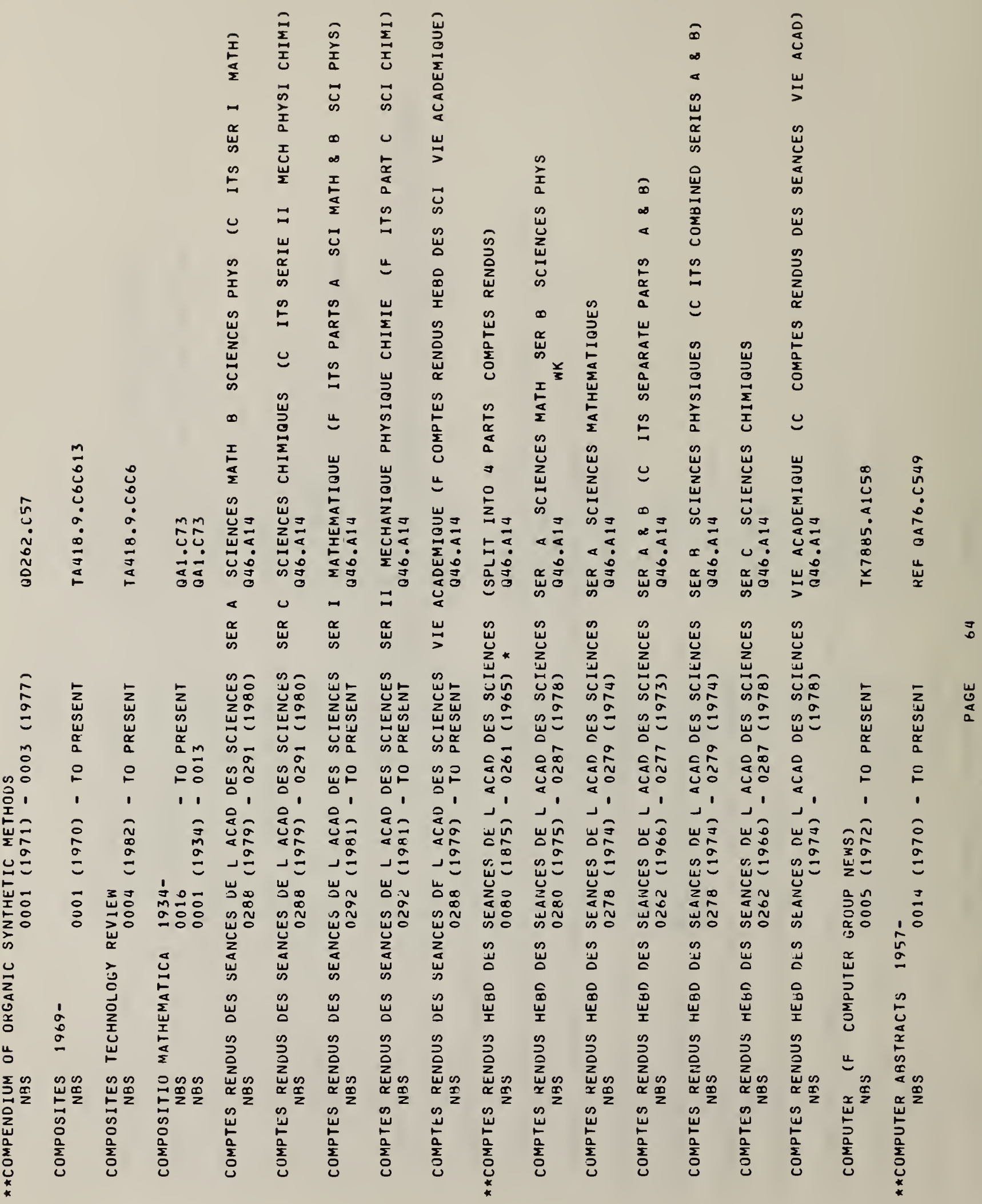




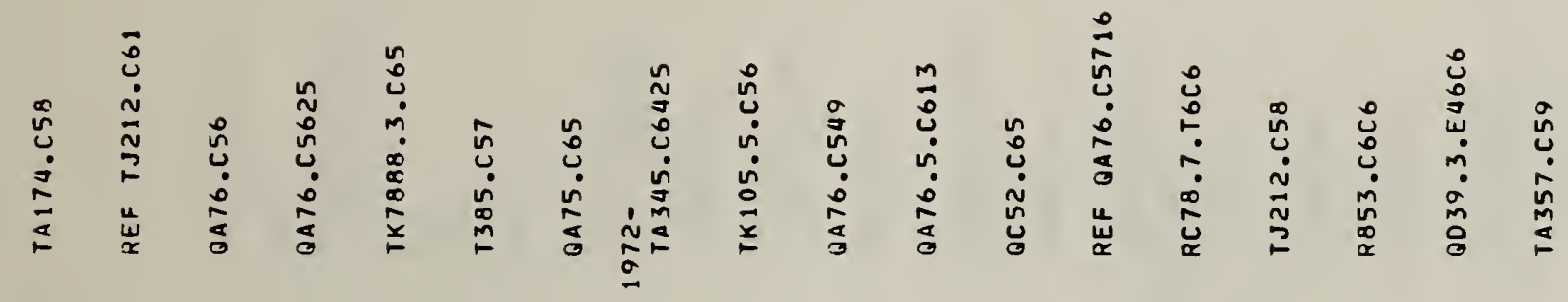

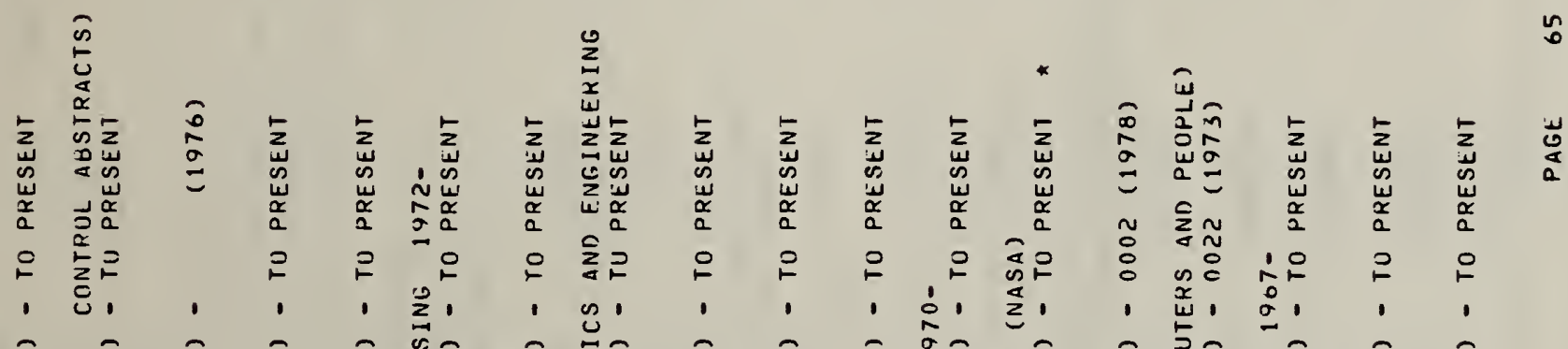

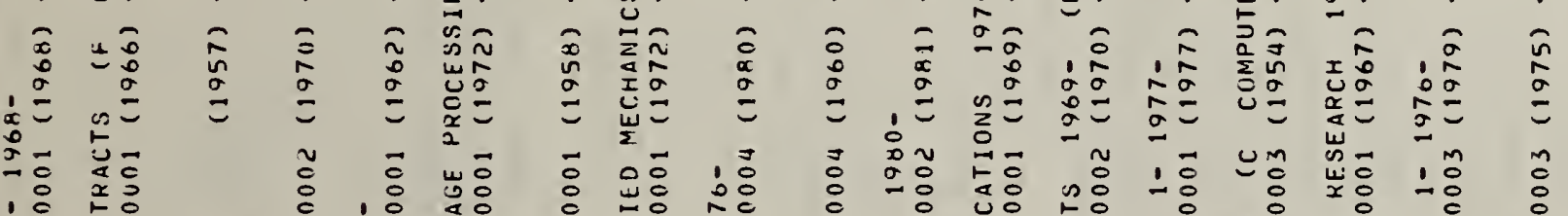

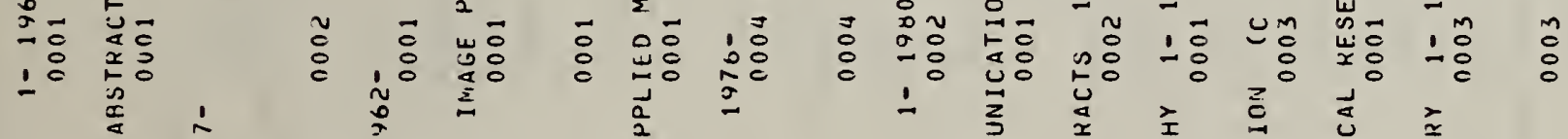

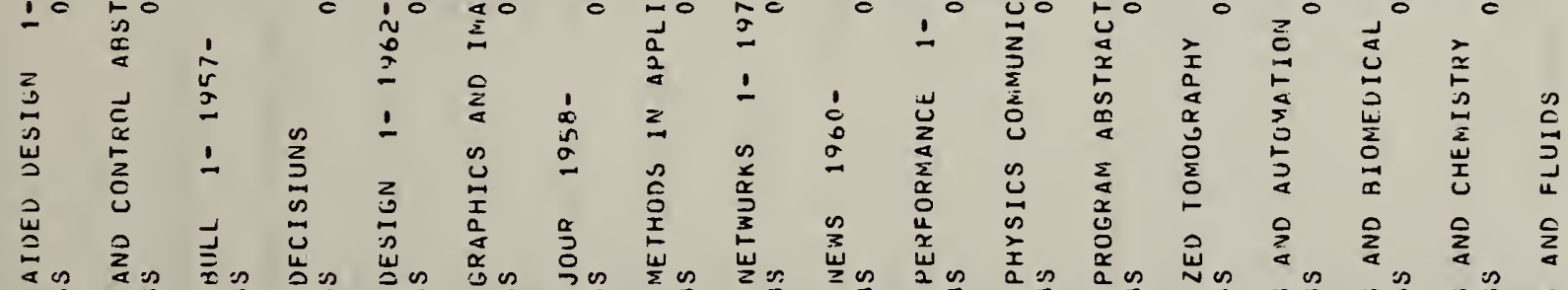

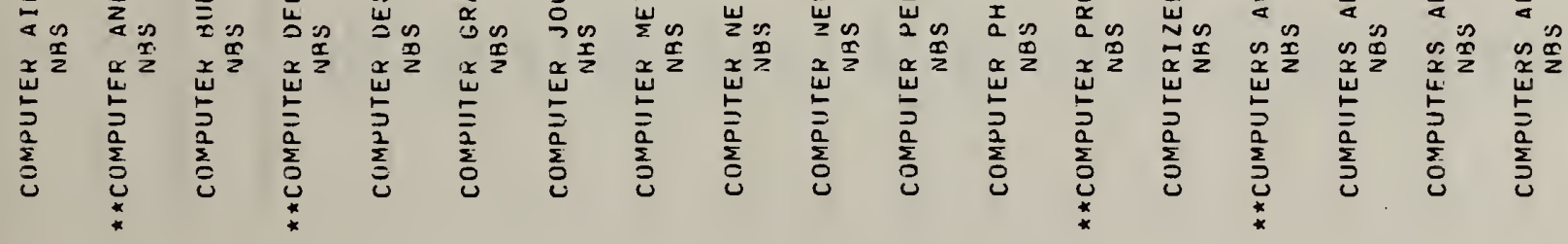




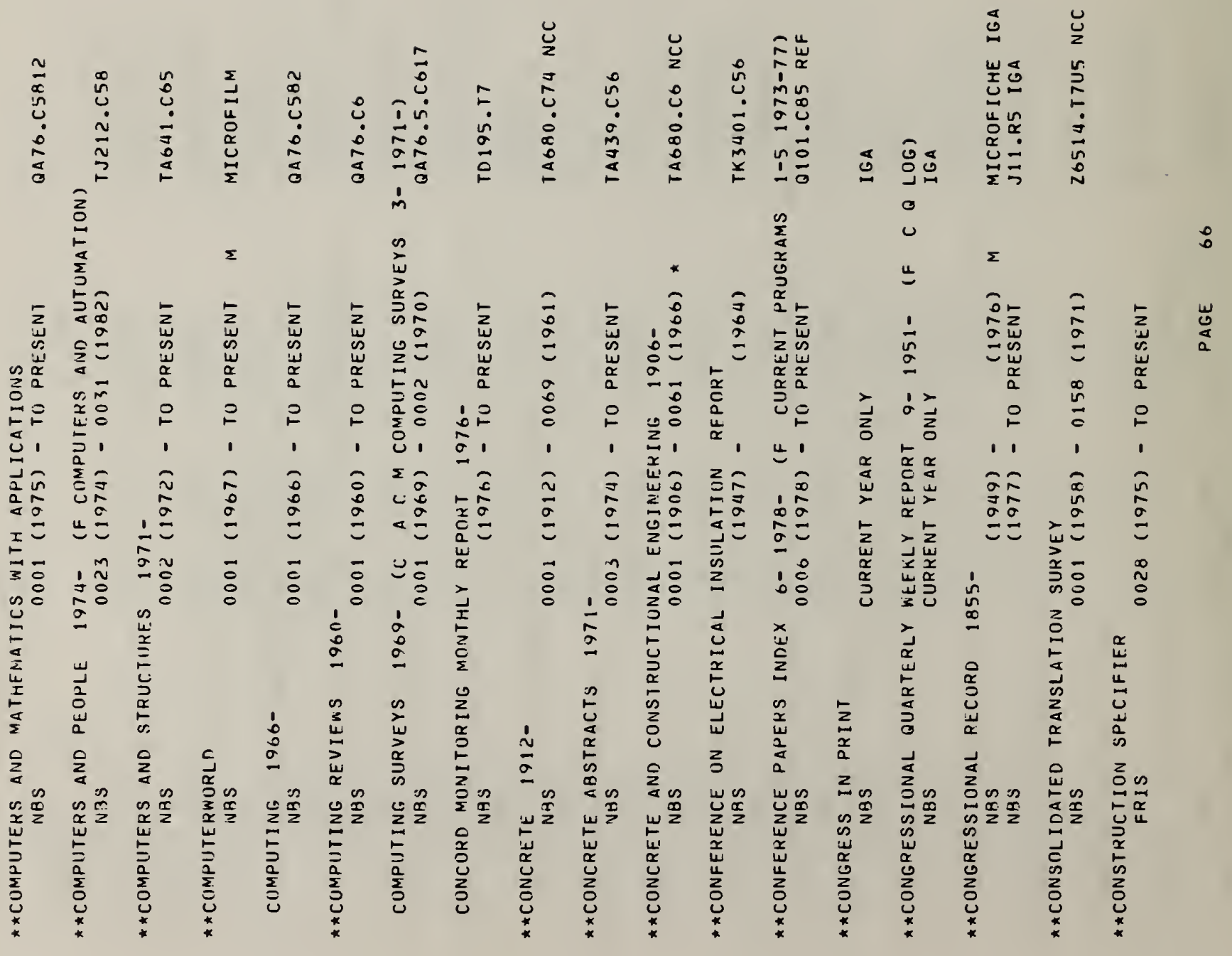




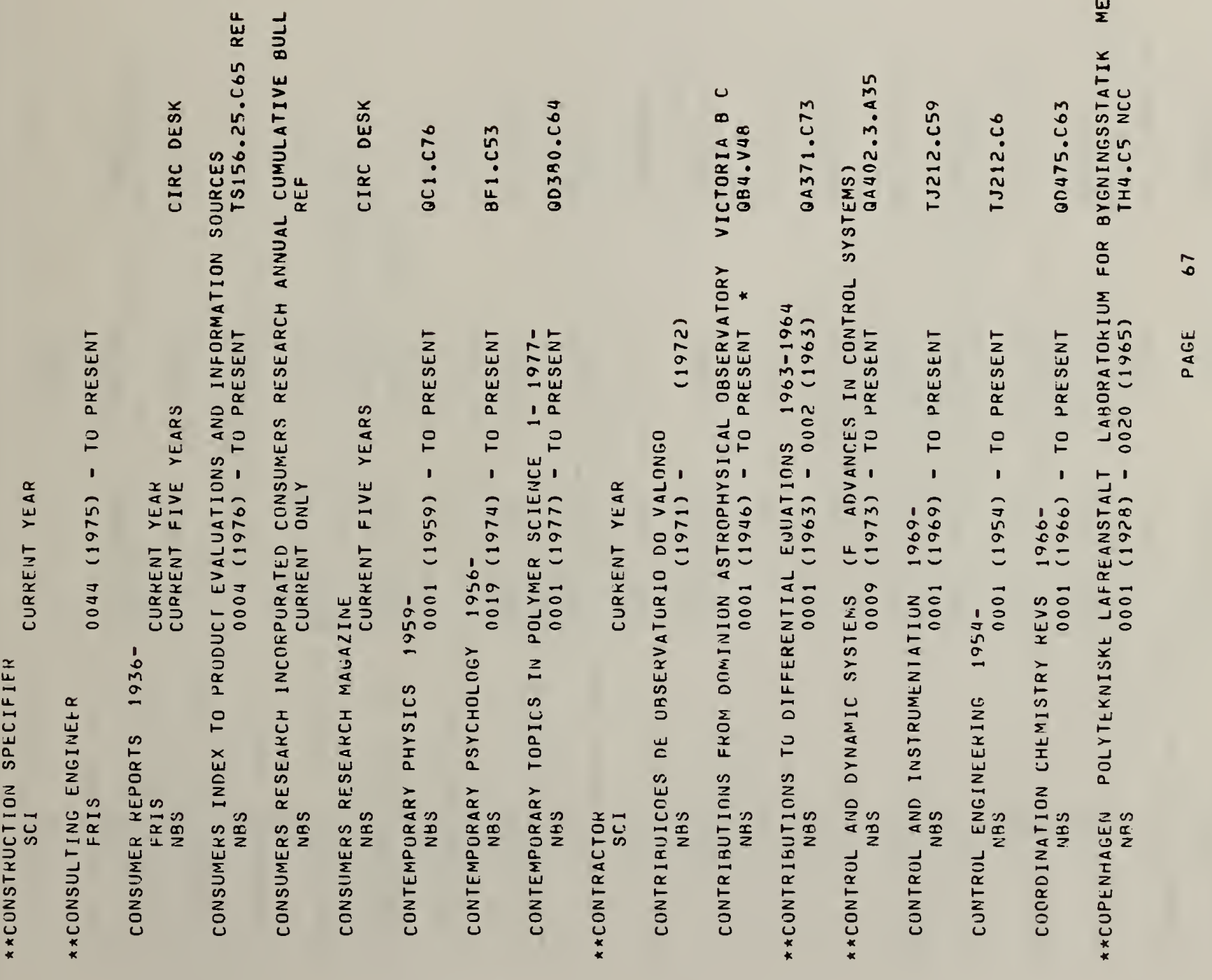




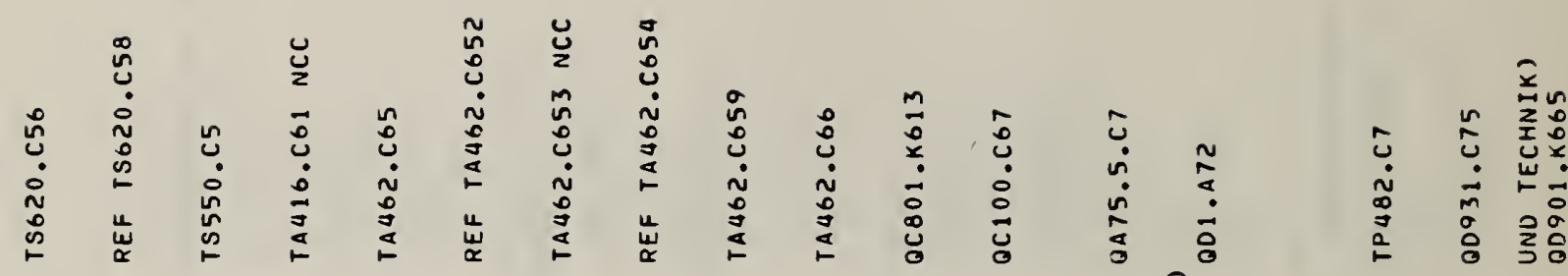
高

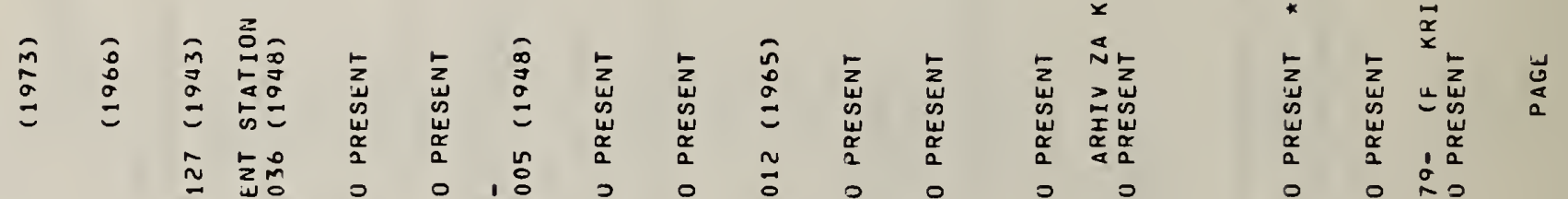

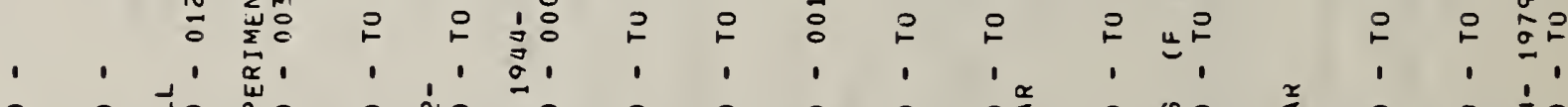

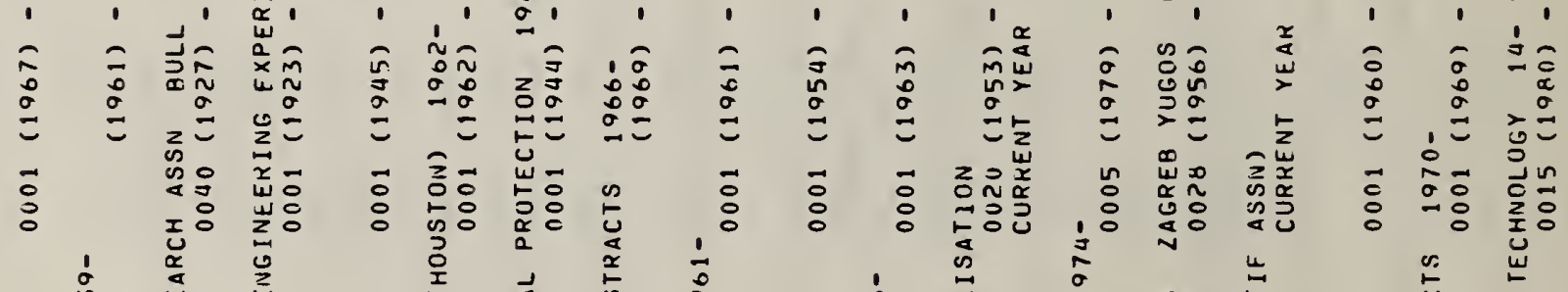

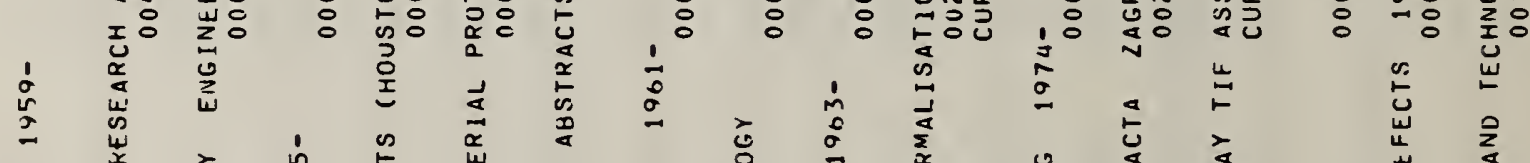

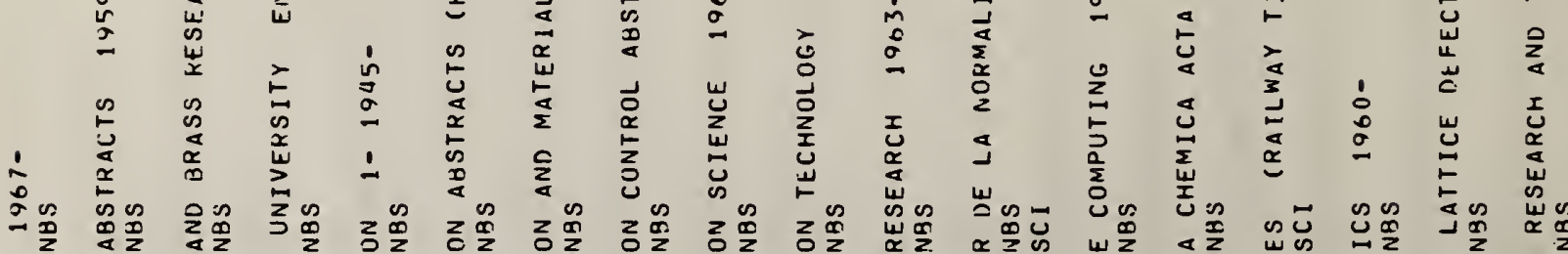

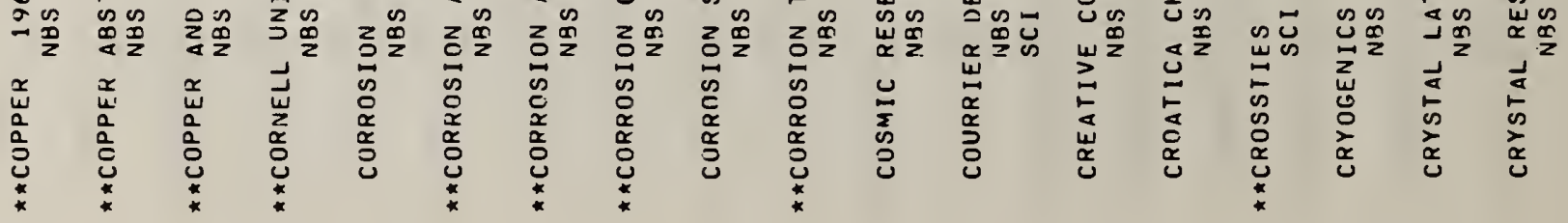




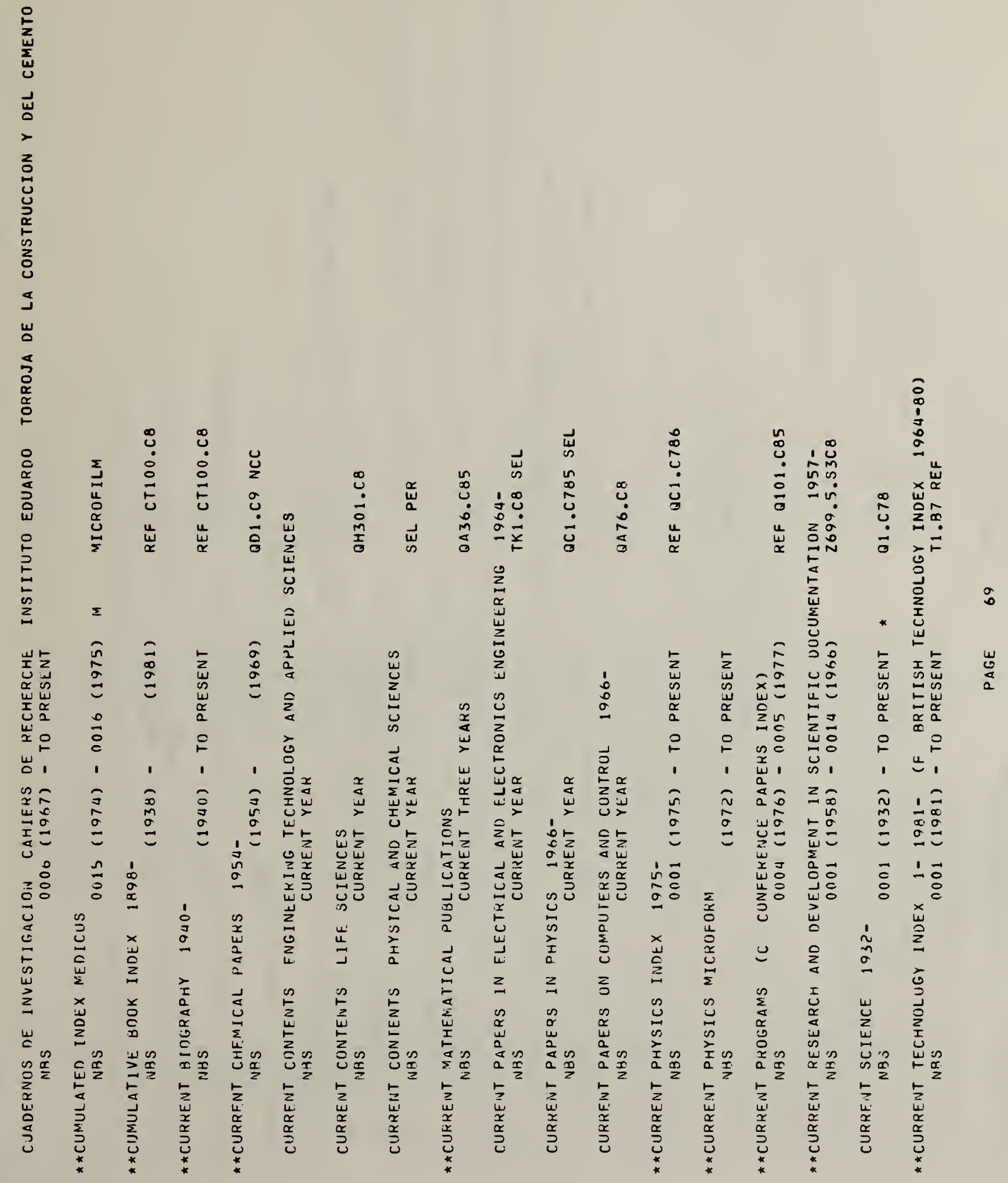




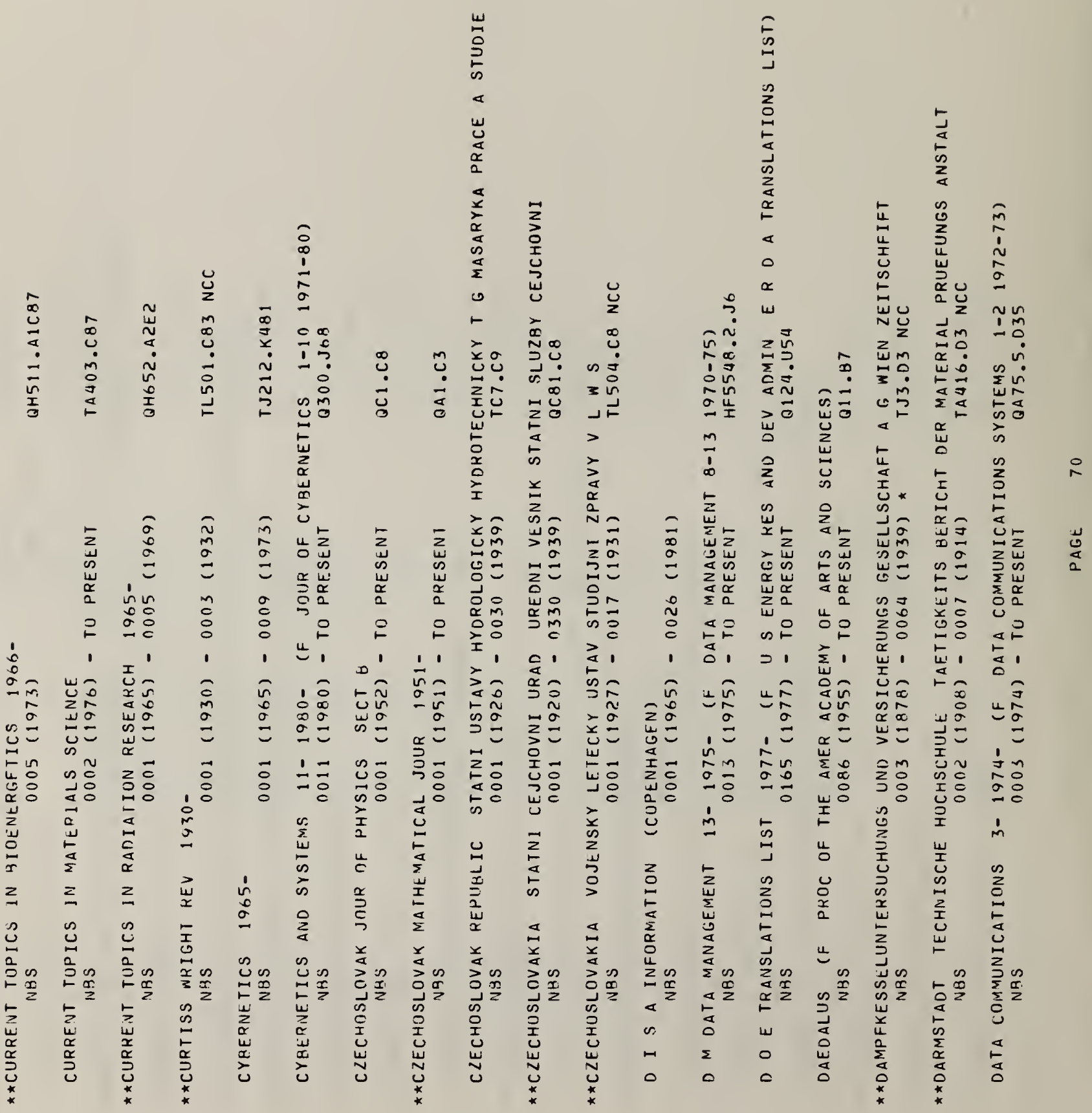




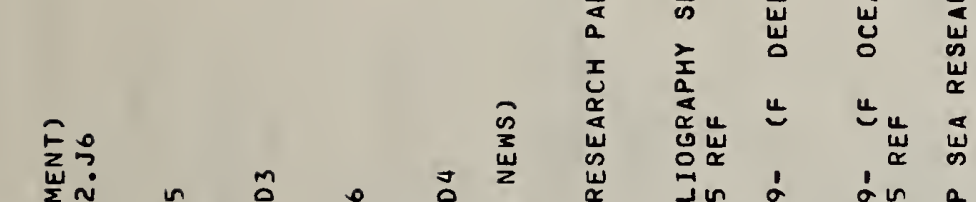

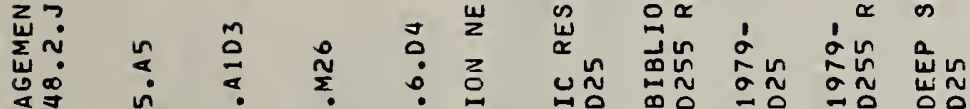

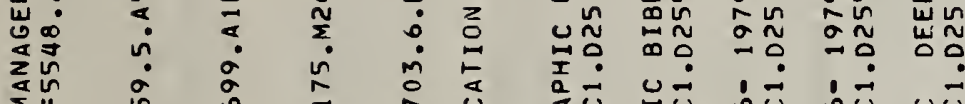

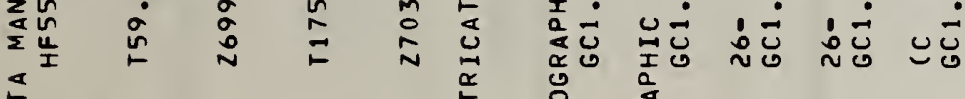

$\stackrel{\square}{a}$

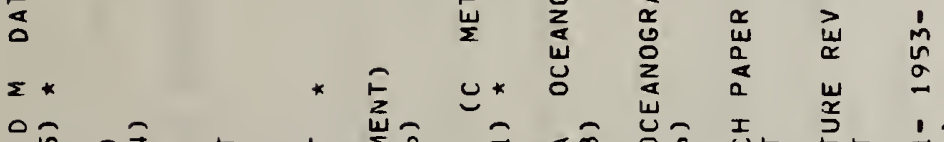

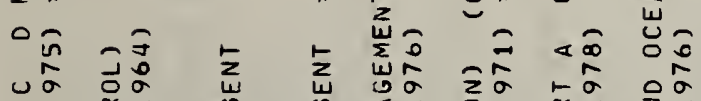

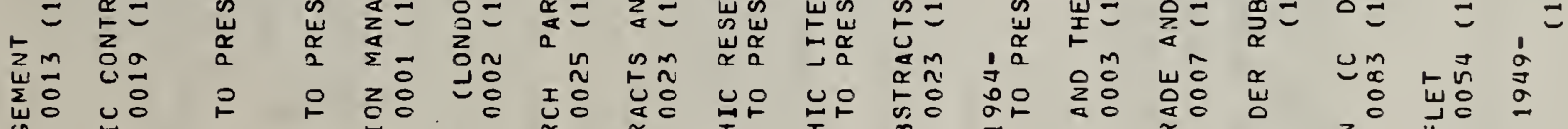

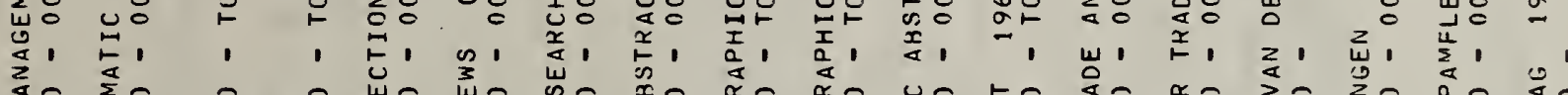

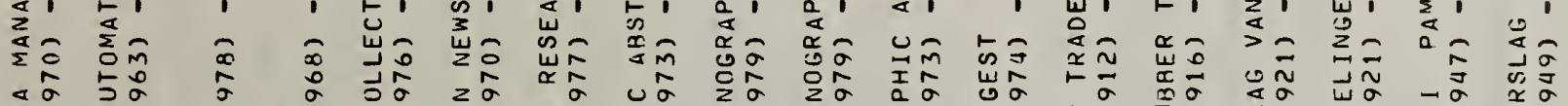

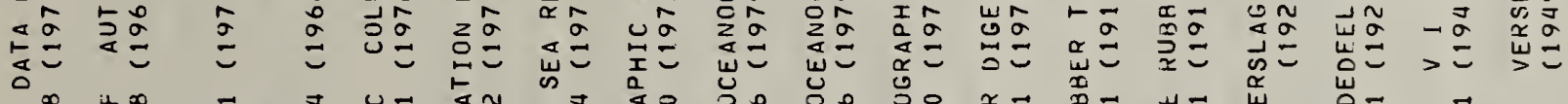

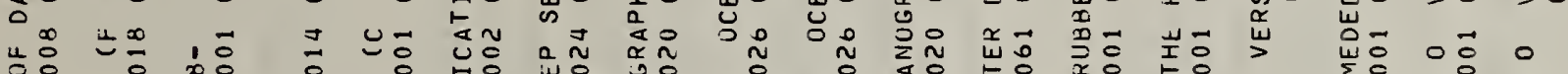

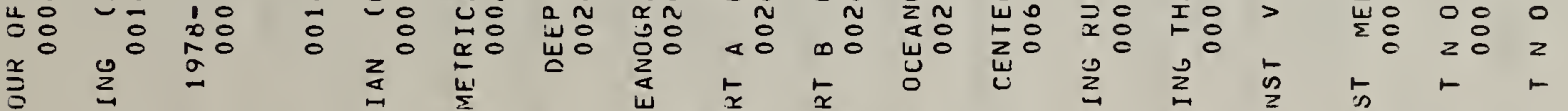

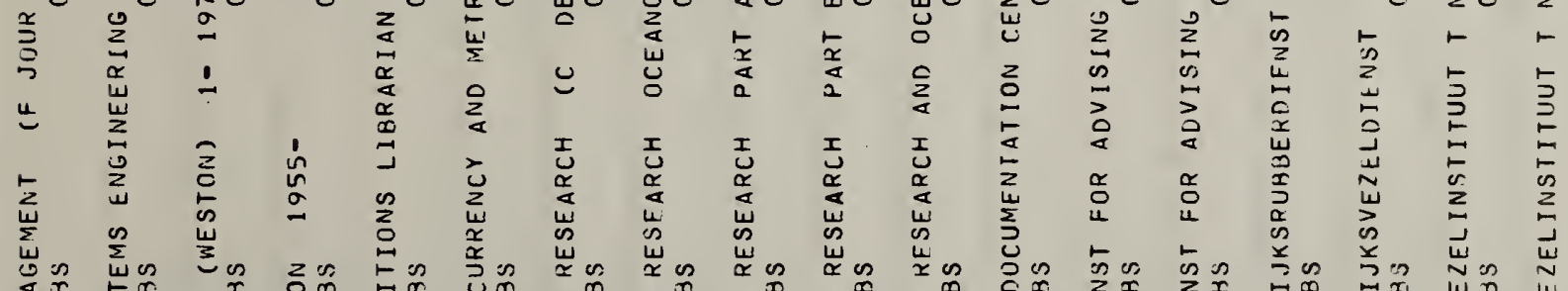

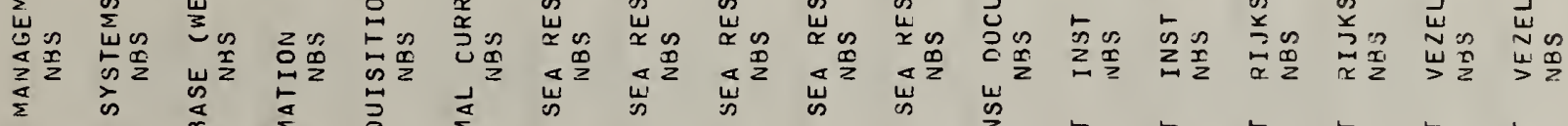

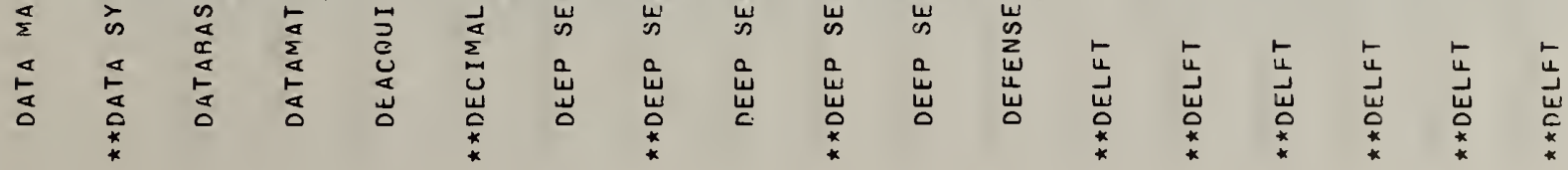




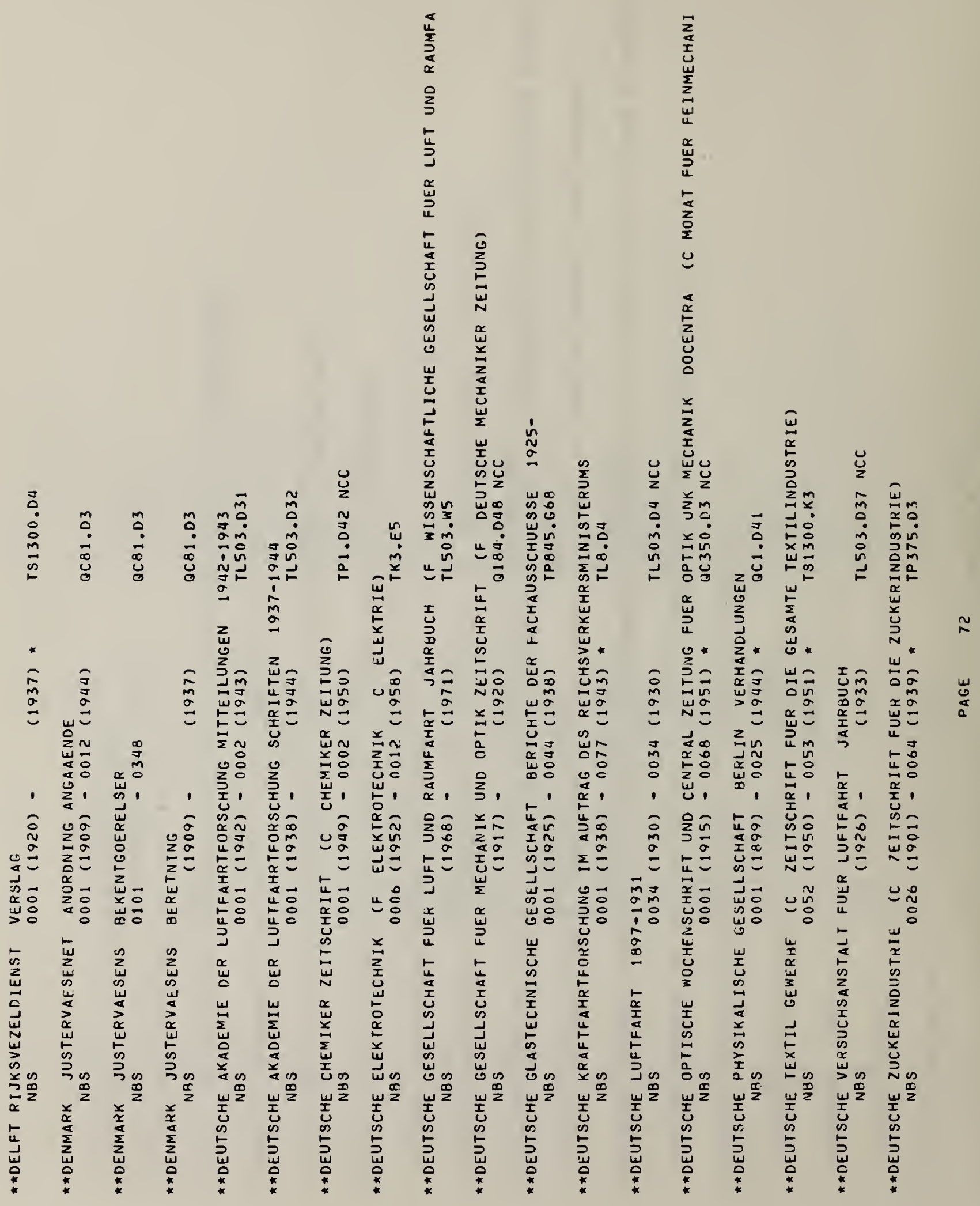




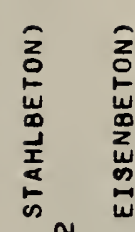

(1)

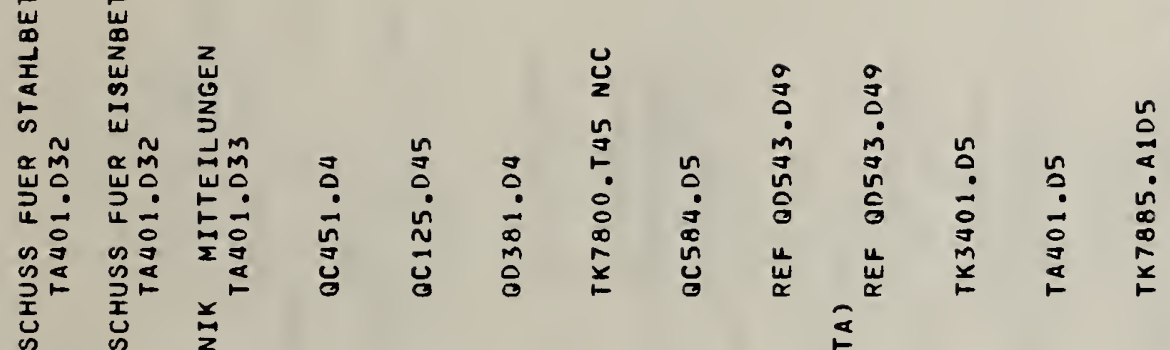

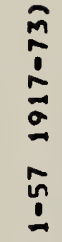

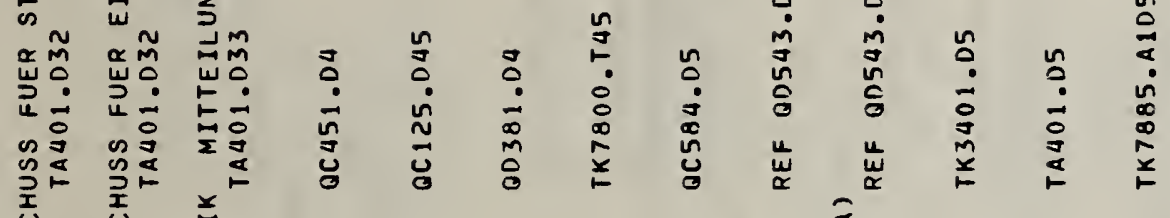

(1)

旁旁

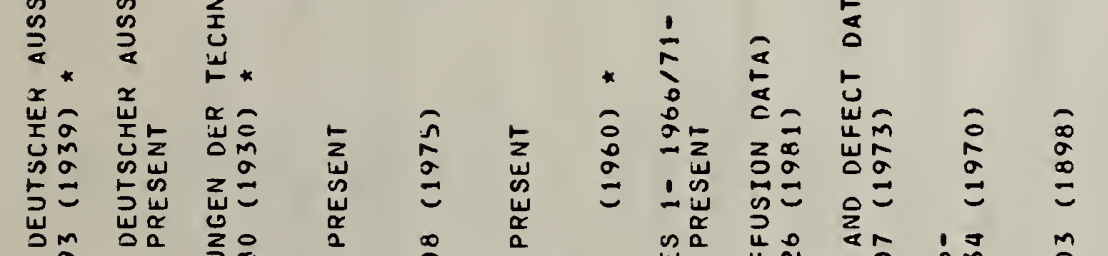

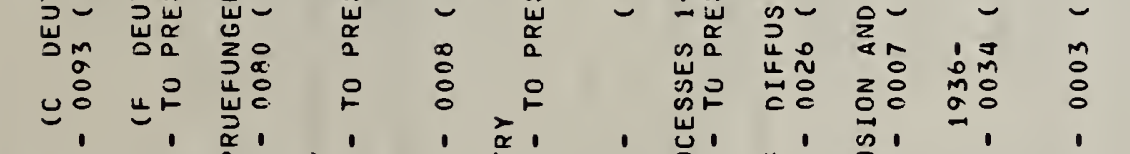

$\begin{array}{llll} & \\ 0\end{array}$

$\begin{array}{llll} & \\ 0\end{array}$

$\begin{array}{llll} & \\ 0\end{array}$

更 


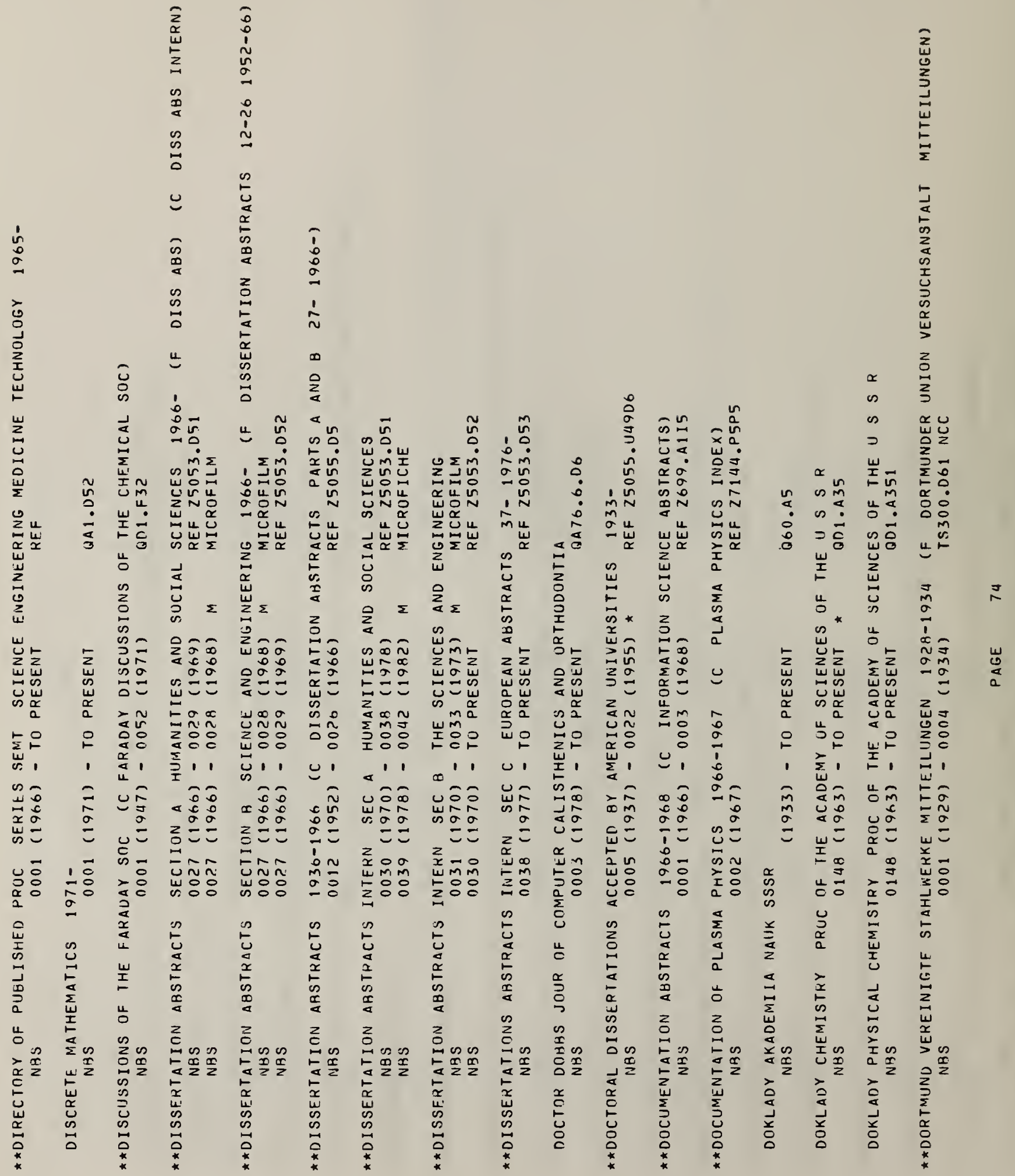


政

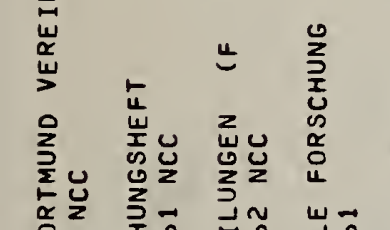

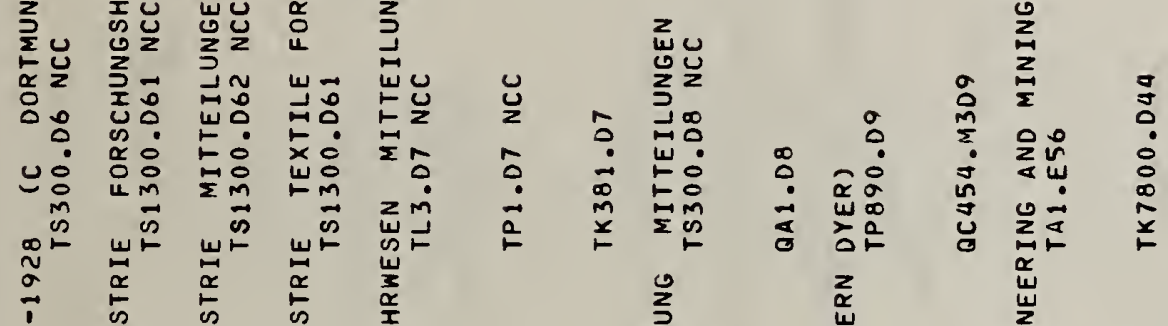<smiles>C1CC1</smiles>

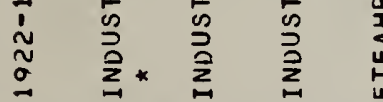

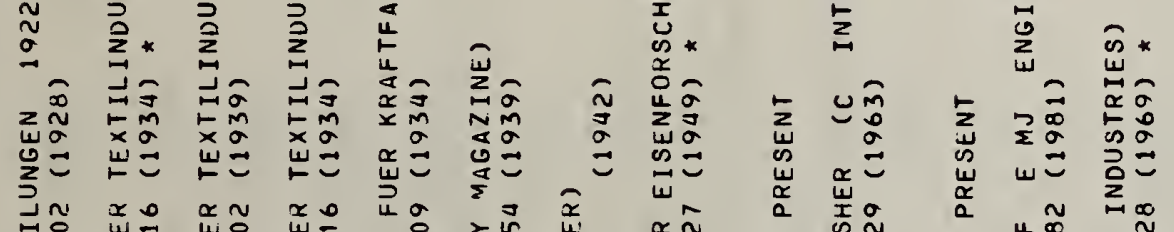

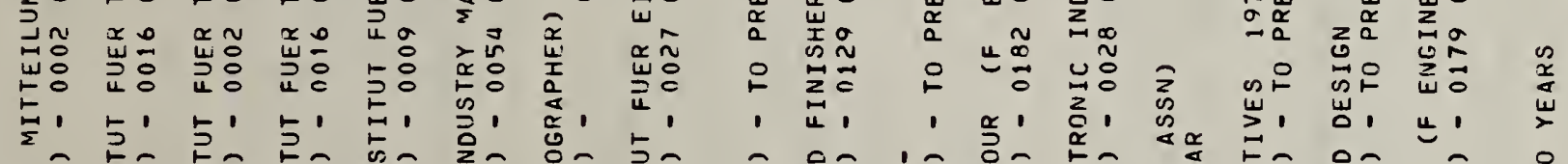

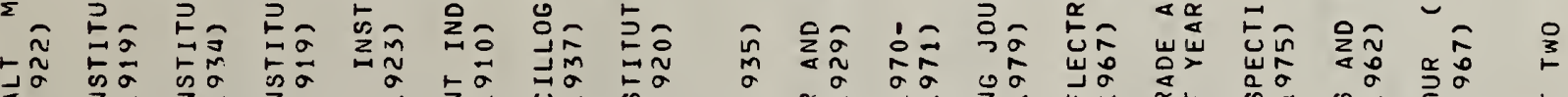

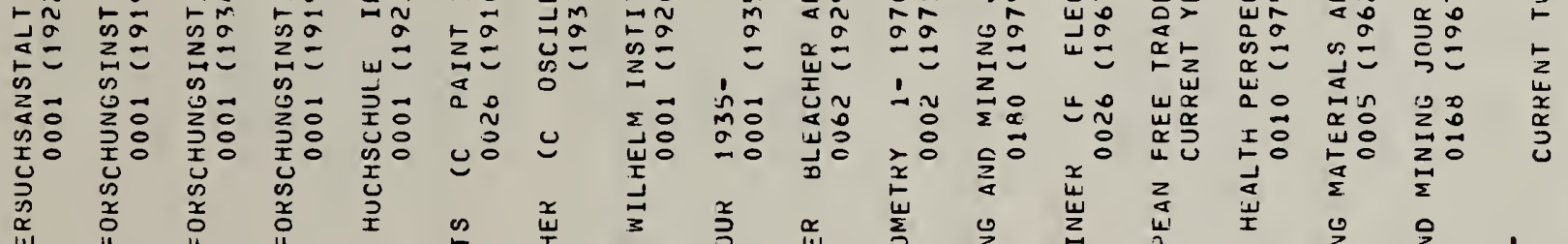

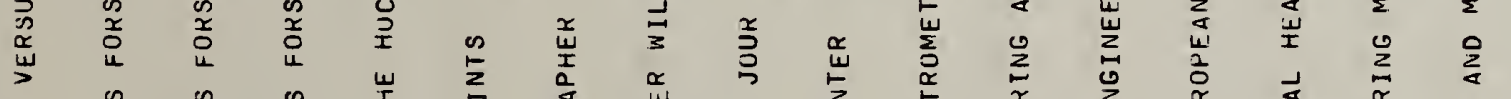

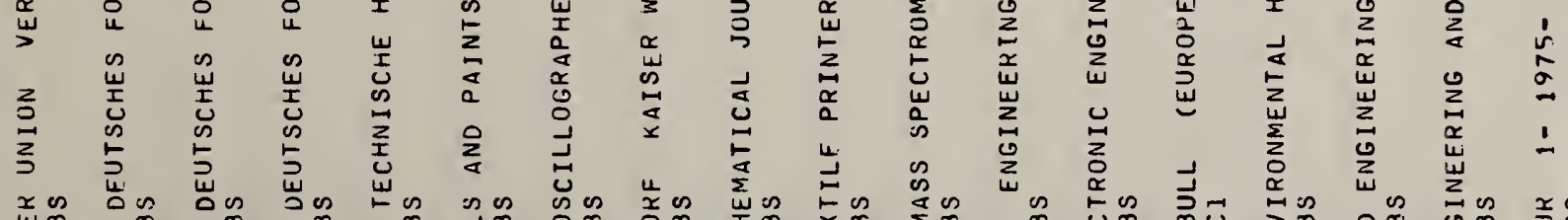

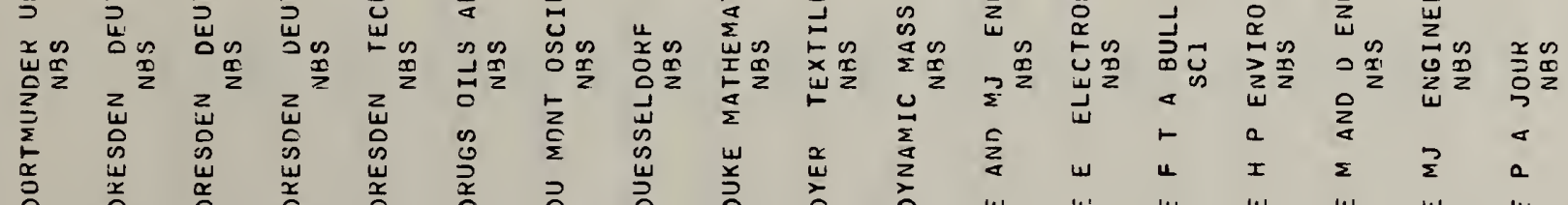




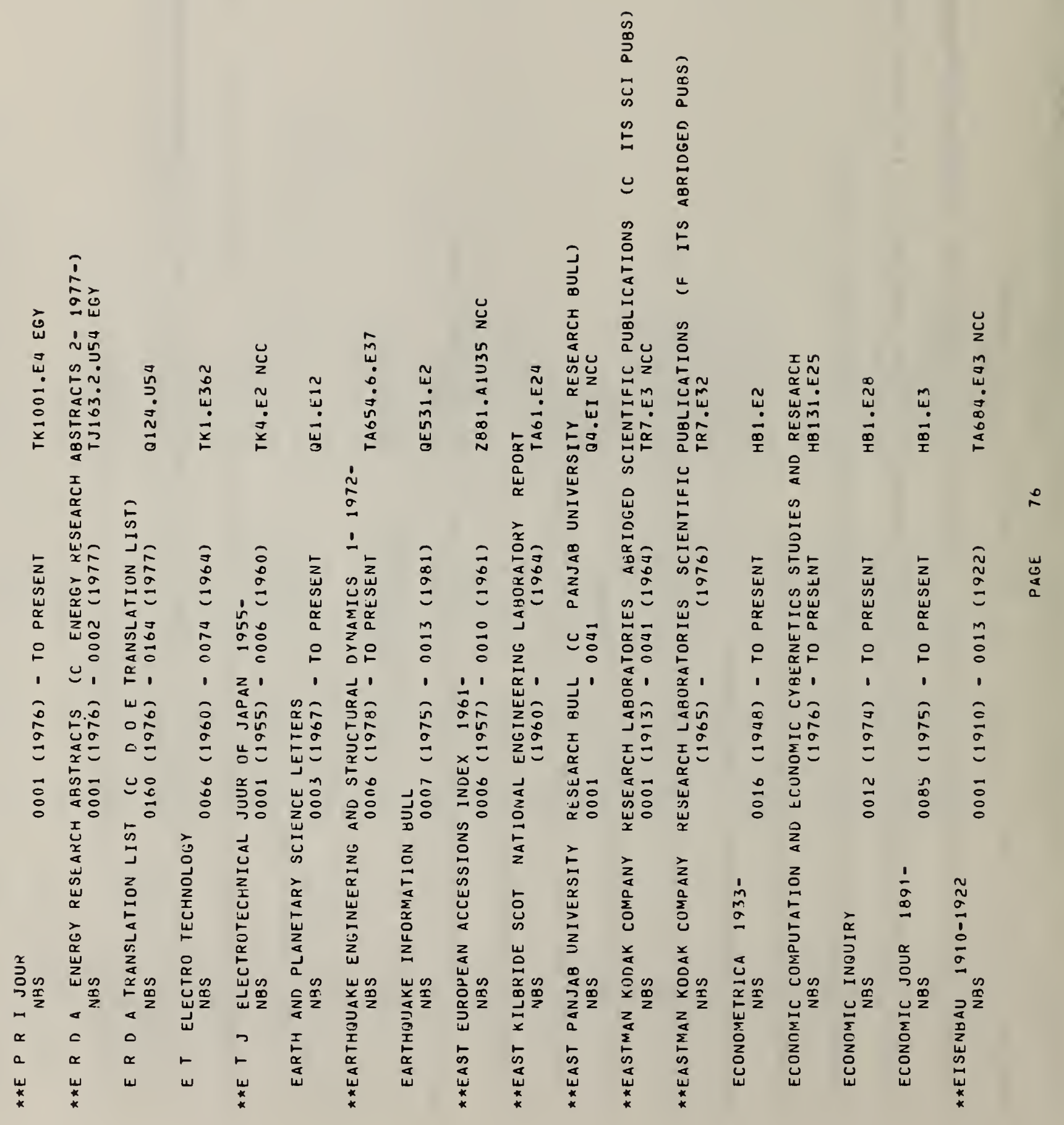




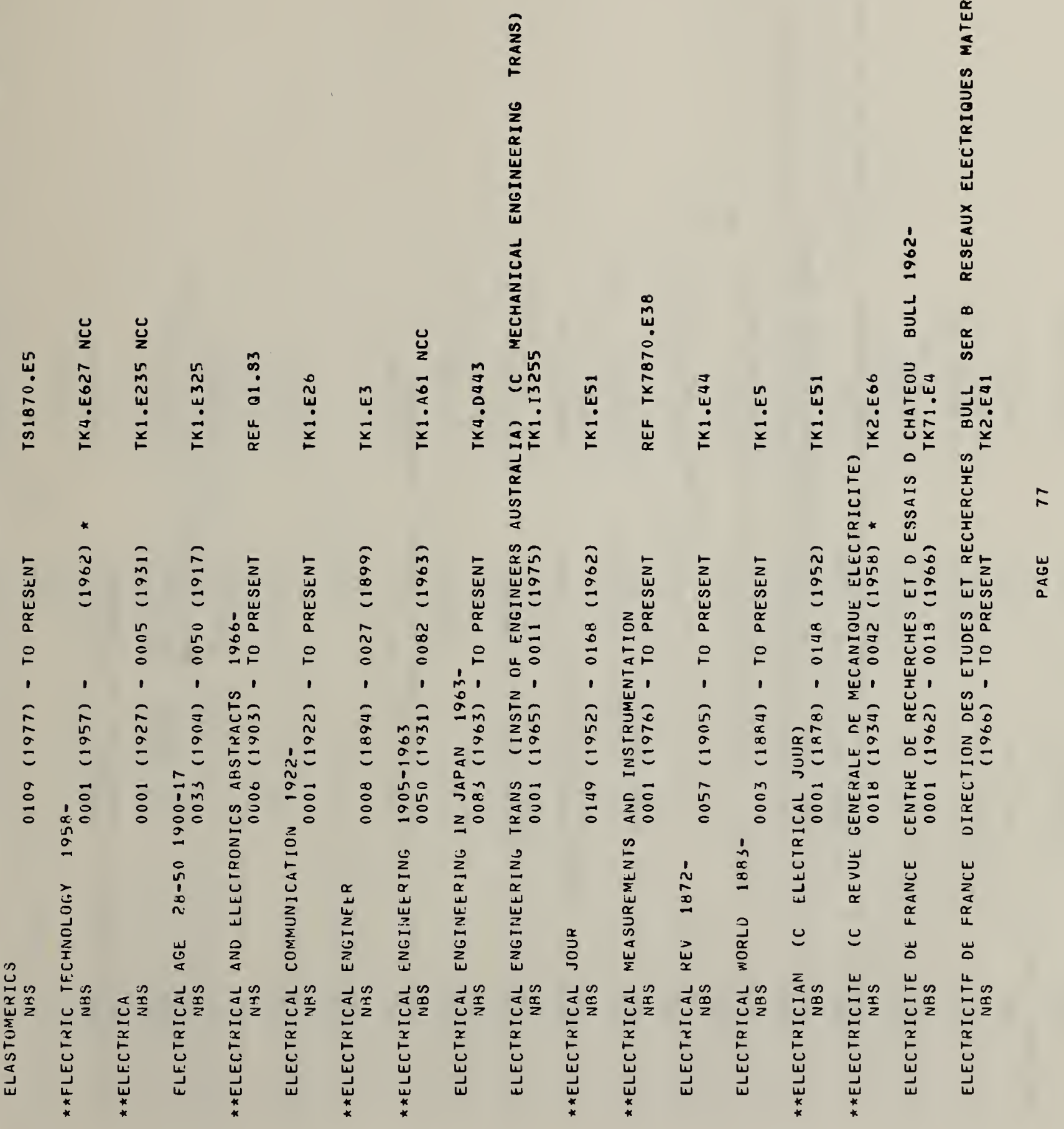




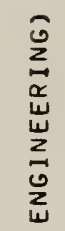

$$
\begin{aligned}
& \text { 站 } \\
& \sum_{2}
\end{aligned}
$$

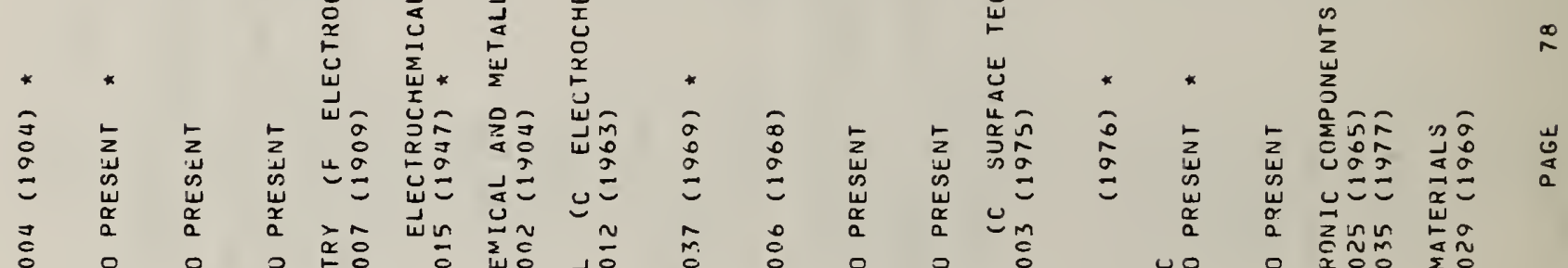

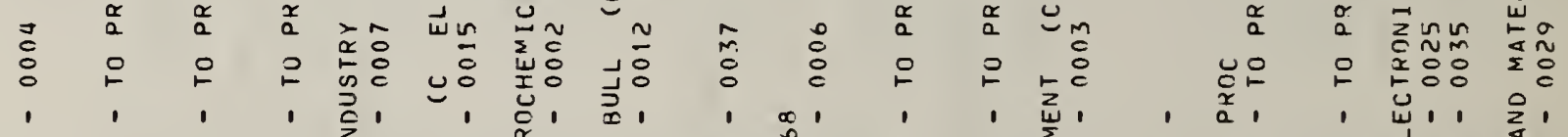

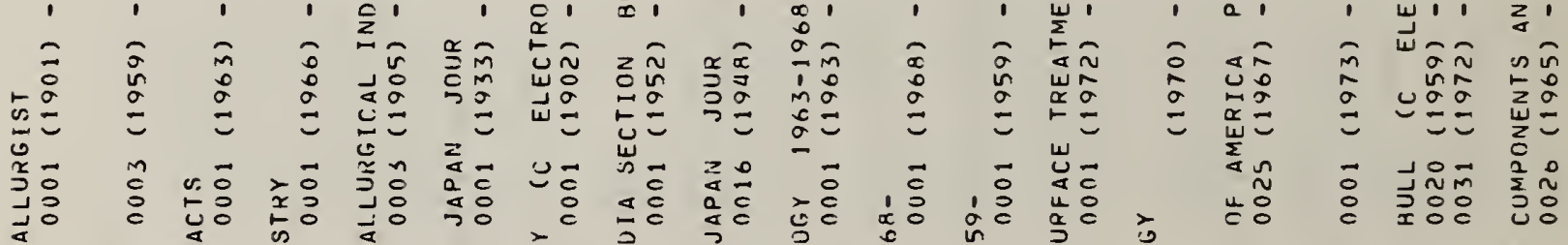

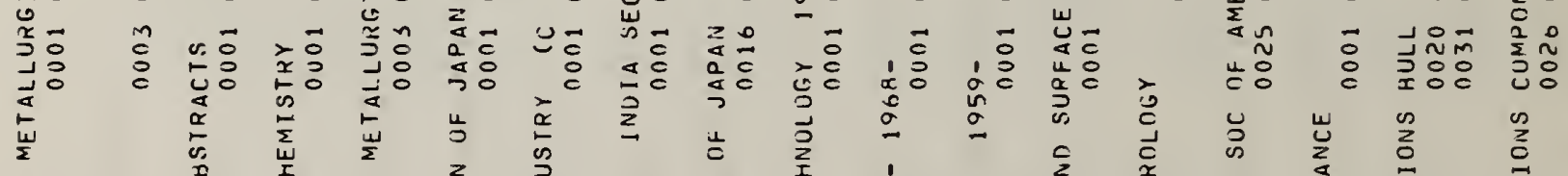

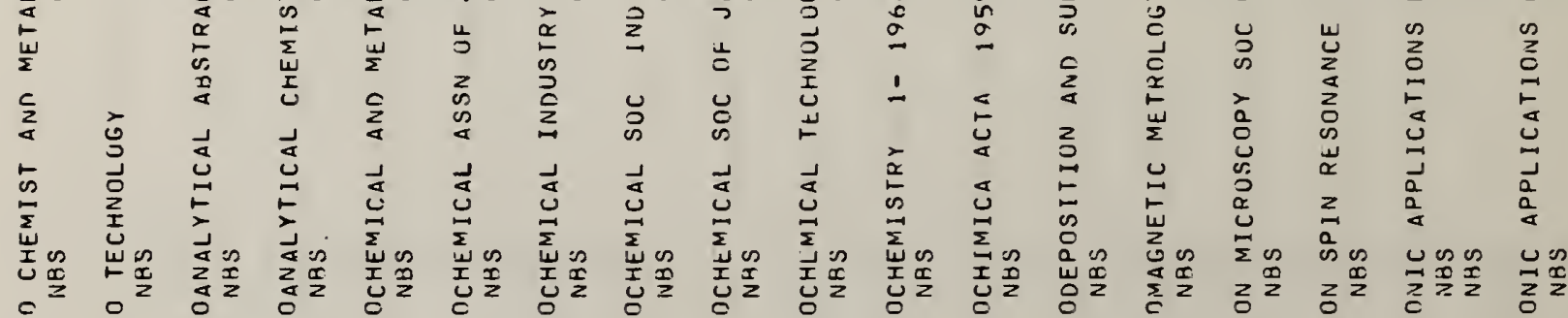

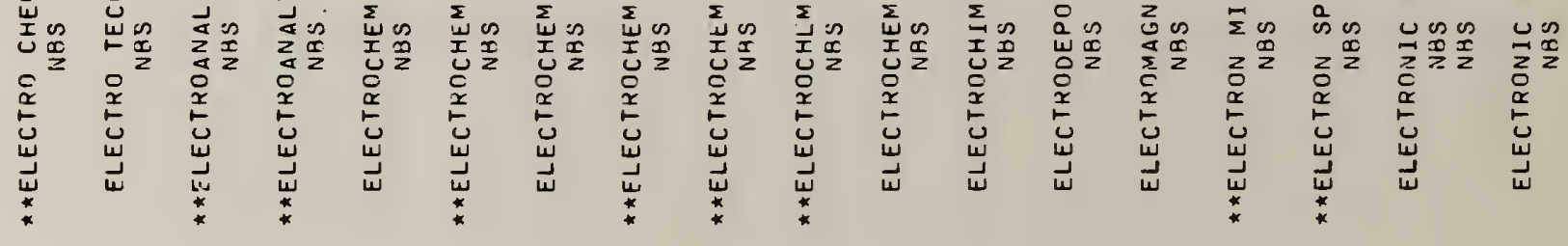




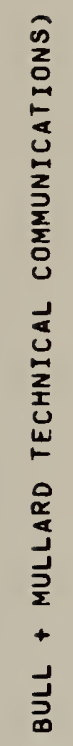

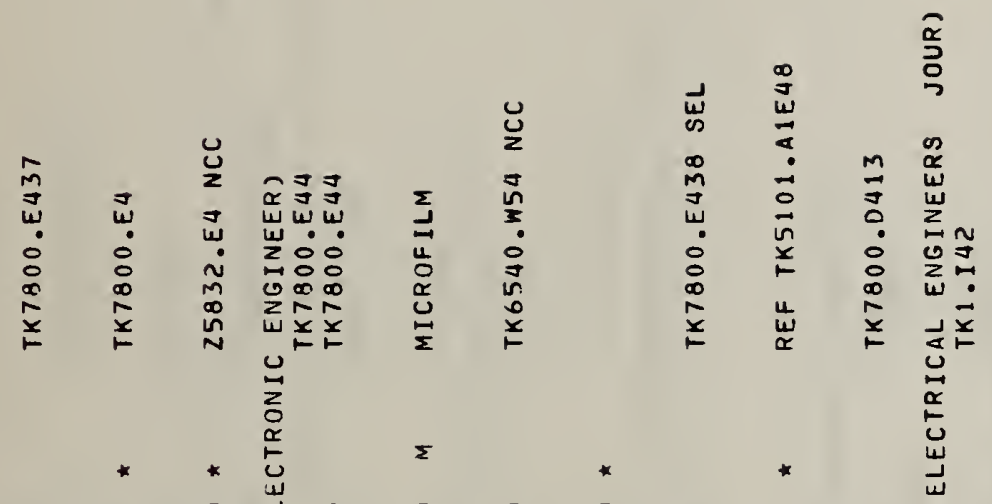

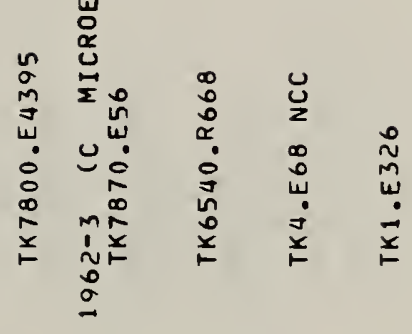

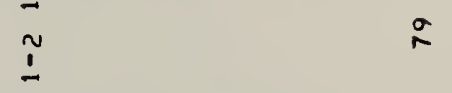

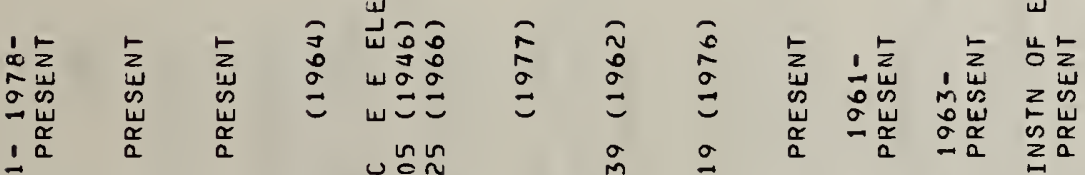

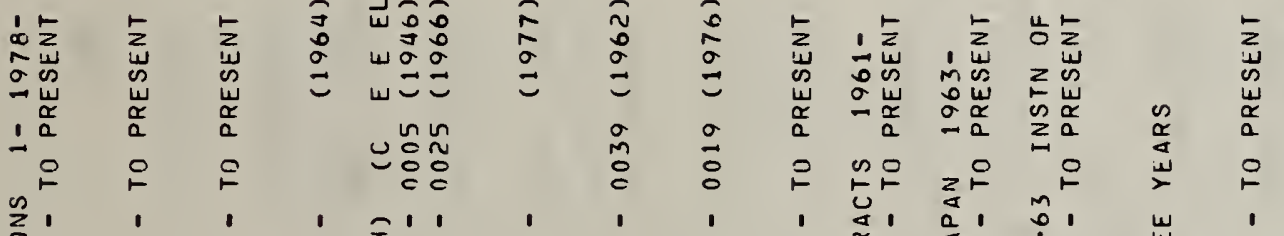

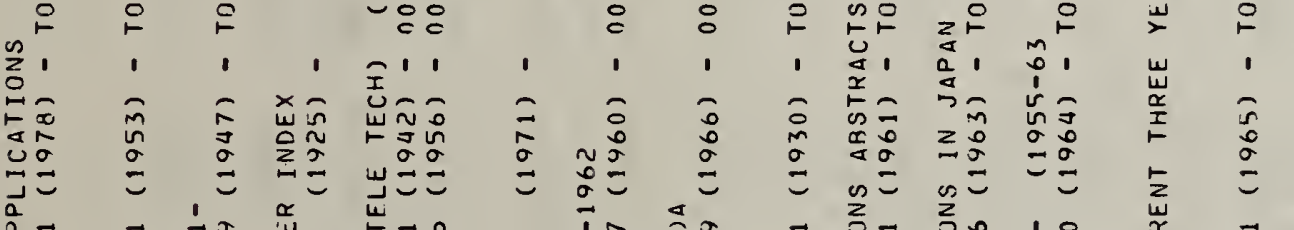

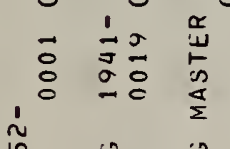

는

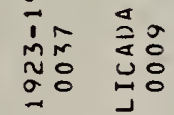

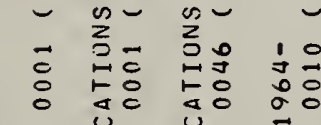

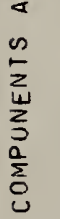

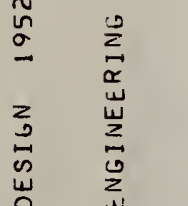




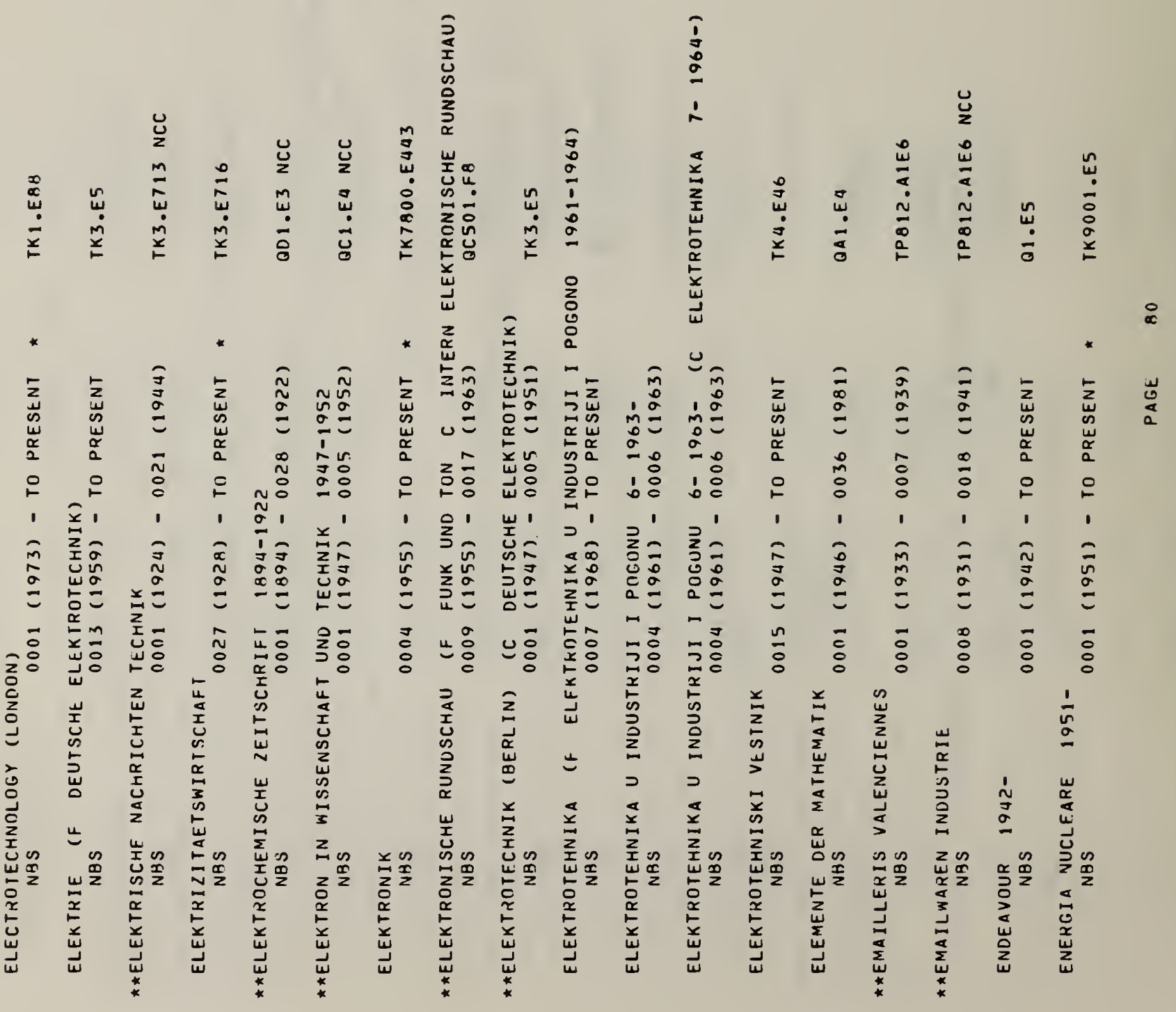




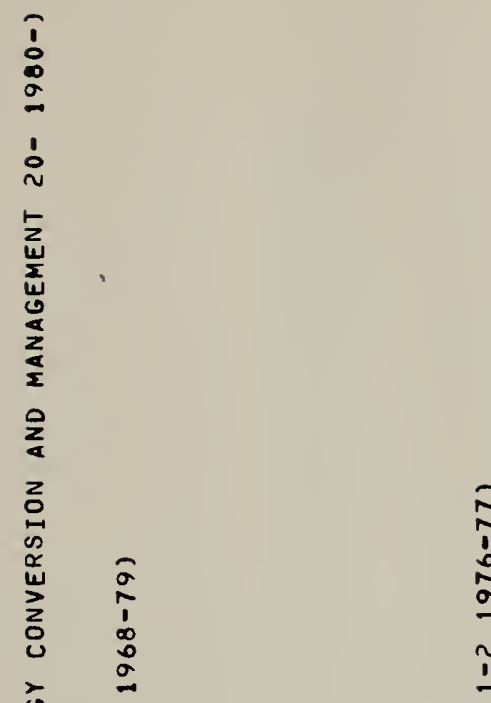

울울 퐆

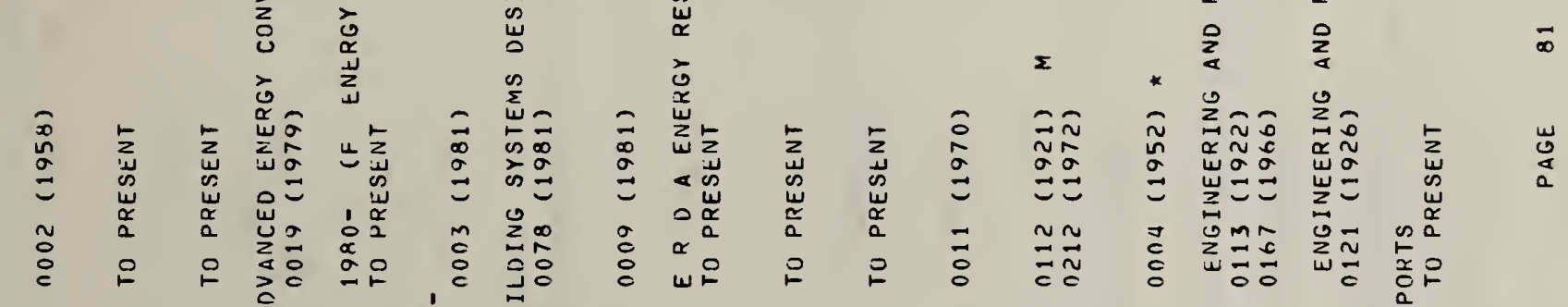

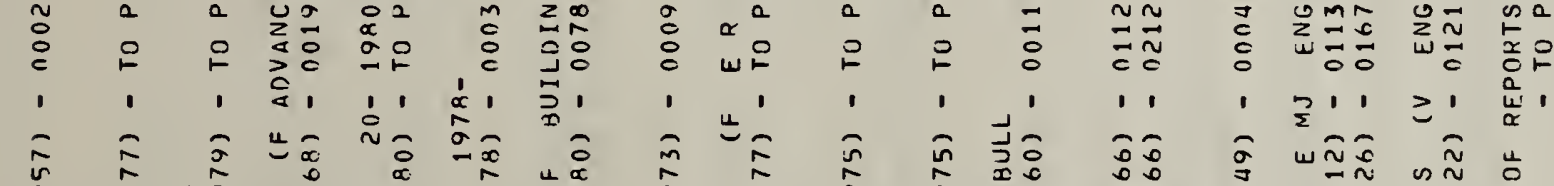

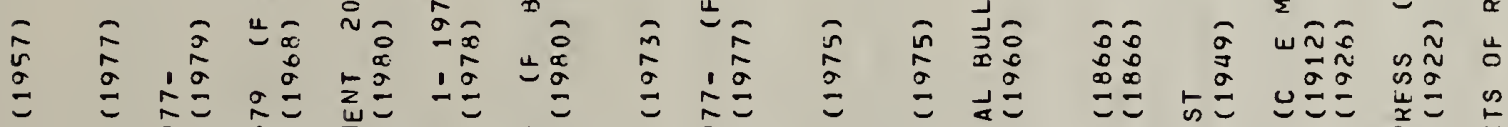

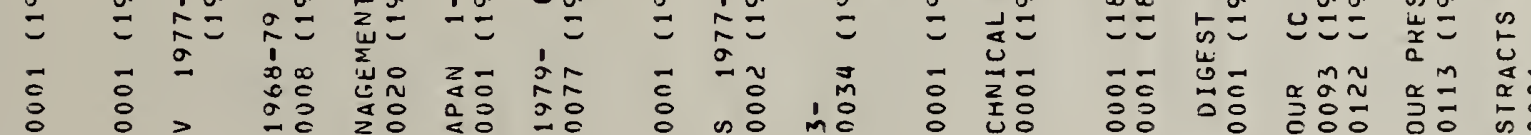

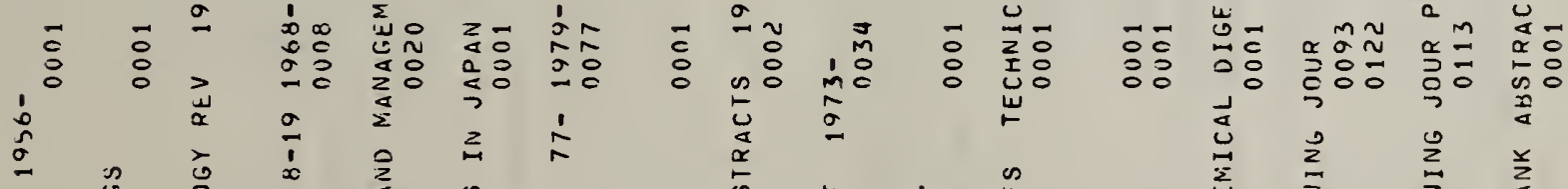

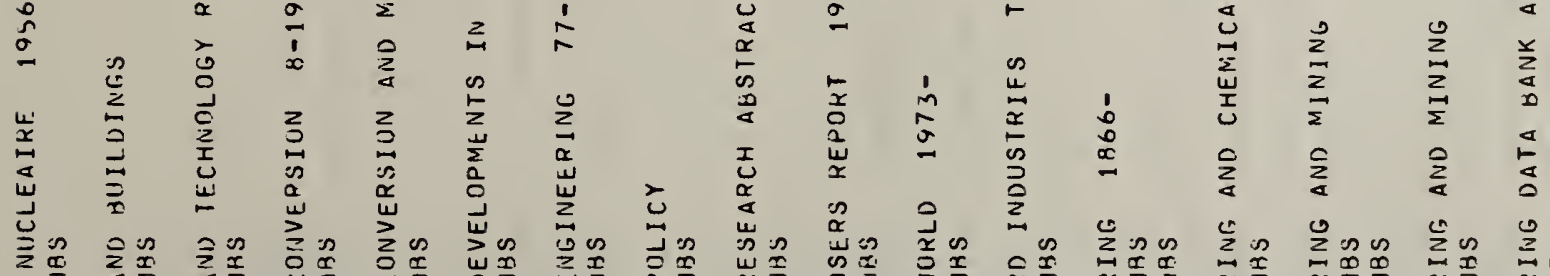

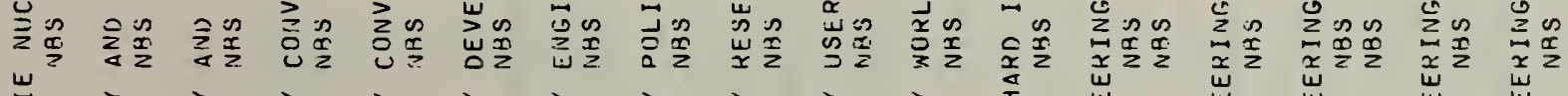

竞

离

离

交

离

空 


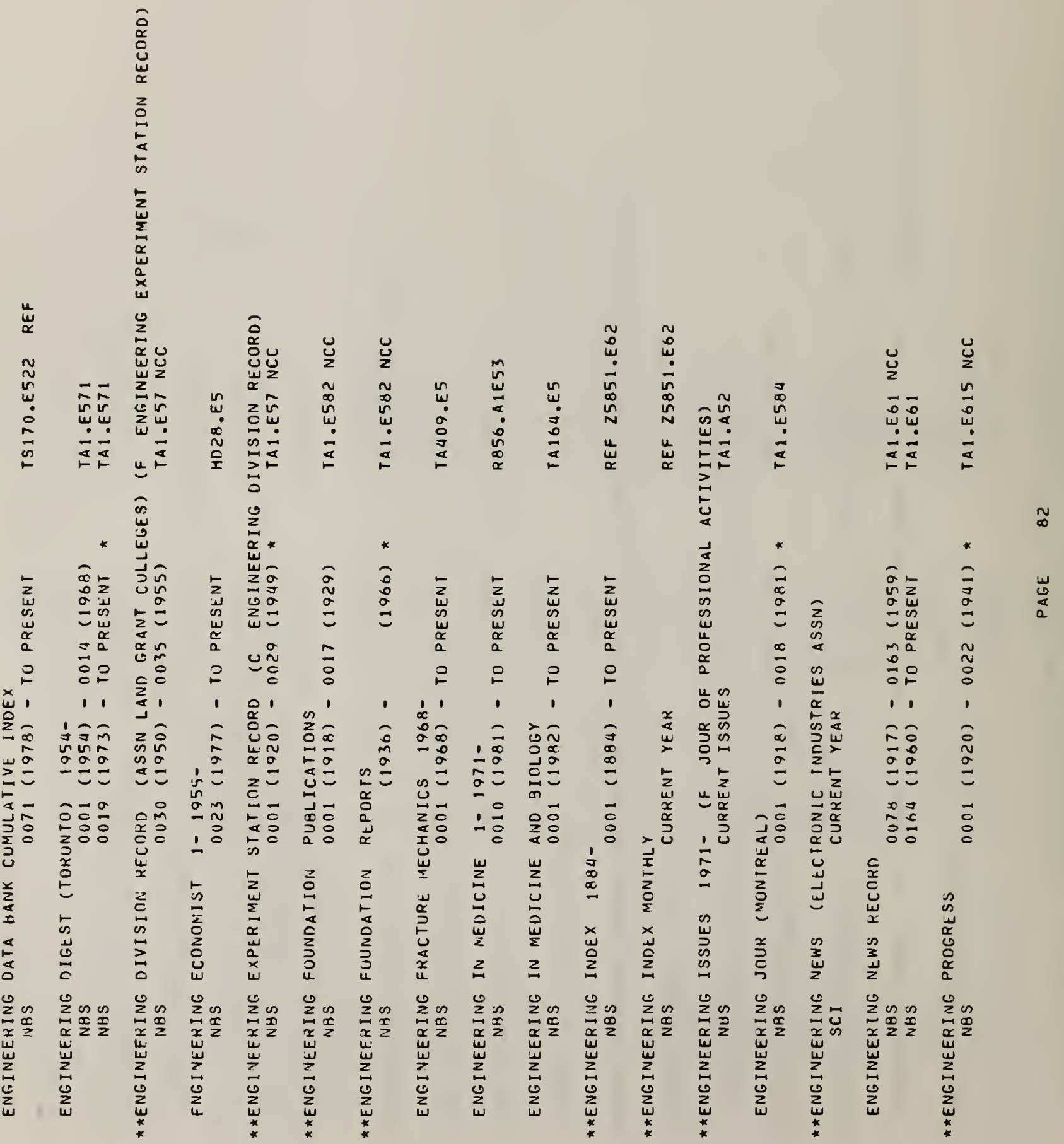




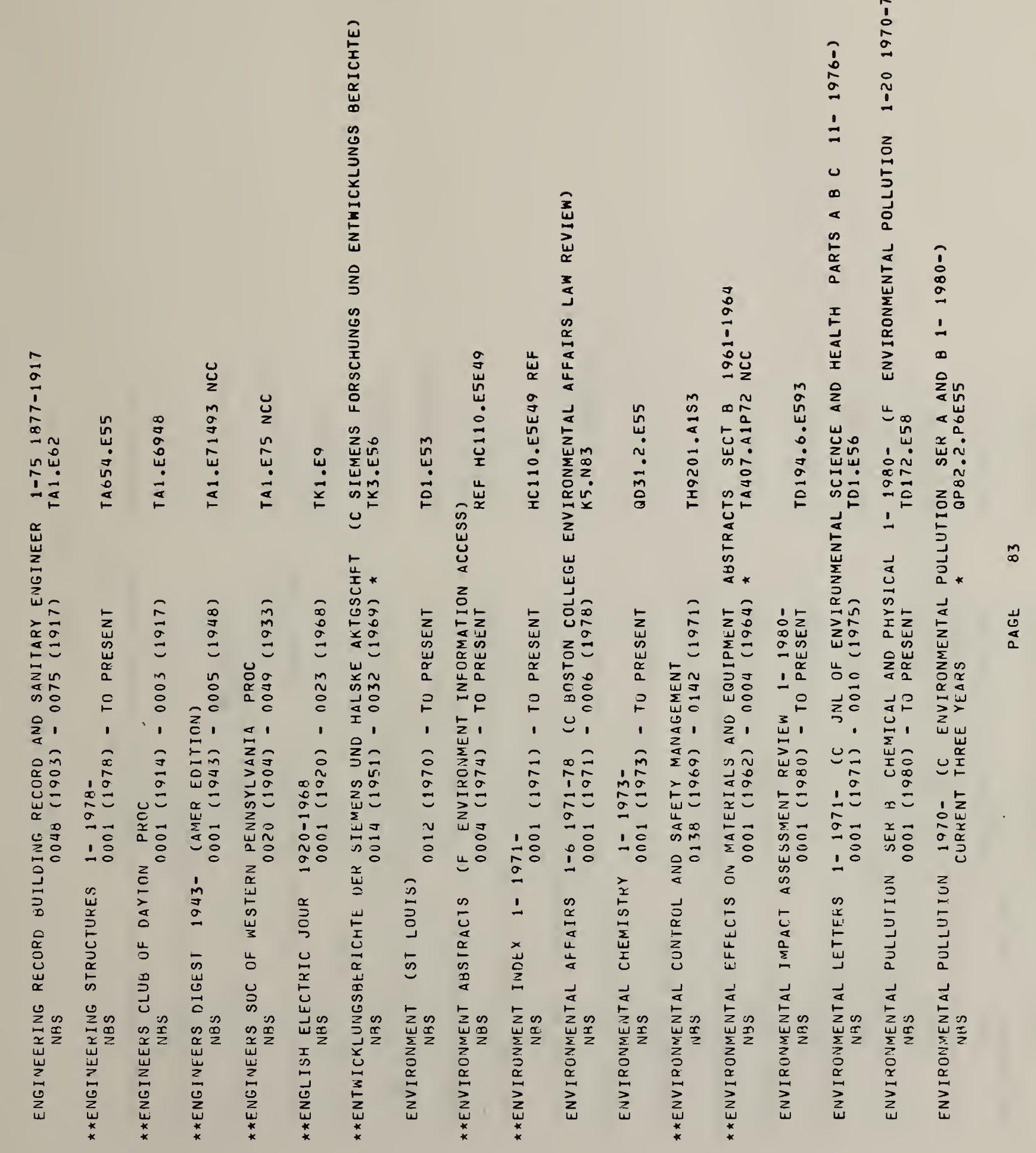




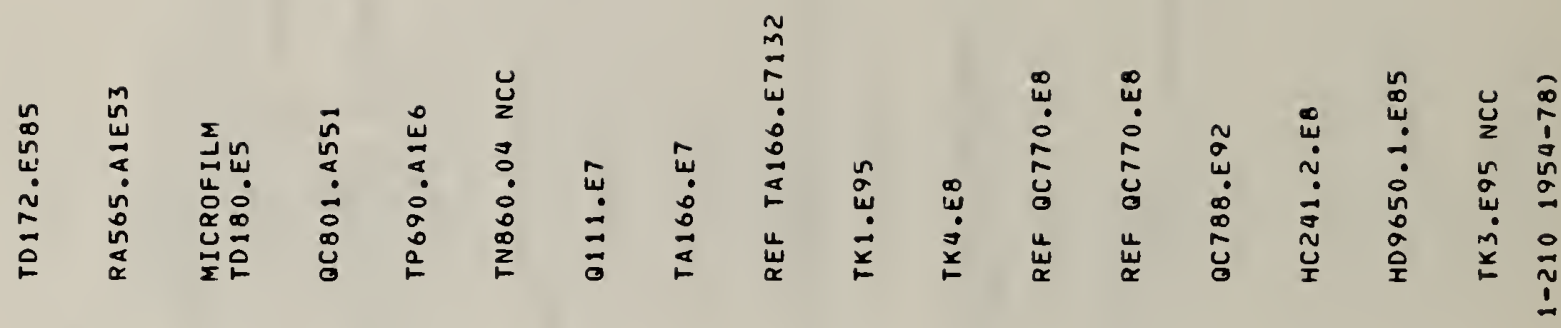

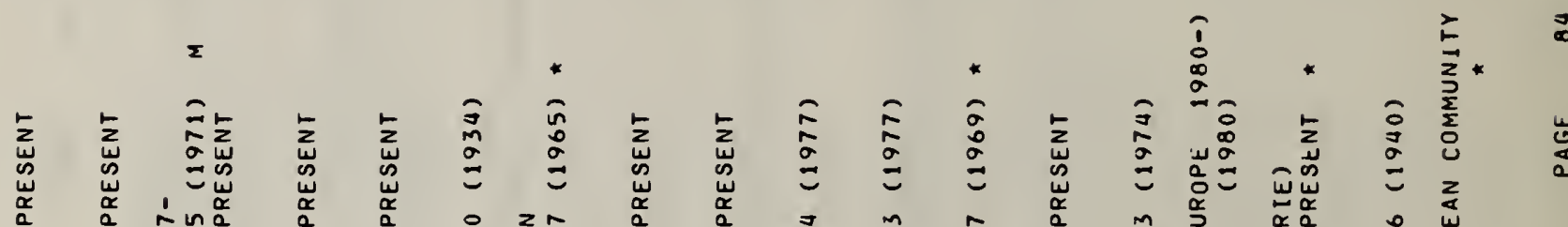

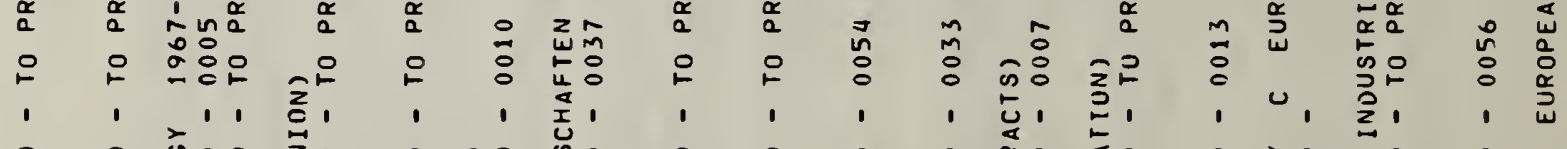

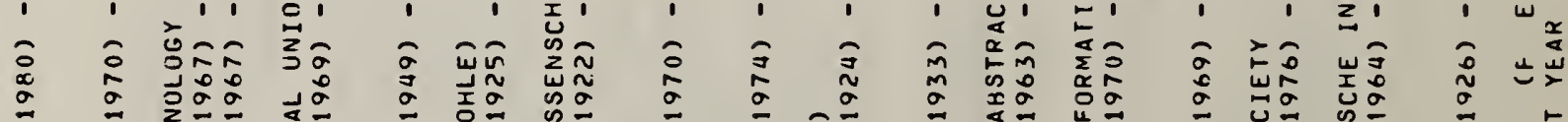

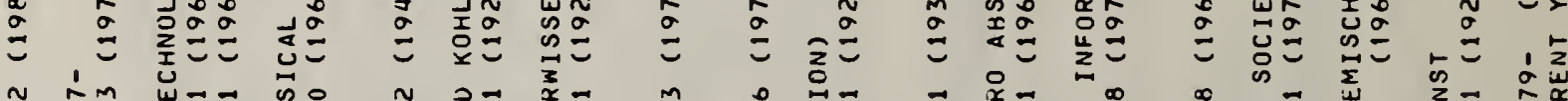

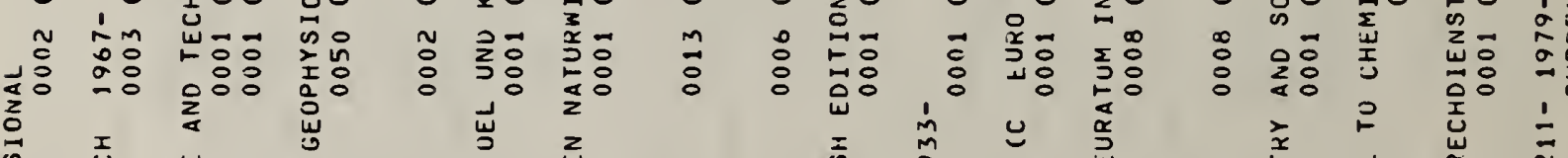

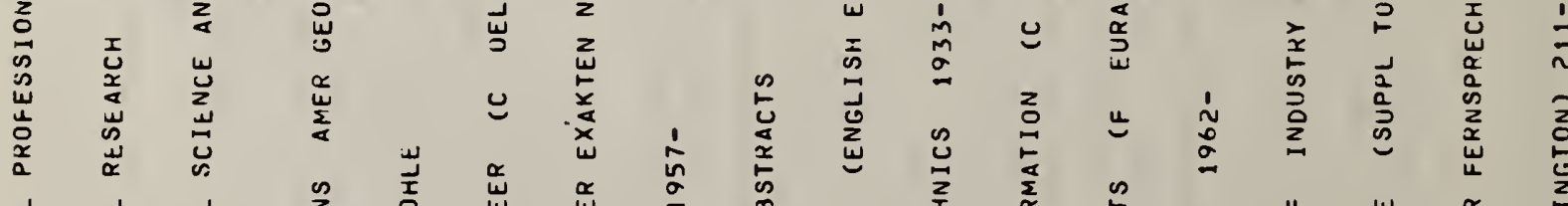

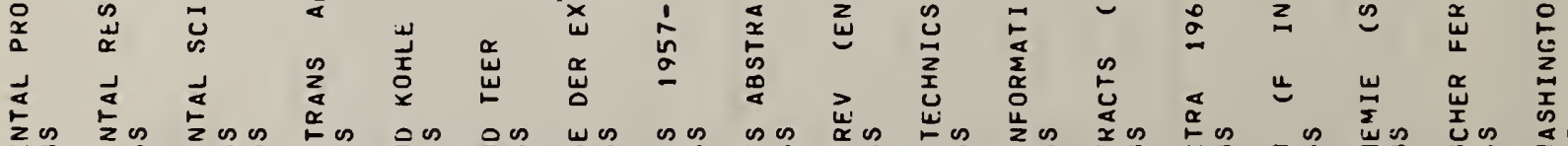

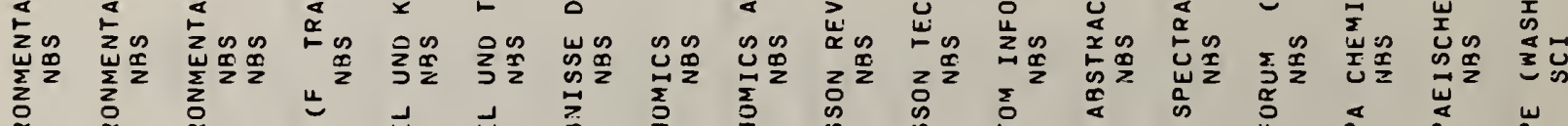

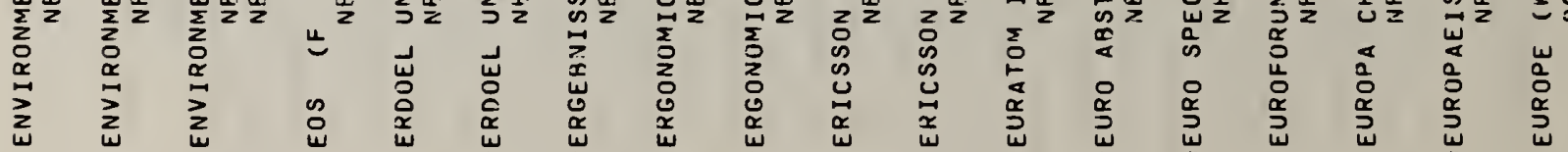




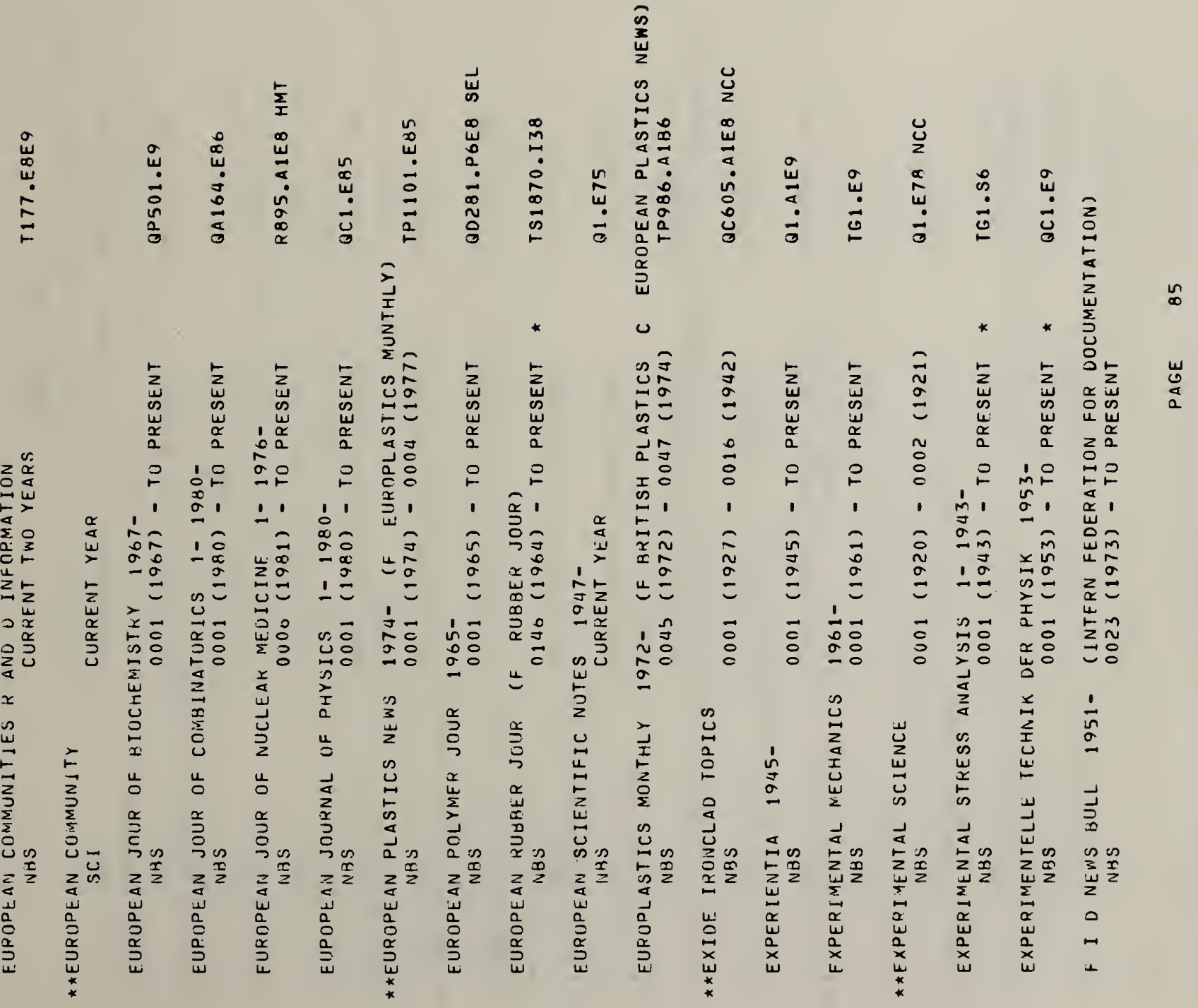




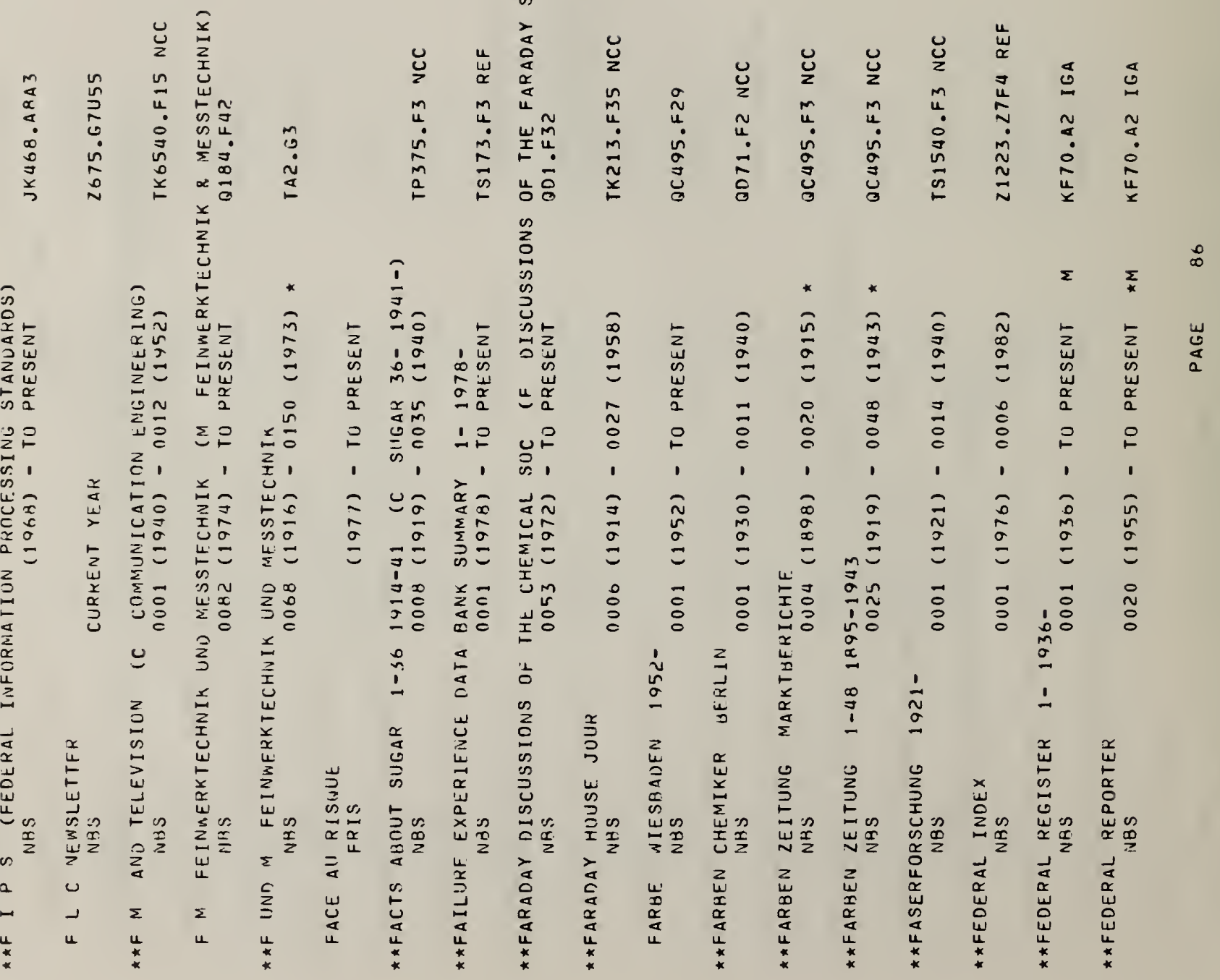




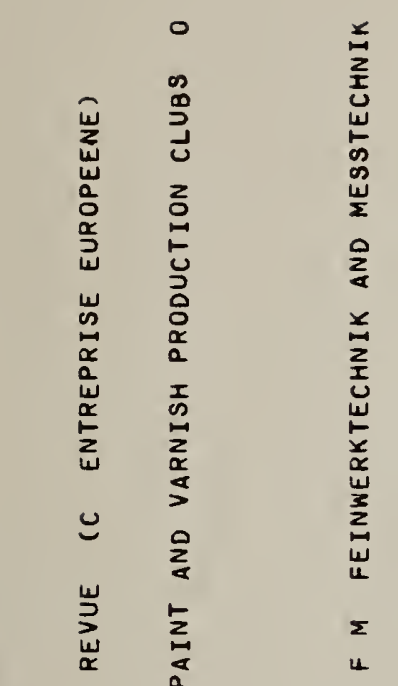

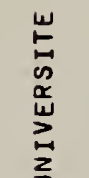

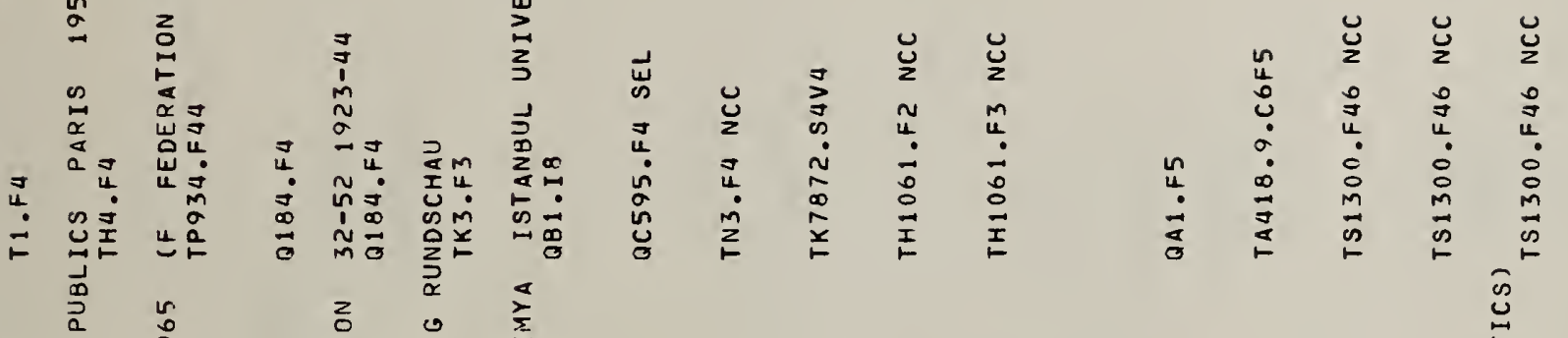

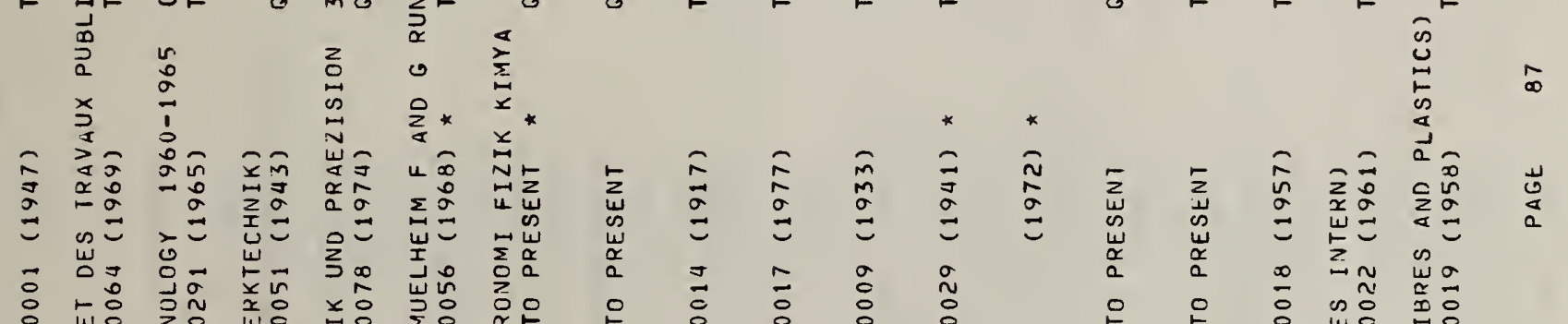

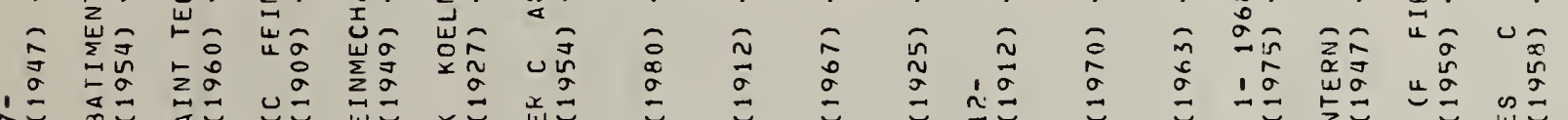

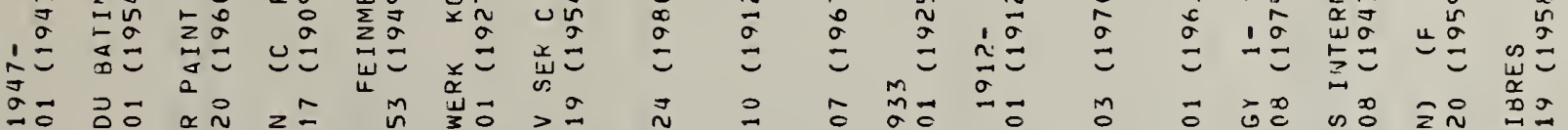

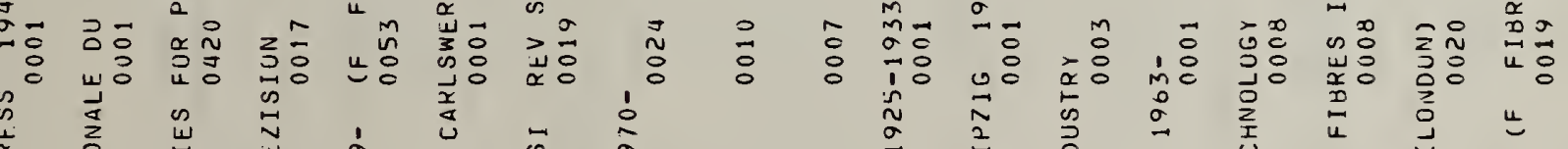

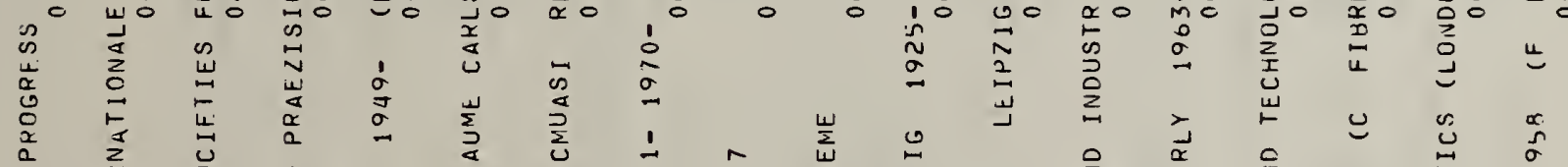

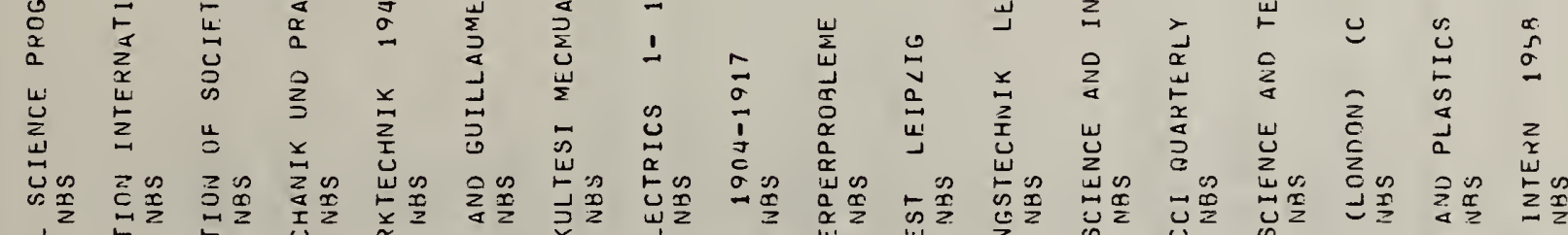

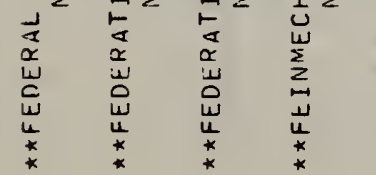

$$
\begin{aligned}
& \text { 赔 }
\end{aligned}
$$

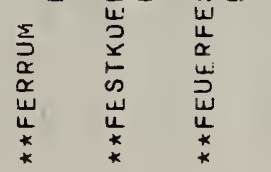

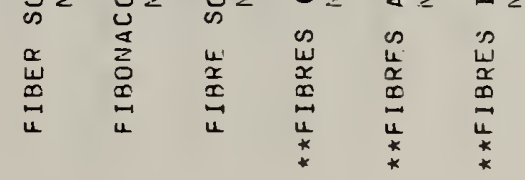




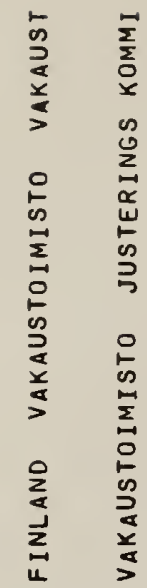

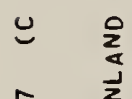

$$
\begin{aligned}
& \stackrel{\sim}{n} \quad \stackrel{\frac{1}{2}}{\pi} \\
& \tilde{\tilde{v}} \quad \text { ㄴ }
\end{aligned}
$$

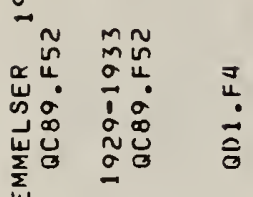

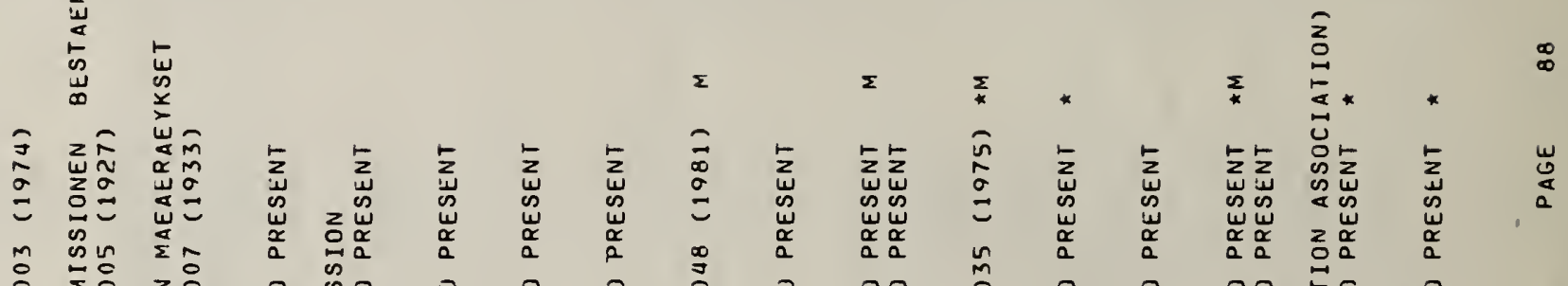

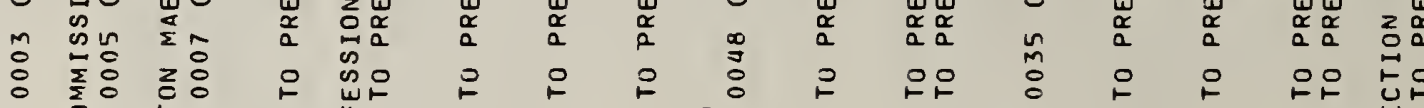

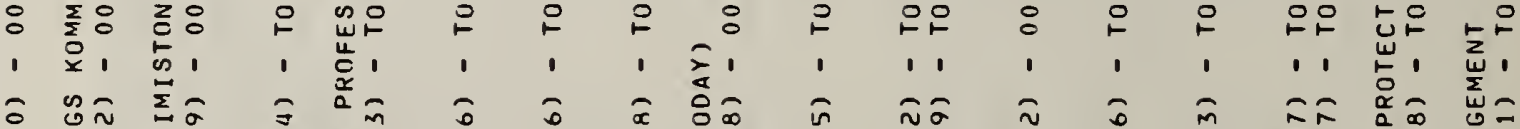

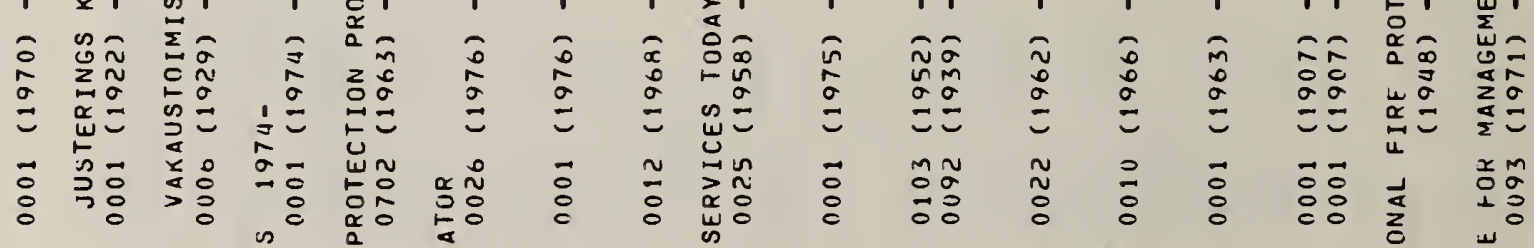

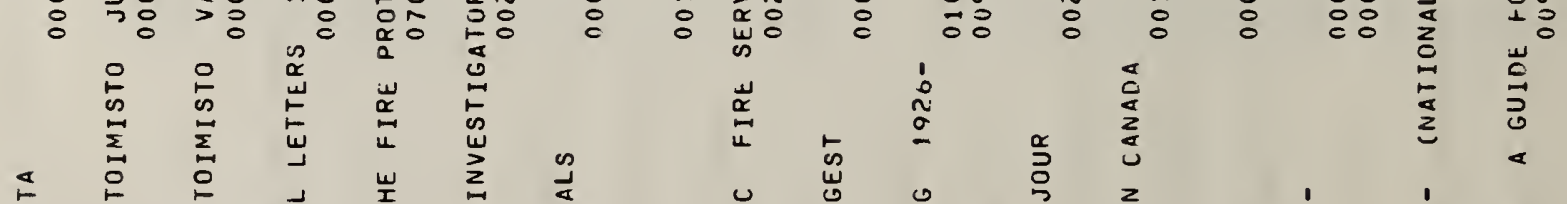

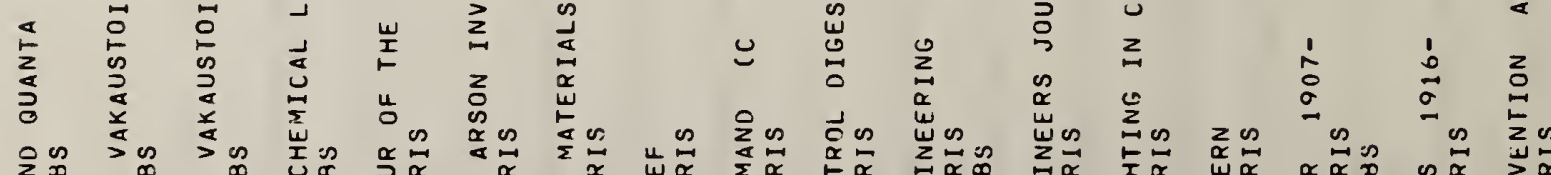

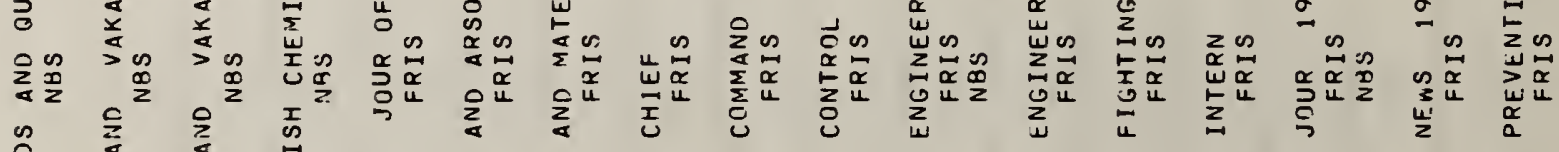

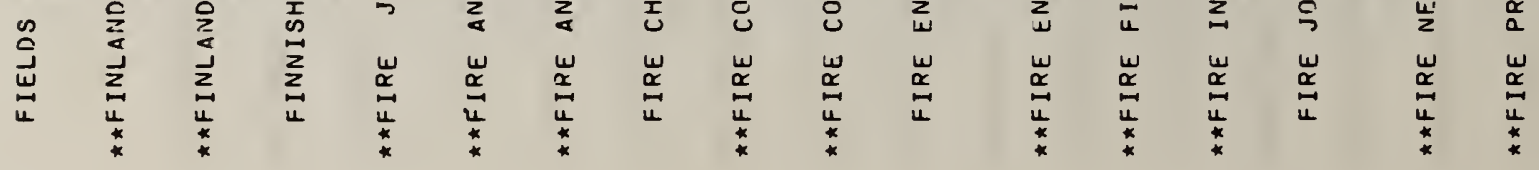



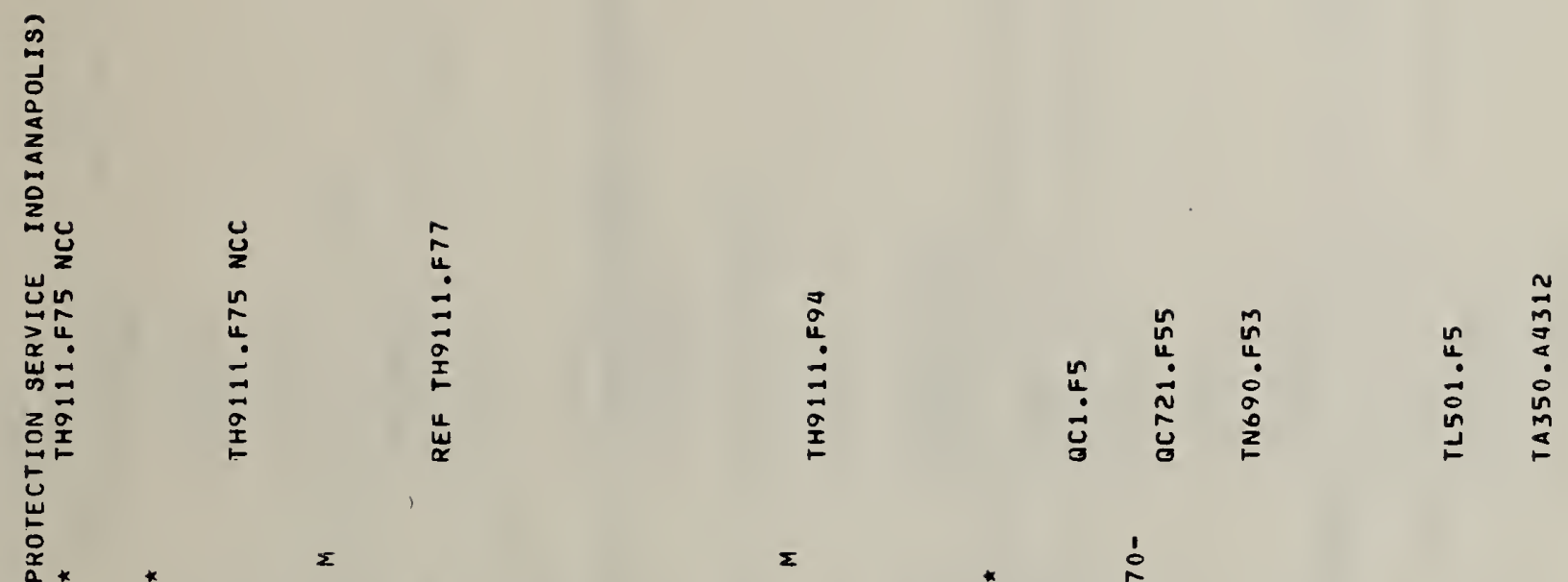

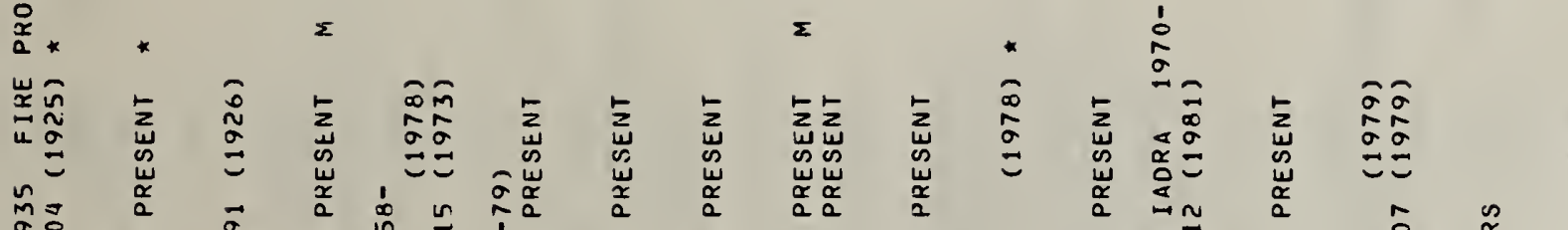

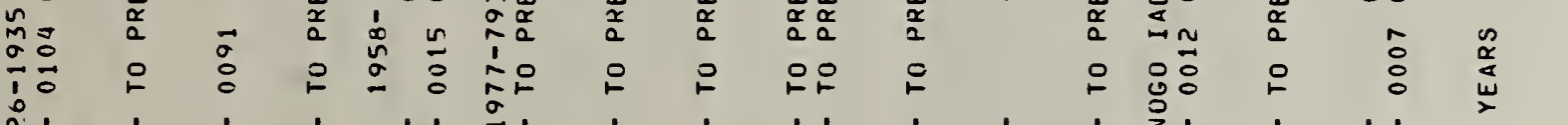

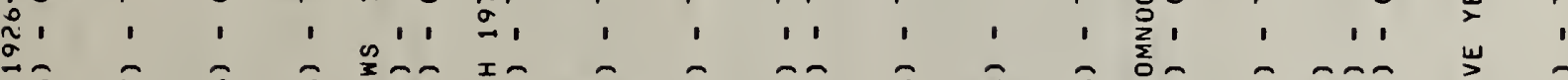

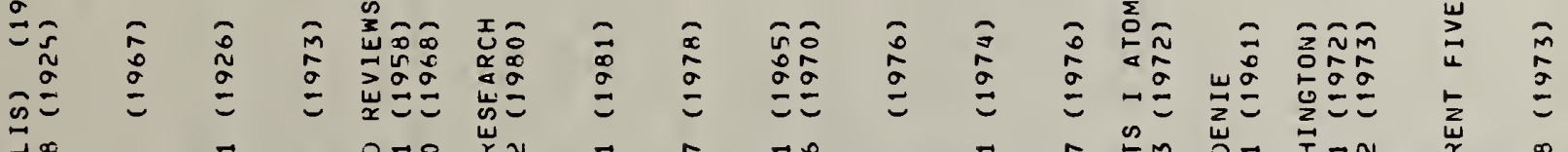

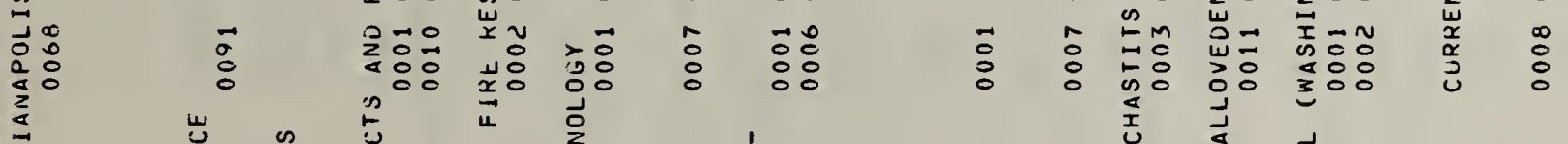

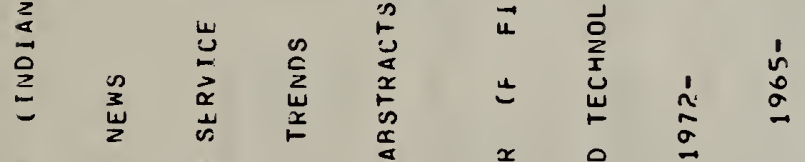

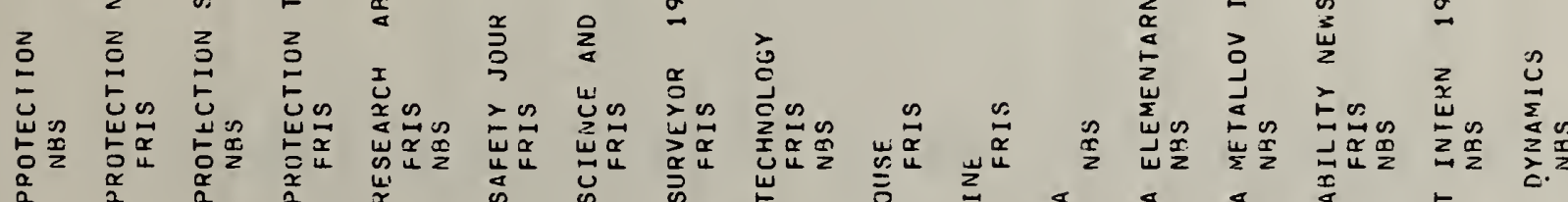

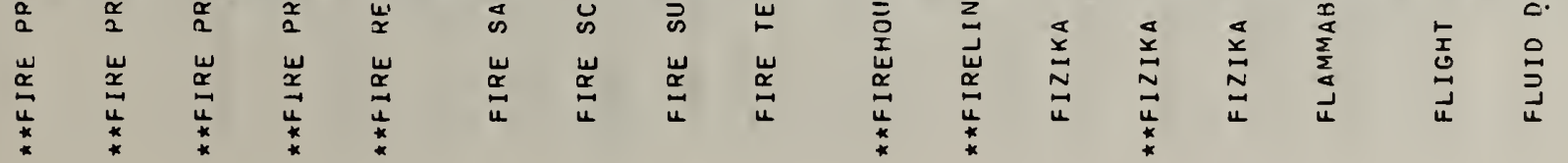




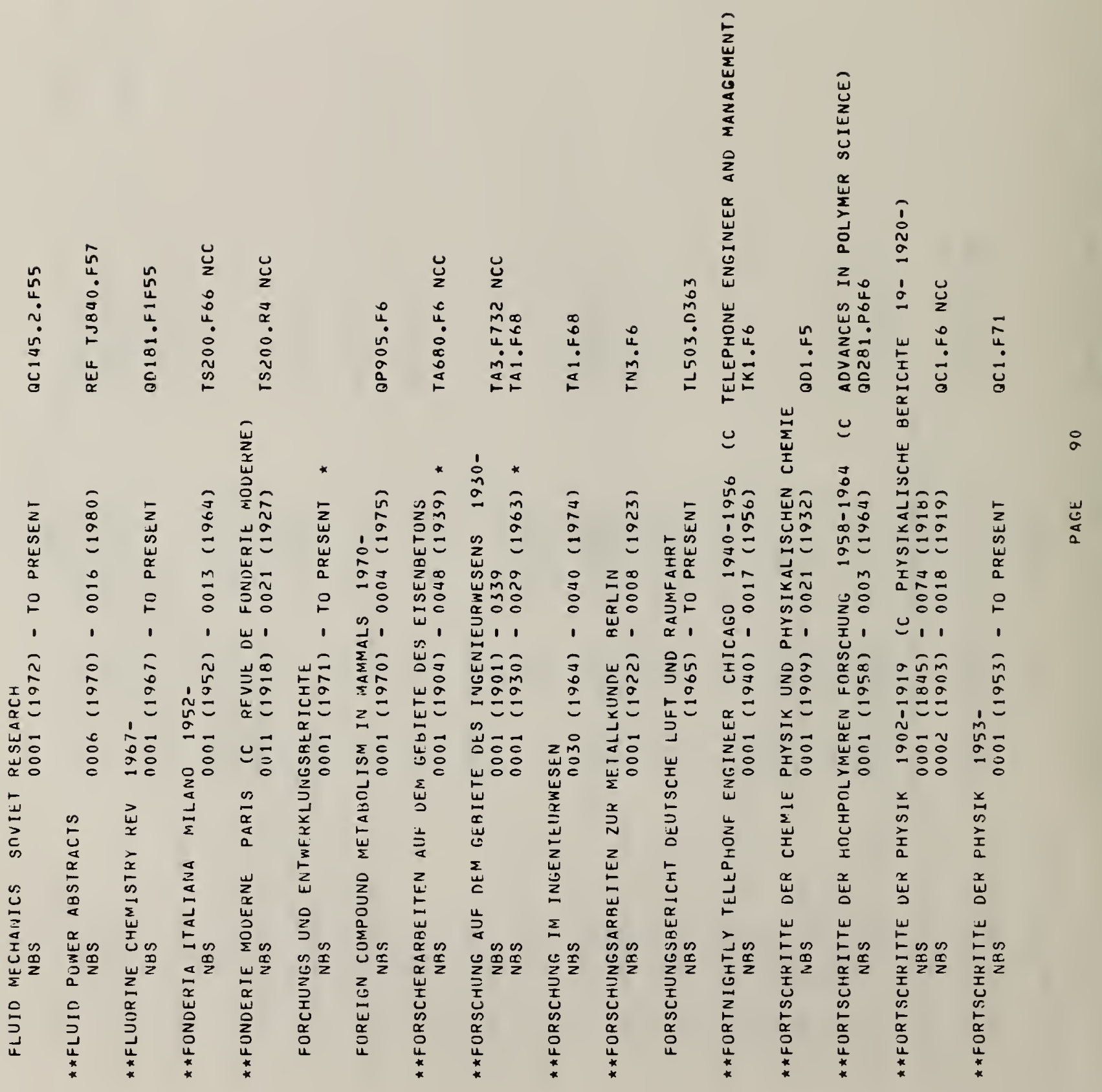




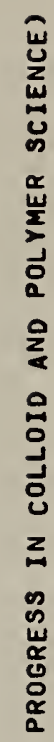

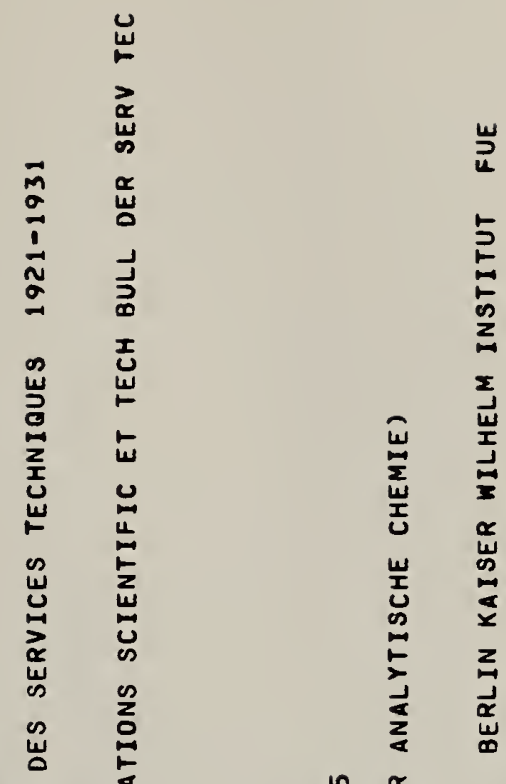

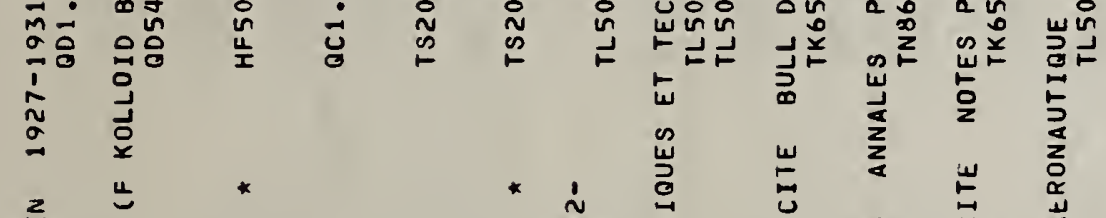

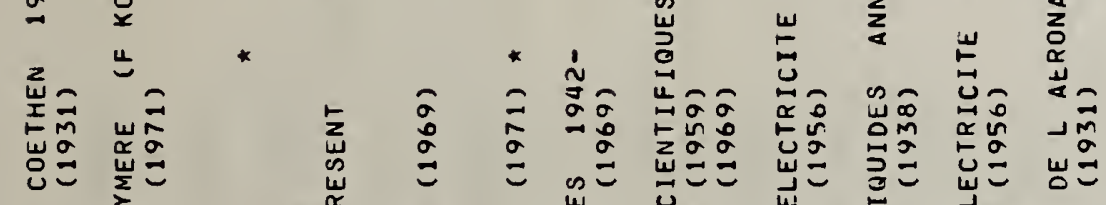

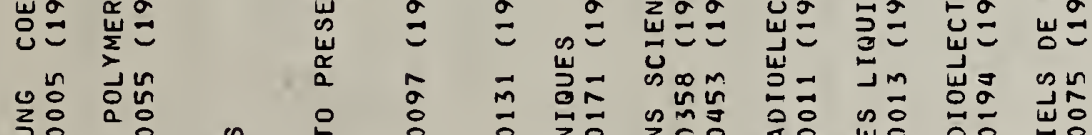

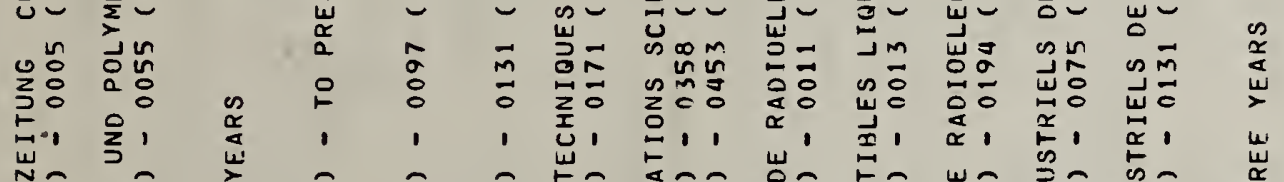

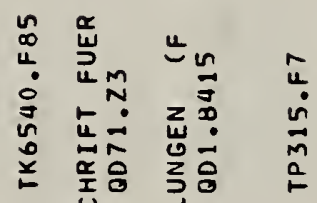

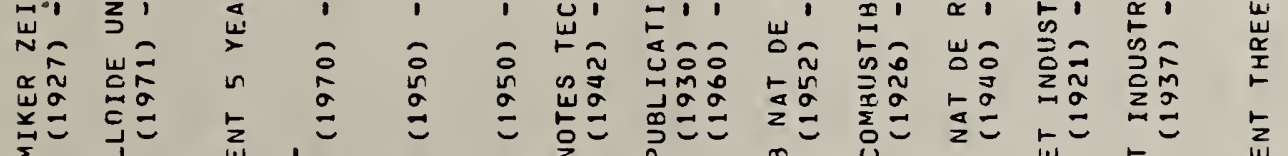

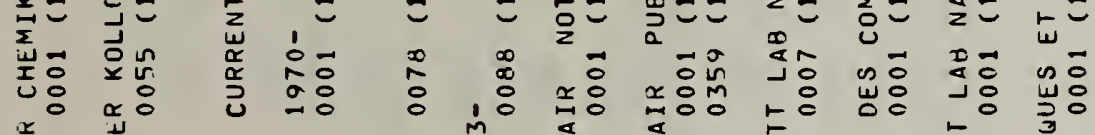

(

旁

ํ.

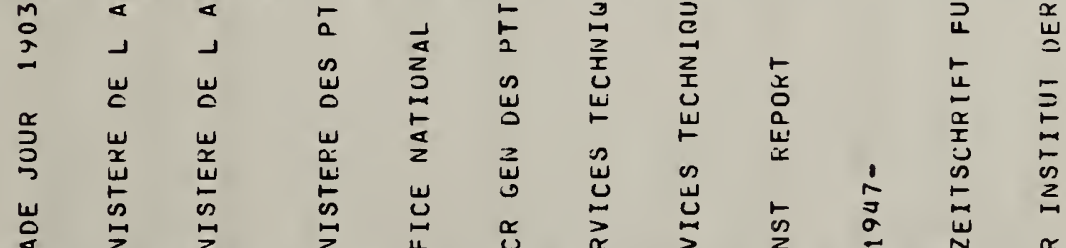

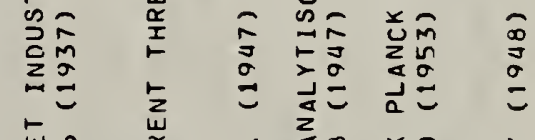

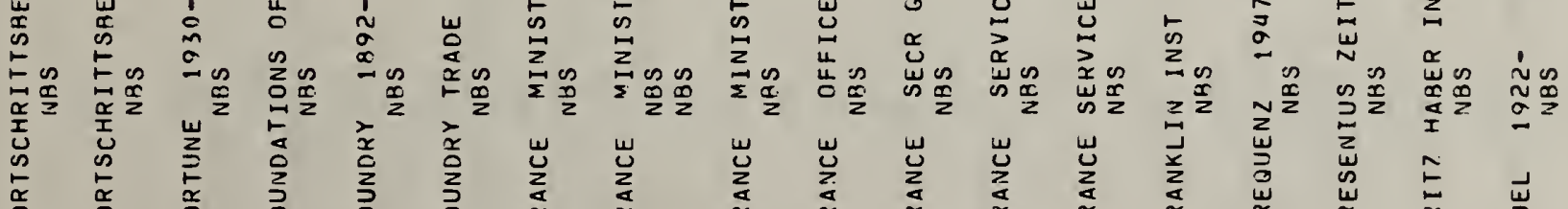

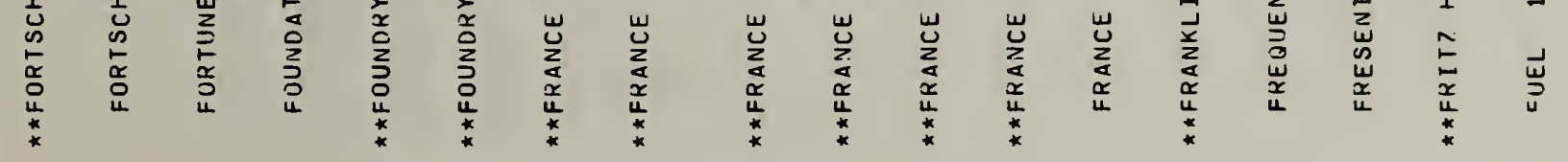


$\breve{z}$

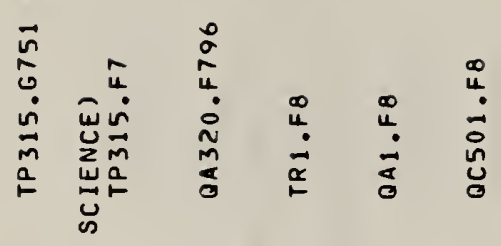

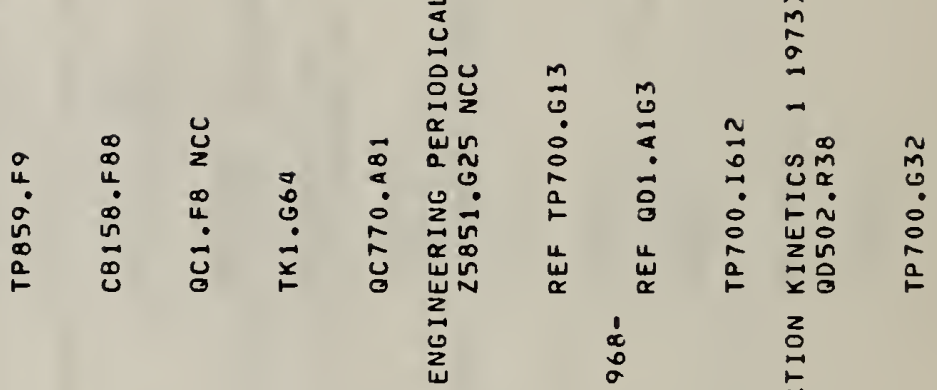

閼.

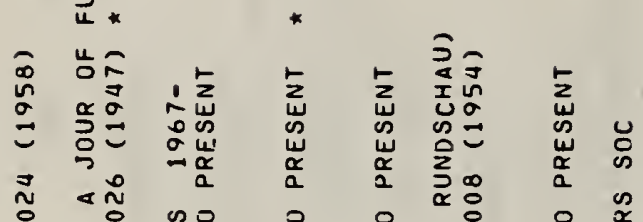

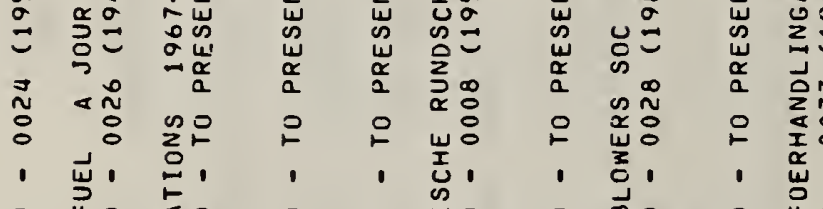

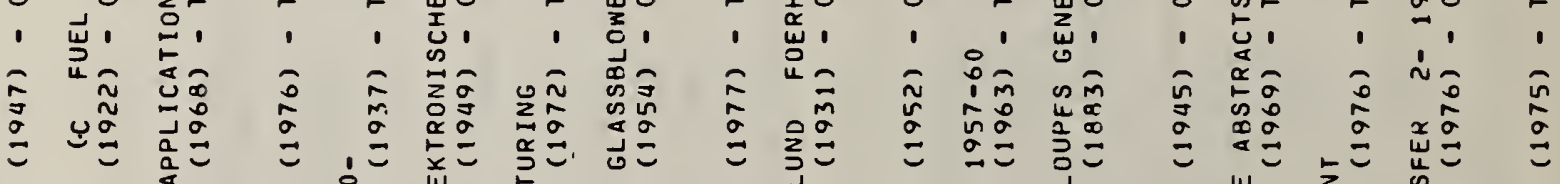

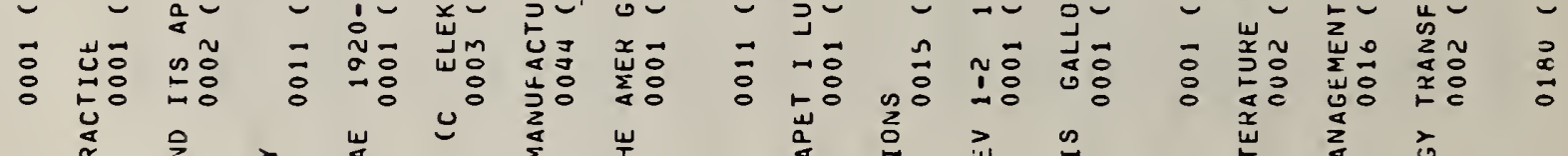

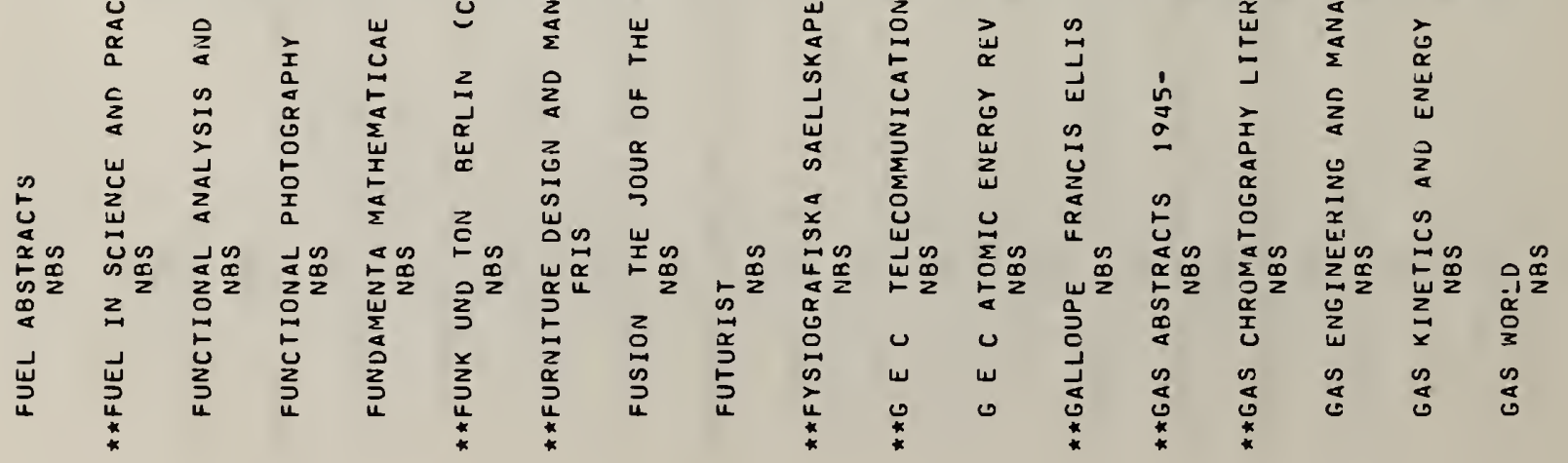




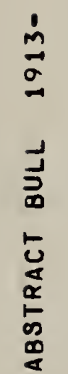

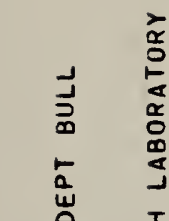

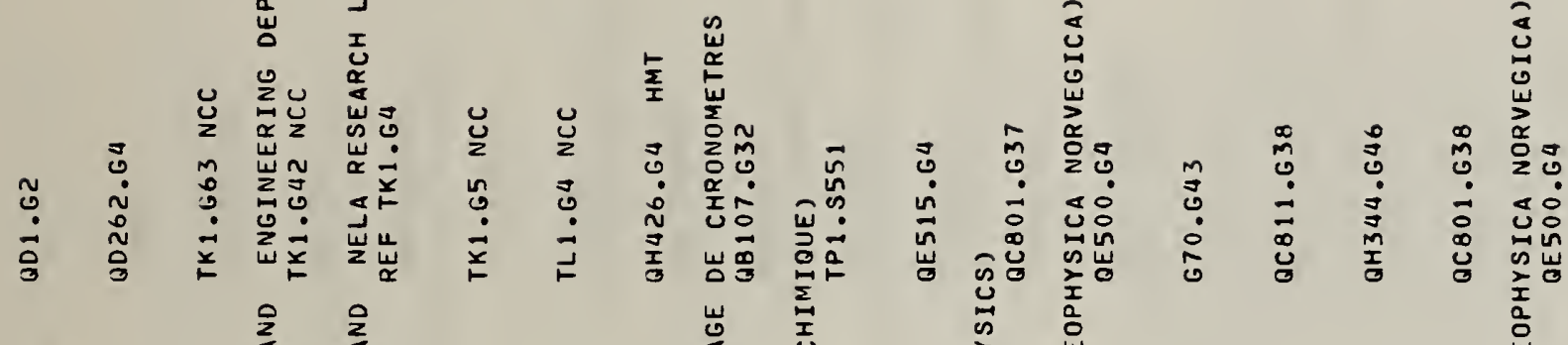

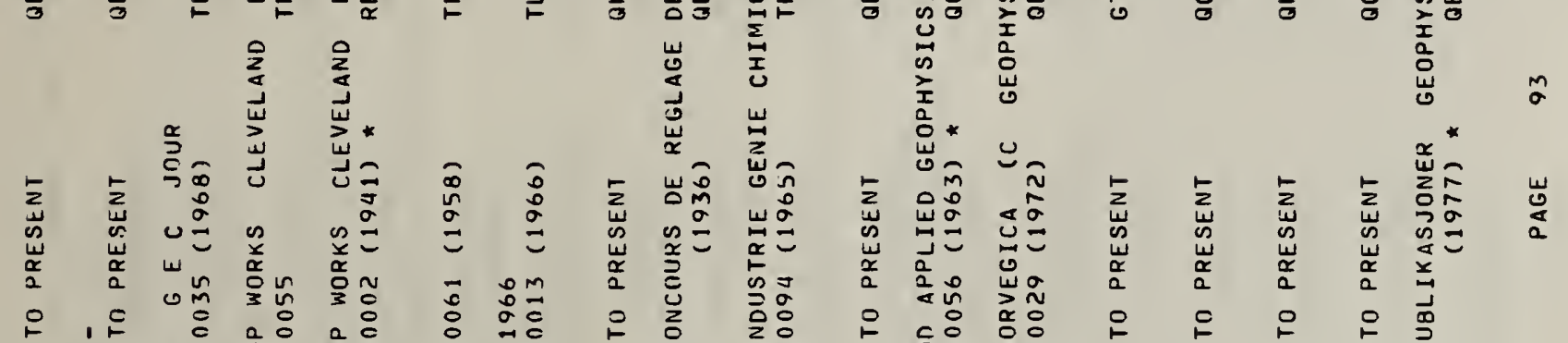

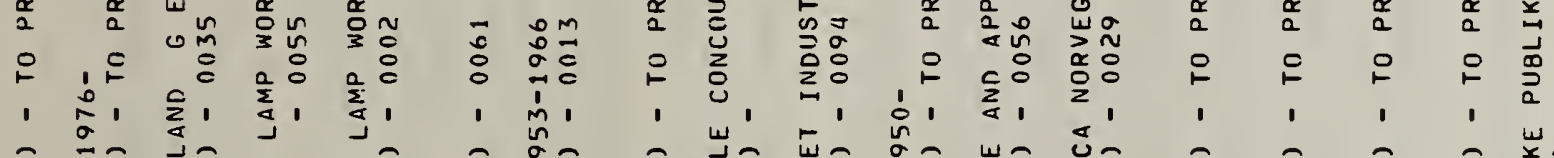

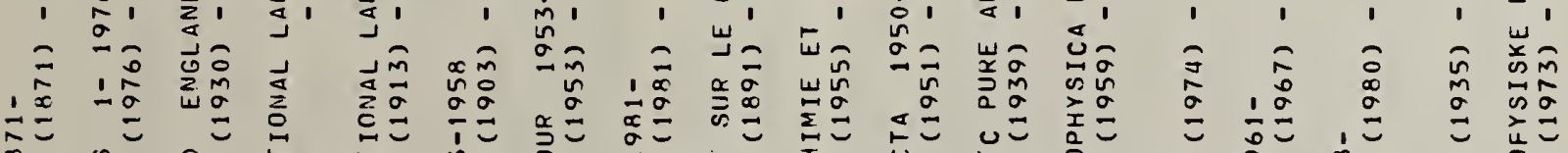

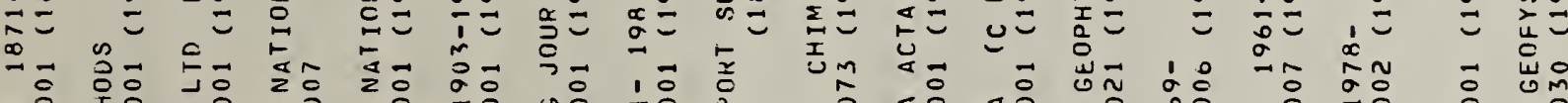

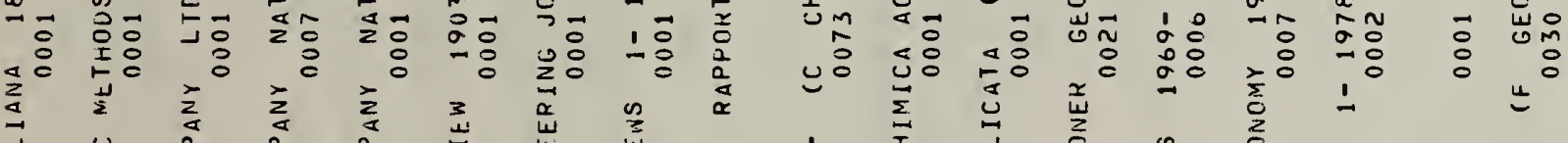

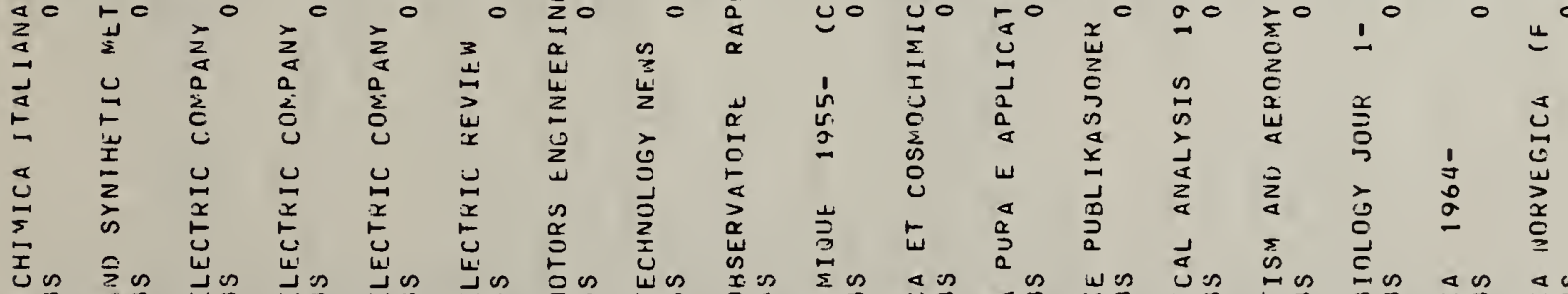

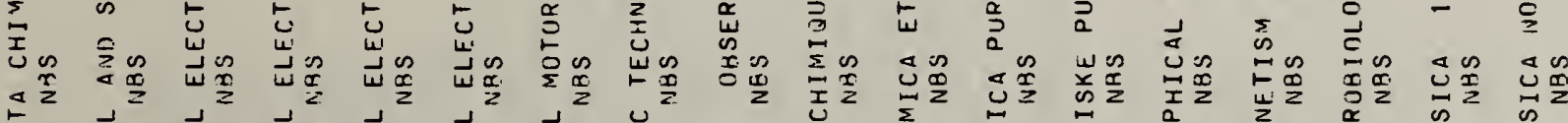

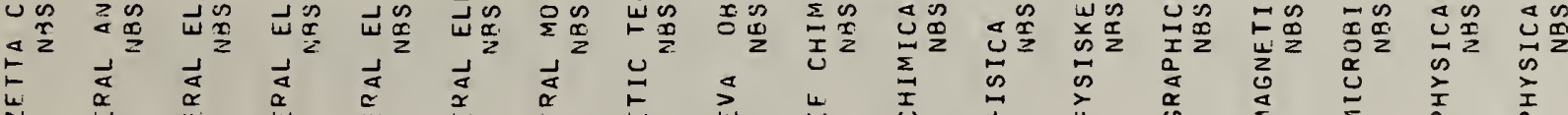

占 $\begin{aligned} & \text { d } \\ & \text { d } \\ & \text { d }\end{aligned}$

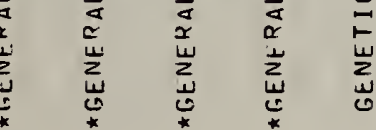




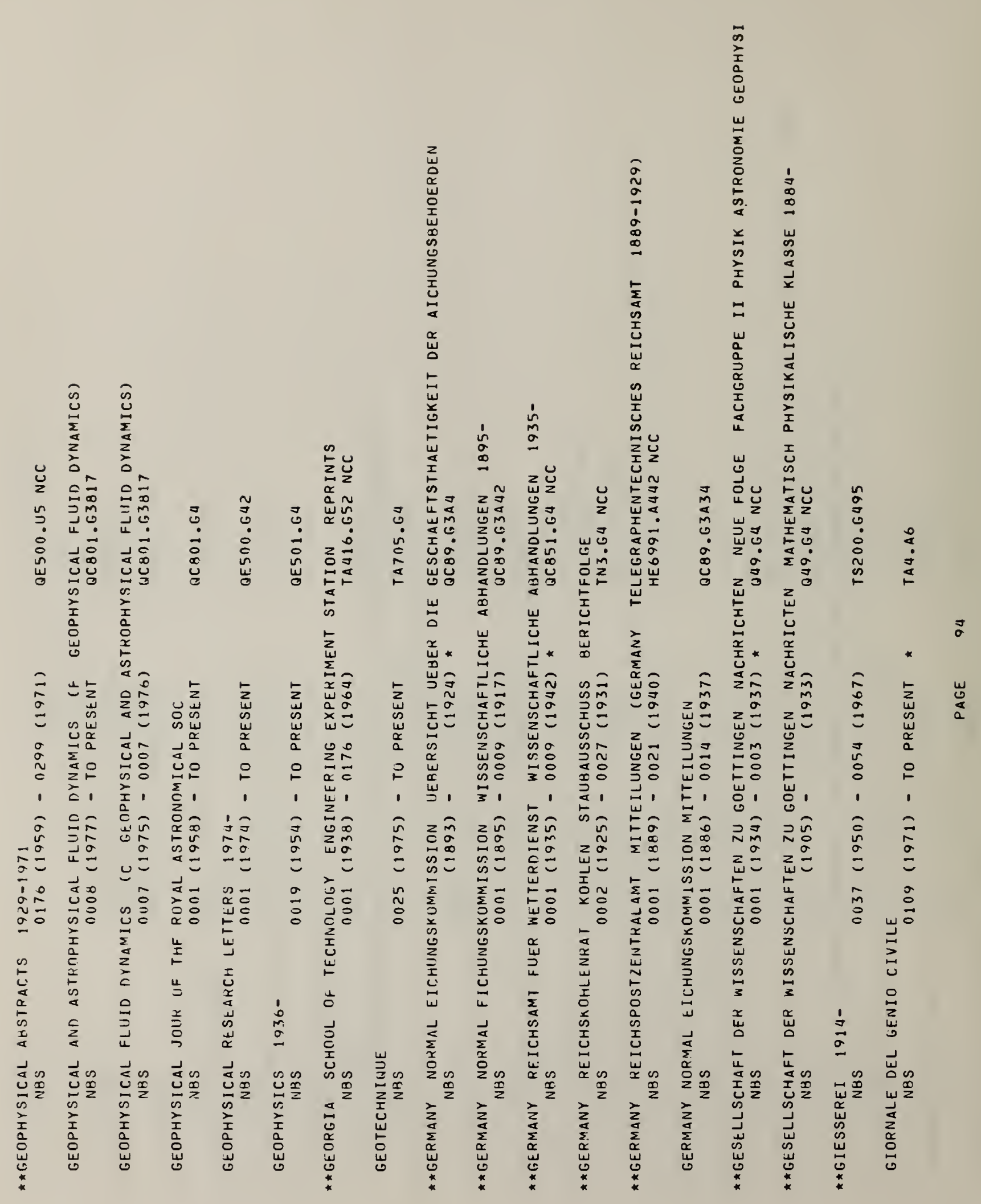


髣

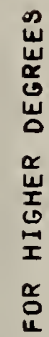

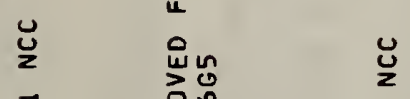

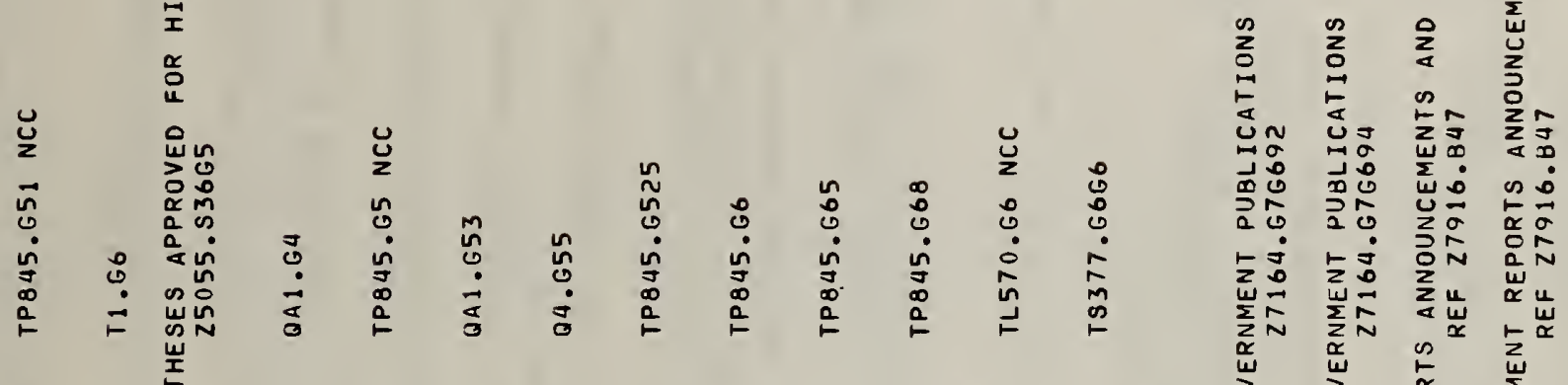

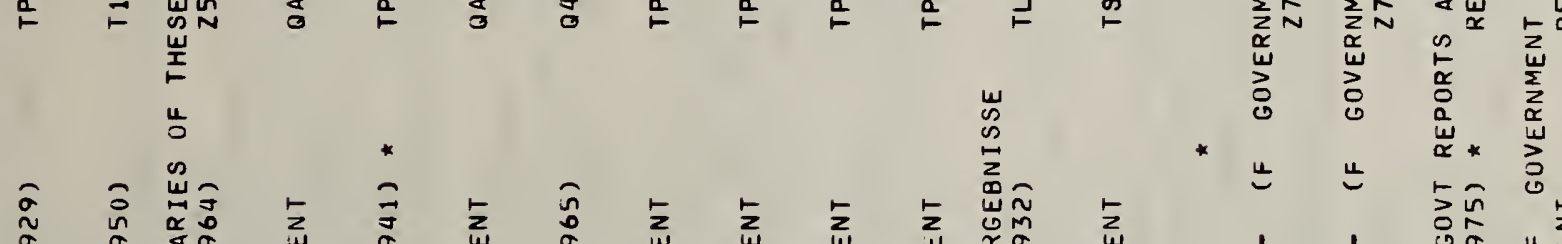

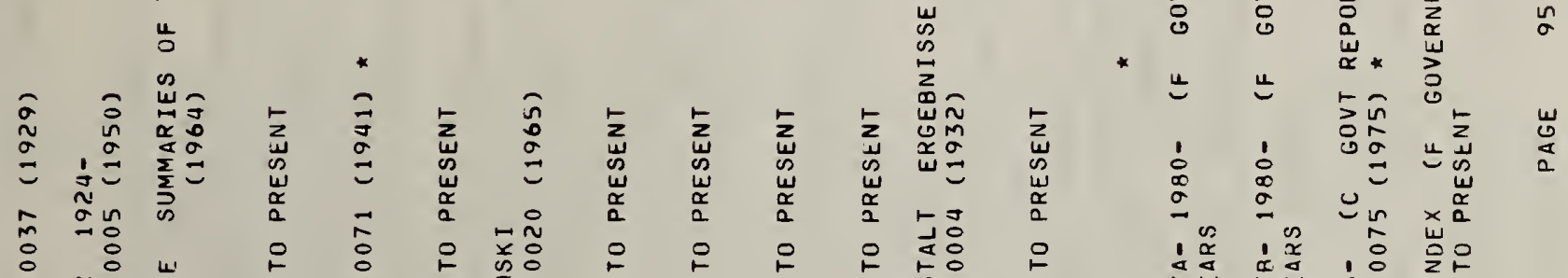

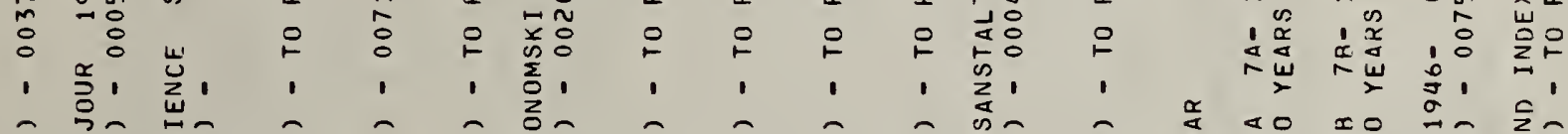

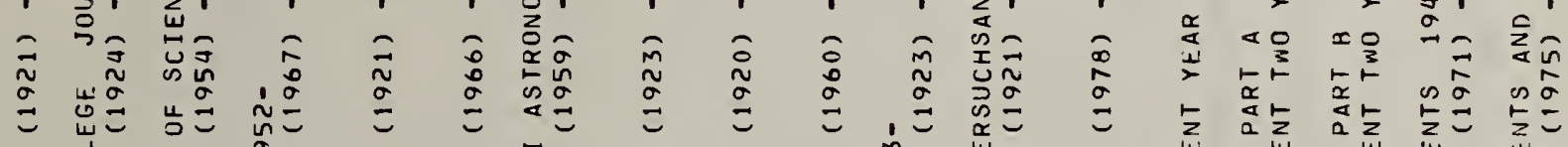

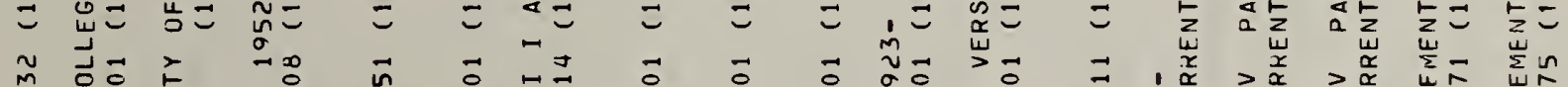

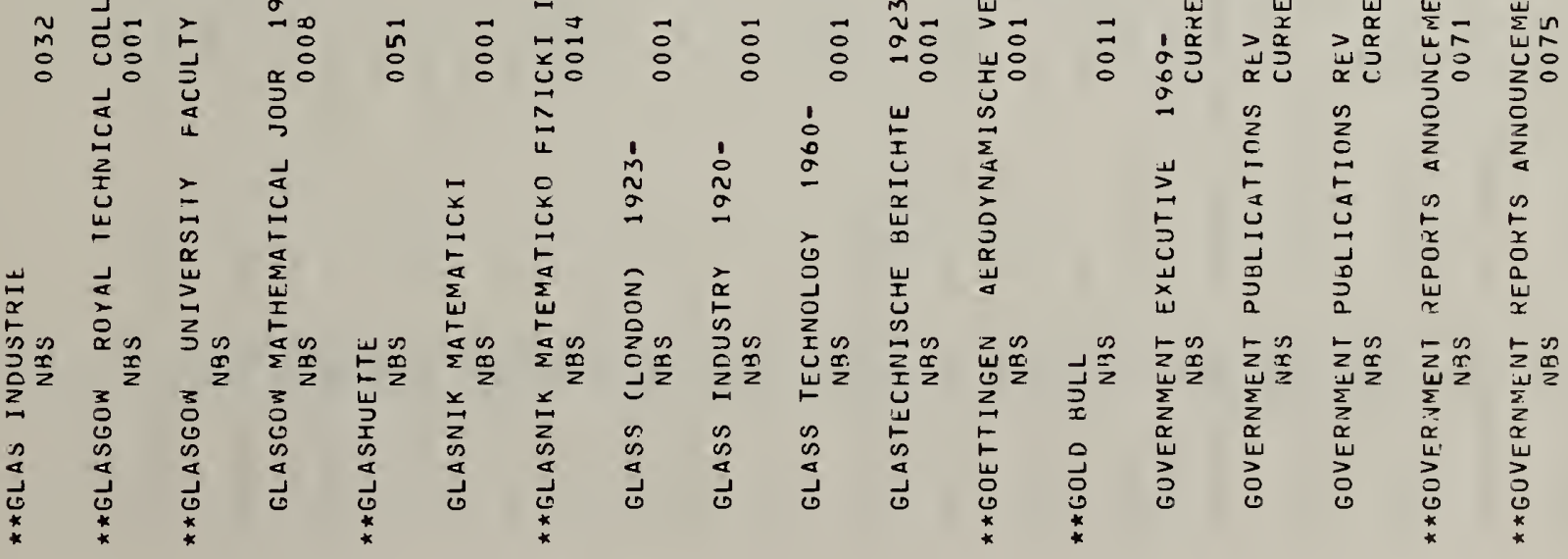




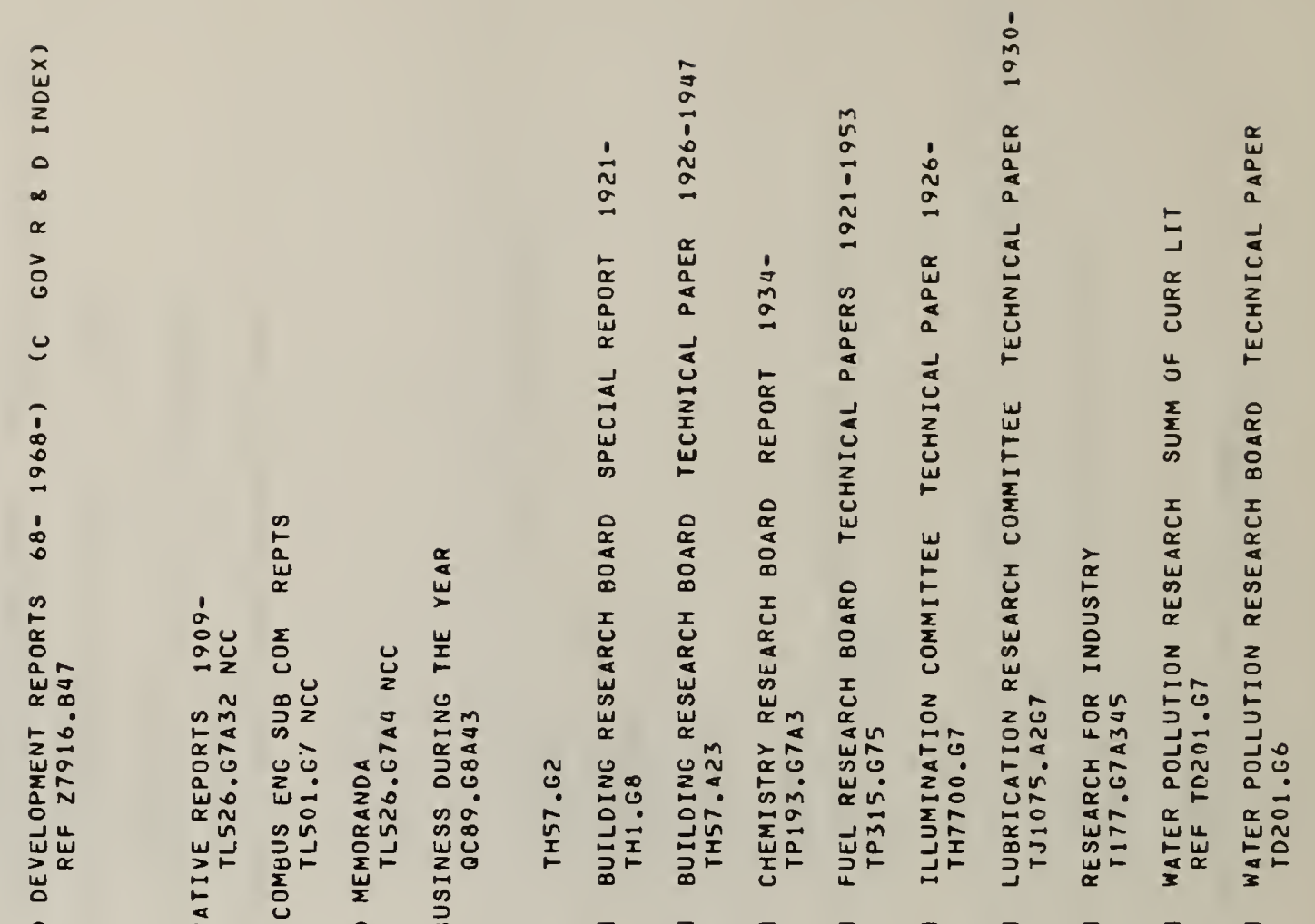

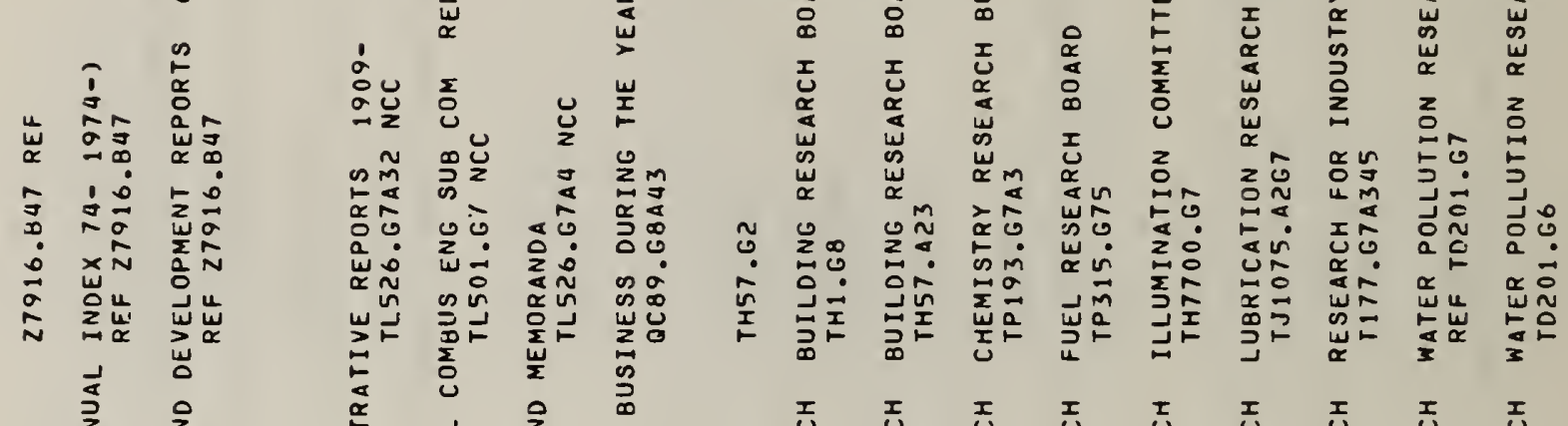

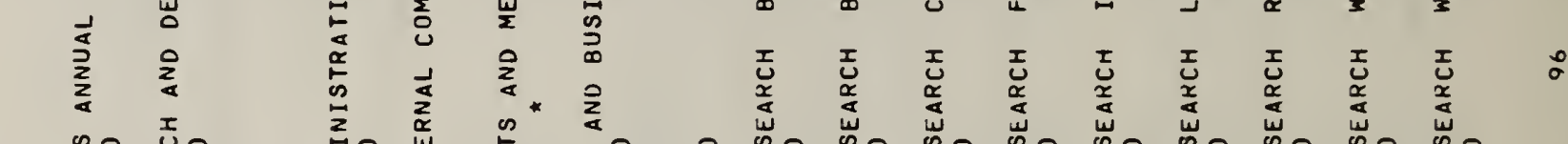

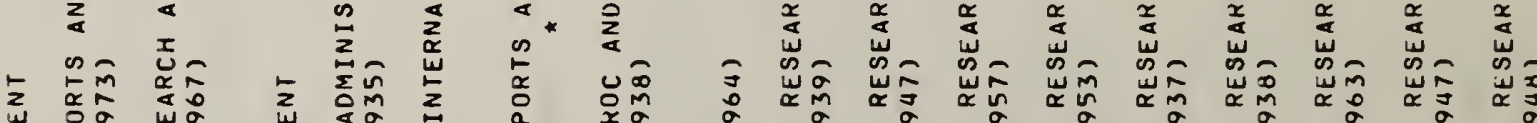

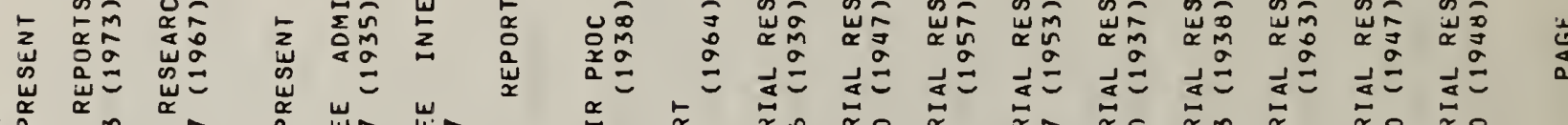

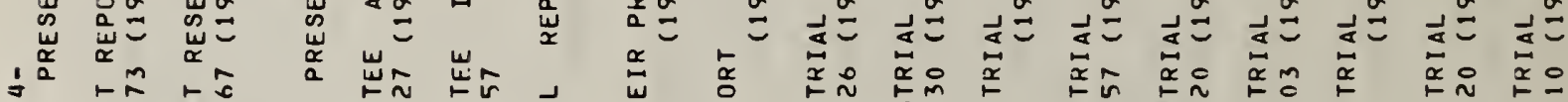

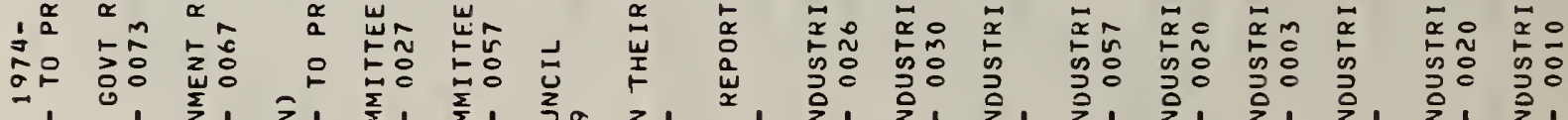

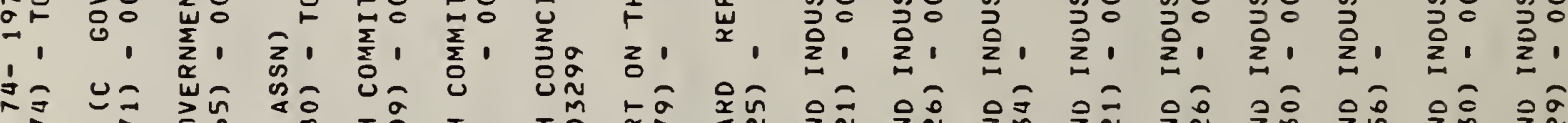

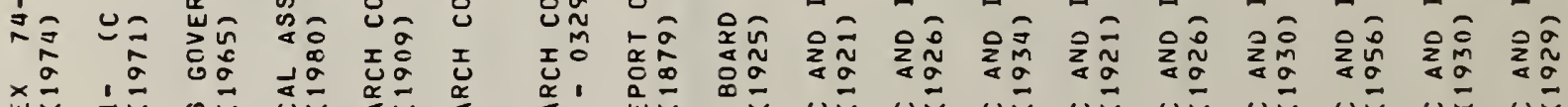

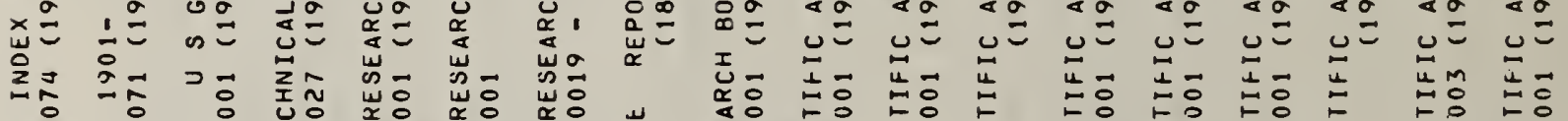

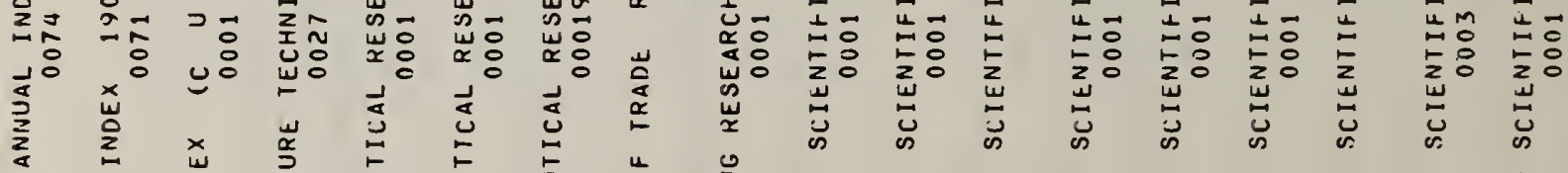

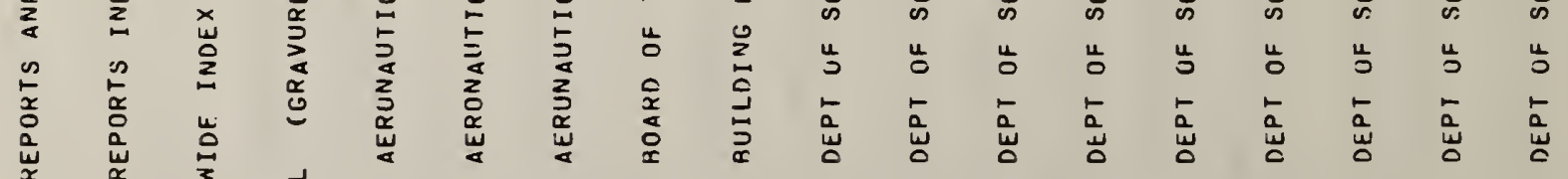

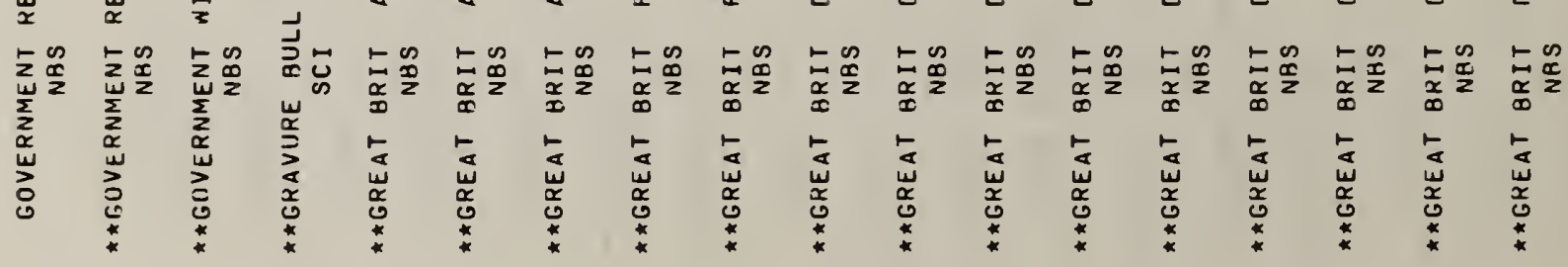




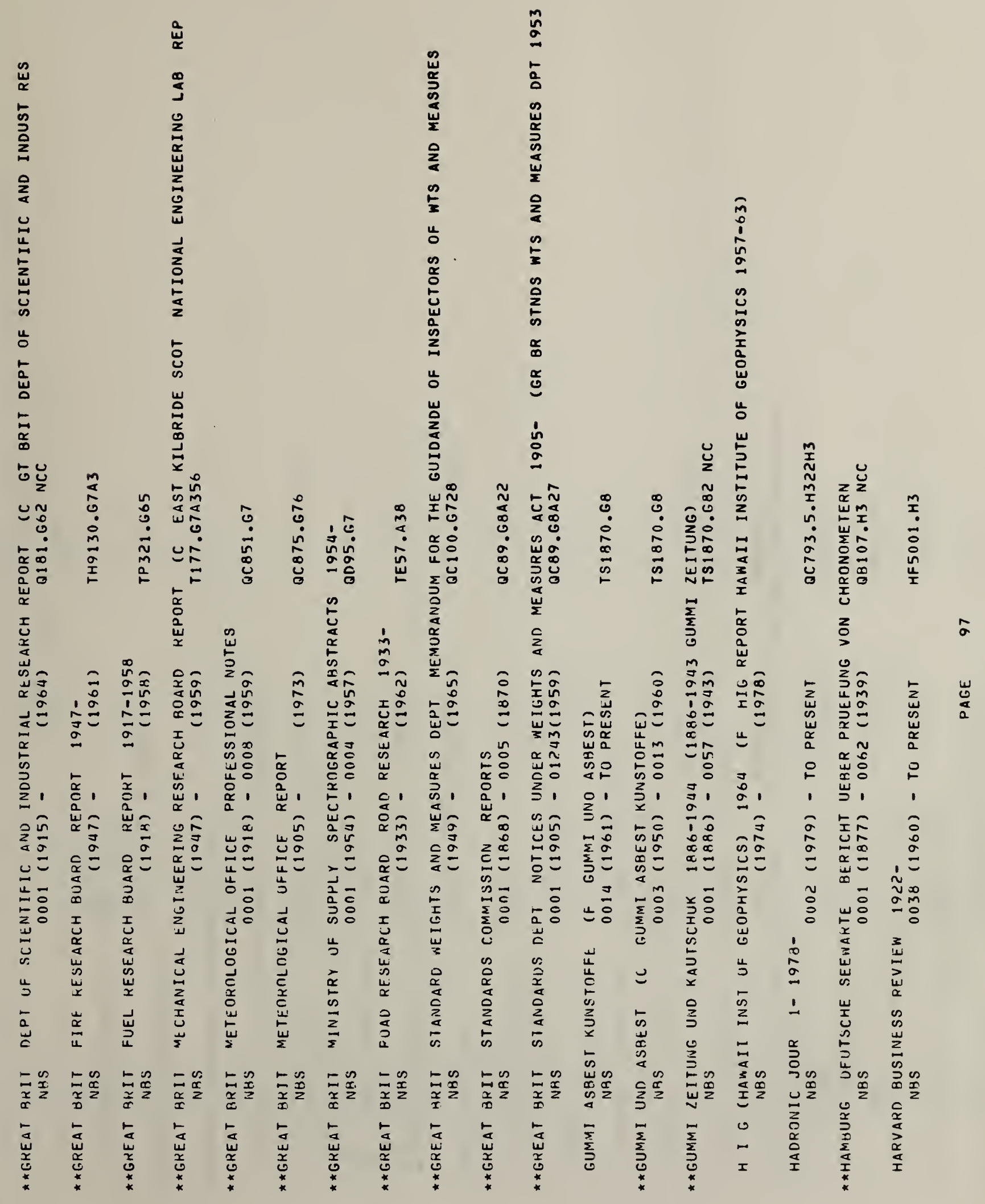




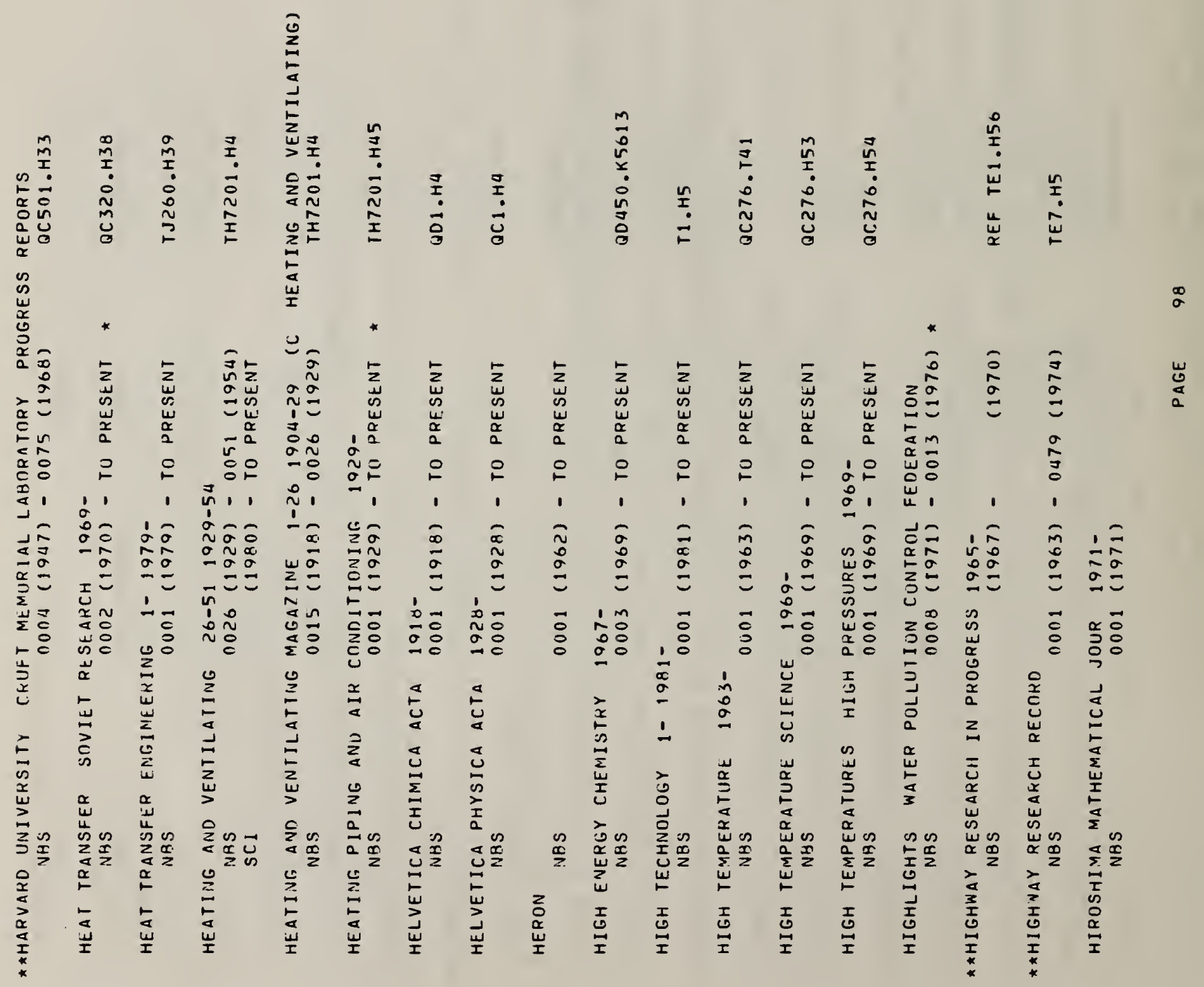


a

告

I

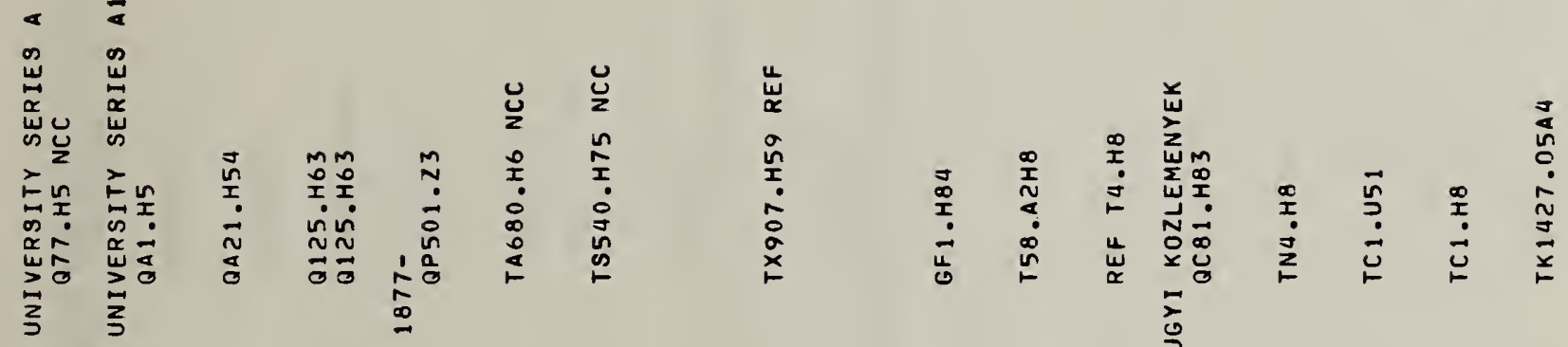

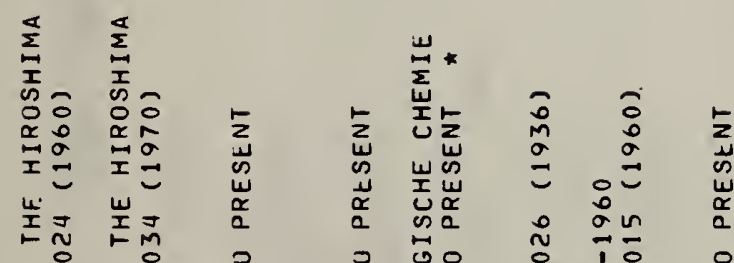

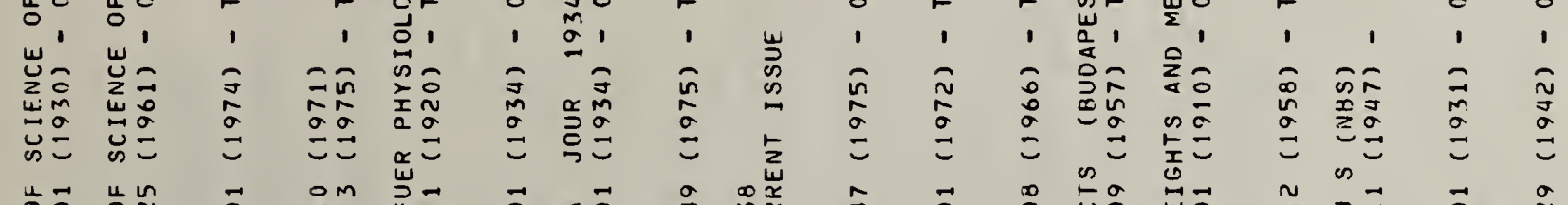

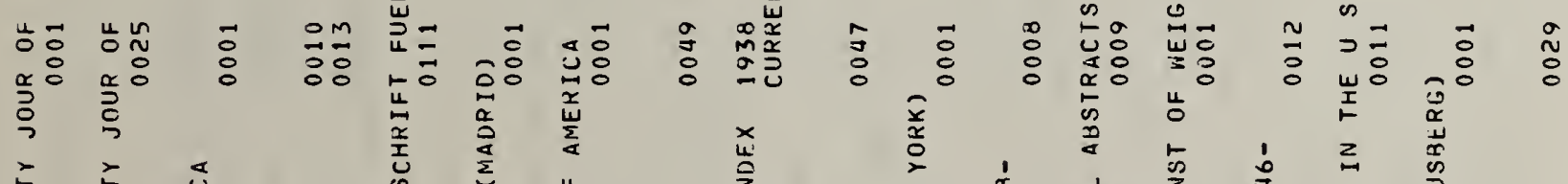

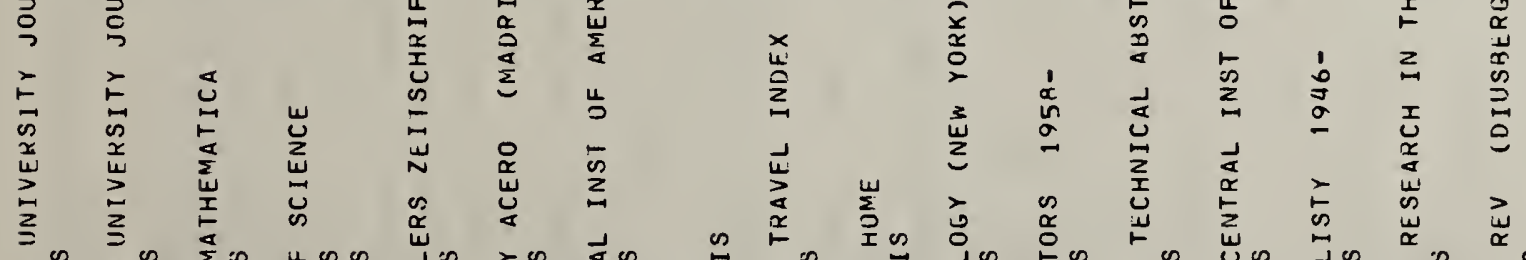

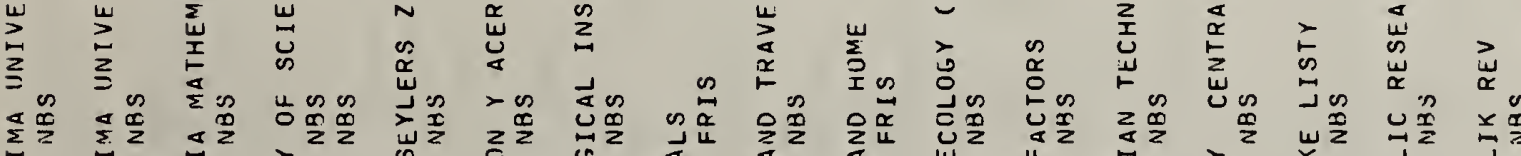

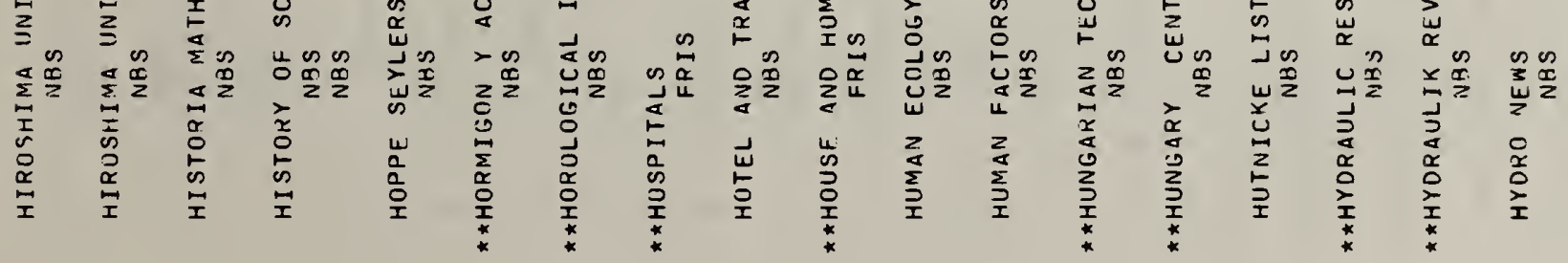




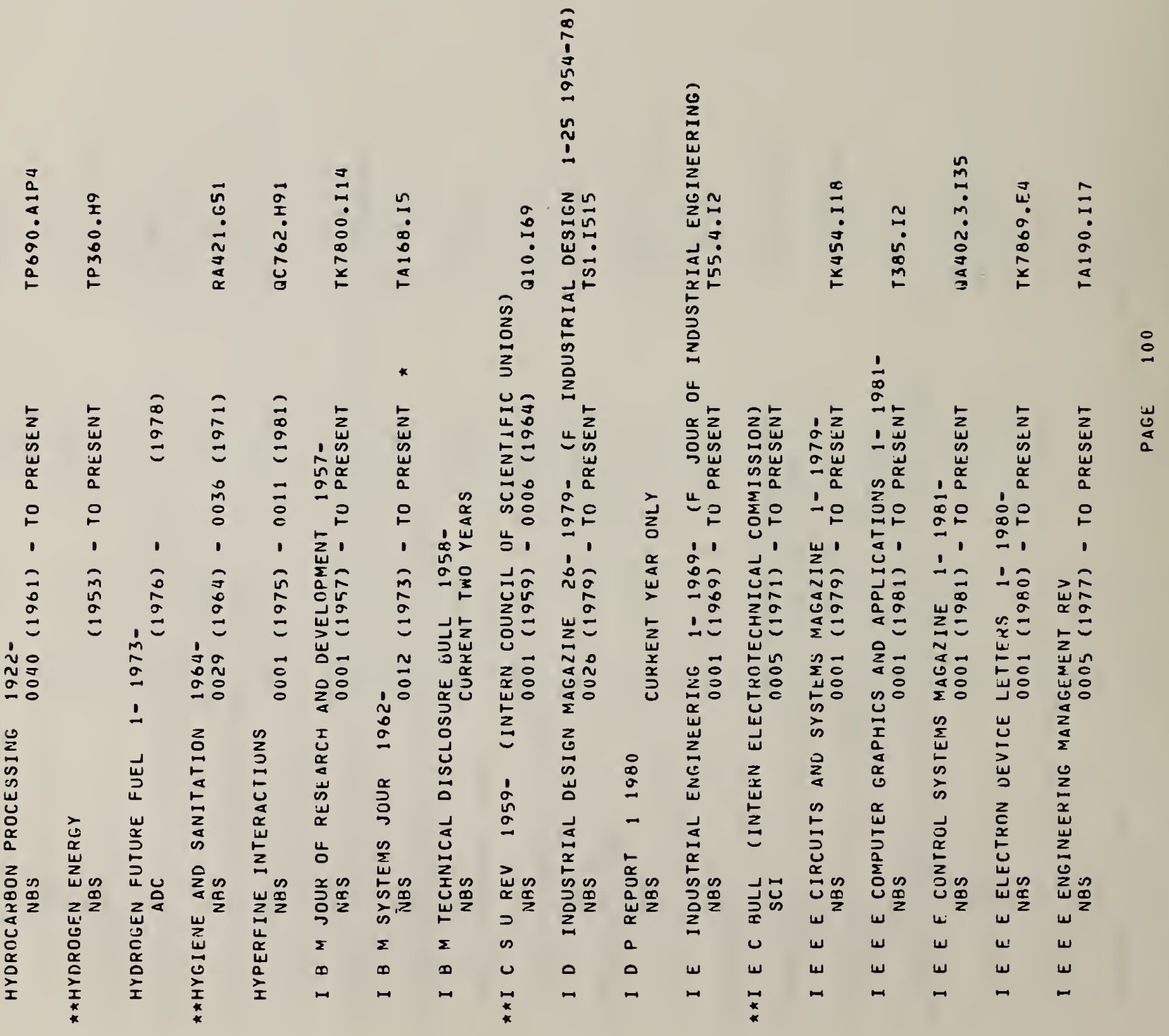




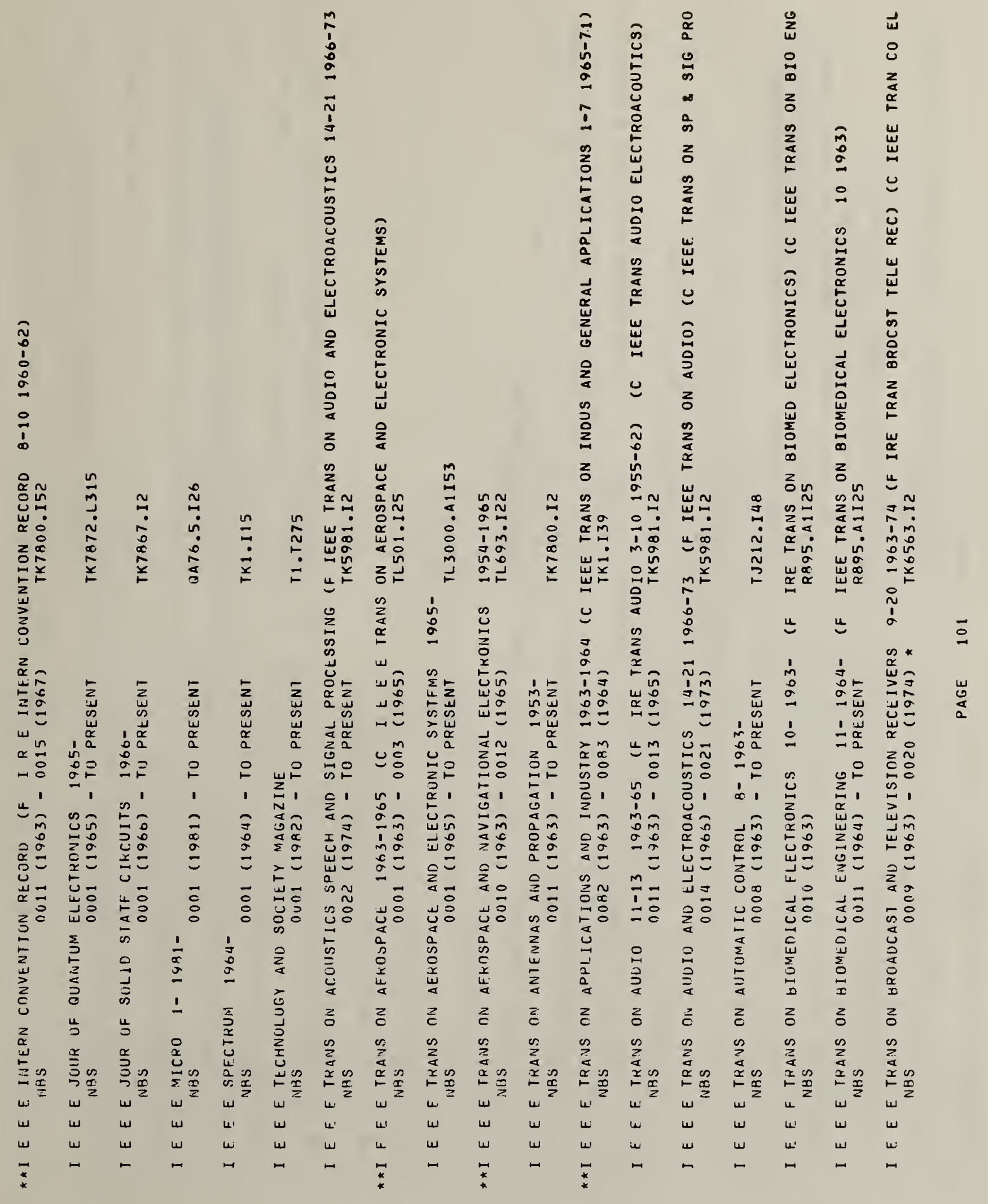




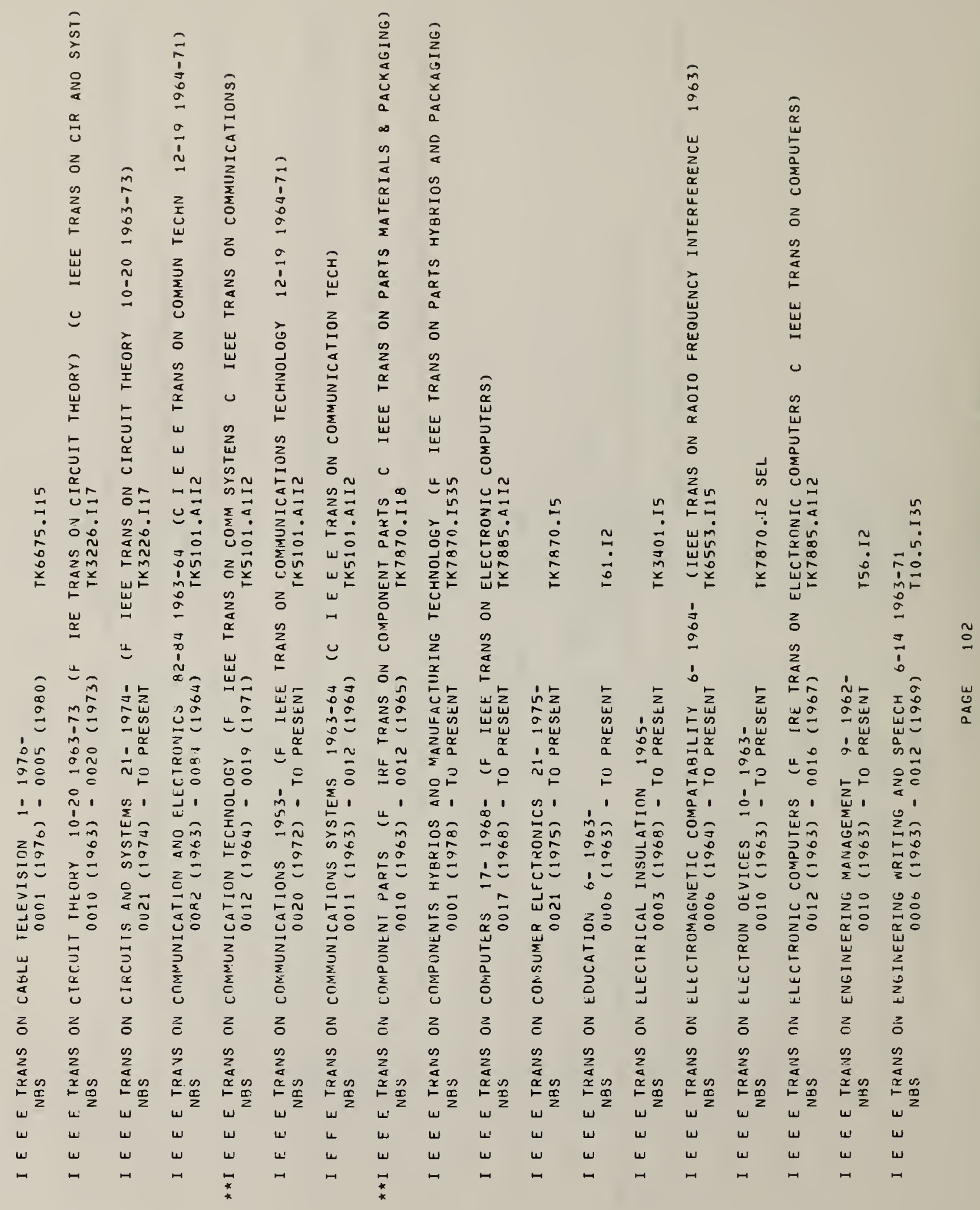




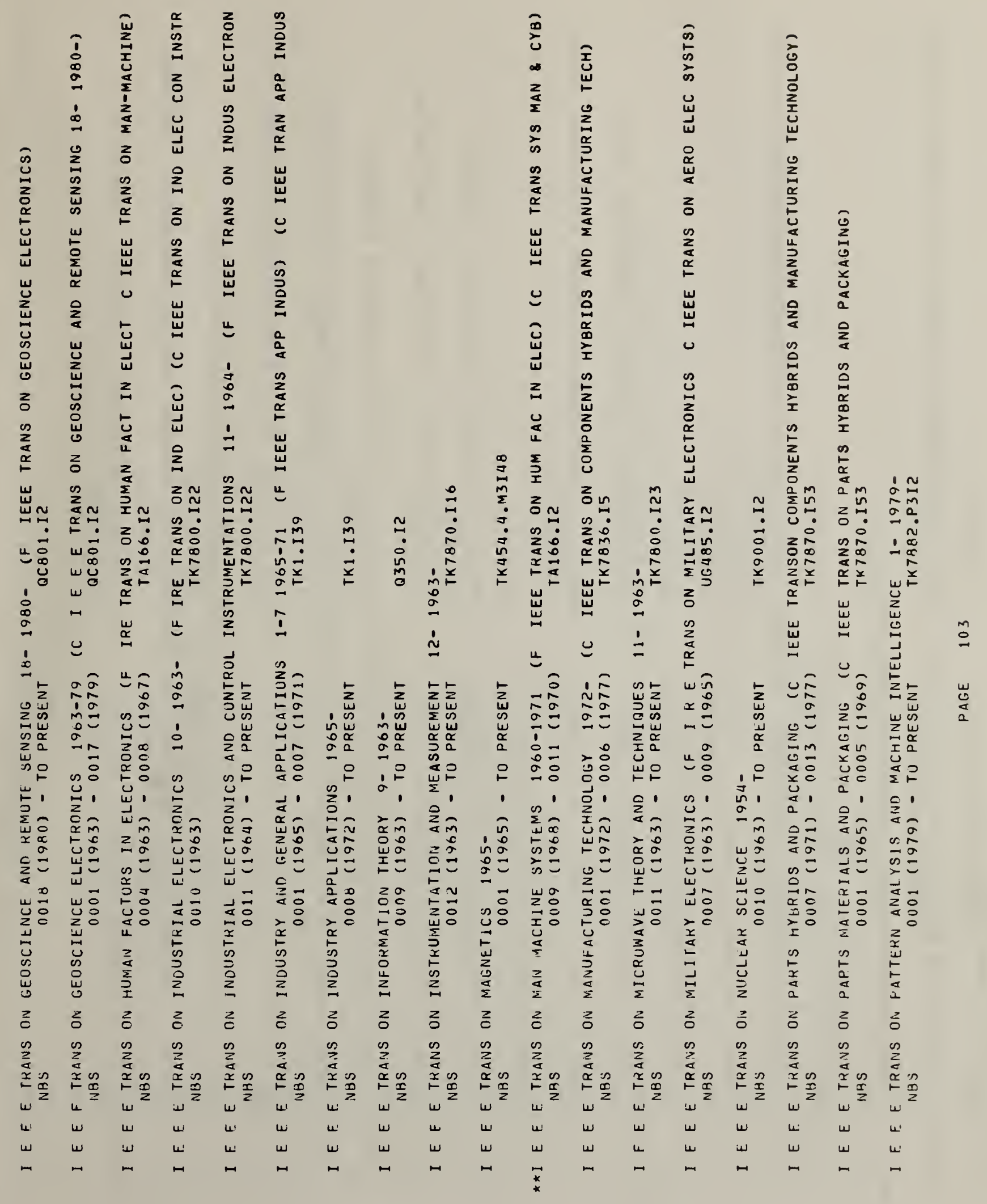




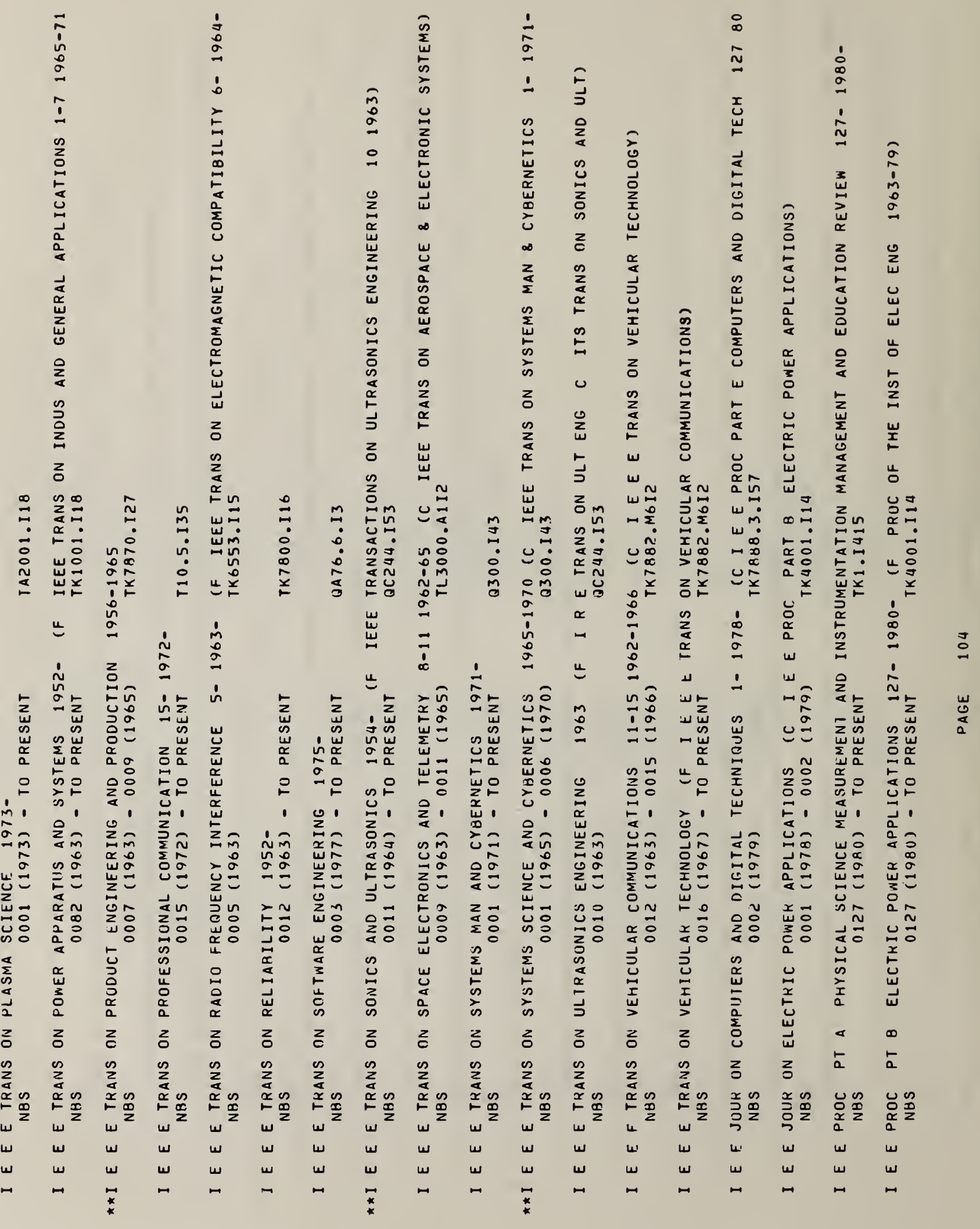




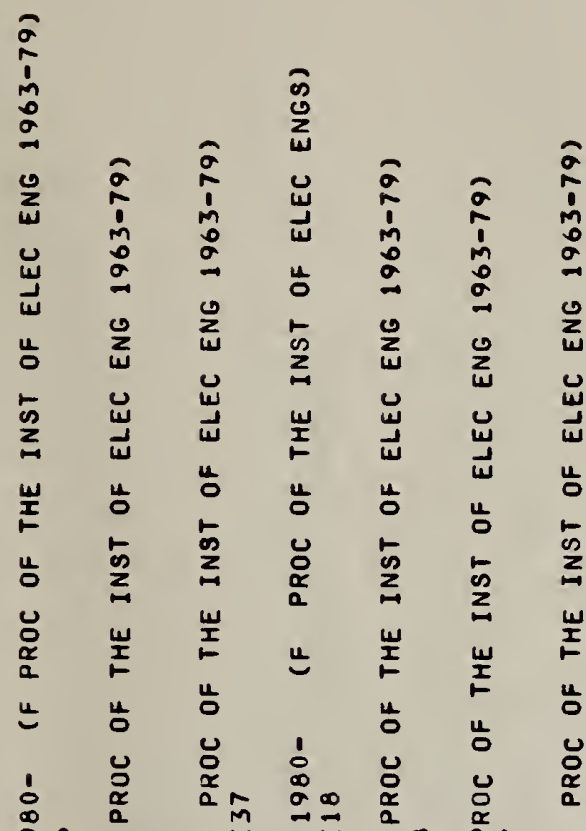

蕰, 过

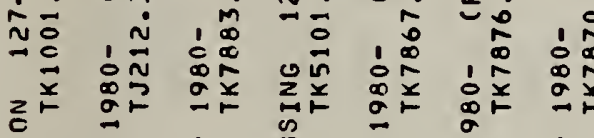

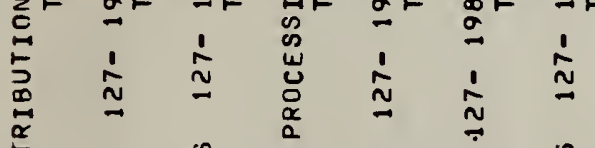

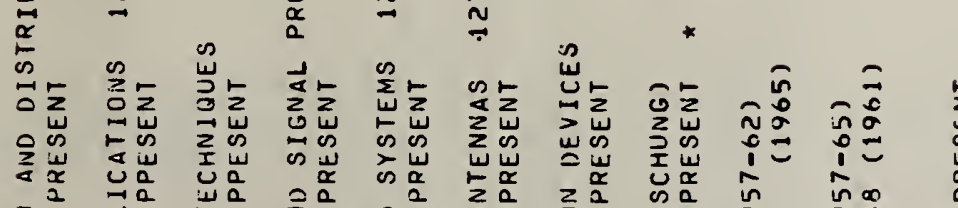

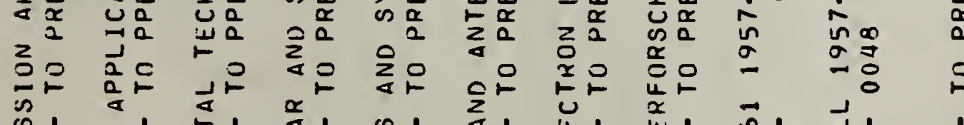

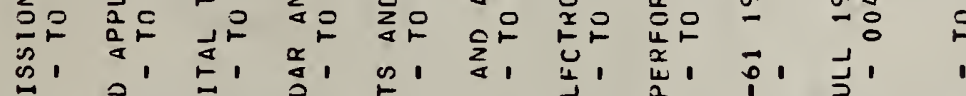

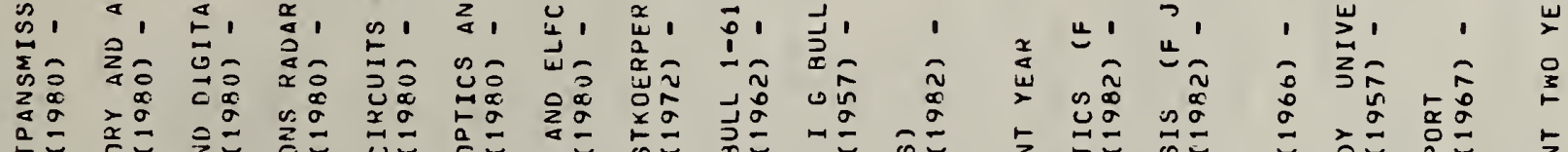

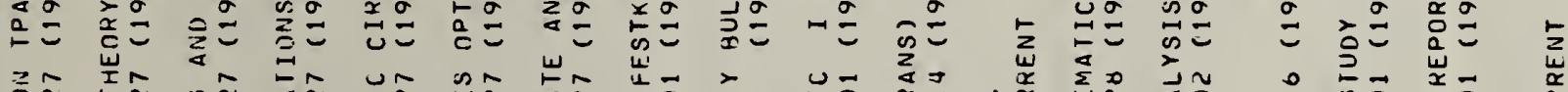

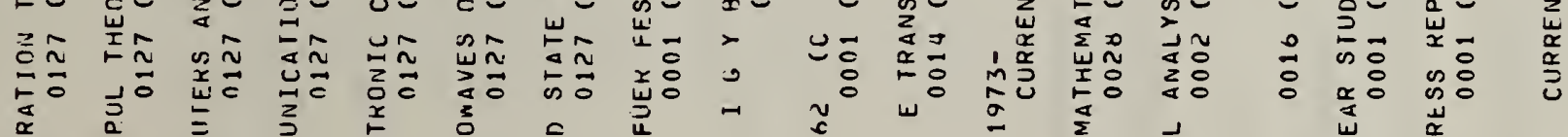

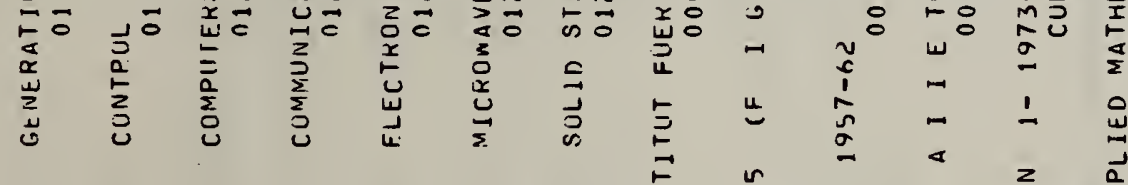

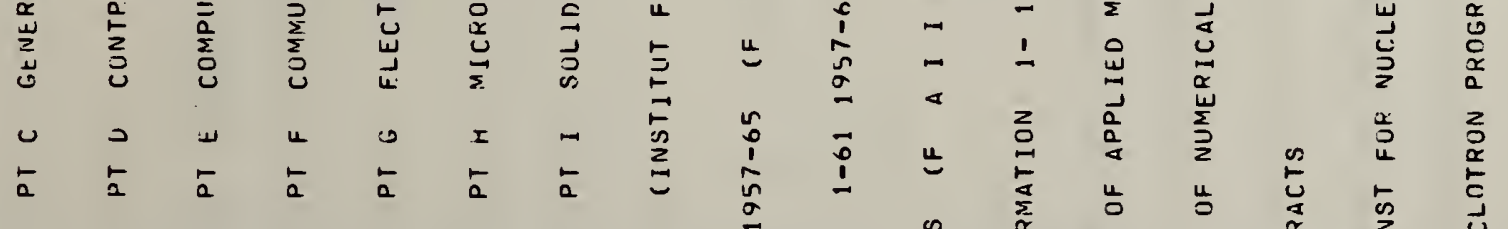

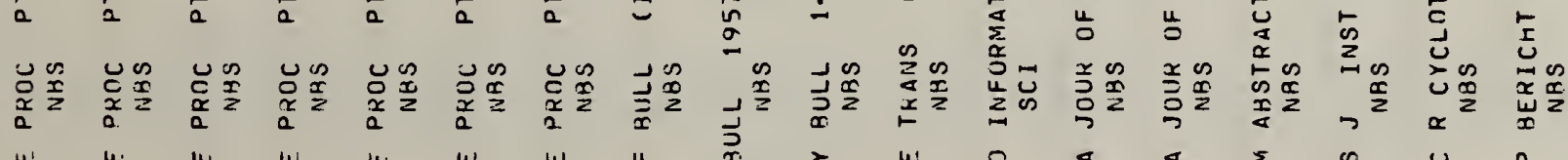

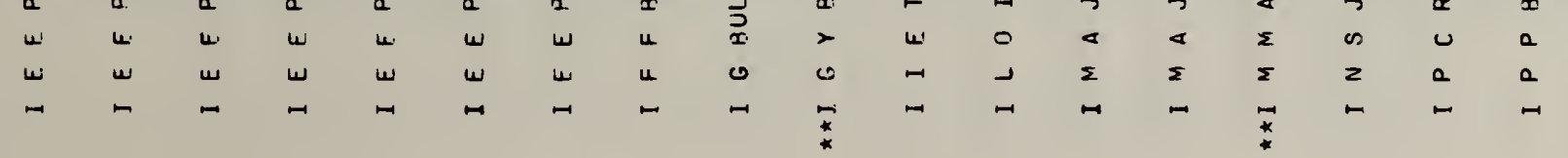




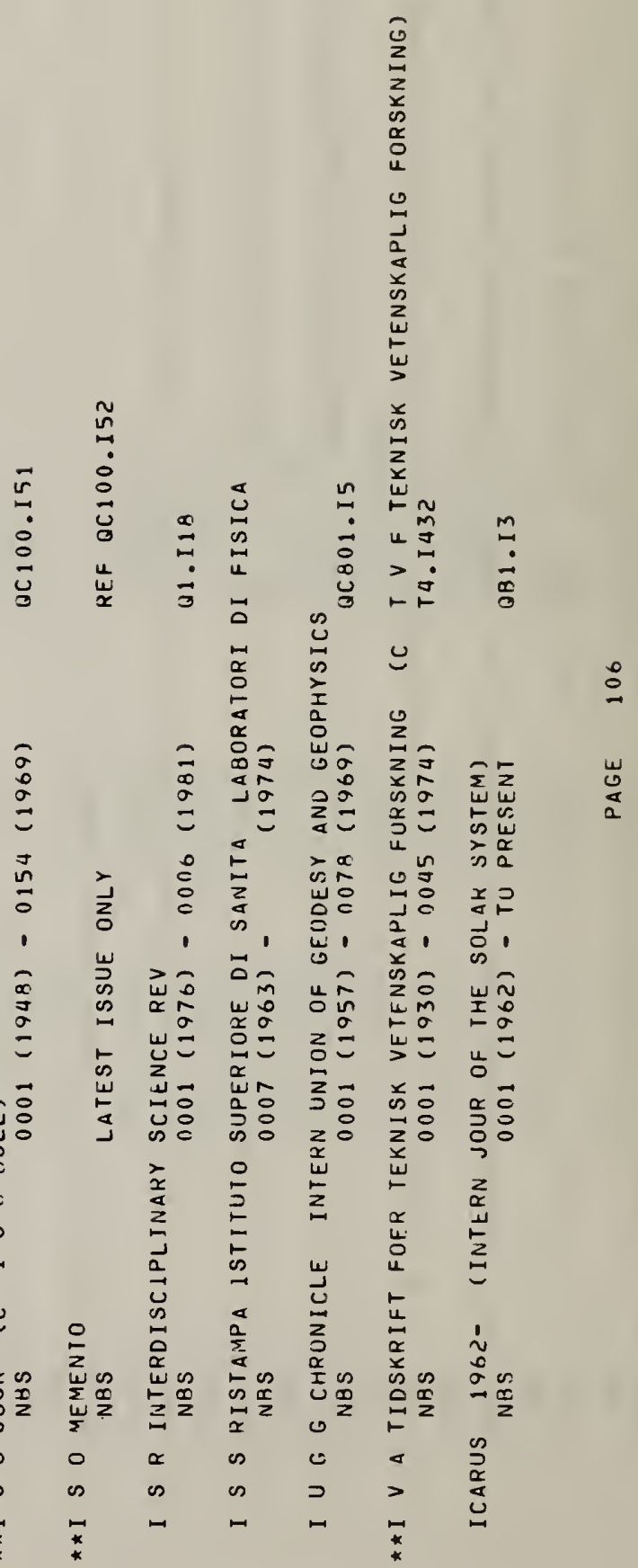


$a$
0
$\vdots$
$\vdots$
$\vdots$
$\vdots$
$m$
$\vdots$
0
2
2
$a$
0

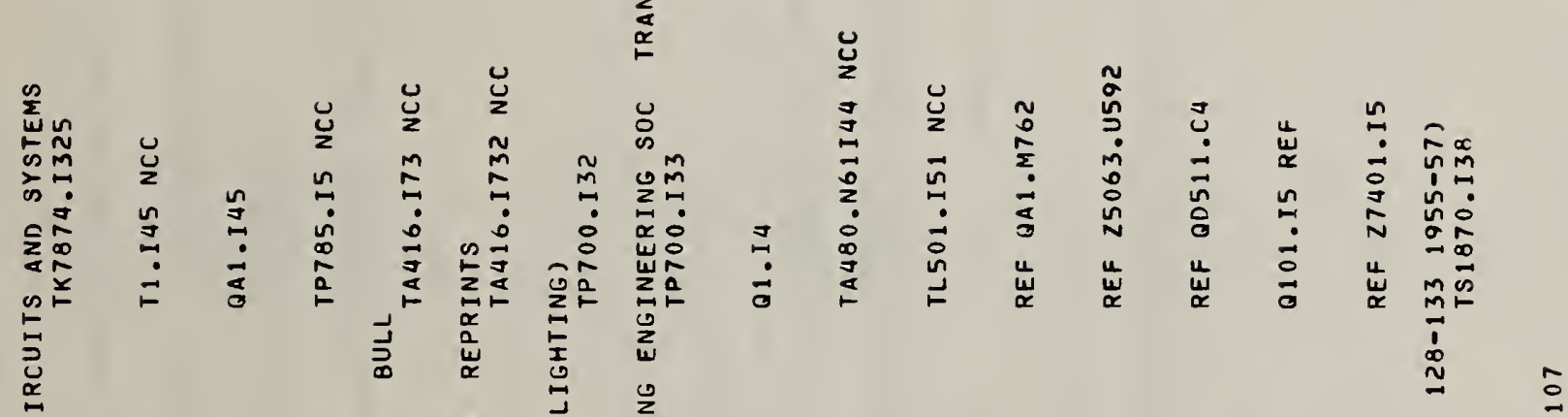
ż

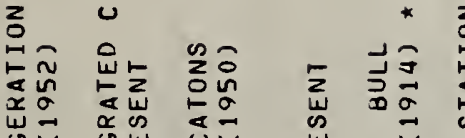

こ出过

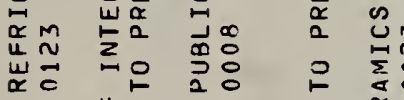

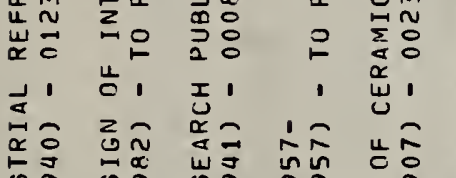

क

言き

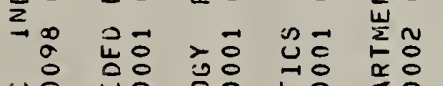

岃:

z

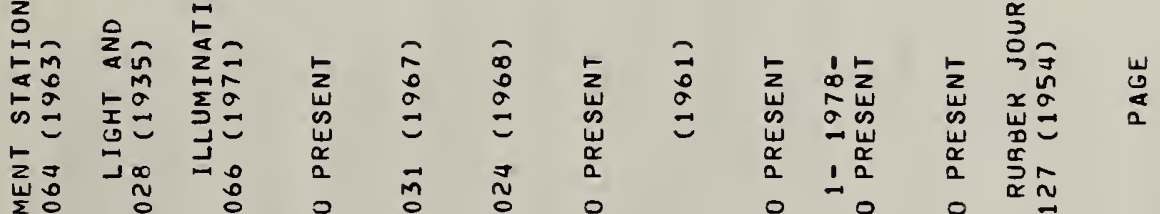

焉:

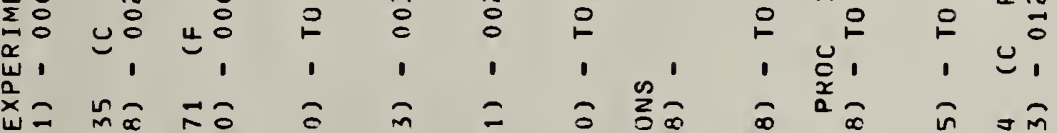

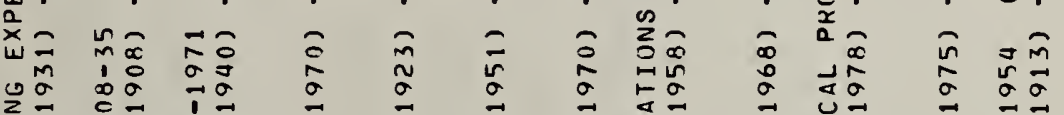

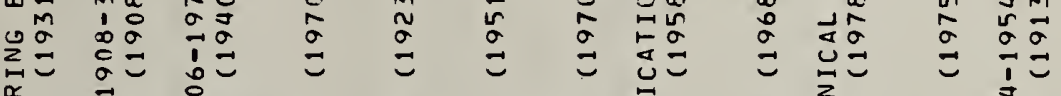

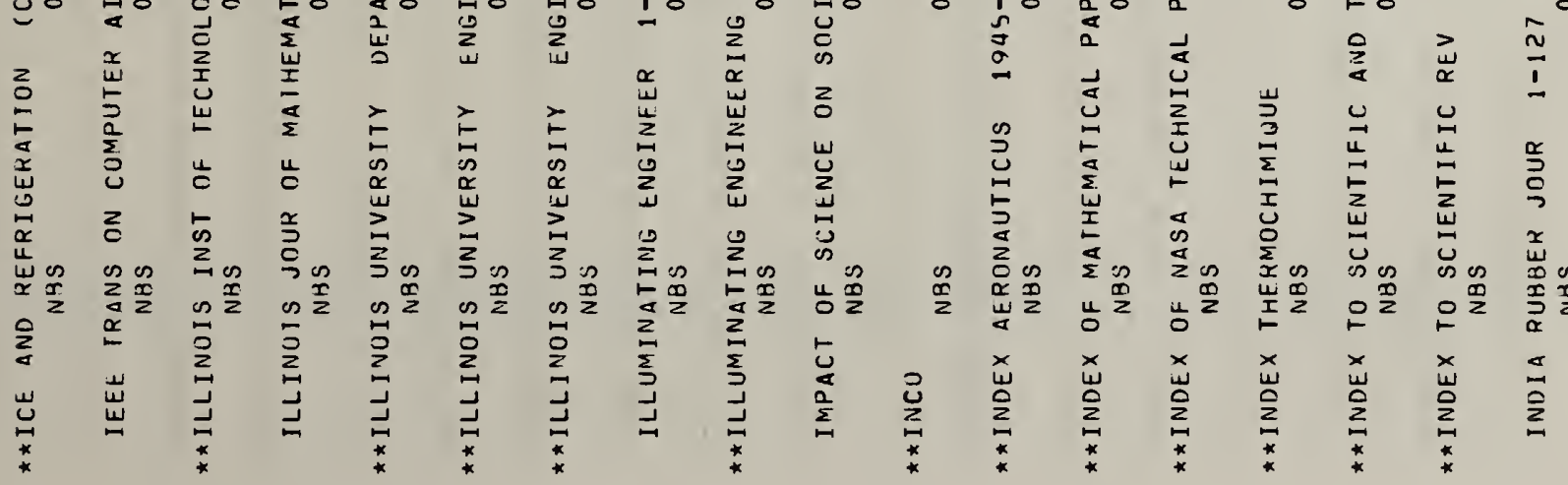




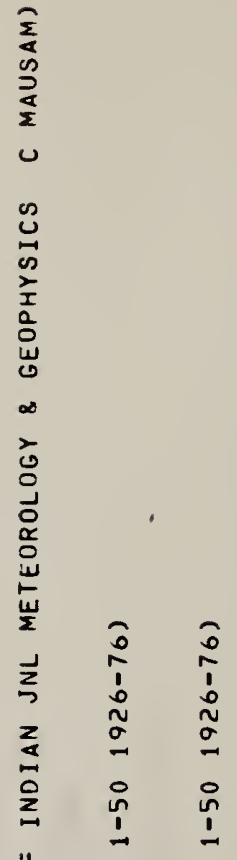

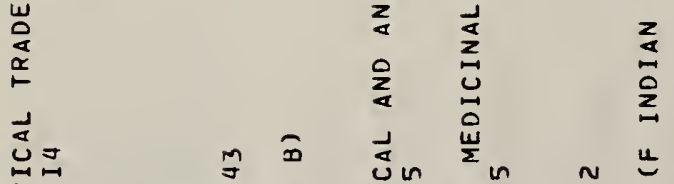

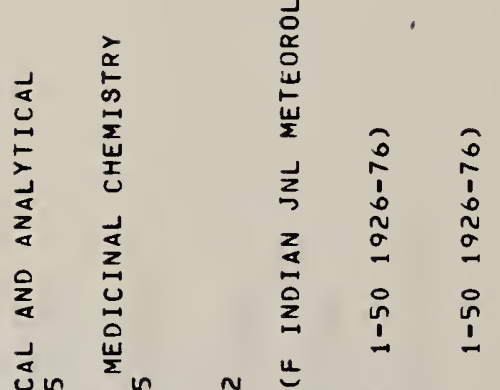

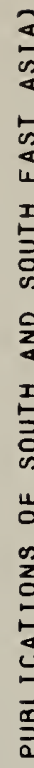

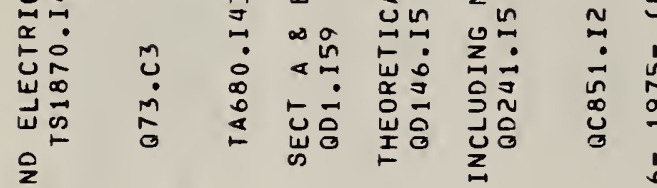

$\frac{0}{2}$

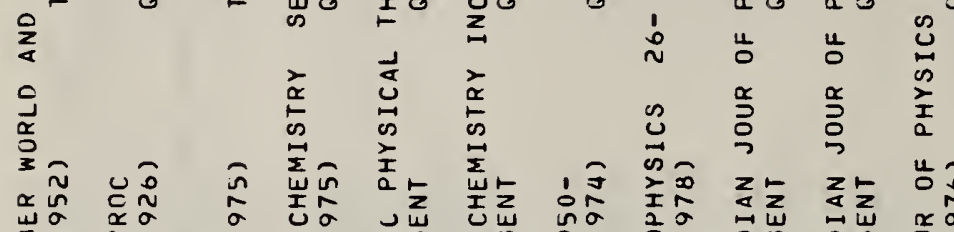

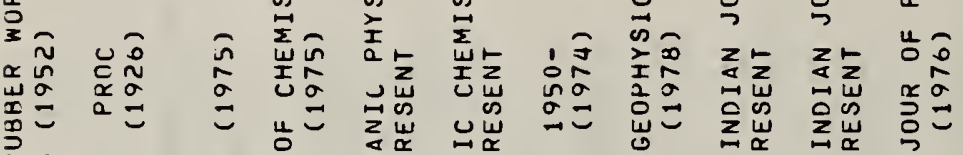

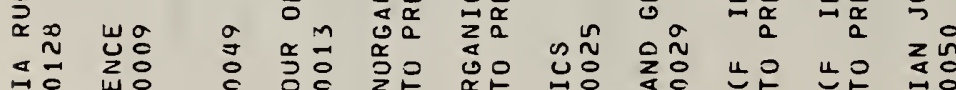

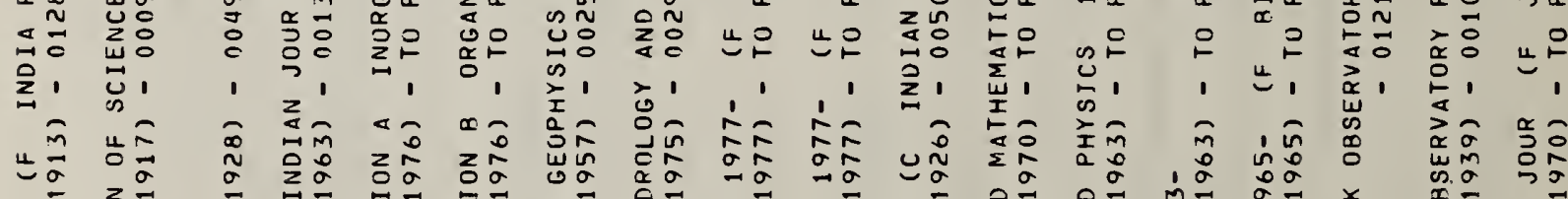

こ

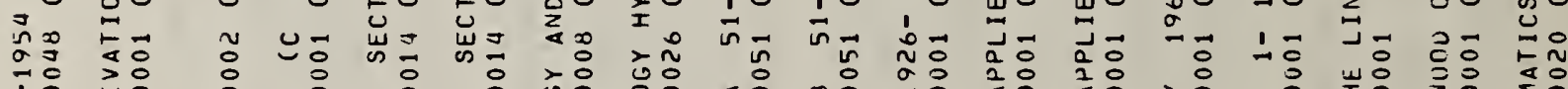

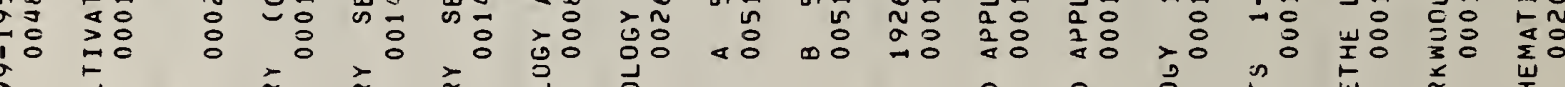

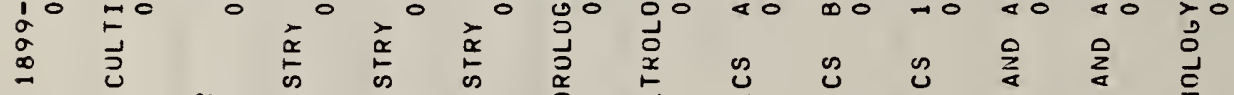

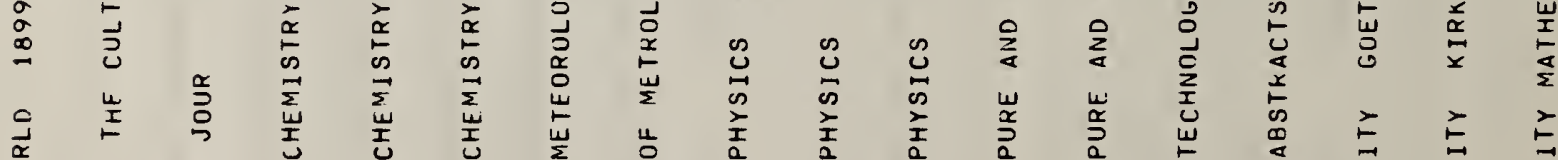

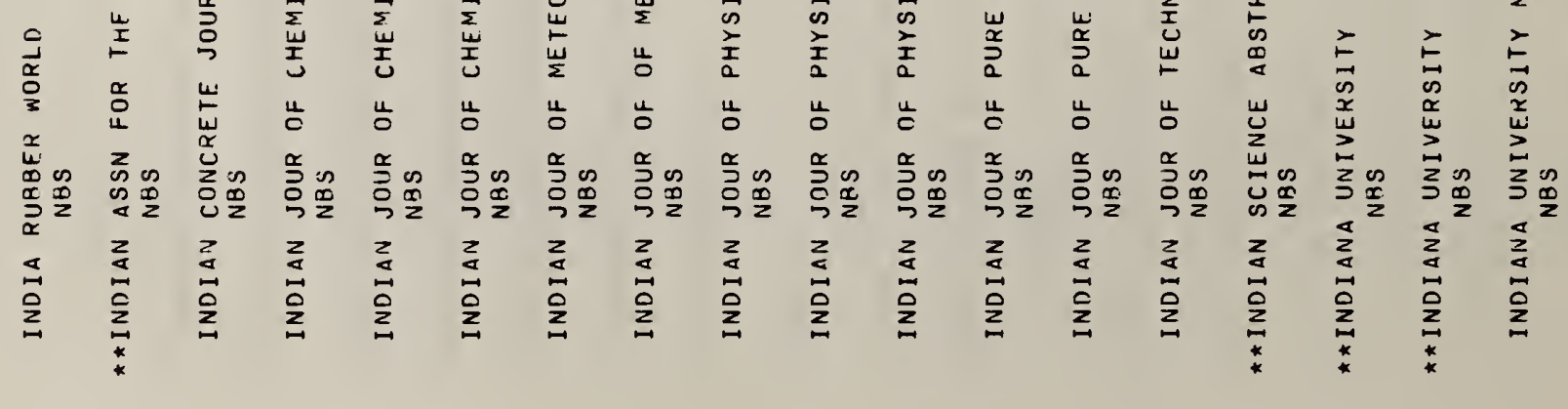




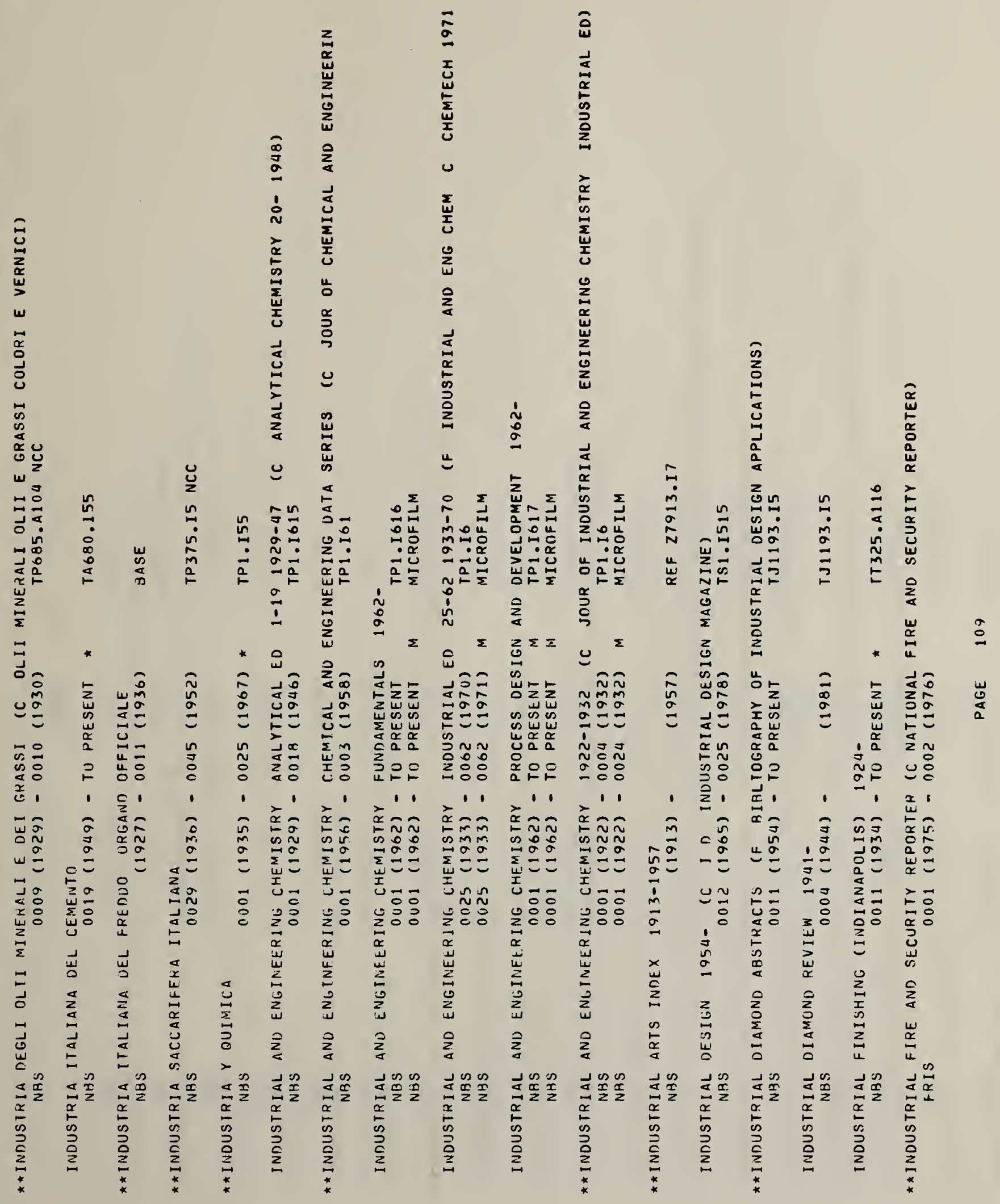




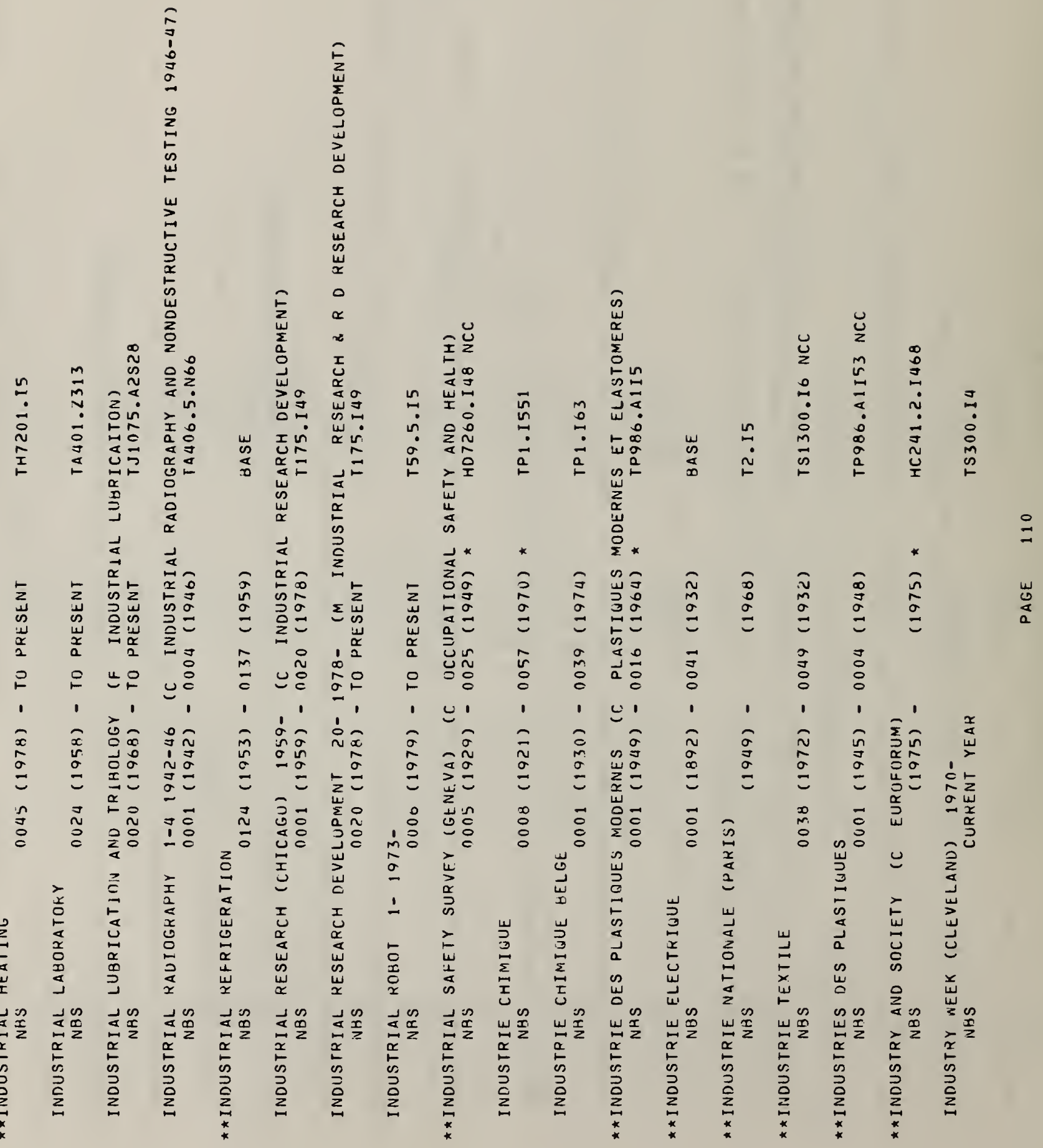




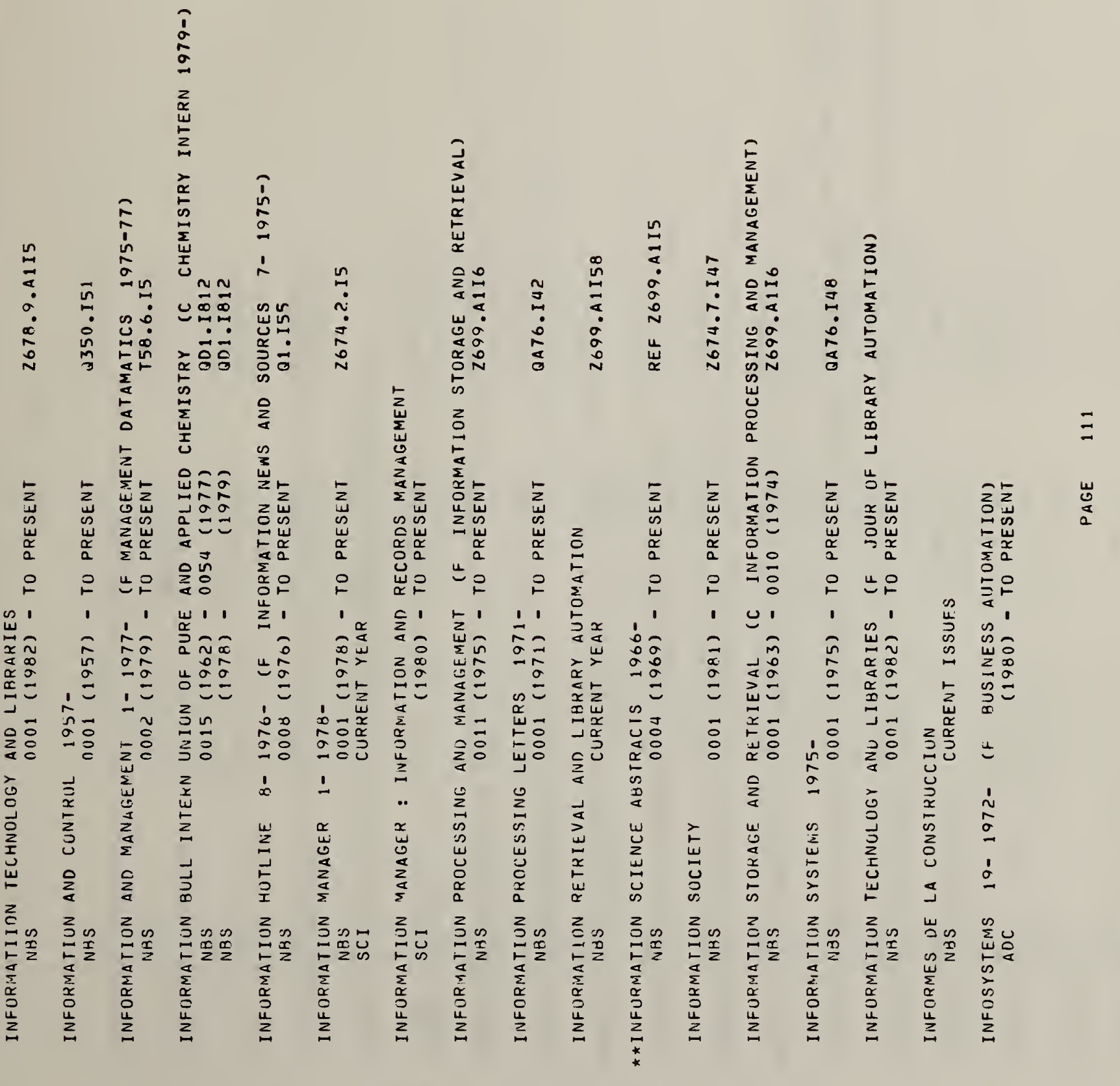




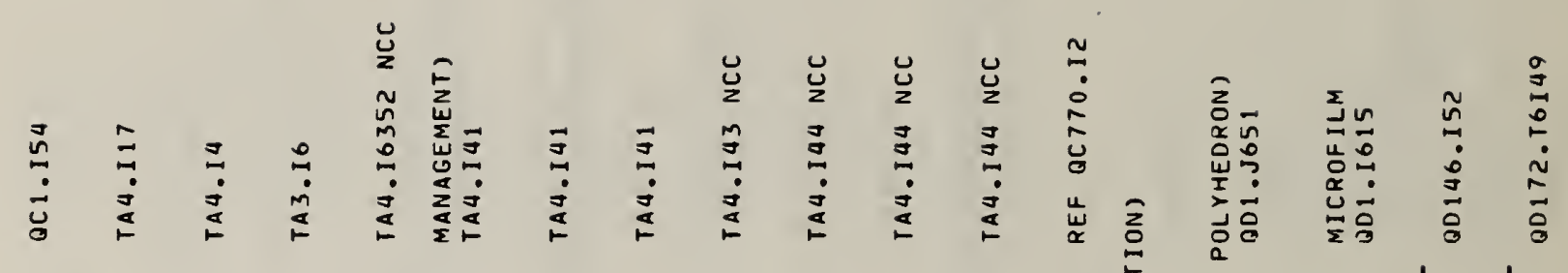

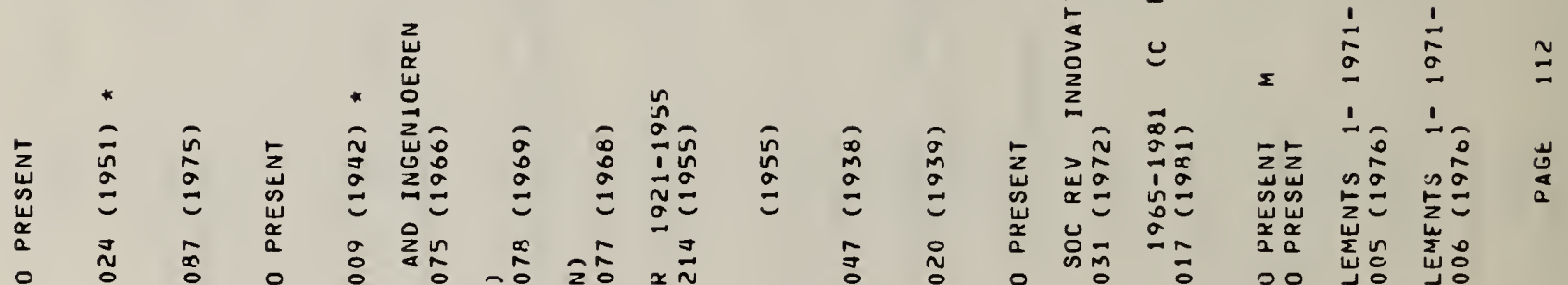

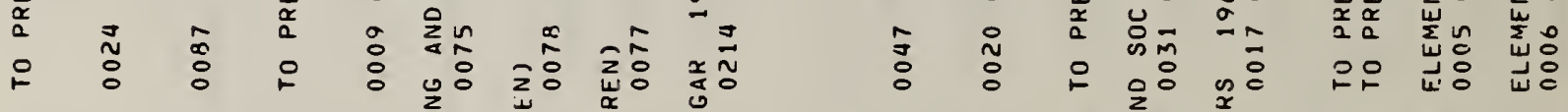

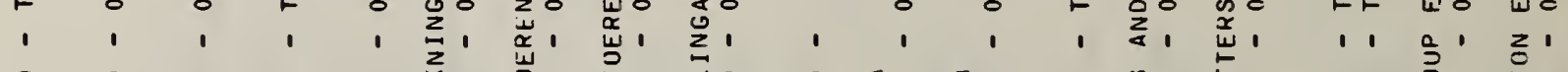

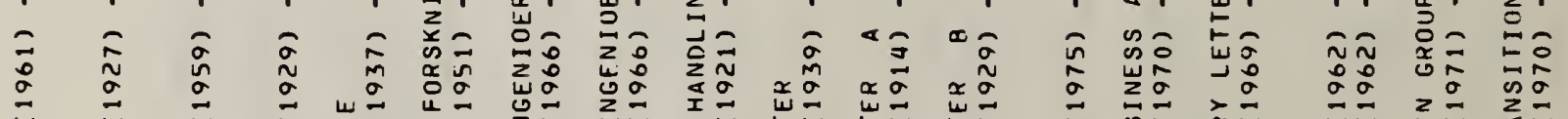

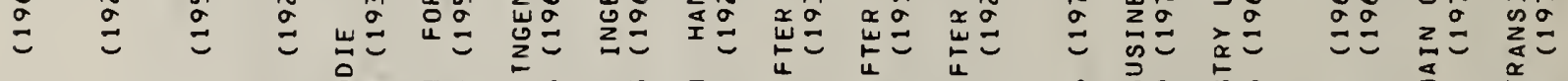

รั

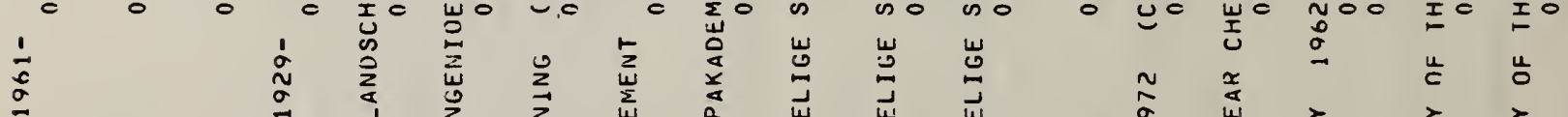

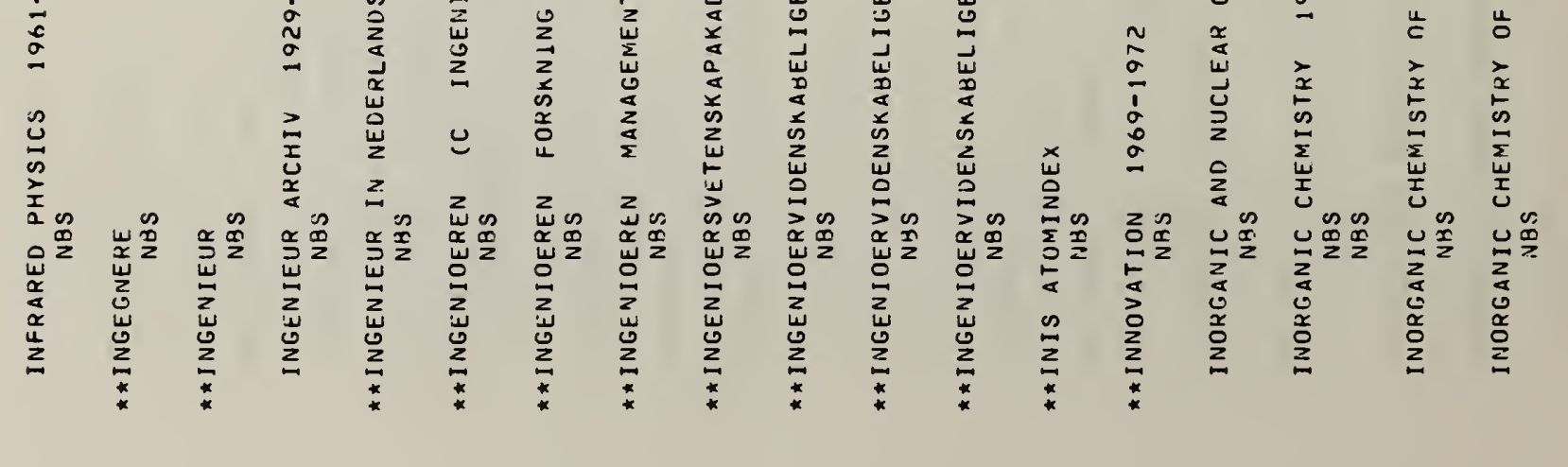




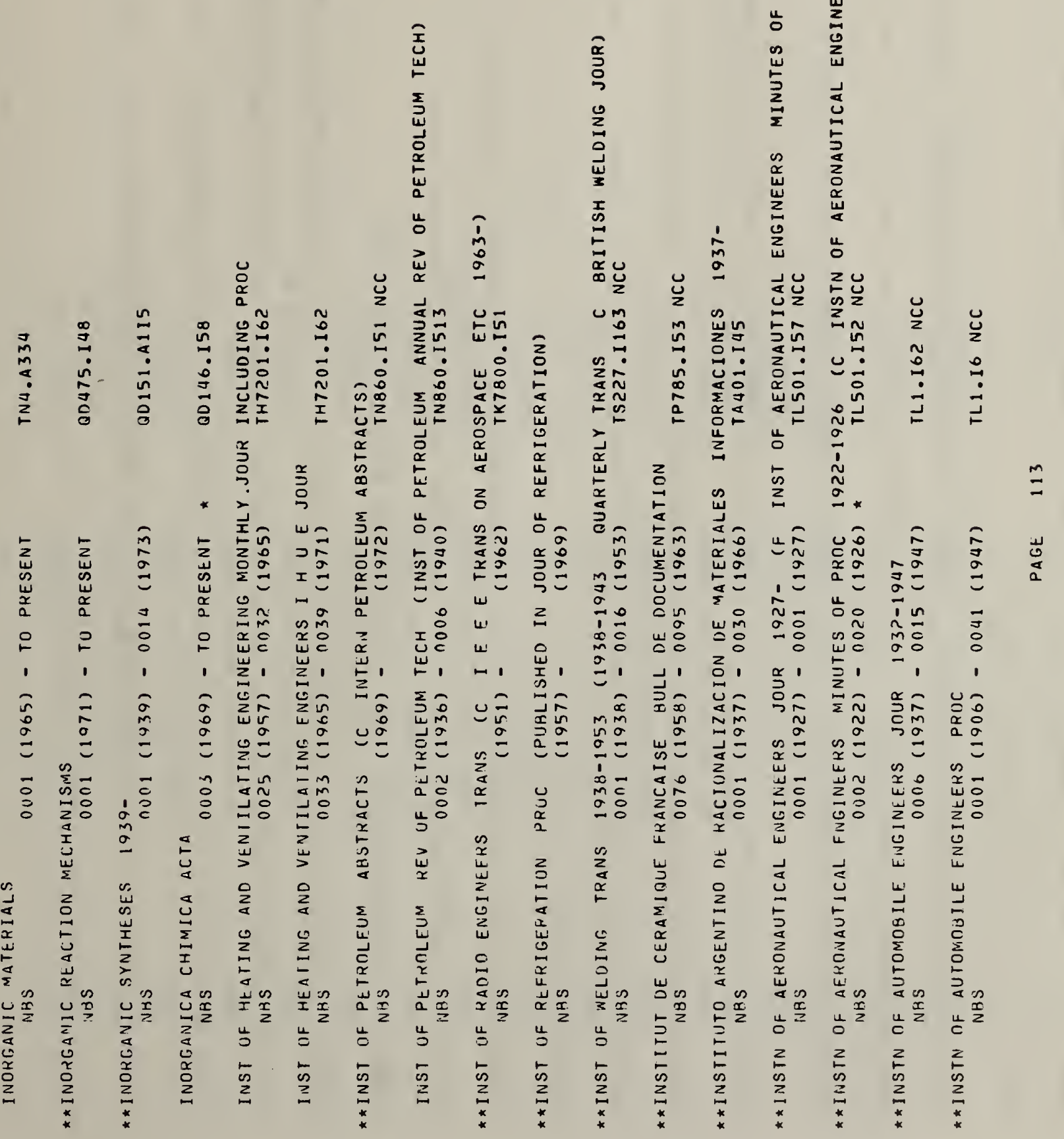




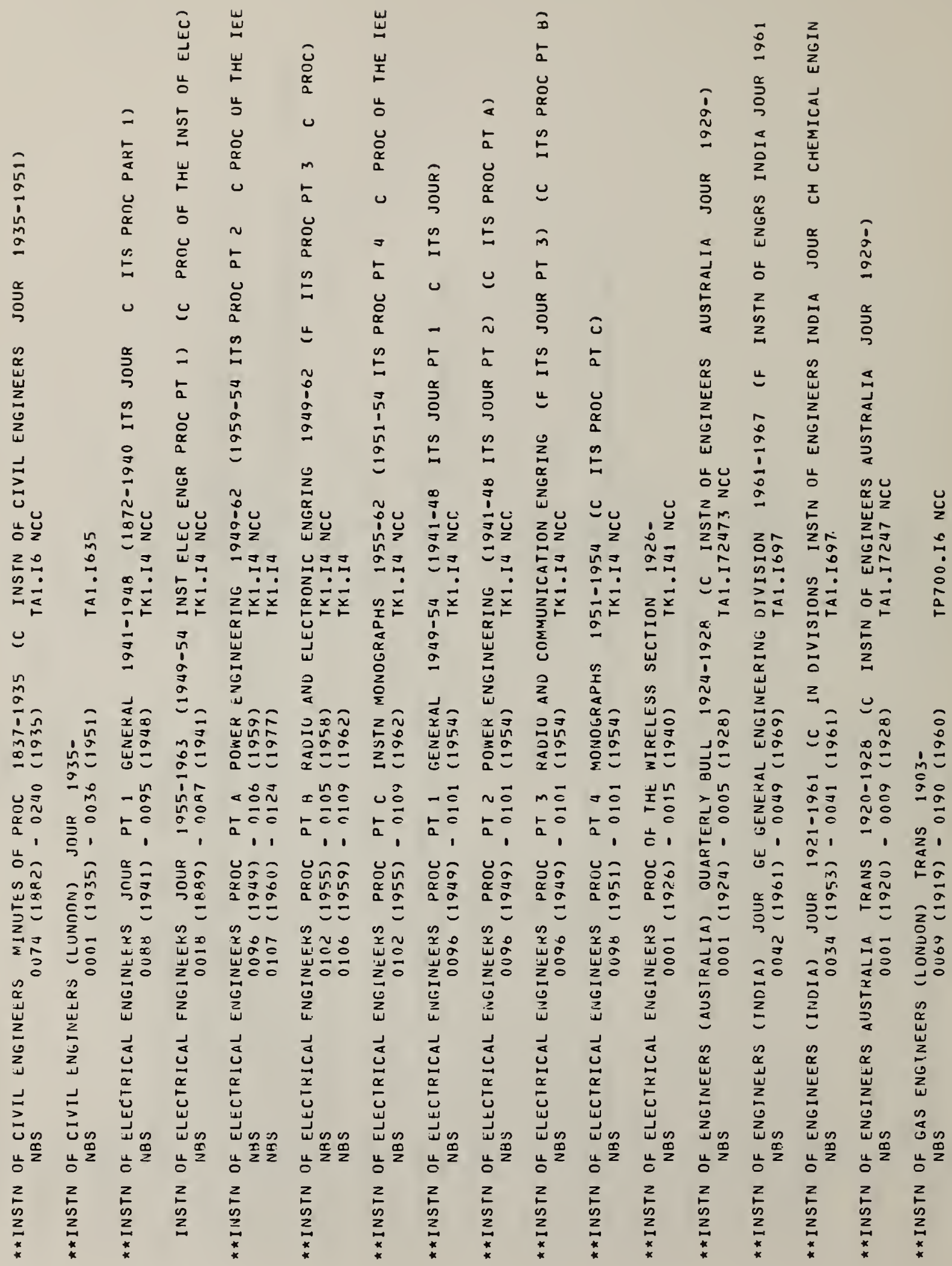



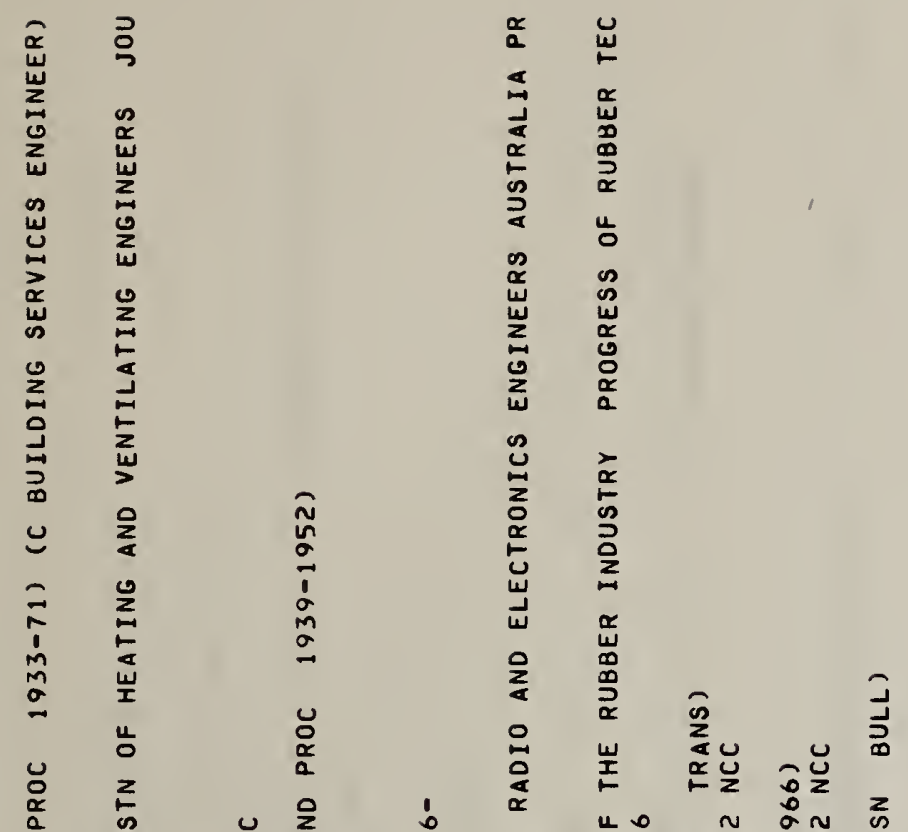

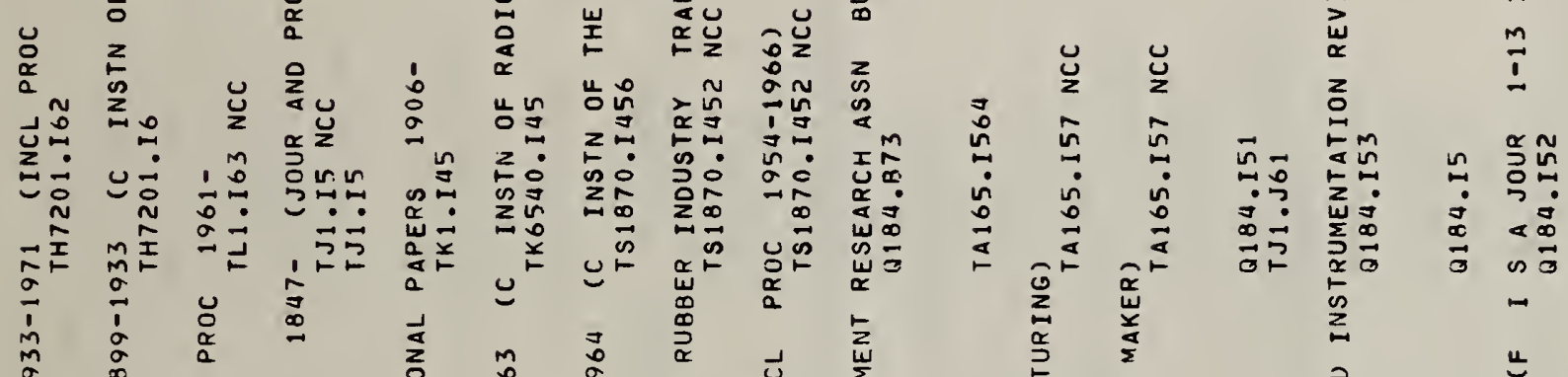

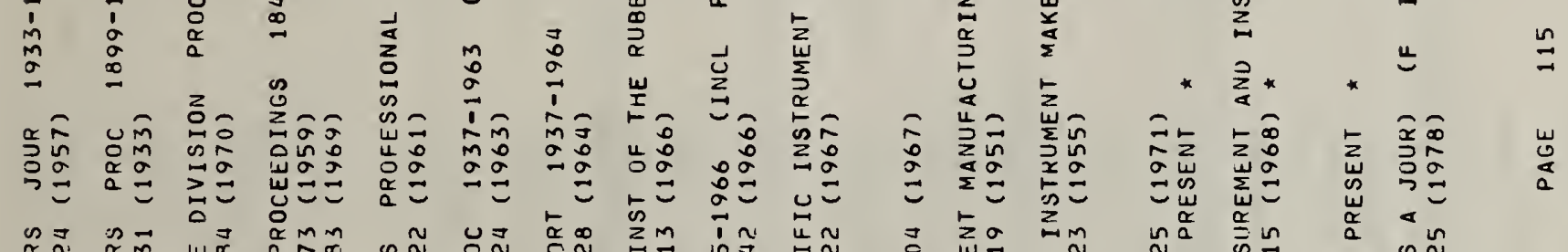

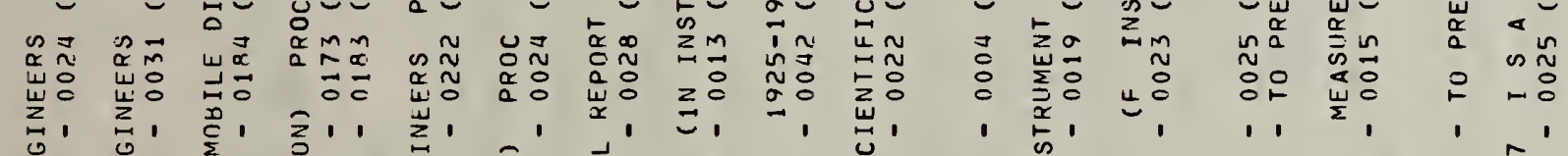

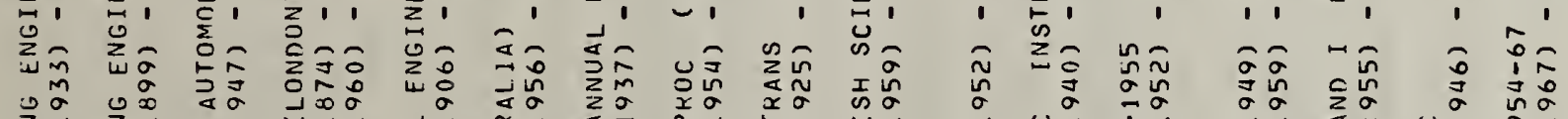

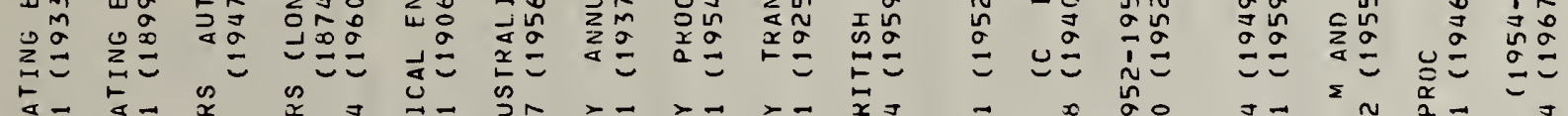

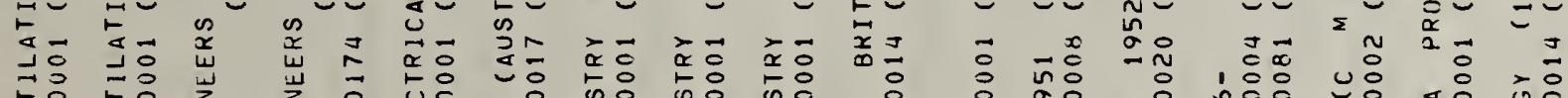

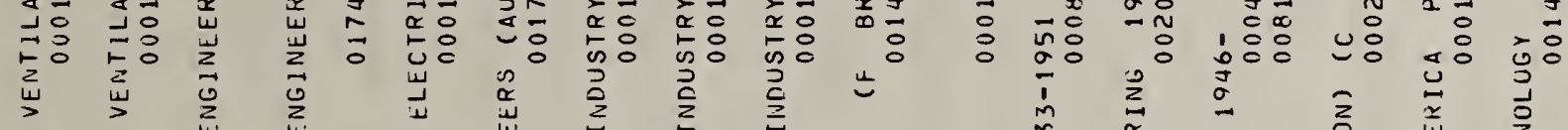

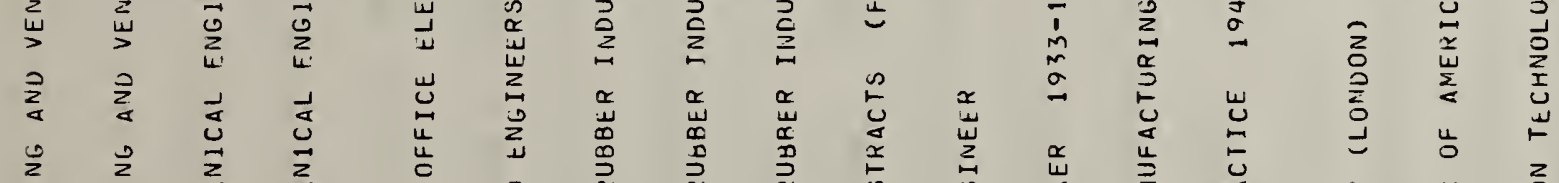

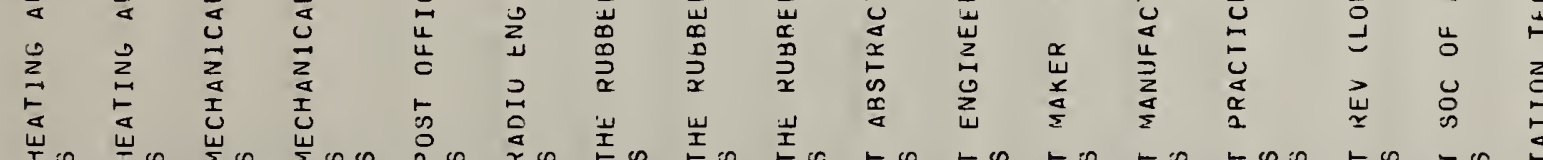

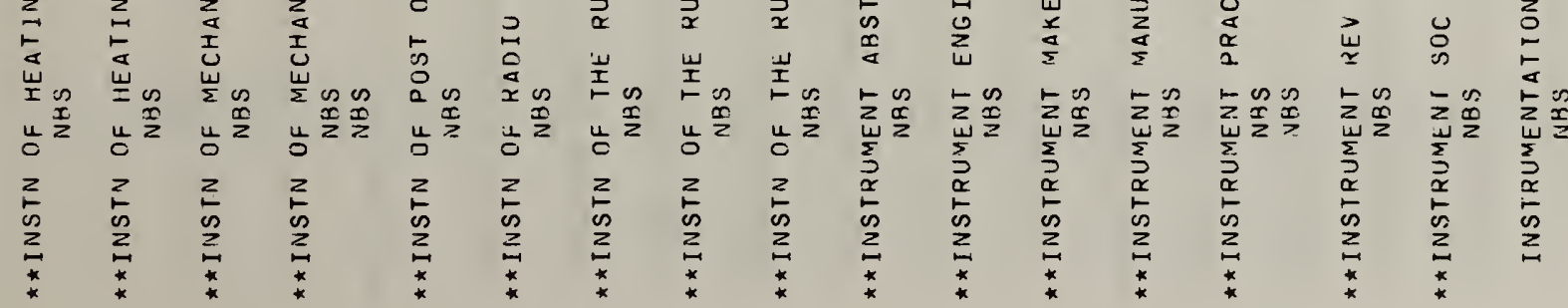


$\sum_{0}$

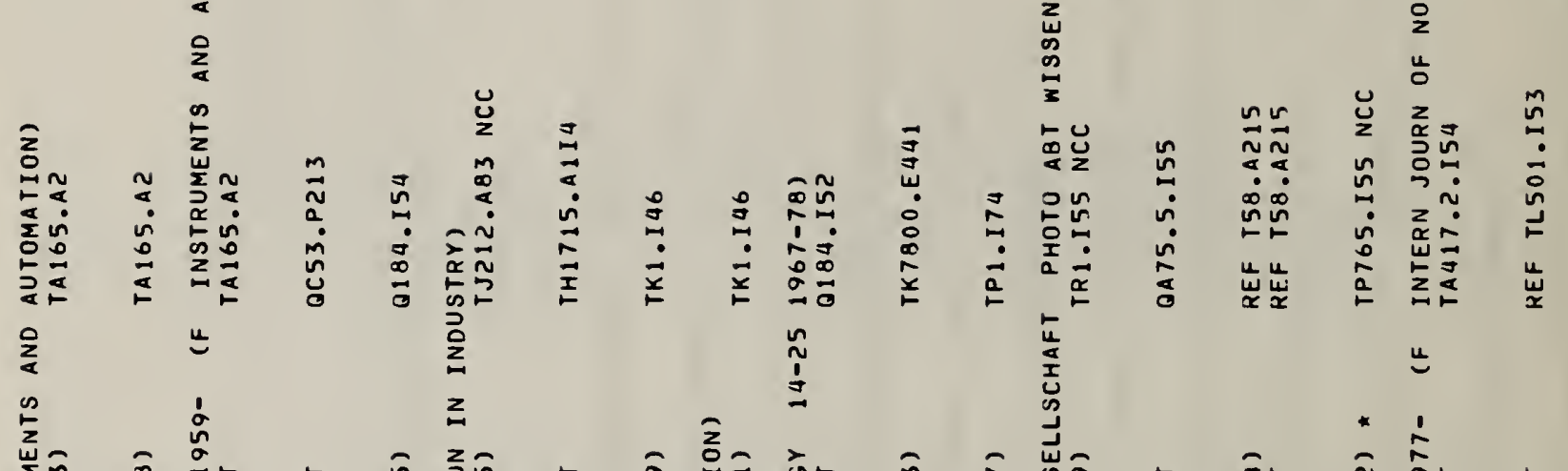

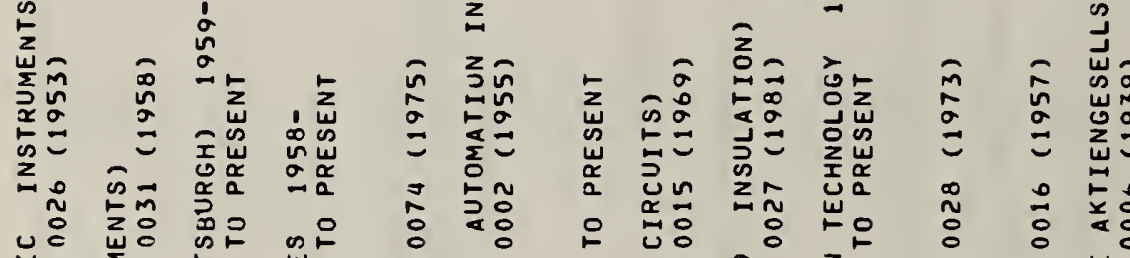

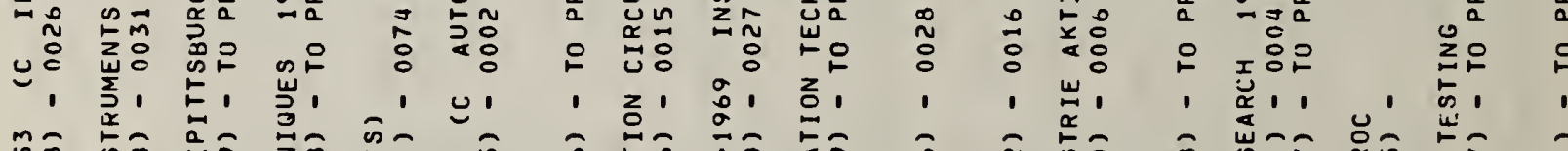

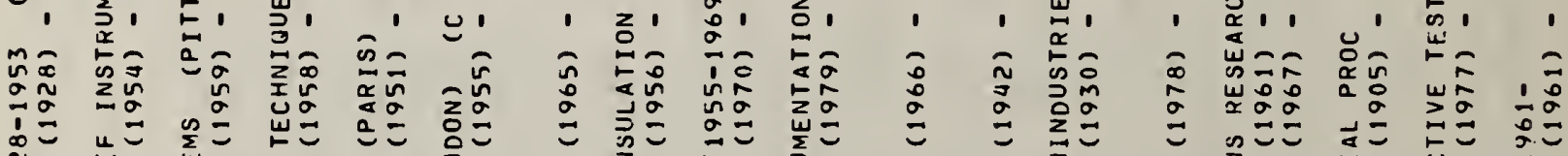

定

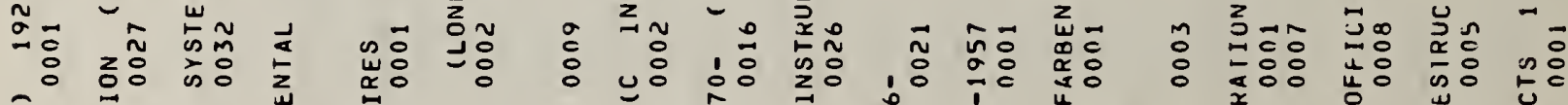

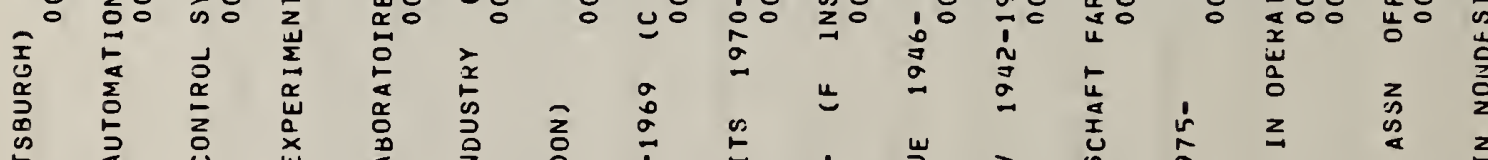

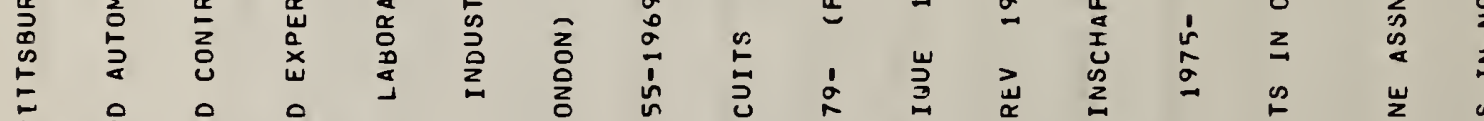

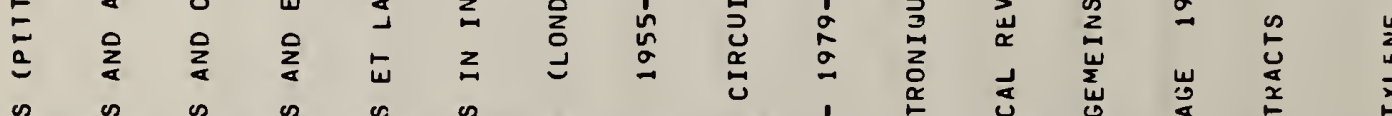

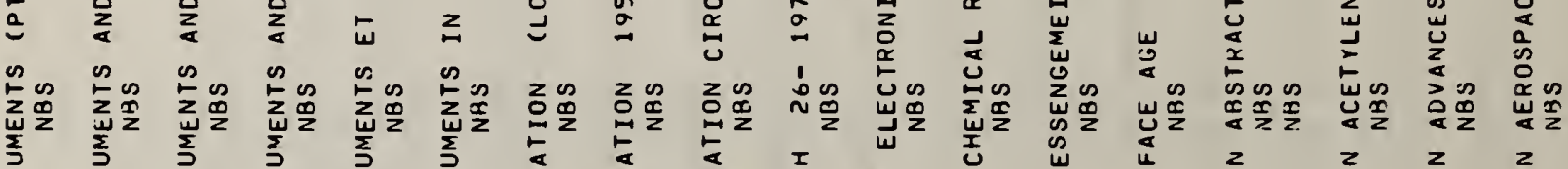

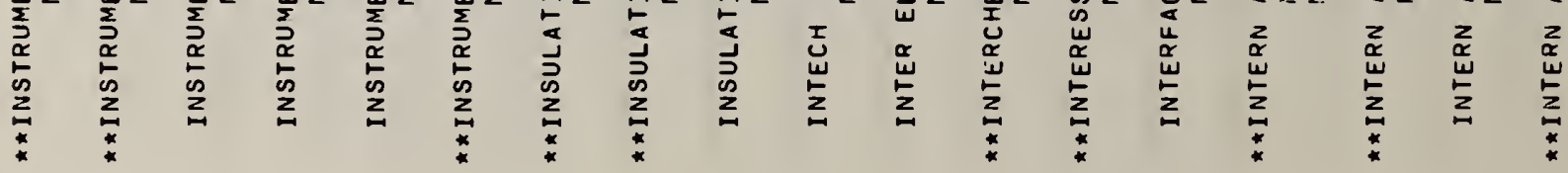




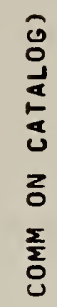

כ)

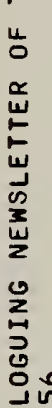

zon

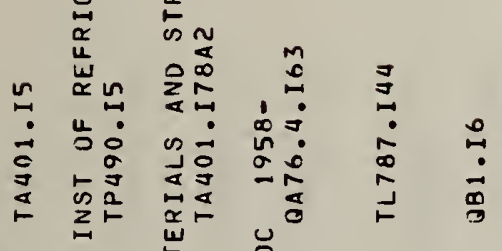

岁

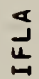

堊

$\underset{\substack{\alpha \\ a}}{\text { L }}$

$\sum_{\substack{0 \\ \hdashline}}^{\infty}$

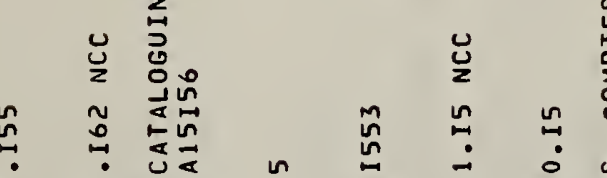

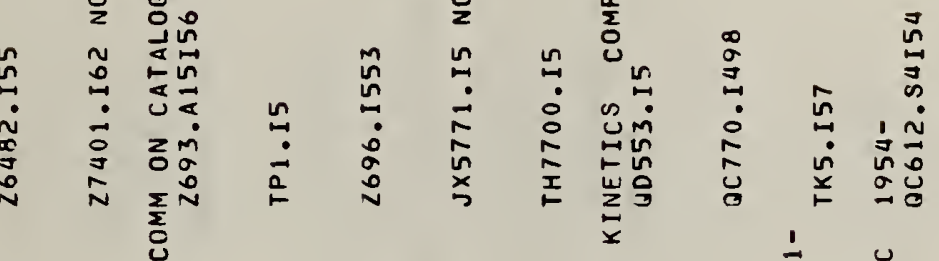

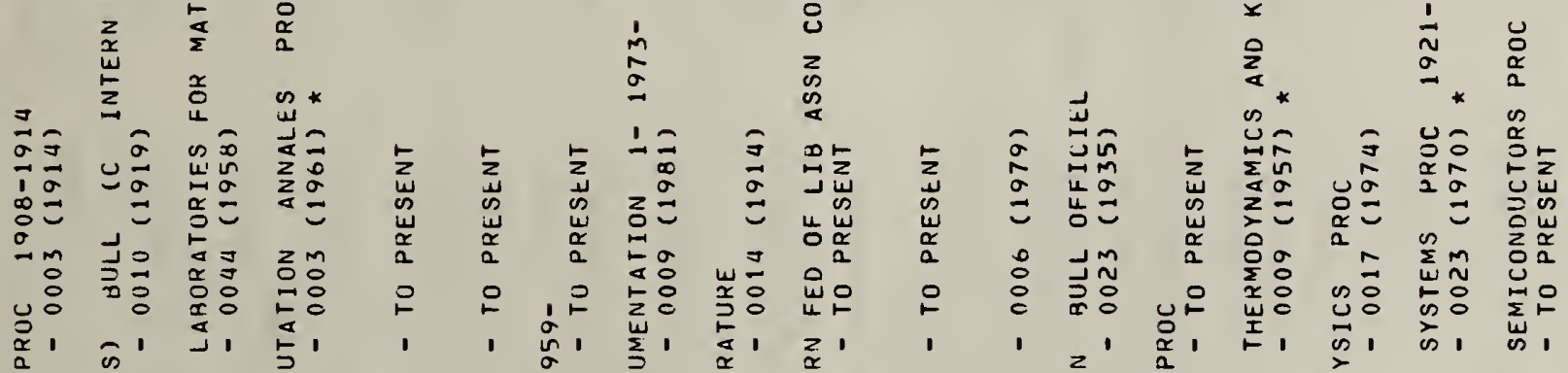

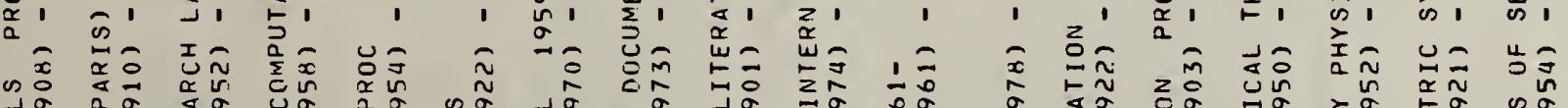

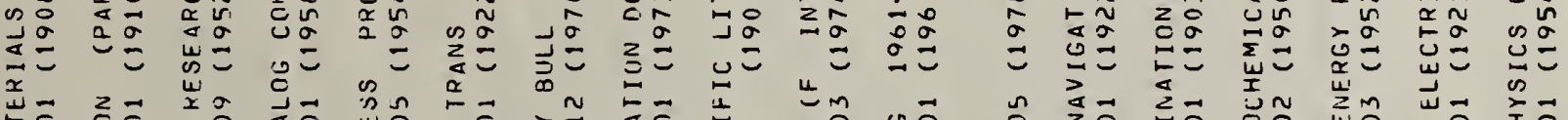

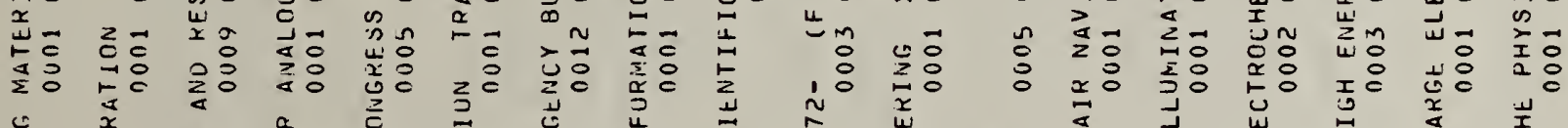

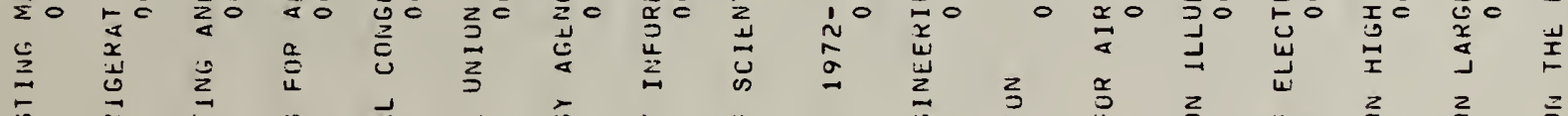

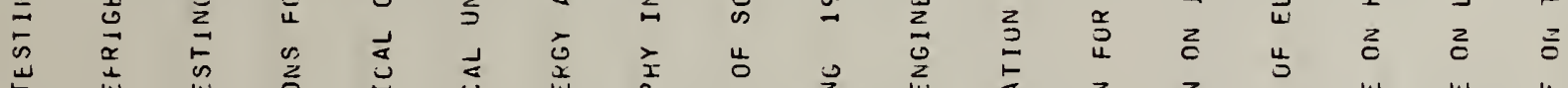

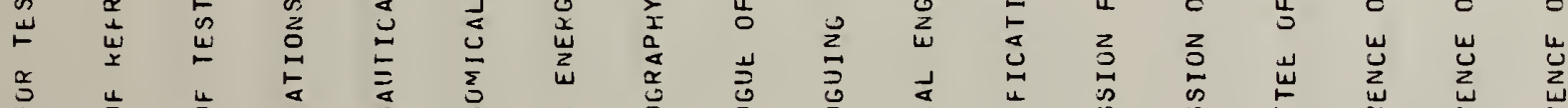

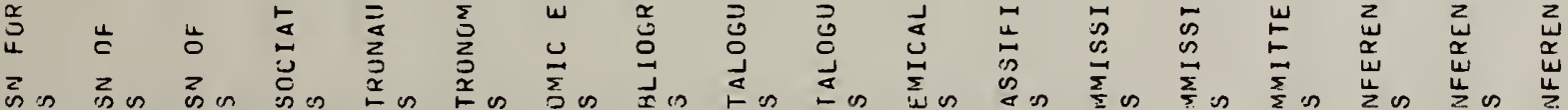

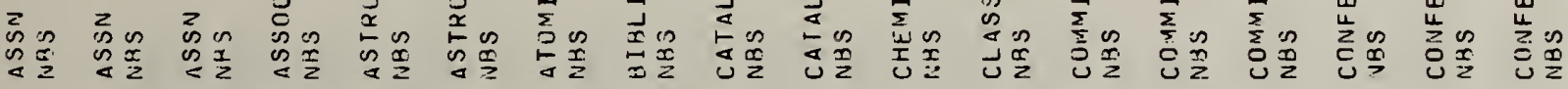

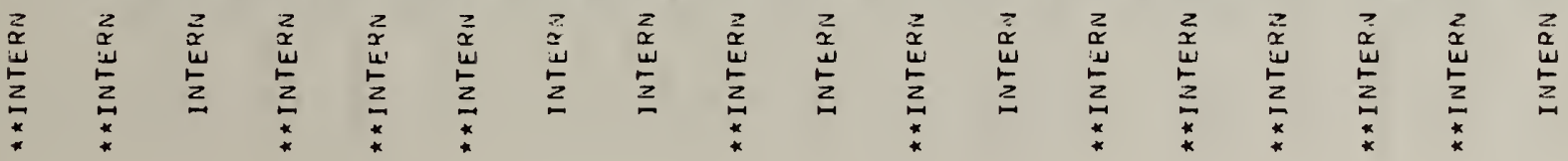




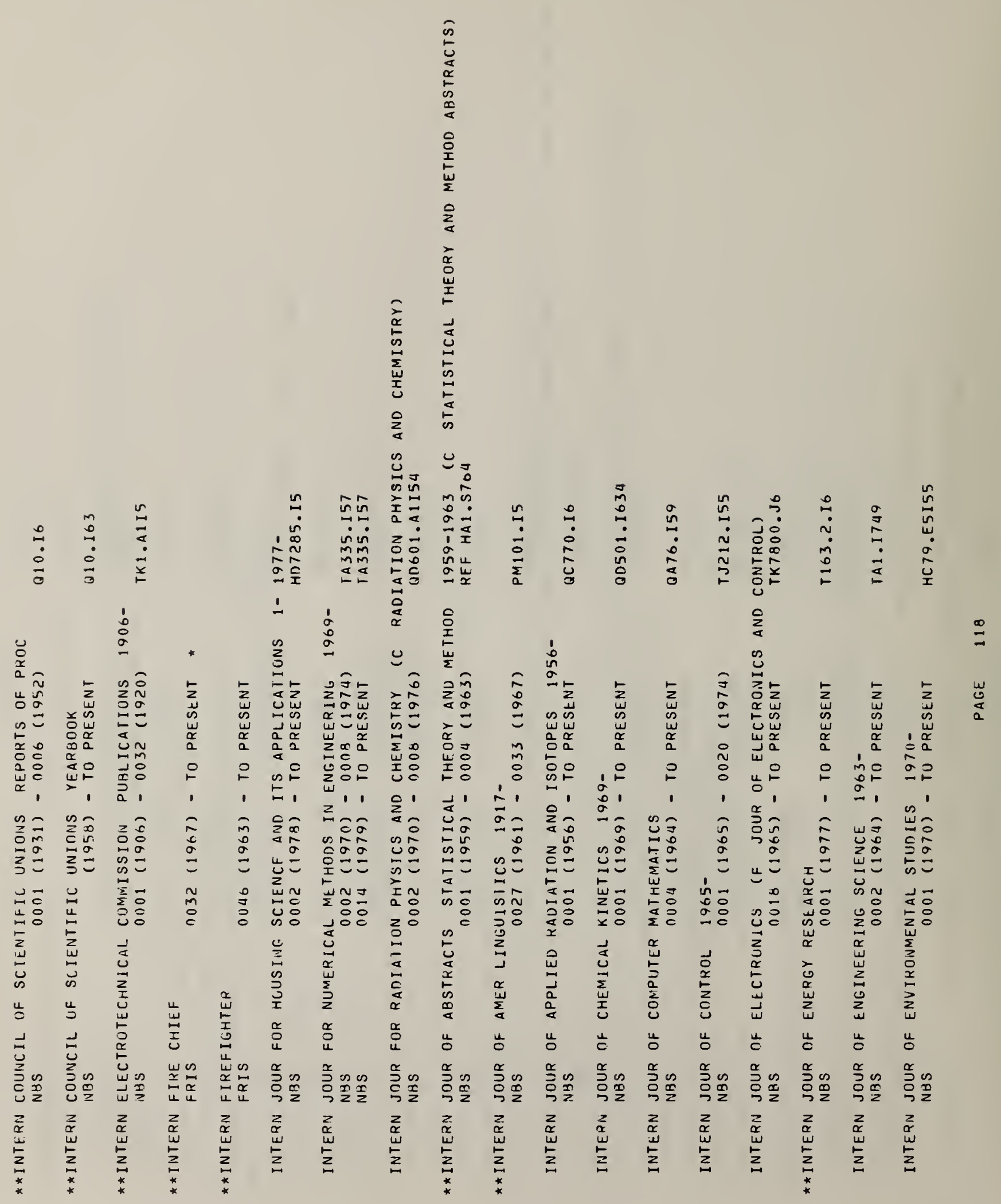




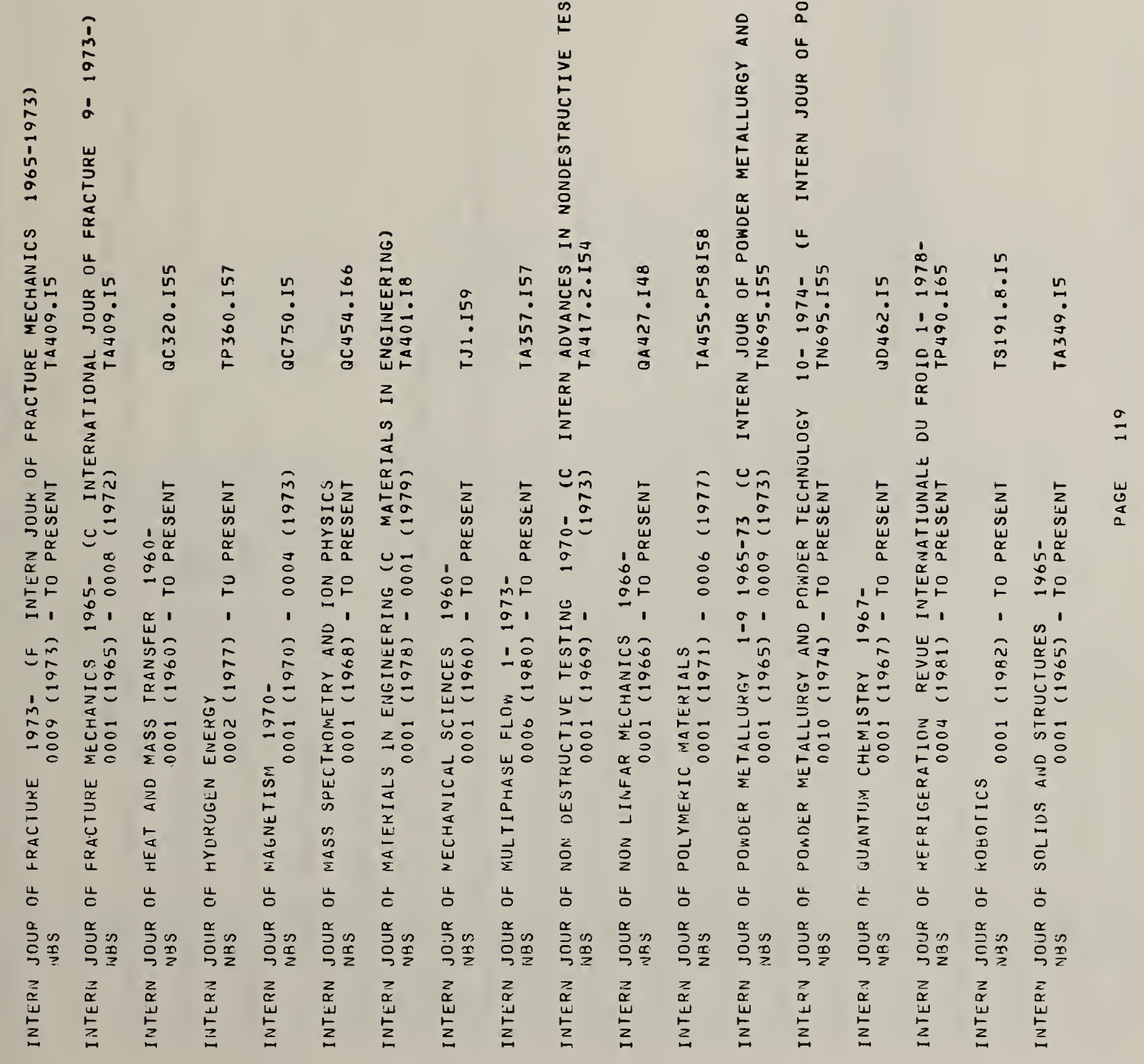




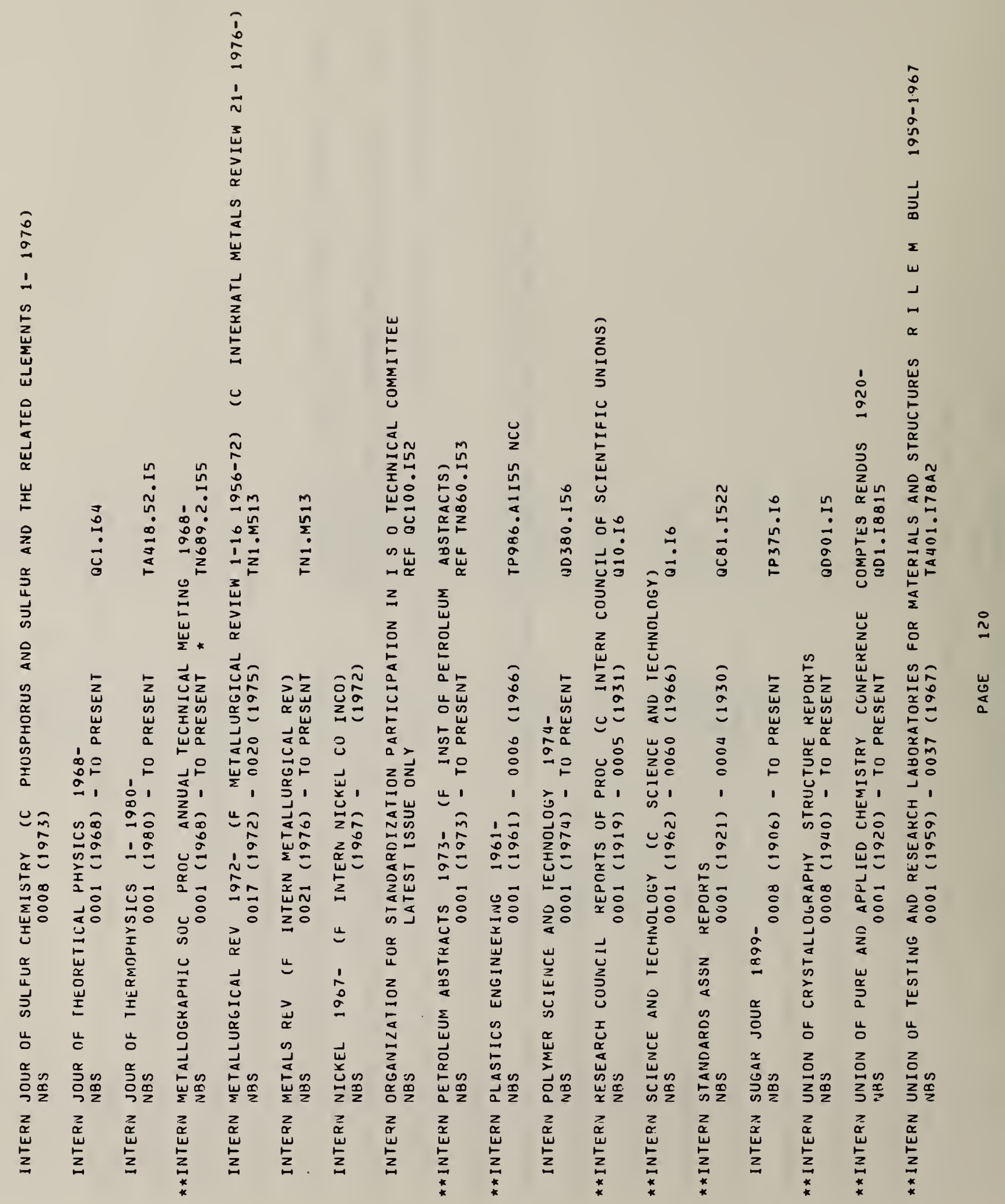




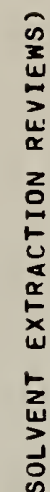

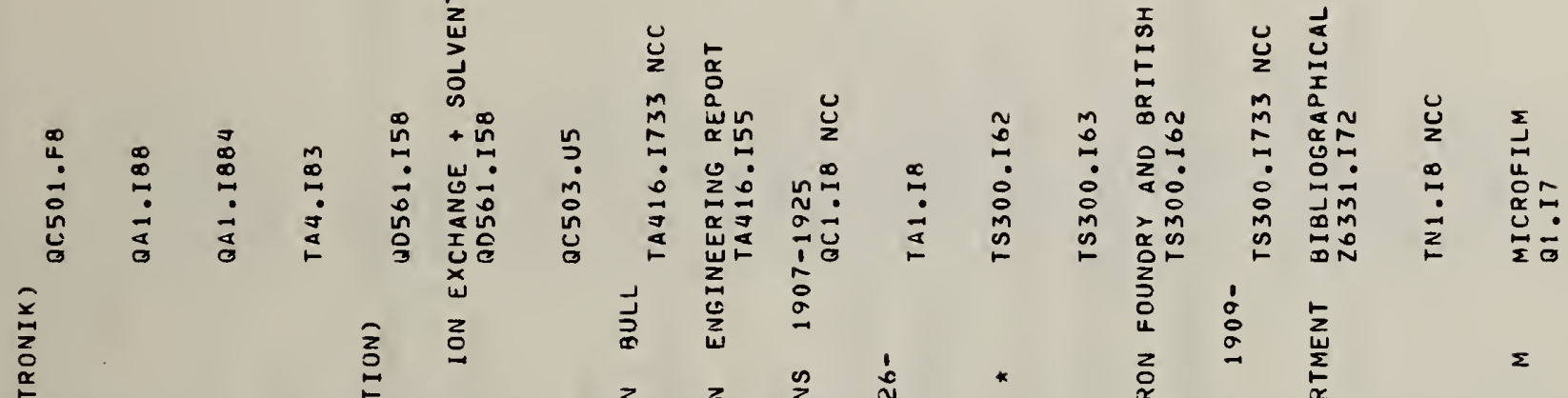

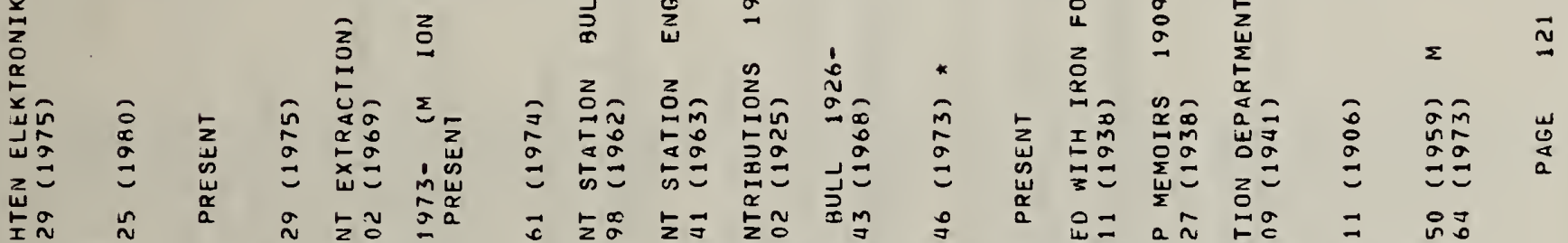

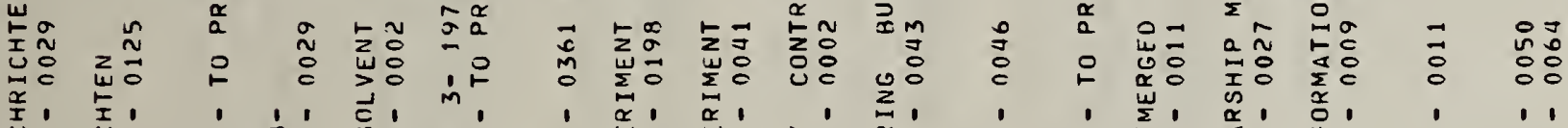

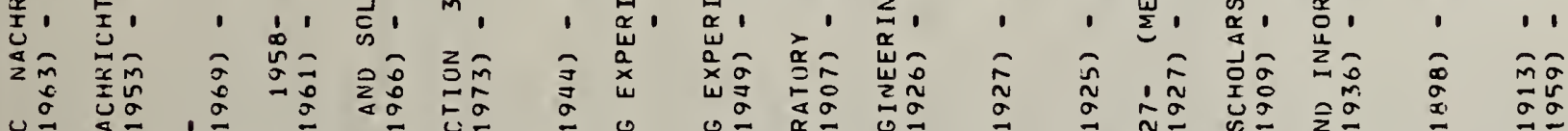

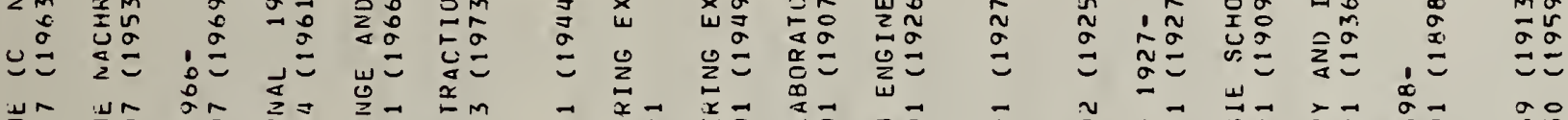

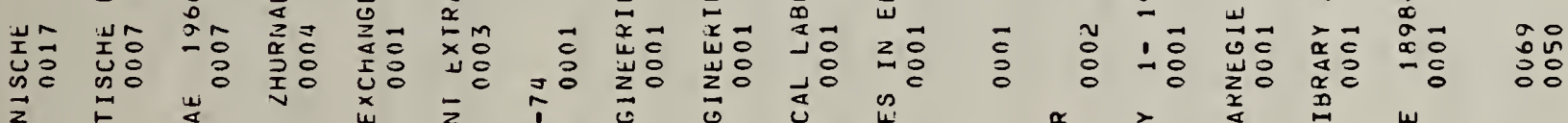

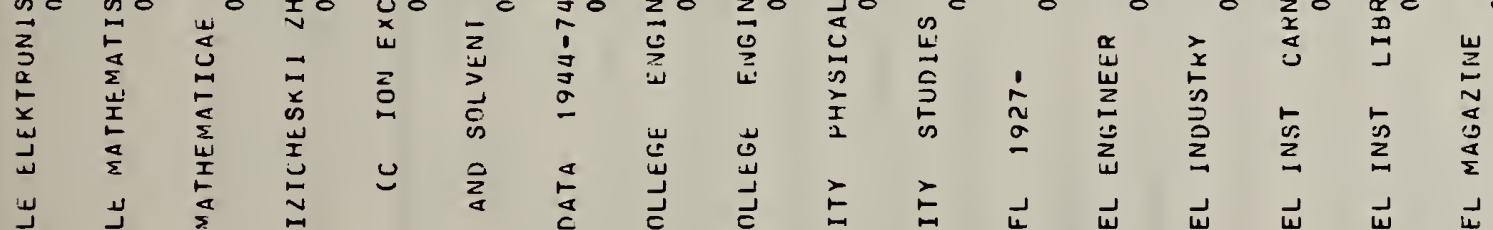

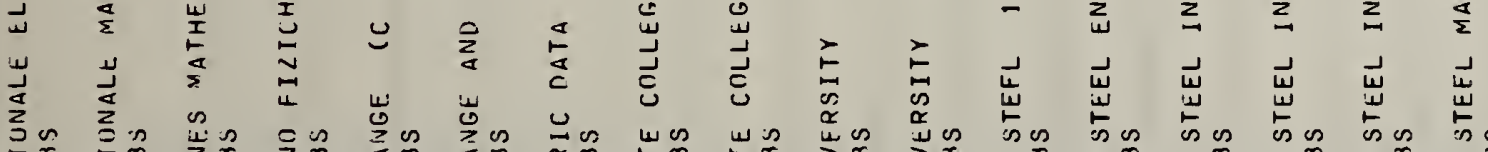

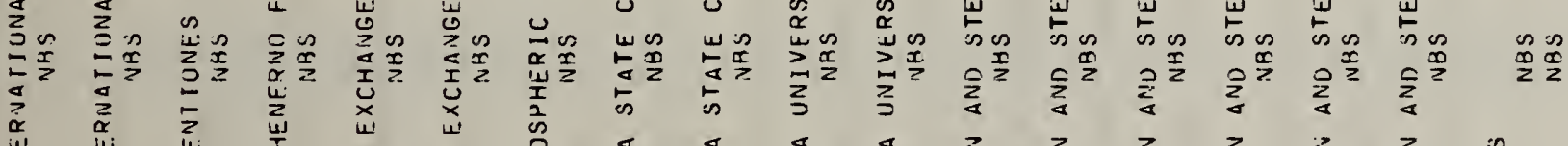

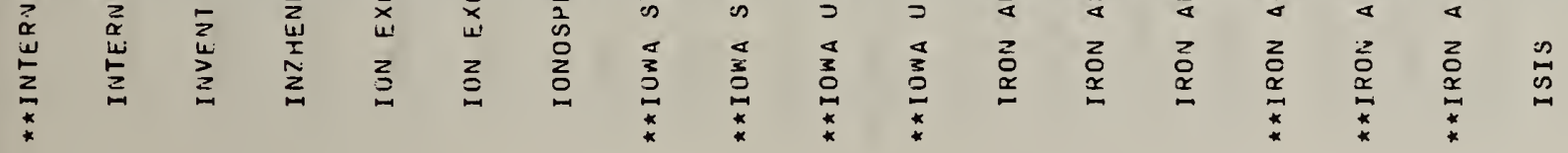




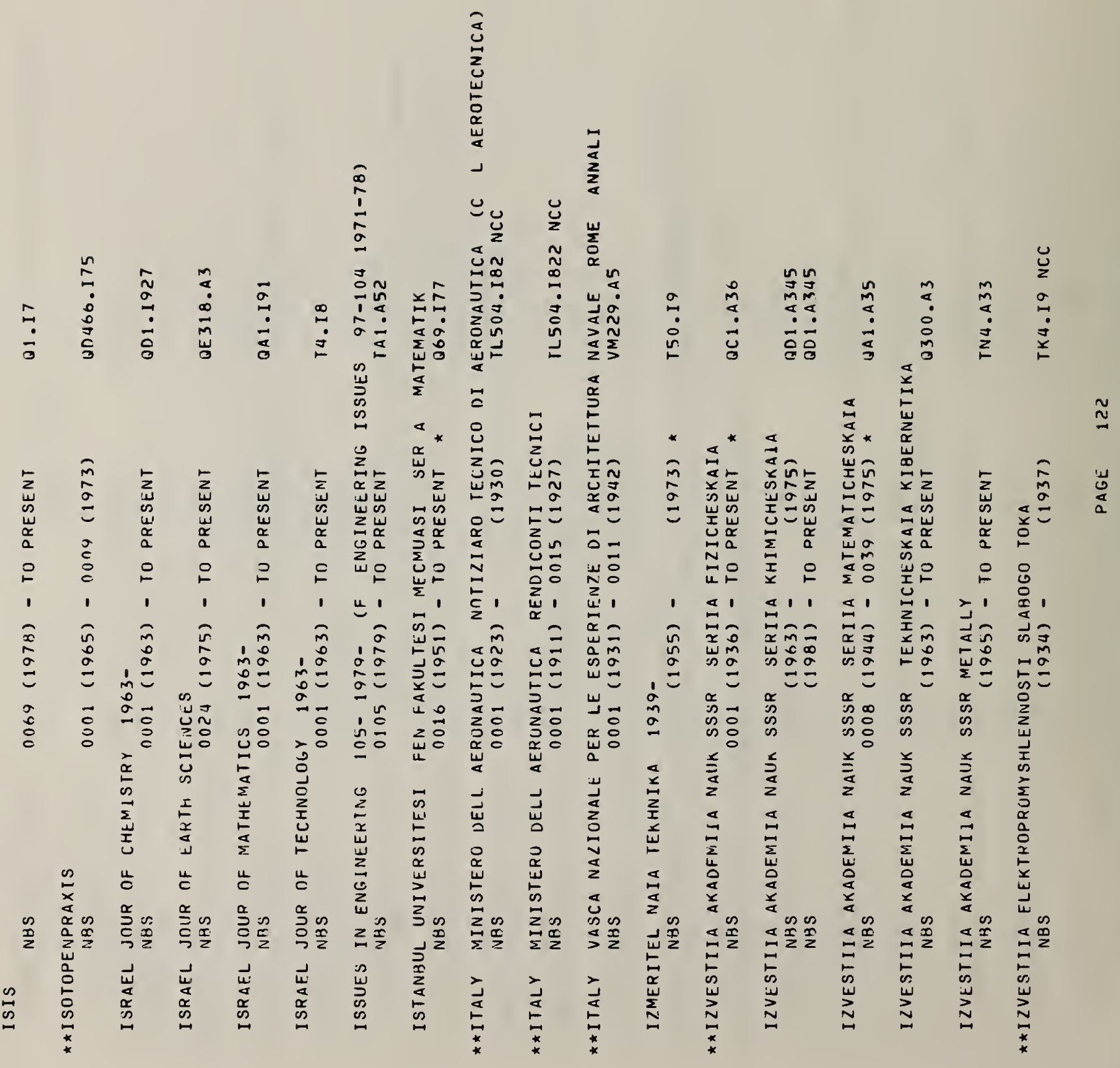




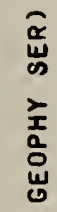

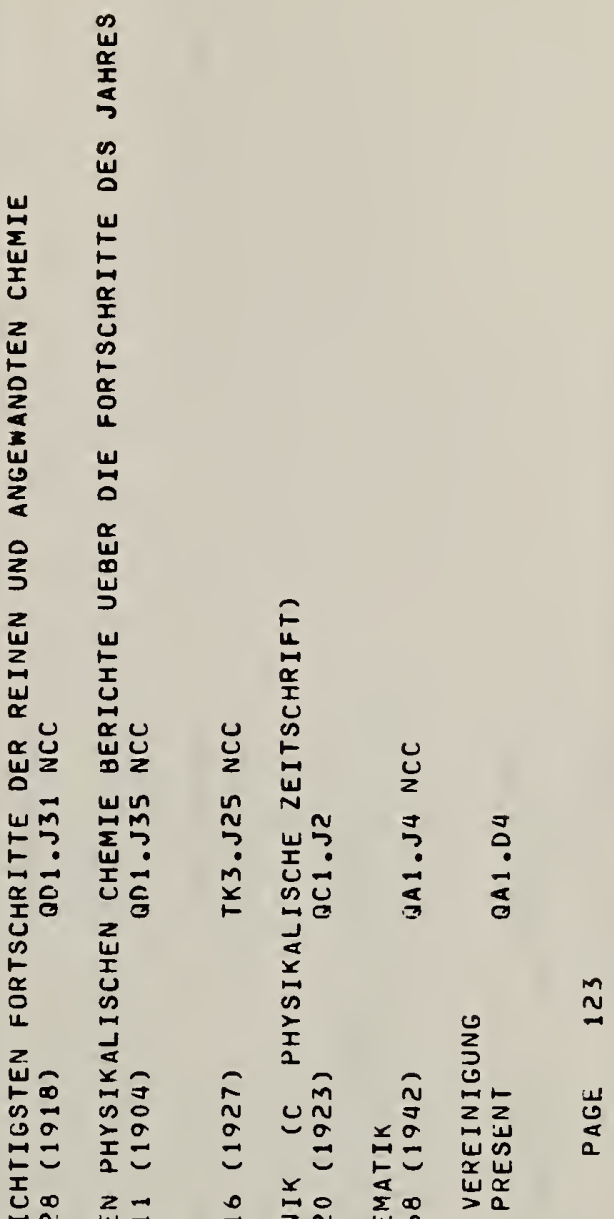

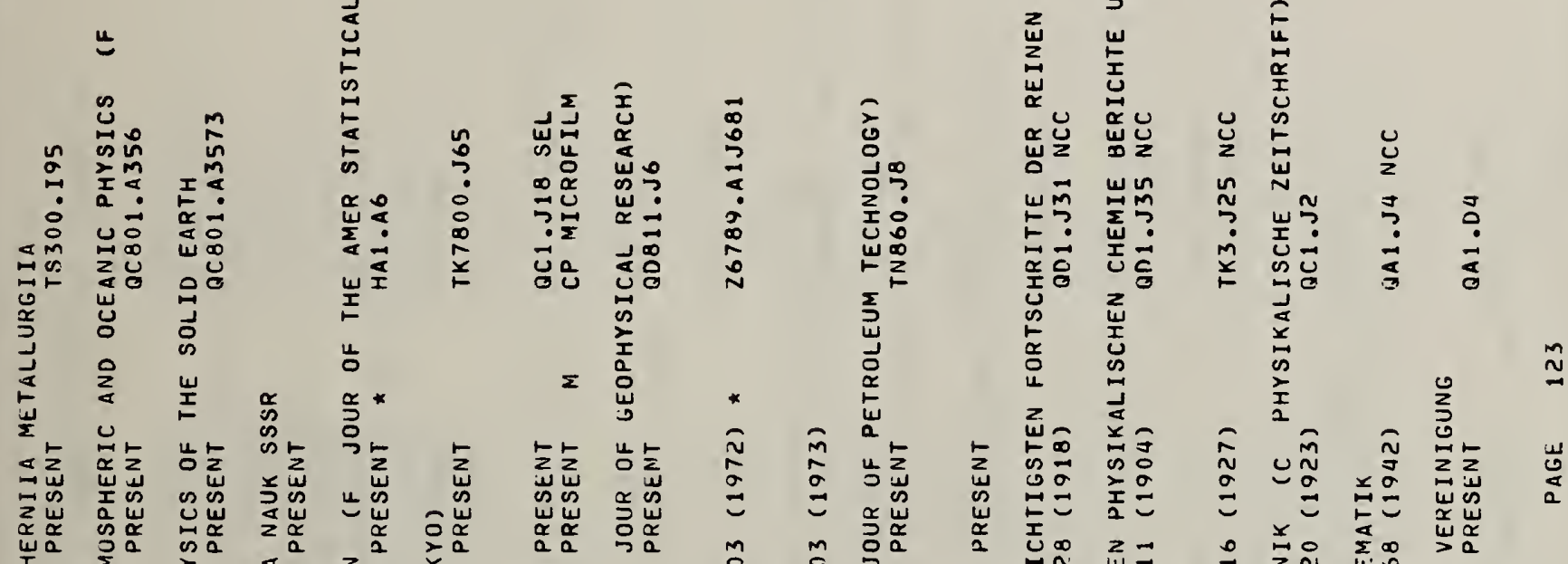

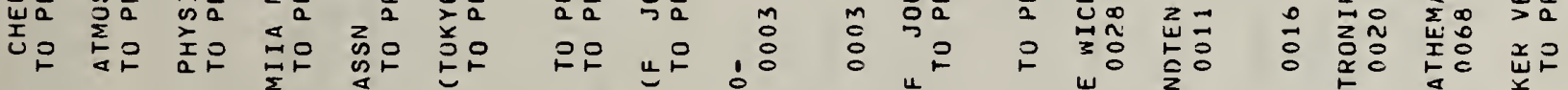

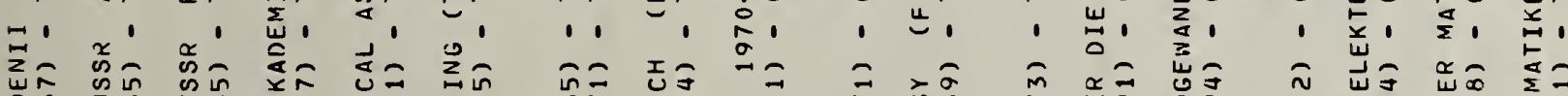

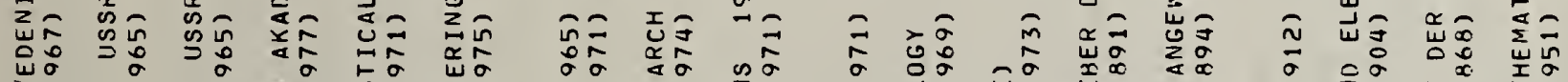

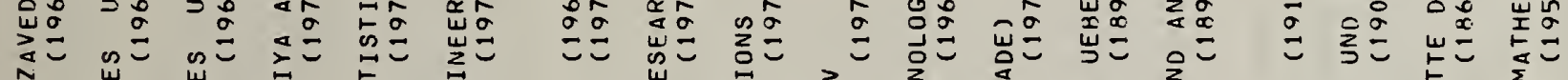

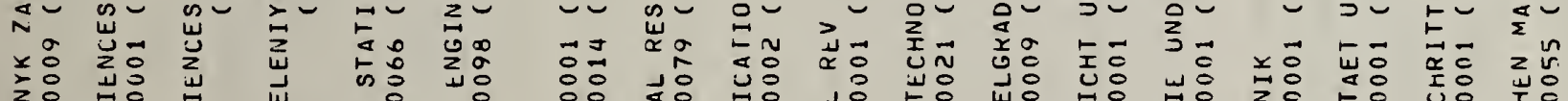

部品

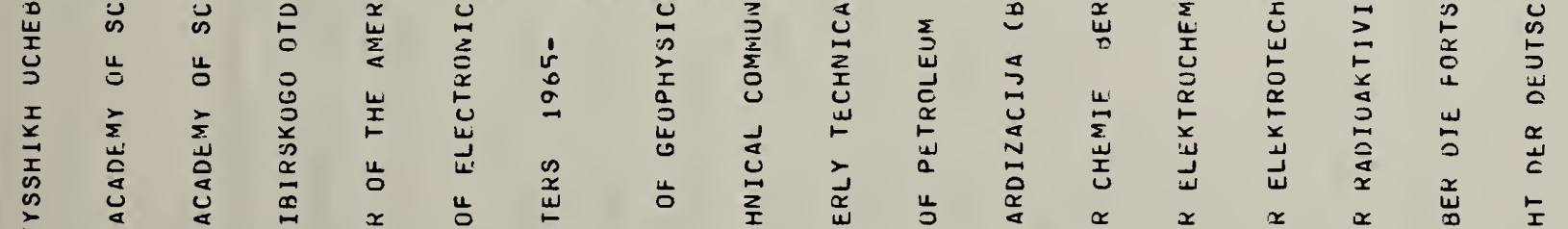

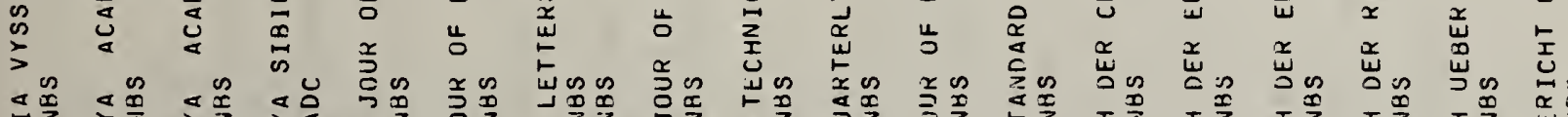

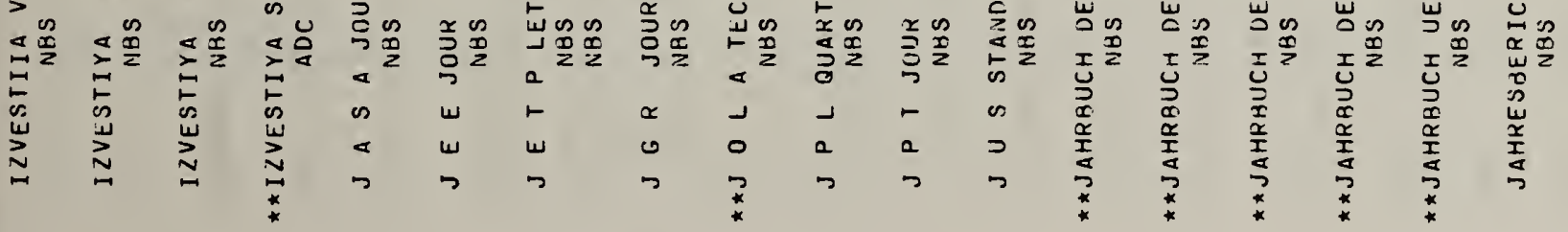




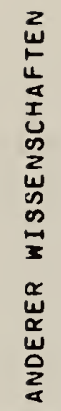

$\frac{5}{0}$

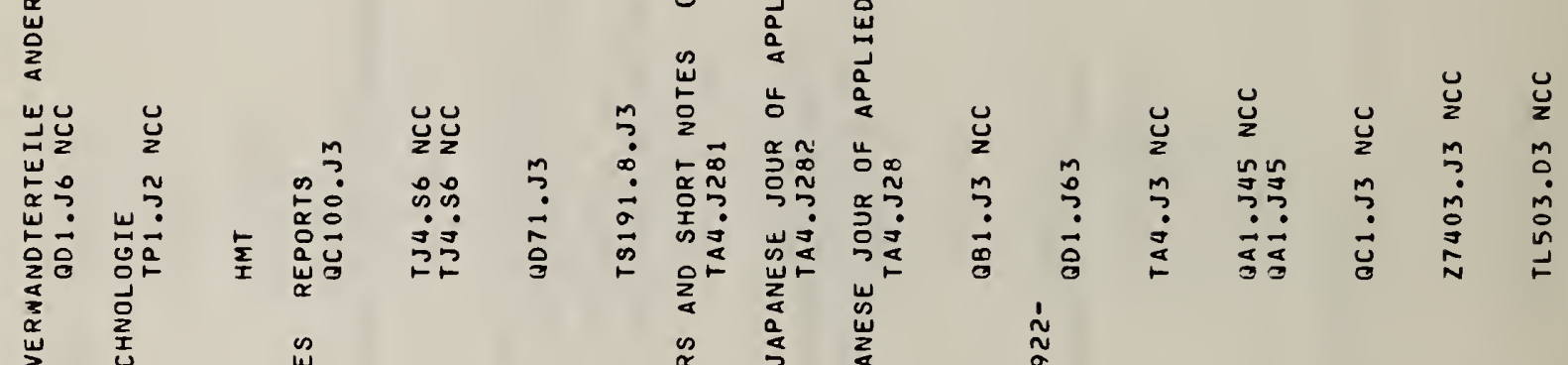

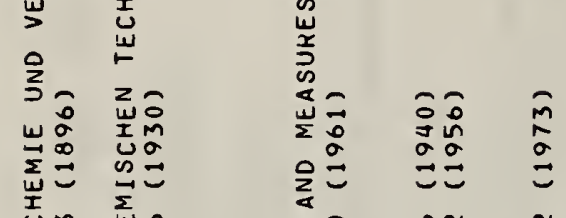

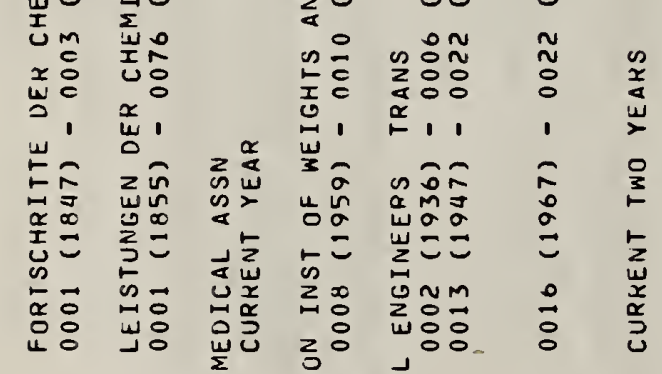

능

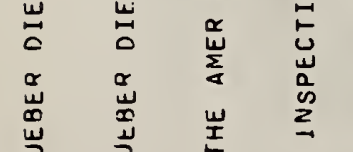

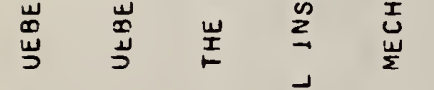

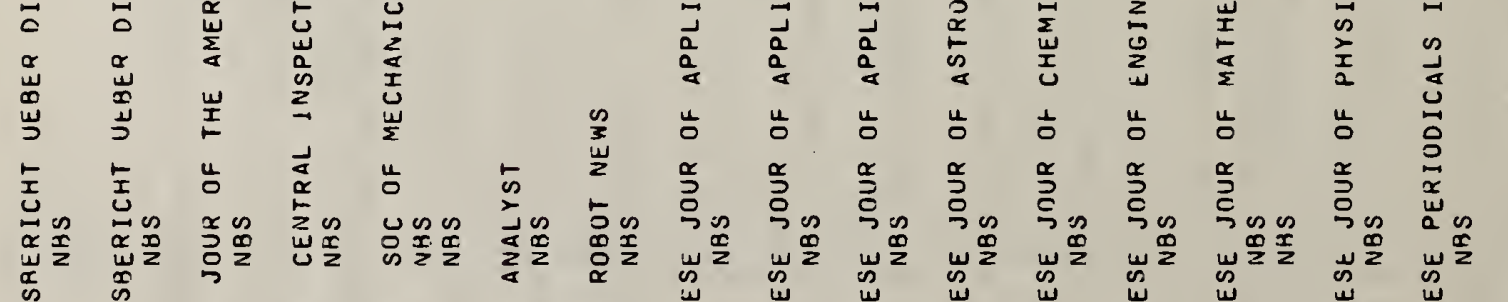

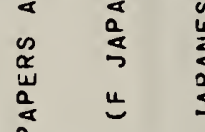
$\stackrel{\dot{\sim}}{\approx}$

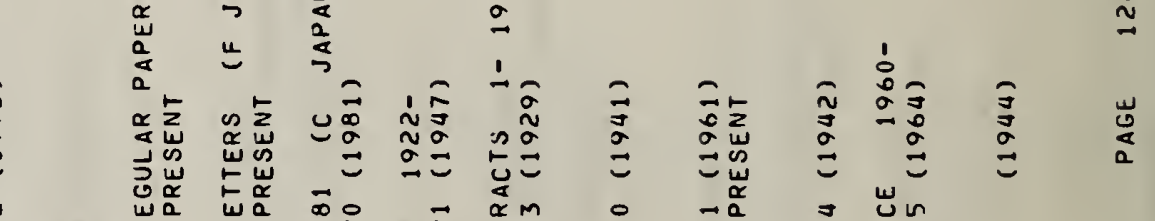

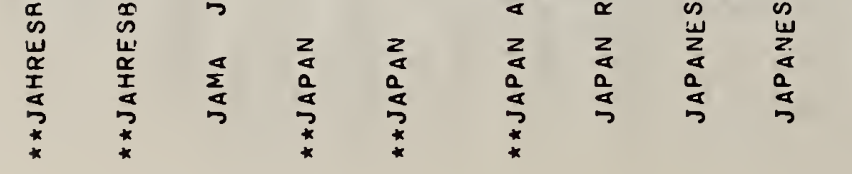




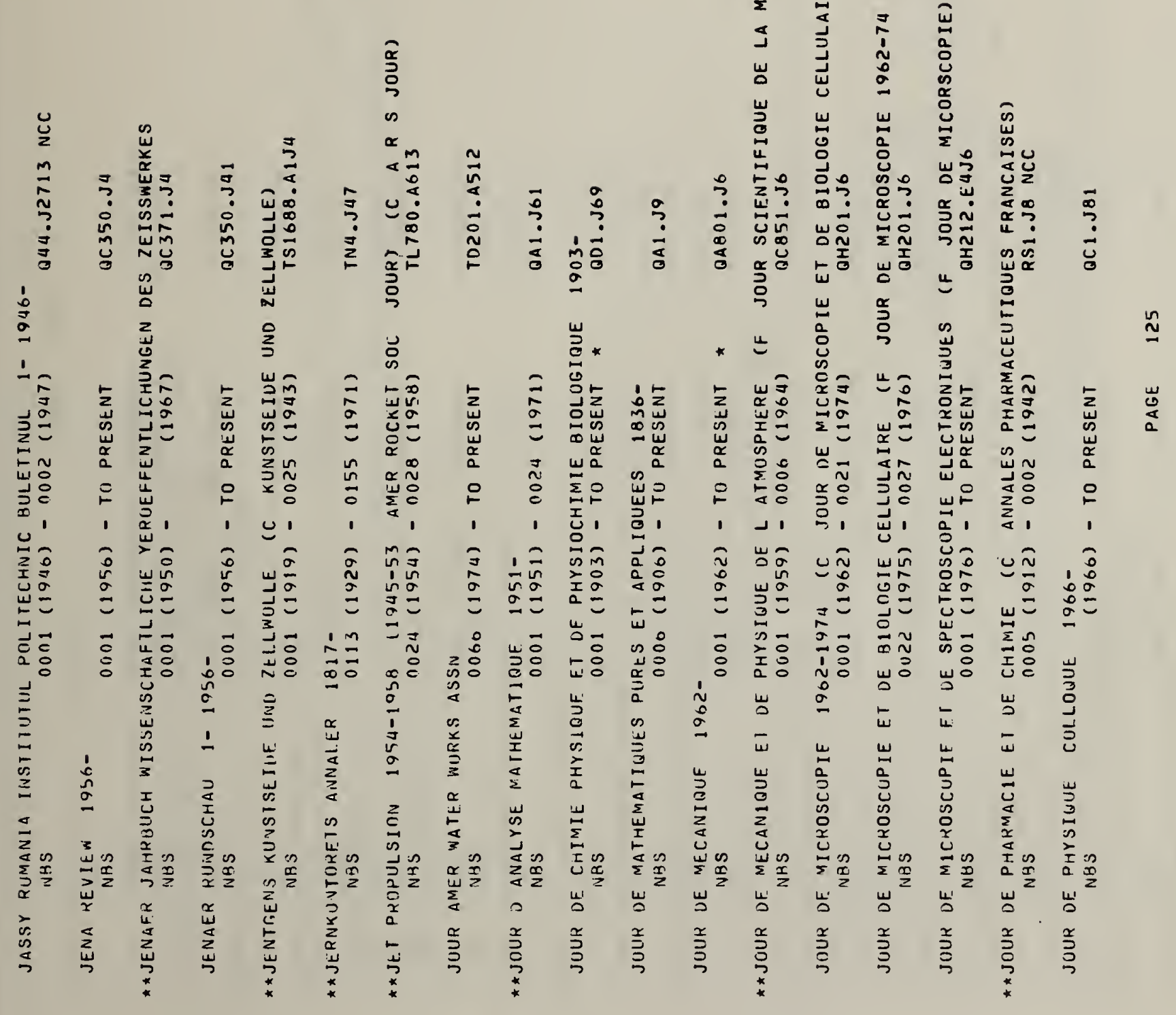




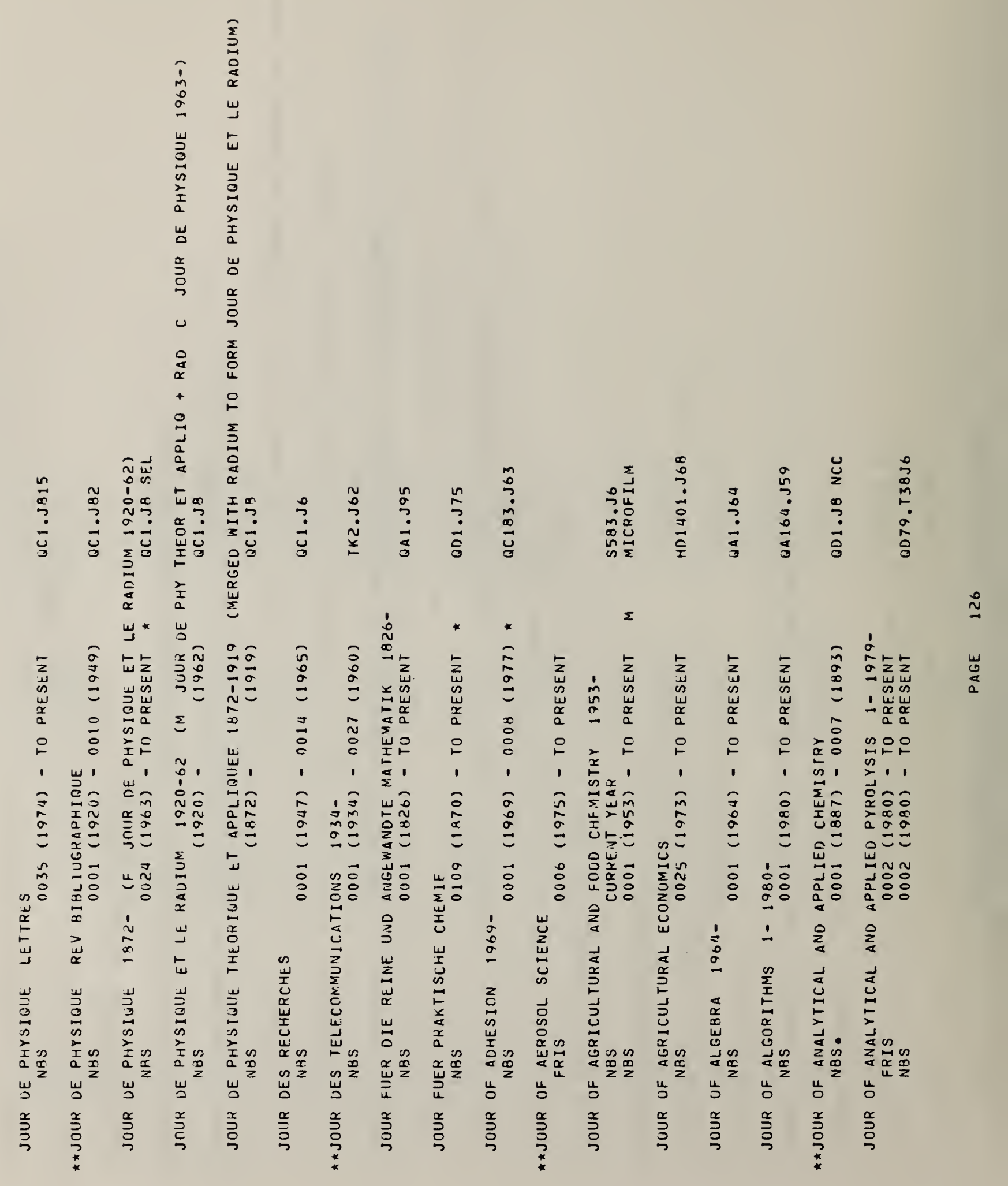




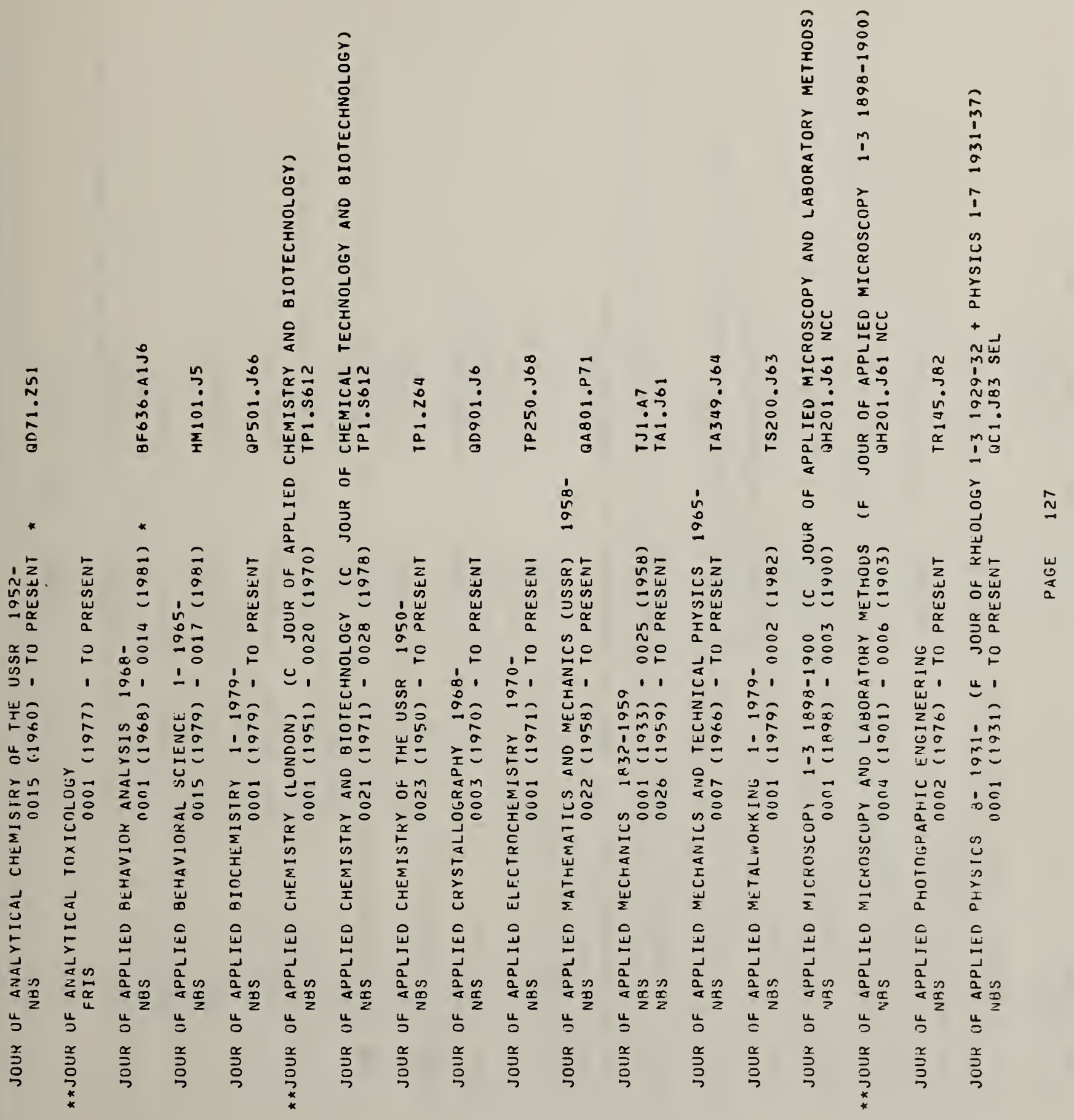


$\frac{\sqrt{m}}{\frac{1}{m}}$

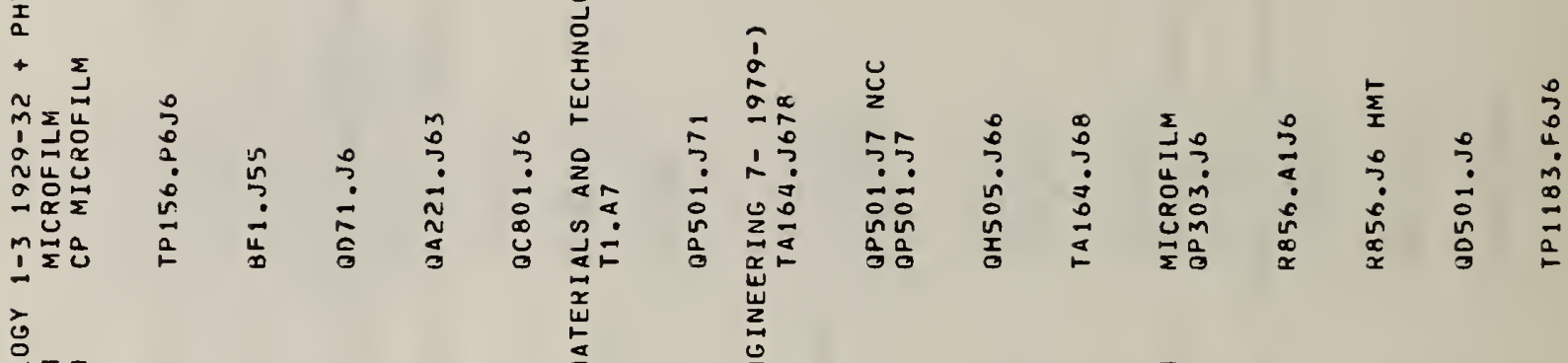

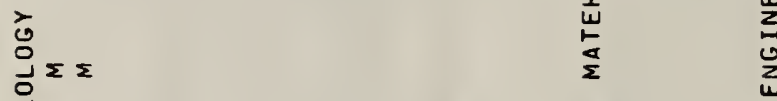

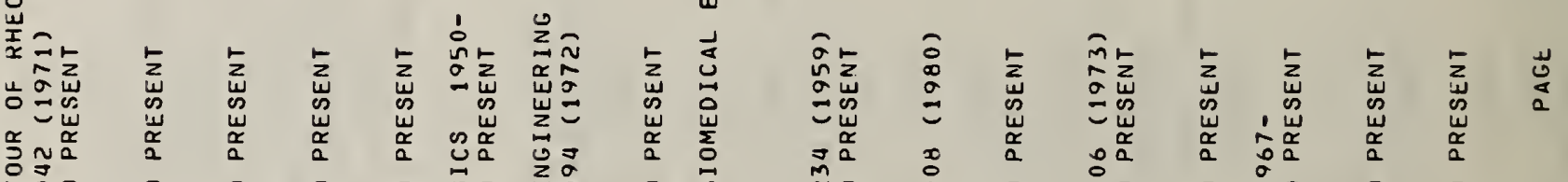

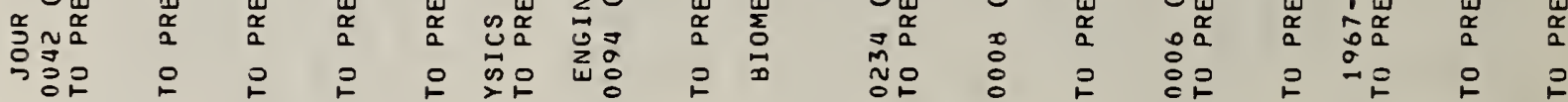

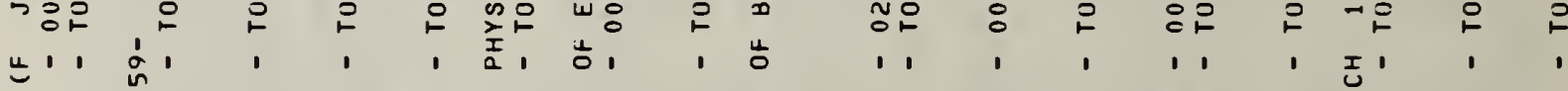

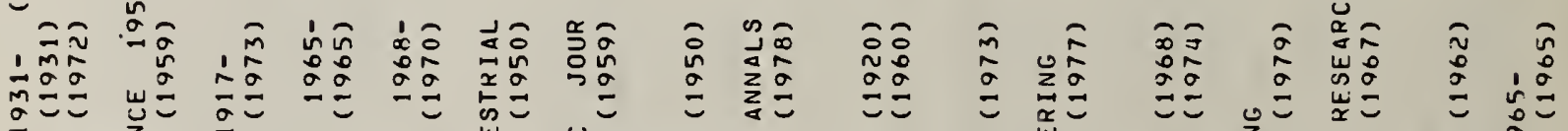

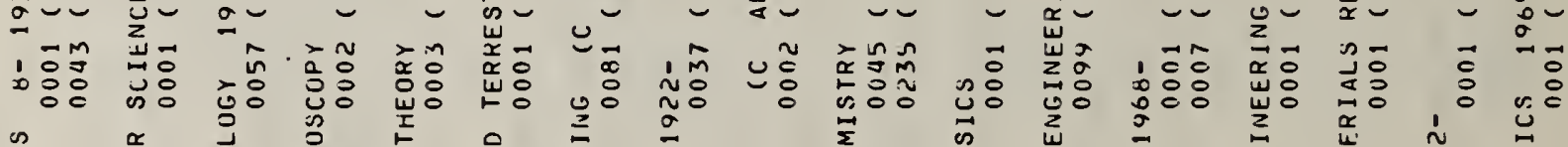

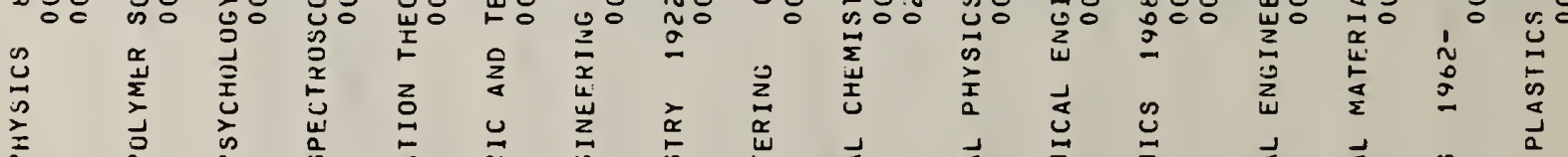

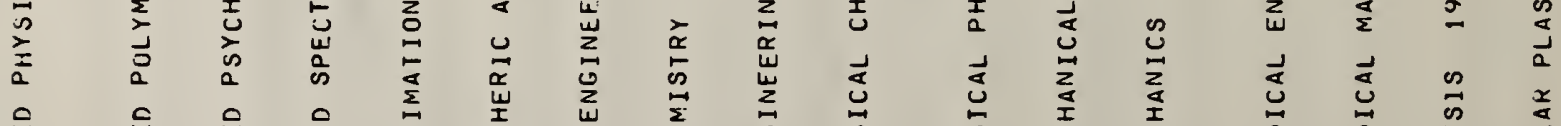

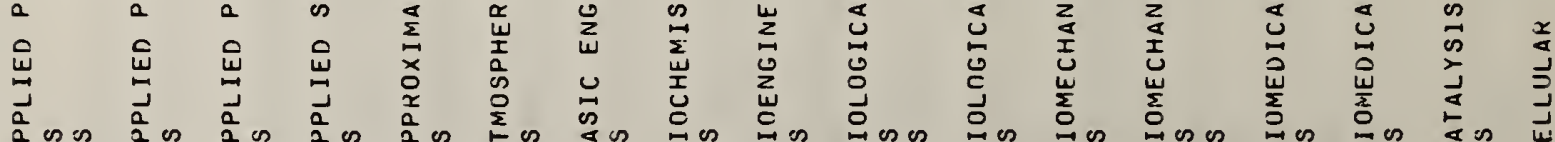

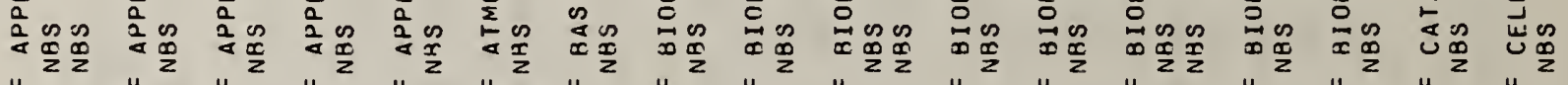
u

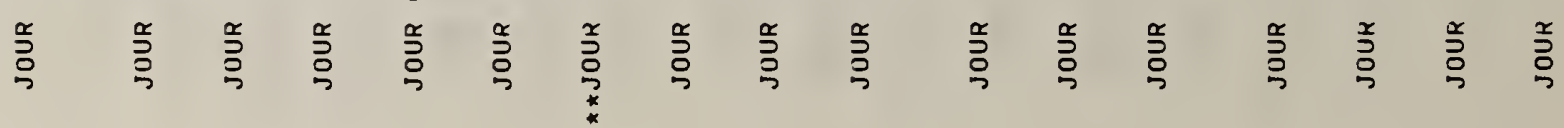


峁

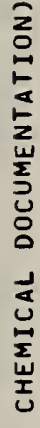

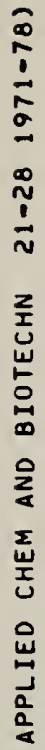

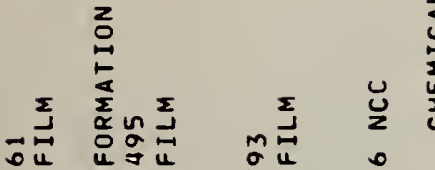

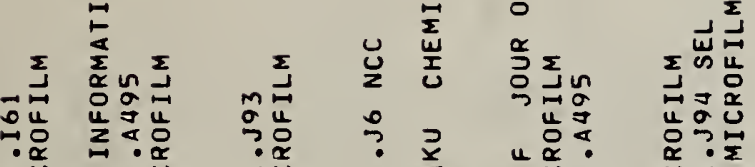

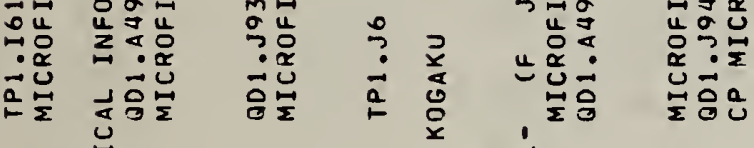

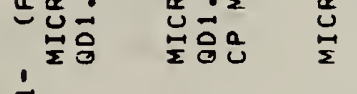

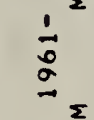

¿
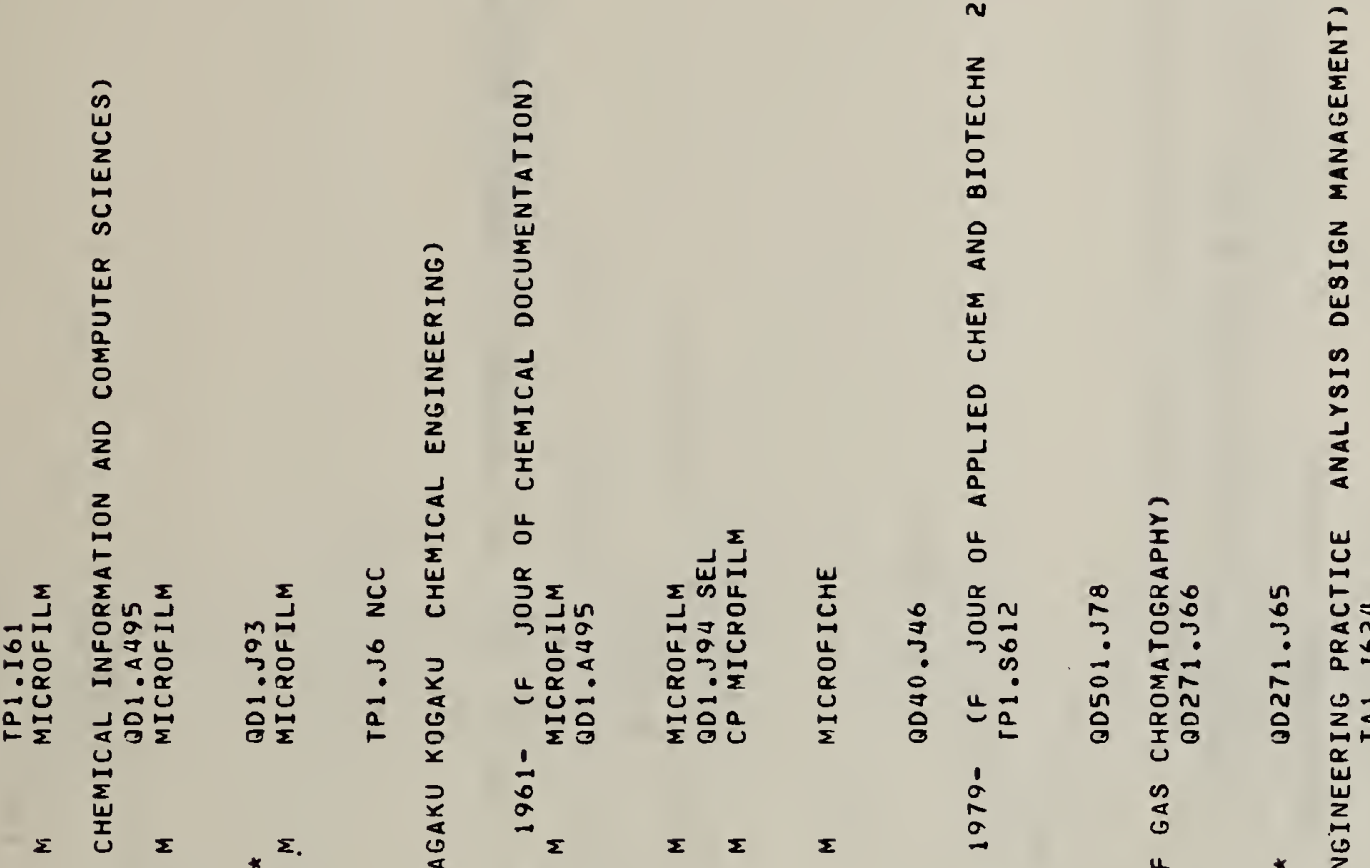

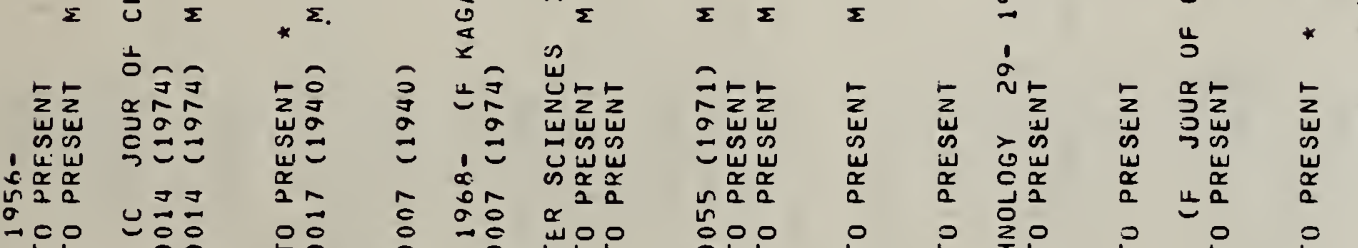

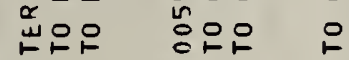

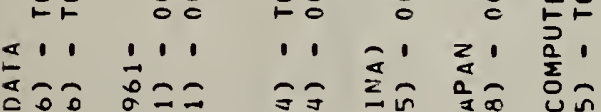

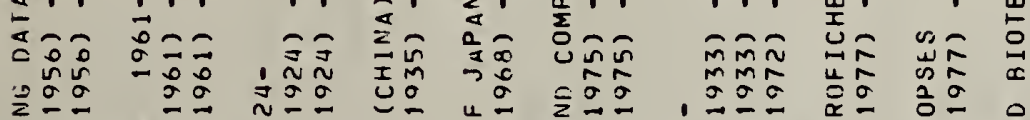

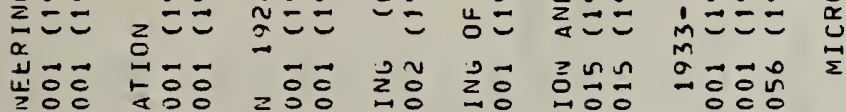

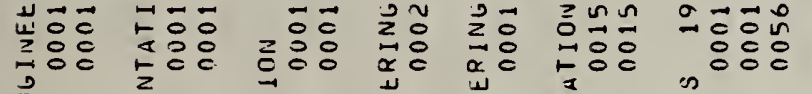

列

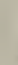

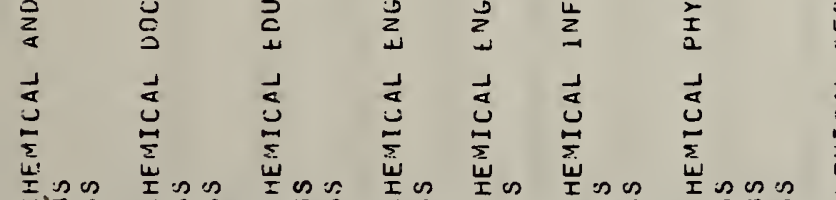

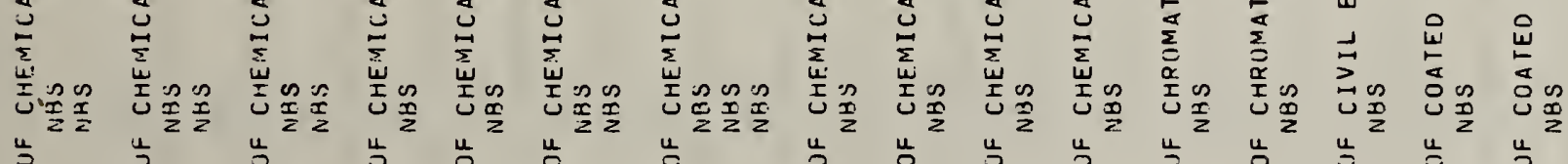

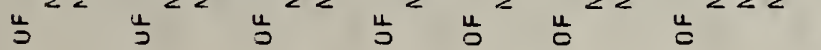

言

言

言

$\stackrel{3}{3}$

言

言

言

ง

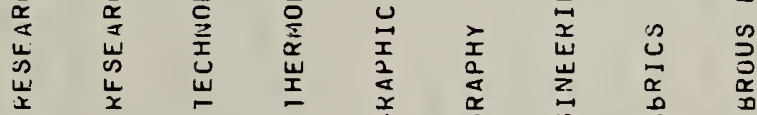

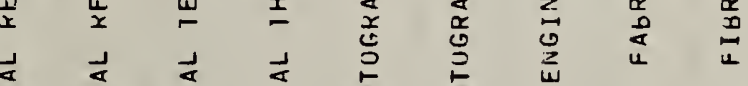




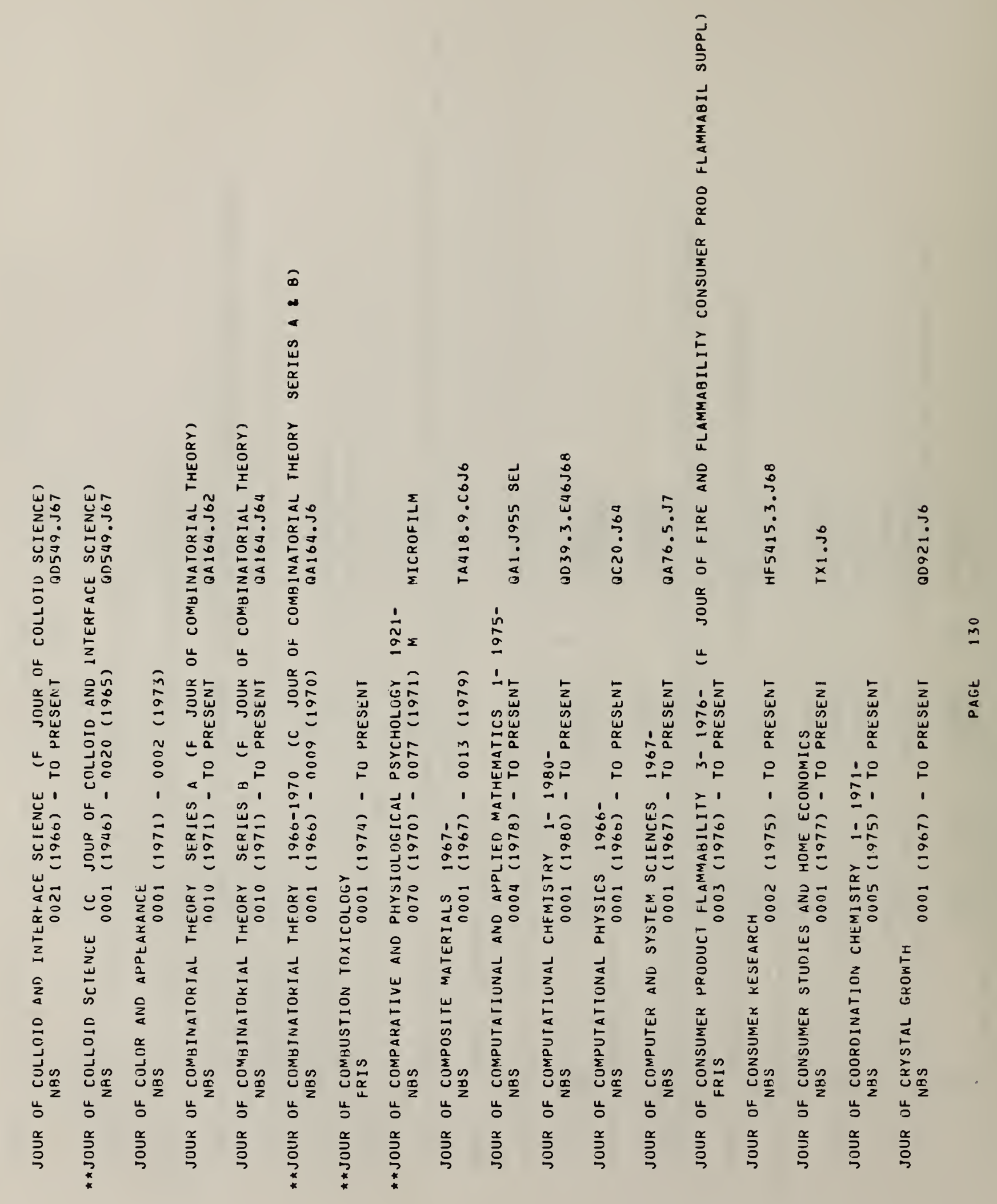




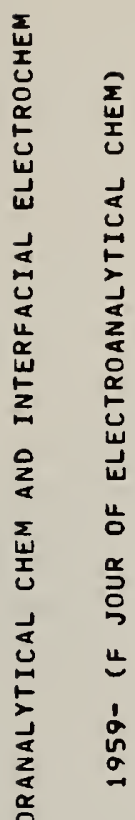

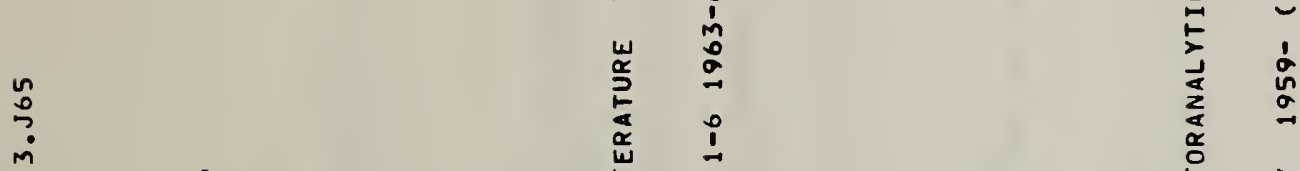

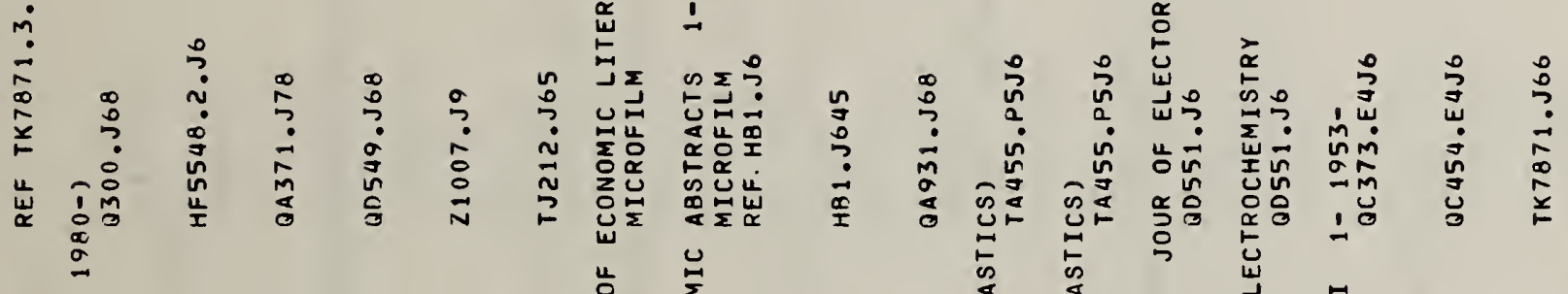

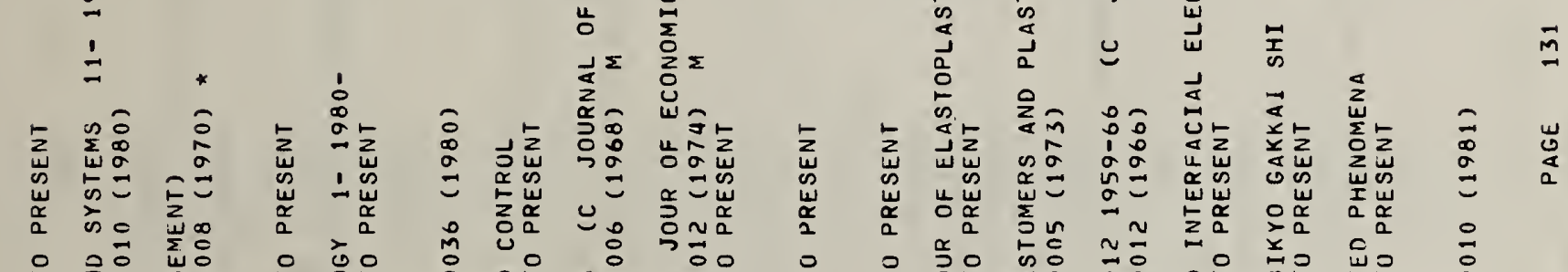

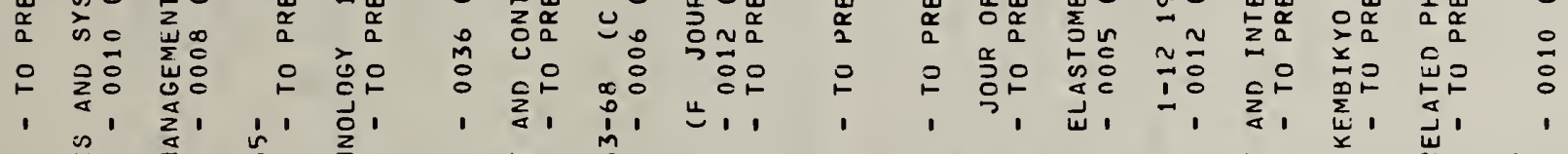

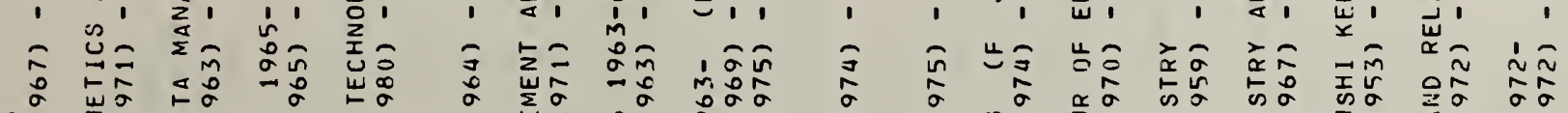

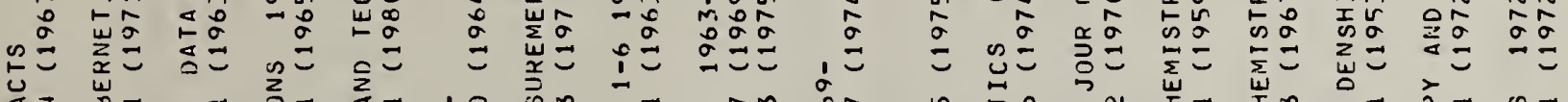

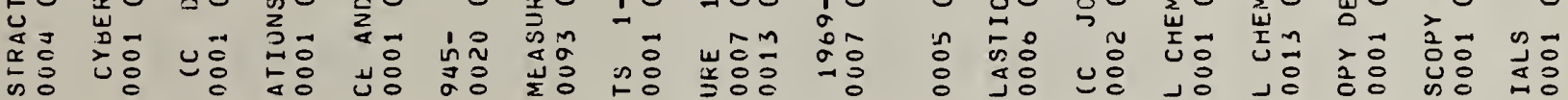

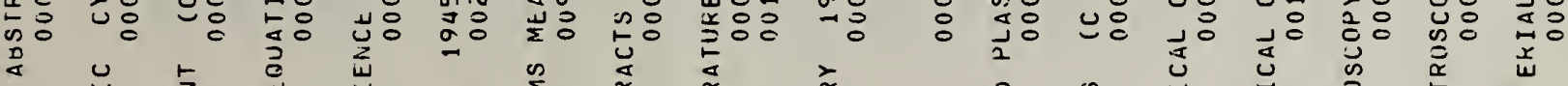

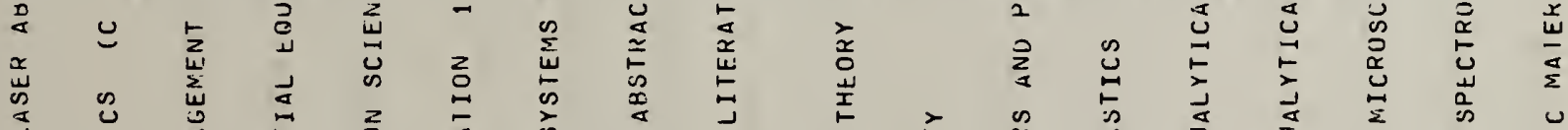

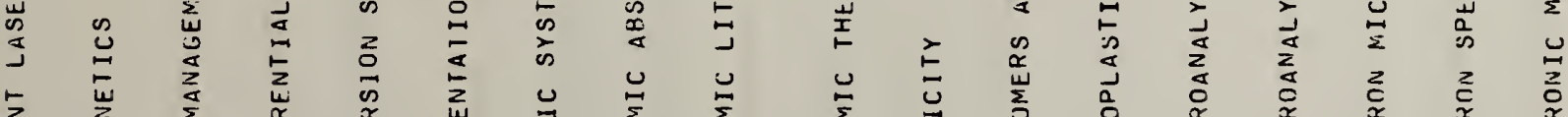

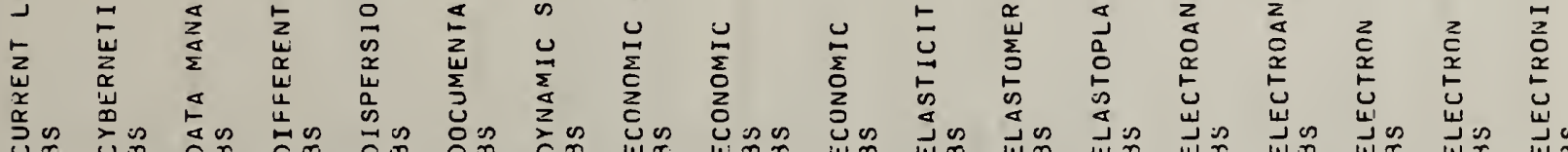

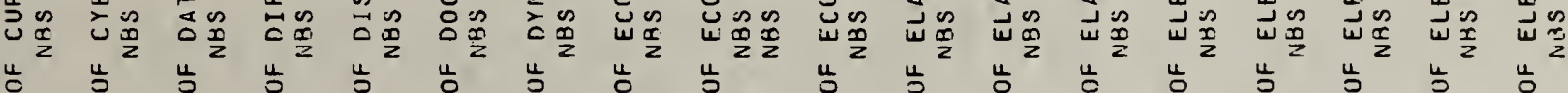

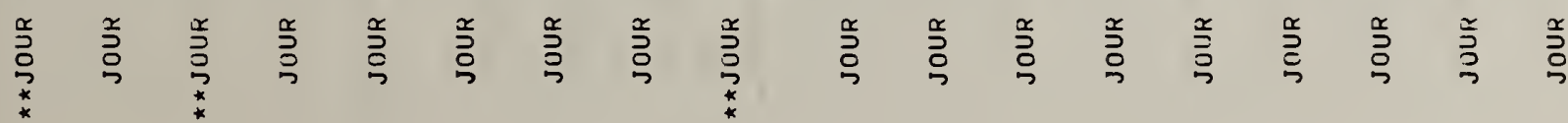




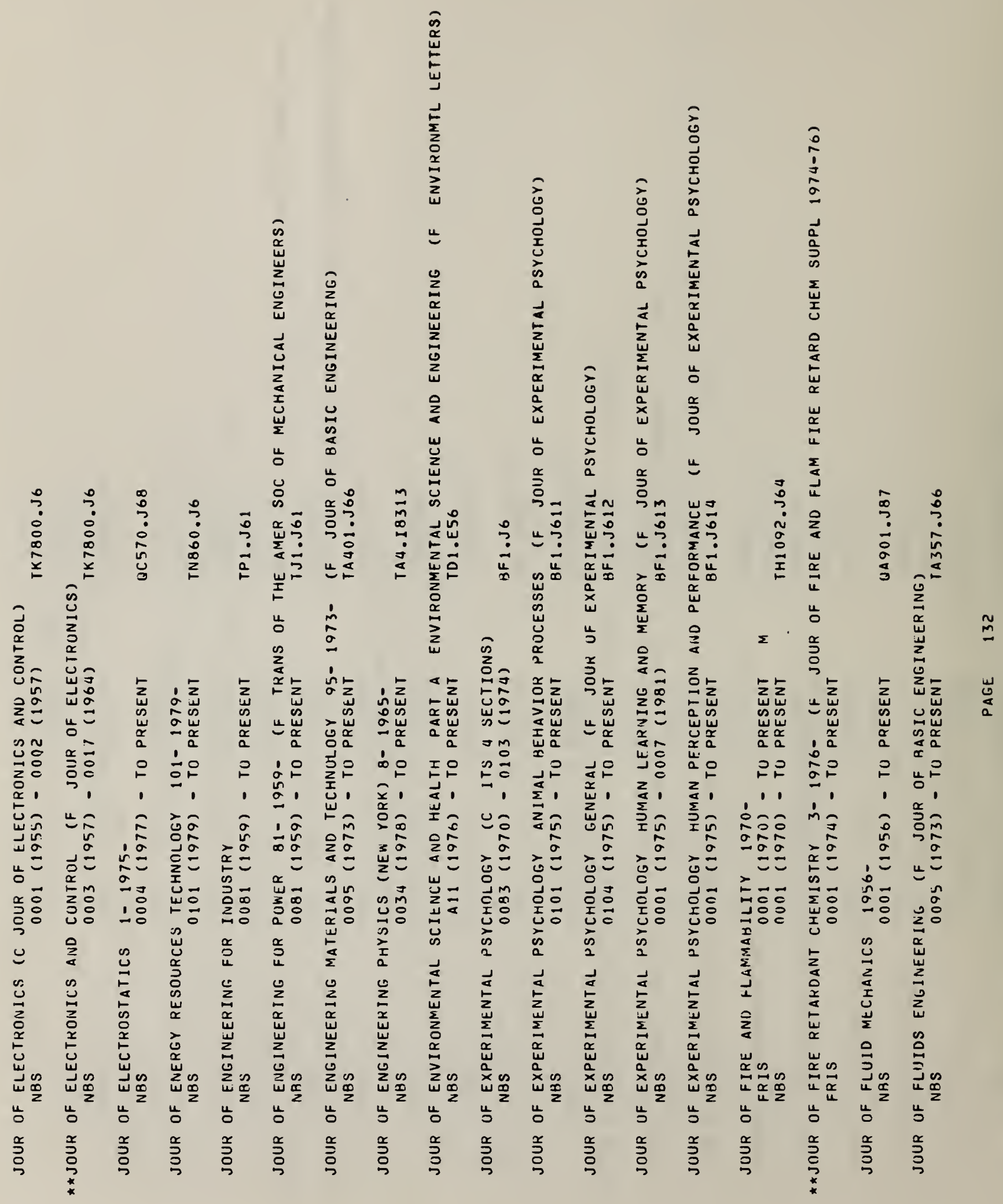




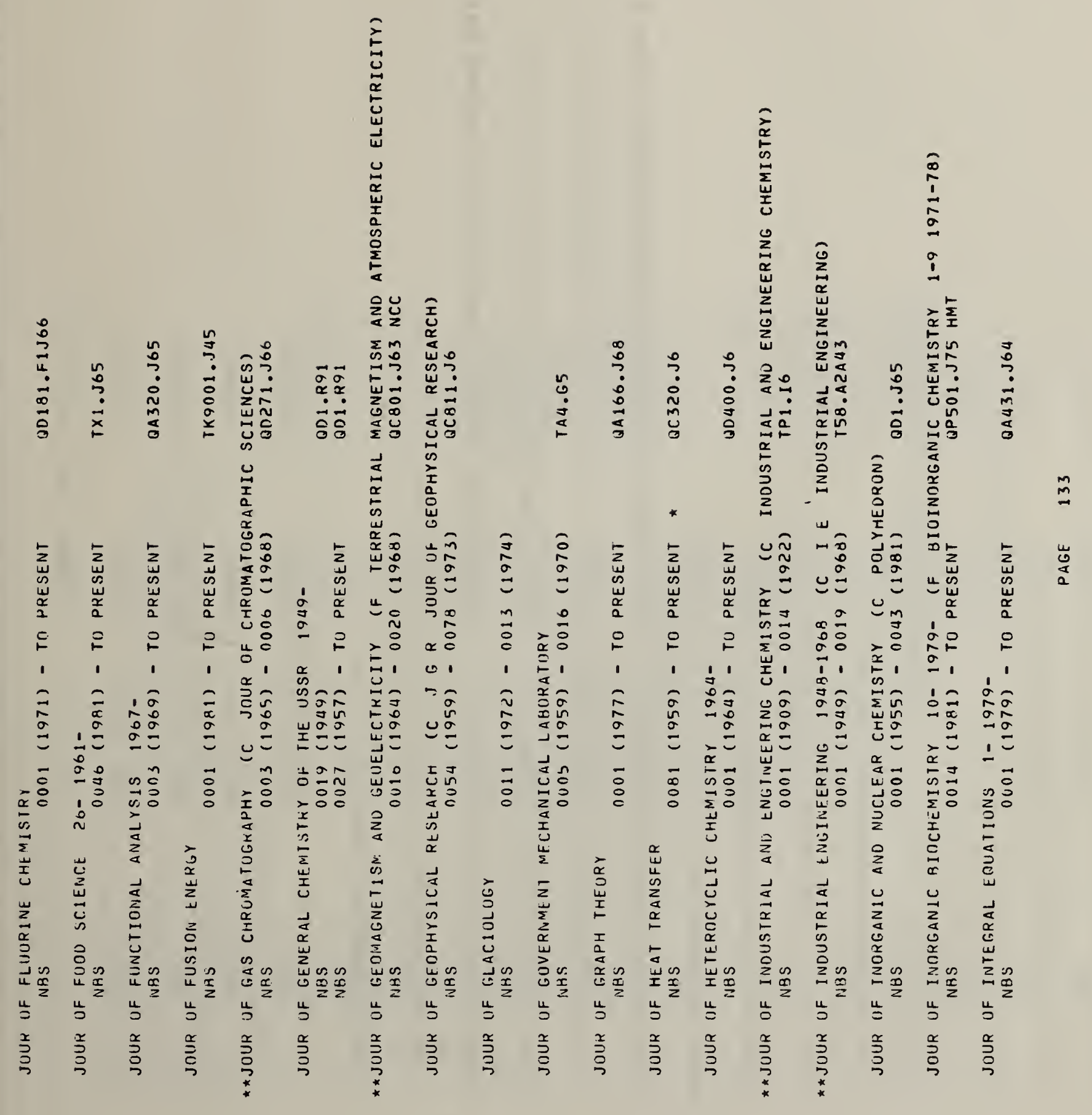




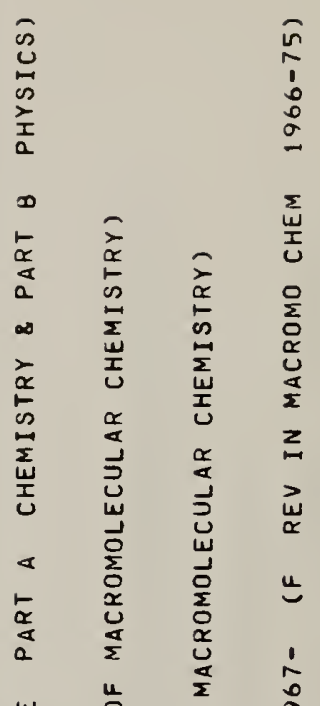

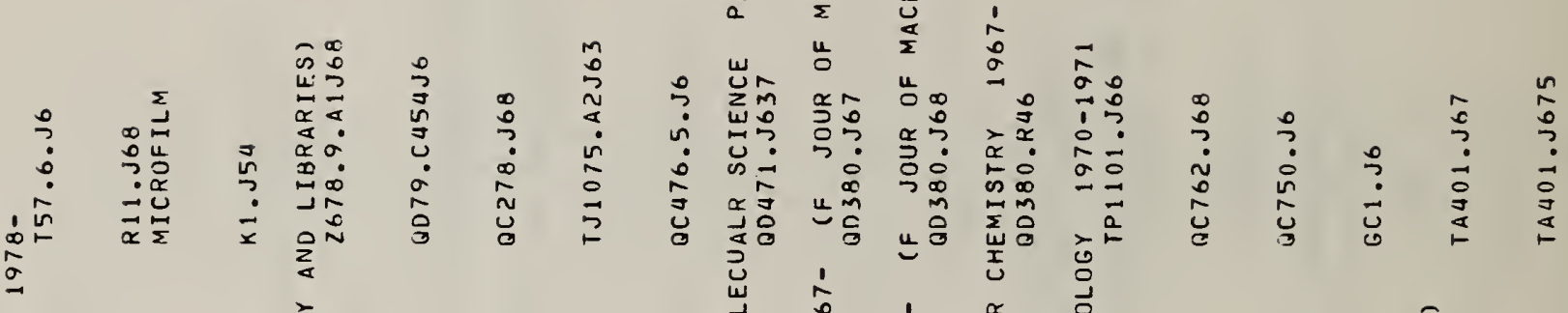

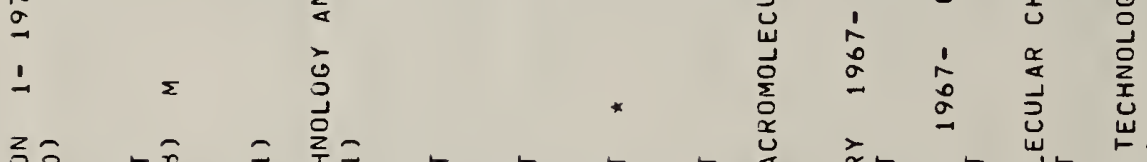

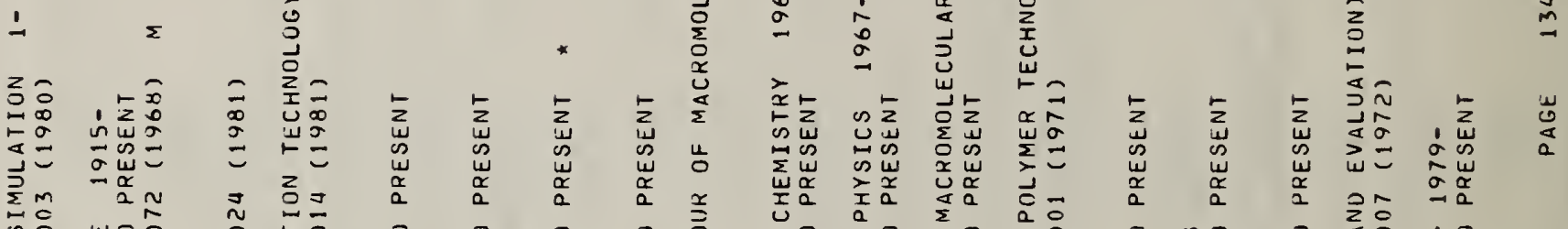

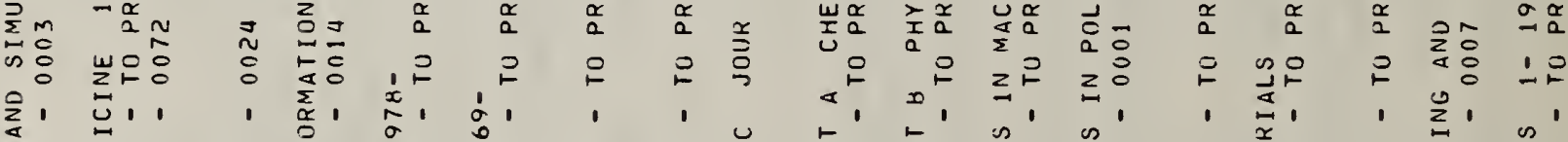

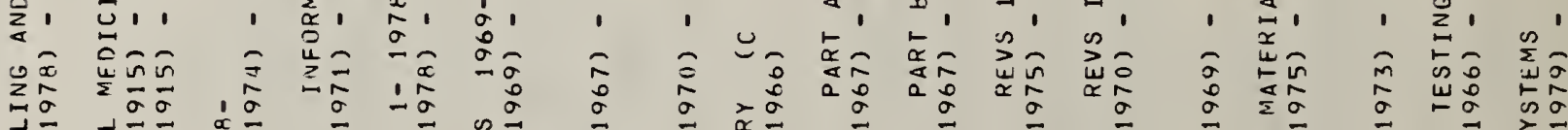

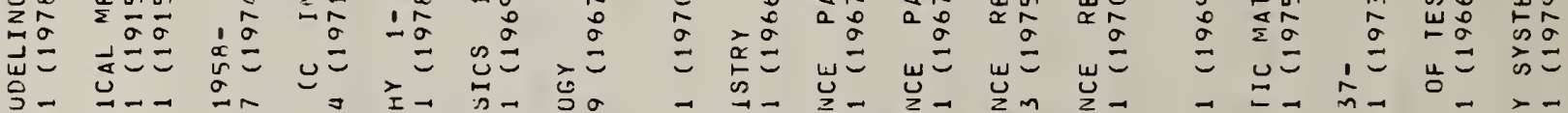

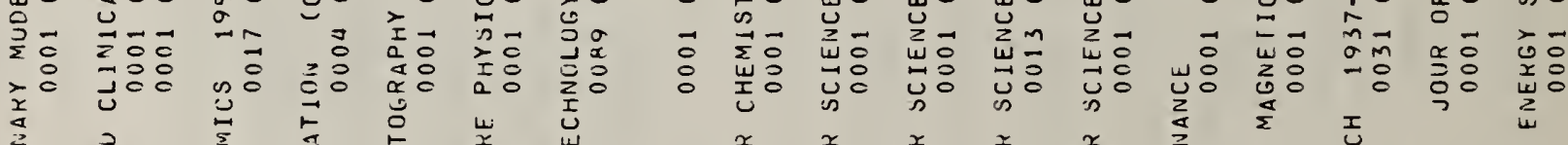

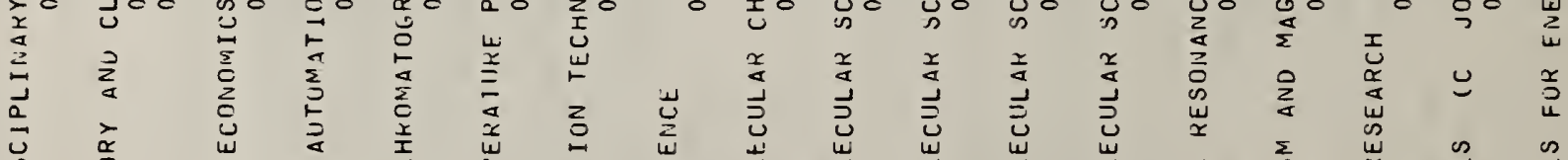

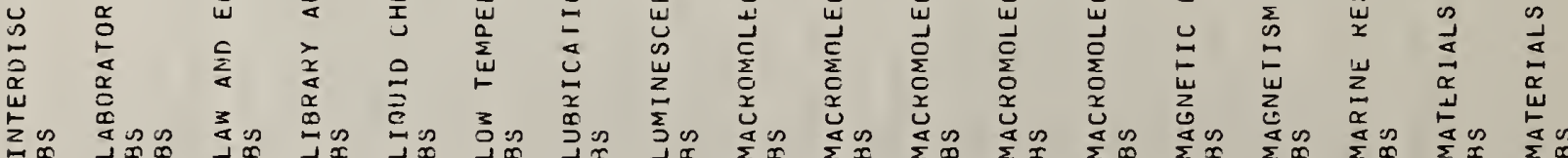

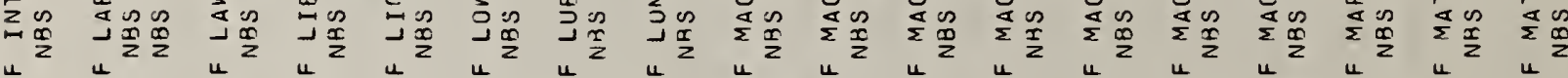

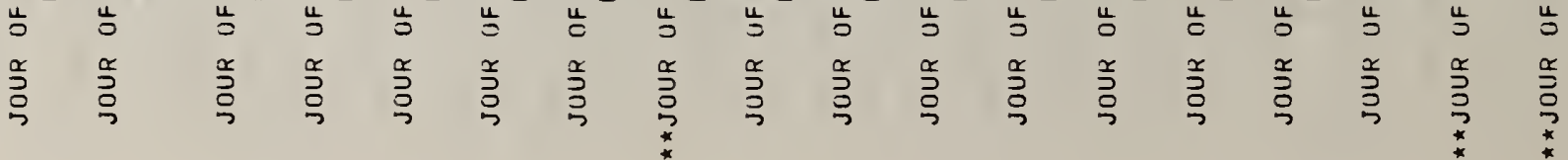




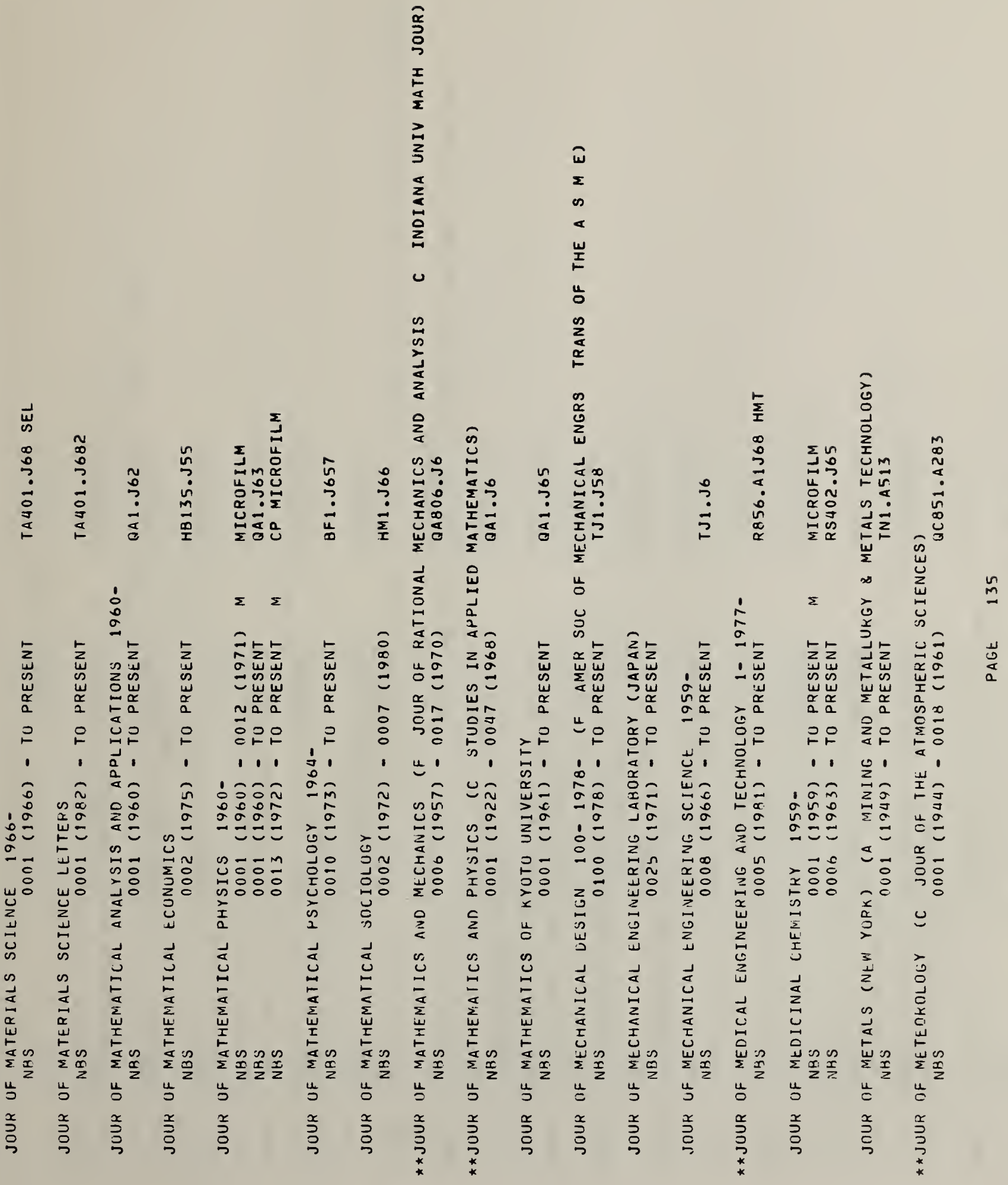




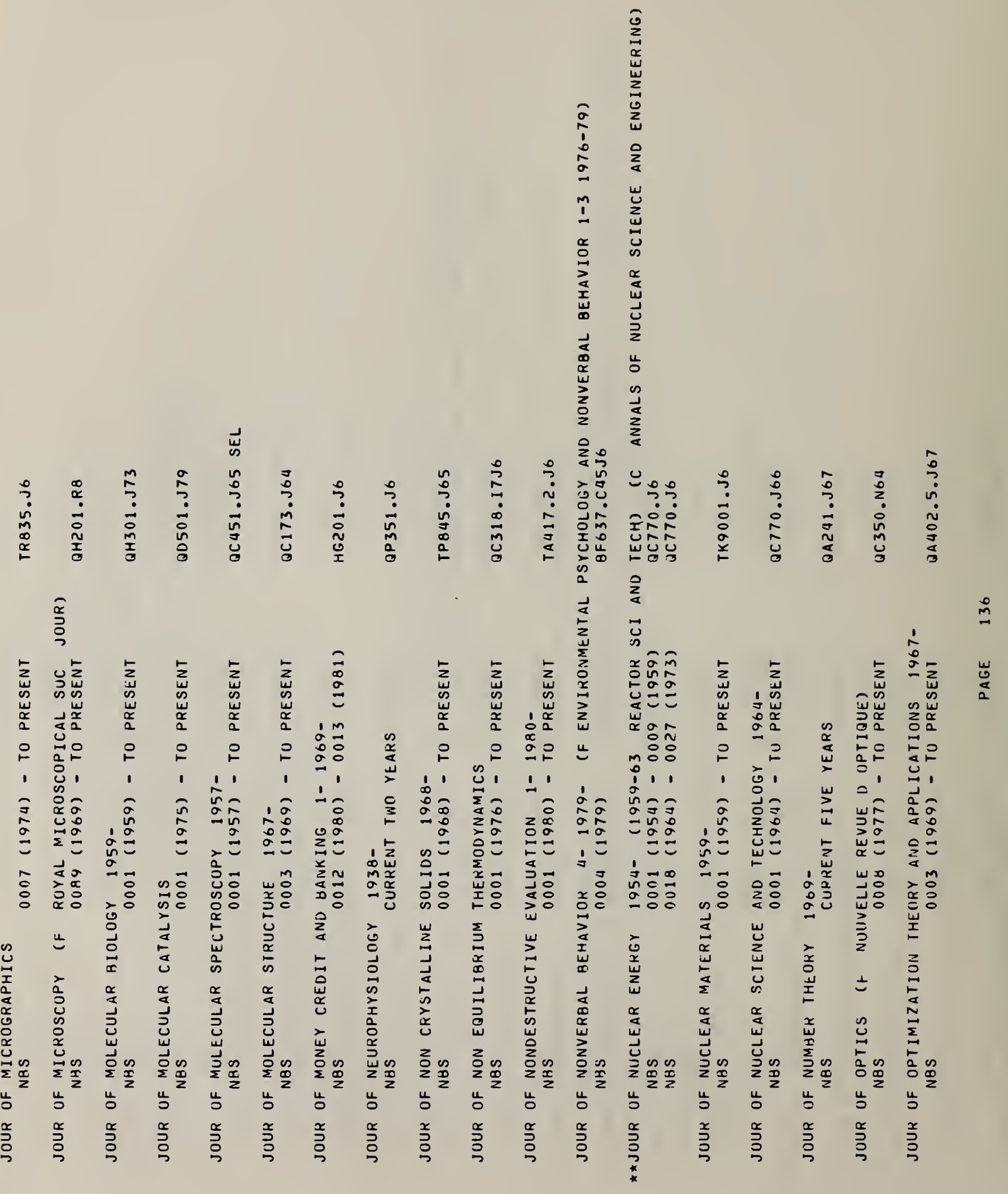




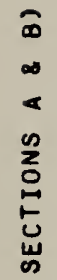

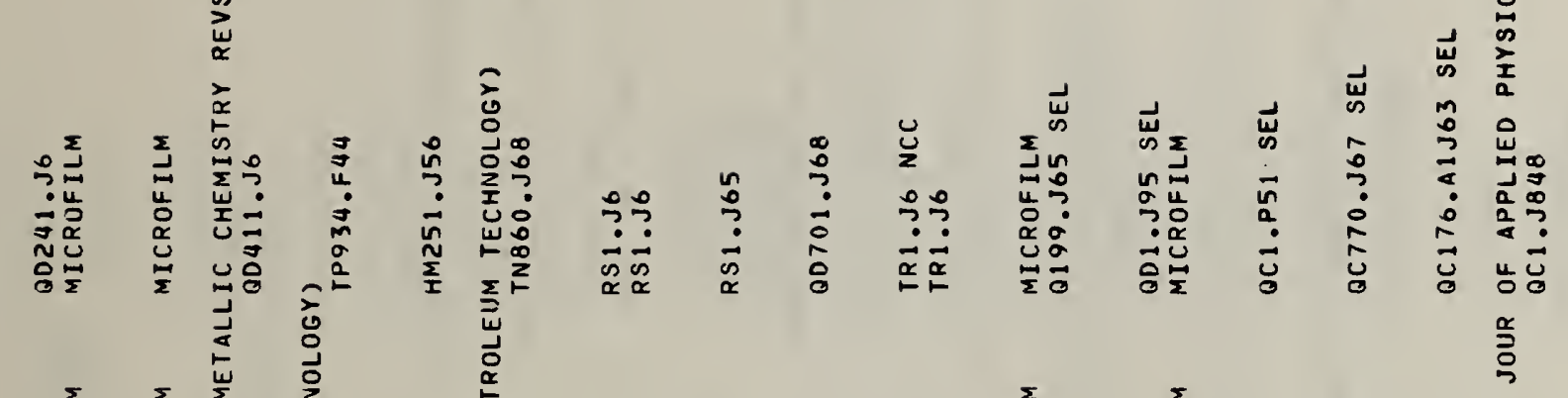

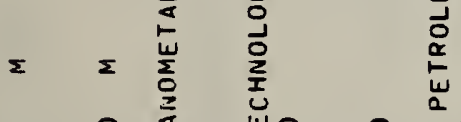

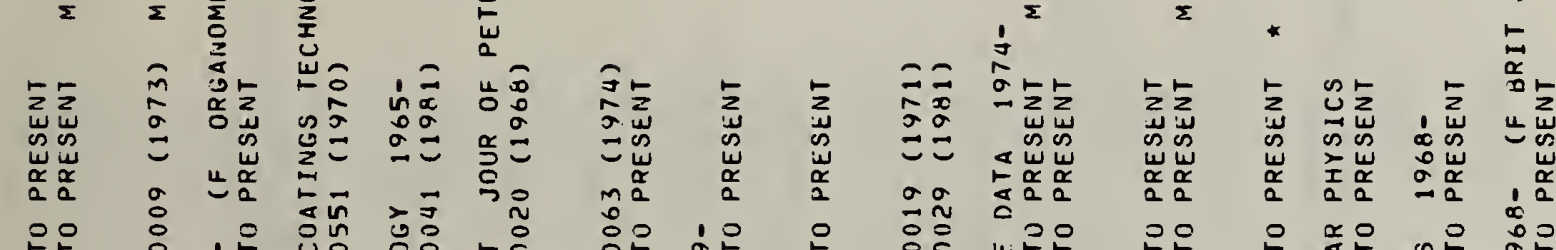

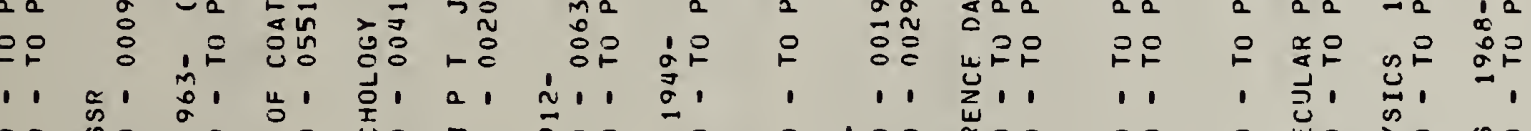
วิํํำ

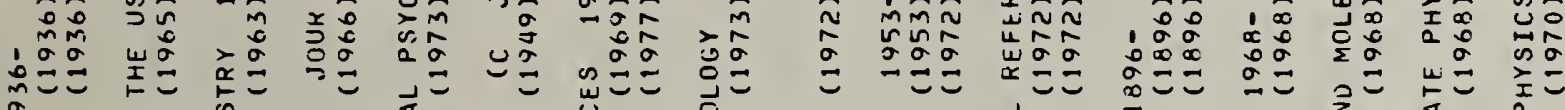

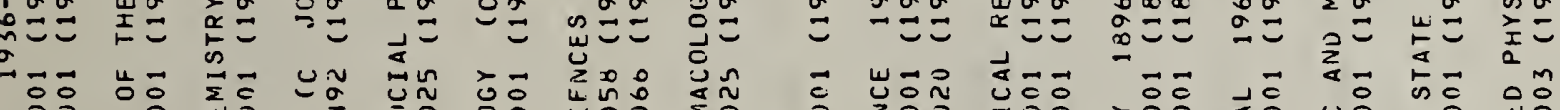

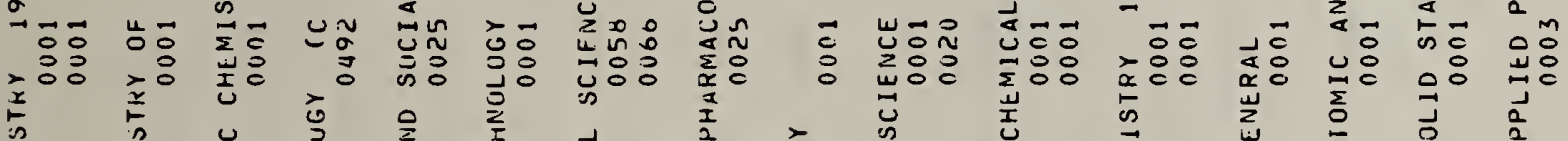

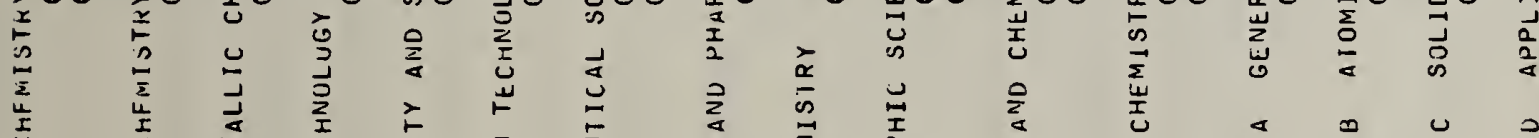

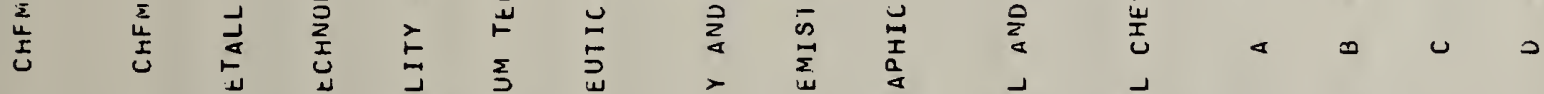

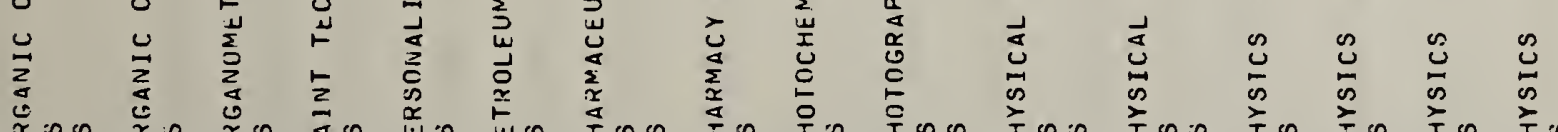

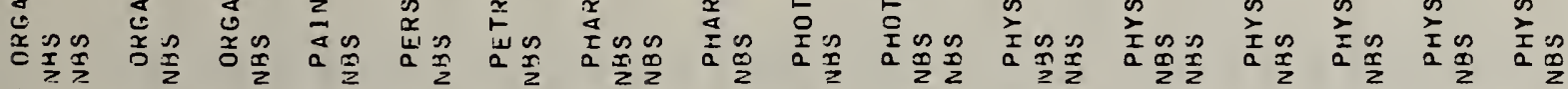

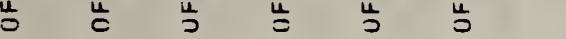
$\stackrel{x}{3} \stackrel{x}{3}$

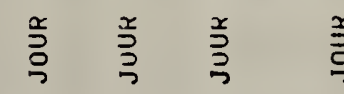

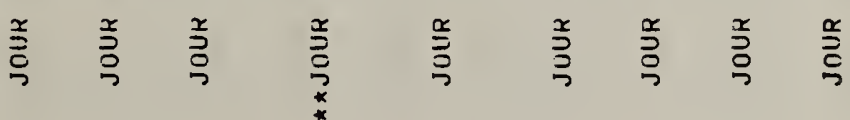


เ

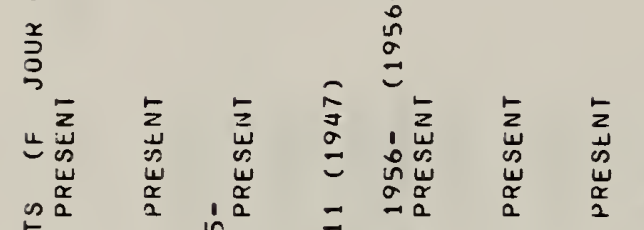
产

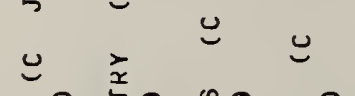

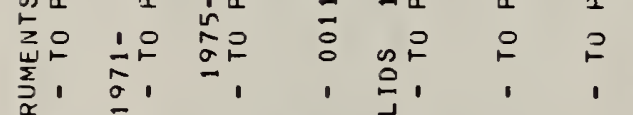

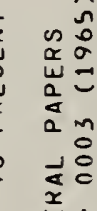

ก

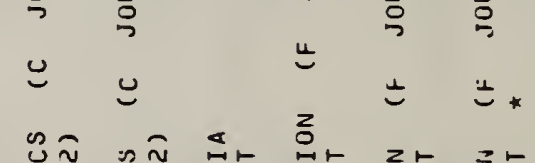

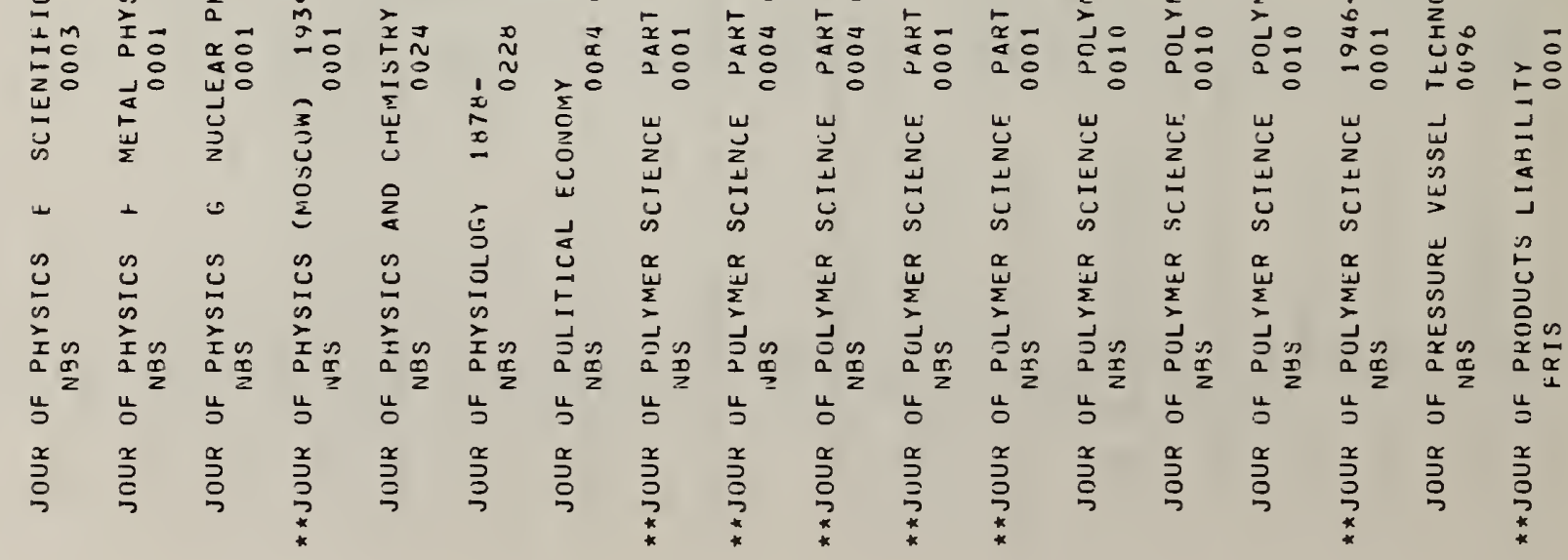




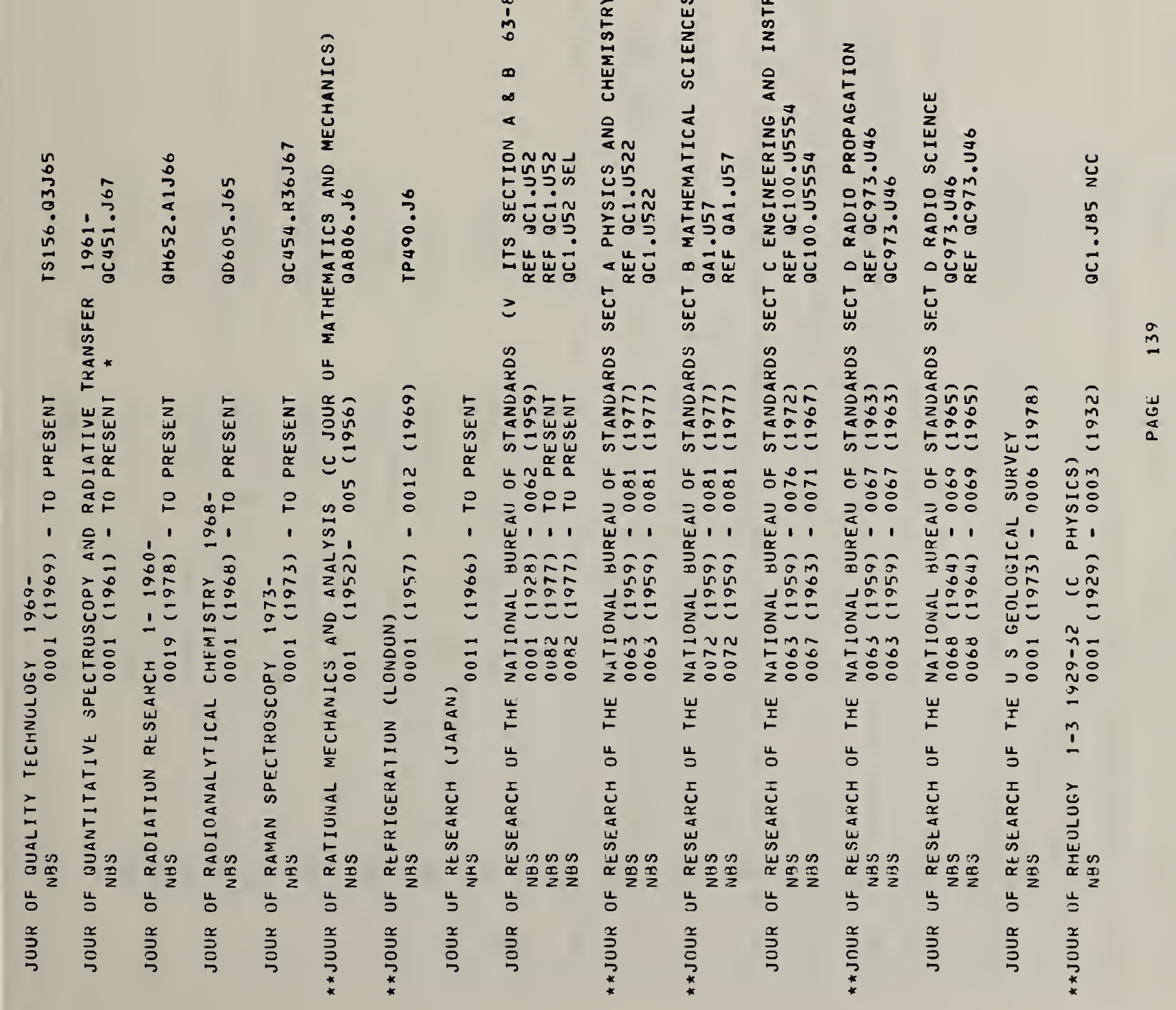




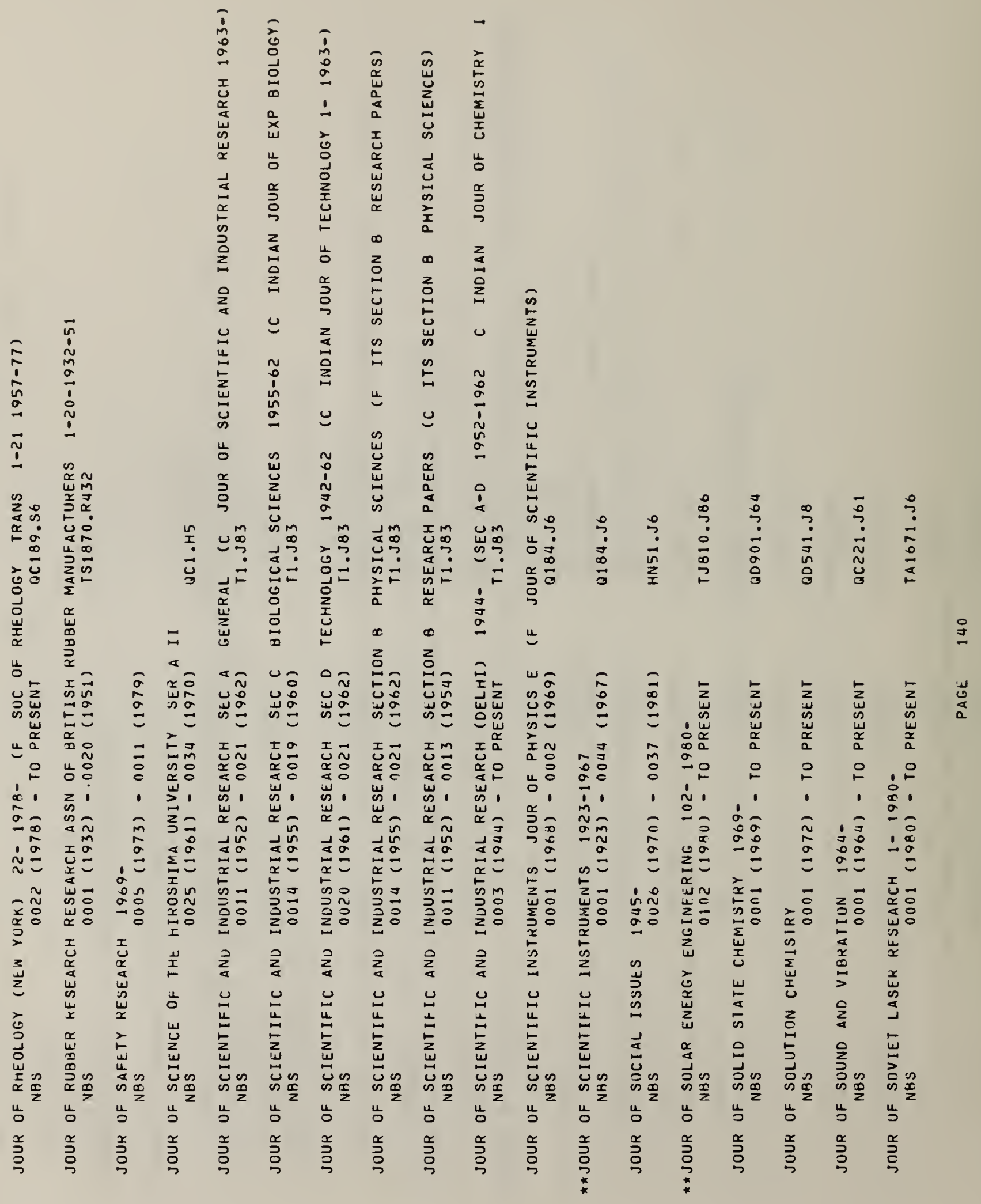




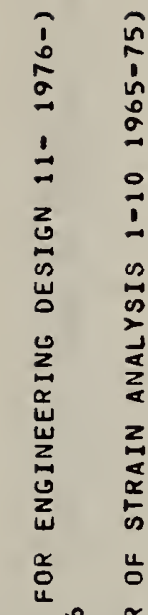

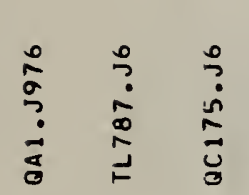

แ。

年

禁变此

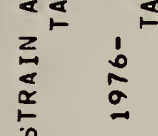

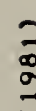

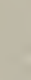

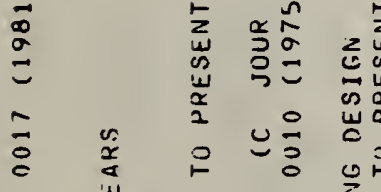

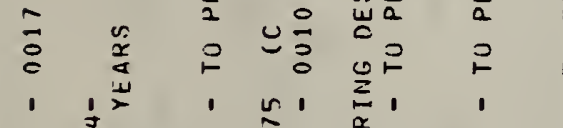

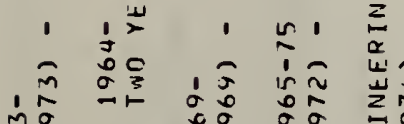

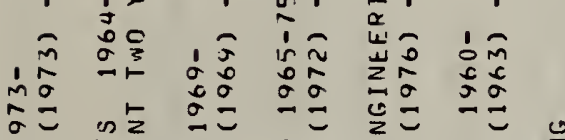

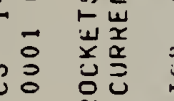

(1)

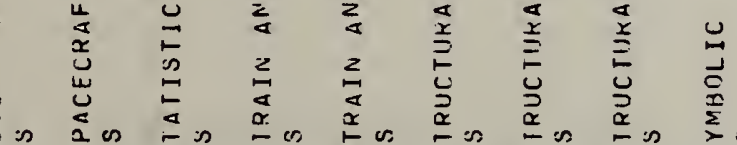

赔

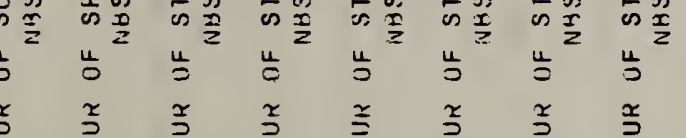

管 


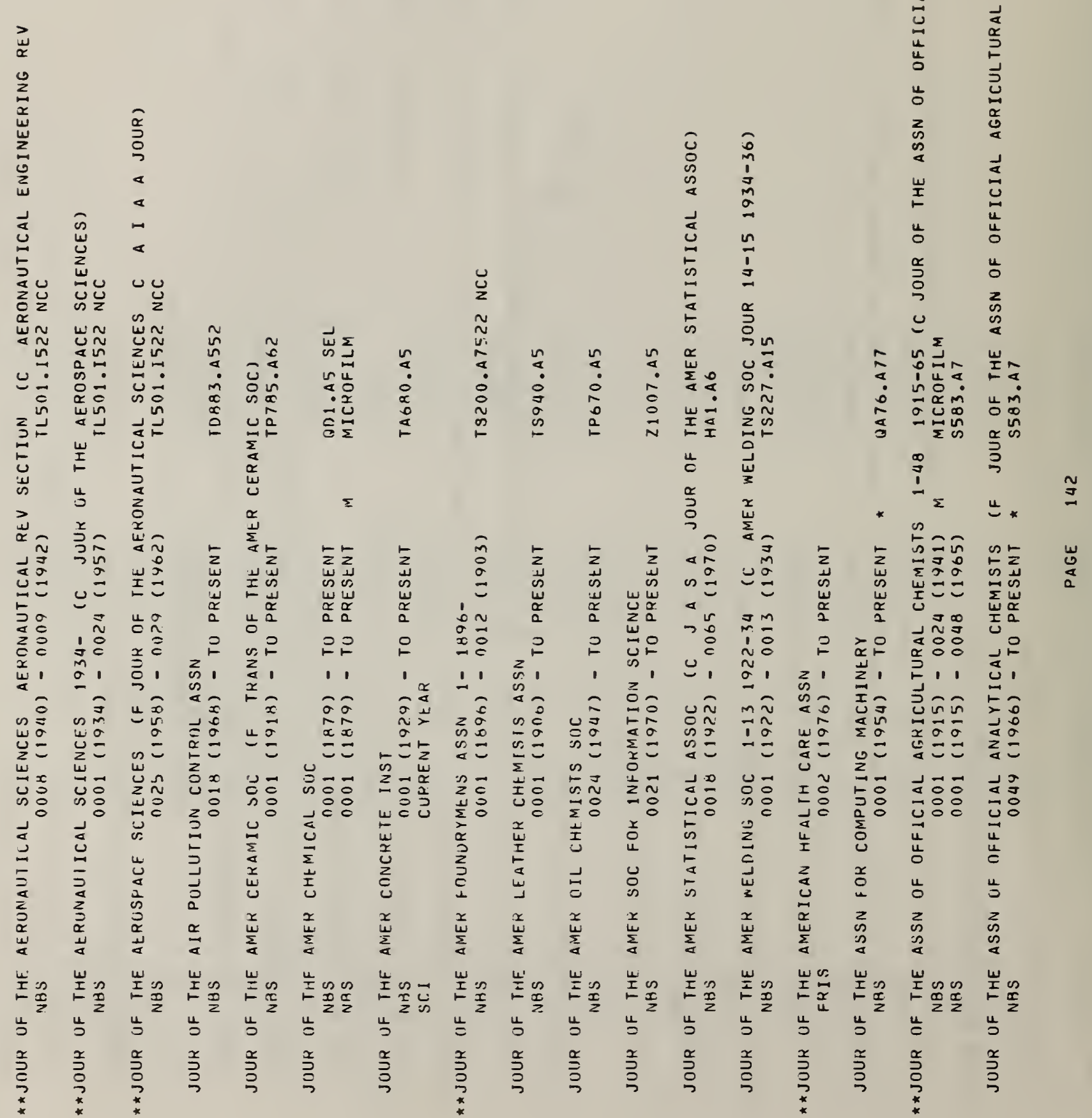




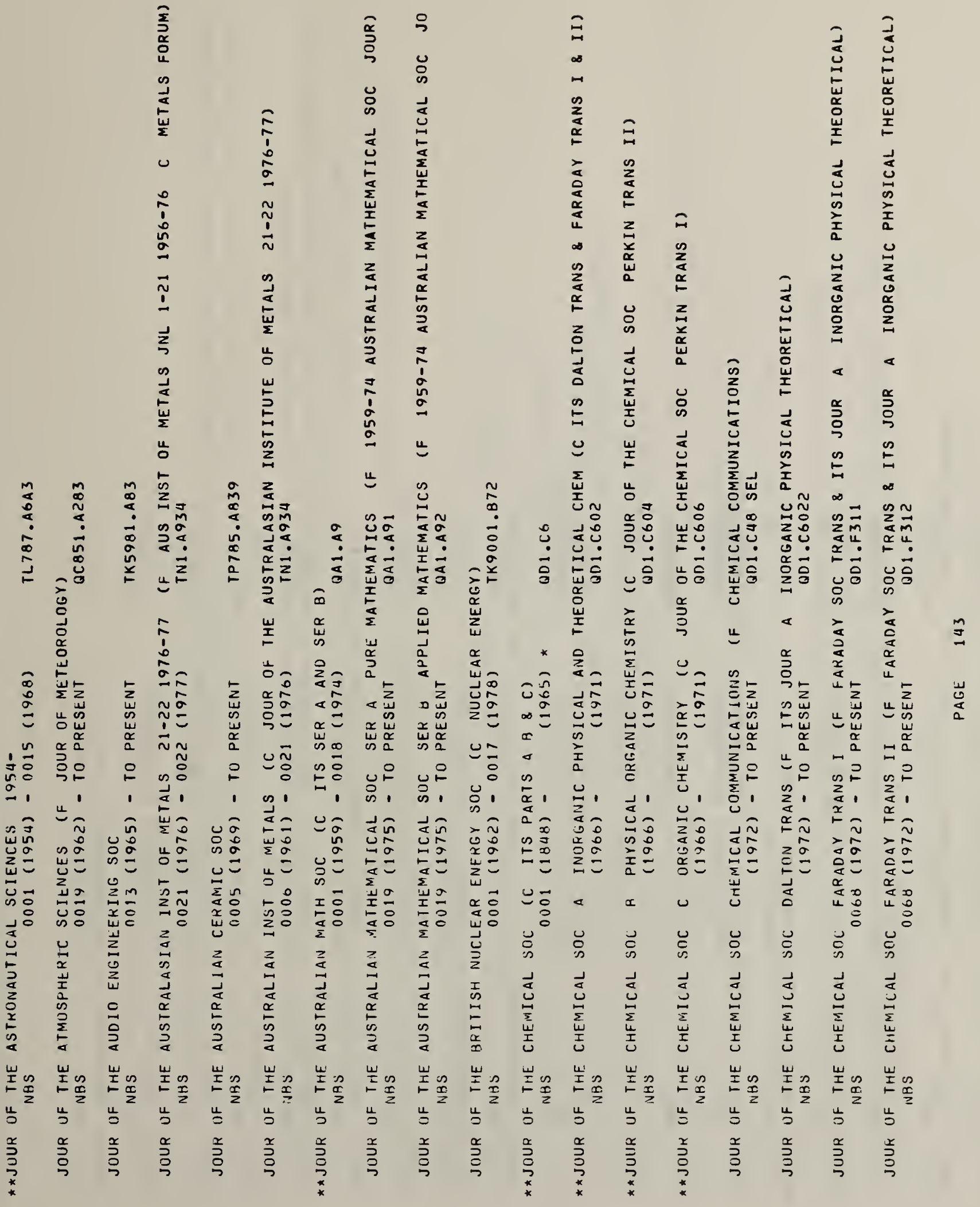




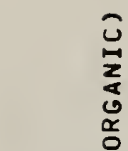

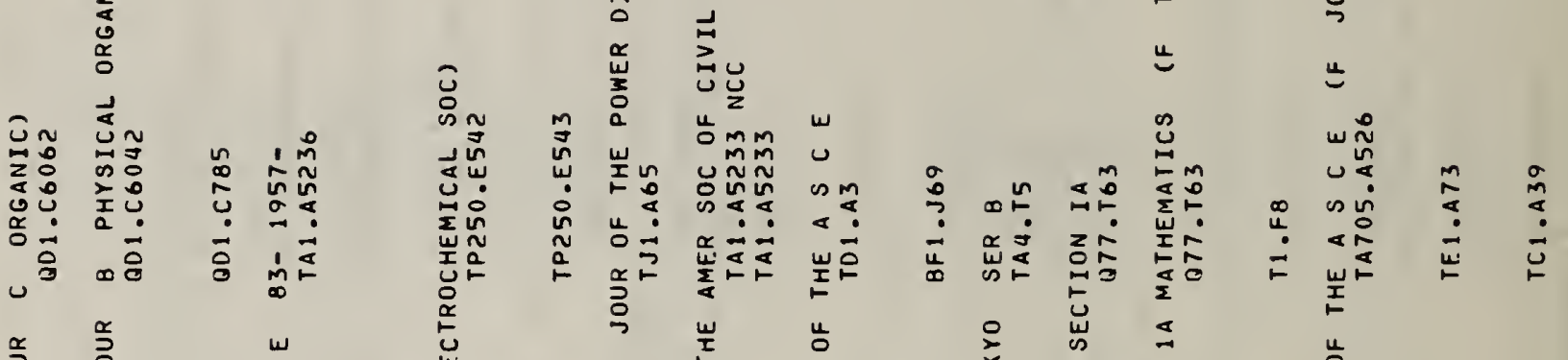

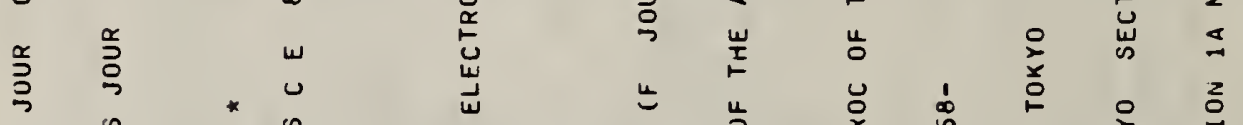

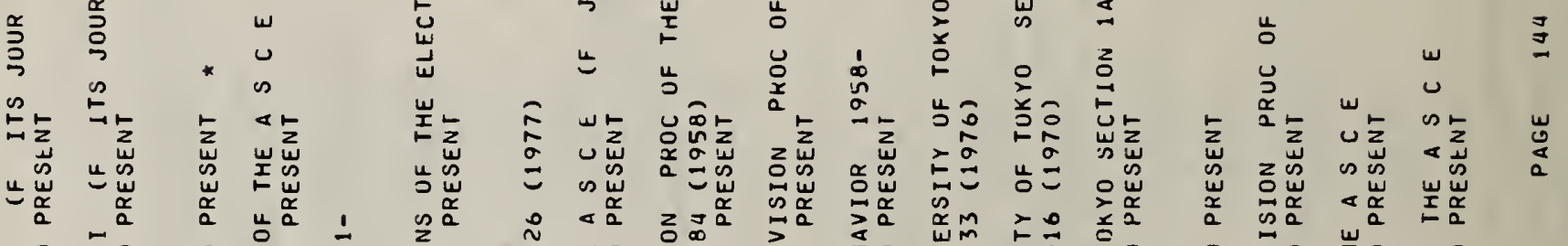

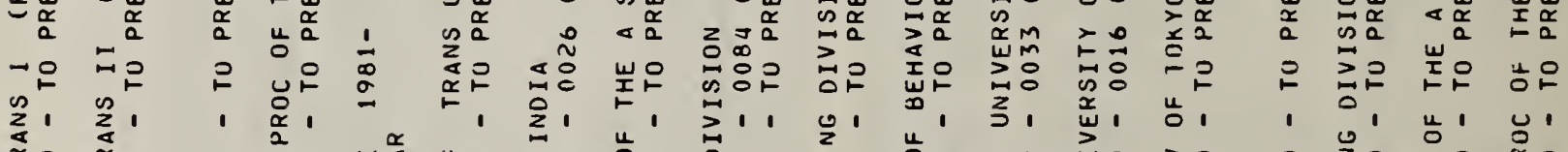

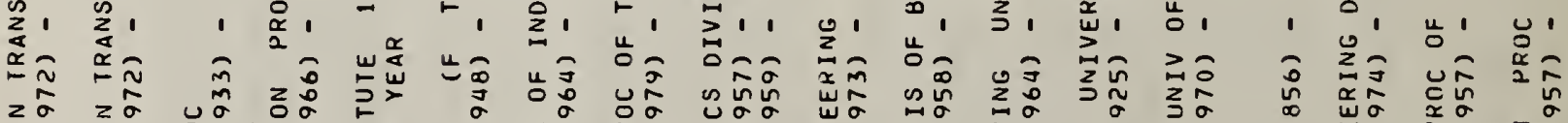

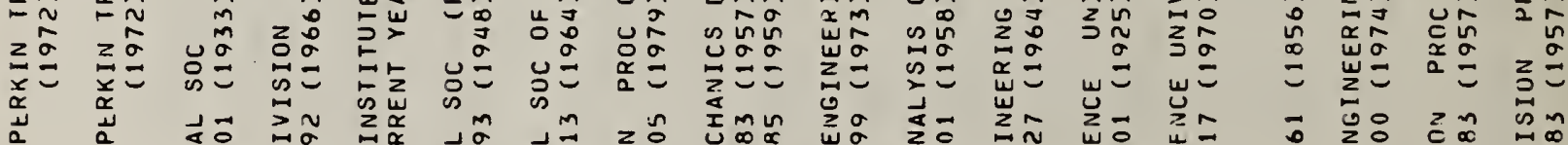

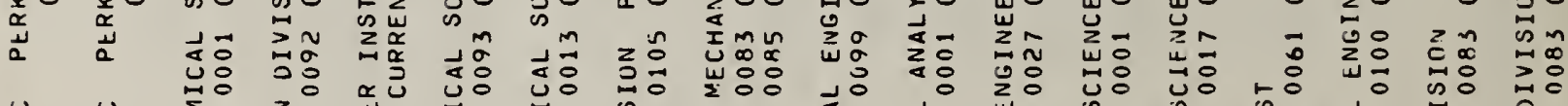

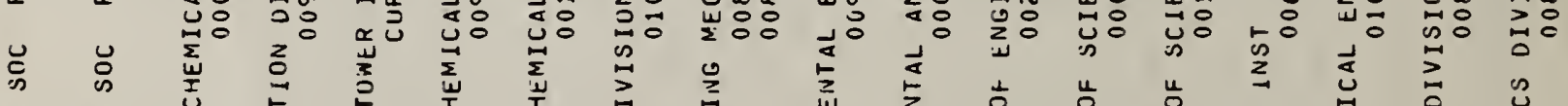

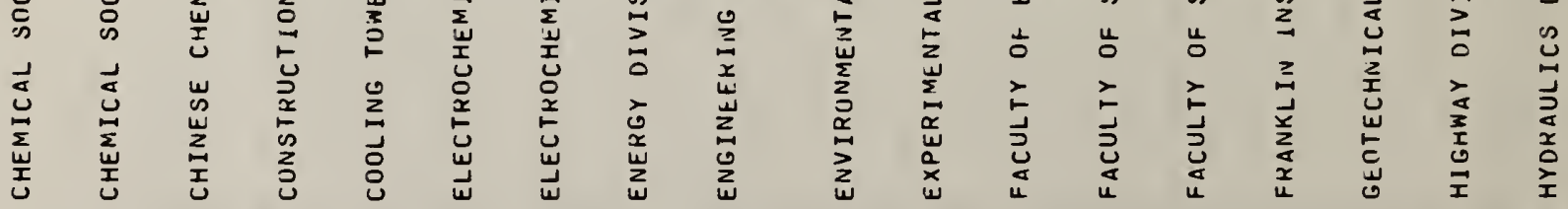

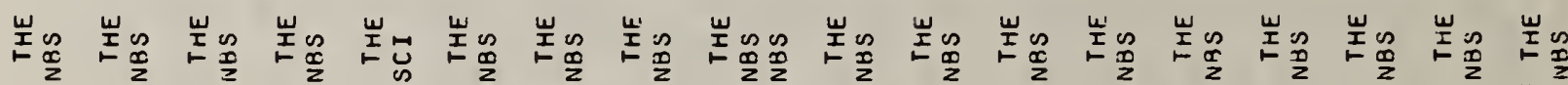

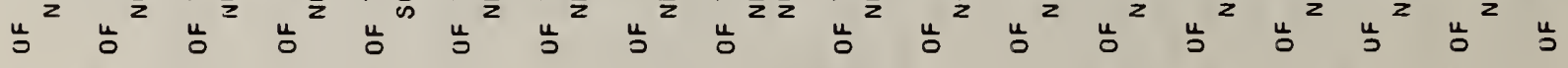

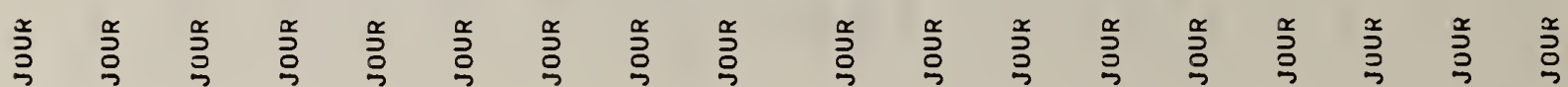




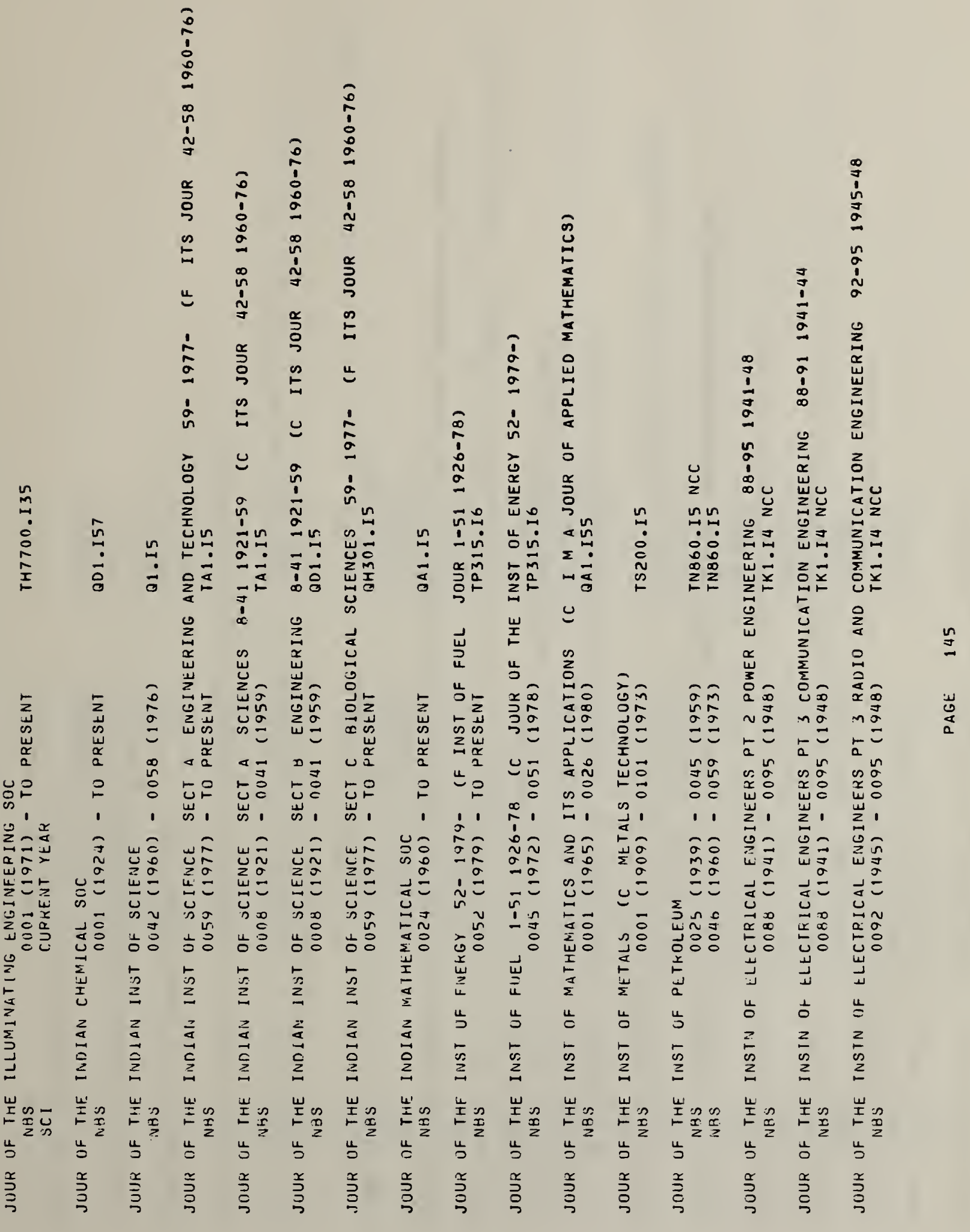




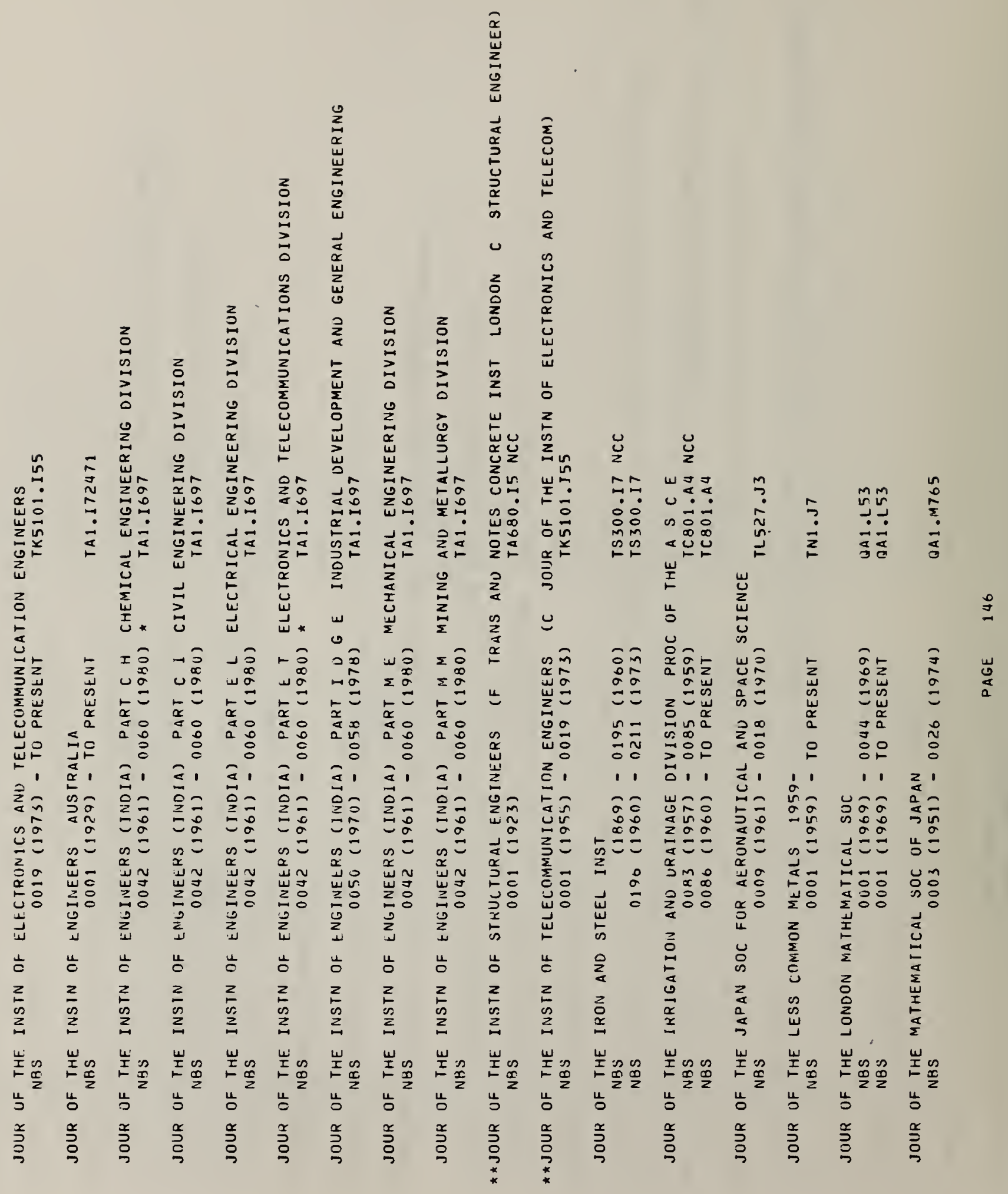




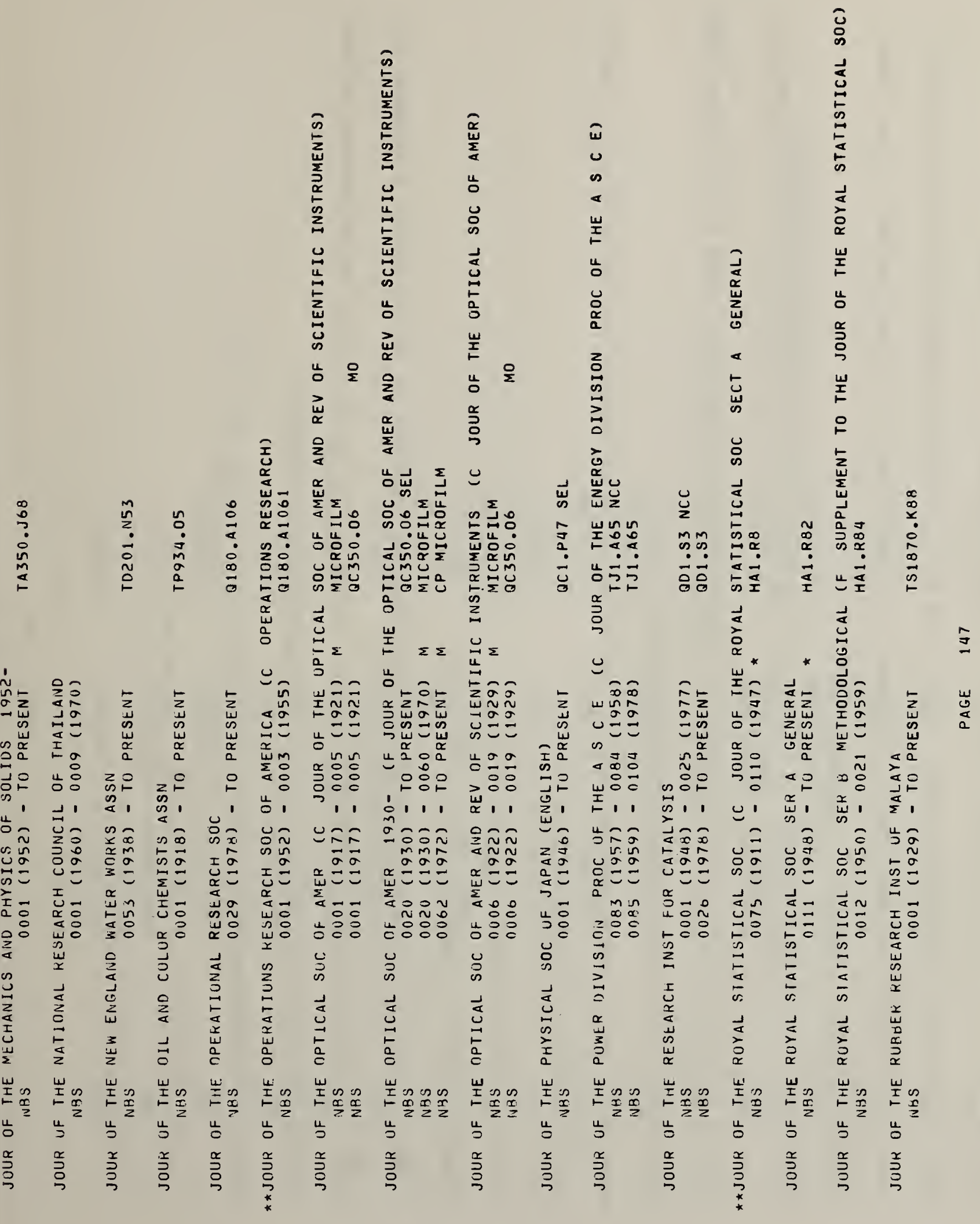




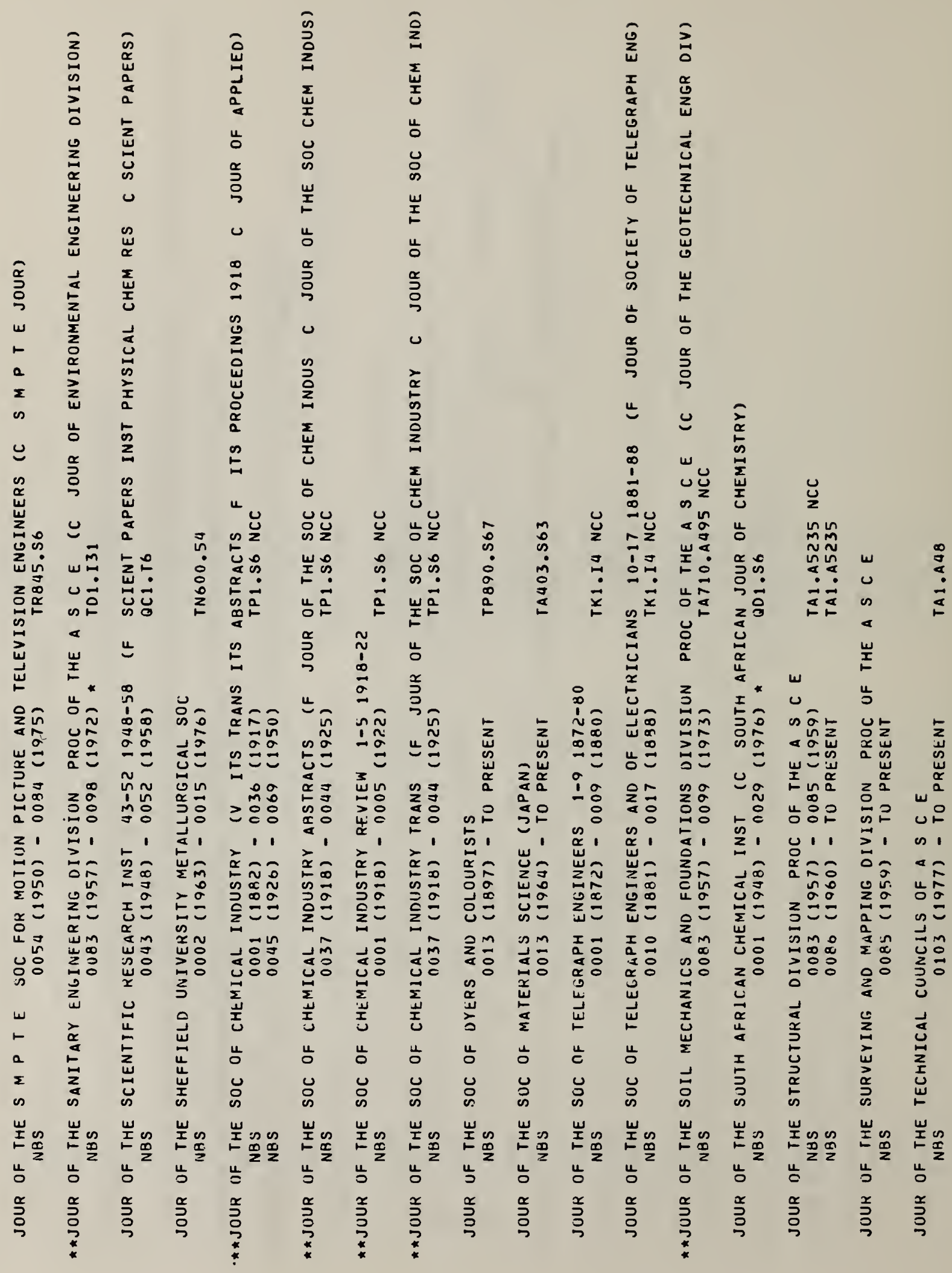




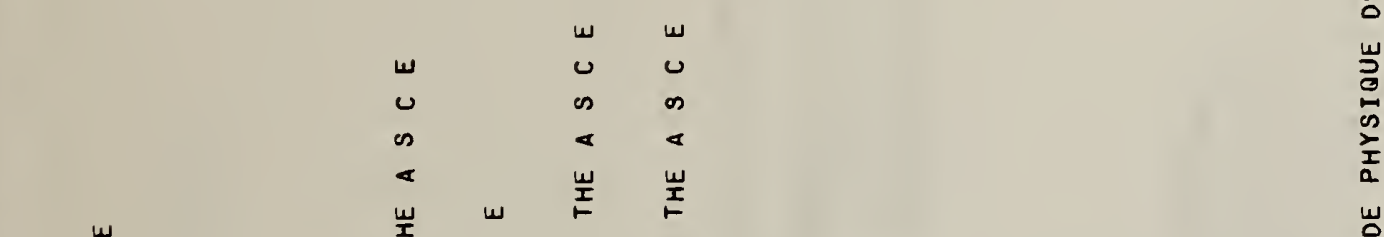

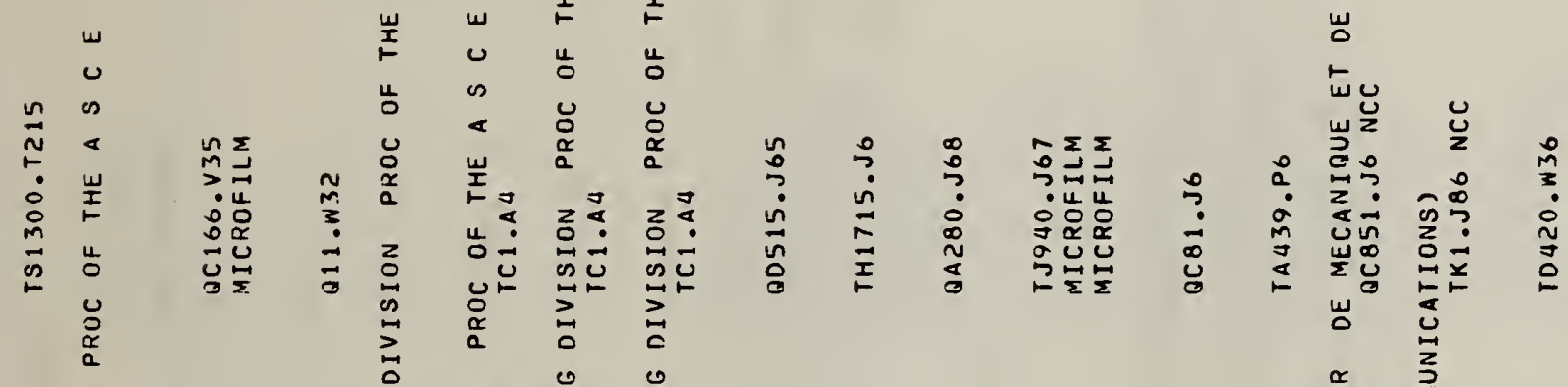

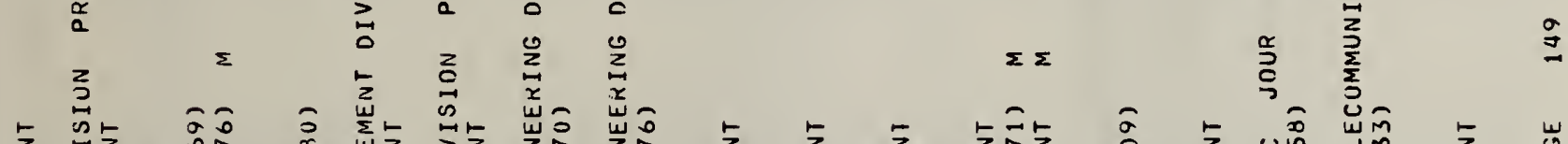

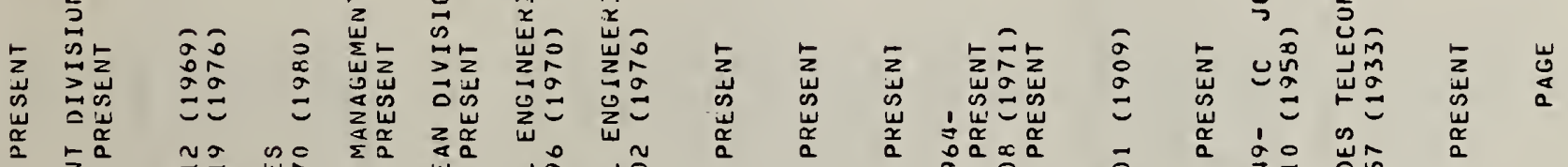

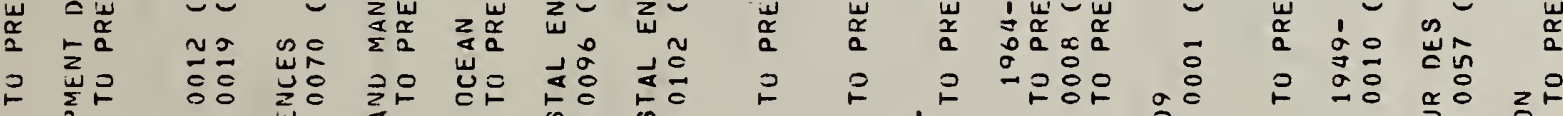

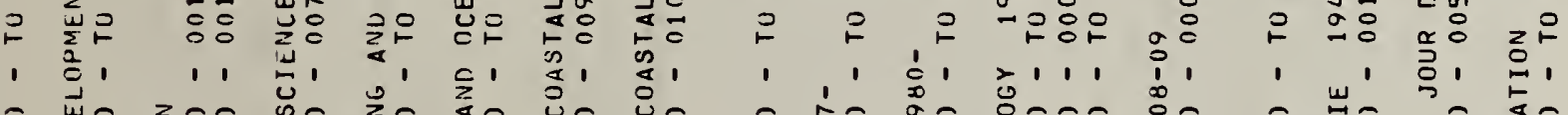

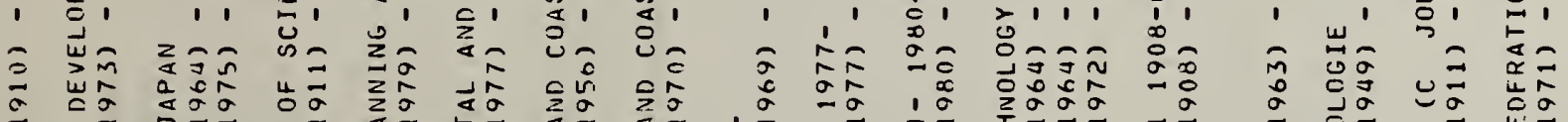

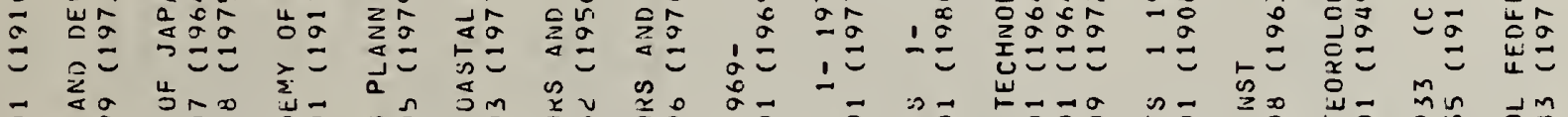

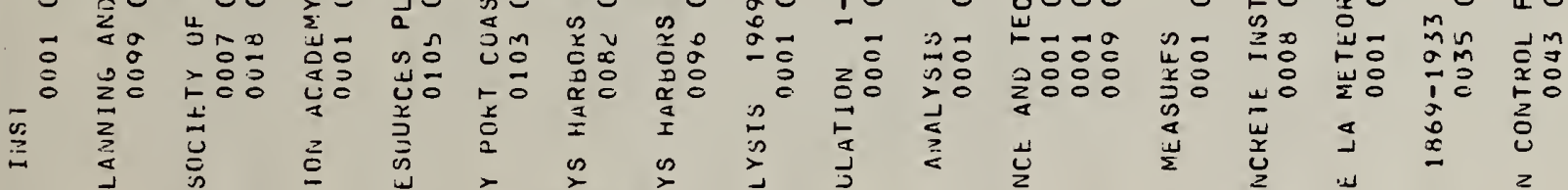

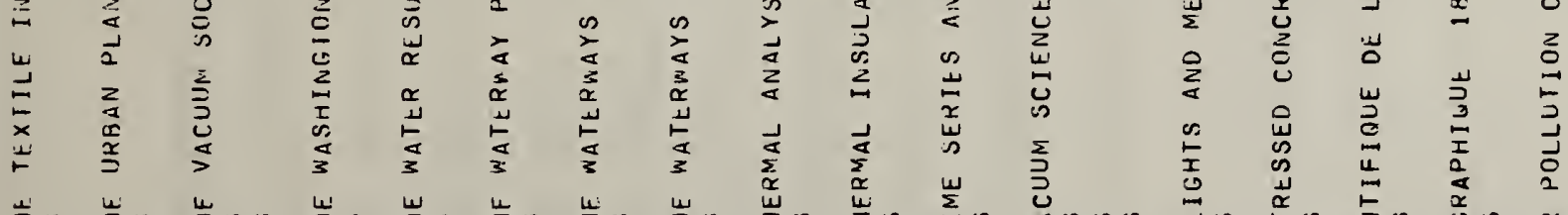

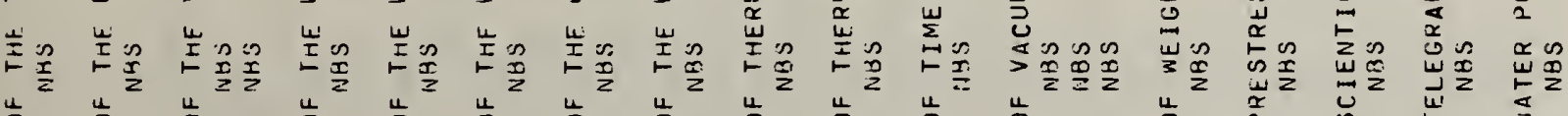

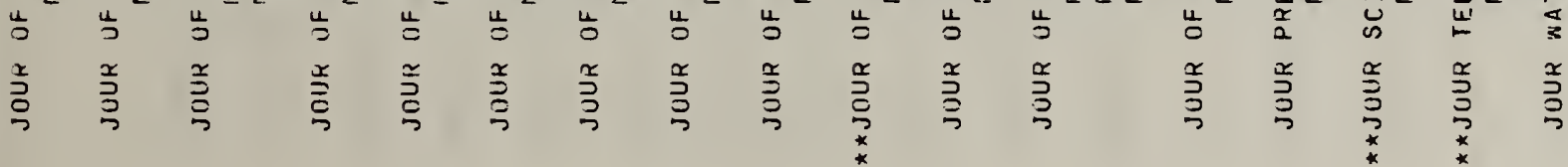




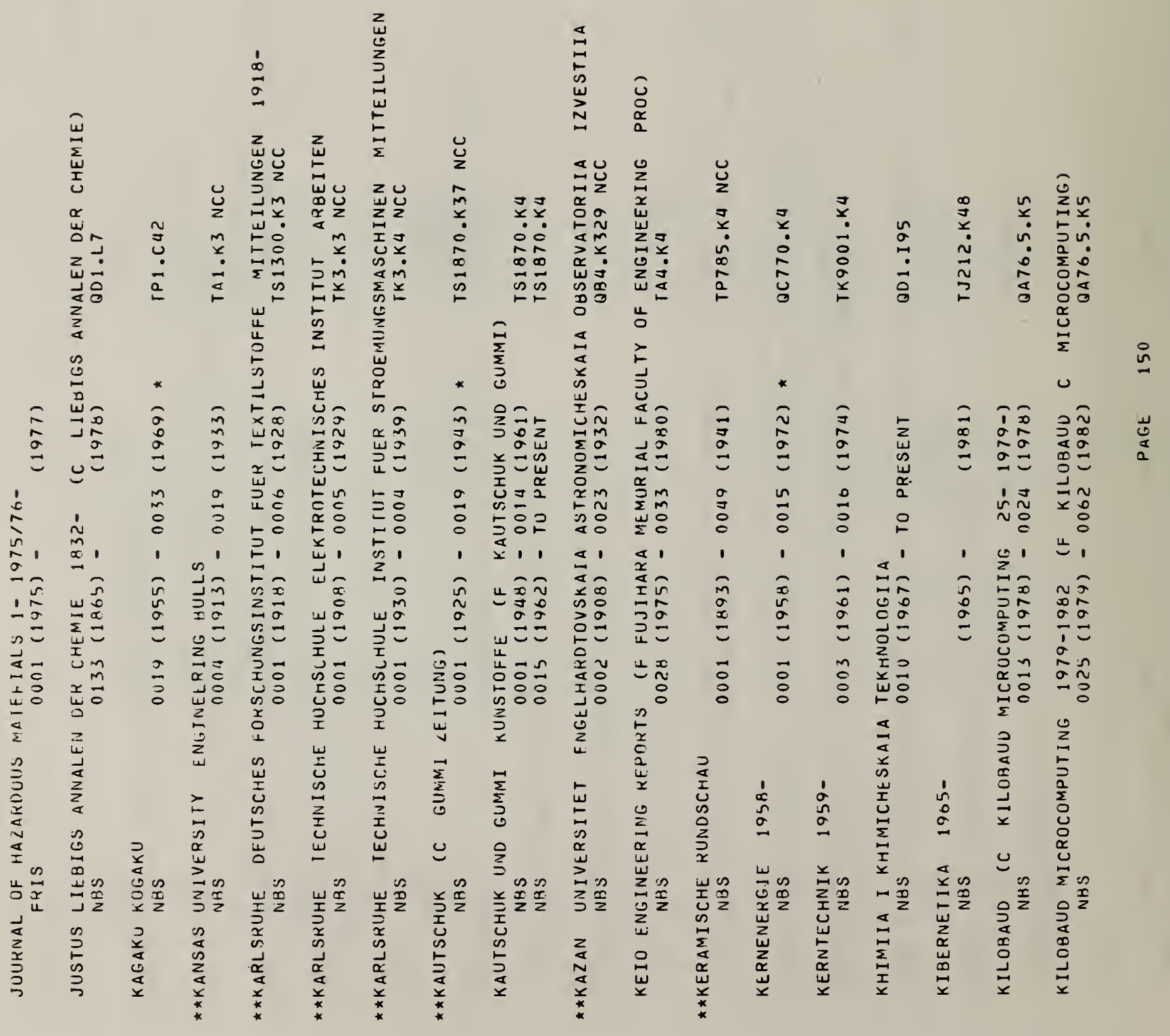




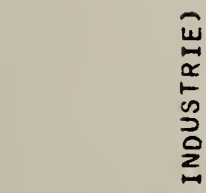

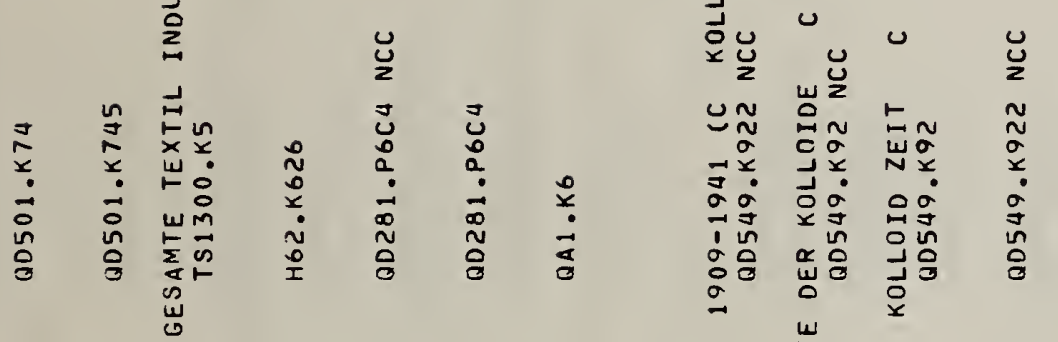

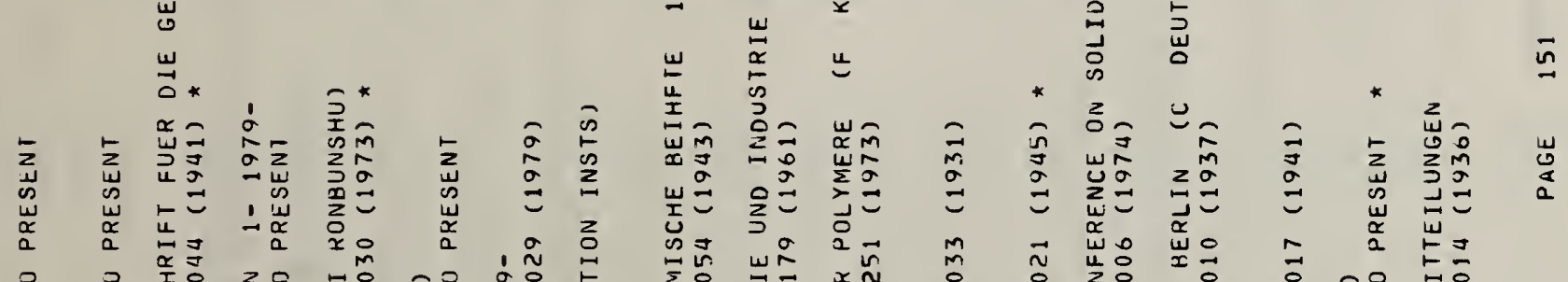

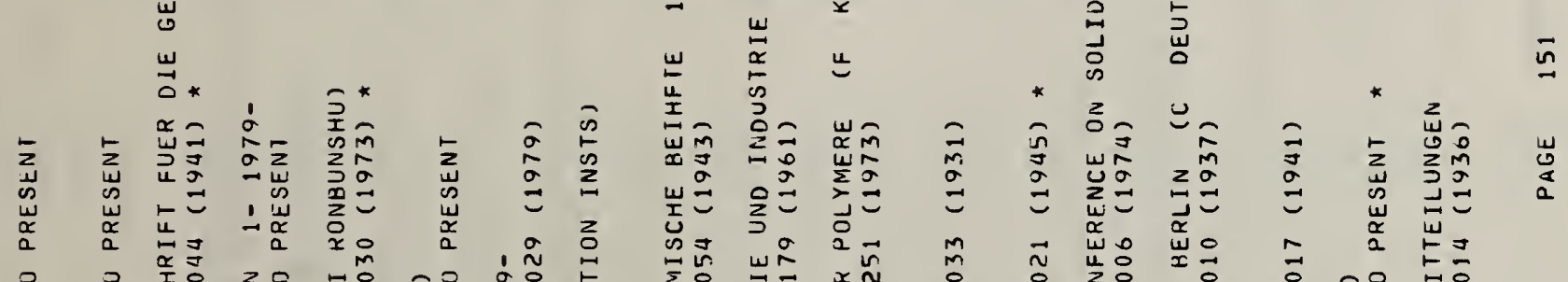

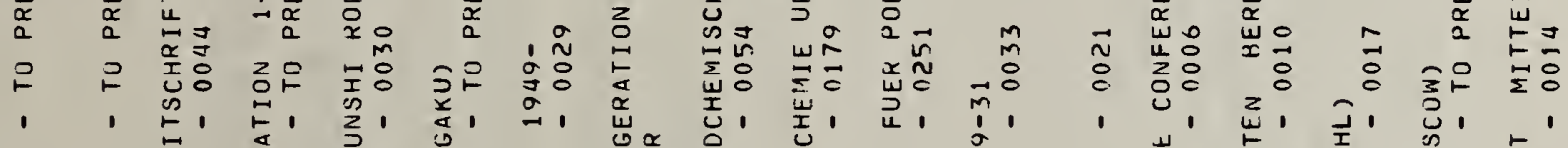

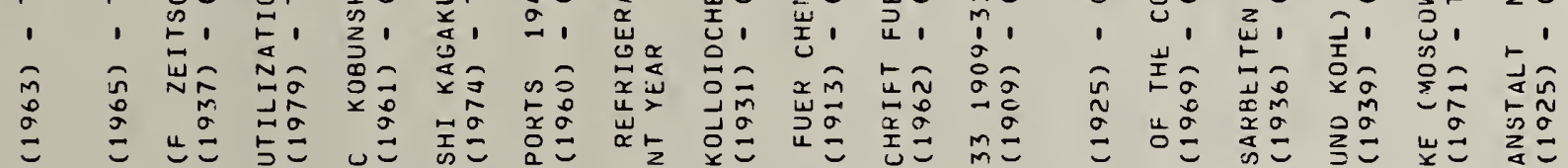

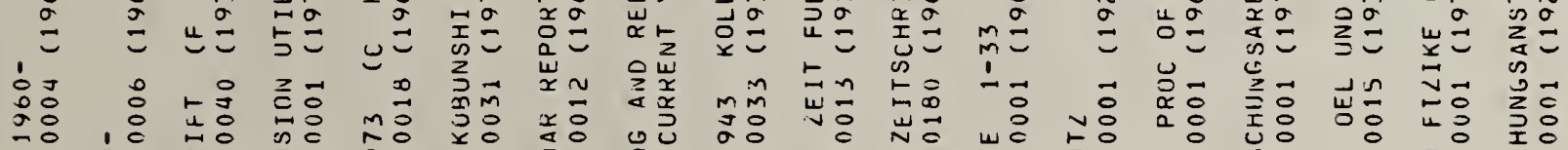

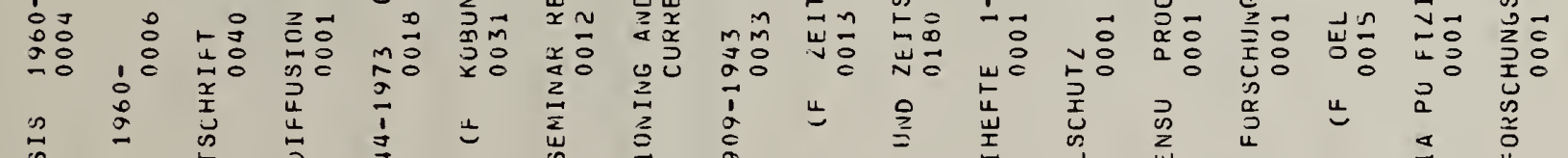

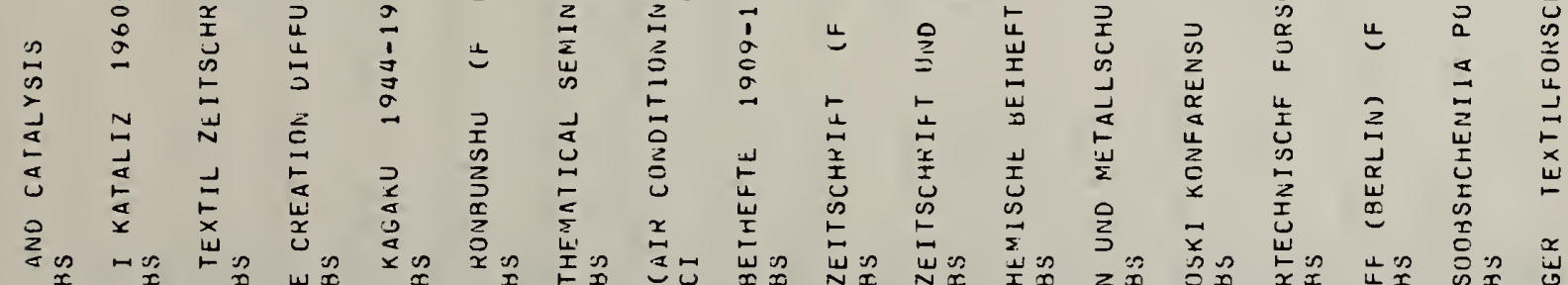

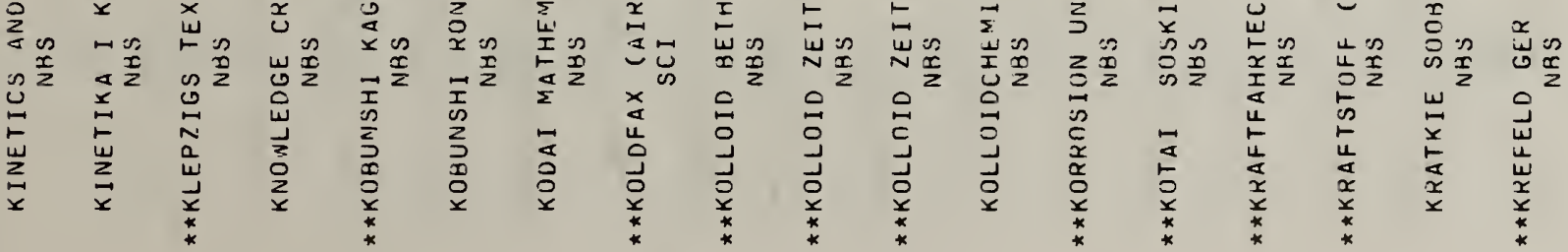




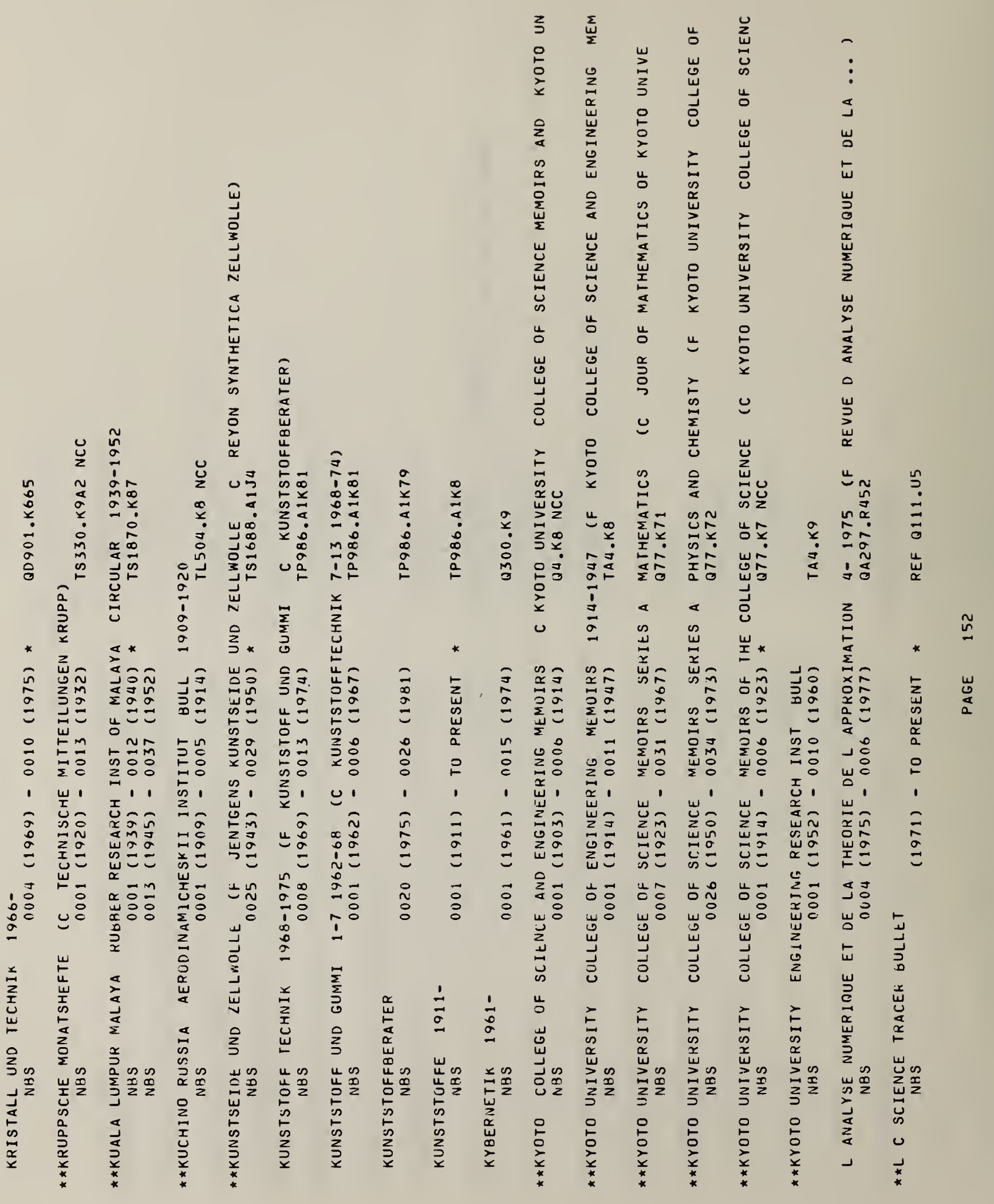




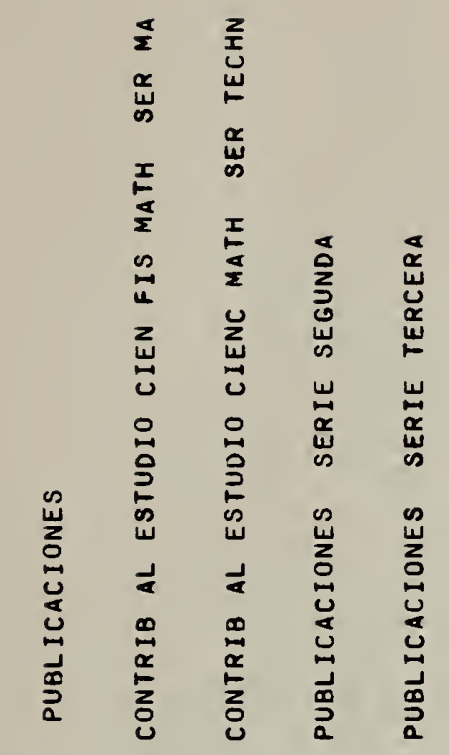

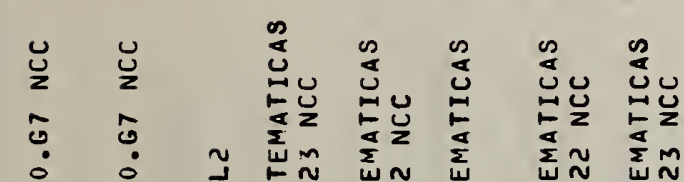

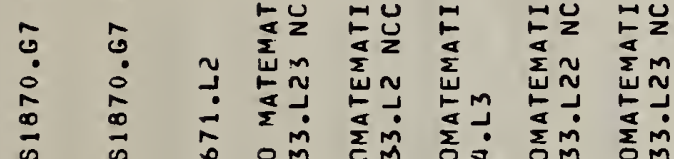

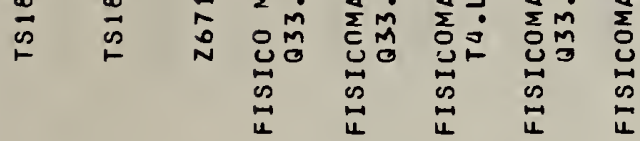

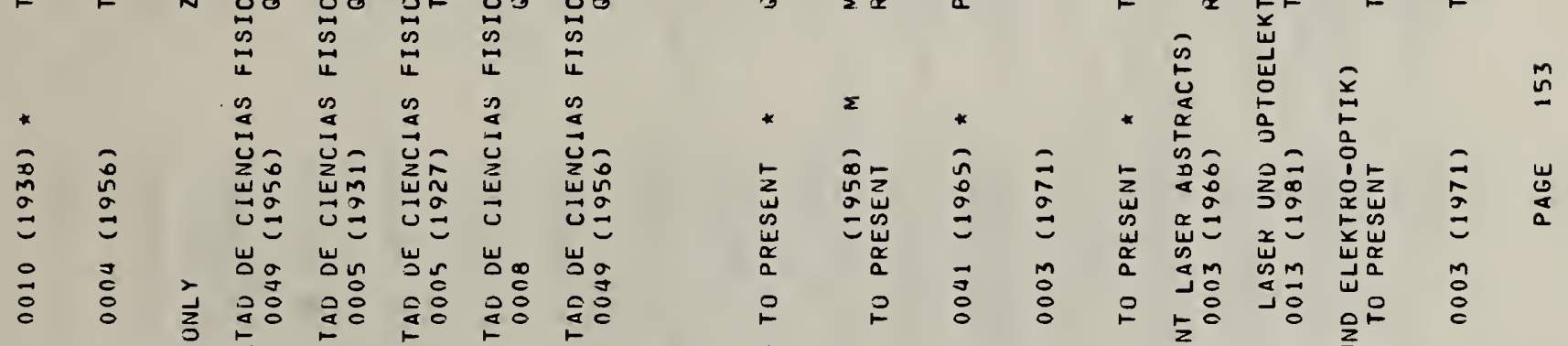

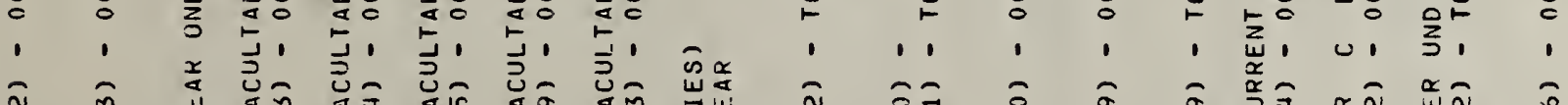

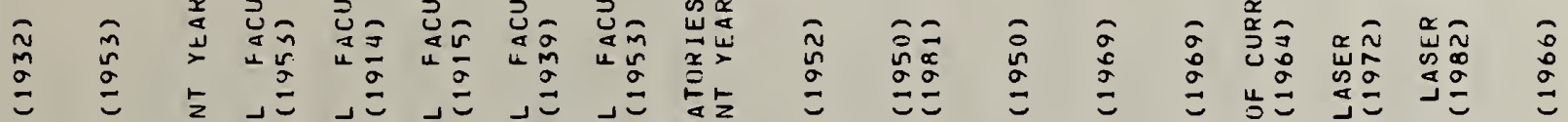

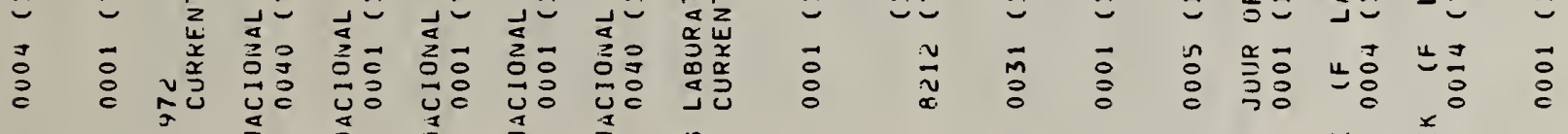

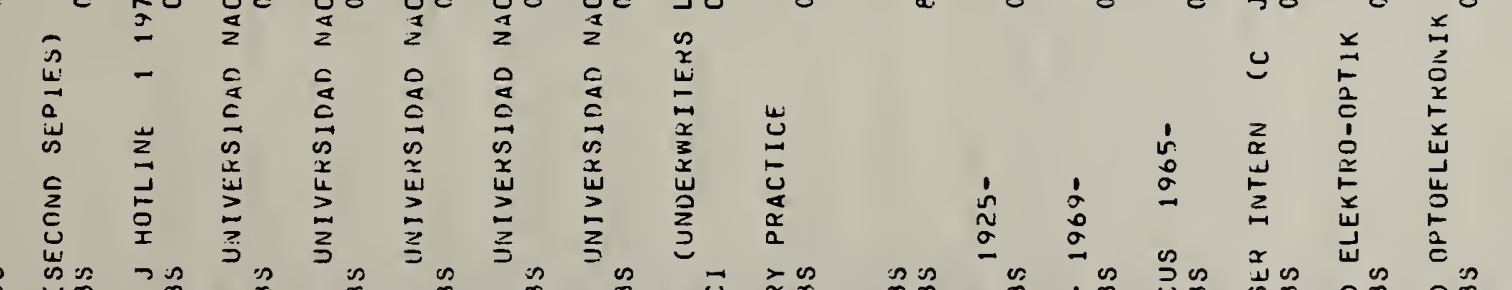

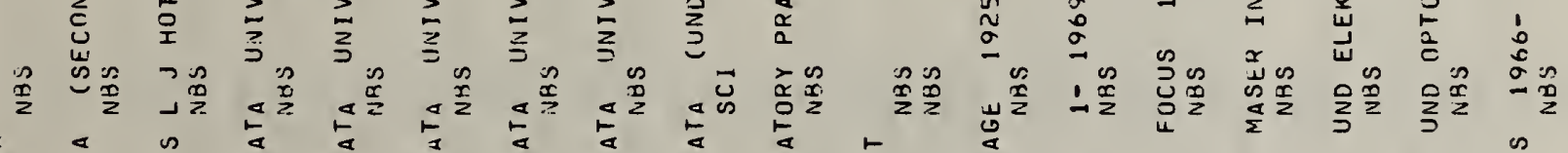

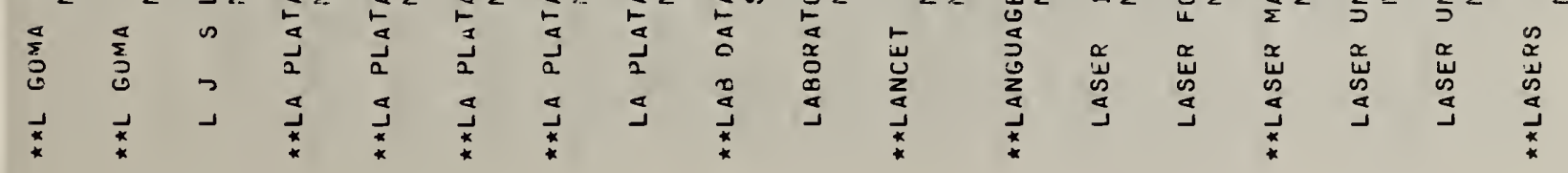




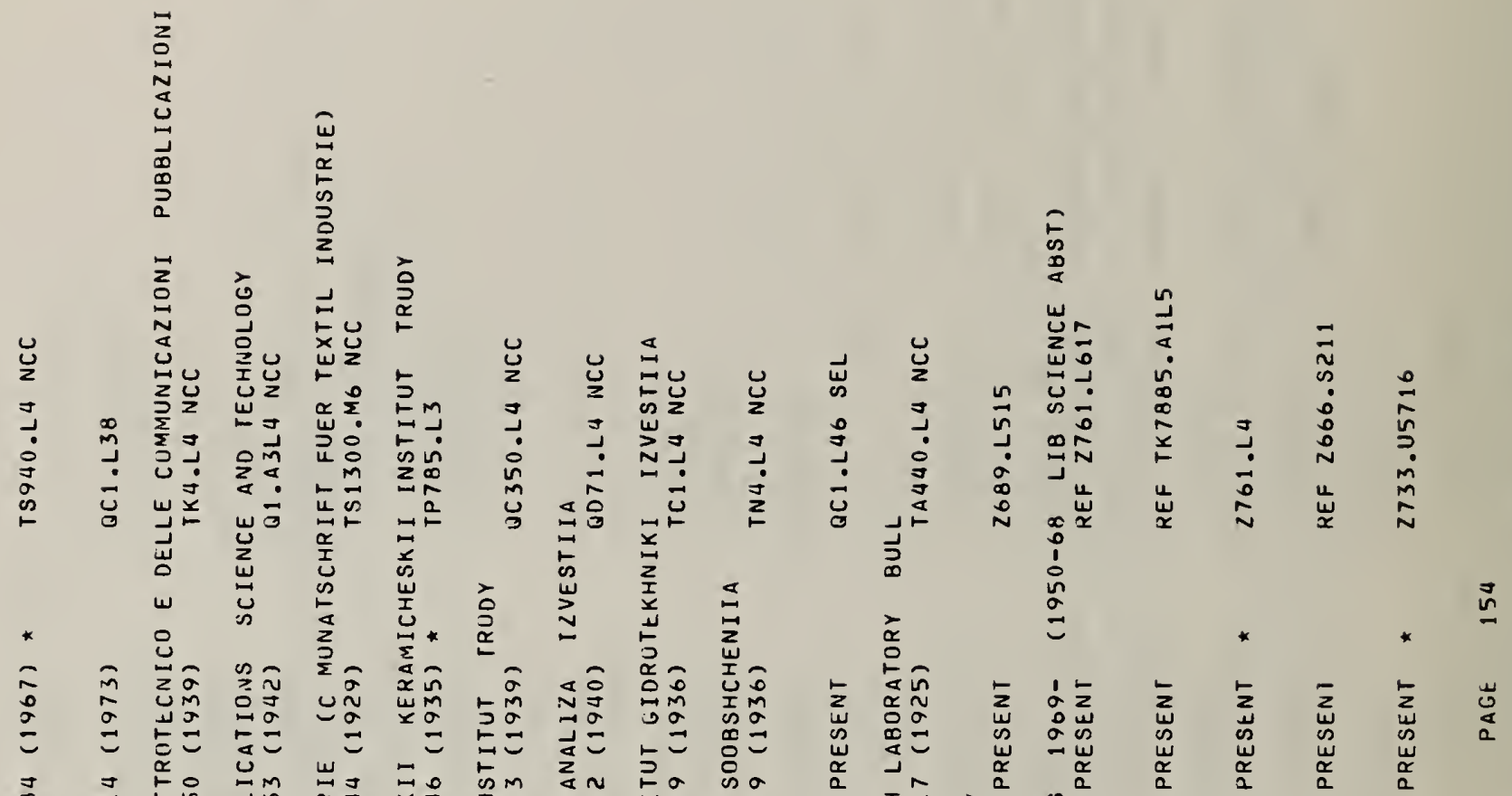

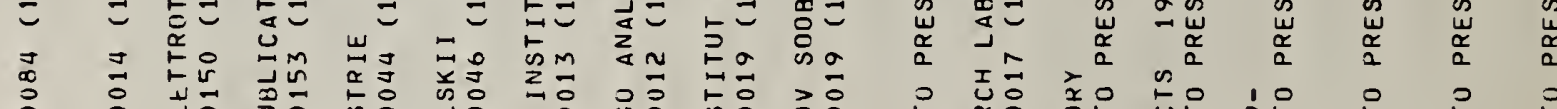

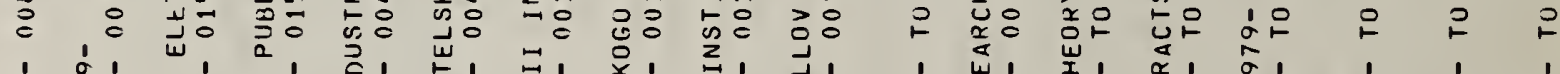

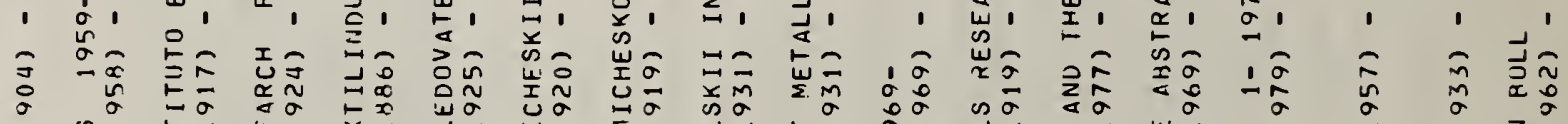

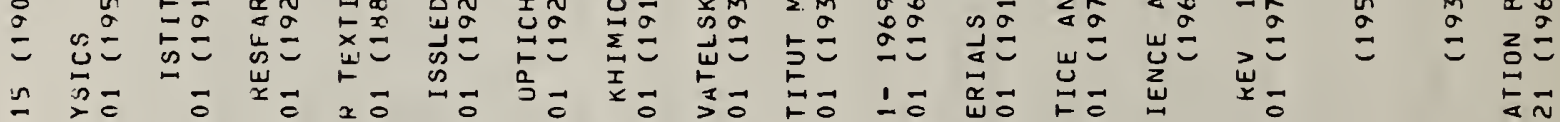

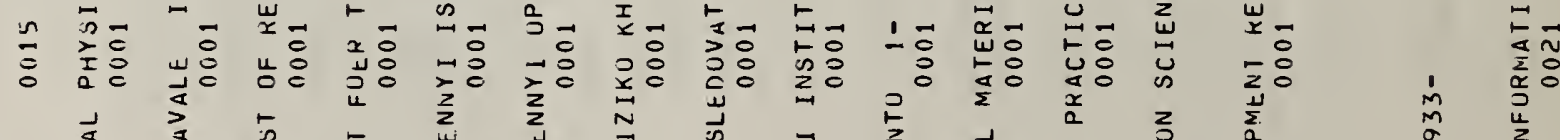

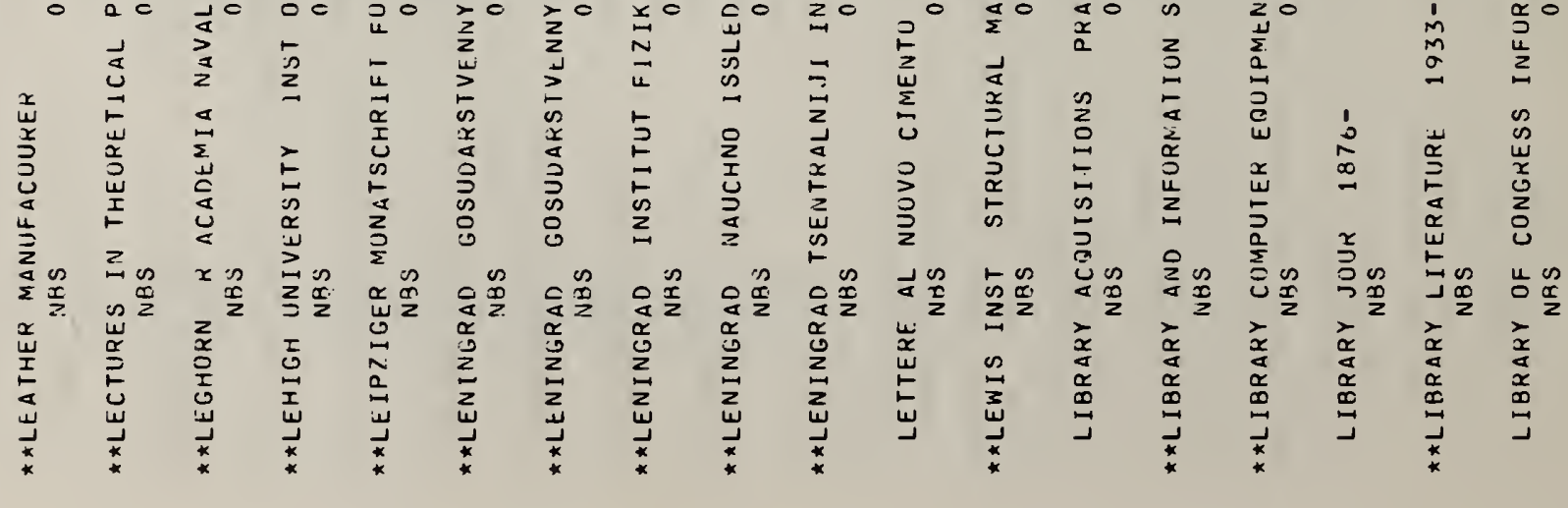


$\frac{1}{20}$

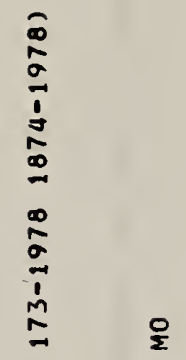

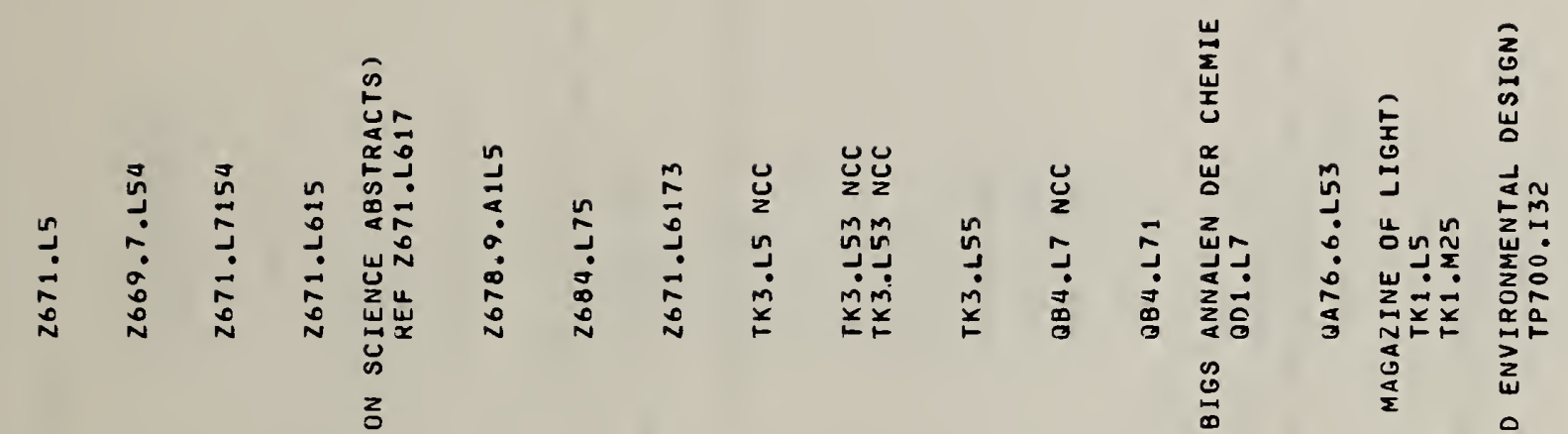

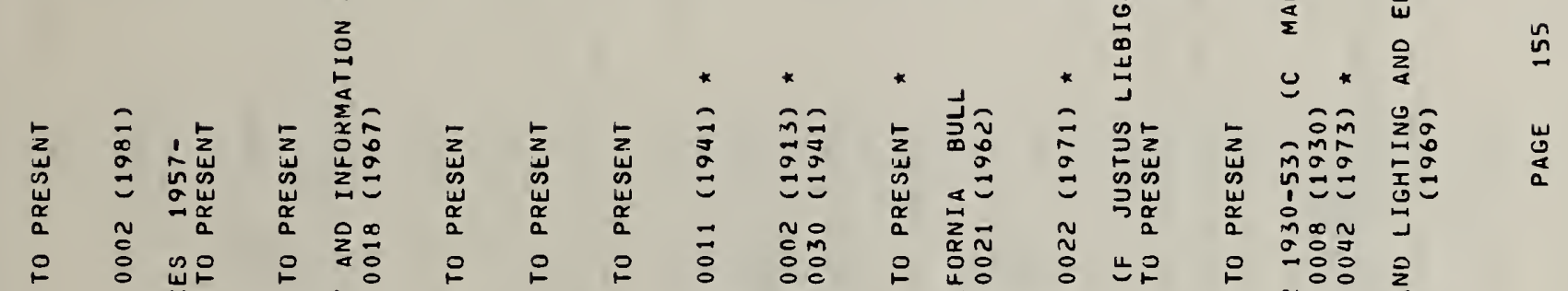

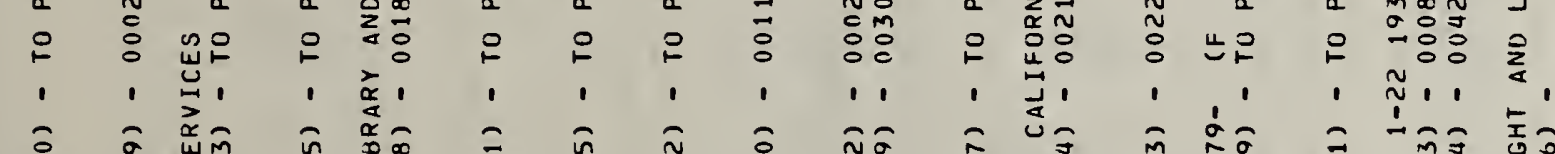

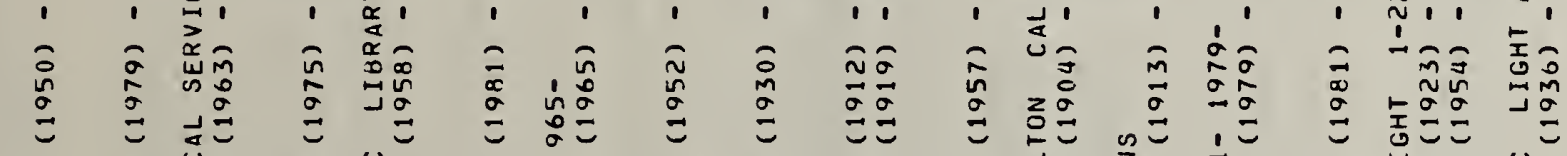

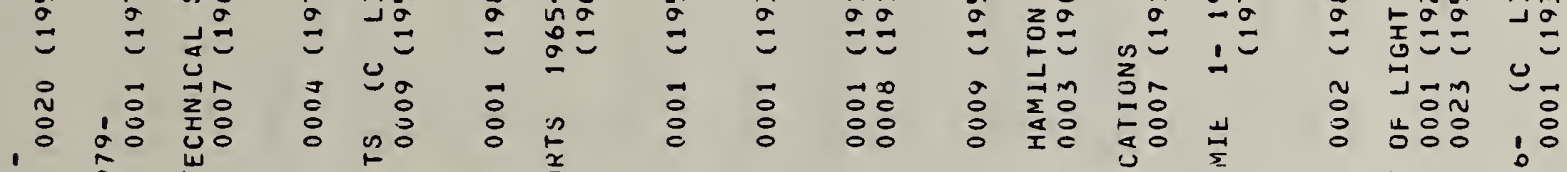

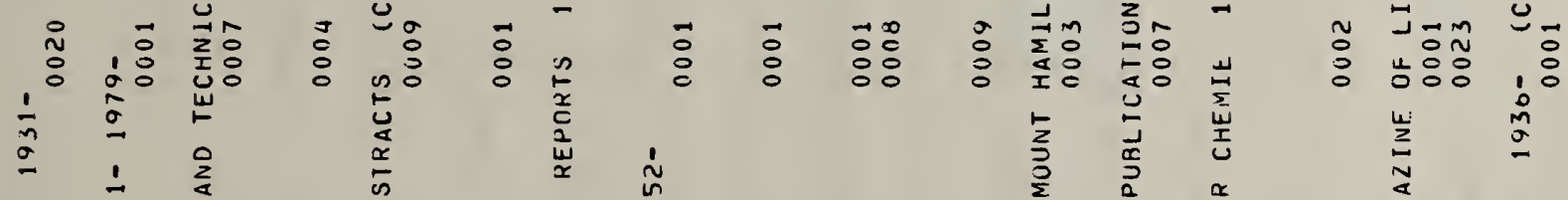

(⿸丆口

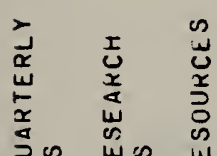

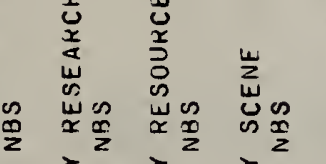

ב

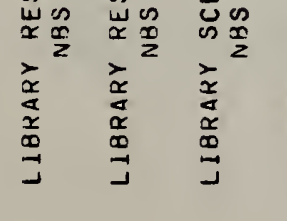

崩

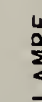

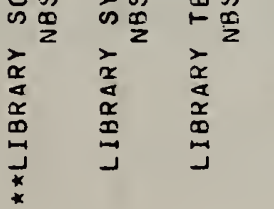

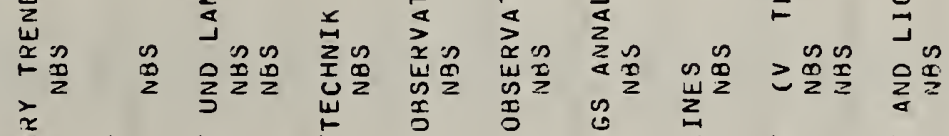

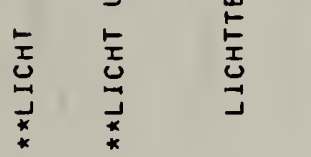

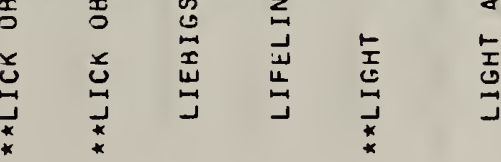




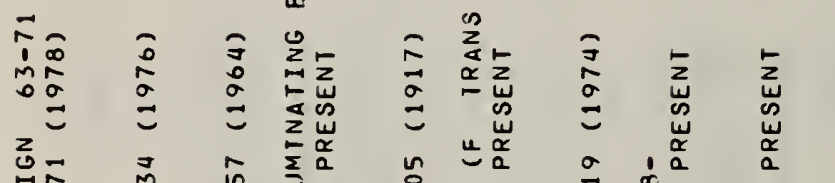

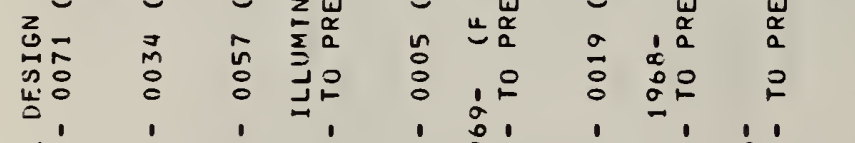

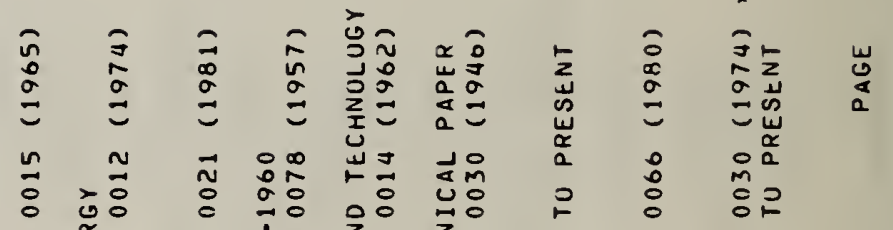

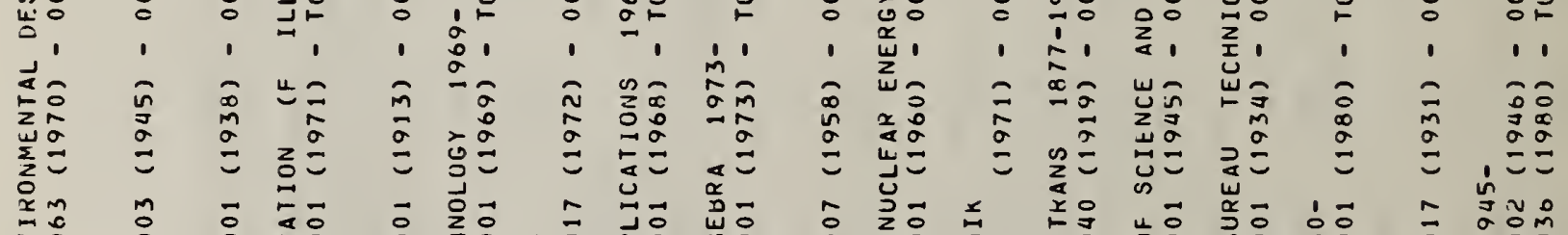

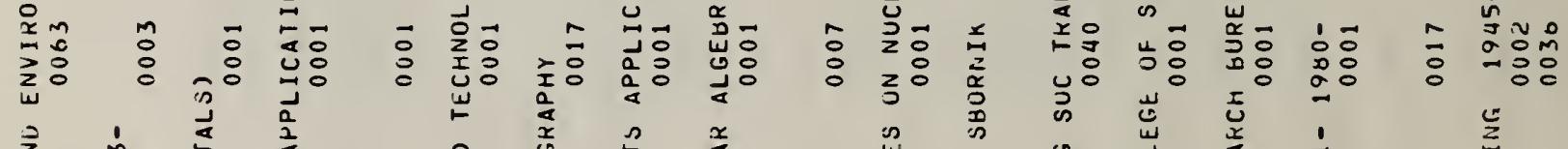

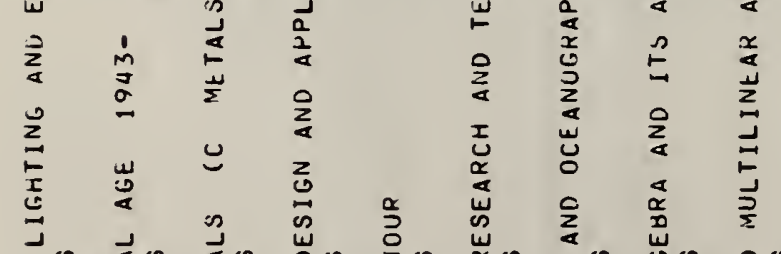

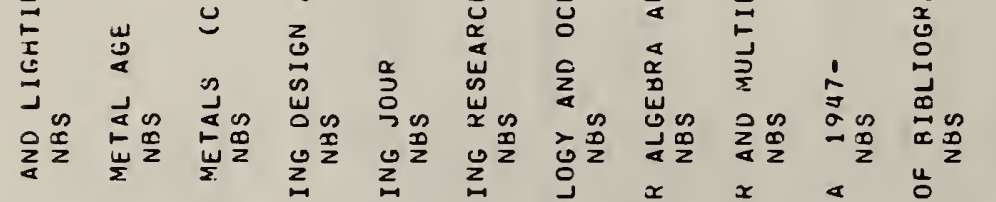




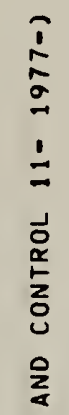

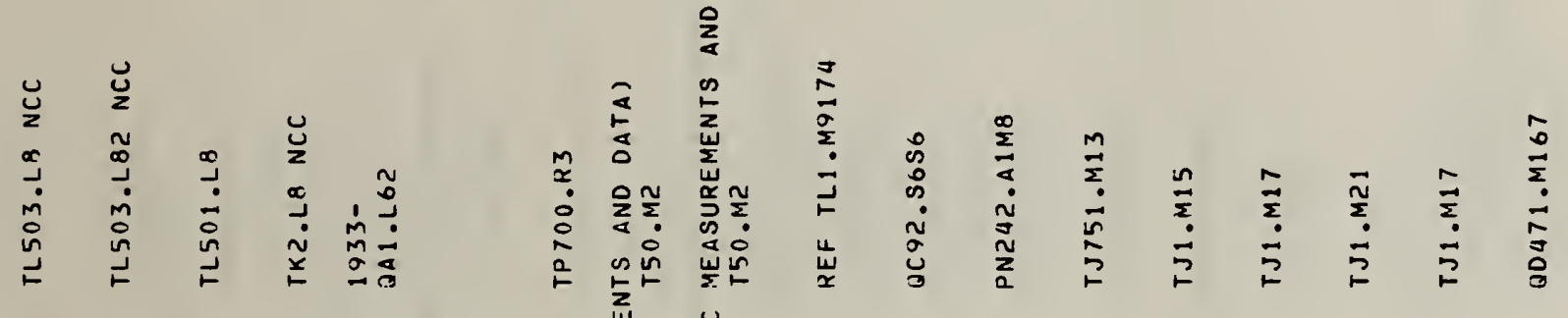

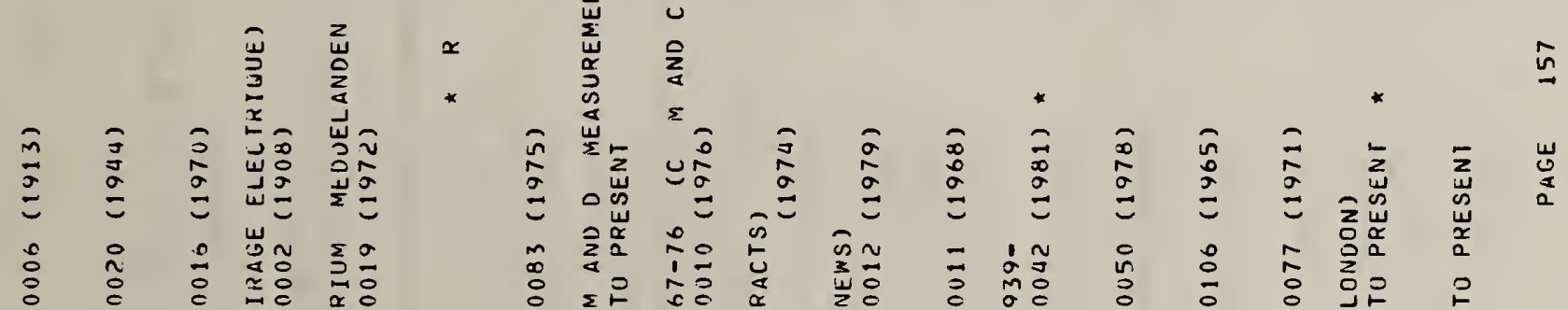

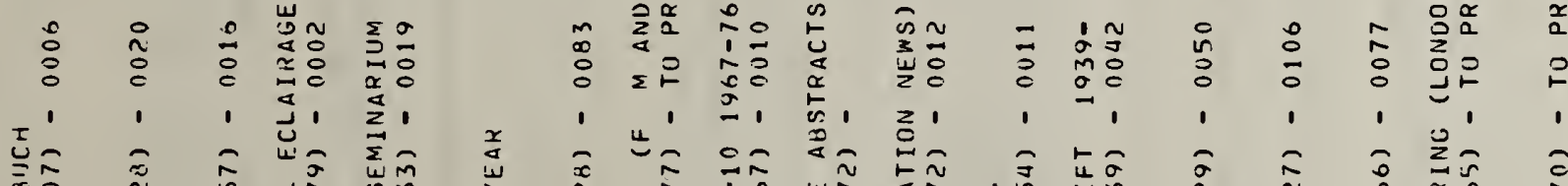

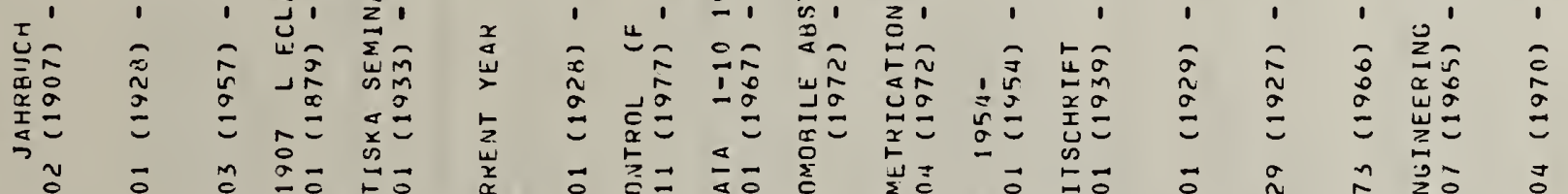

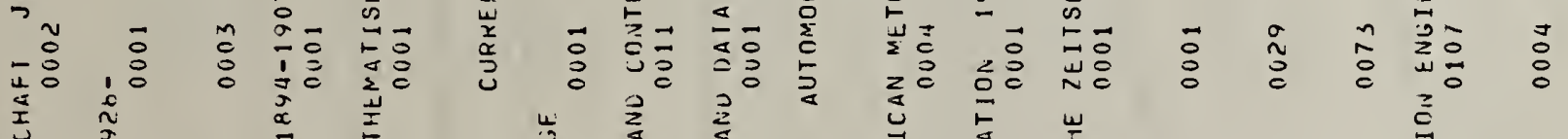

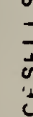




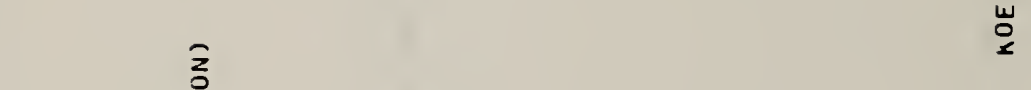

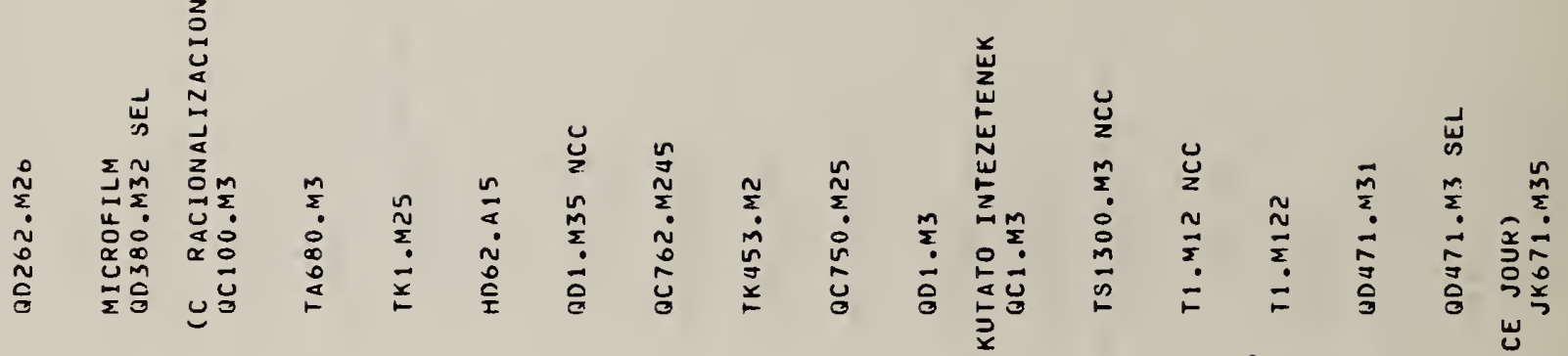

$=\frac{1}{2}$

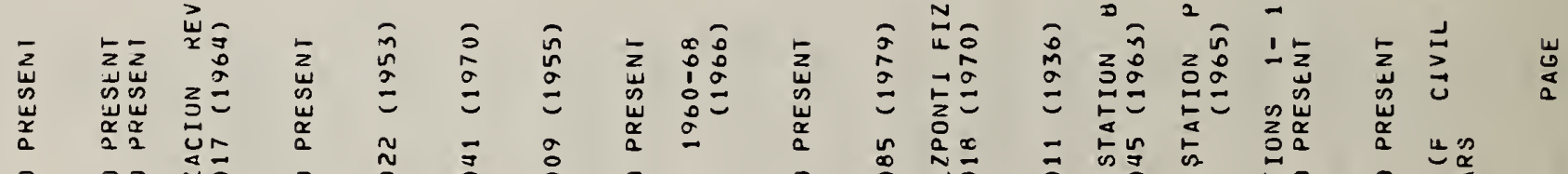

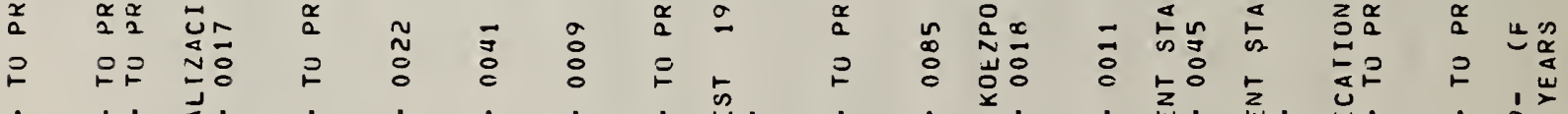

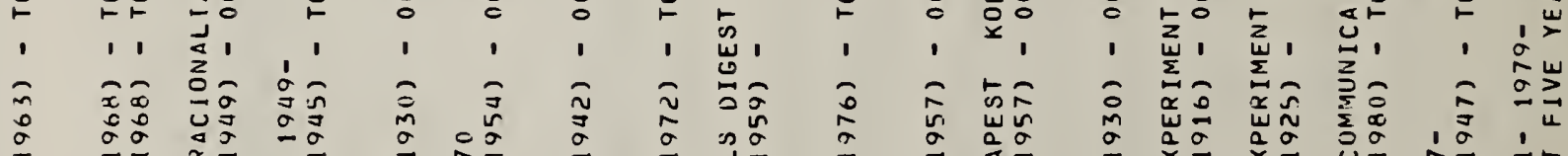

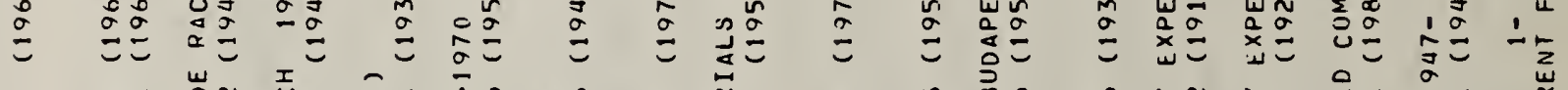

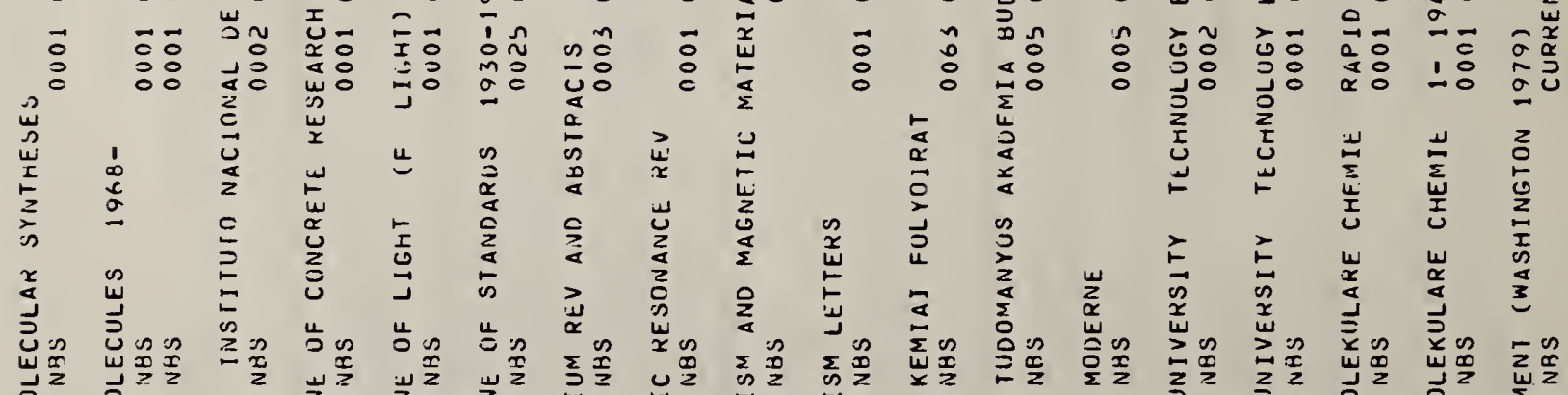

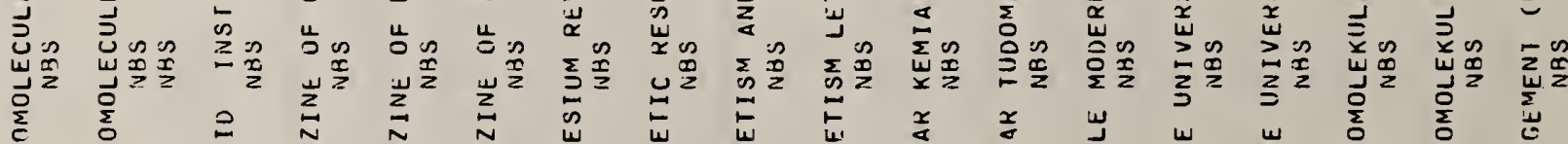
the

(1111!i! 

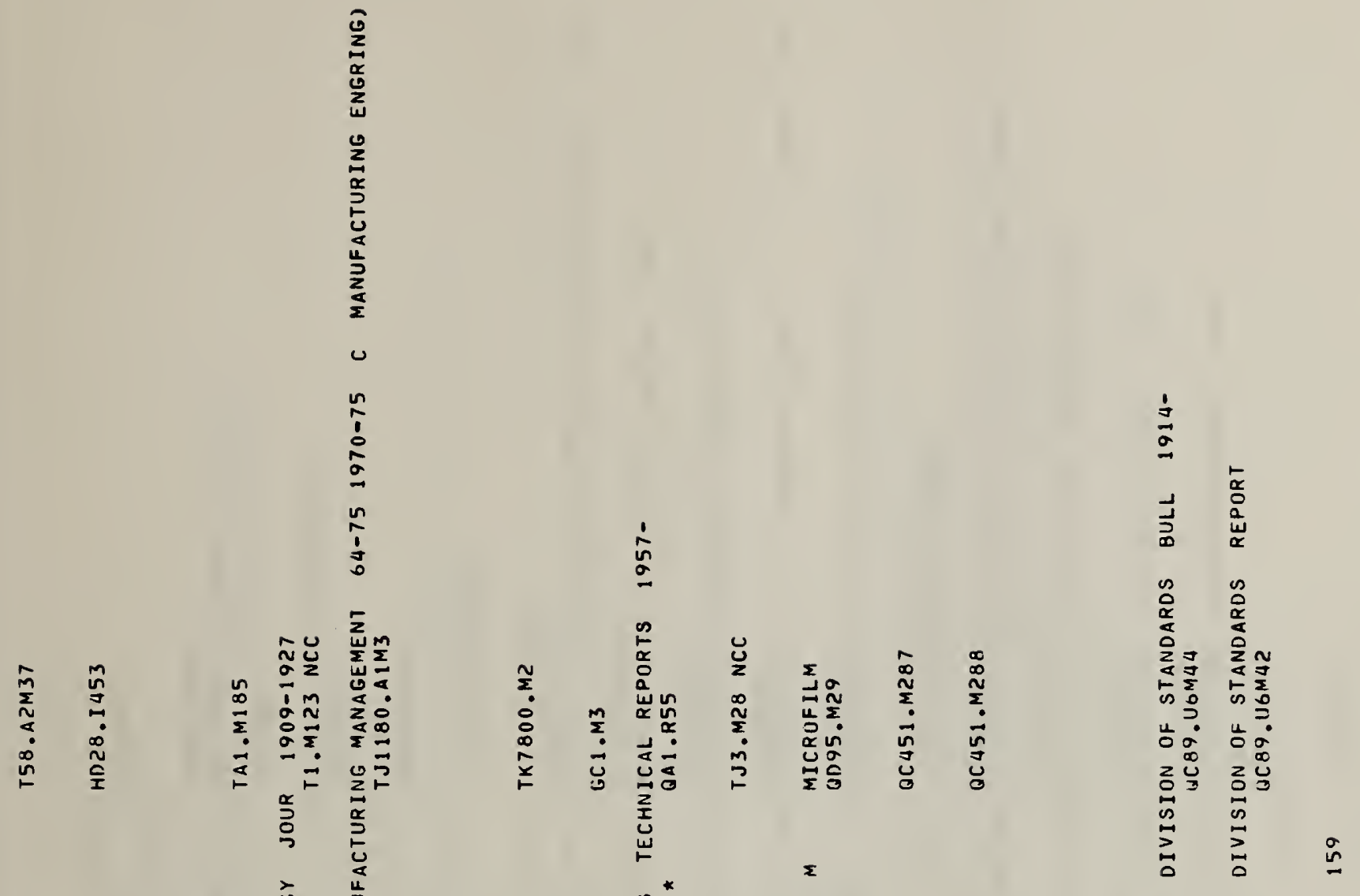

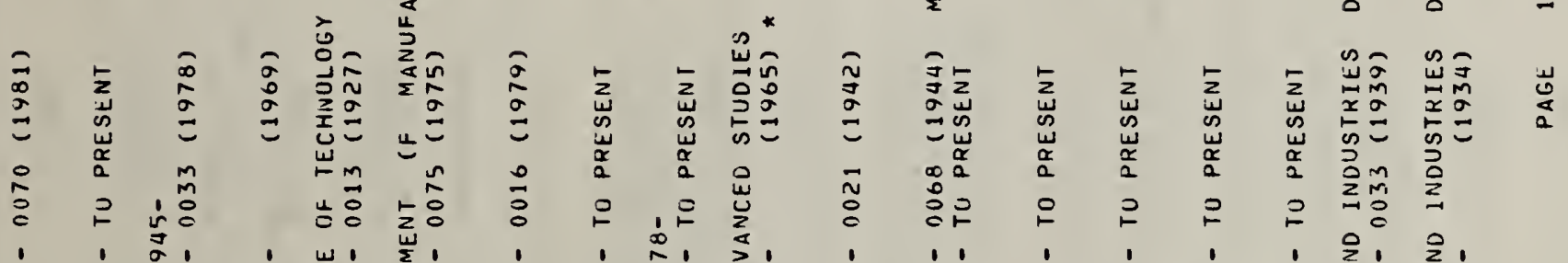

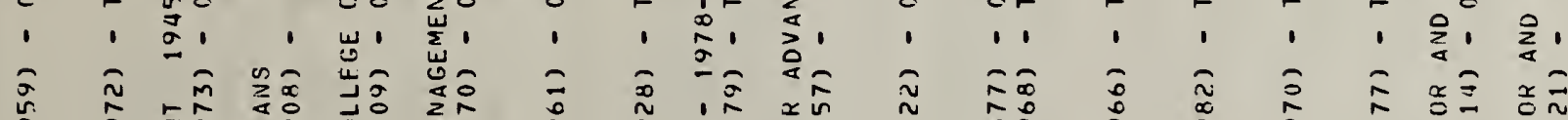

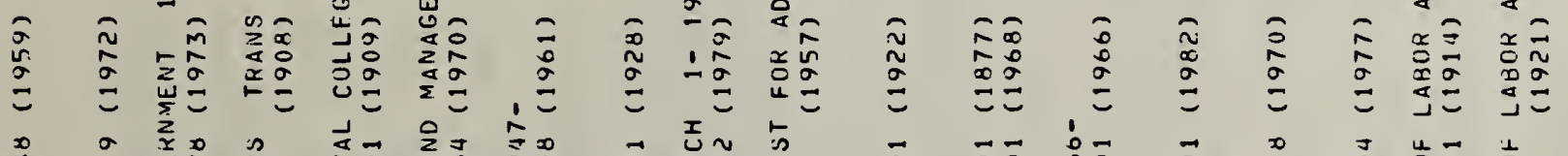

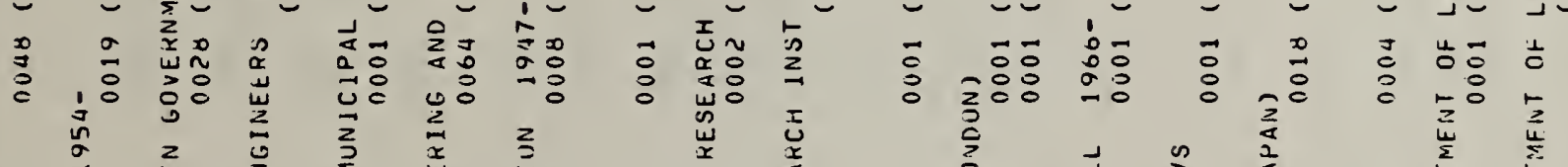

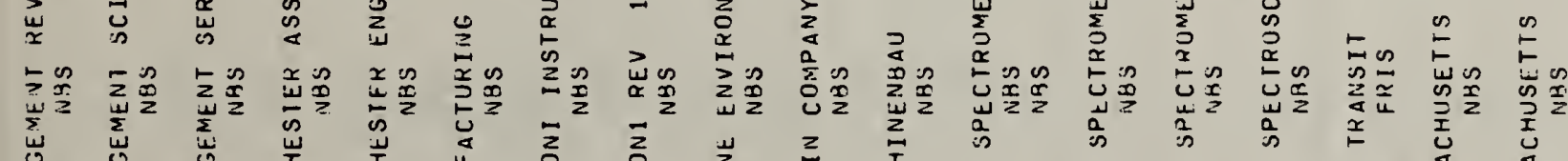

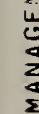




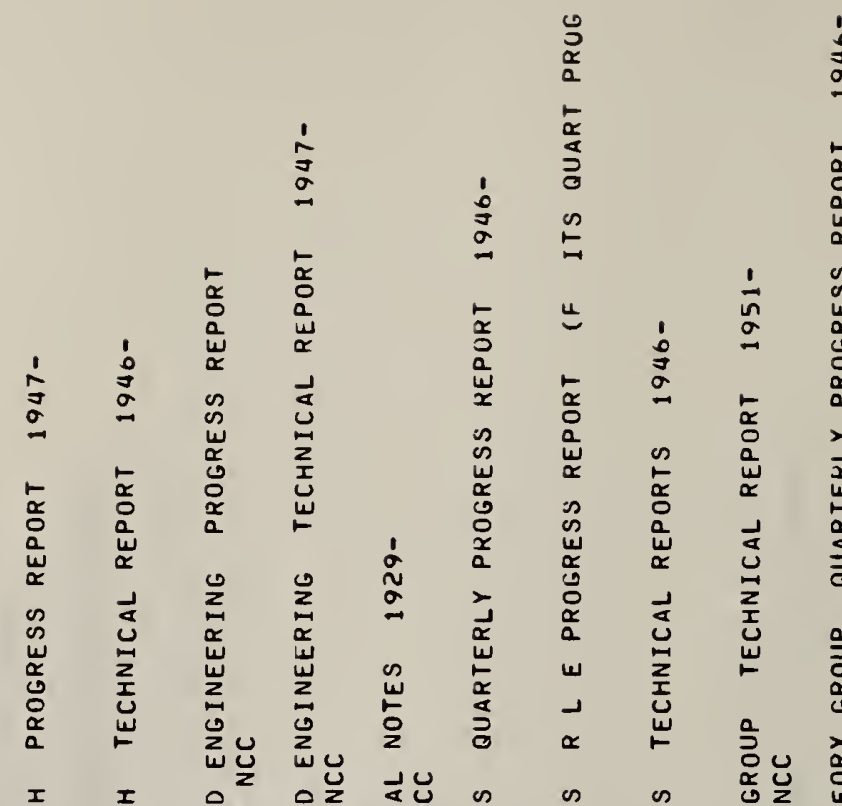

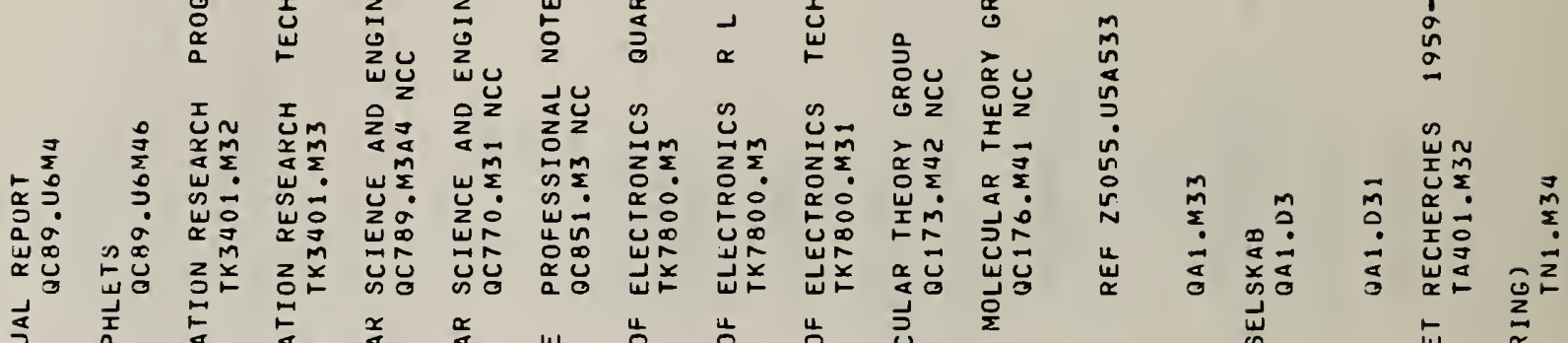

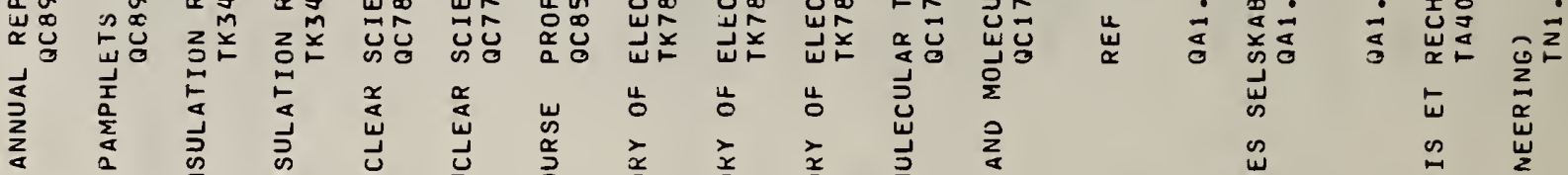

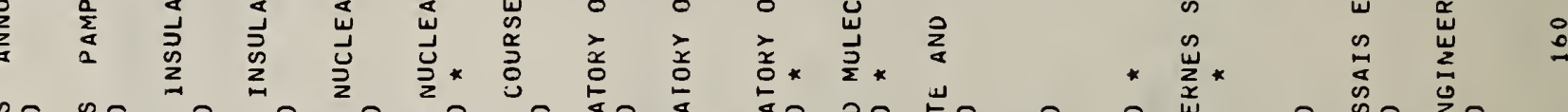

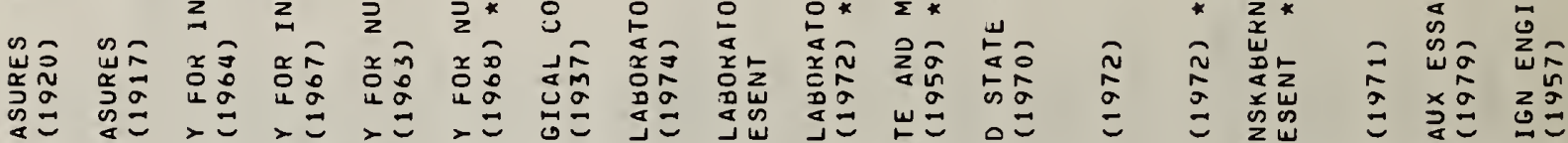

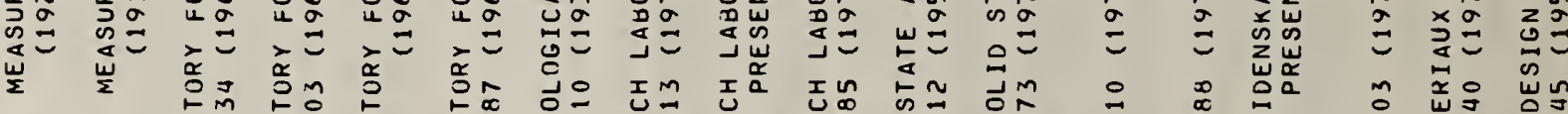

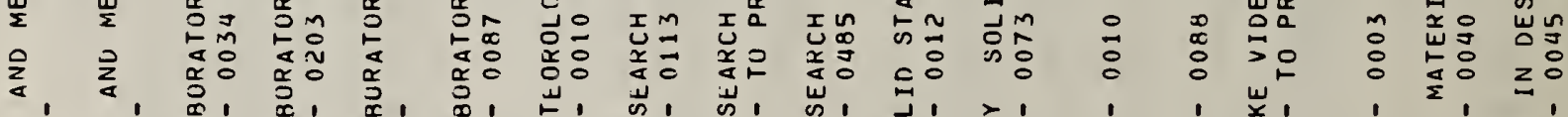

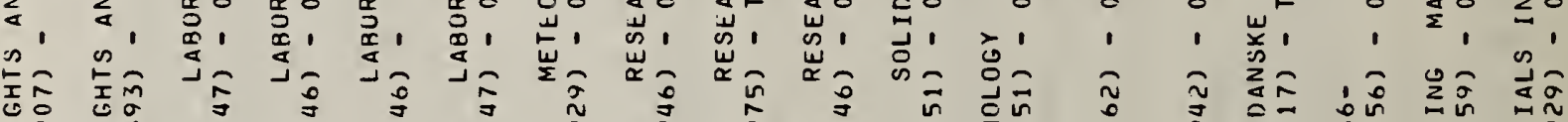

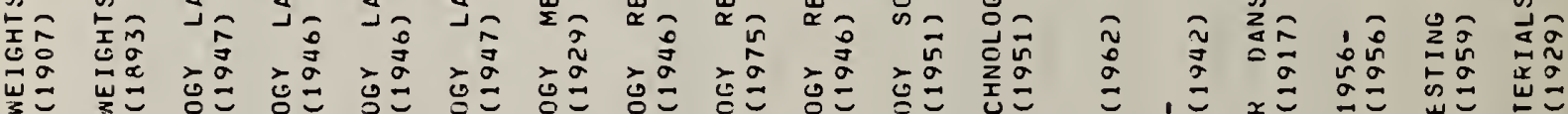

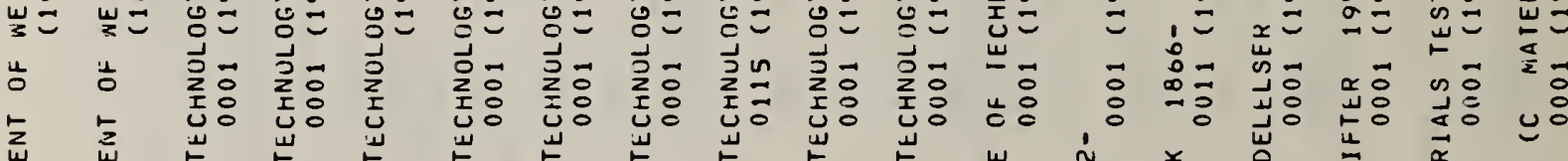

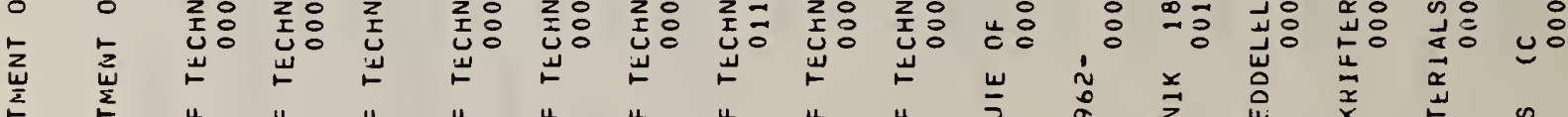

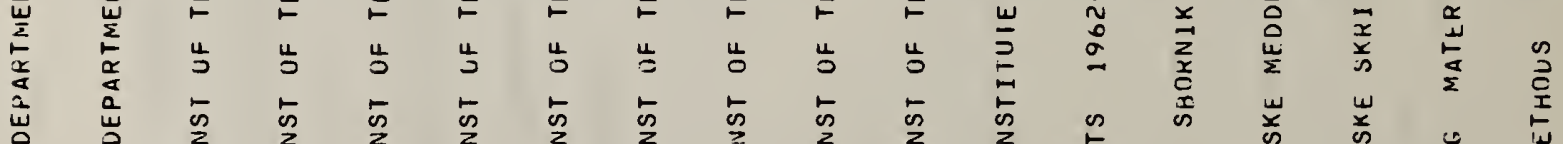
$\begin{array}{lllllllllllll} & \\ 0\end{array}$ 


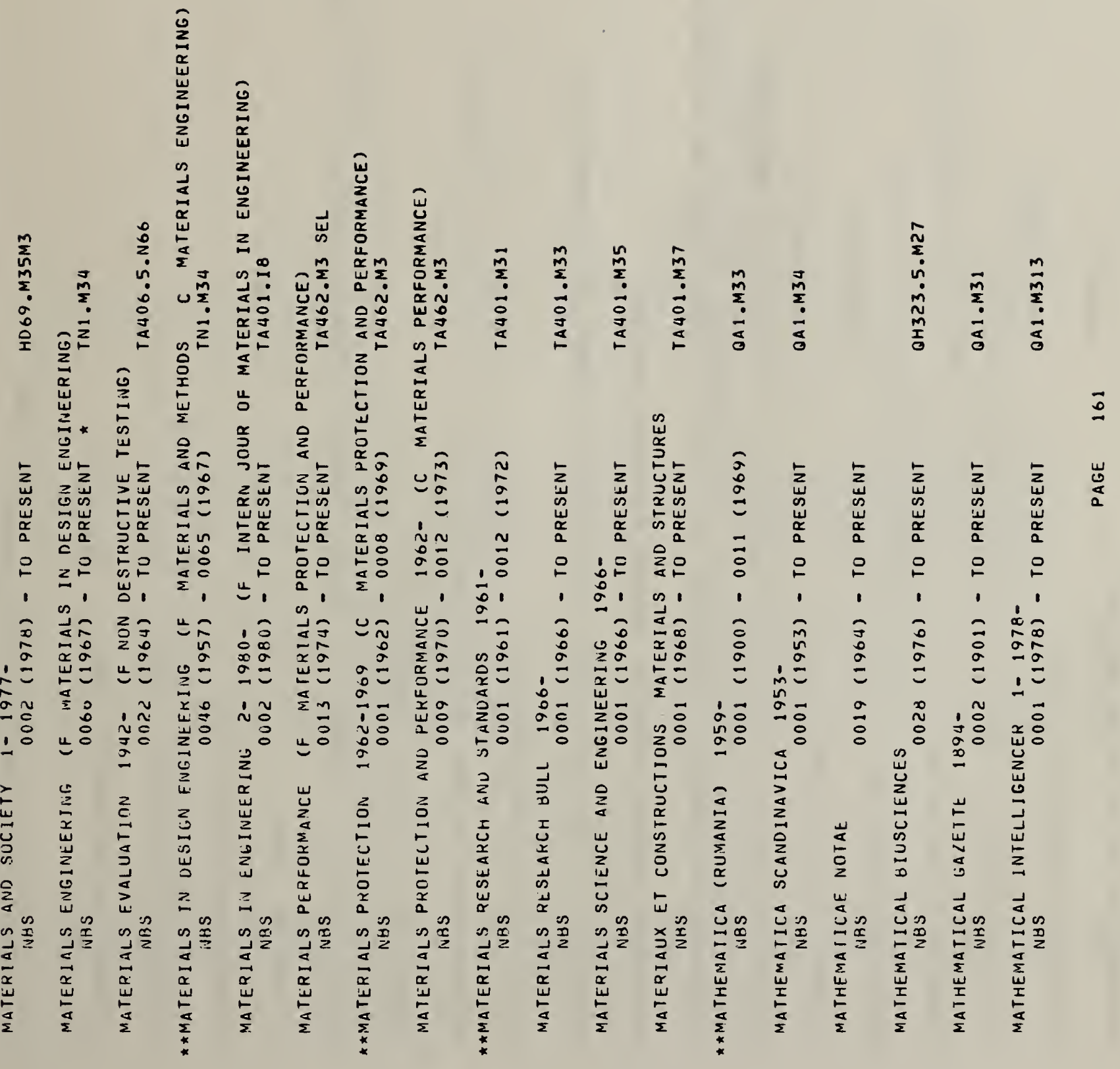




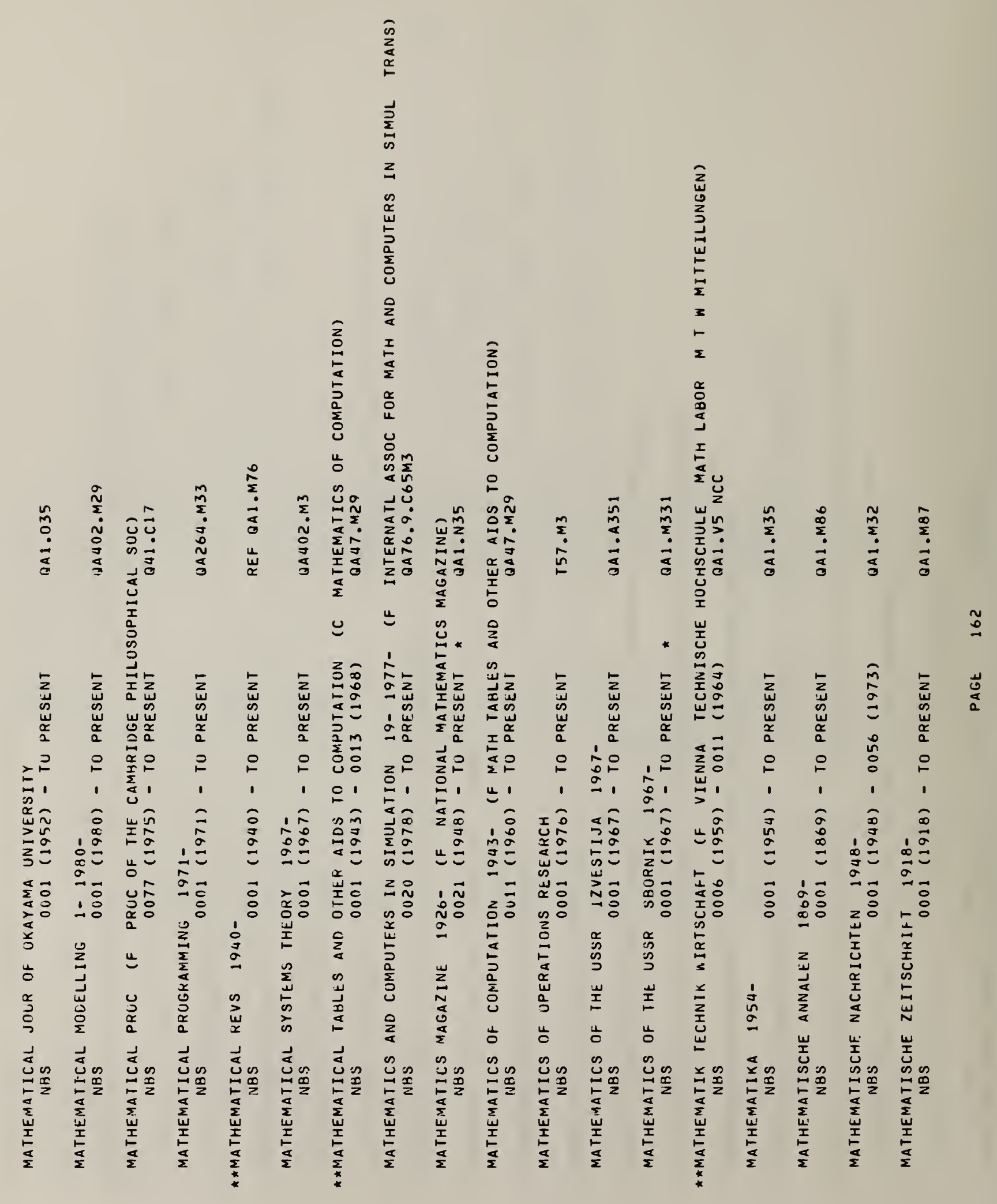




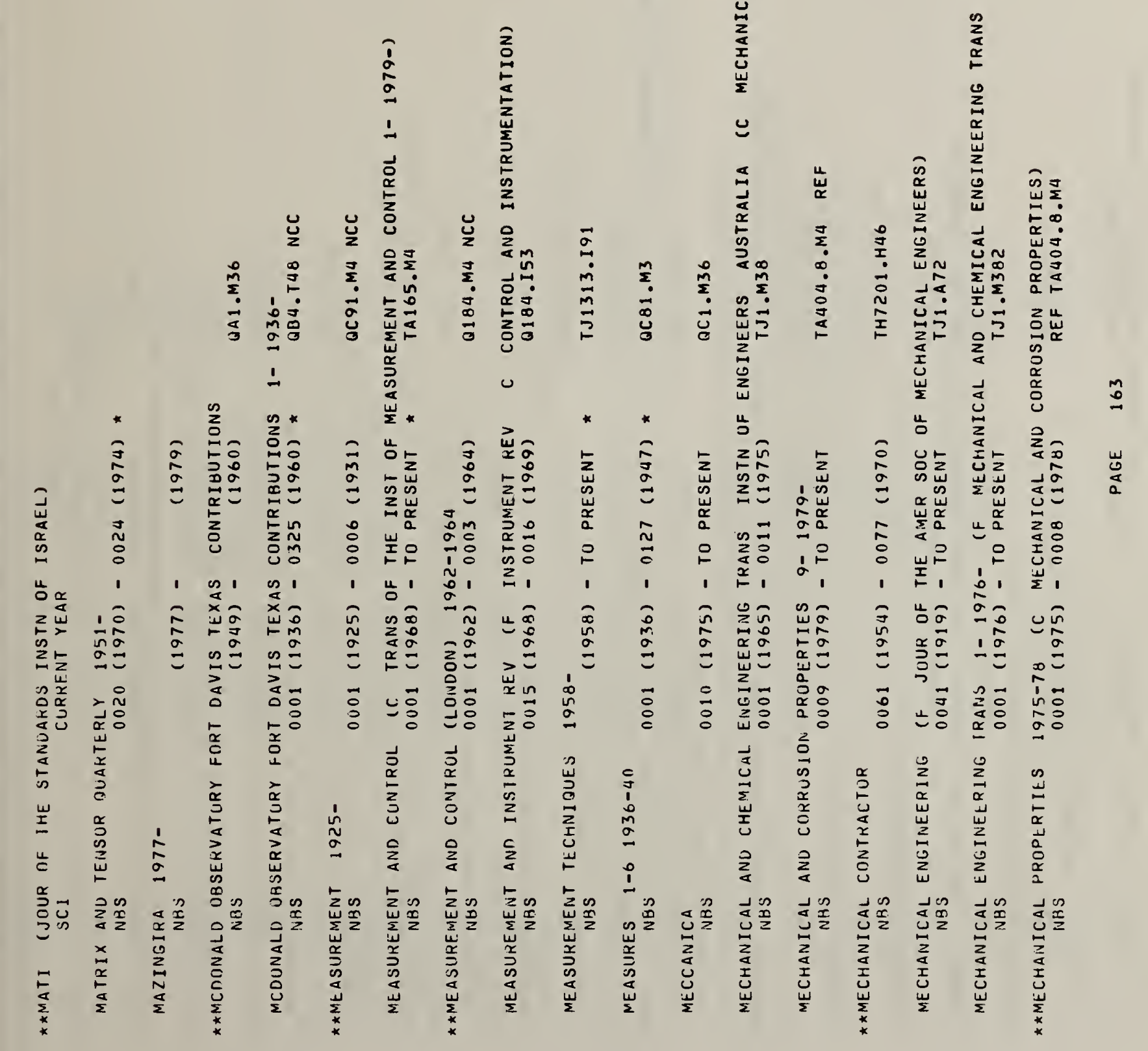


$\hat{g}$
$\dot{\sigma}$
$\dot{\sigma}$

ind

in

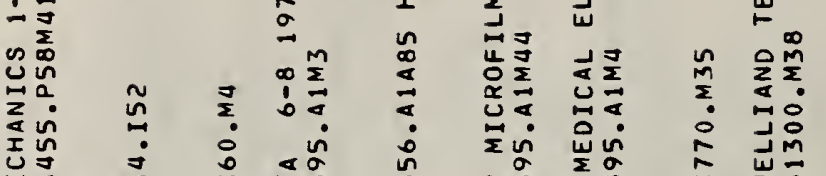

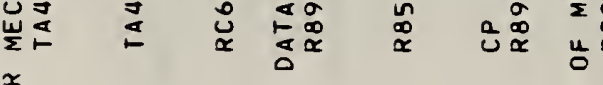

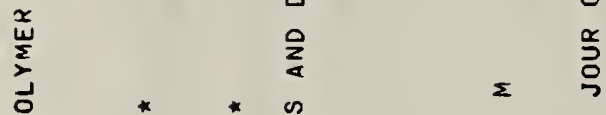

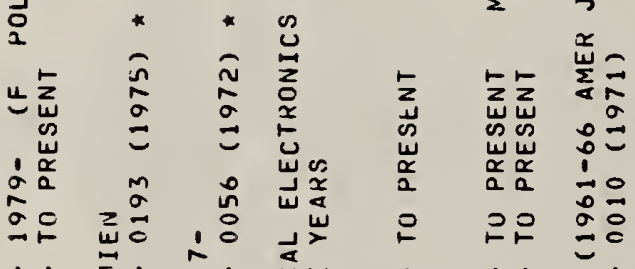

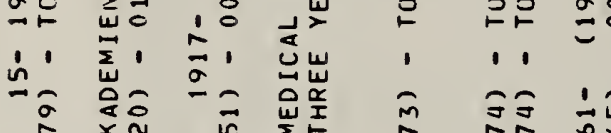

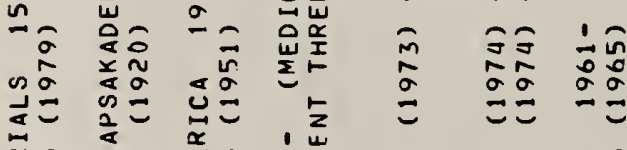

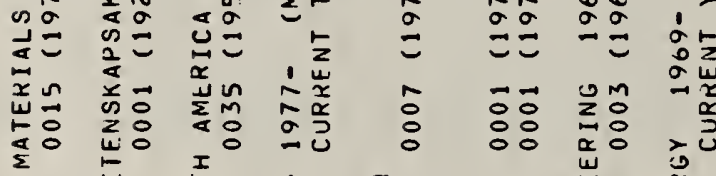

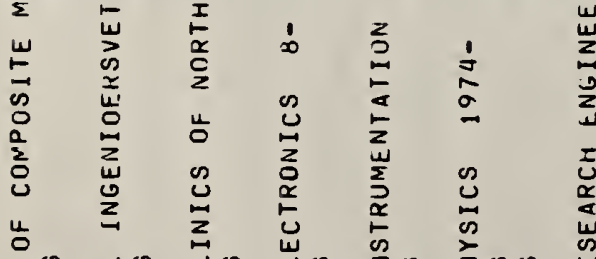

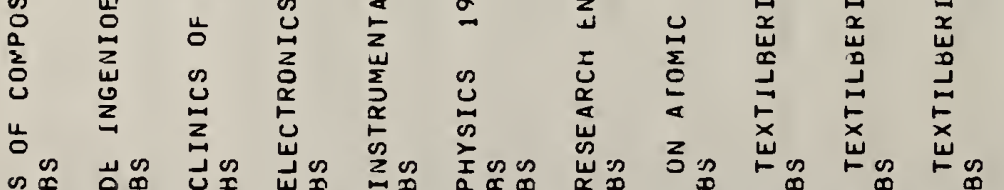

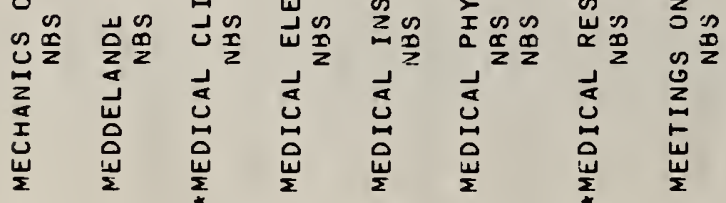

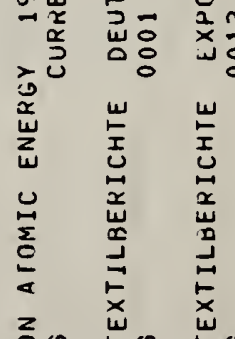

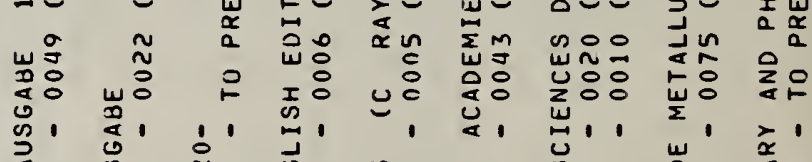

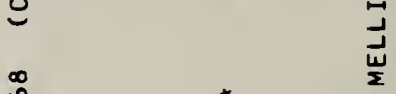
w 


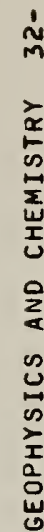

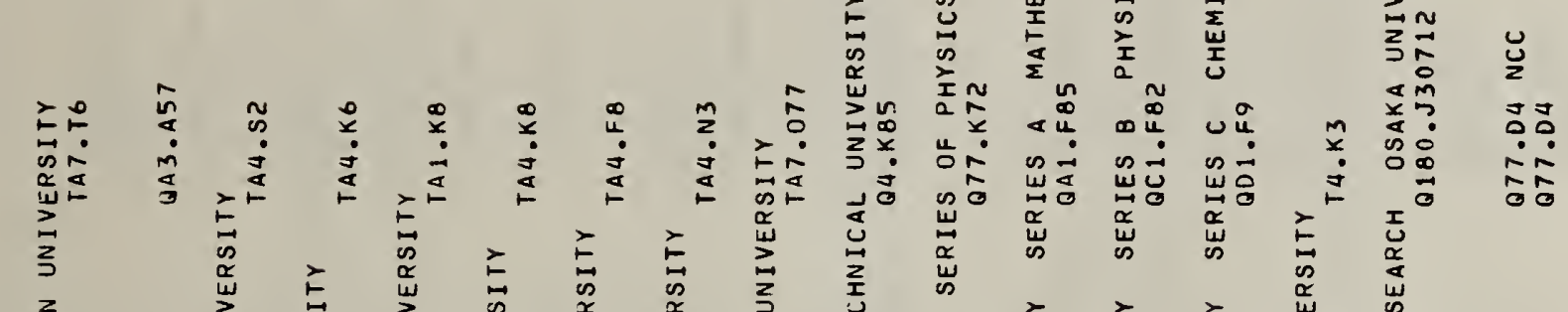

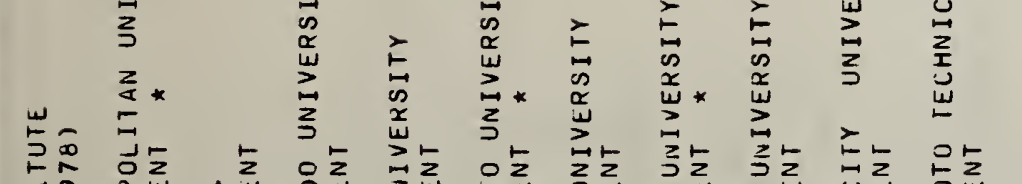

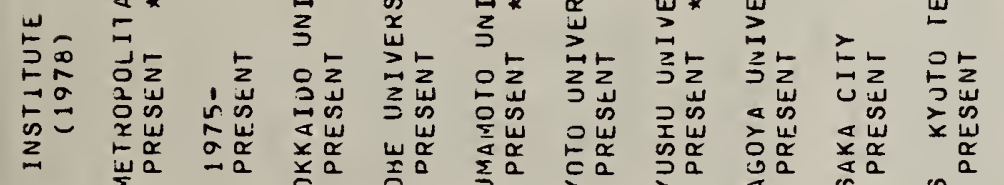

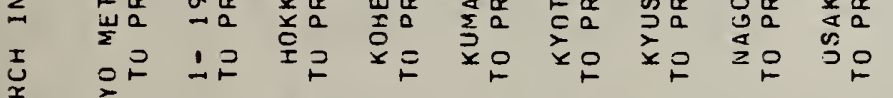

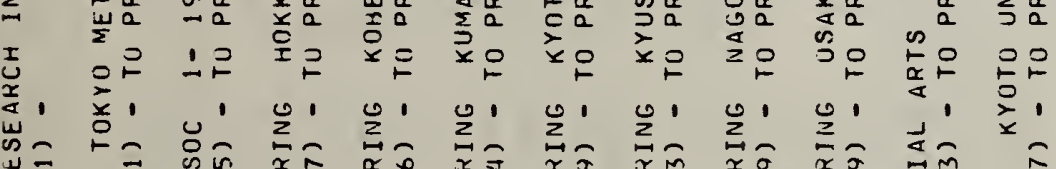

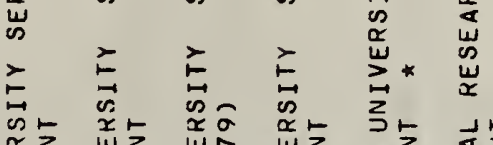

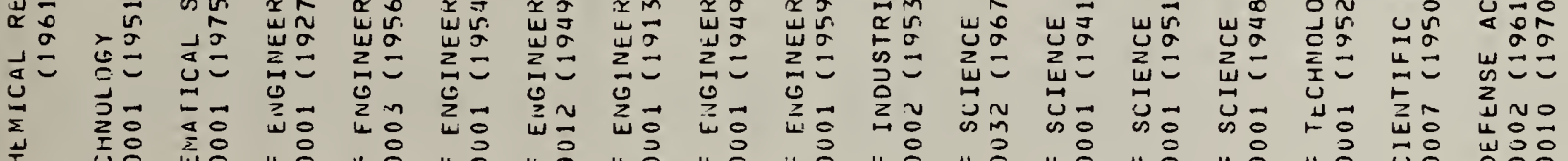
㲾造

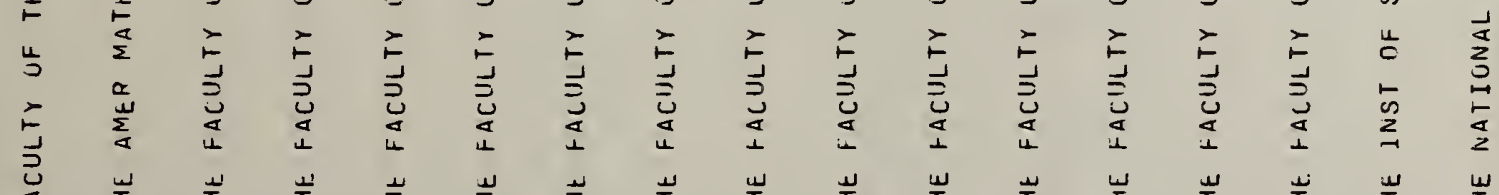

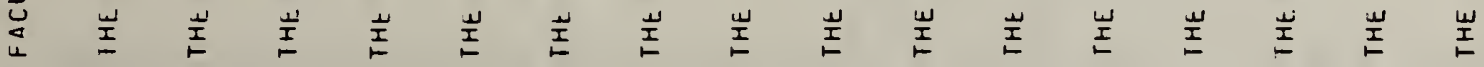

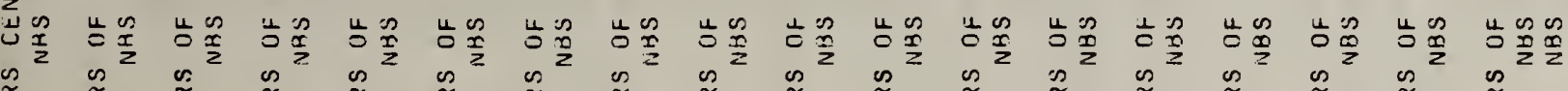

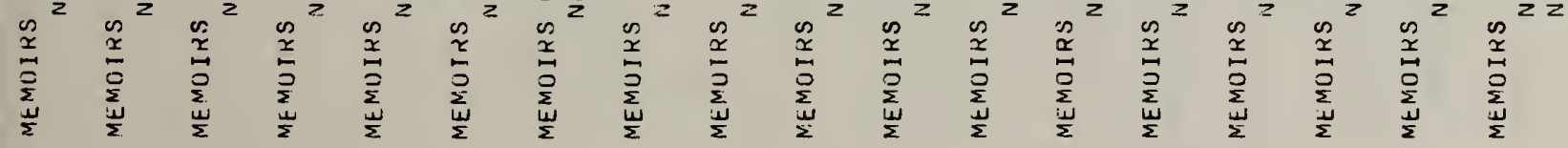




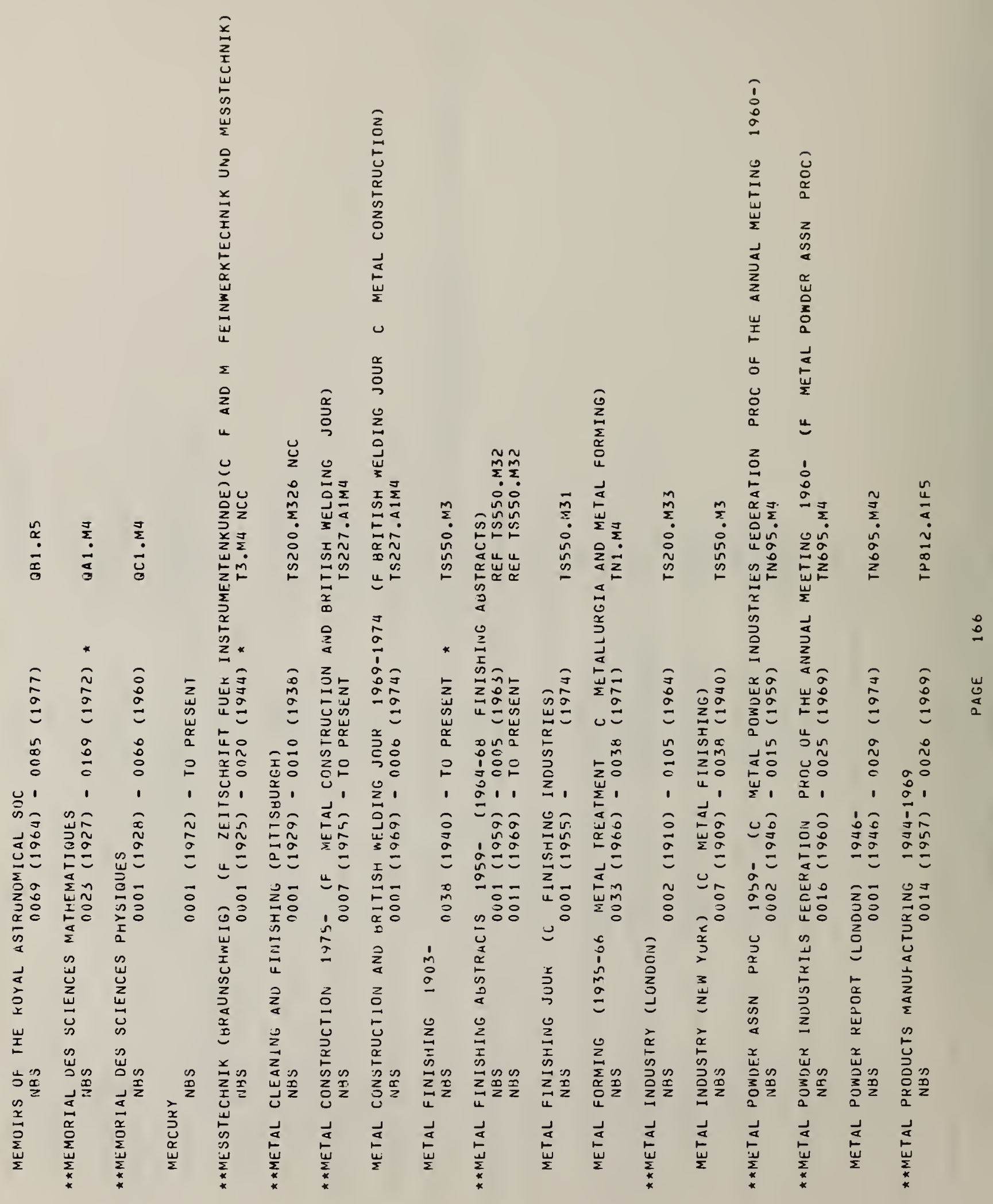




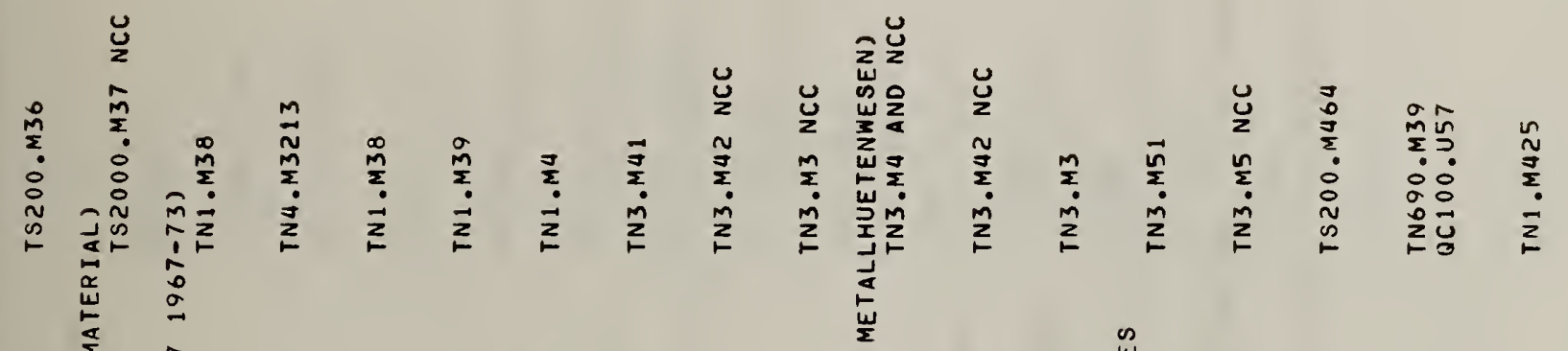

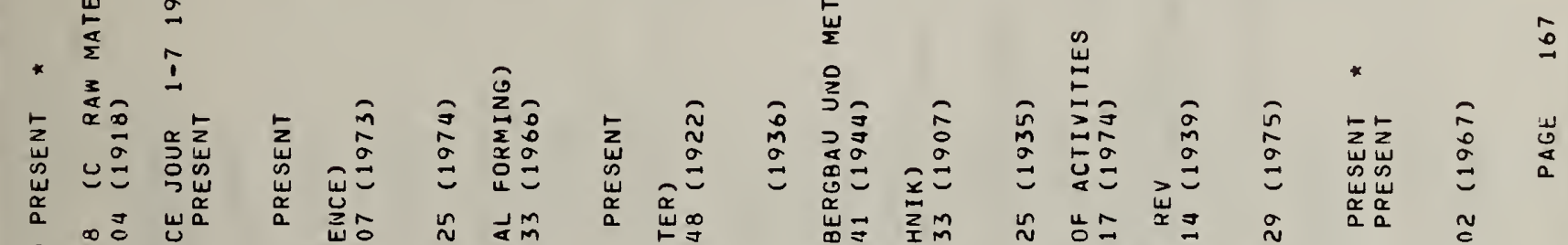

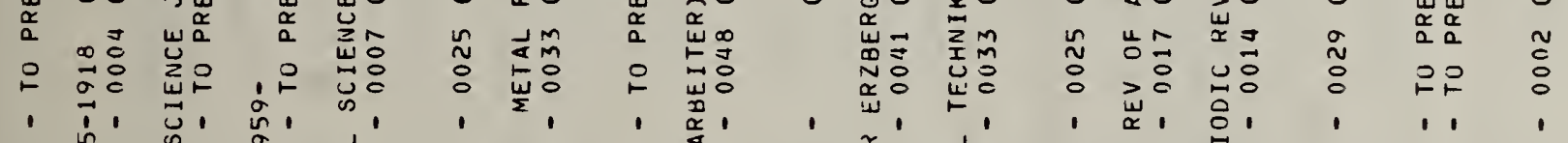

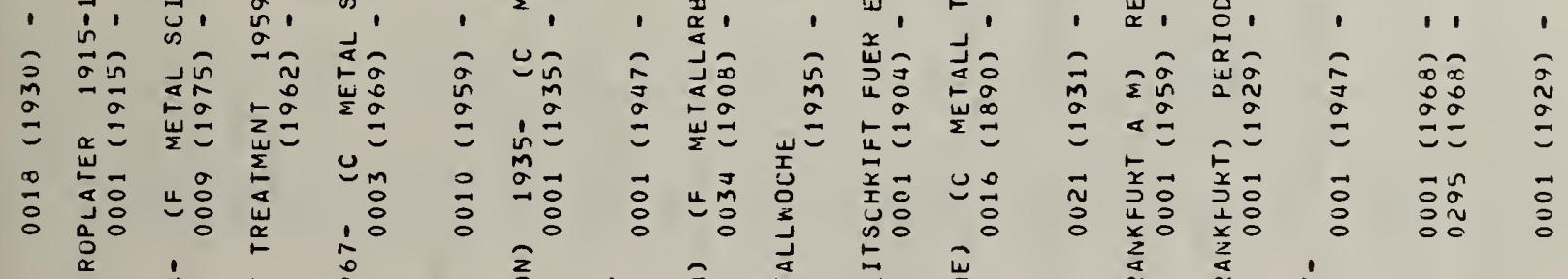 $\begin{array}{lll} & \\ 0\end{array}$

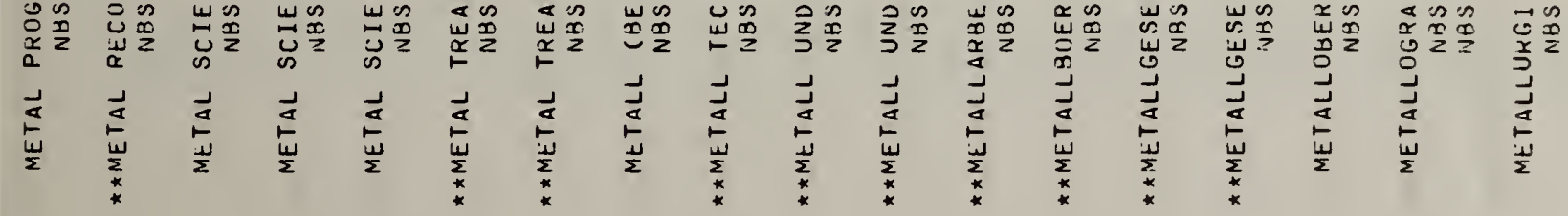




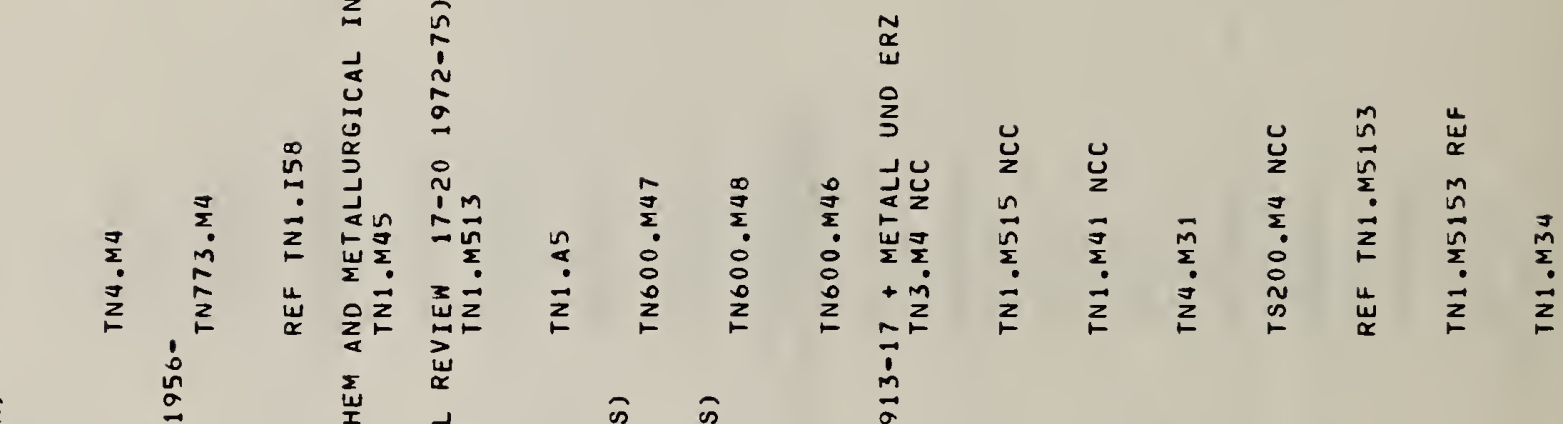

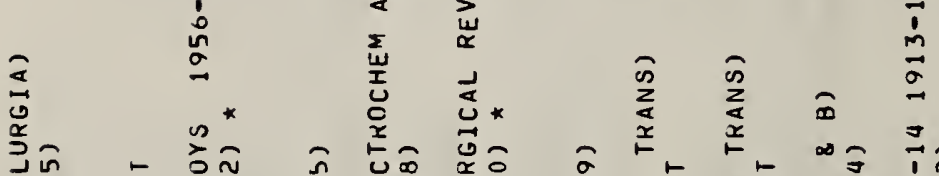

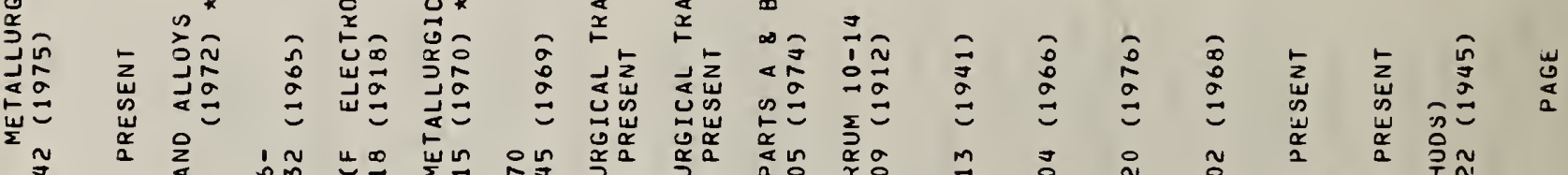

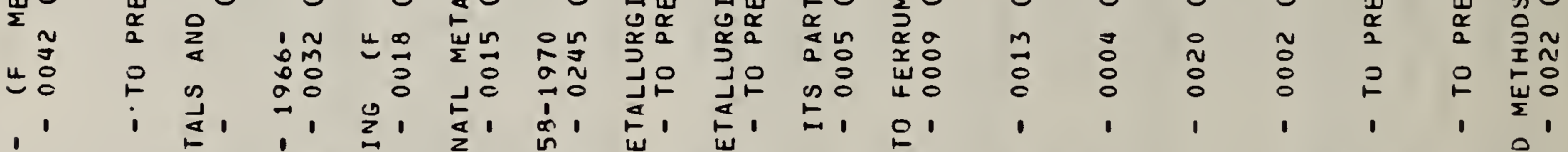

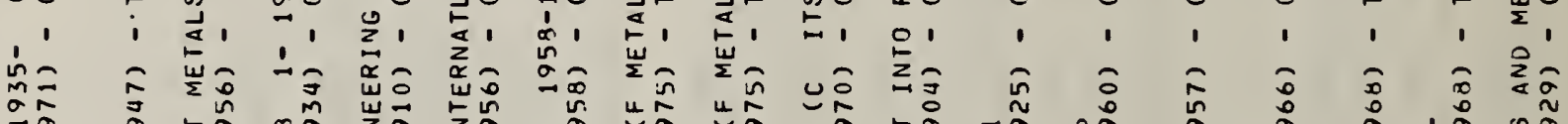

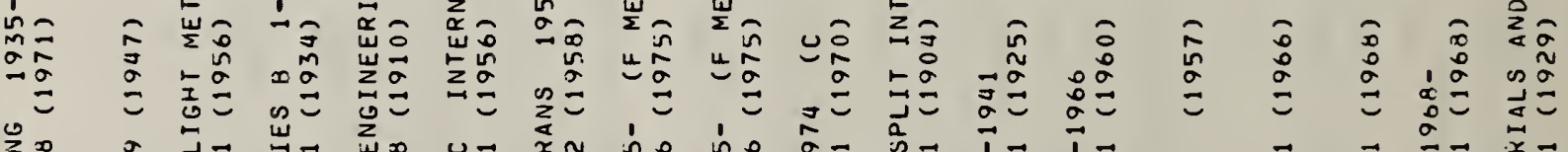

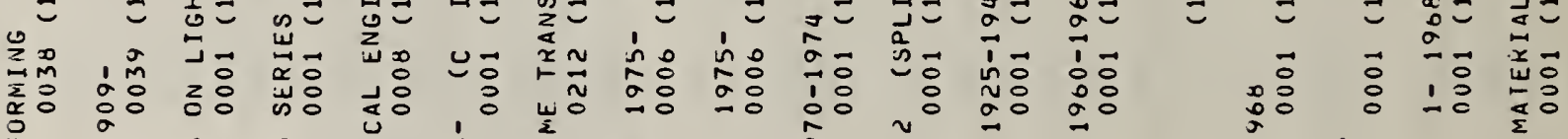

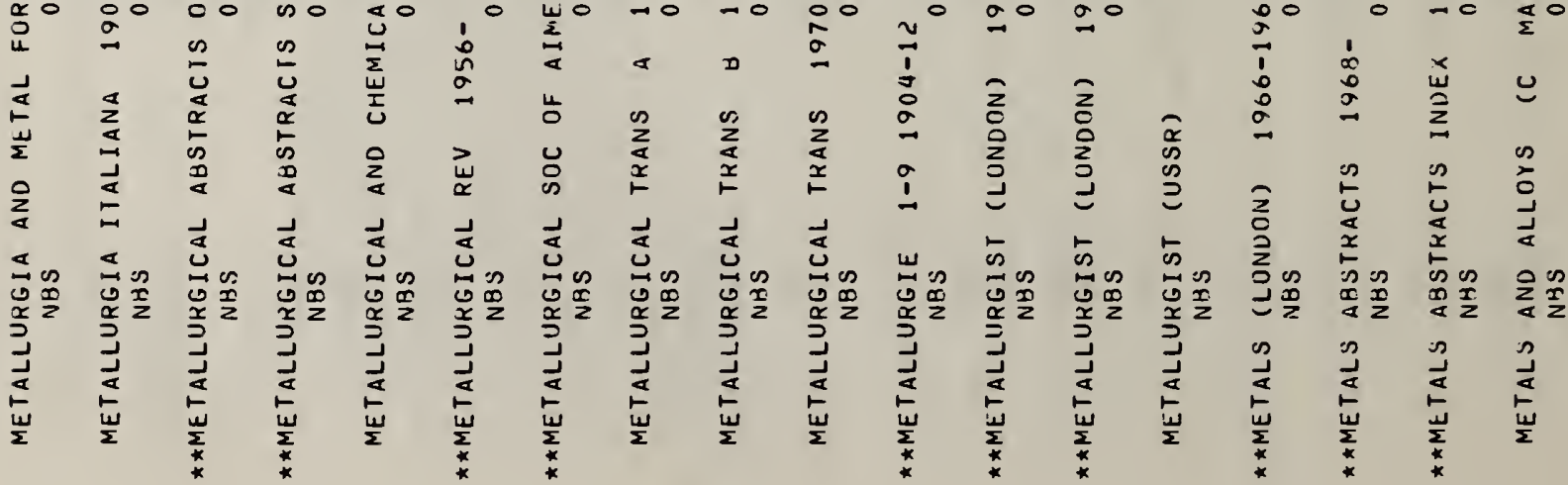




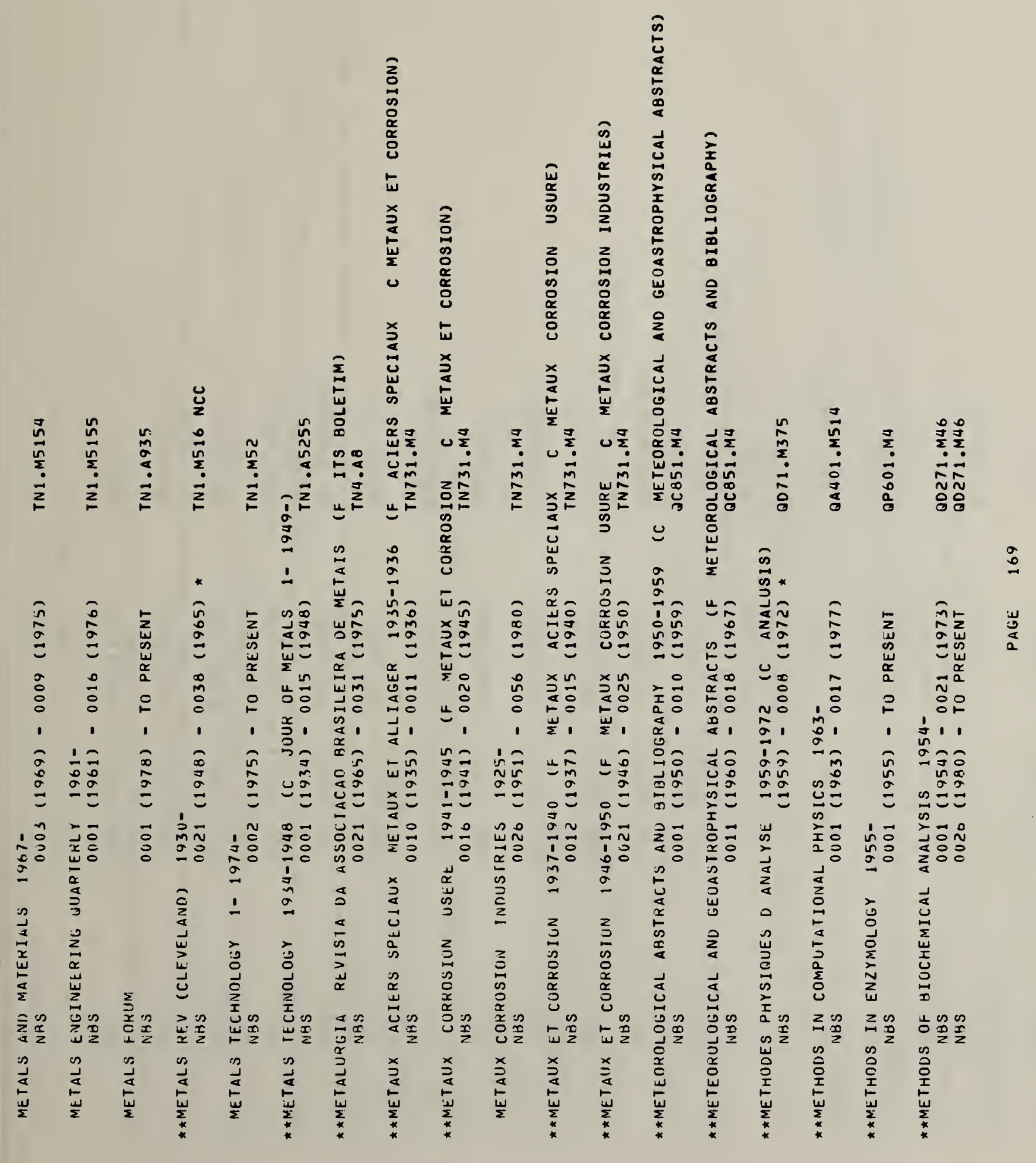




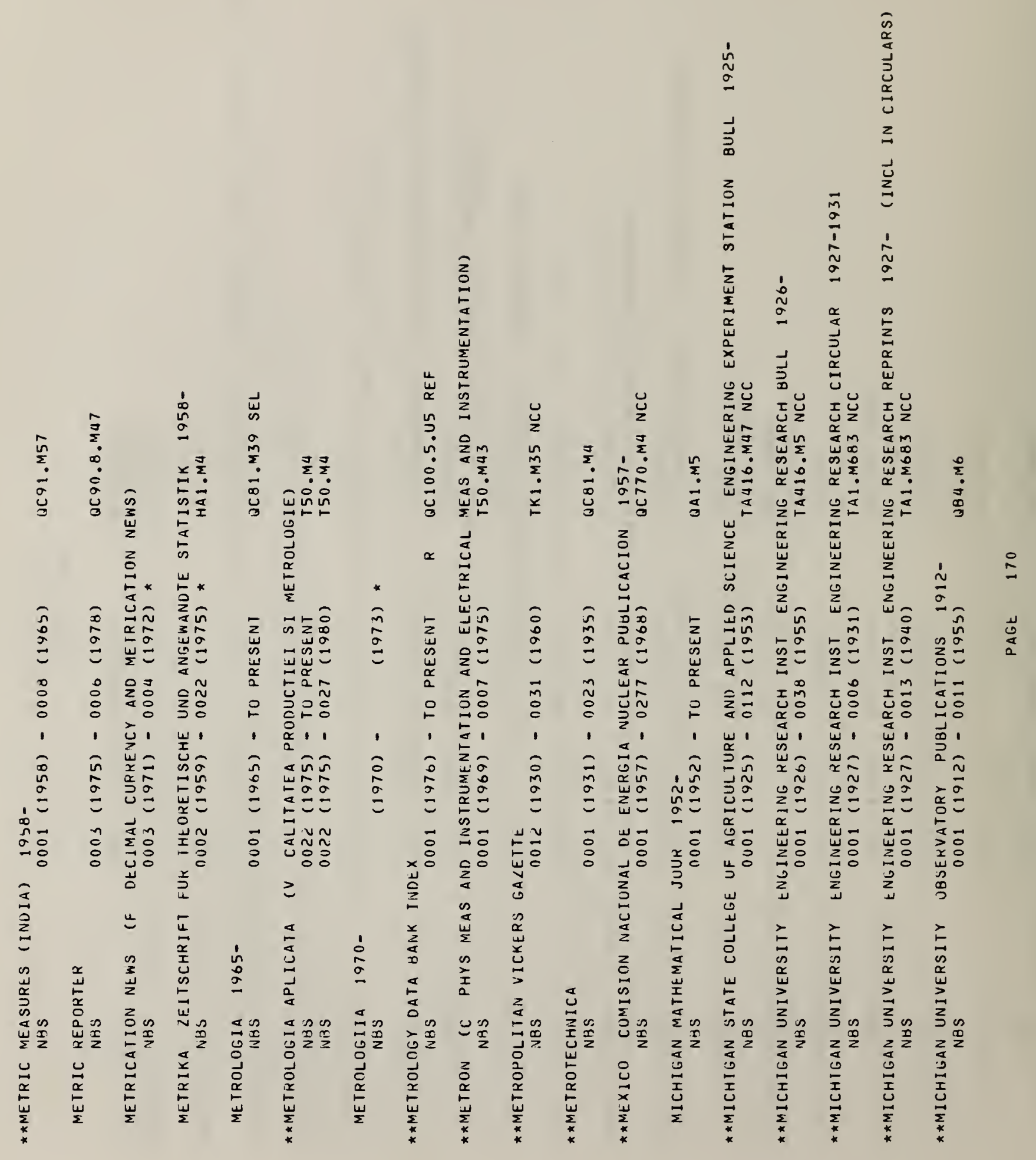




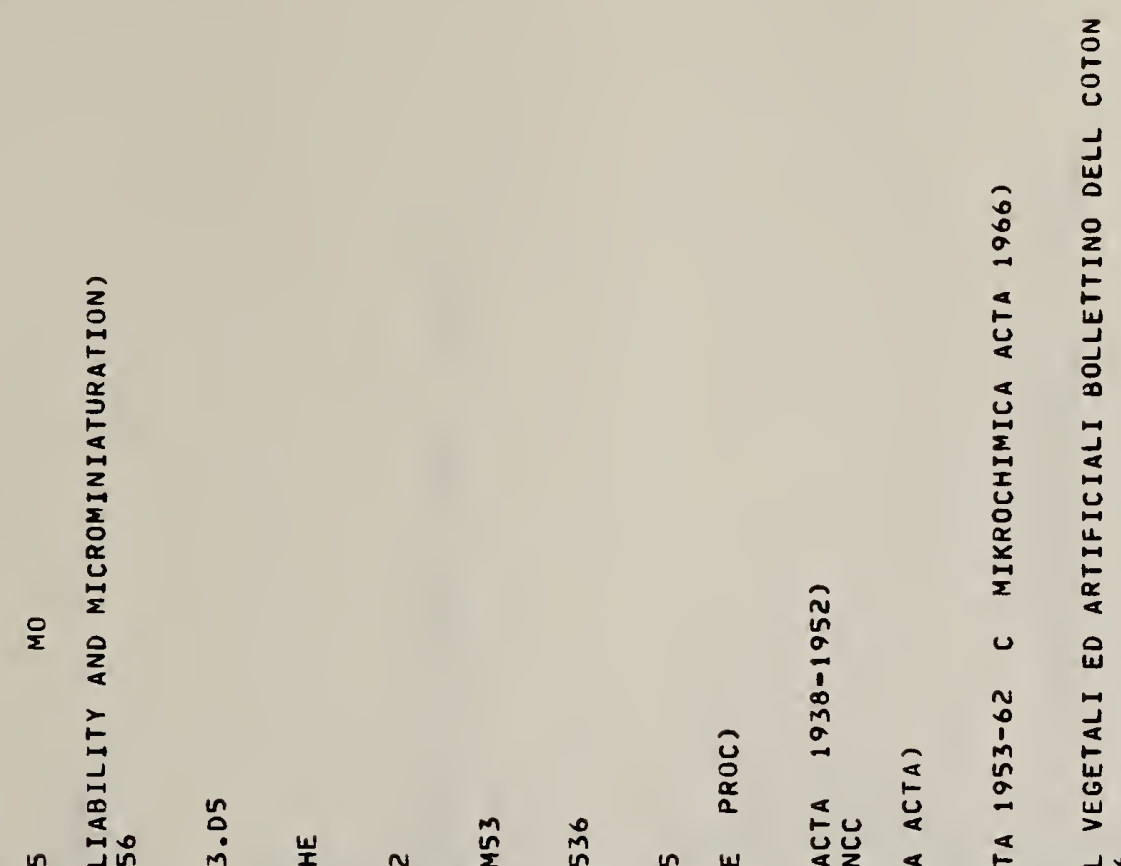

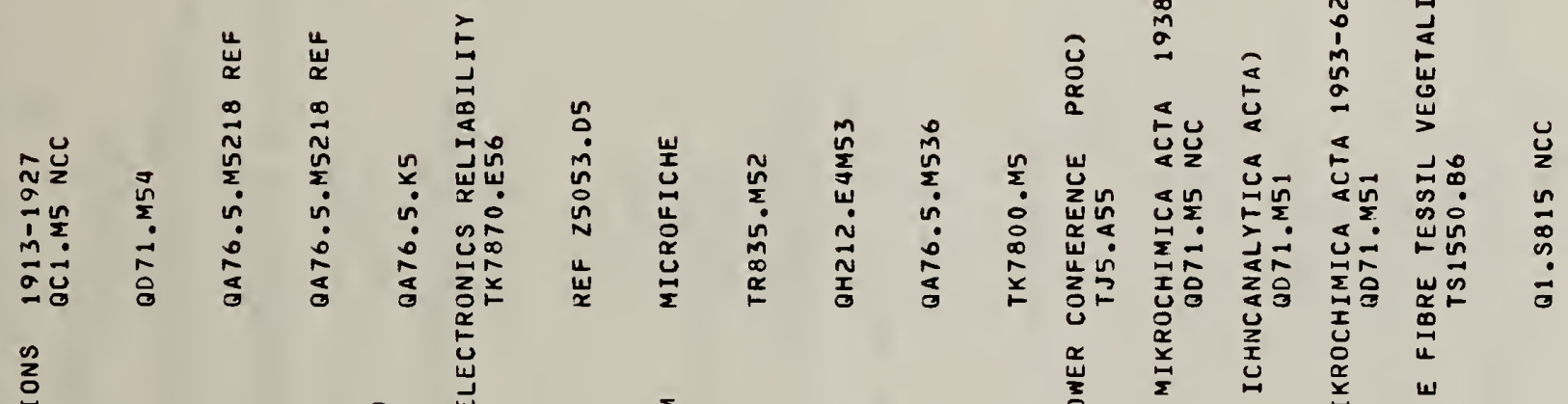

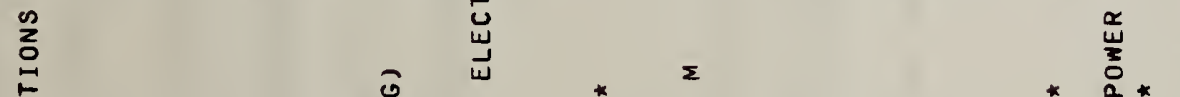

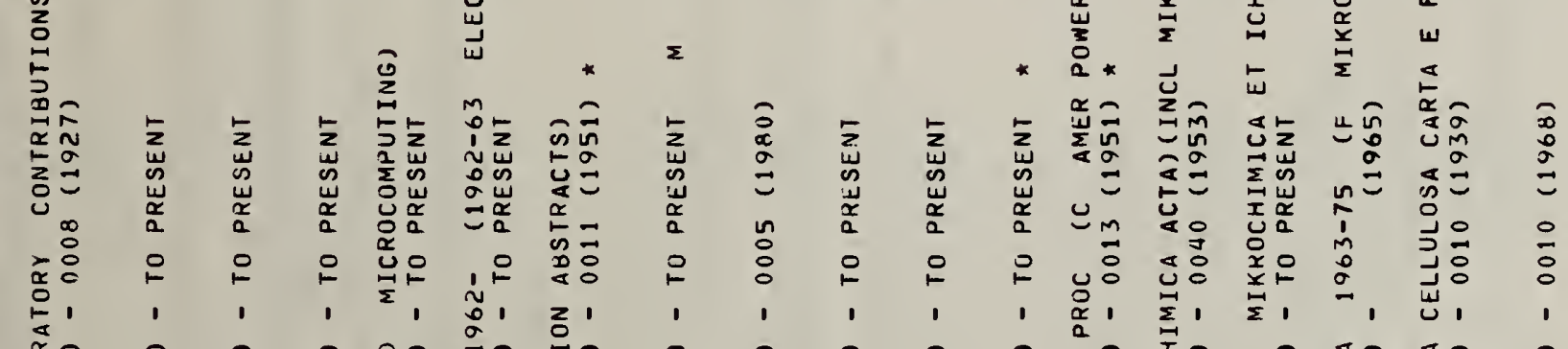

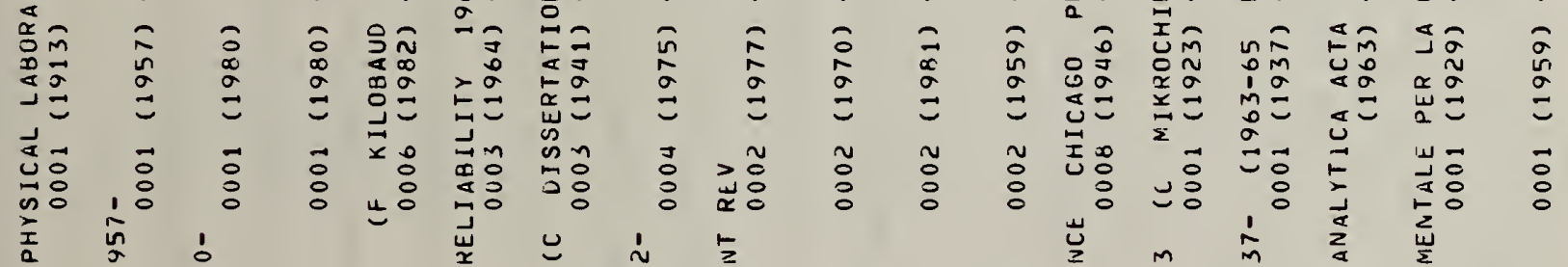

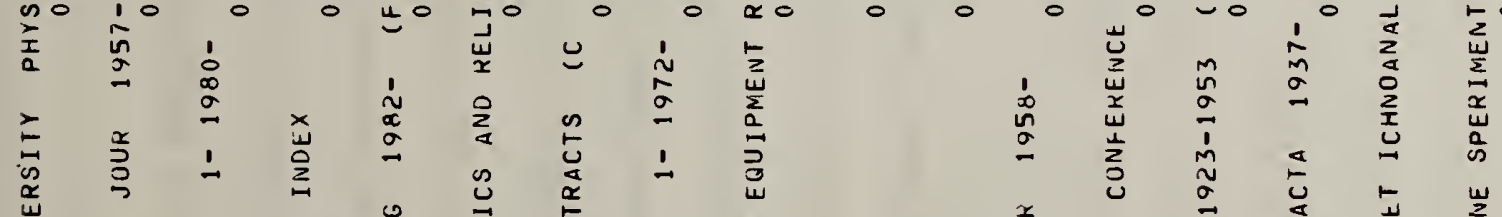

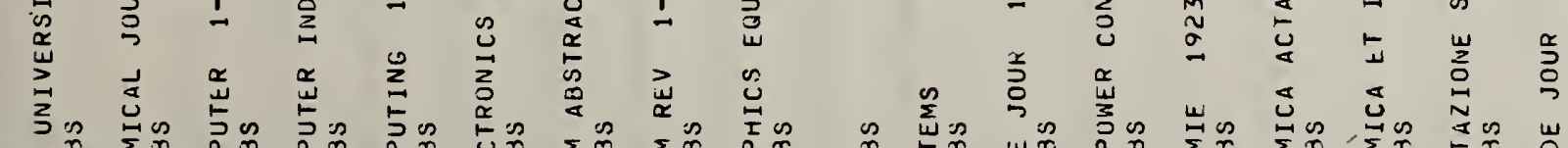

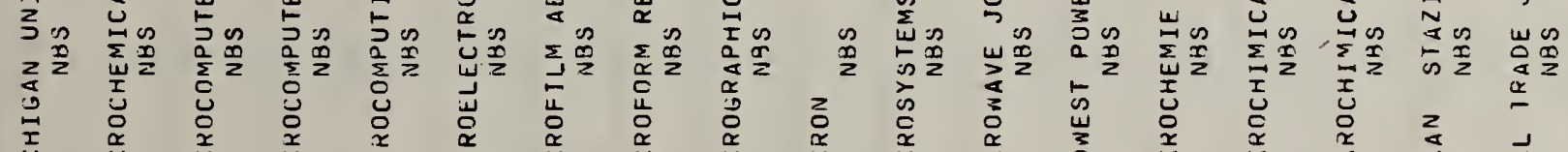

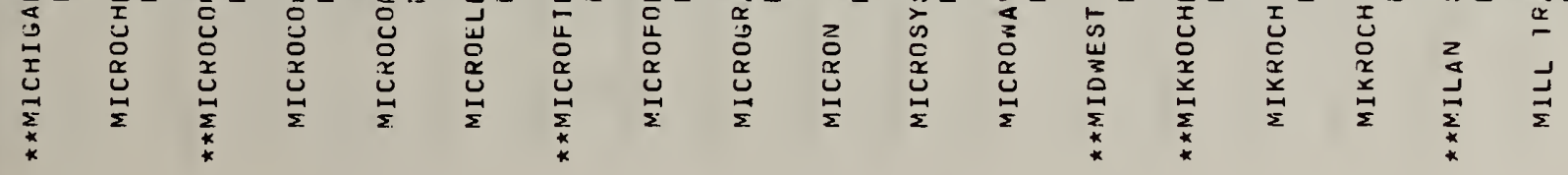




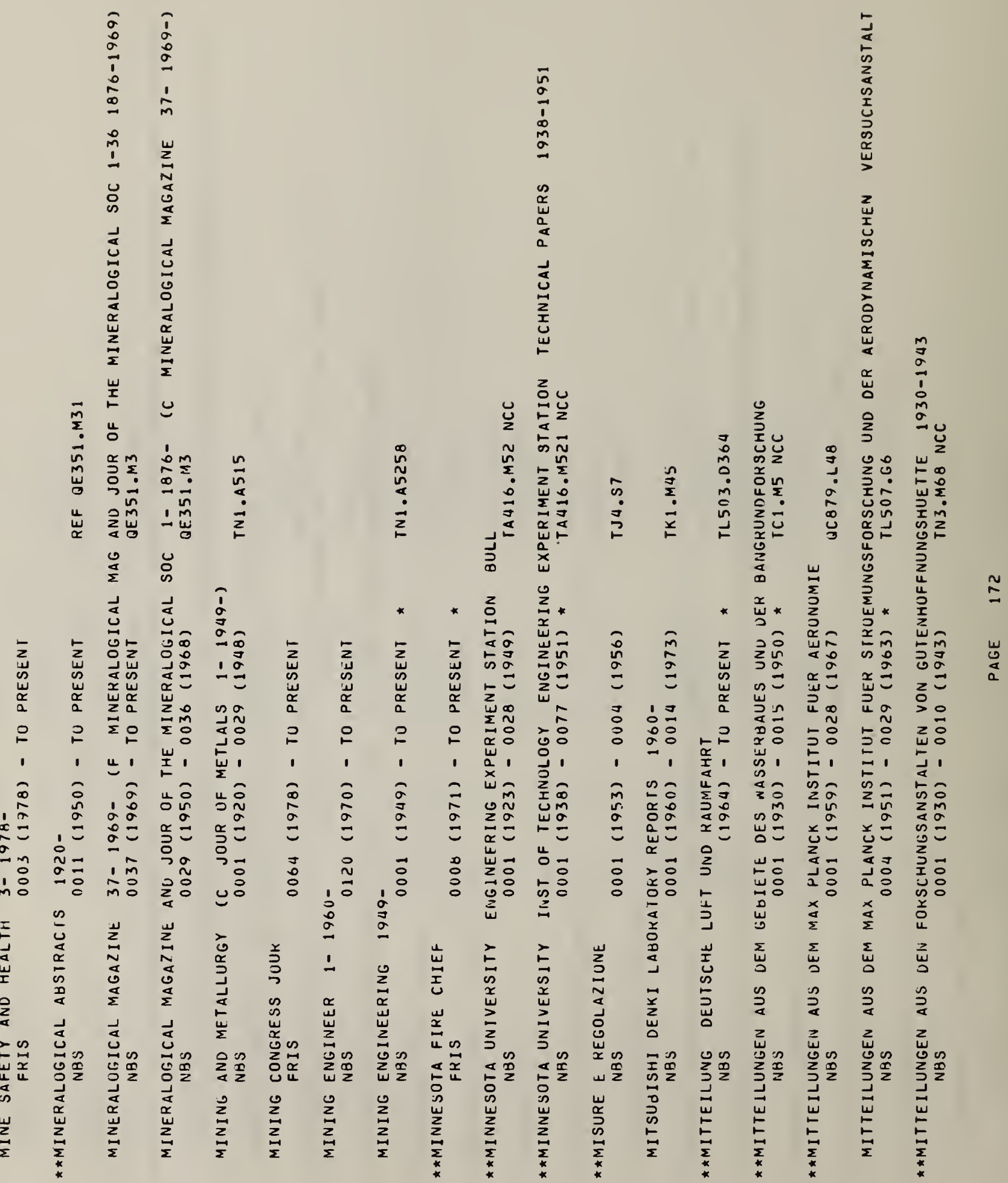




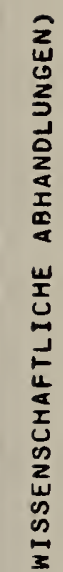

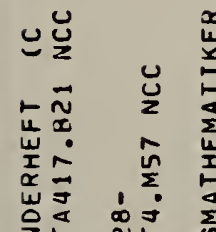

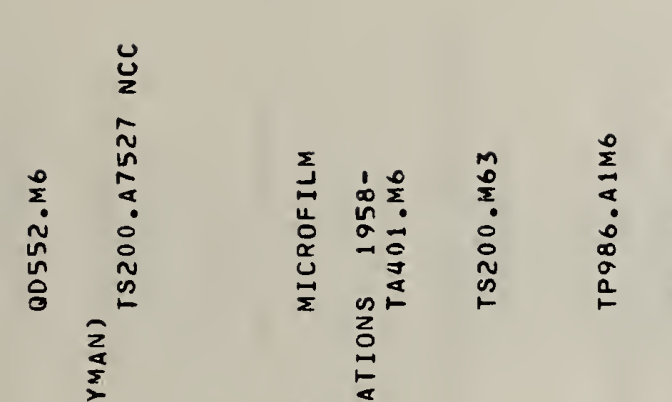

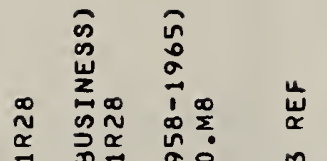

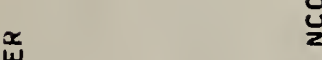

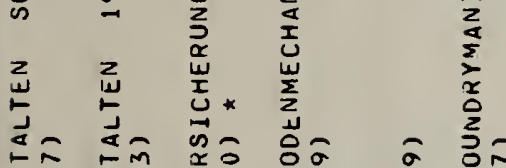

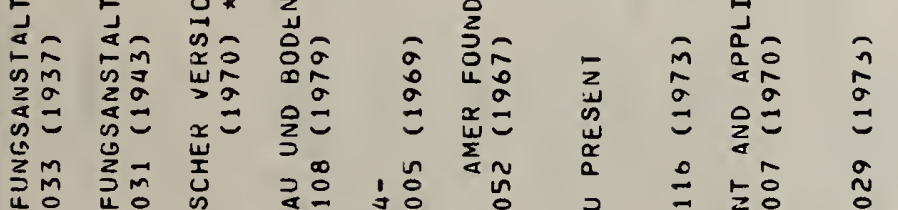

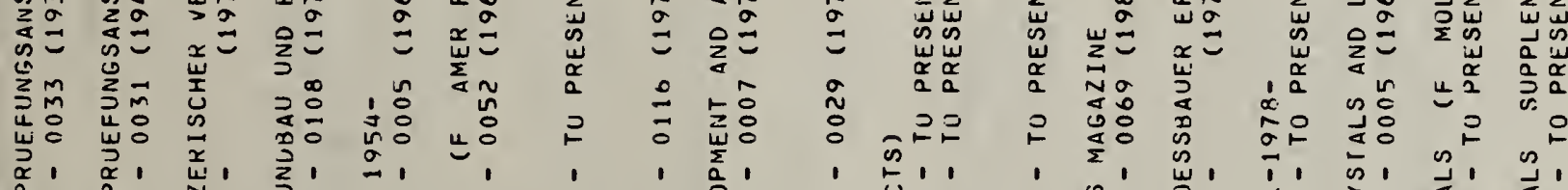

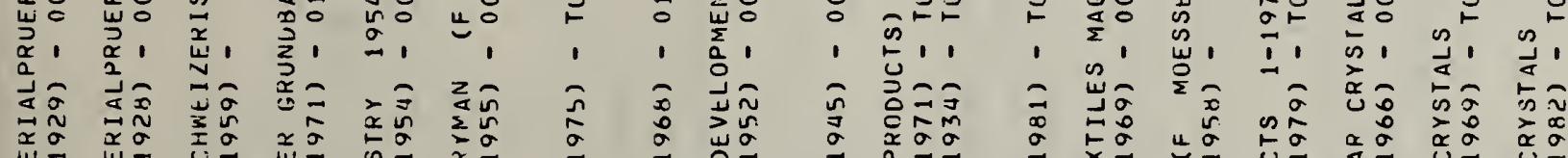
嵌こ

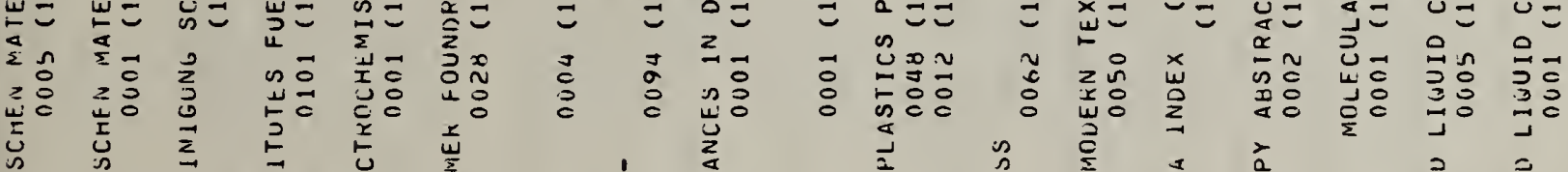

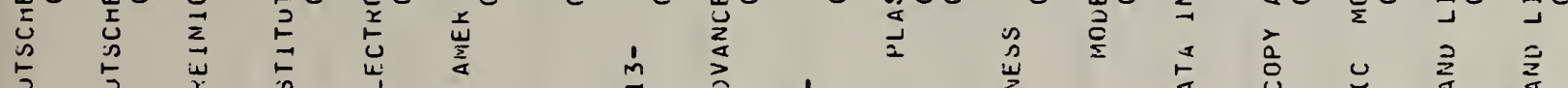

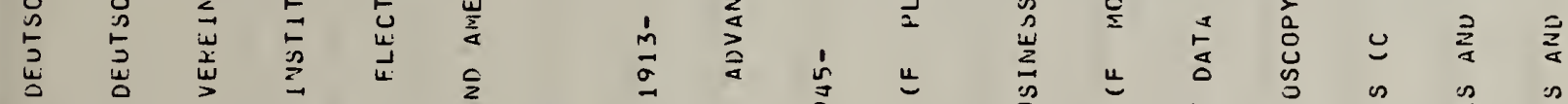

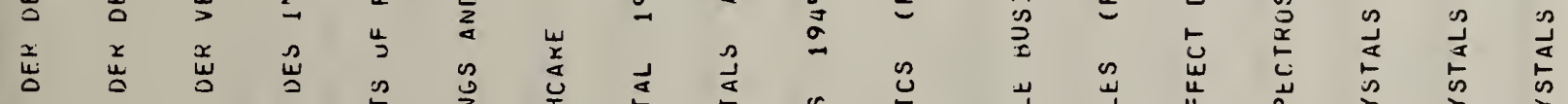

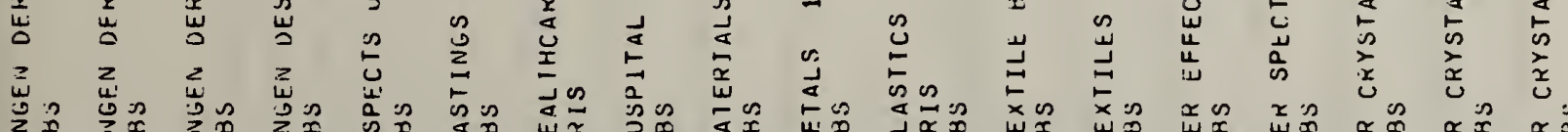

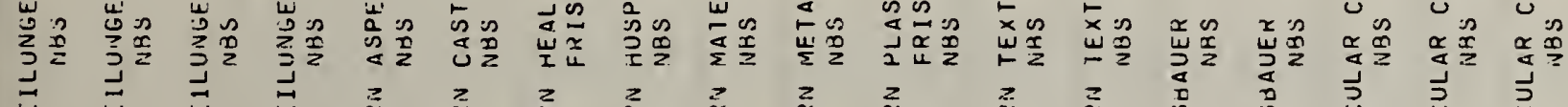

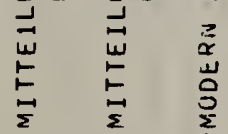
鄯 䇏 嚊 善商

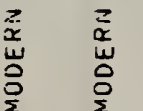
咅旁 


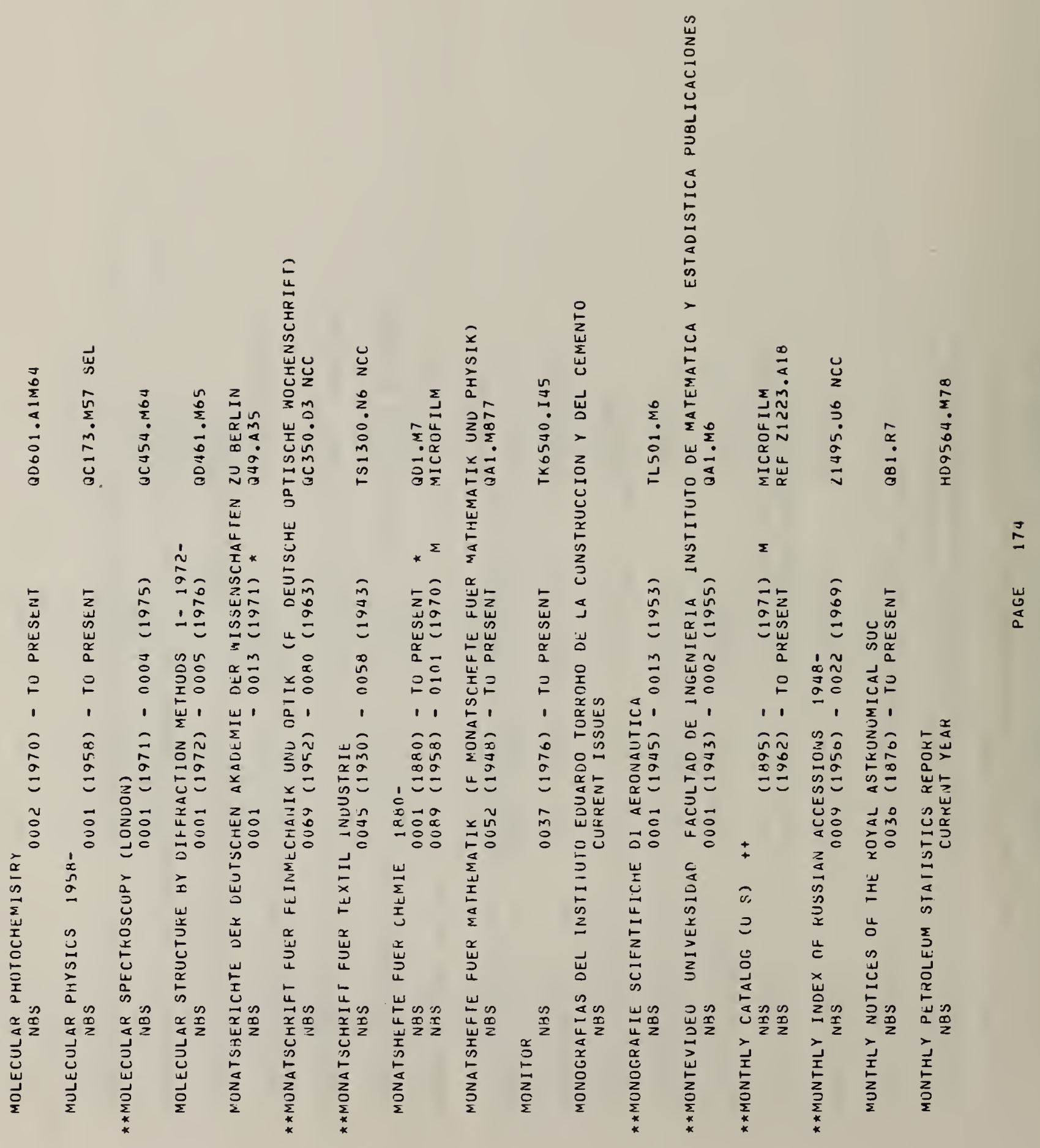




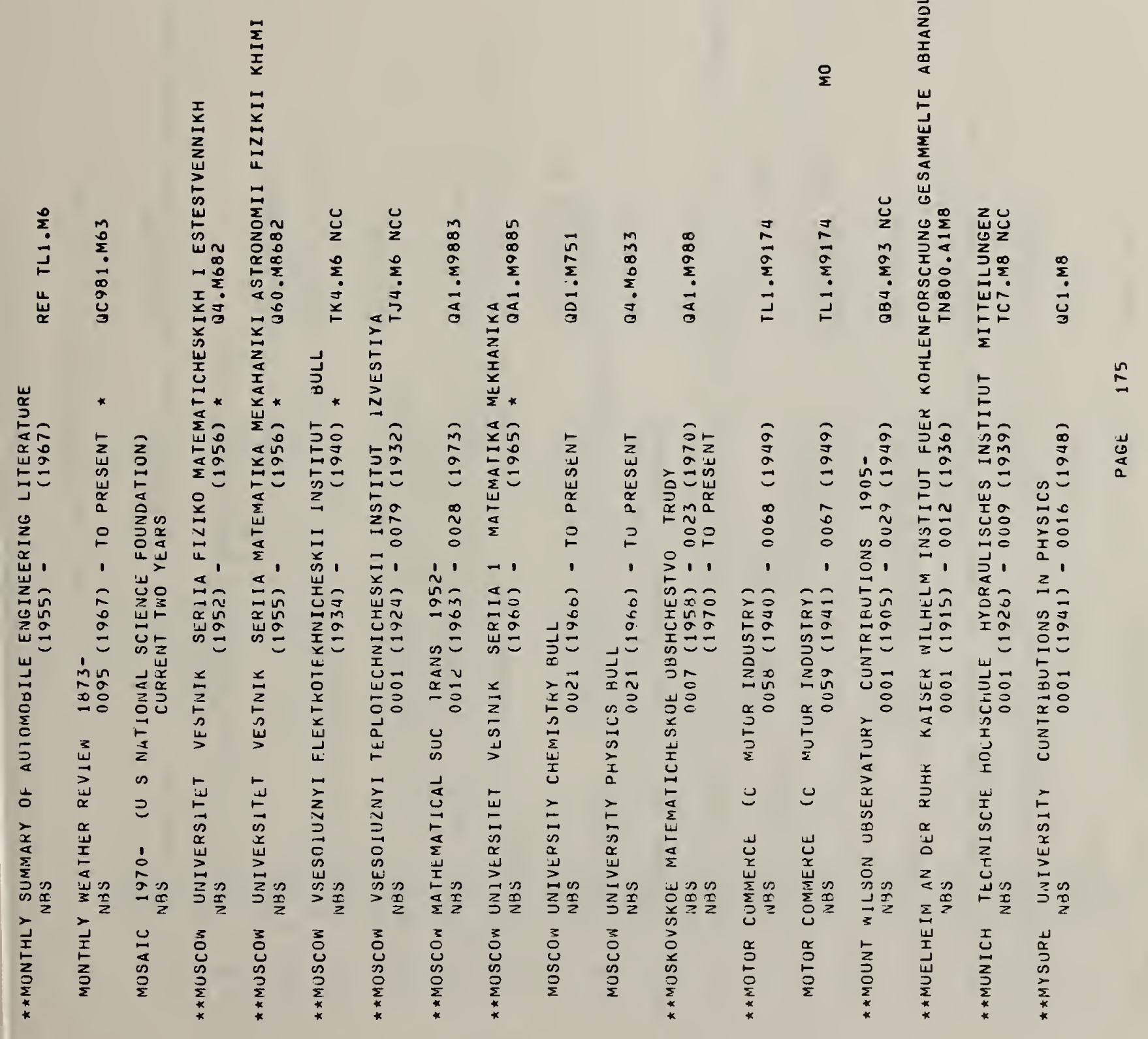




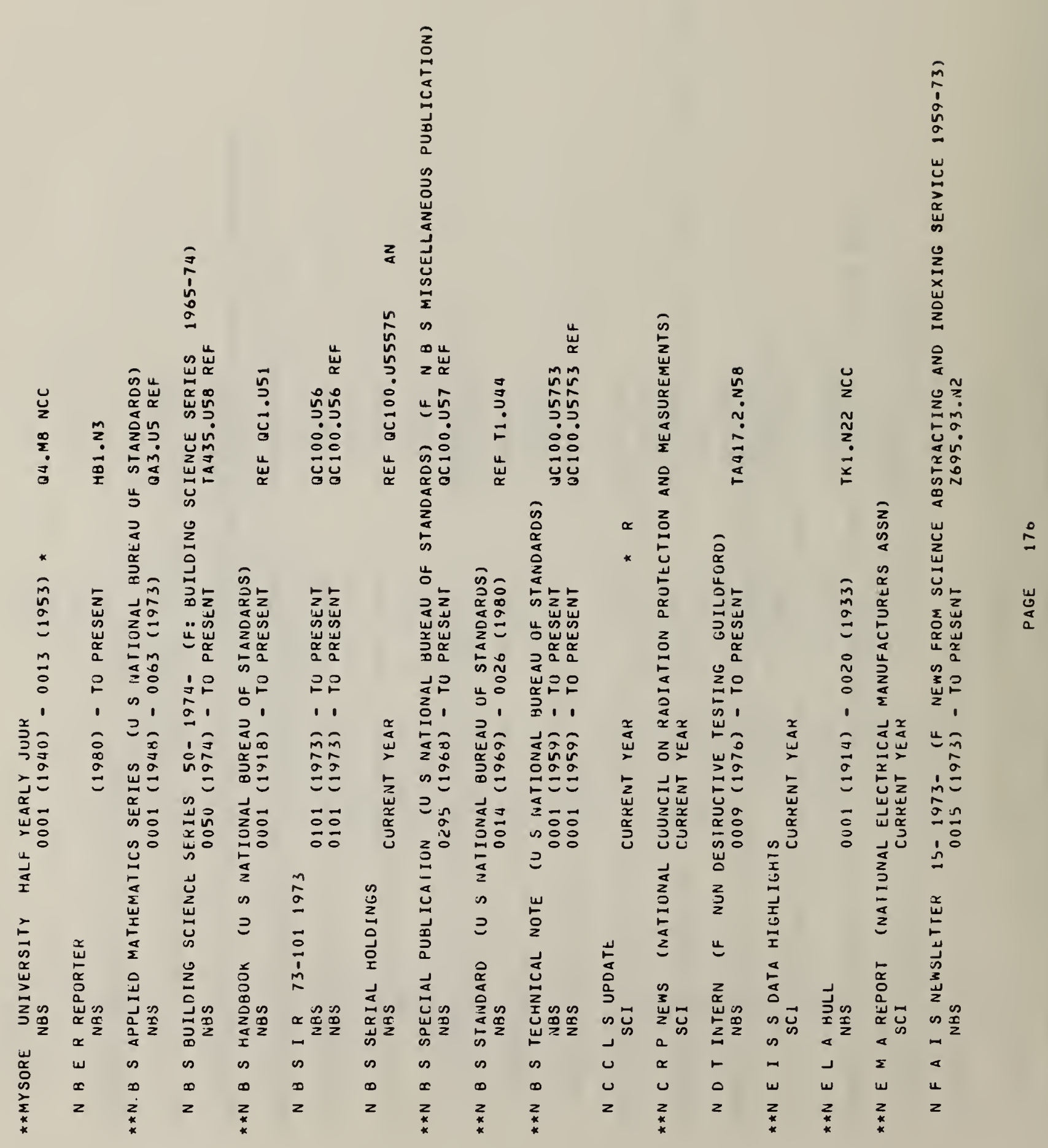




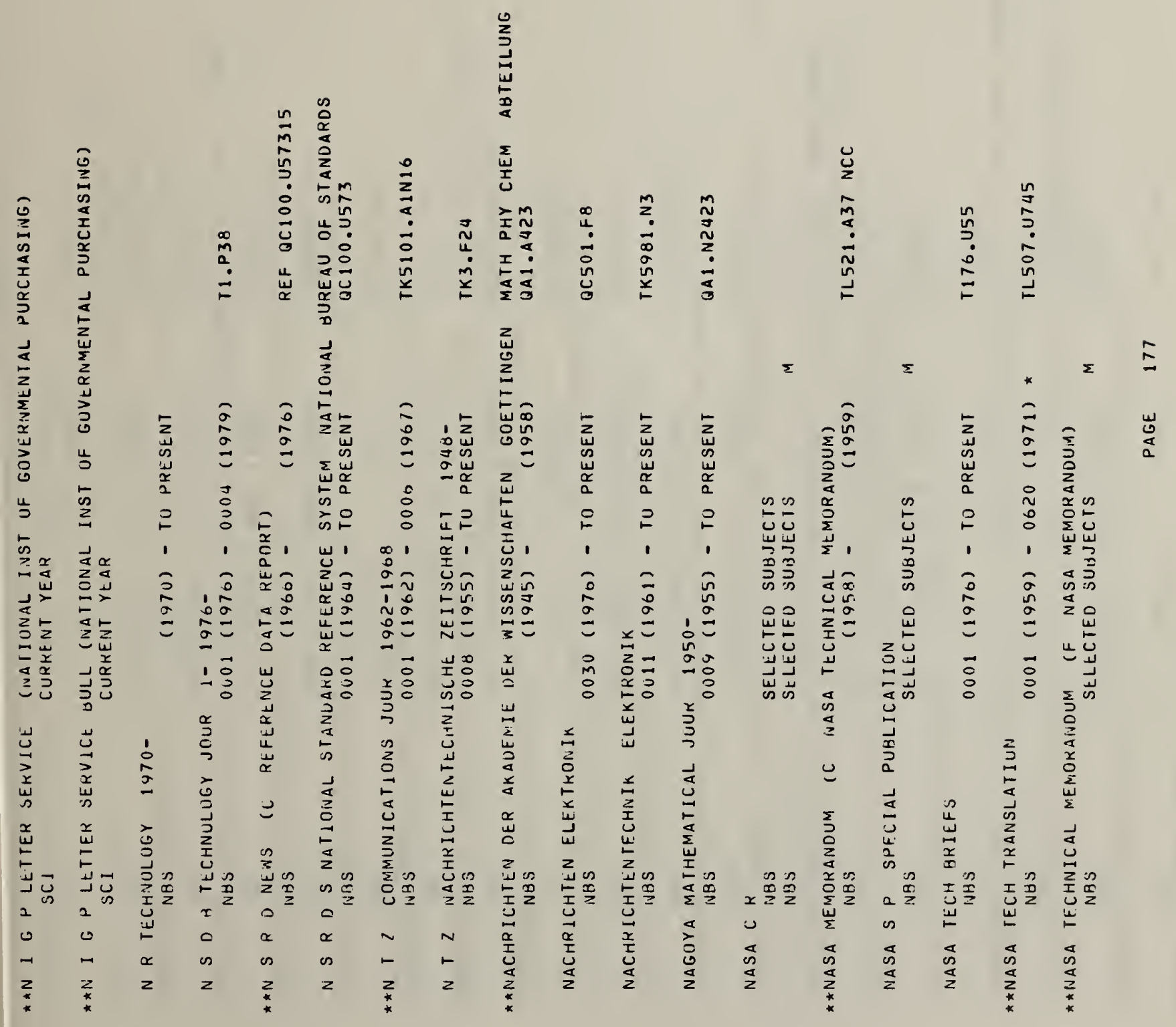




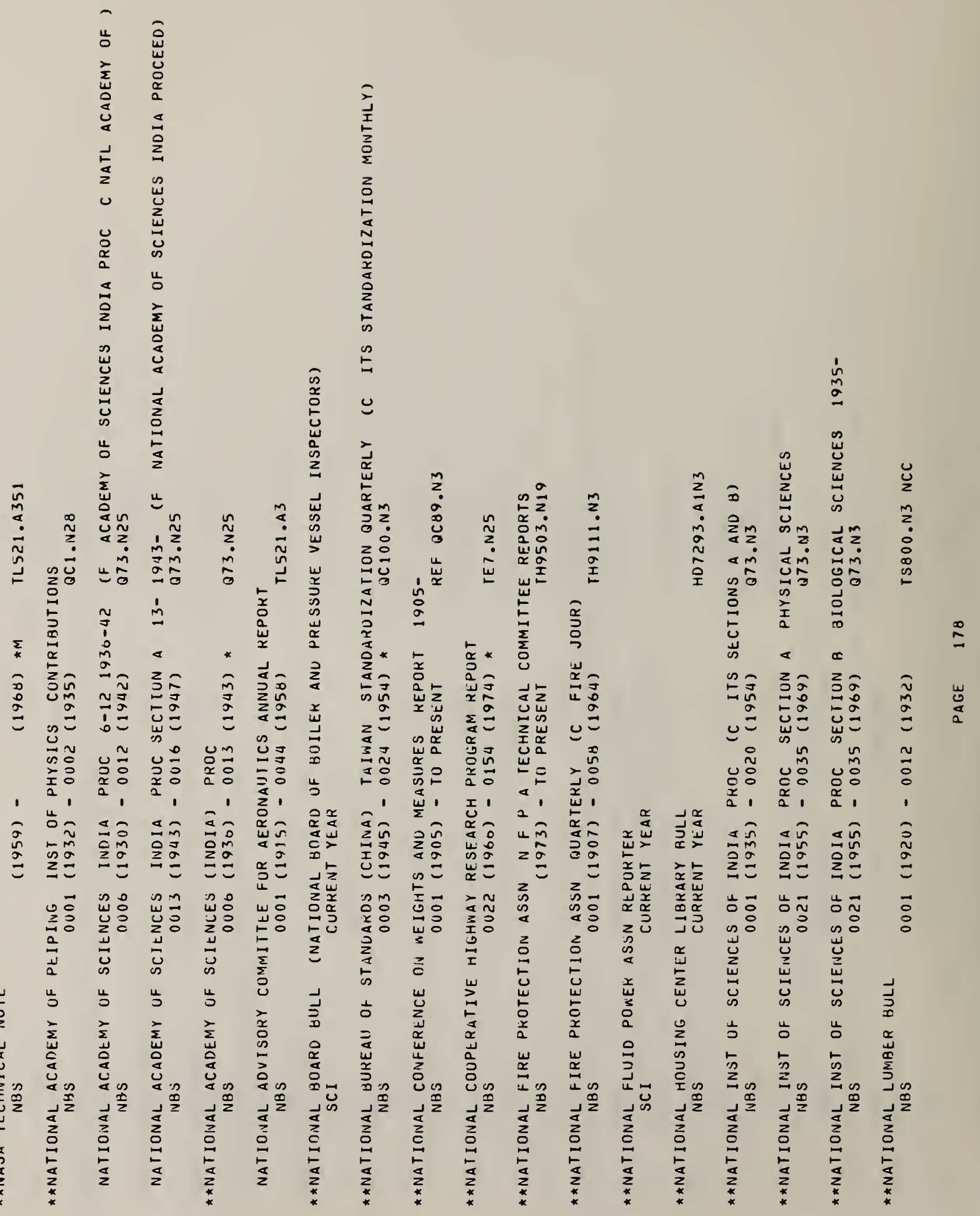




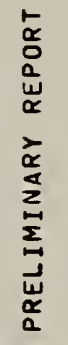

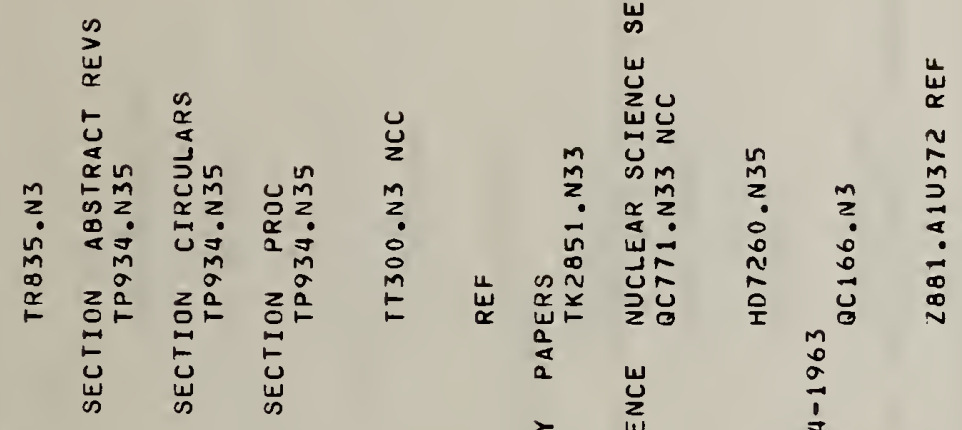
点

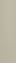

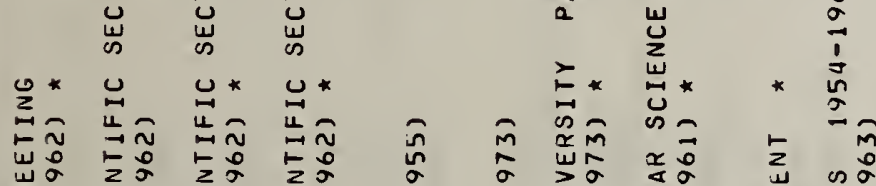

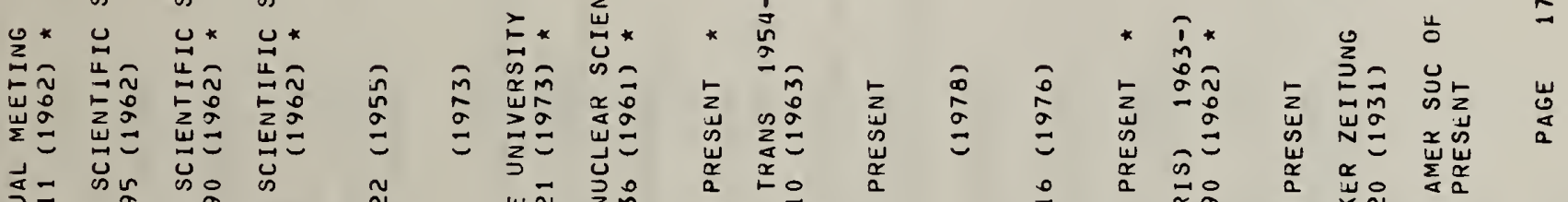

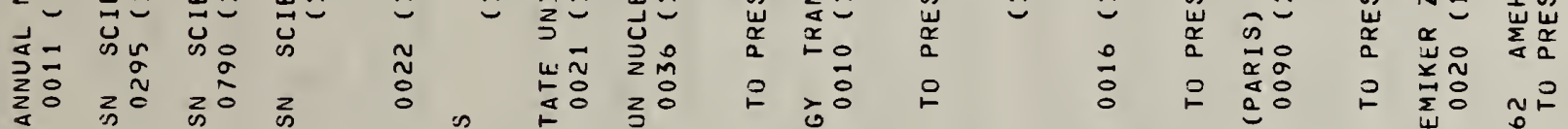

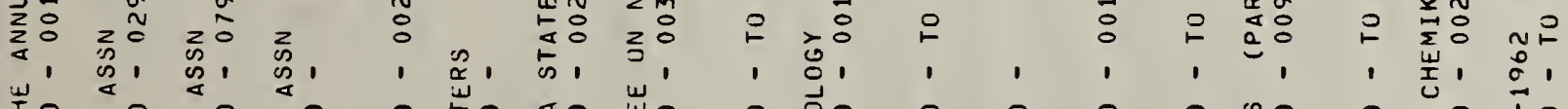

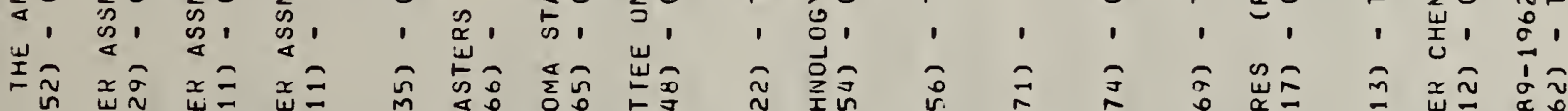

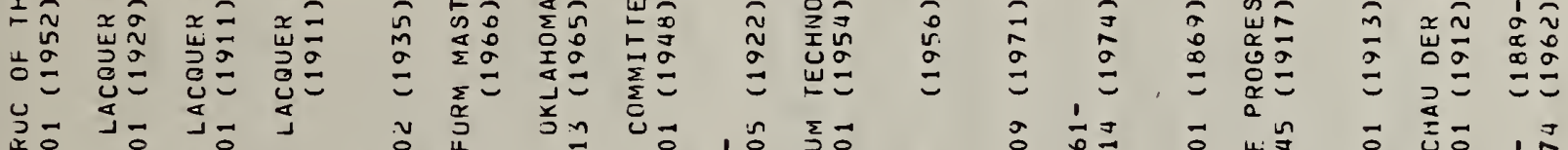

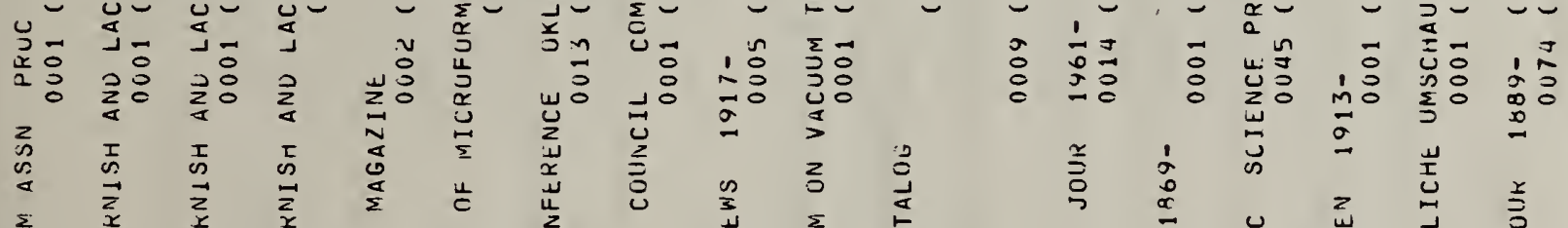




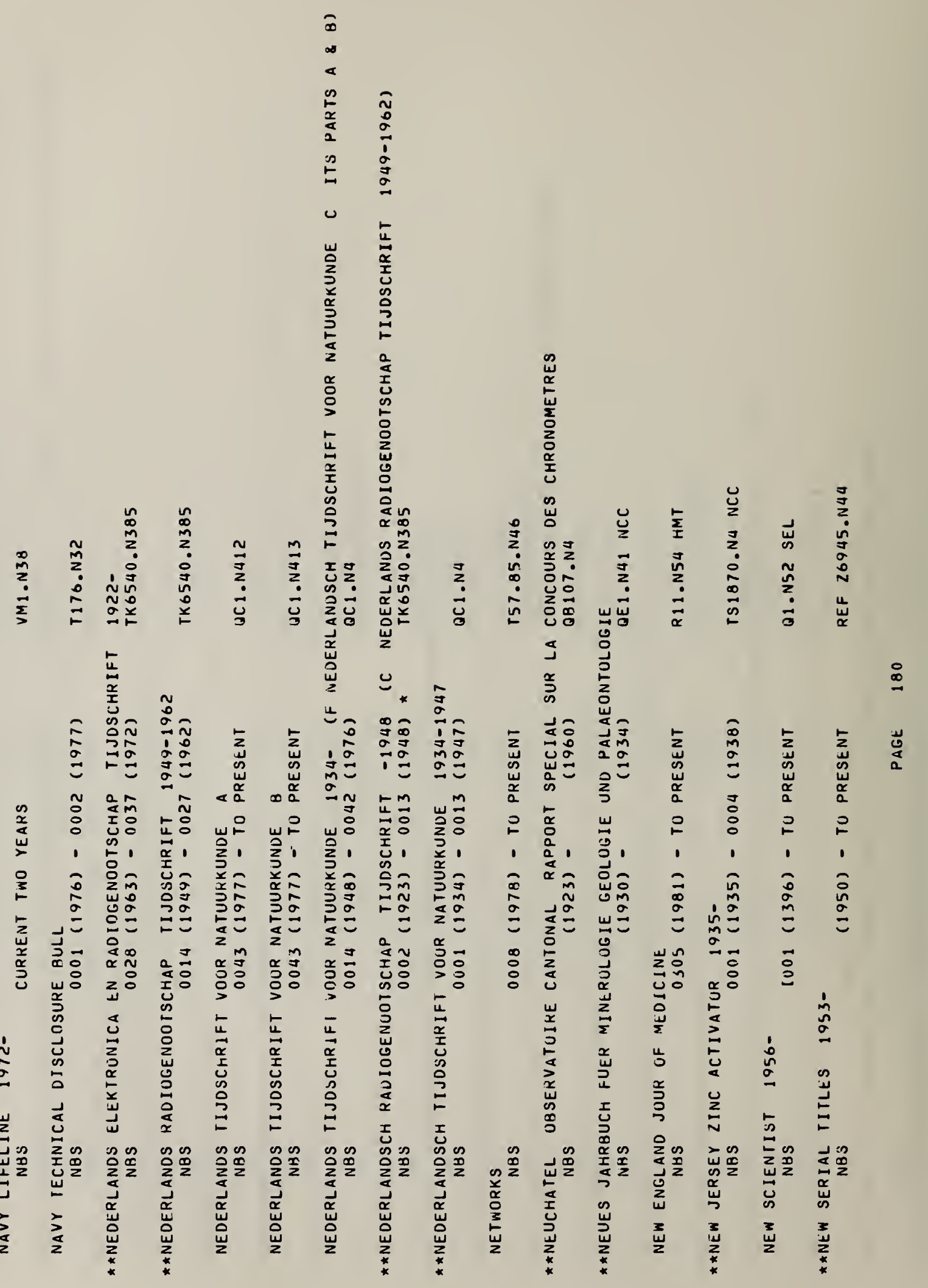




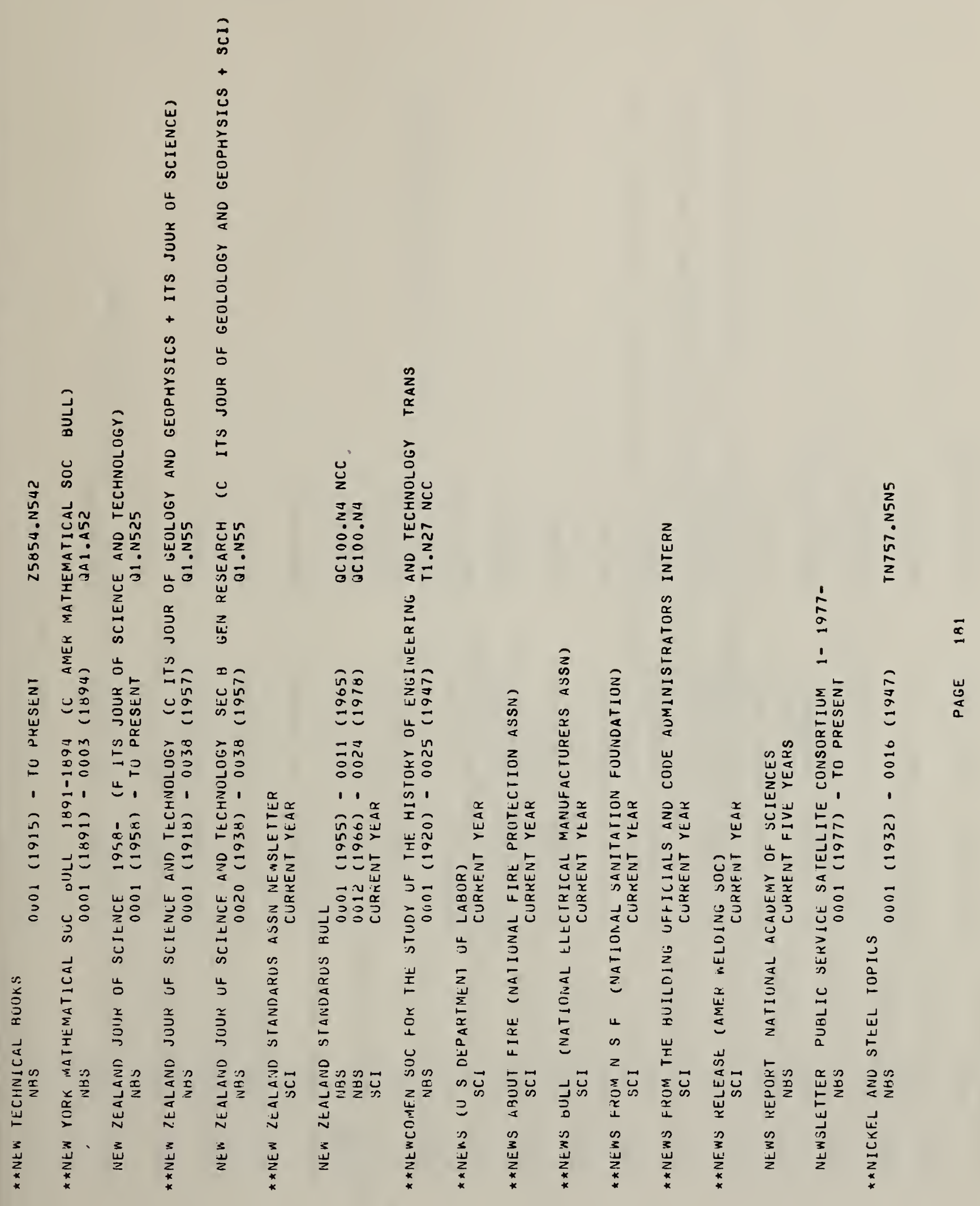


$\stackrel{u}{\mathbf{U}}$

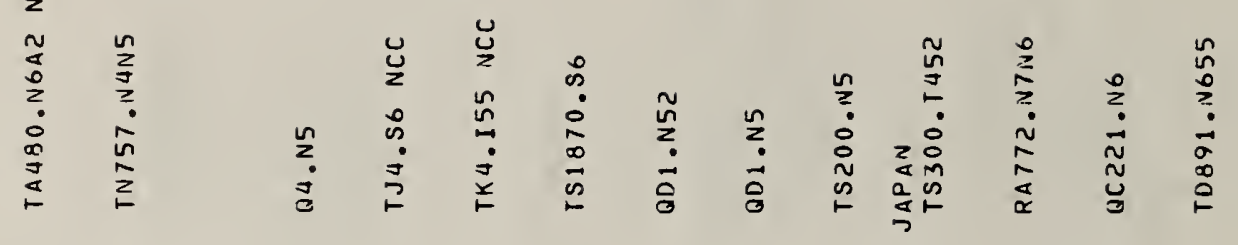

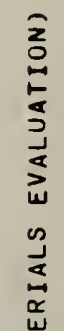

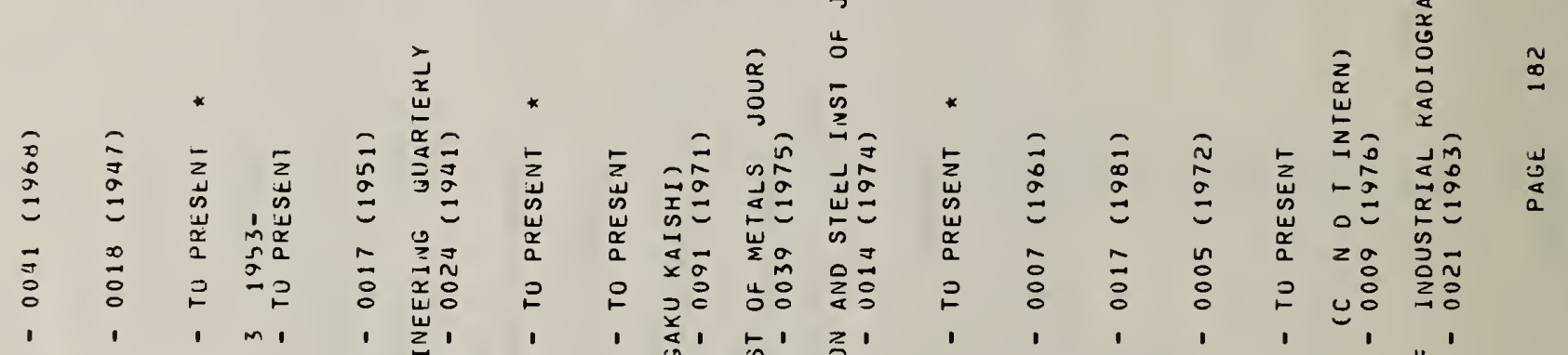

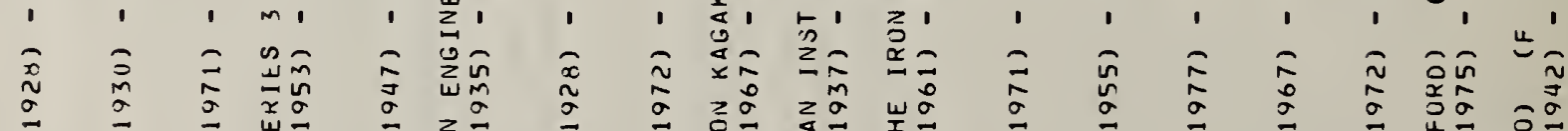

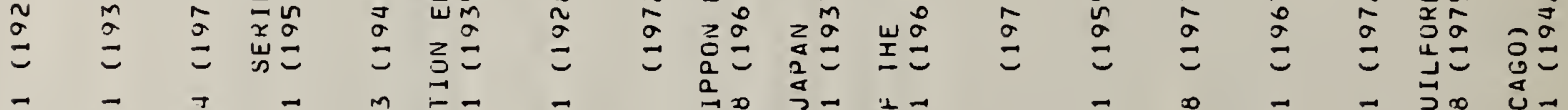

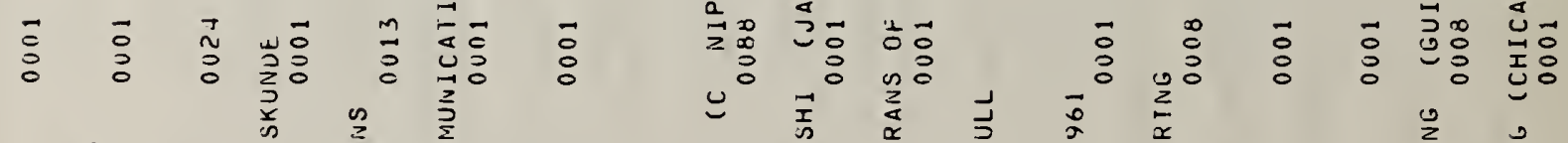

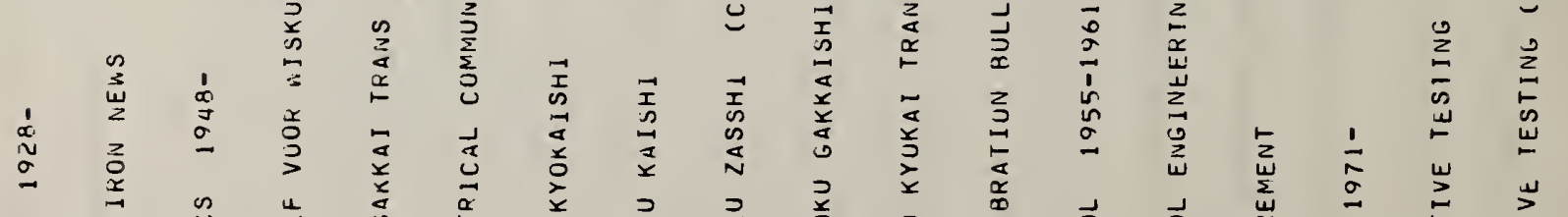

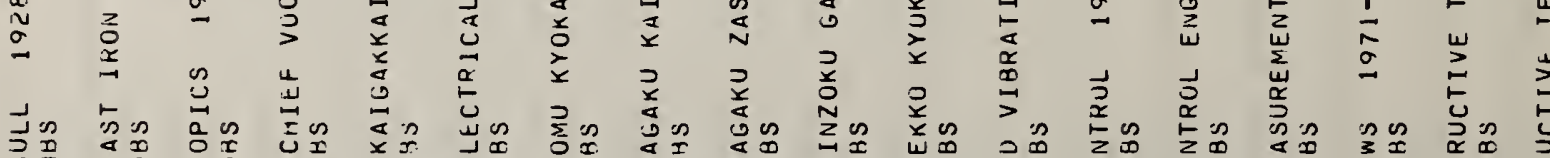

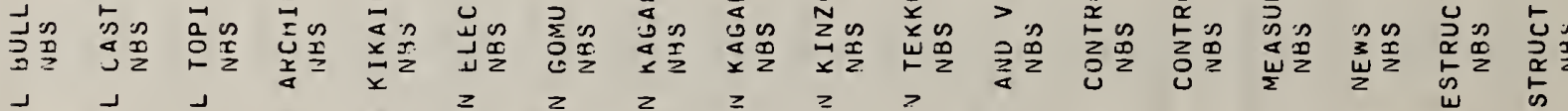

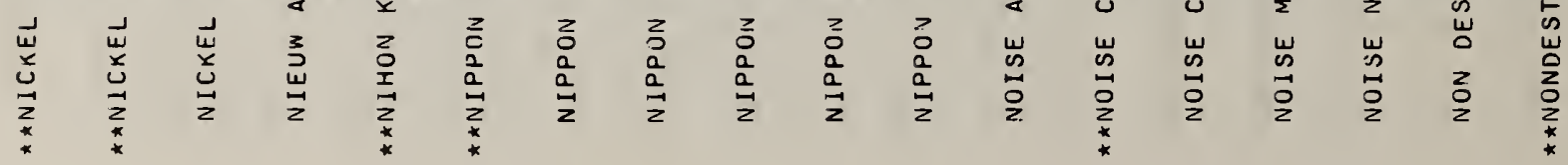




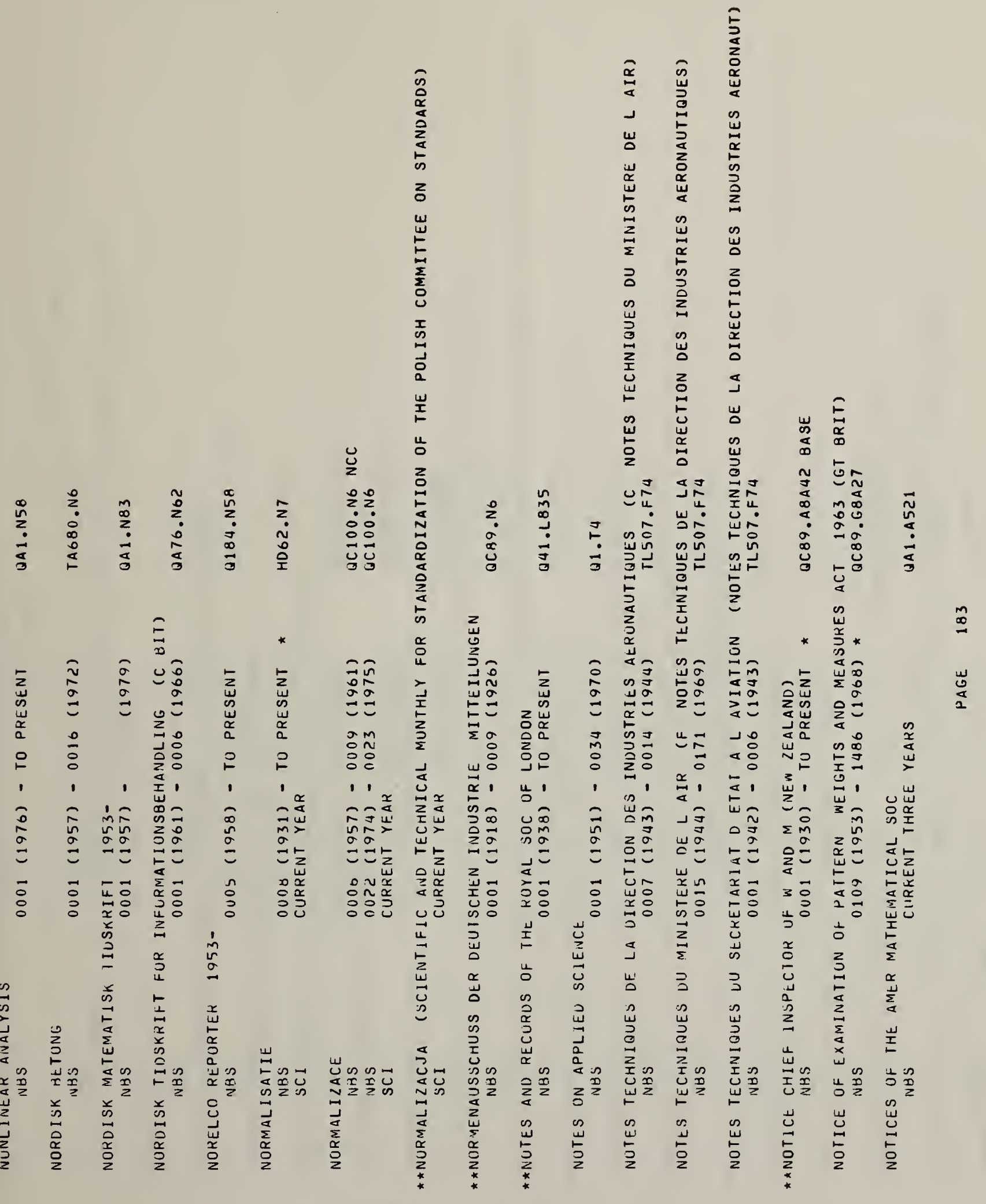


$\stackrel{5}{0}$

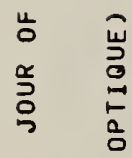

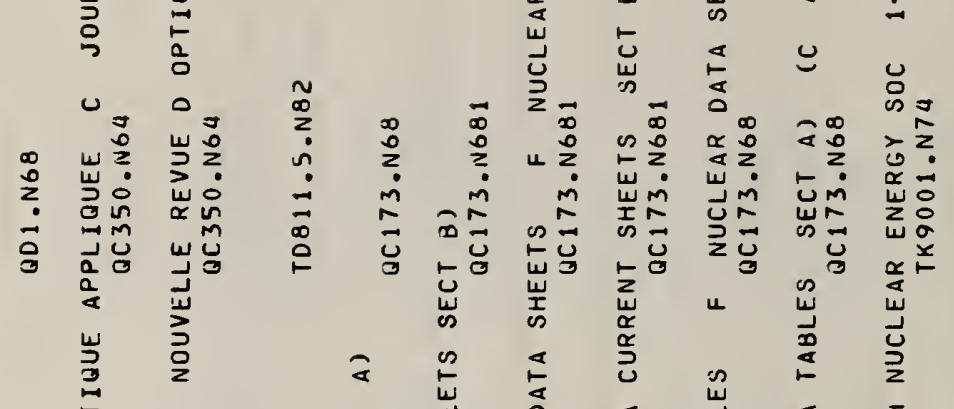

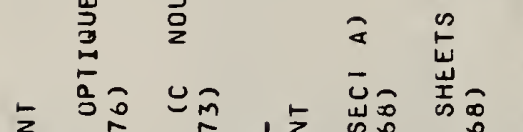

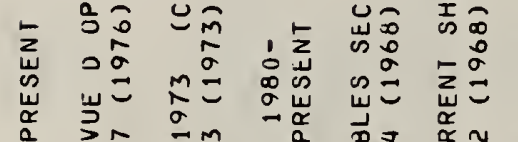

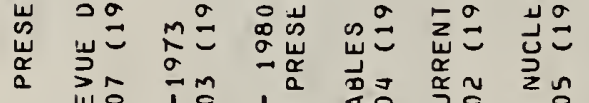

a

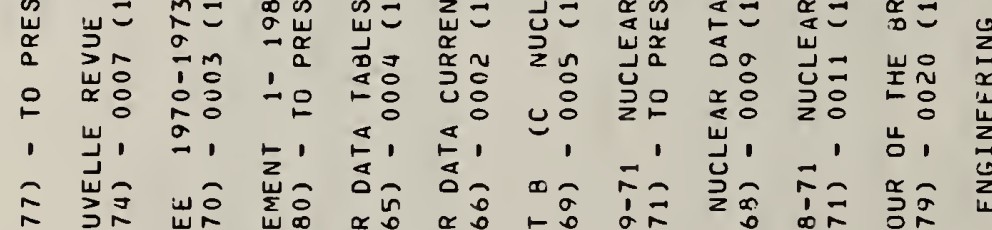

方

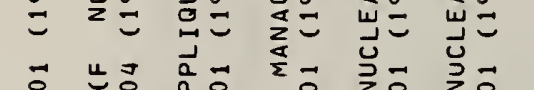

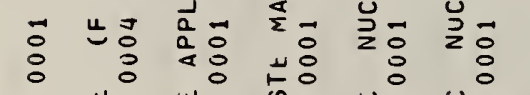

म

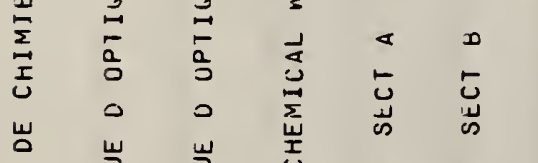

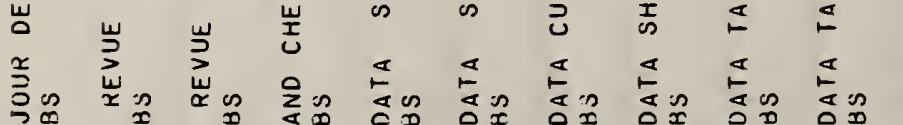

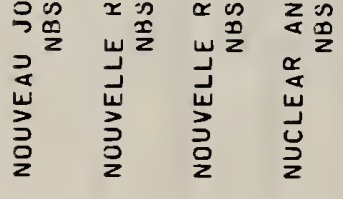

离

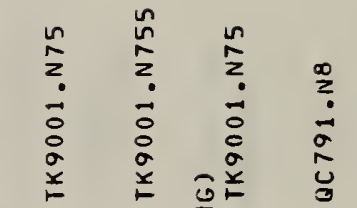

矛

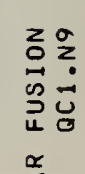

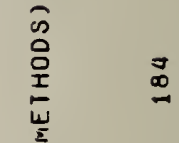

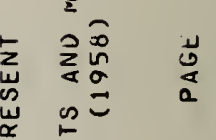

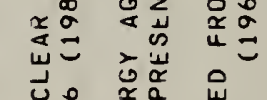

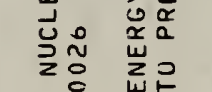

专资

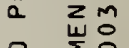

욜용

1 点,

$\sum_{0} \sum_{0} \pi$

$\Xi \frac{\alpha}{\omega} \Xi$

雚

iิ

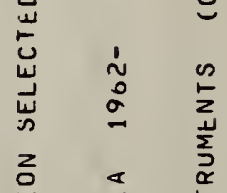

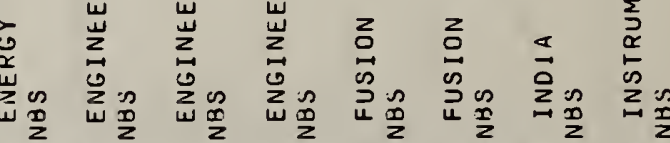

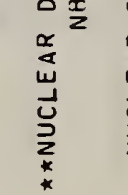

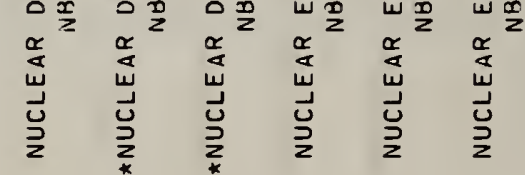

这 $\frac{w_{2}^{2}}{2}$

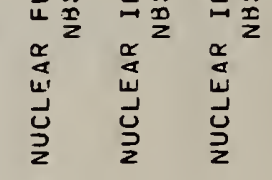




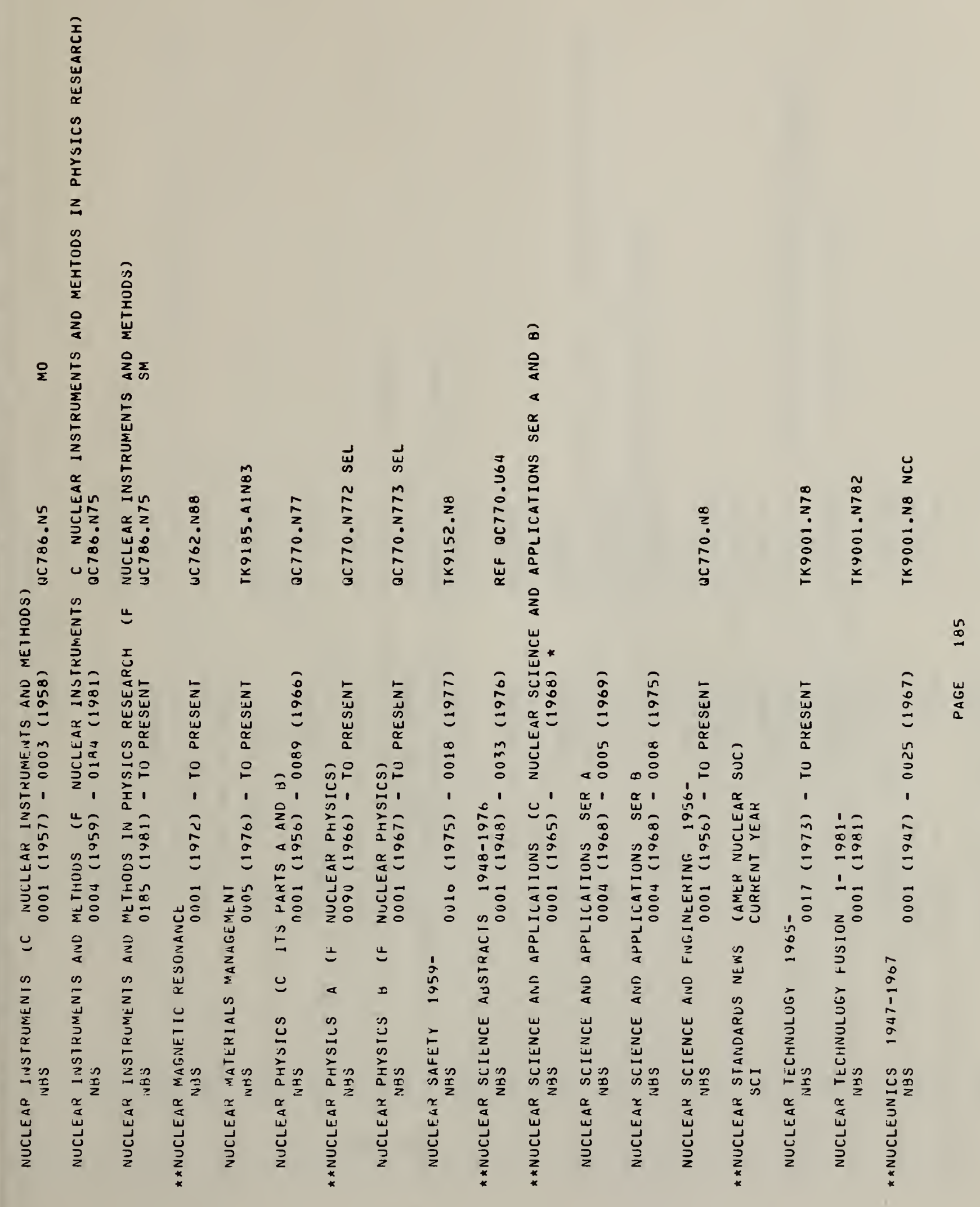




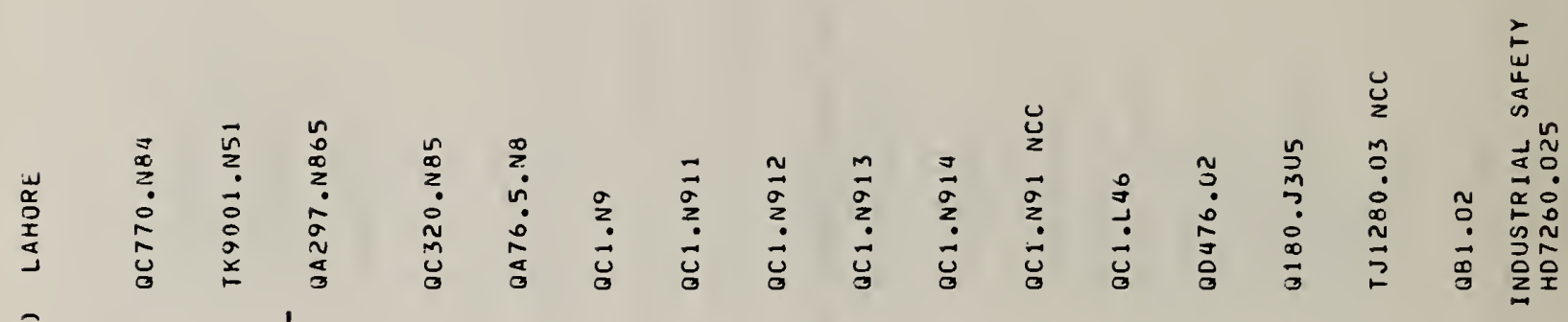

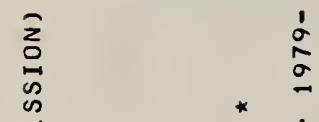

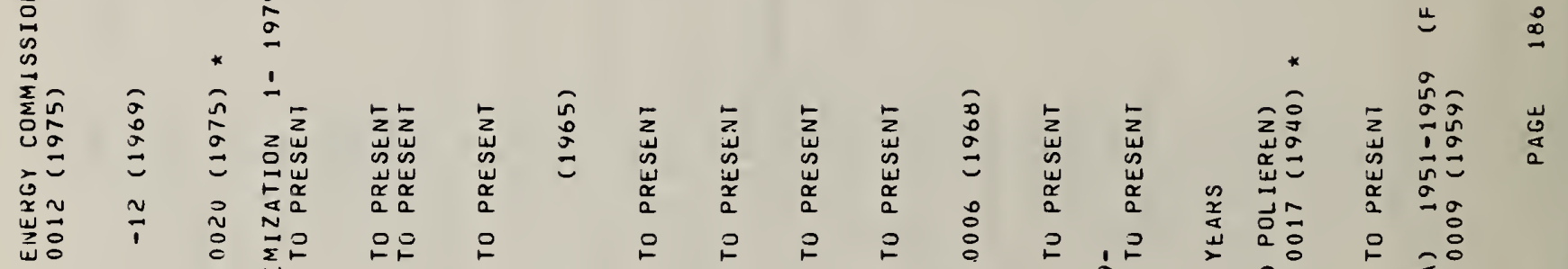

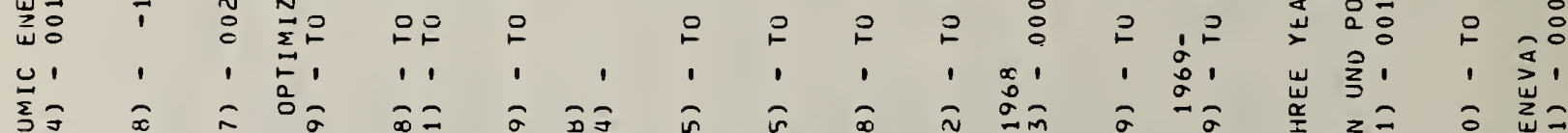

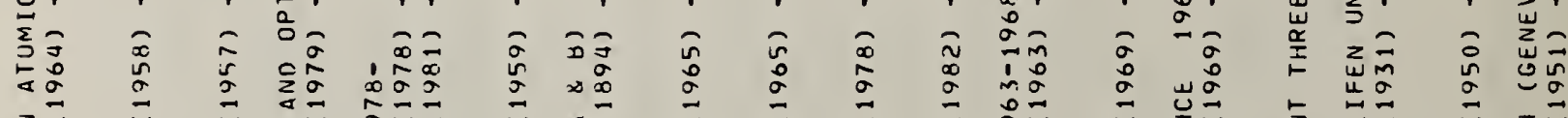

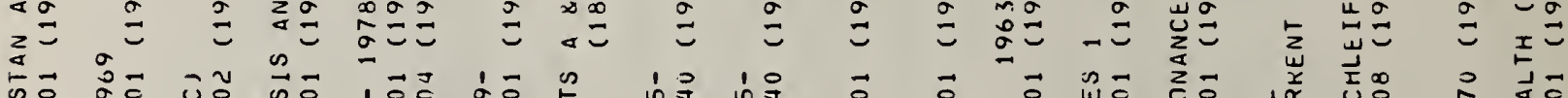

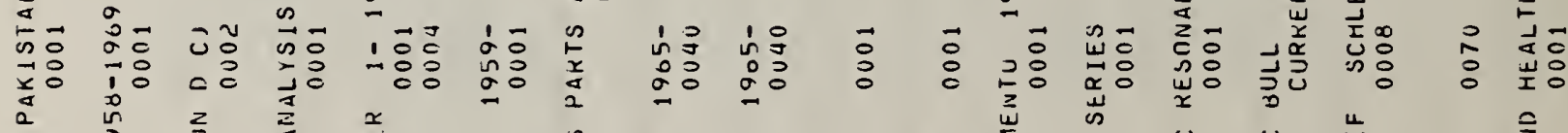

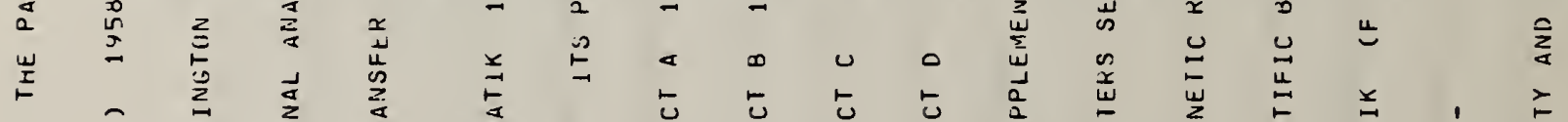

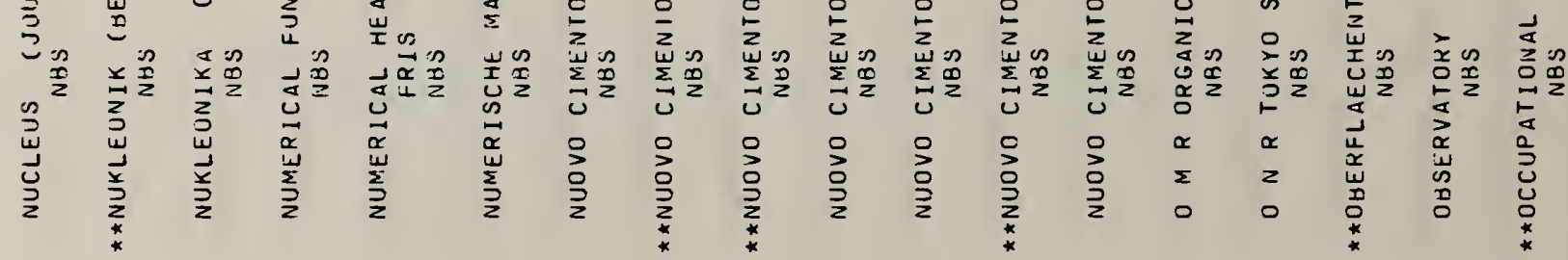




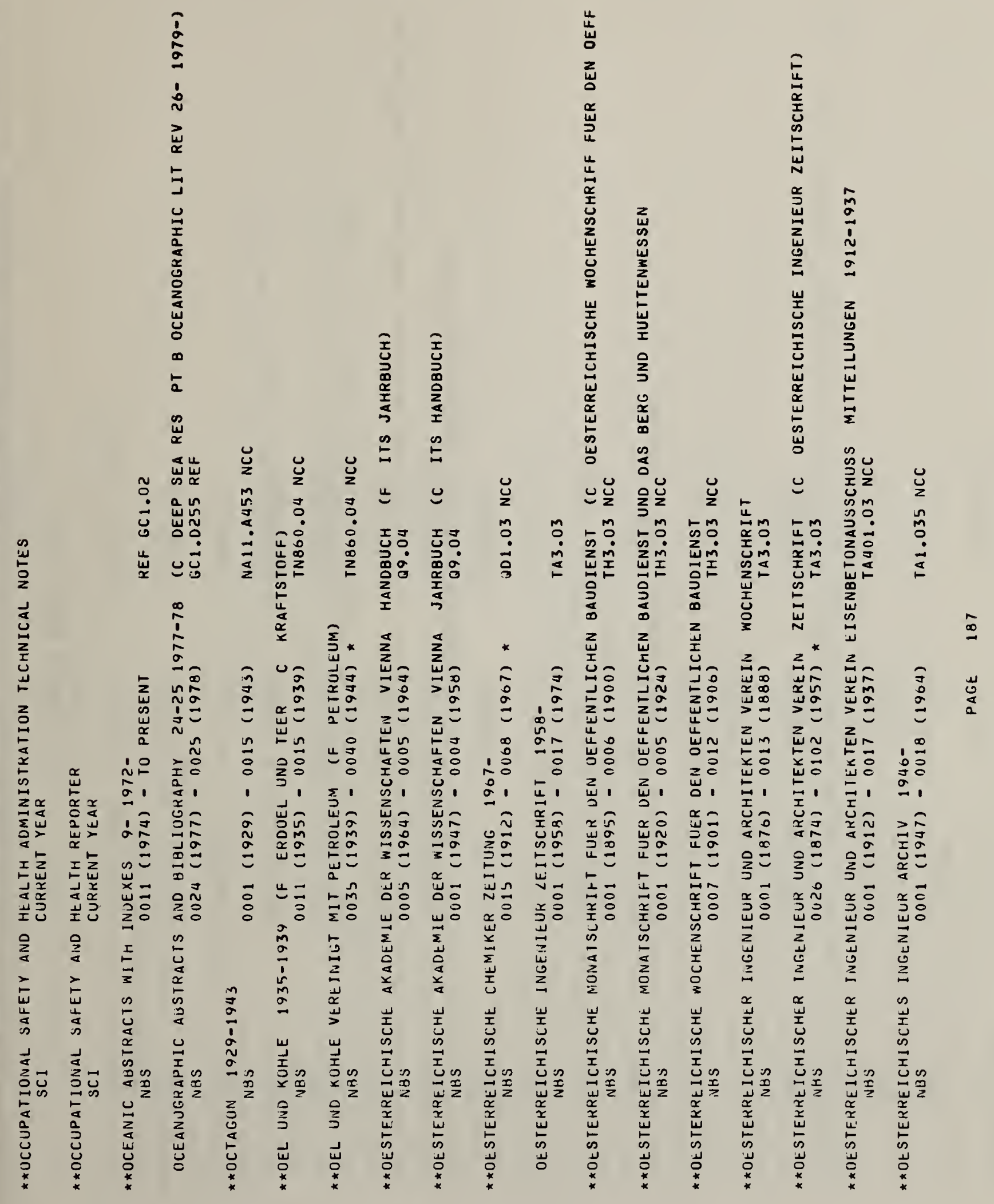




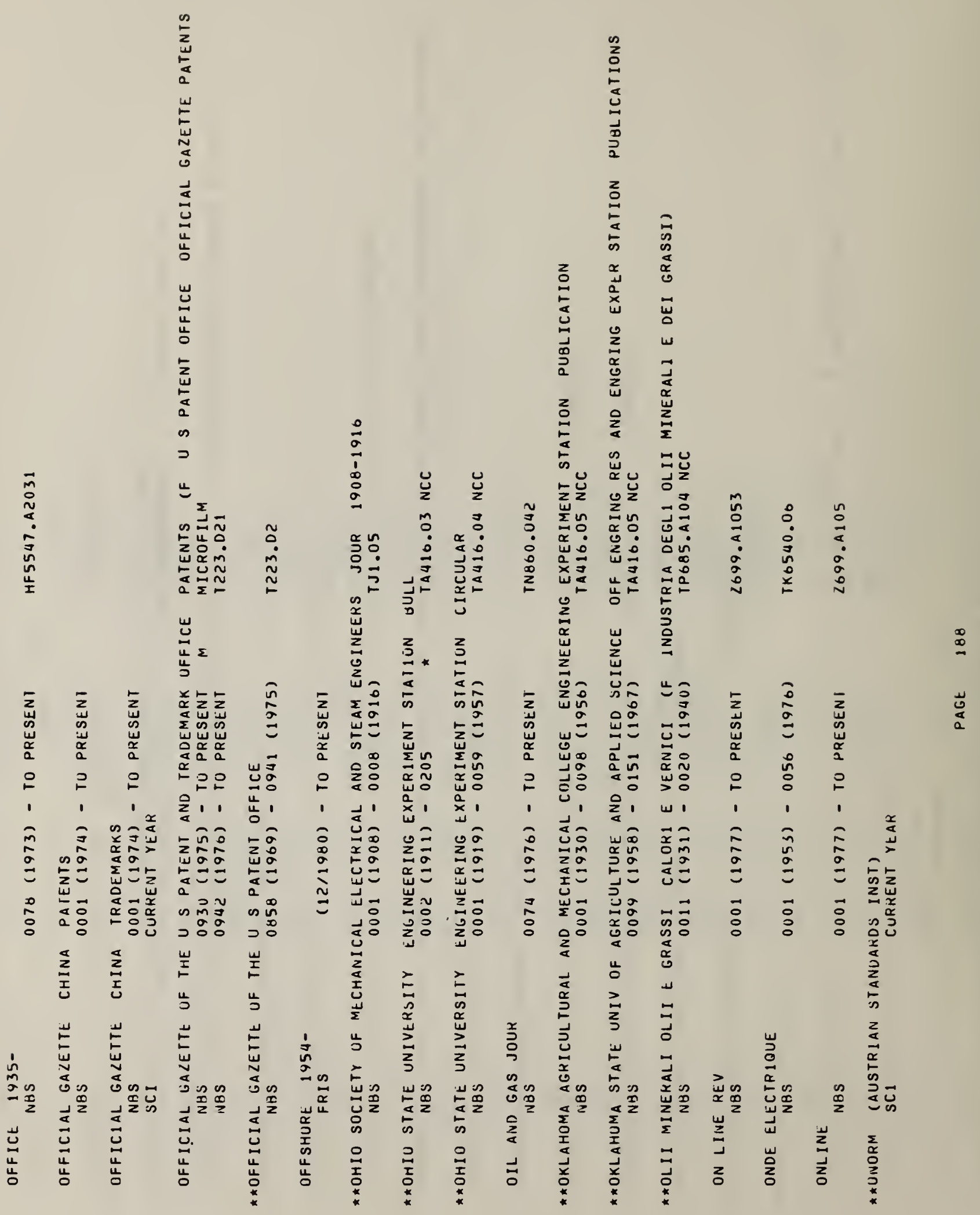




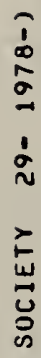

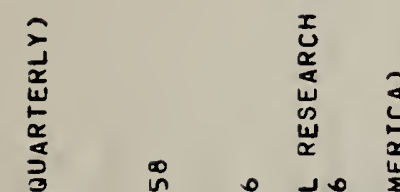

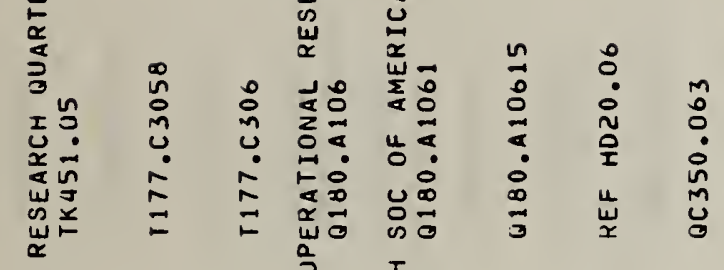
崖

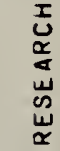

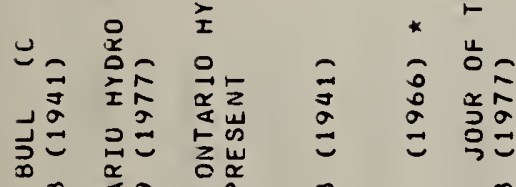

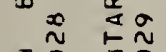

$42, \stackrel{0}{0} \quad$ :

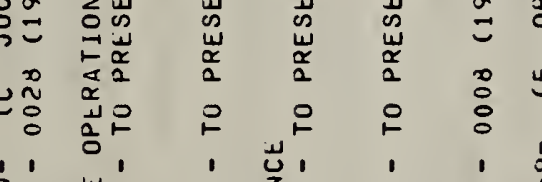

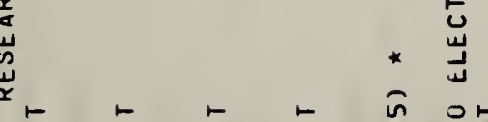

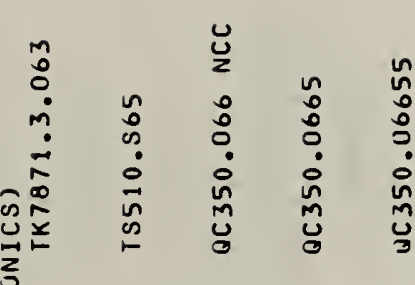

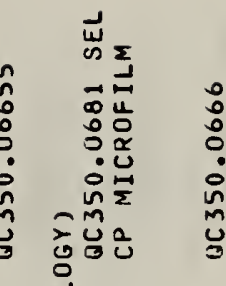

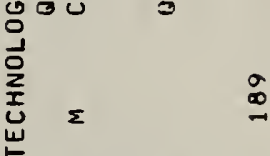

至

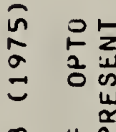

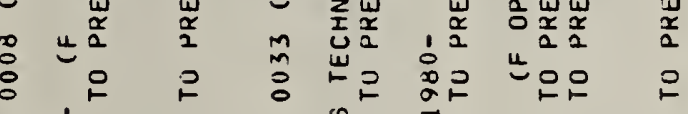

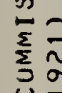

u'

1.

1 in' 1 岂'

1 1 $1,1,1,1,1,1$

$\vec{x}$

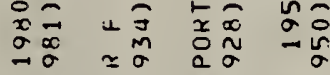

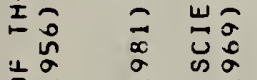

焉

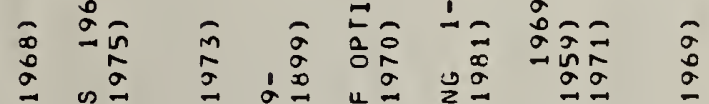

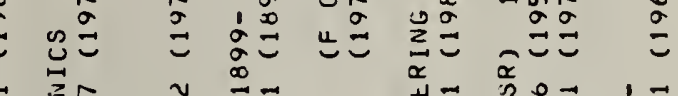

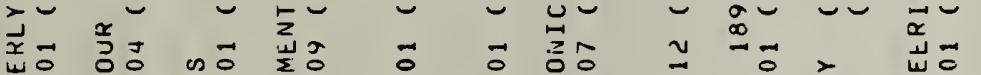

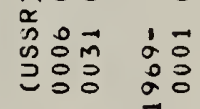

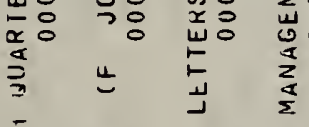

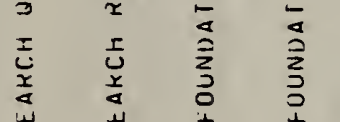

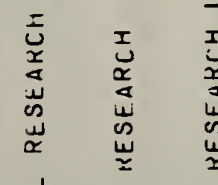

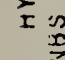

齐 
约

$\Sigma \Sigma$ ₹

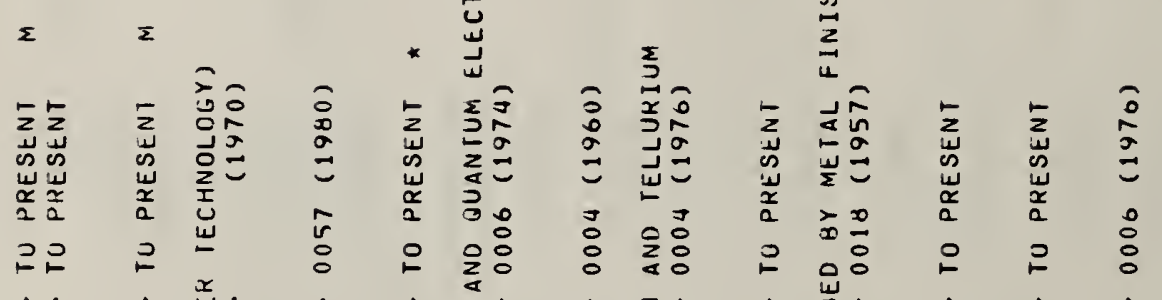

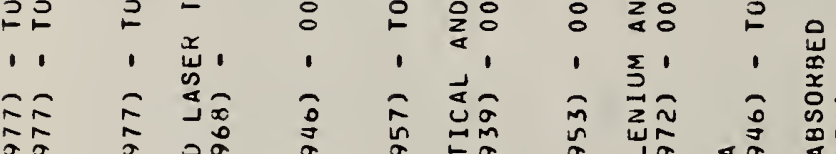

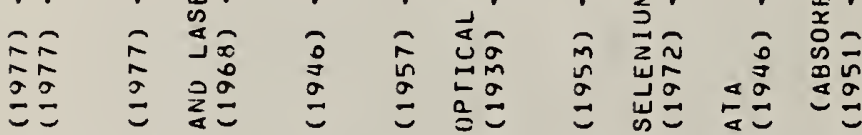

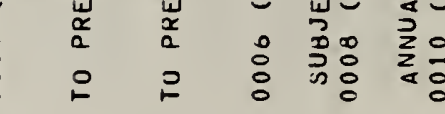

$\sum_{2}^{\frac{1}{2}}$

宸

$\stackrel{\circ}{\circ}$

$\overrightarrow{0} \tilde{0} \hat{0} \overrightarrow{0} \tilde{0}$

กัร

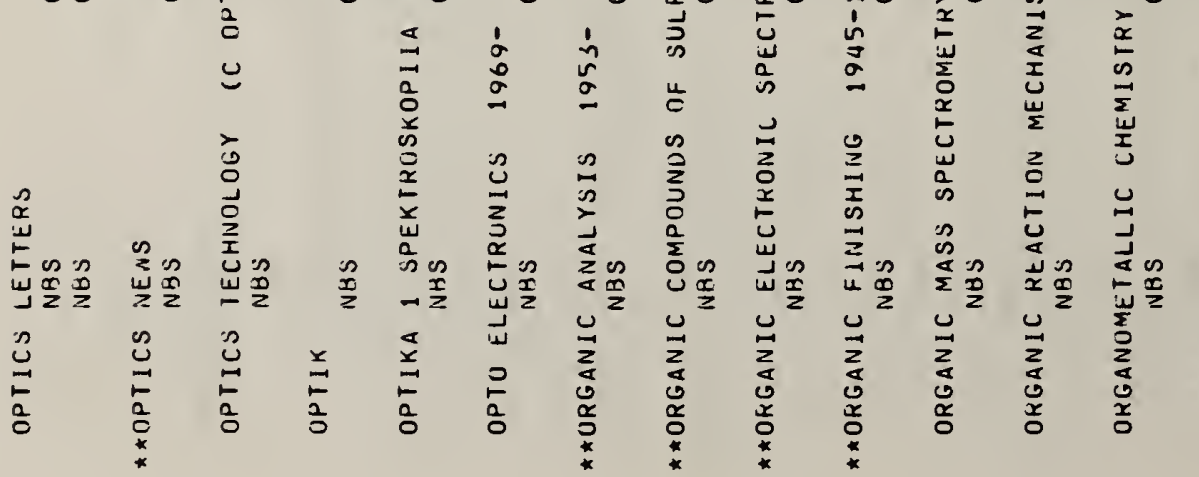

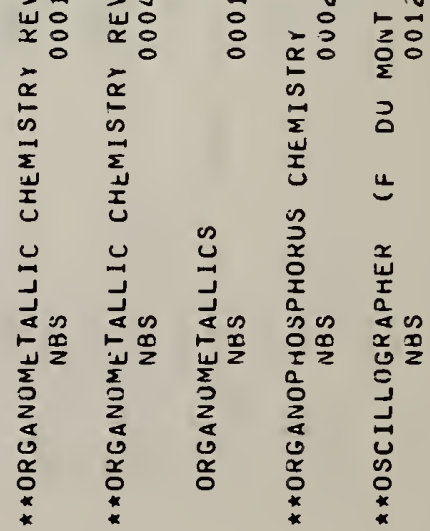




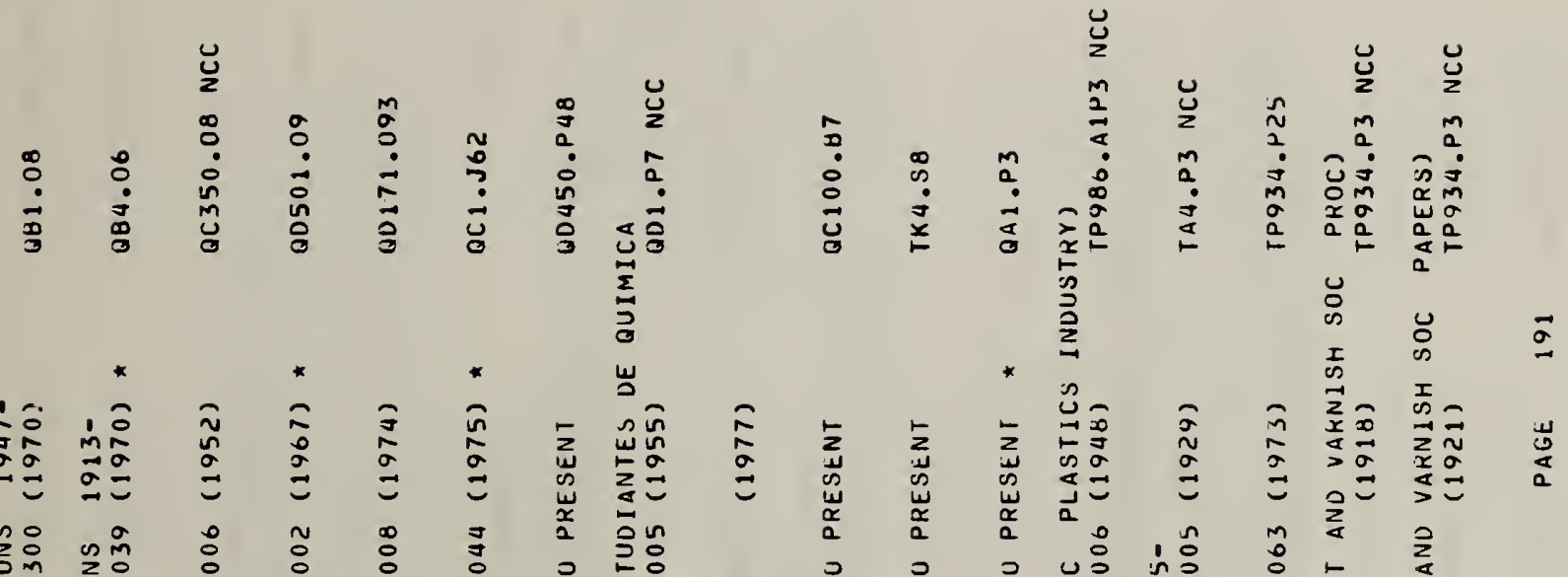

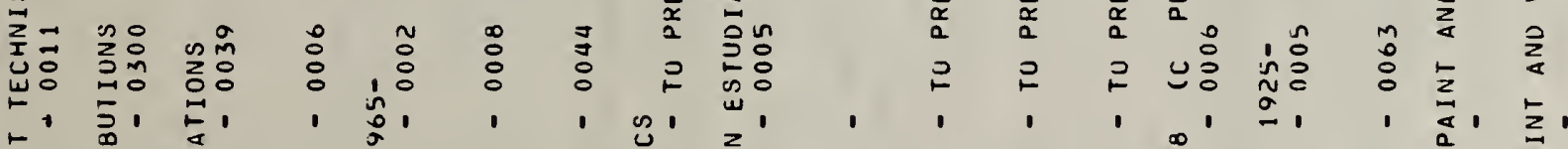

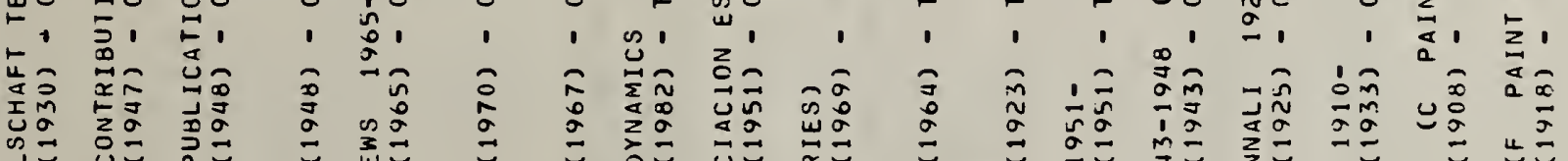
虫

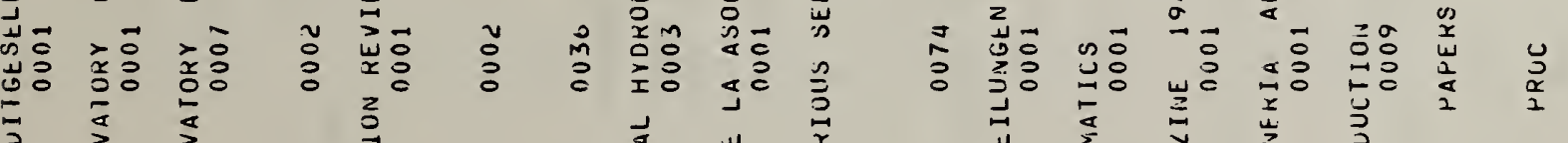

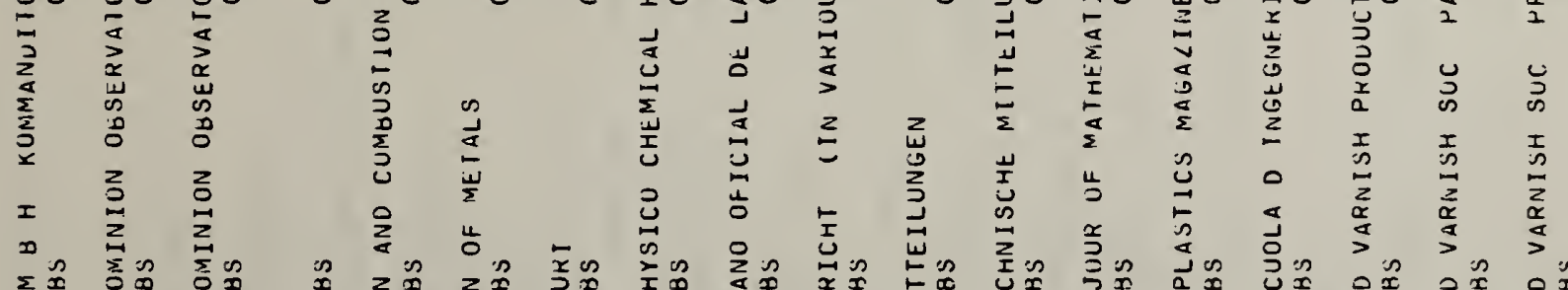

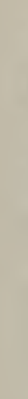

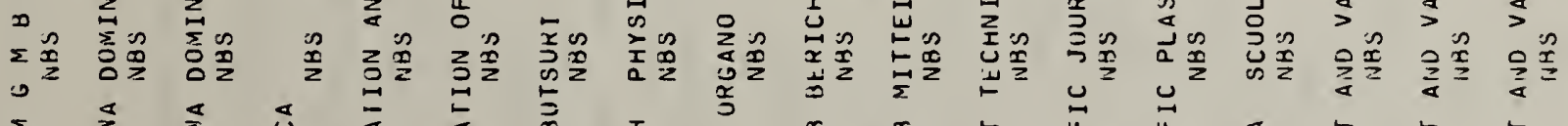

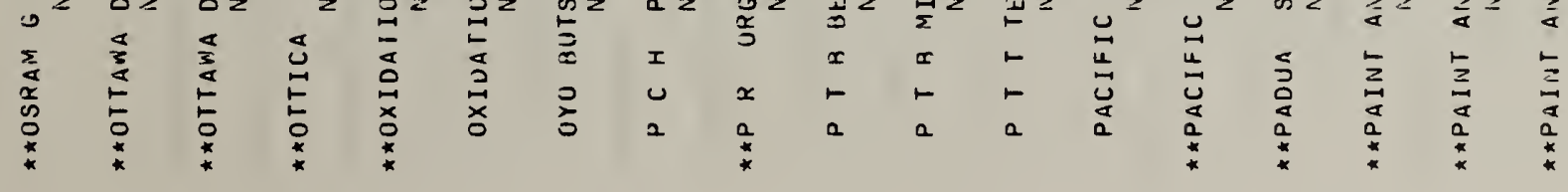




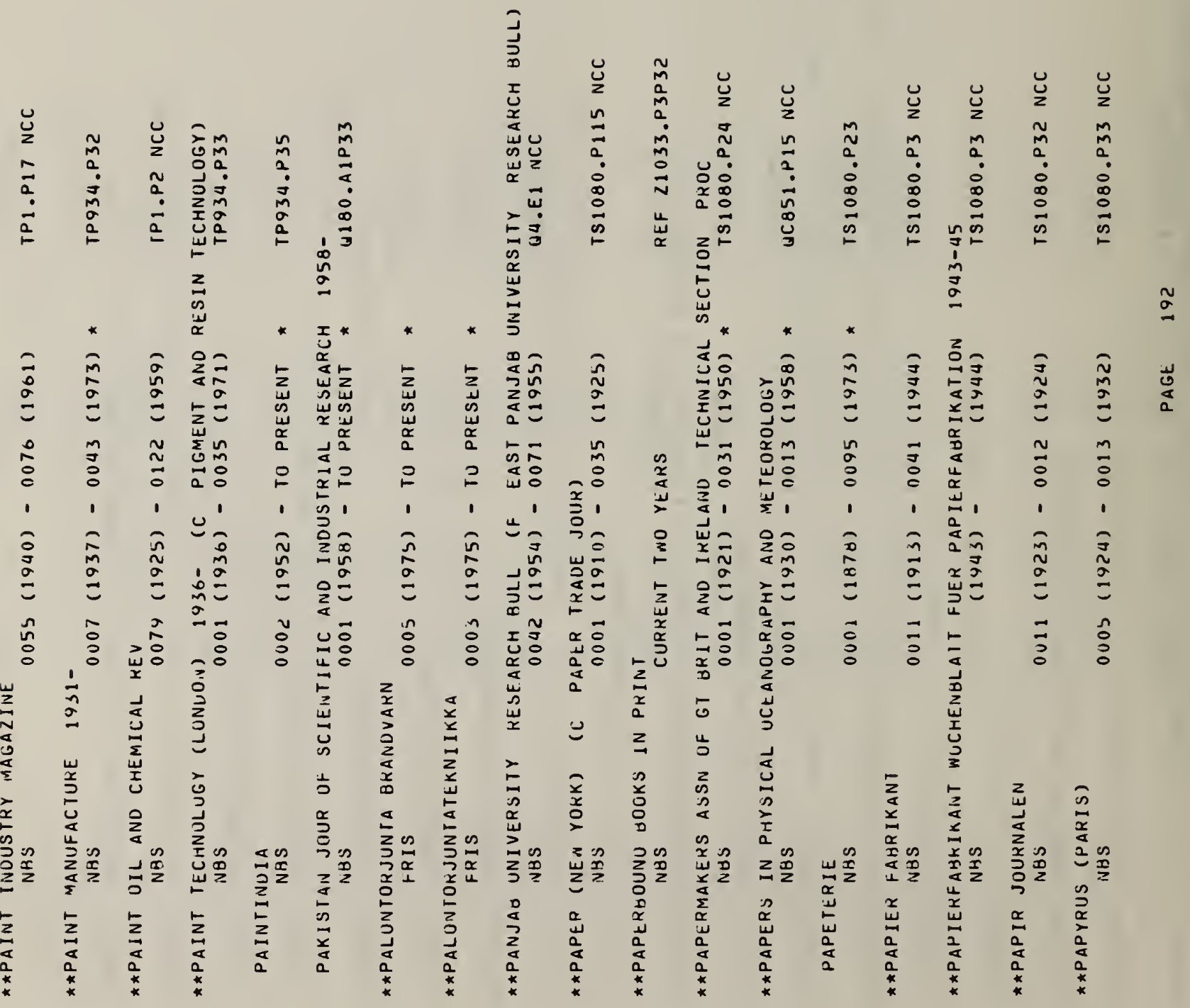


$\overrightarrow{\mathrm{a}}$

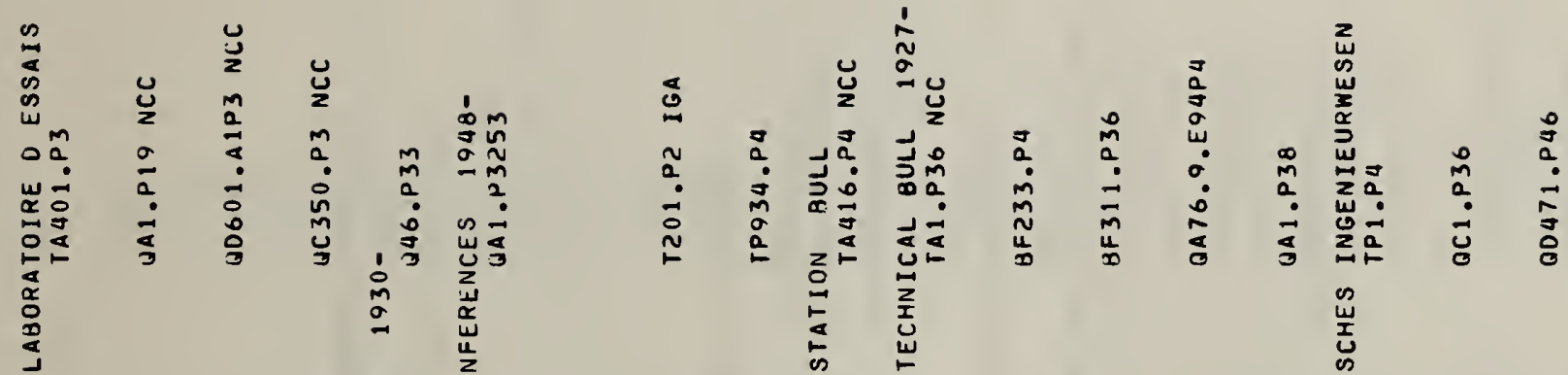

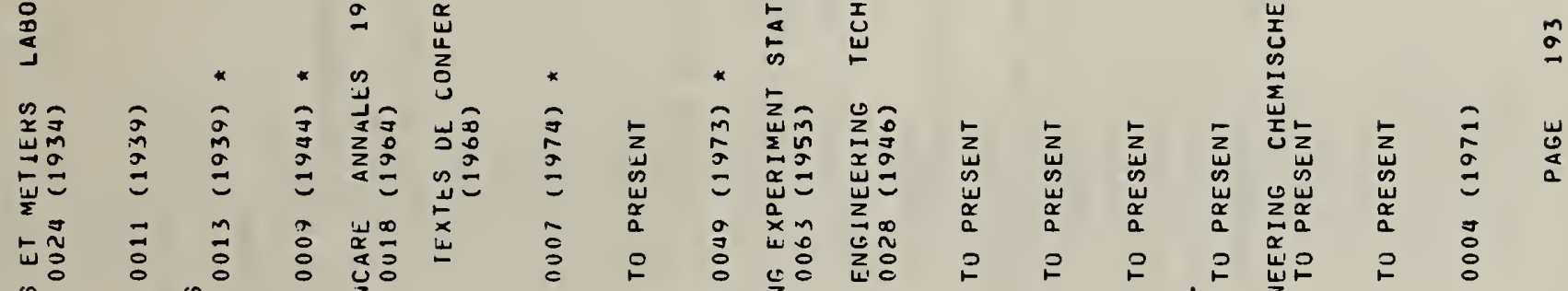

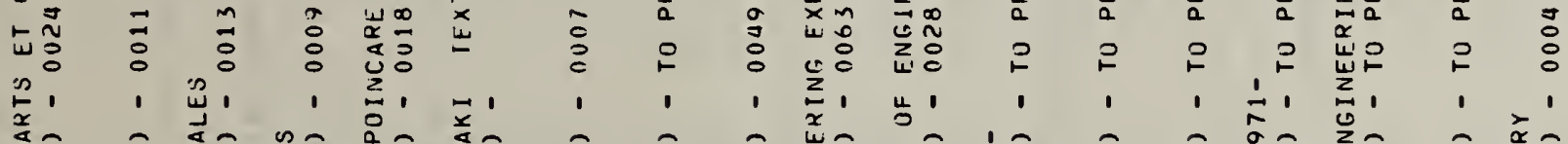

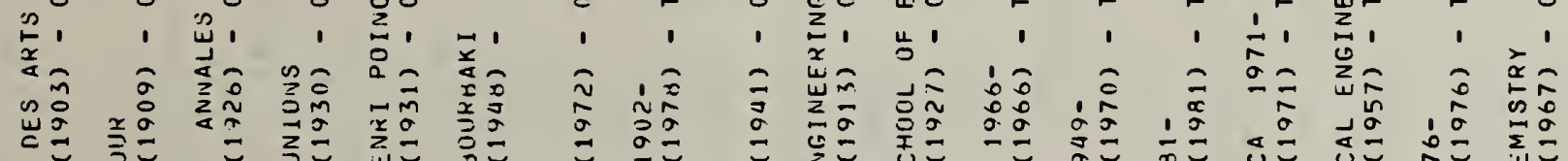

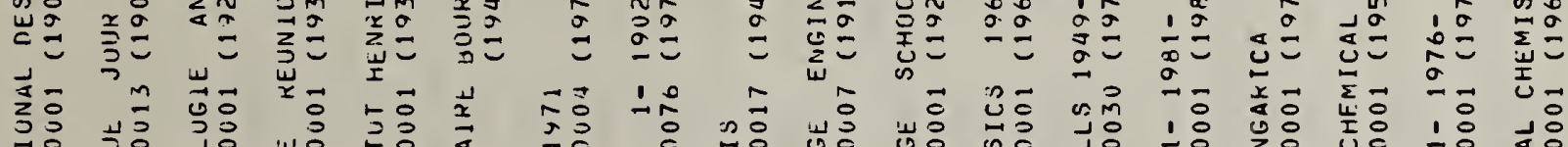

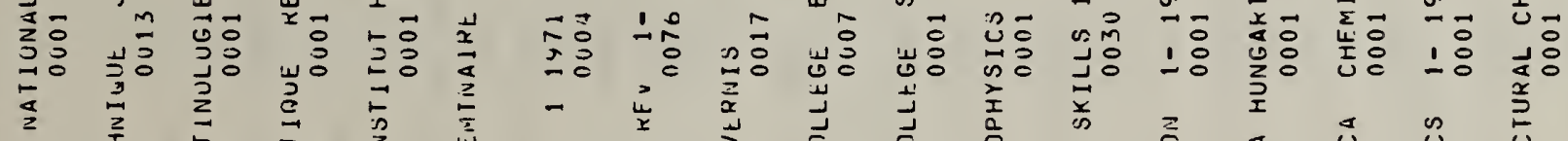

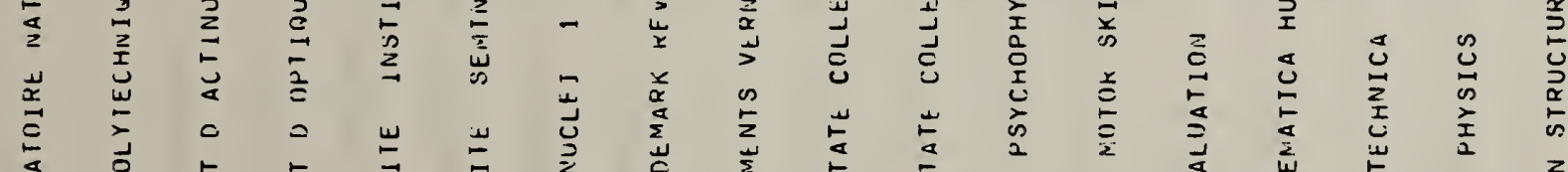

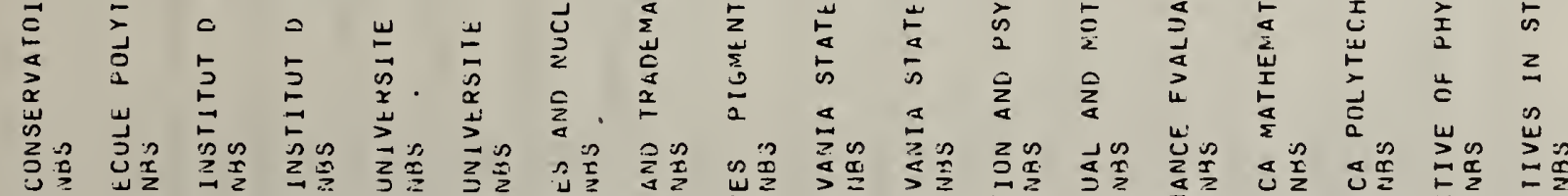

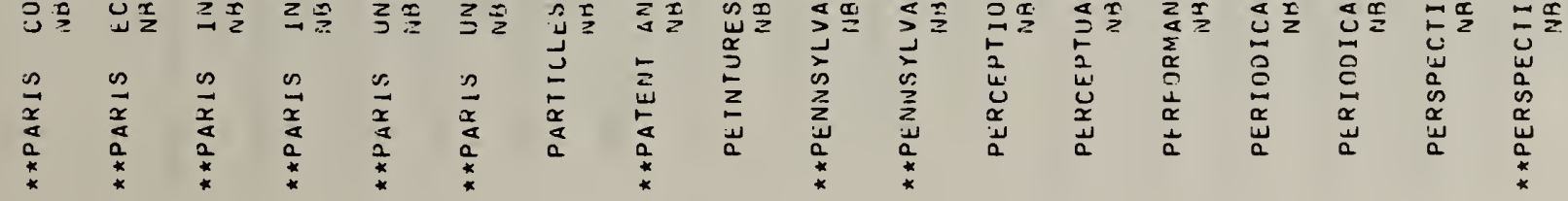


常*

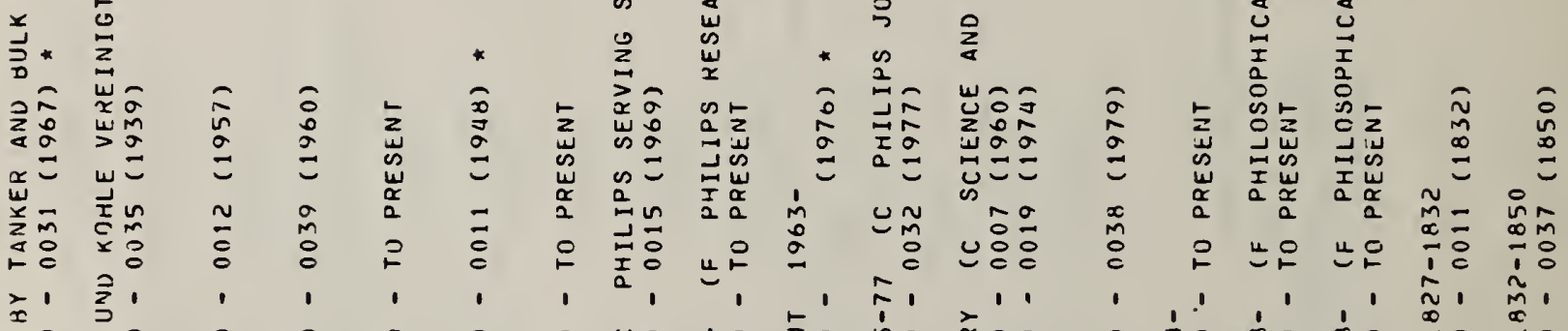

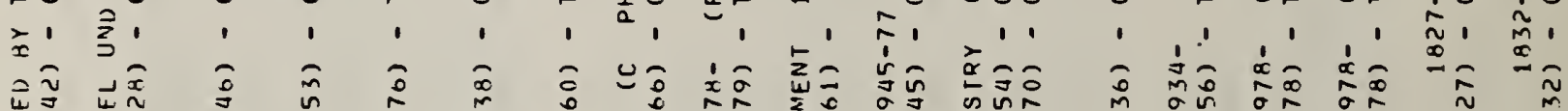

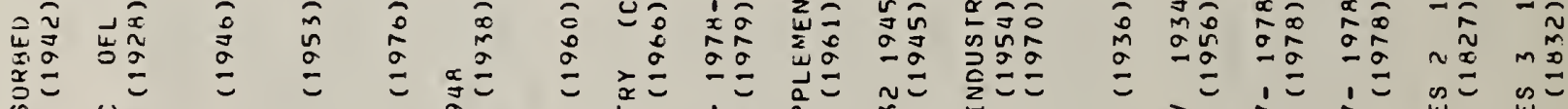

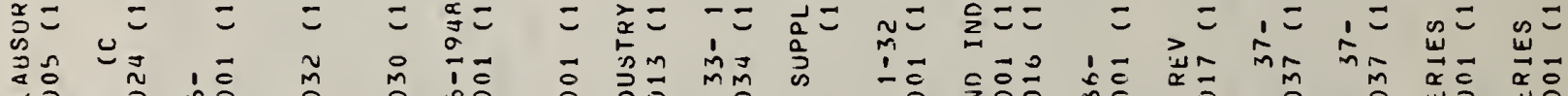

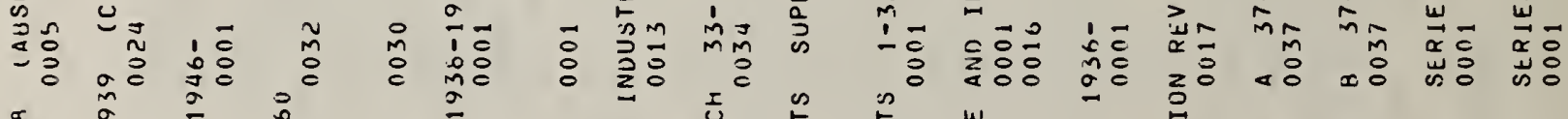

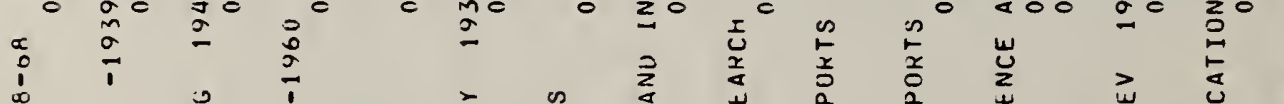

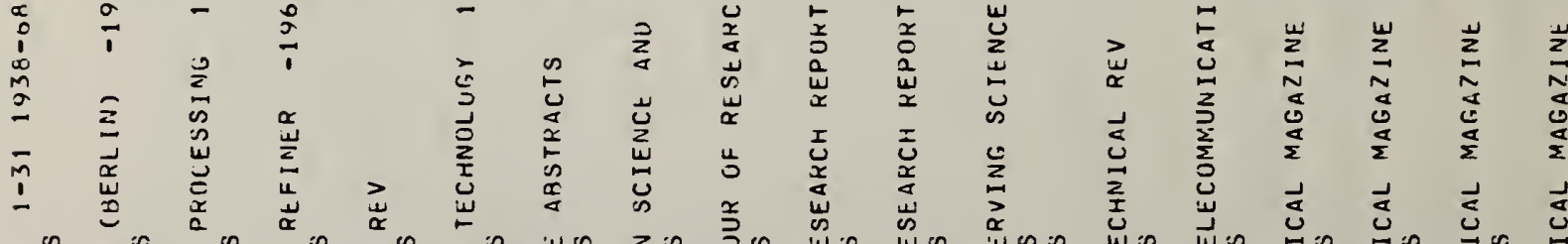

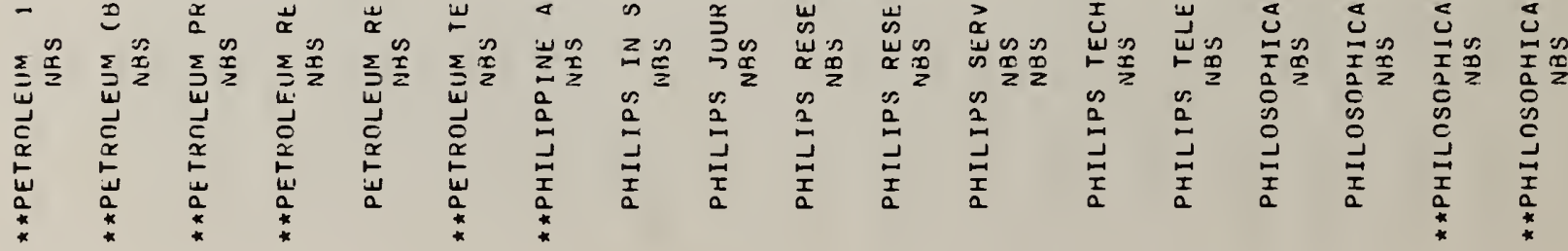




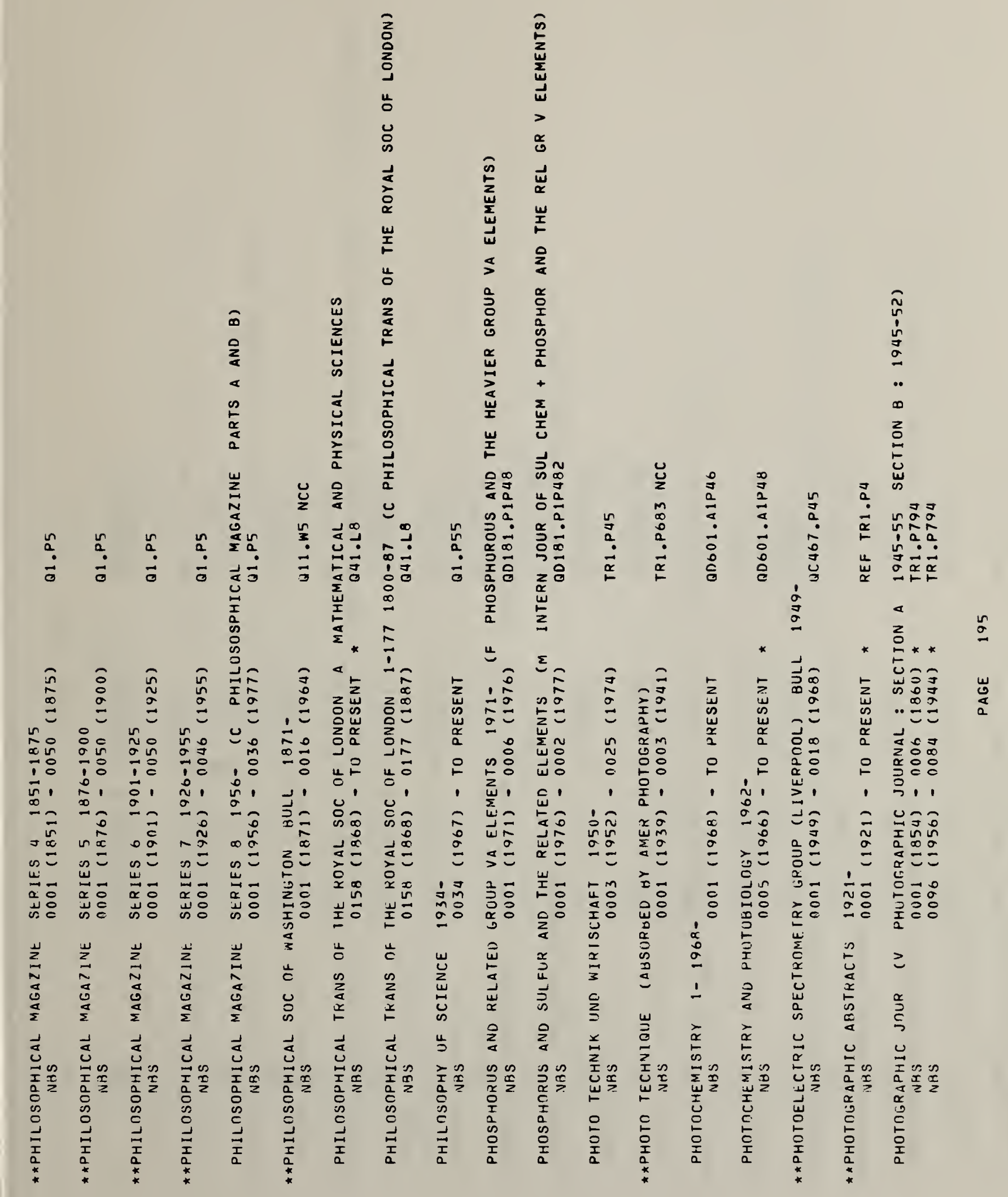




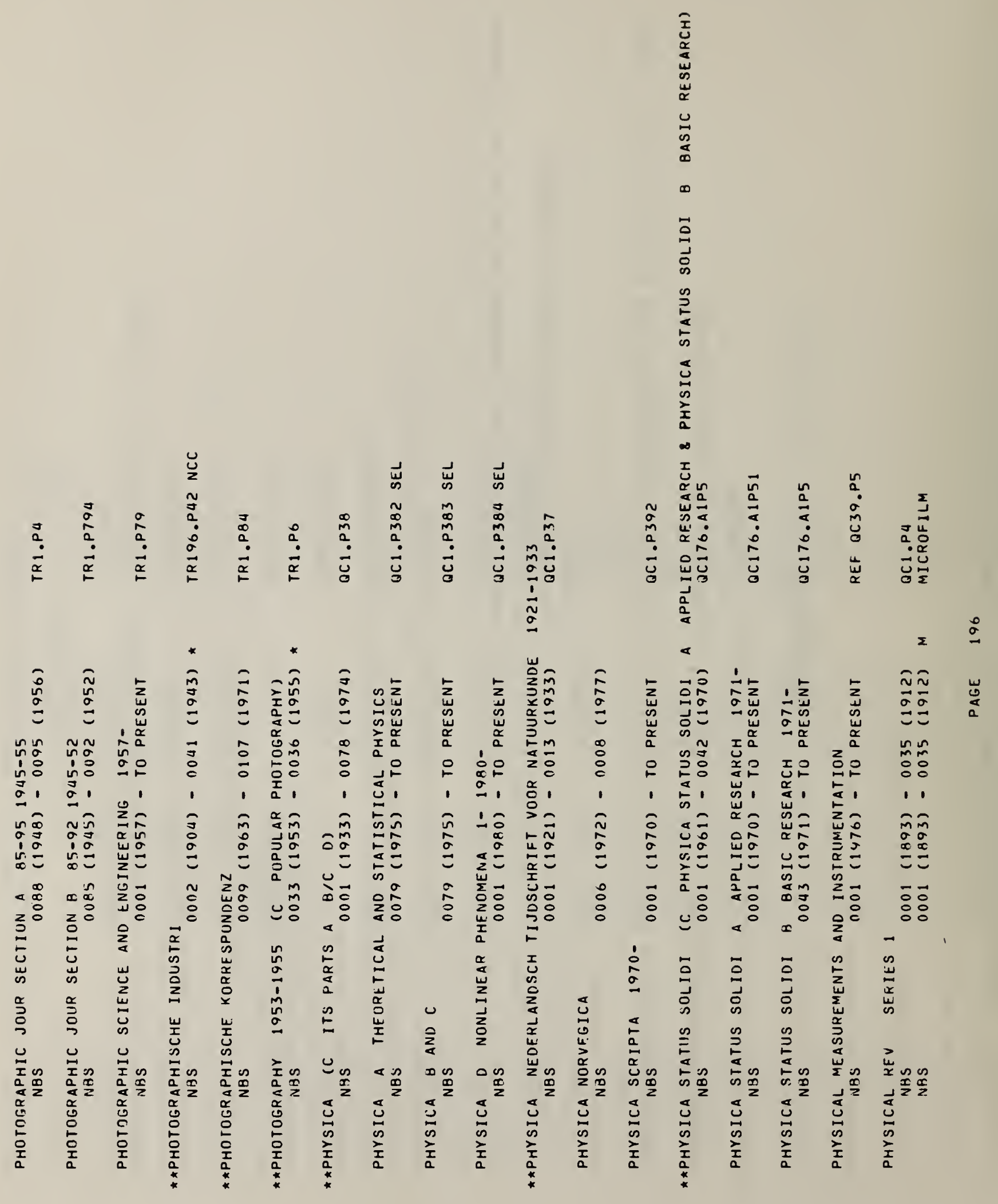




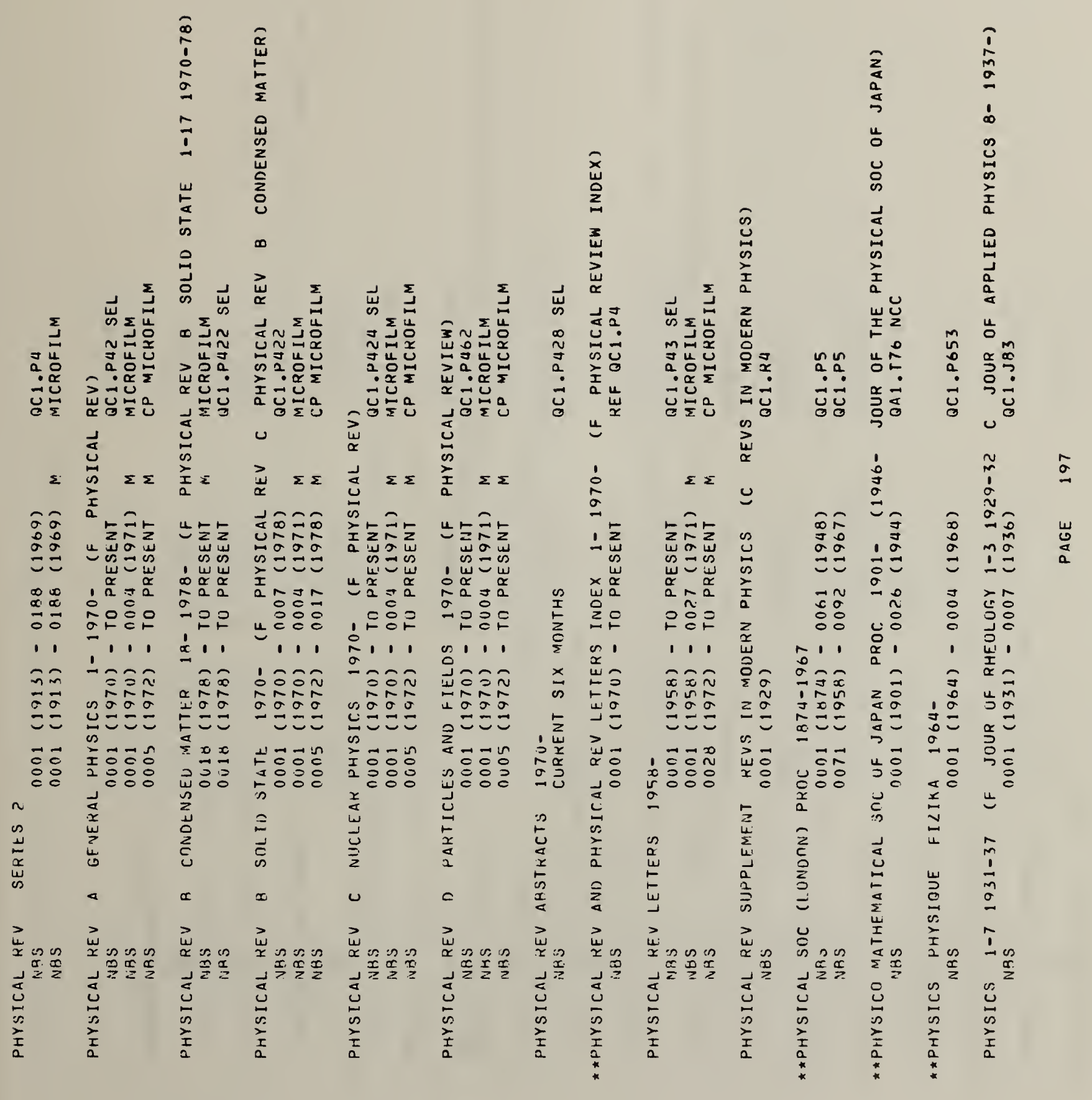




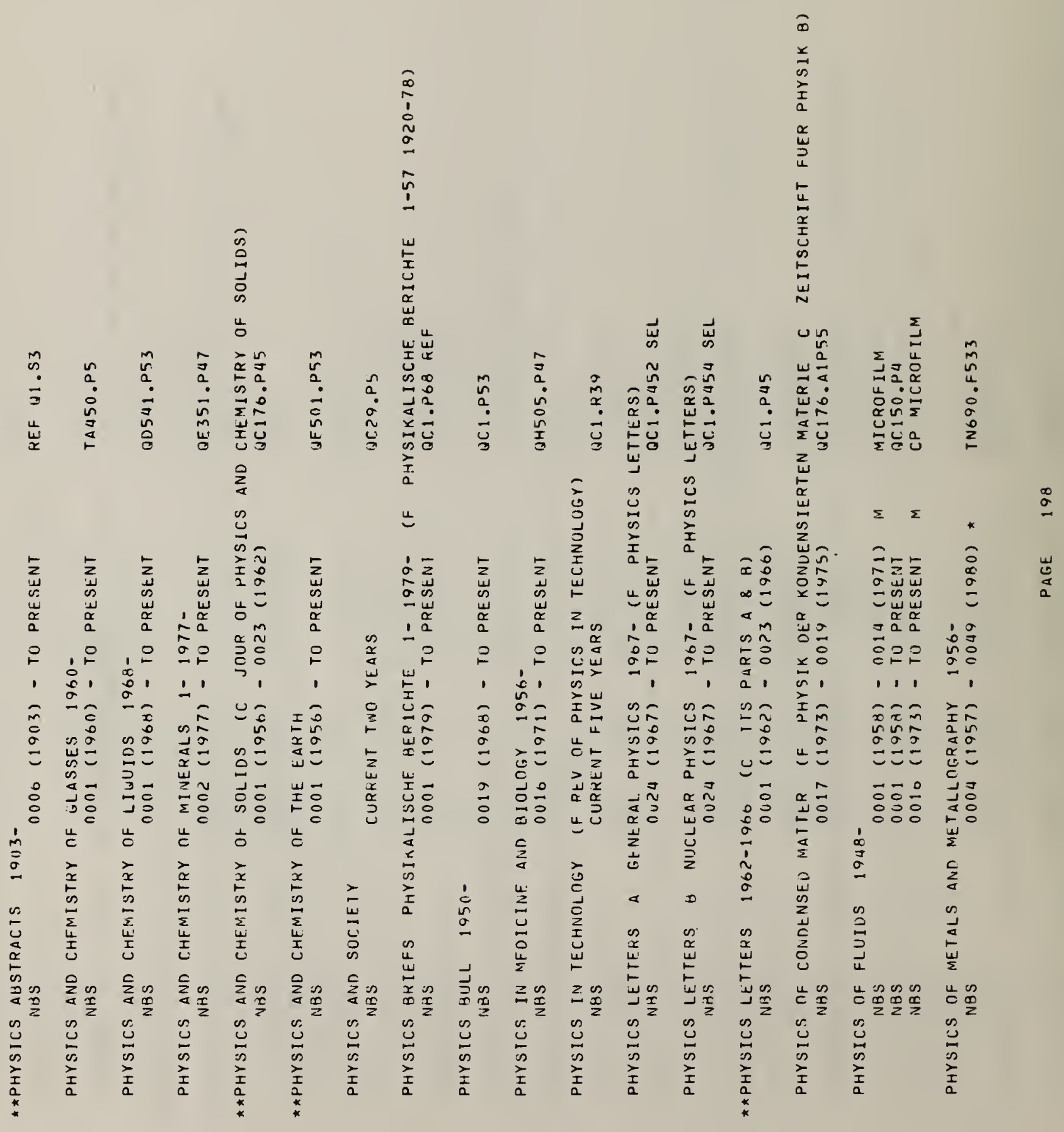




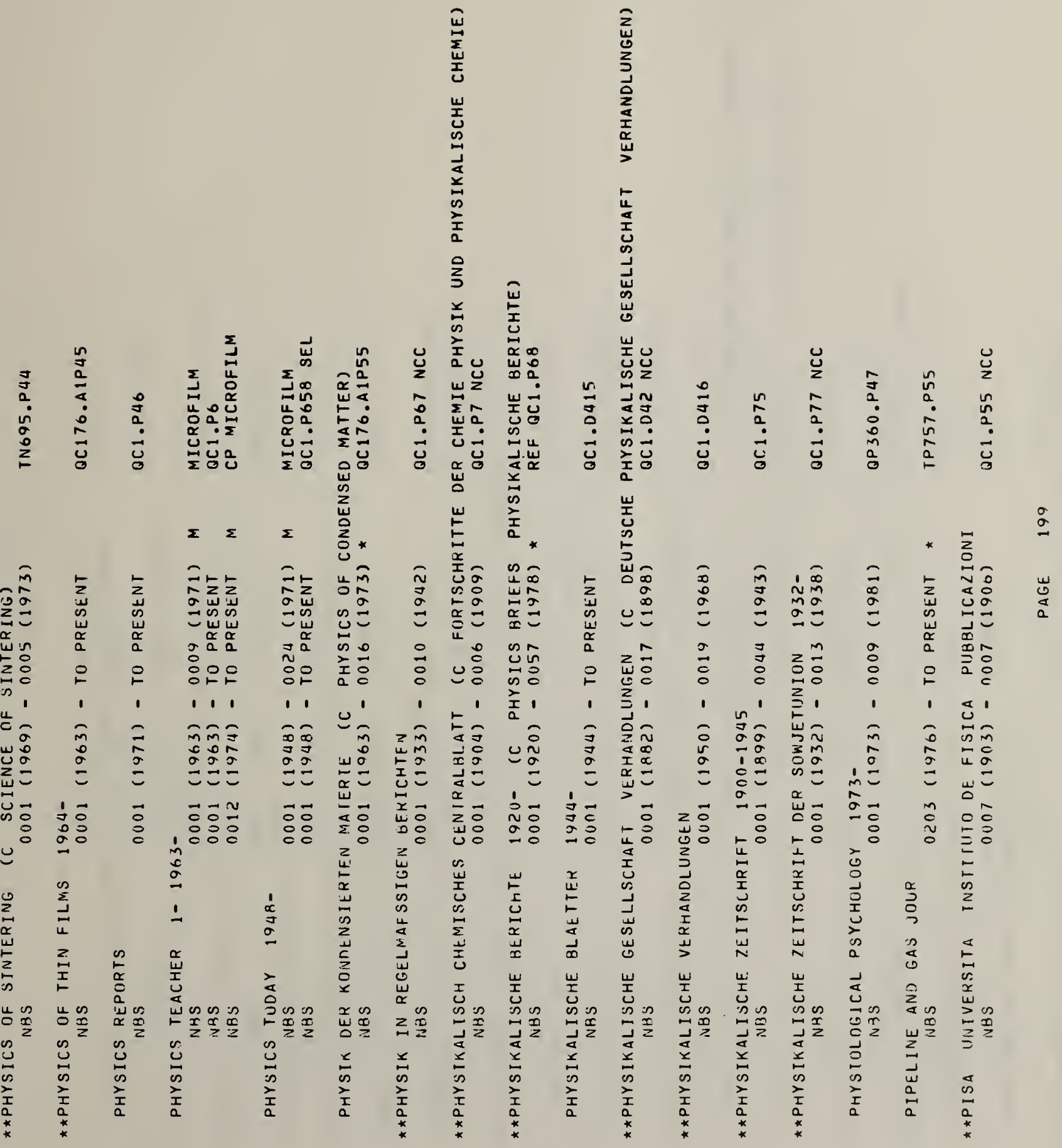




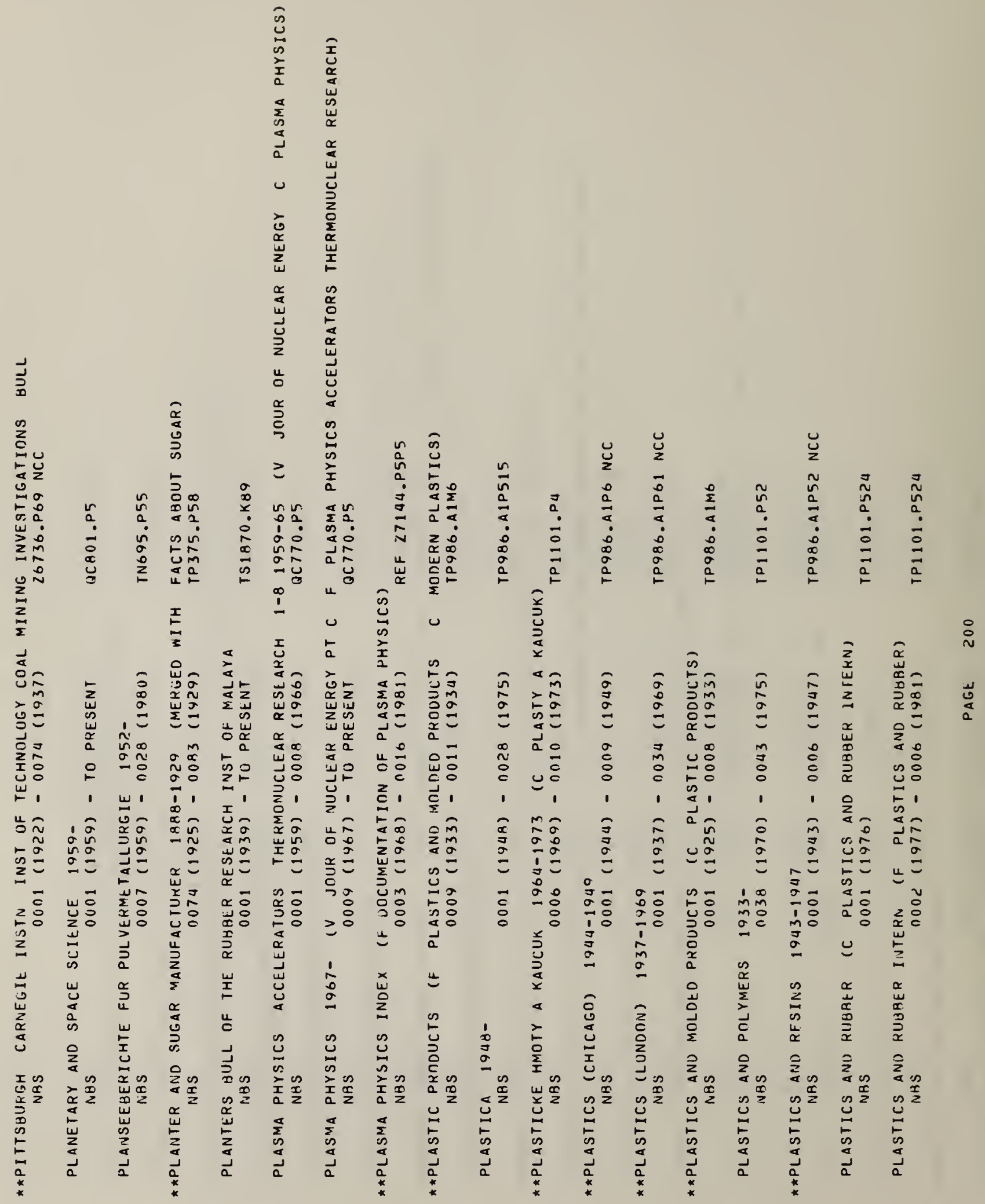




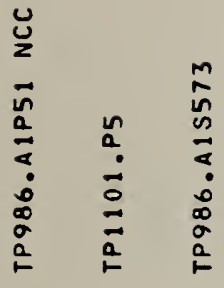

ב)

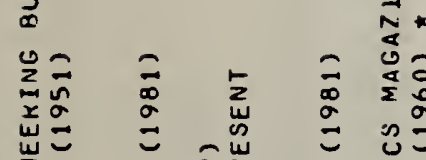

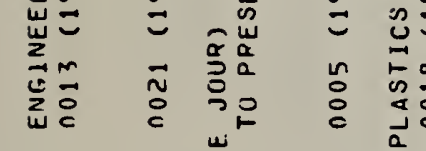

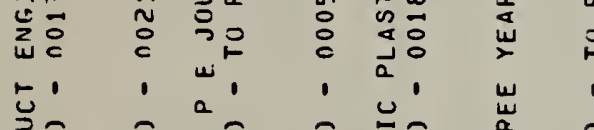

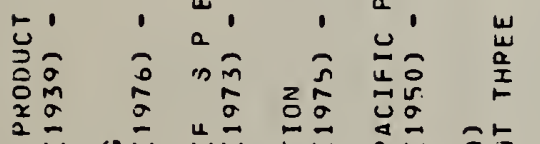

U

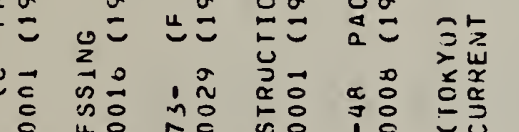

$\frac{m}{9} \frac{1}{2}$

. $u$
$u$
$m$
$a$
$a$
$\vdots$
$\vdots$
$a$
$a$
$a$

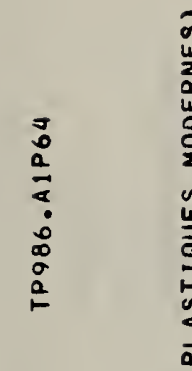

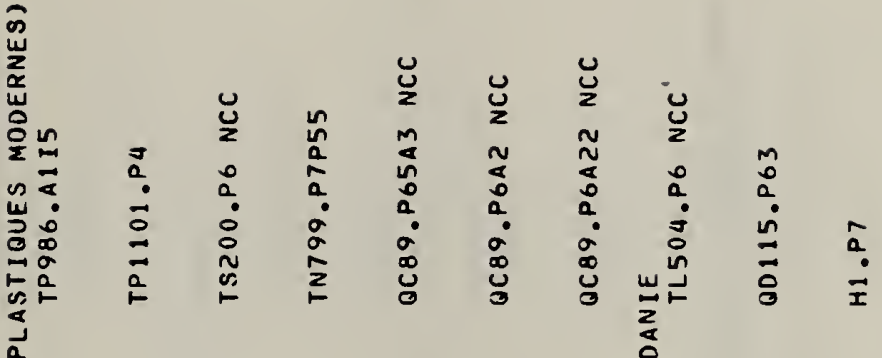

虫

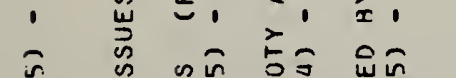




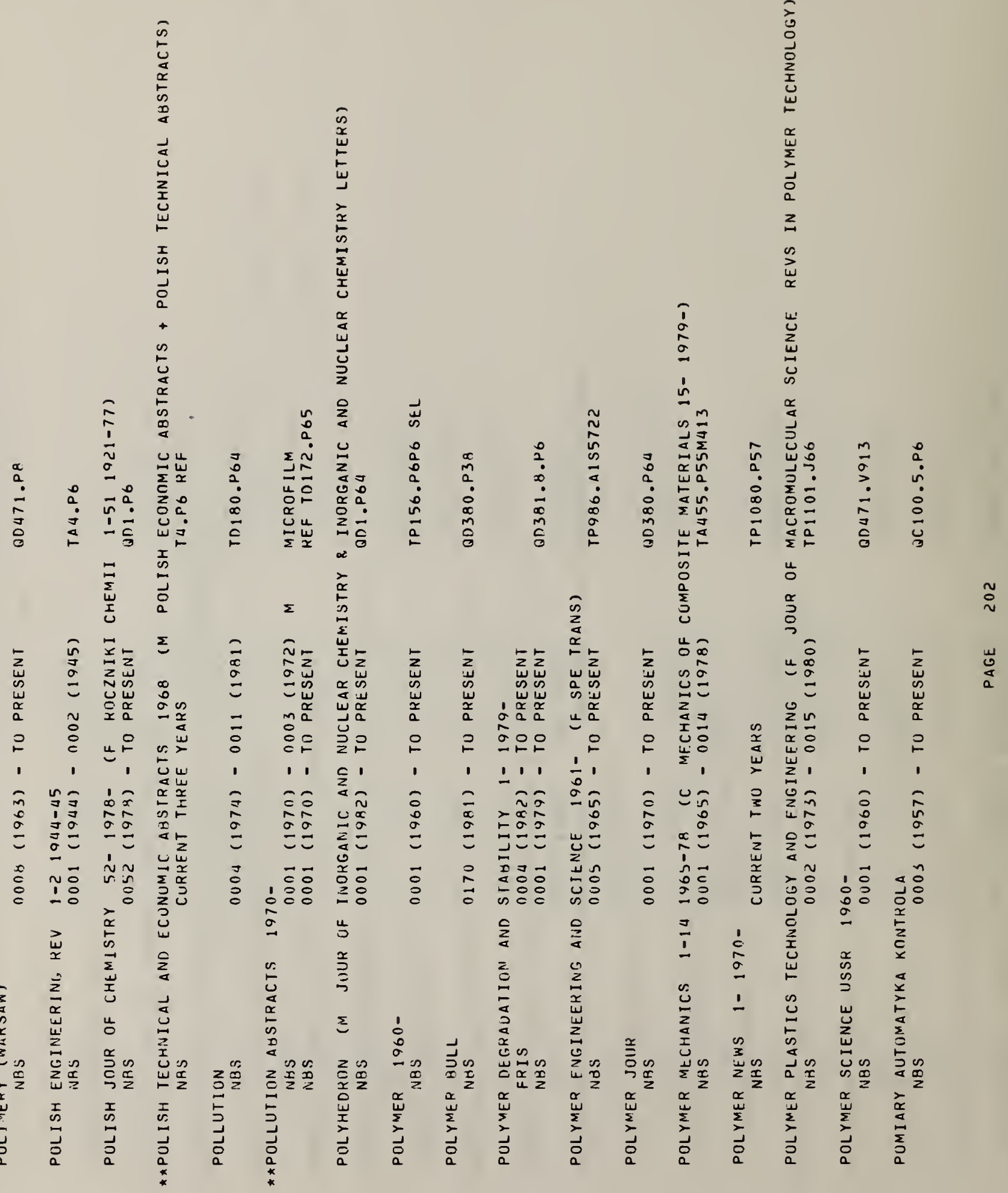




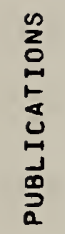

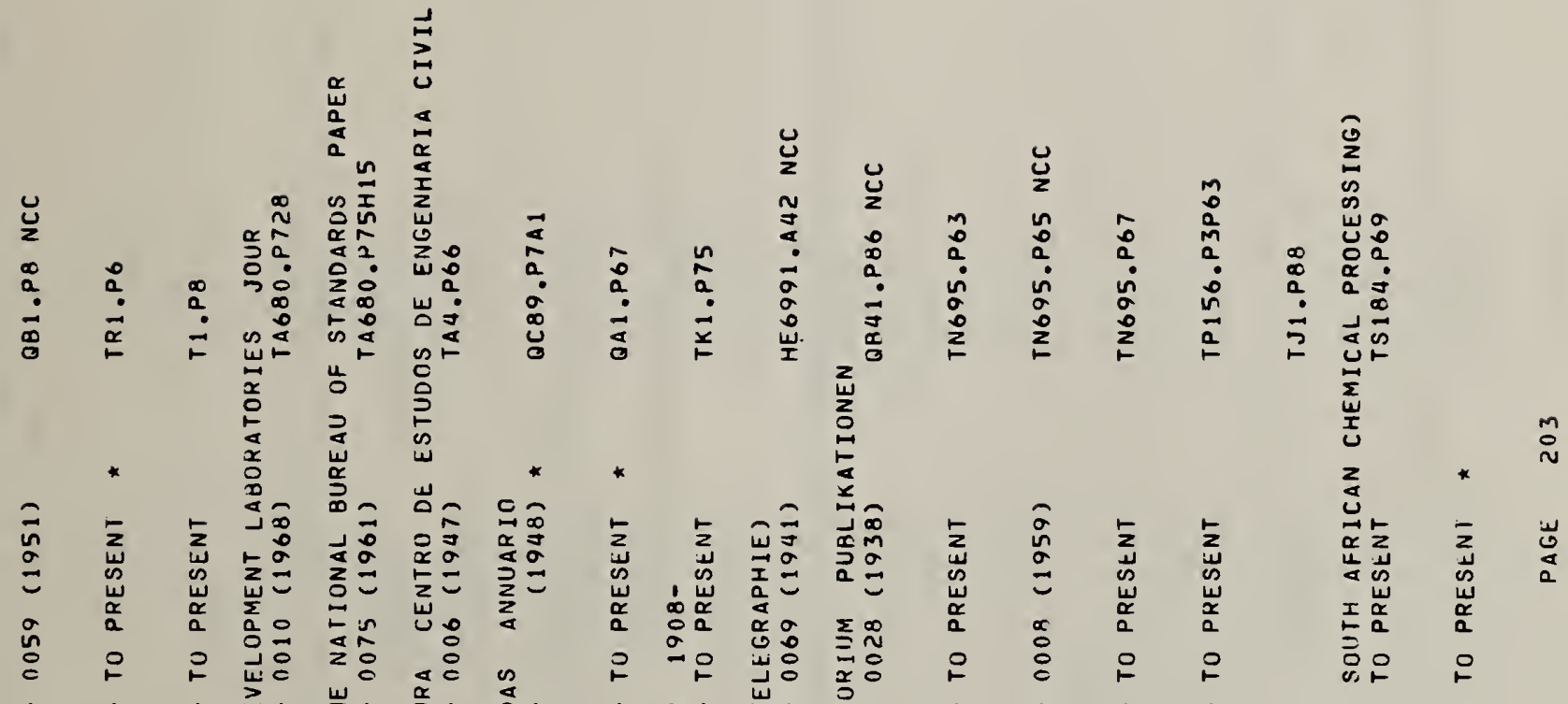

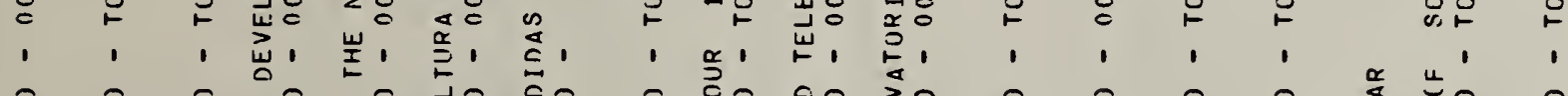

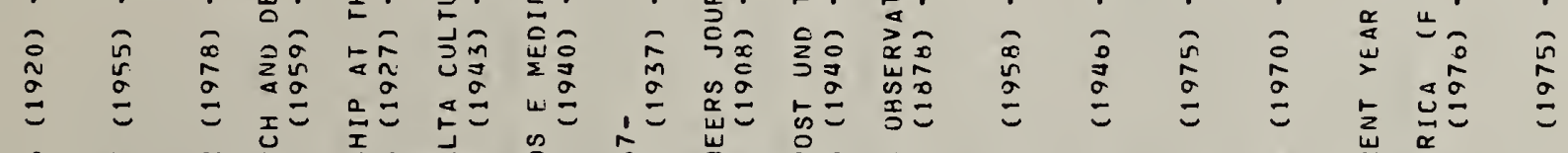

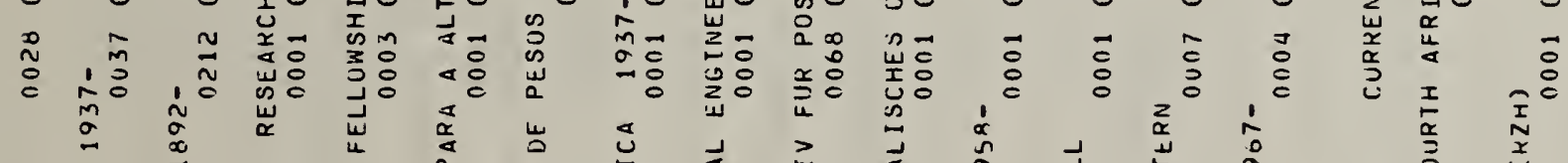

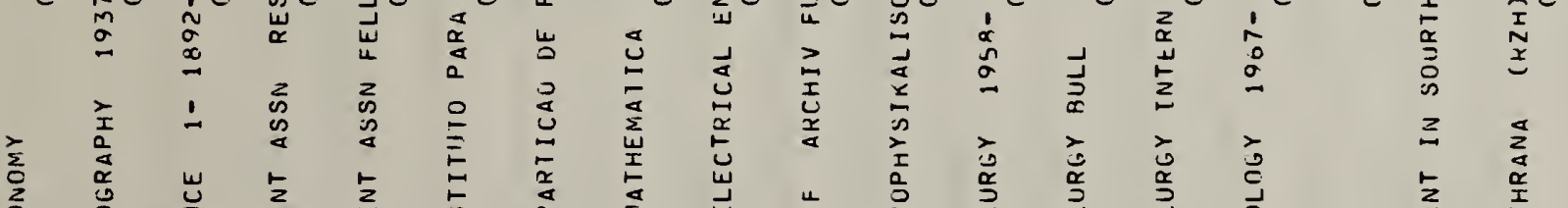

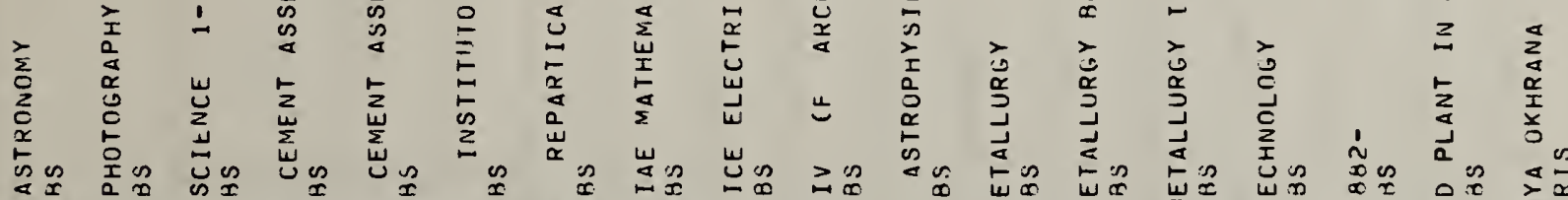

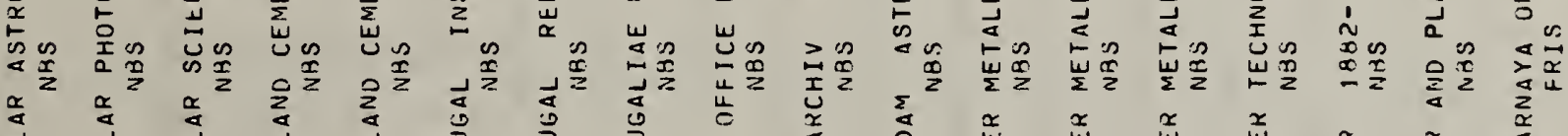

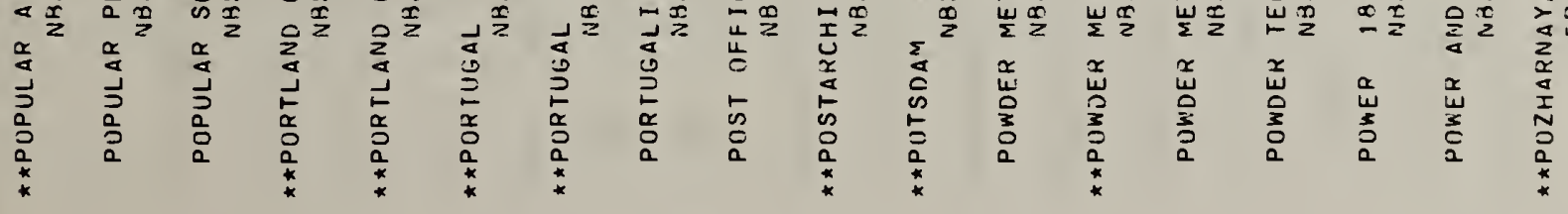




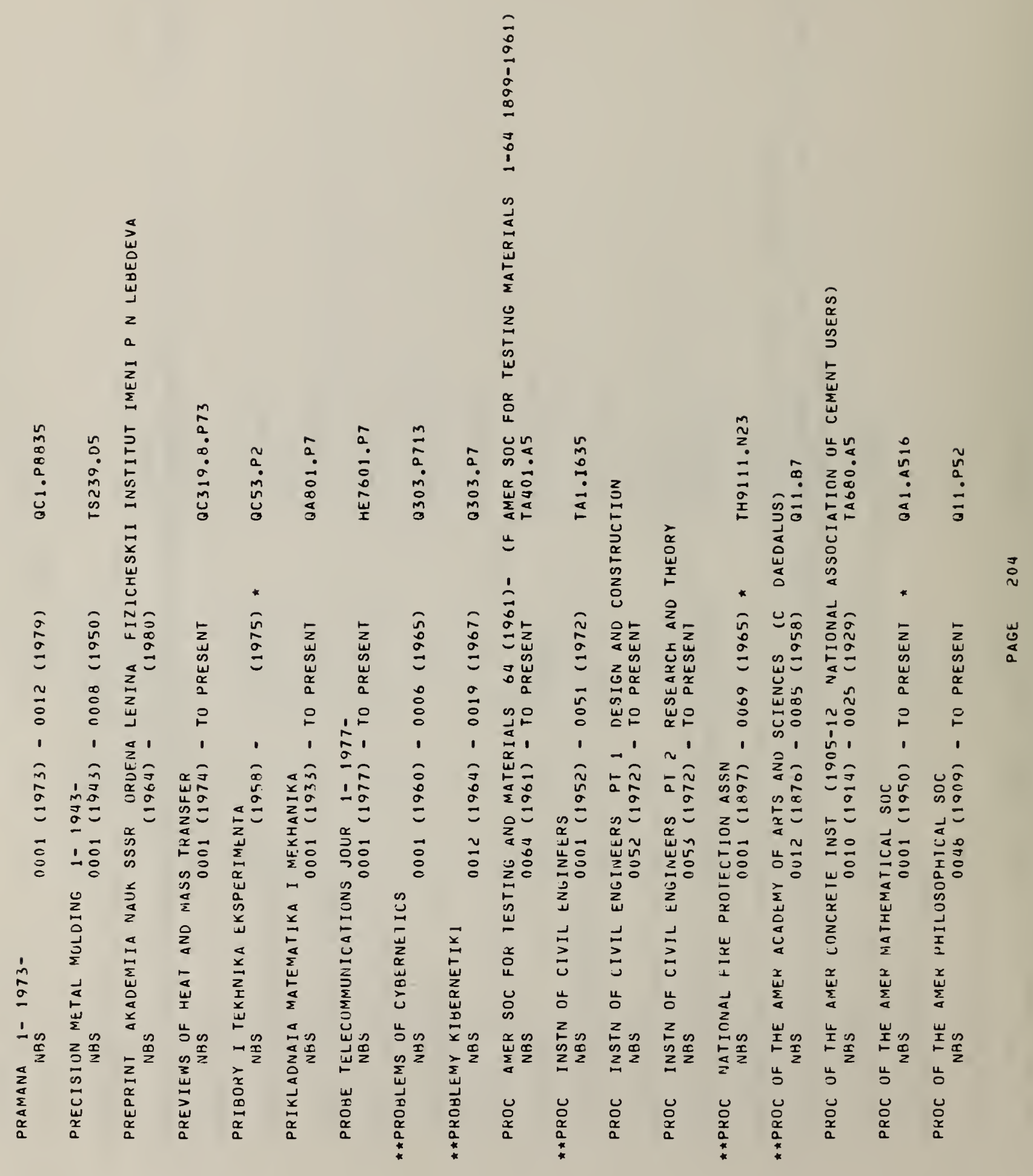




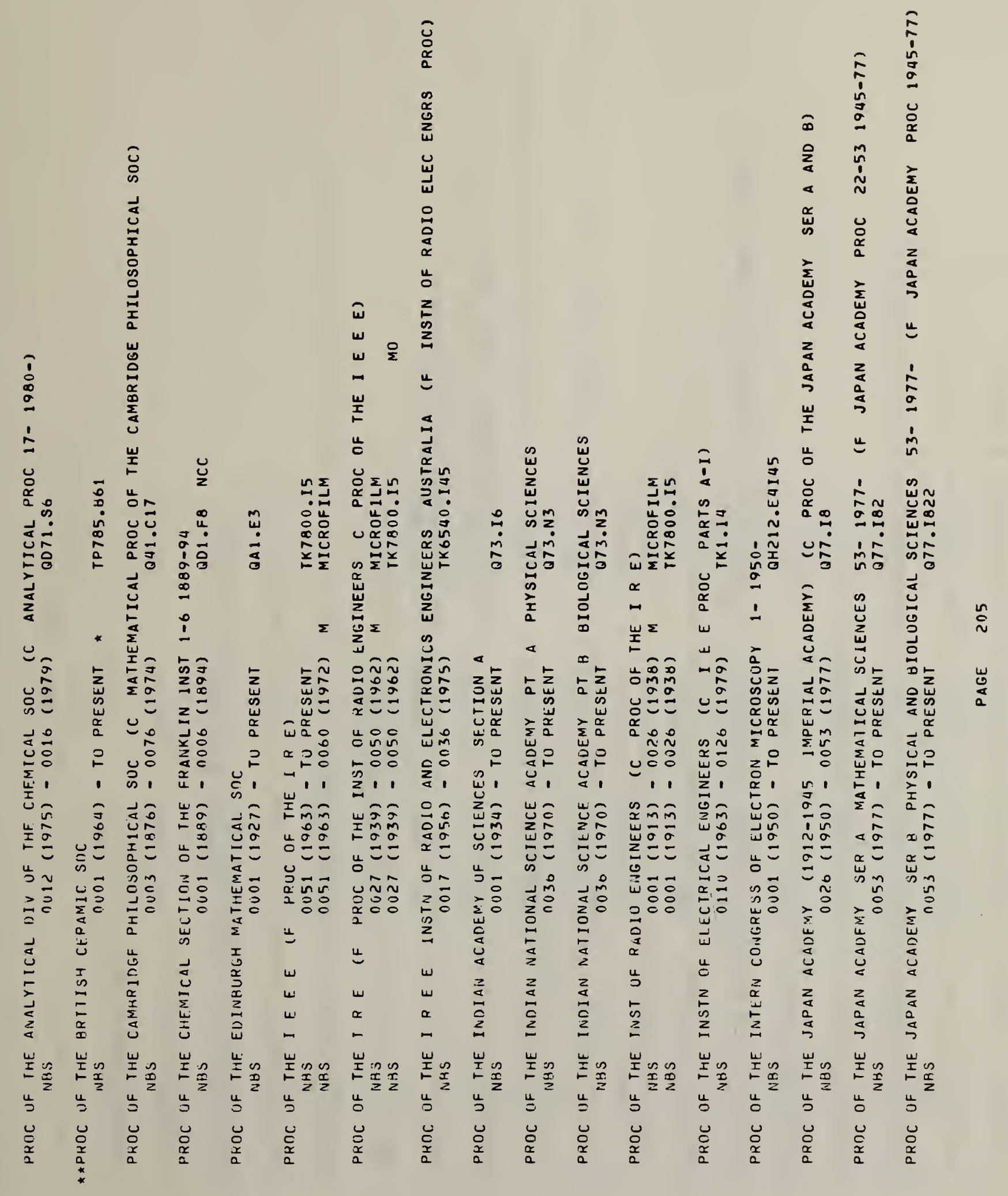




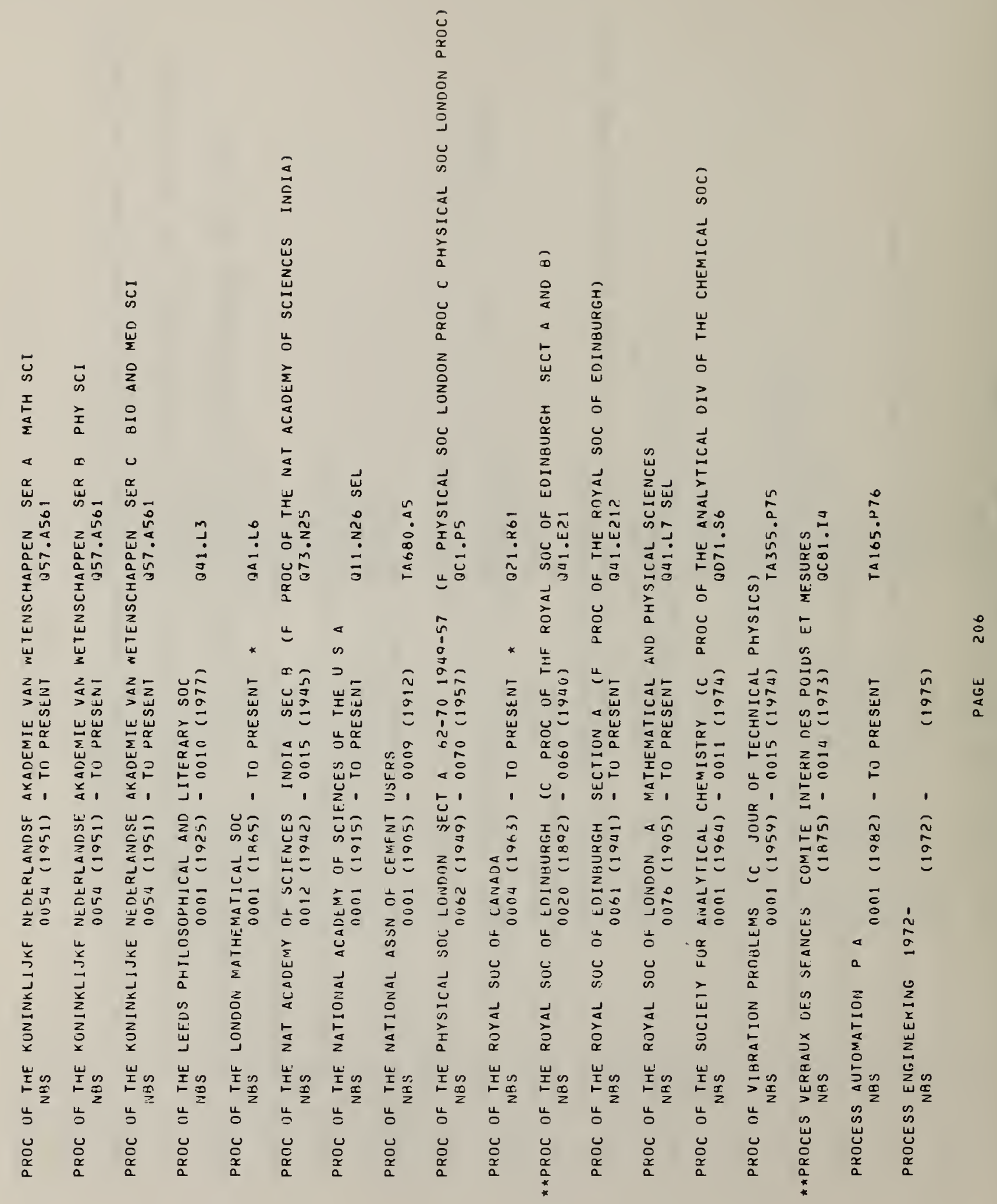




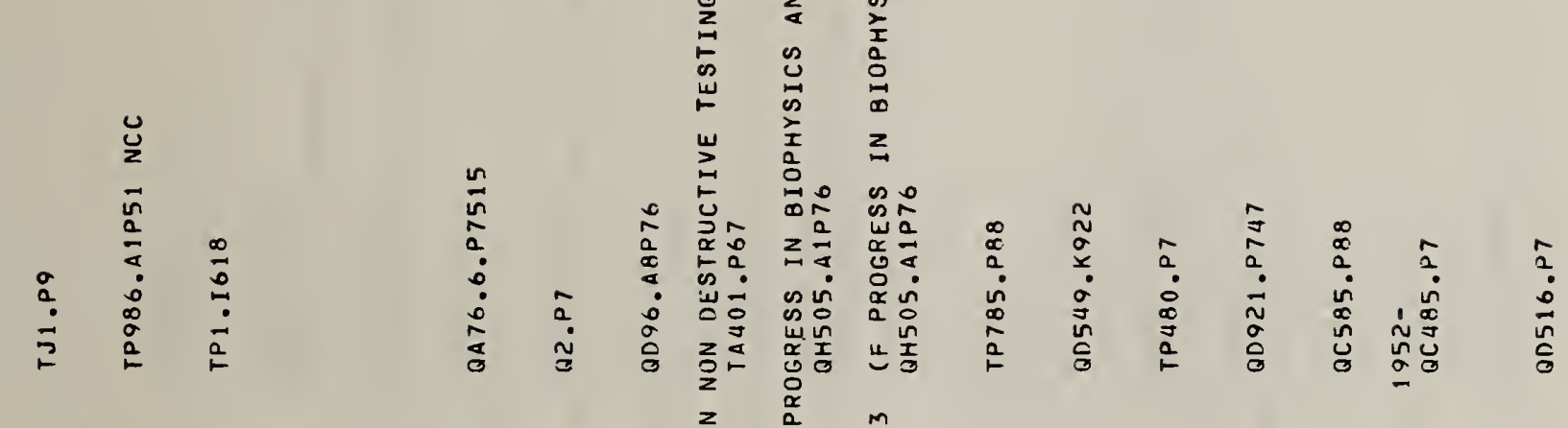

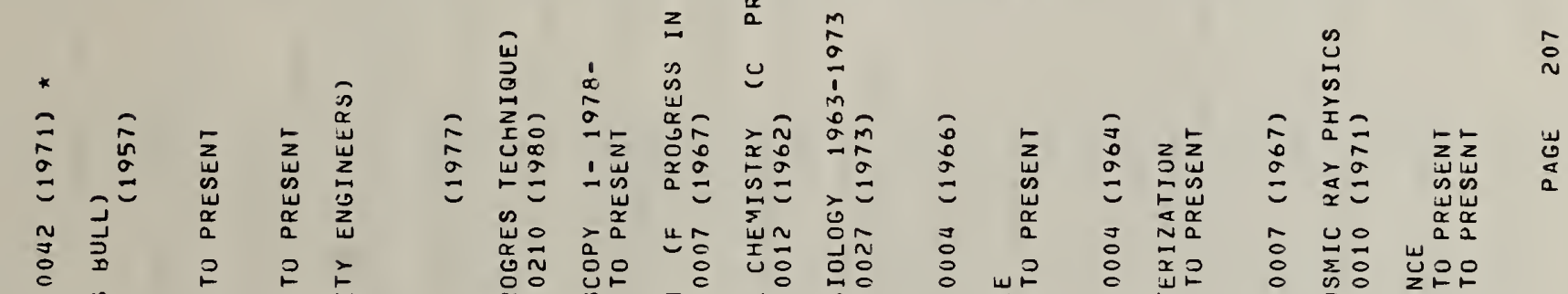

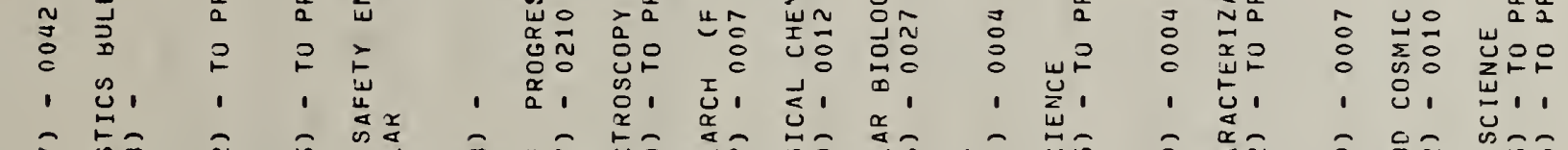

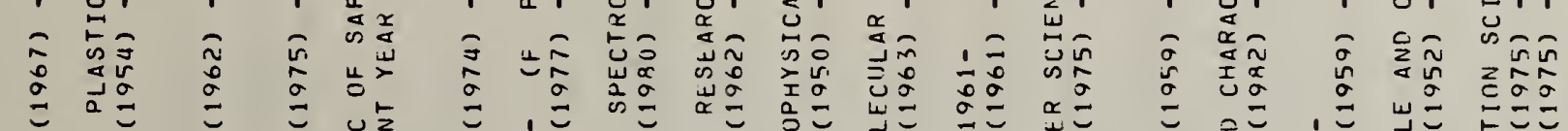

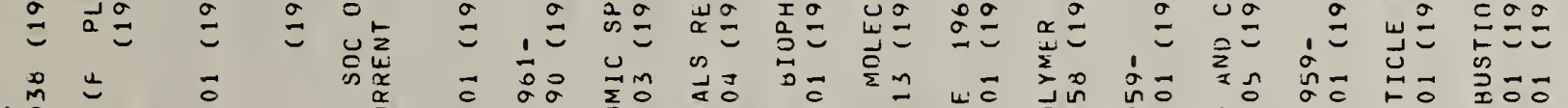

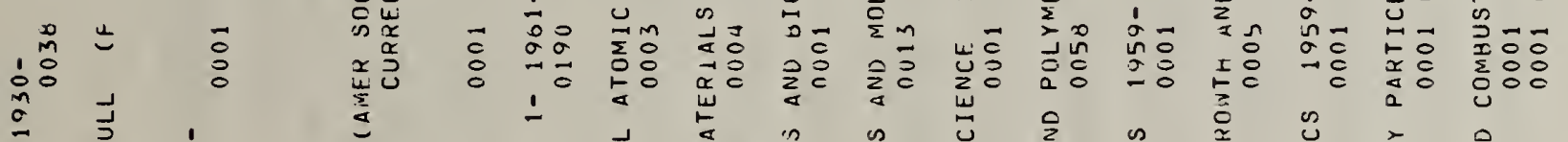




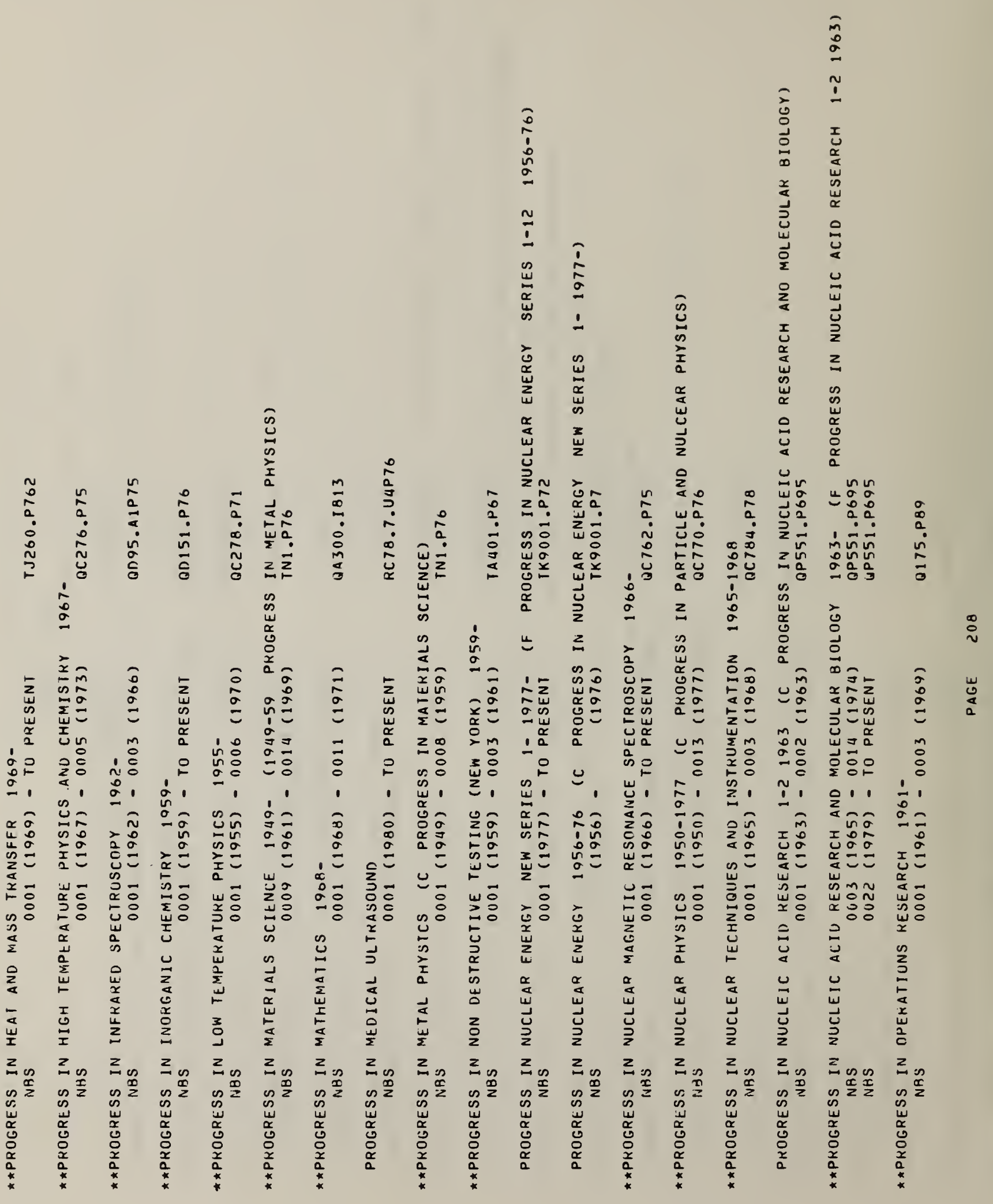




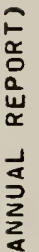

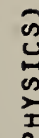

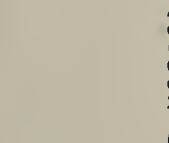

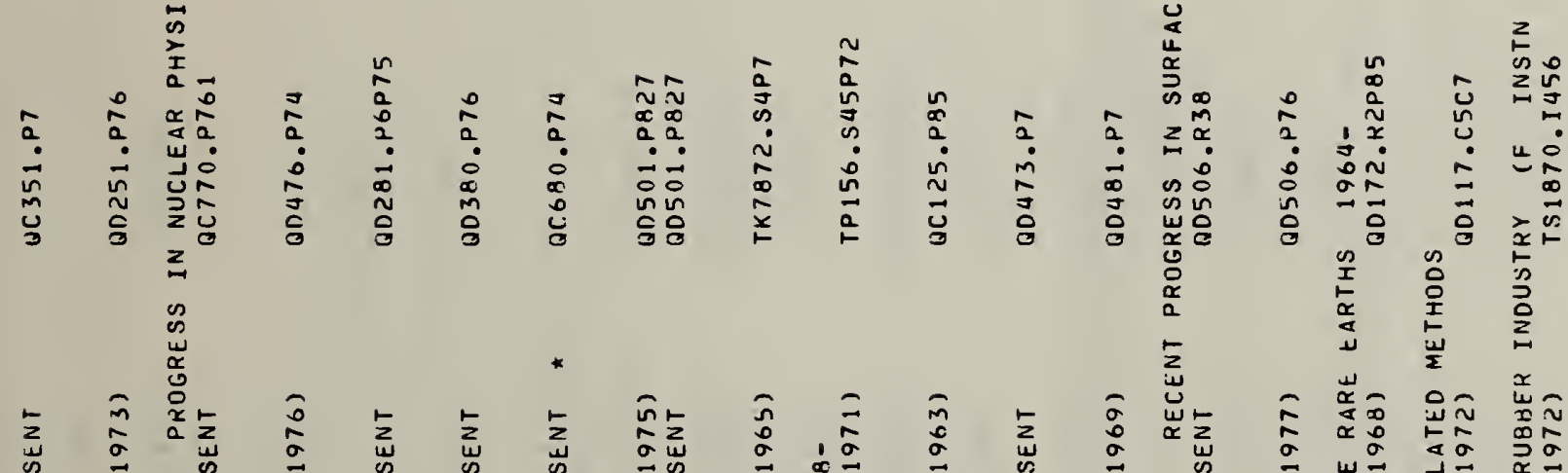

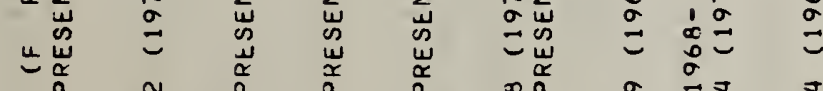

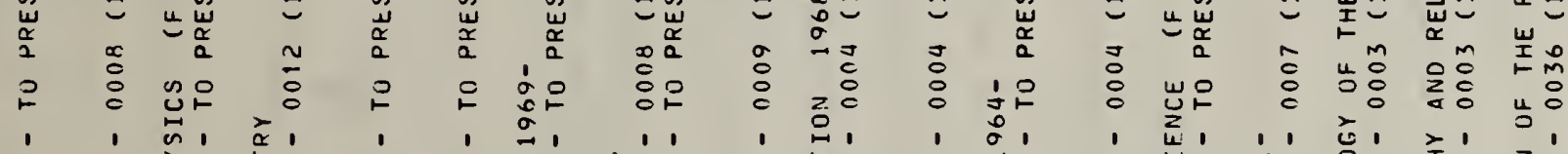

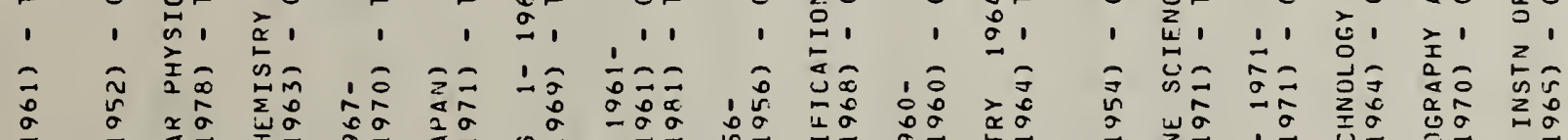
$=$ こ

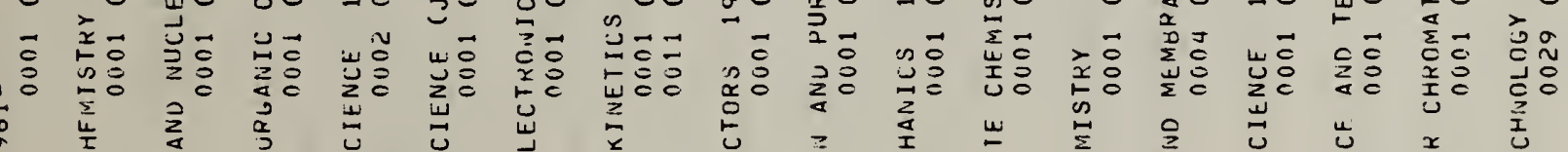

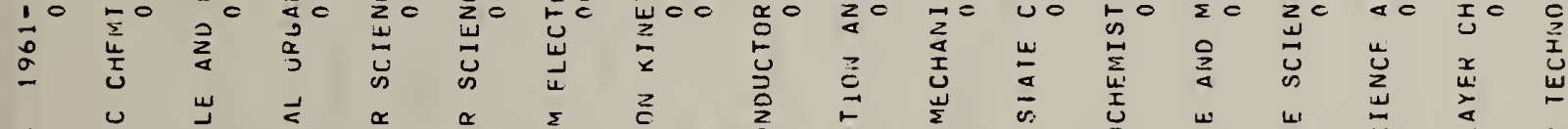

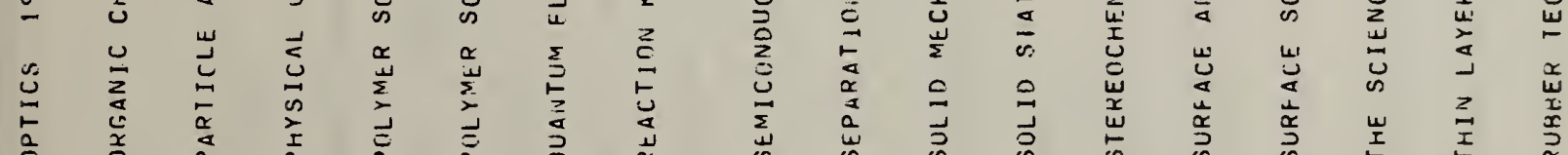

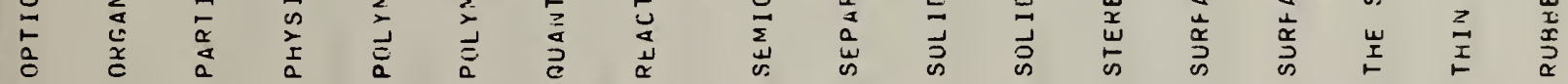

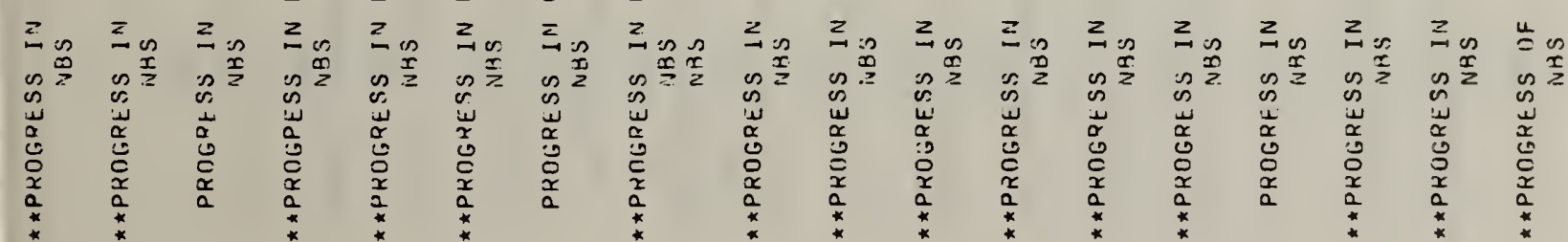


$E$
$\frac{a}{0}$
$a$
$\vec{a}$
$\alpha$
$\vec{a}$
$\sum_{2}^{a}$
$\frac{a}{a}$

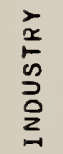

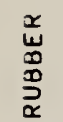

崖

岂

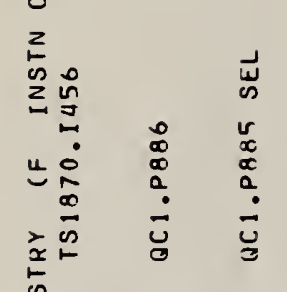

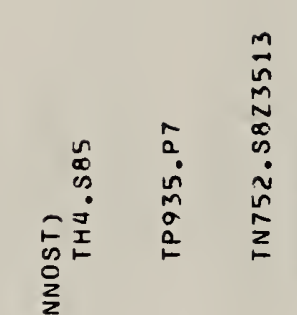

总

$\sum_{3}^{\infty}$

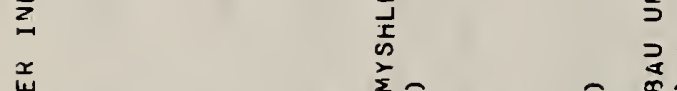

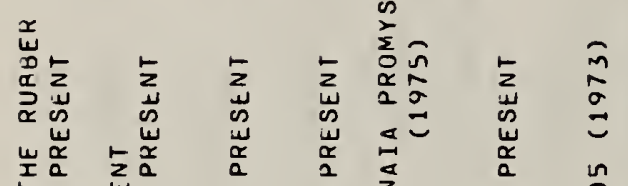

낭 $\sum_{4}$

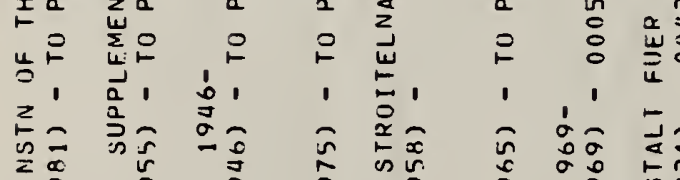

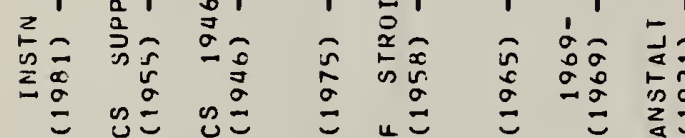

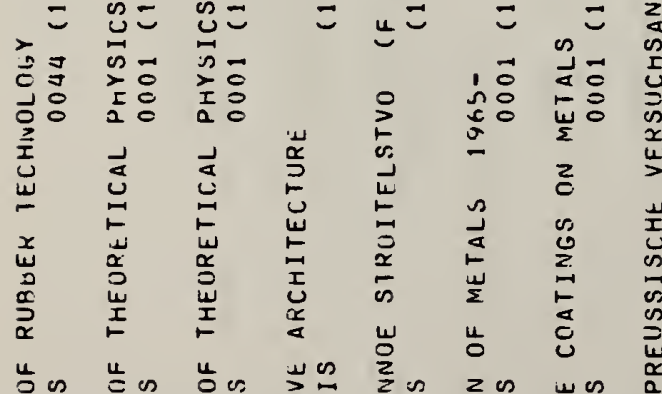

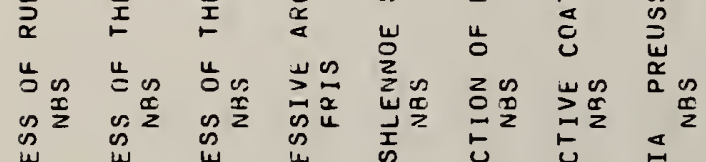

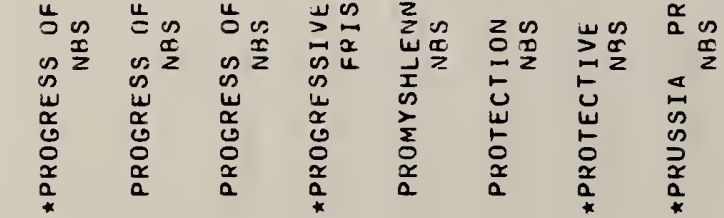


$\frac{a}{a}$

兽

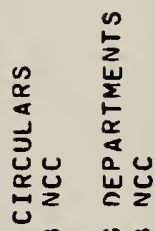

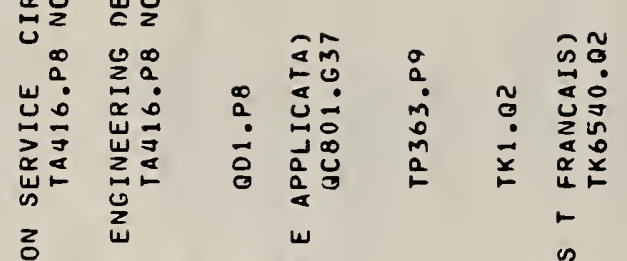

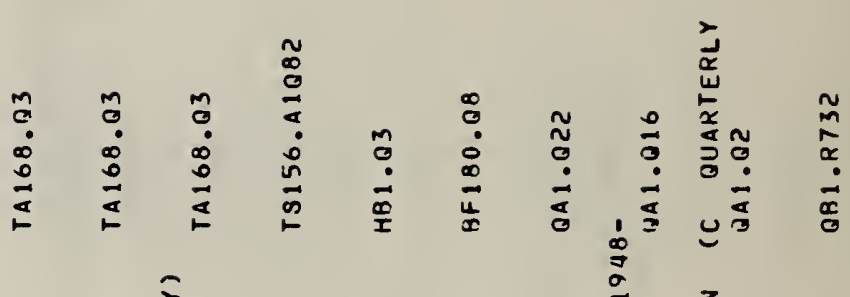

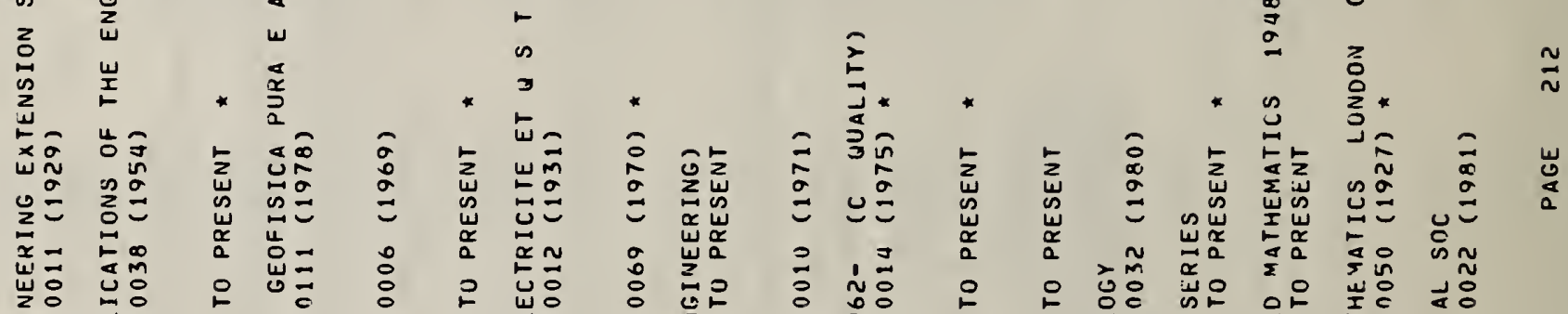

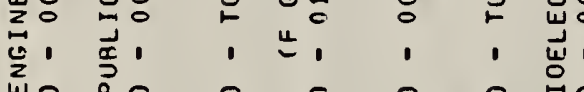

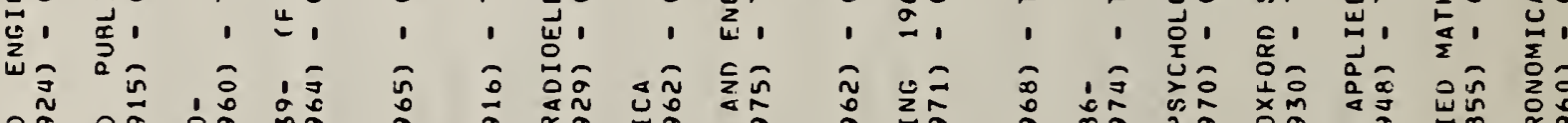

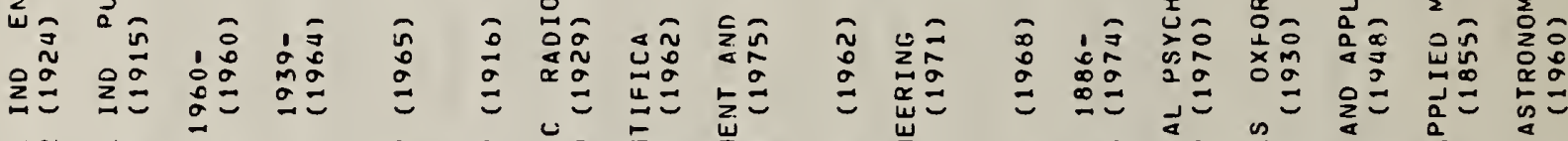

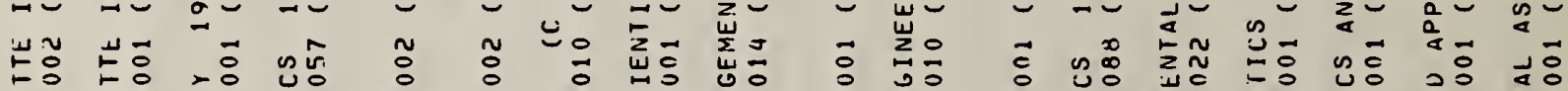
岁号 点:

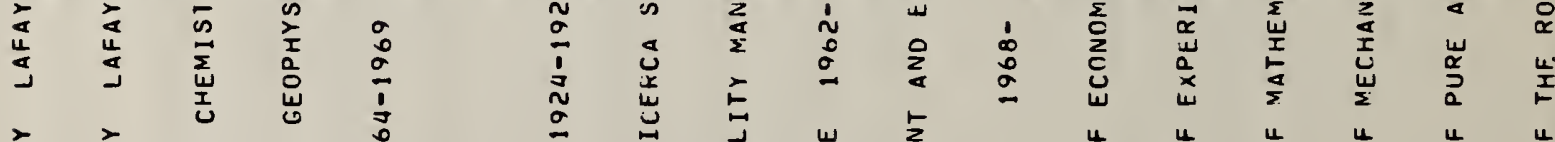
‡

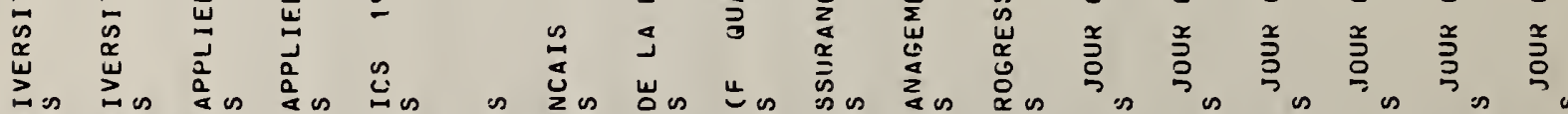

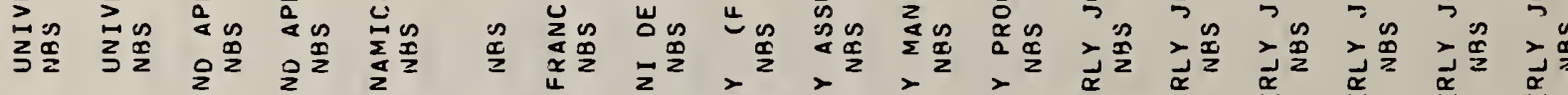

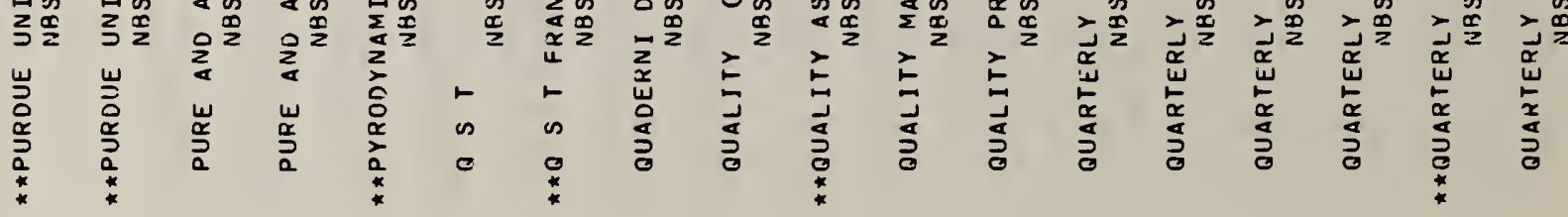




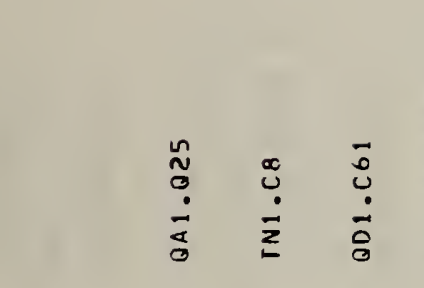

$\begin{array}{ll}u & \overrightarrow{0} \\ z & \stackrel{0}{c}\end{array}$

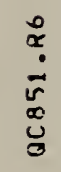

5
0
$\dot{0}$
0
$\sim$
$\sim$

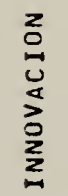

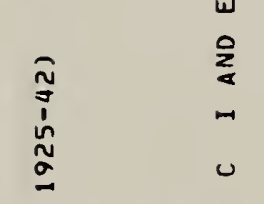

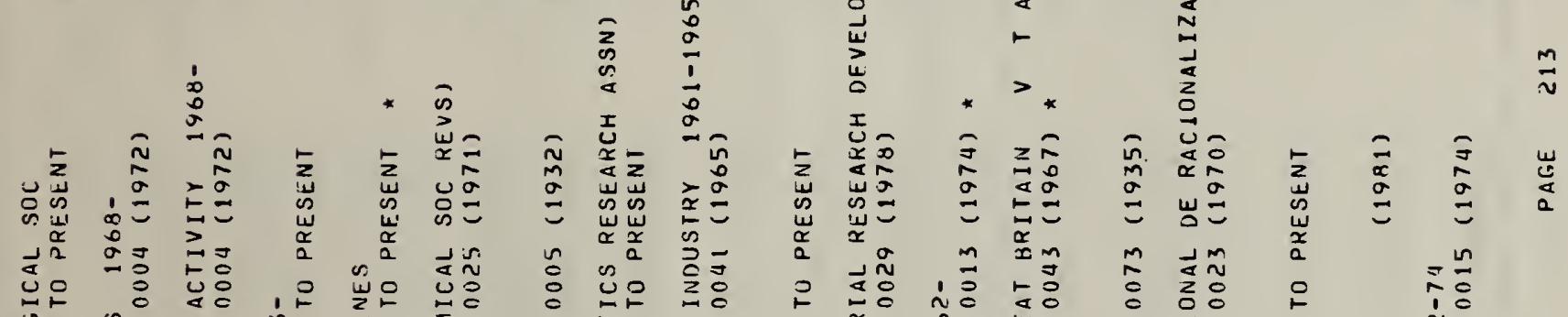

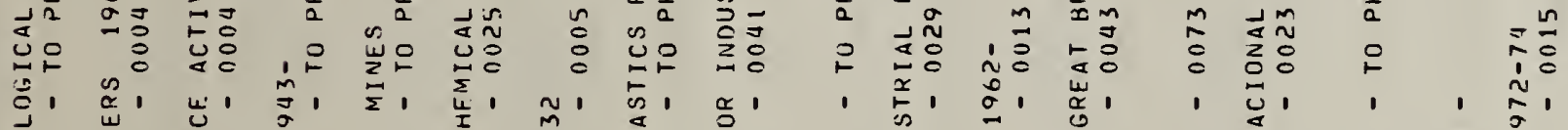

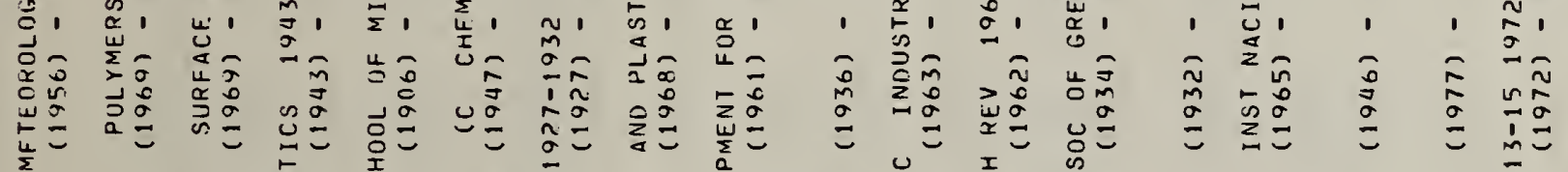

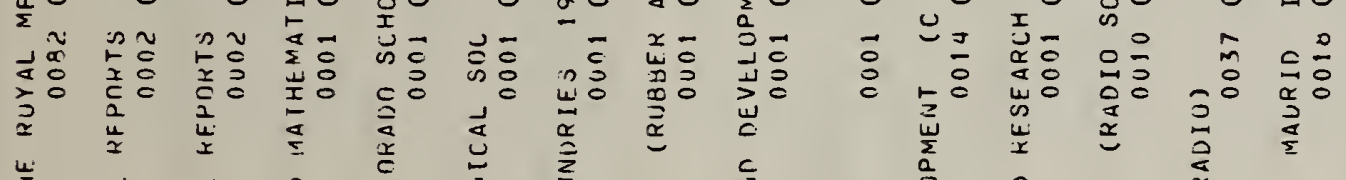

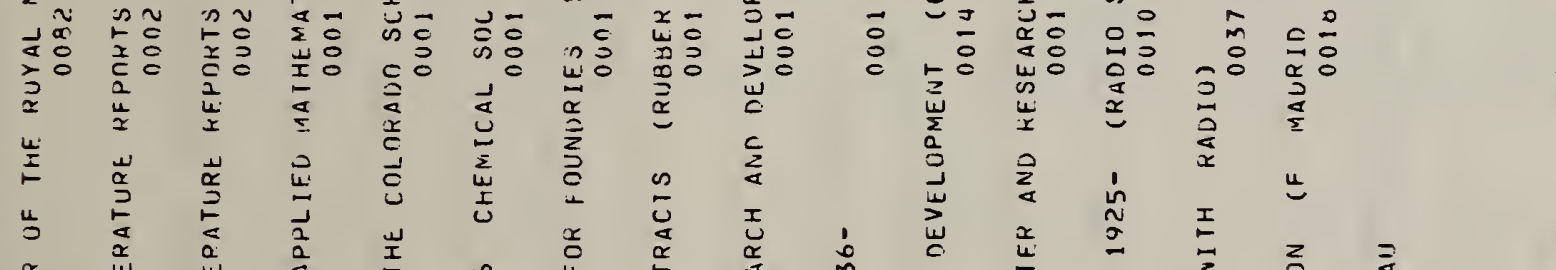

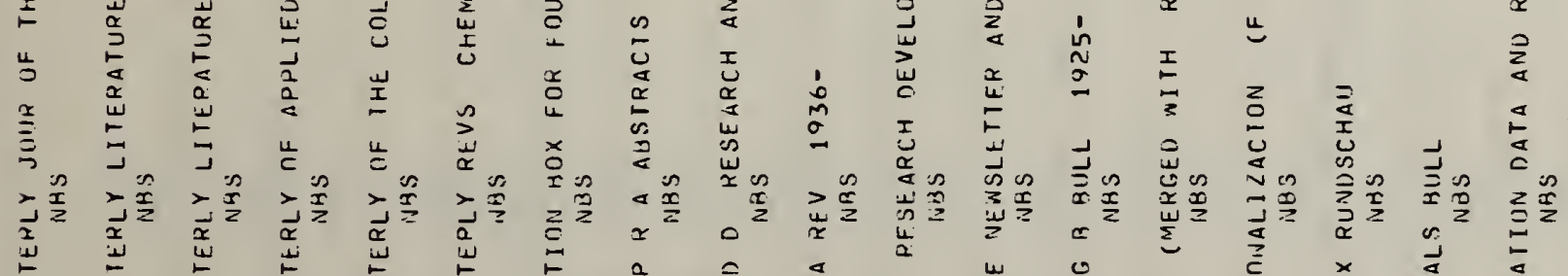

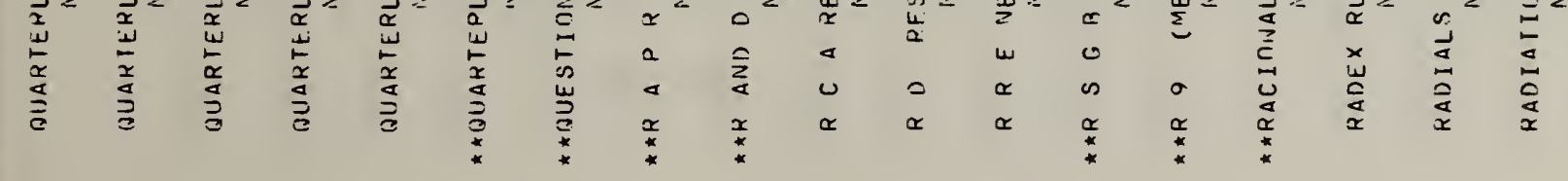




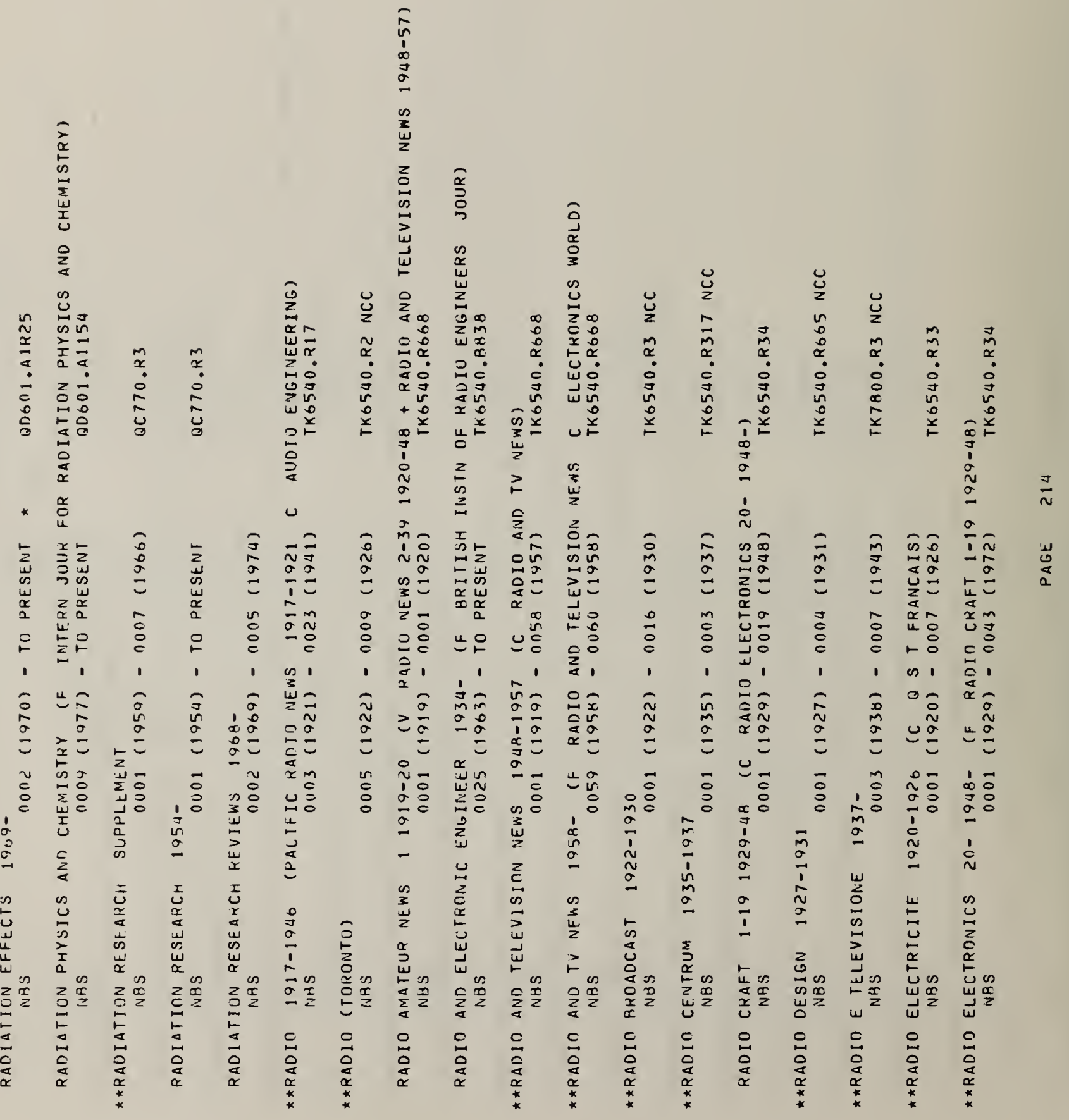




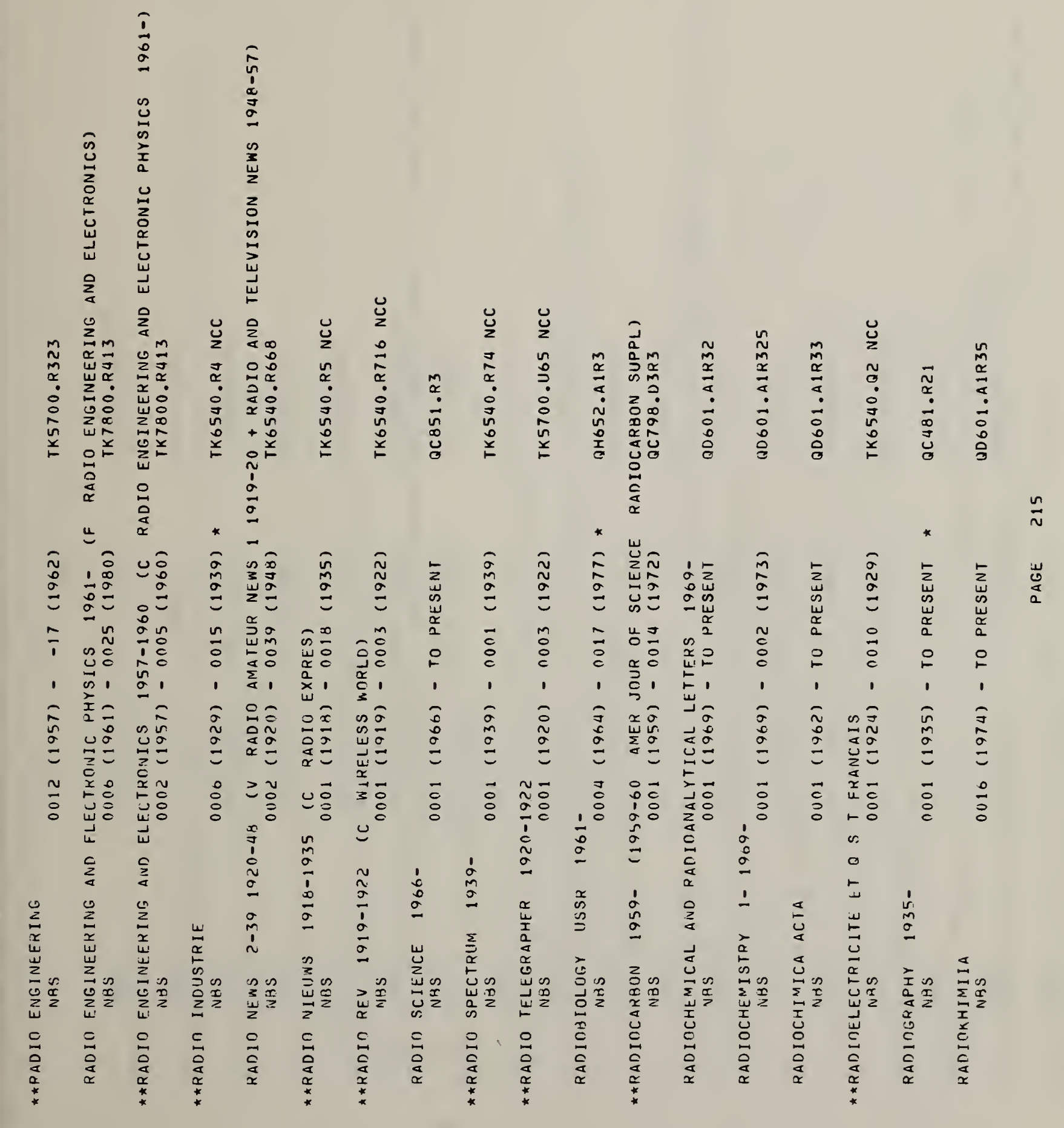




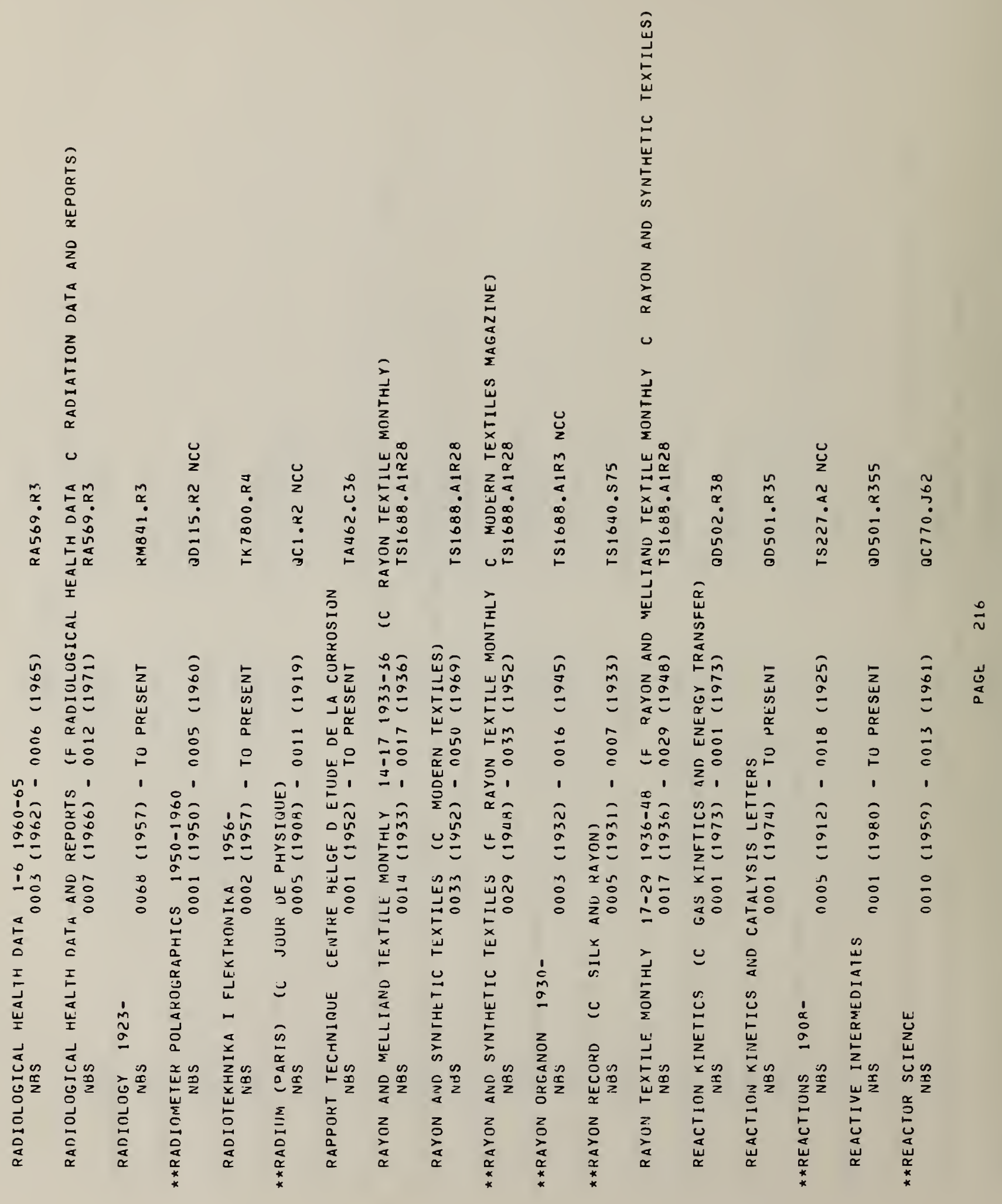




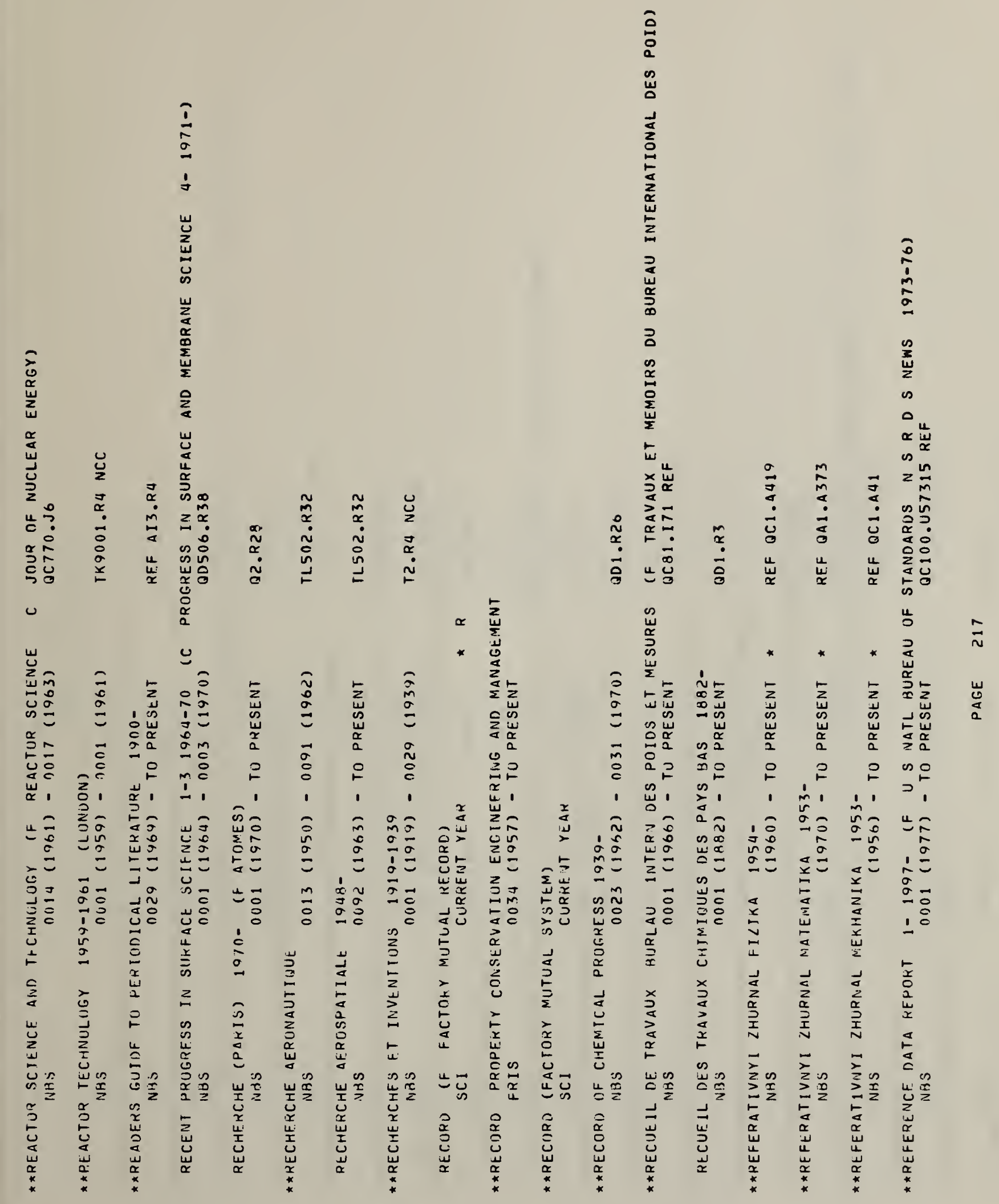




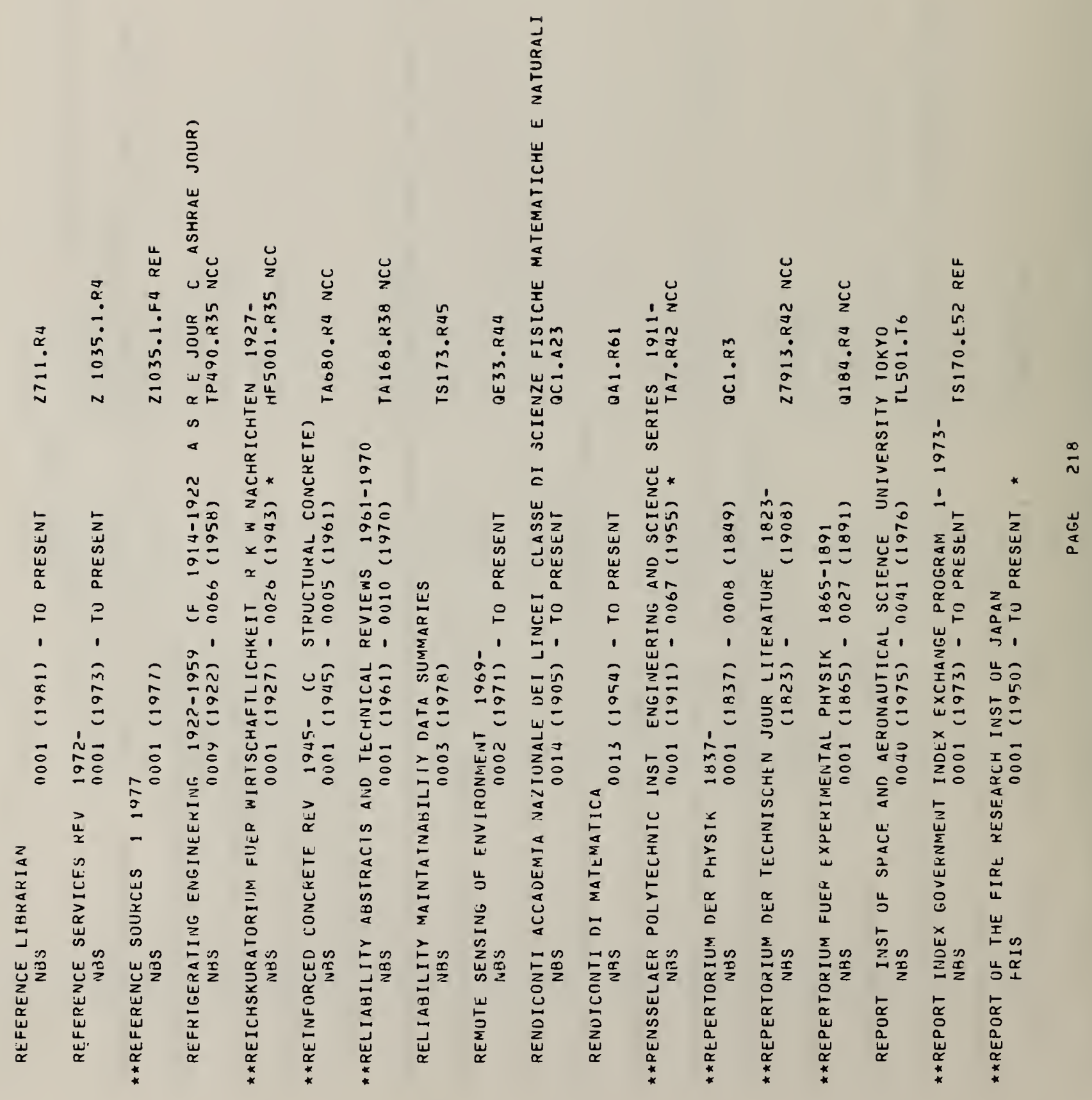




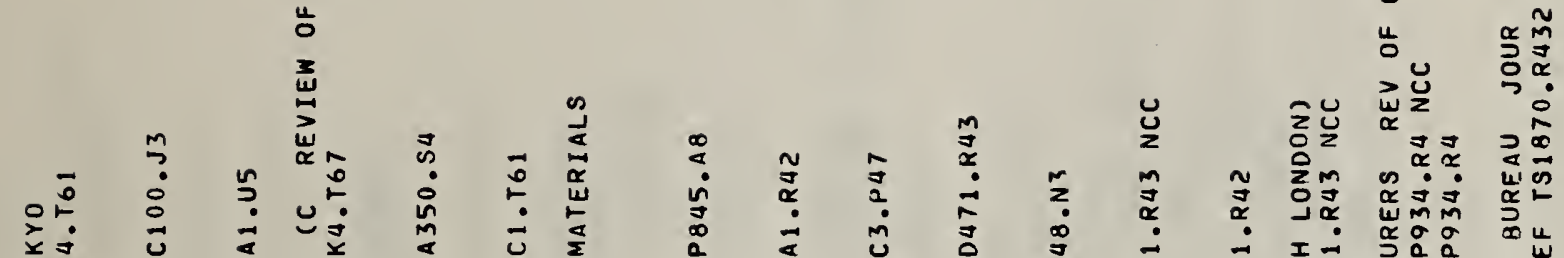

$\underset{\substack{a \\ d}}{0}$

u

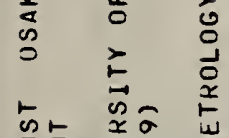

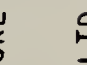

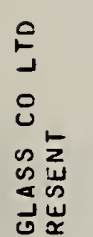

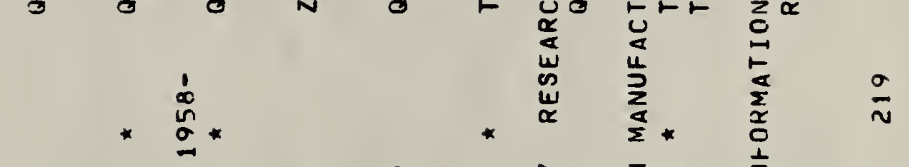

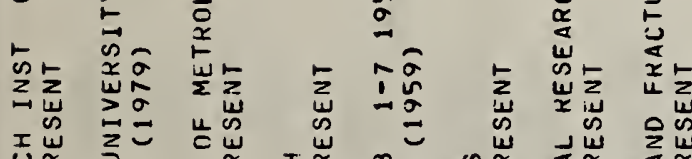

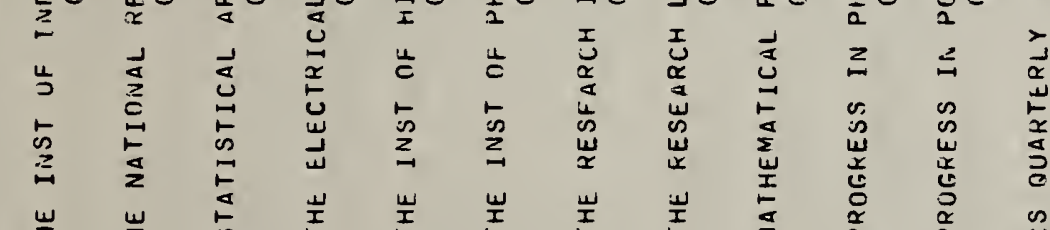




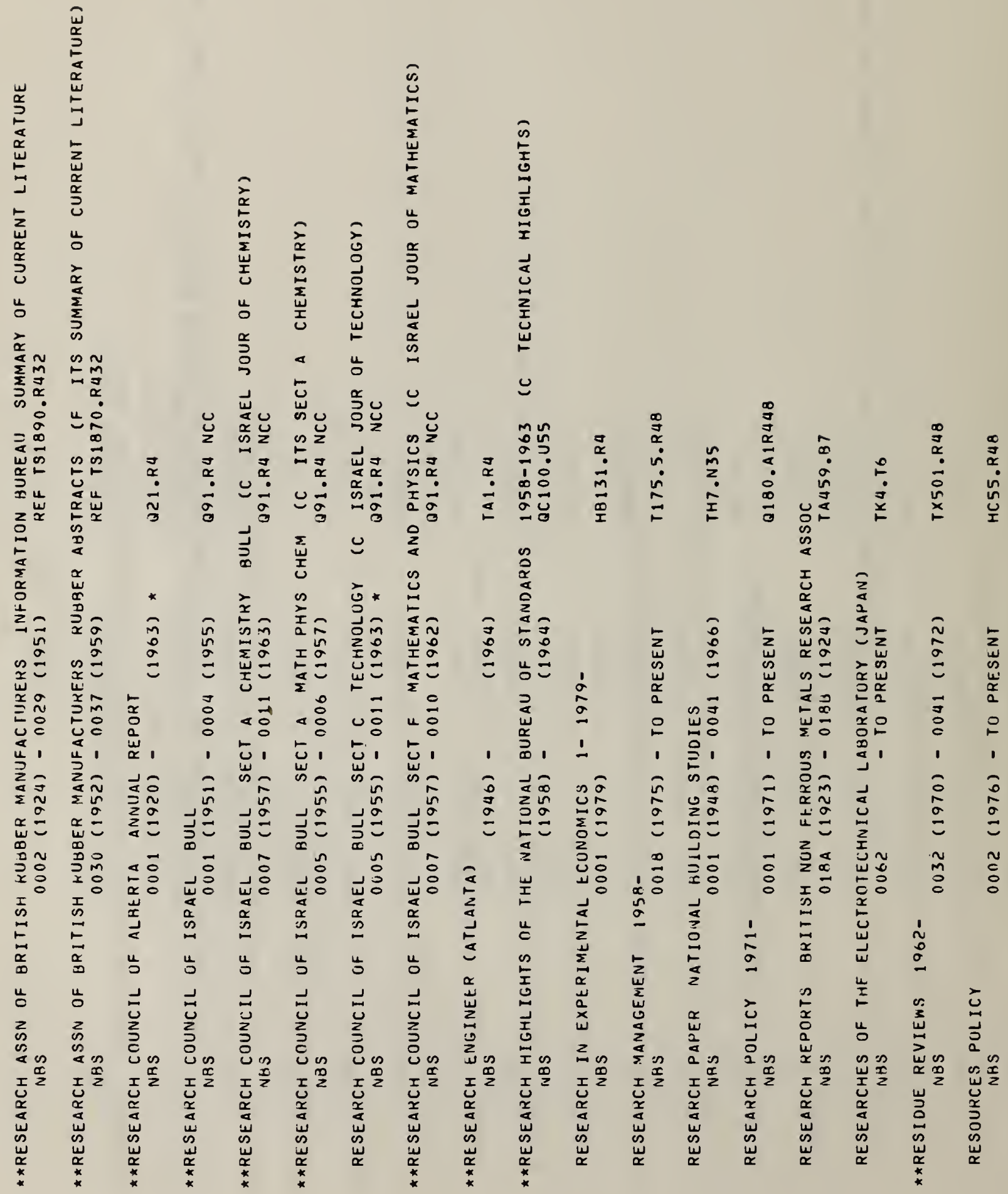




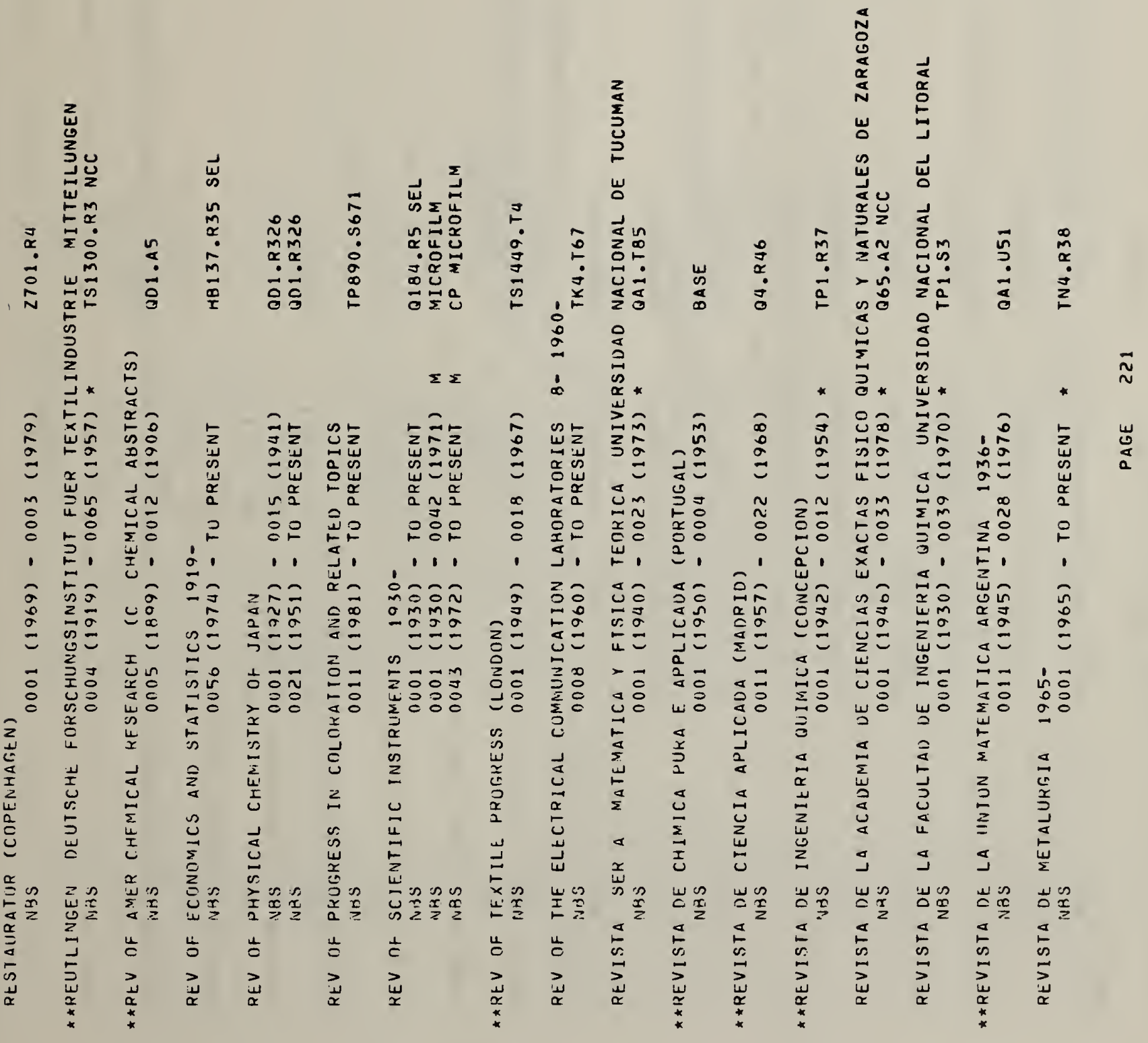




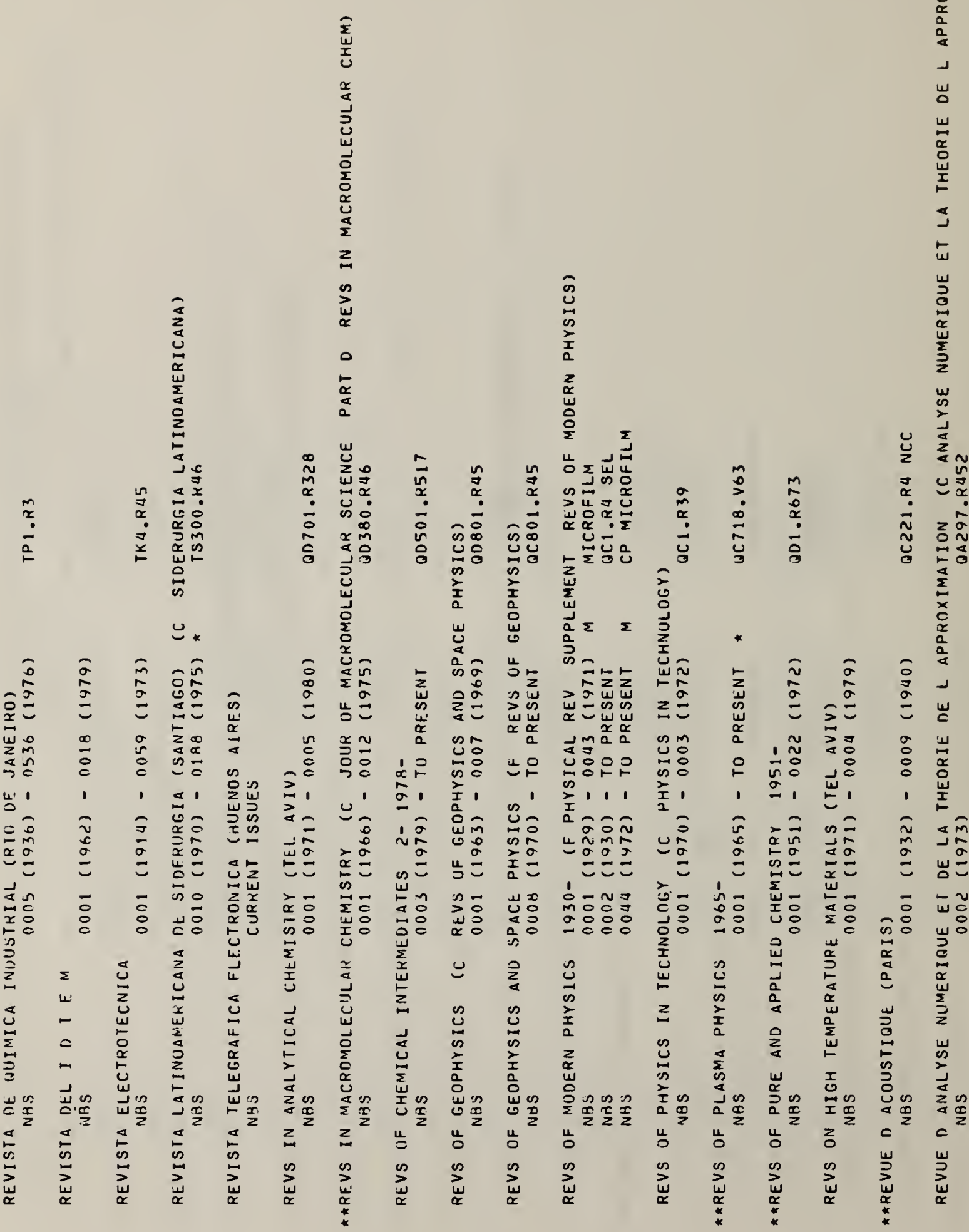




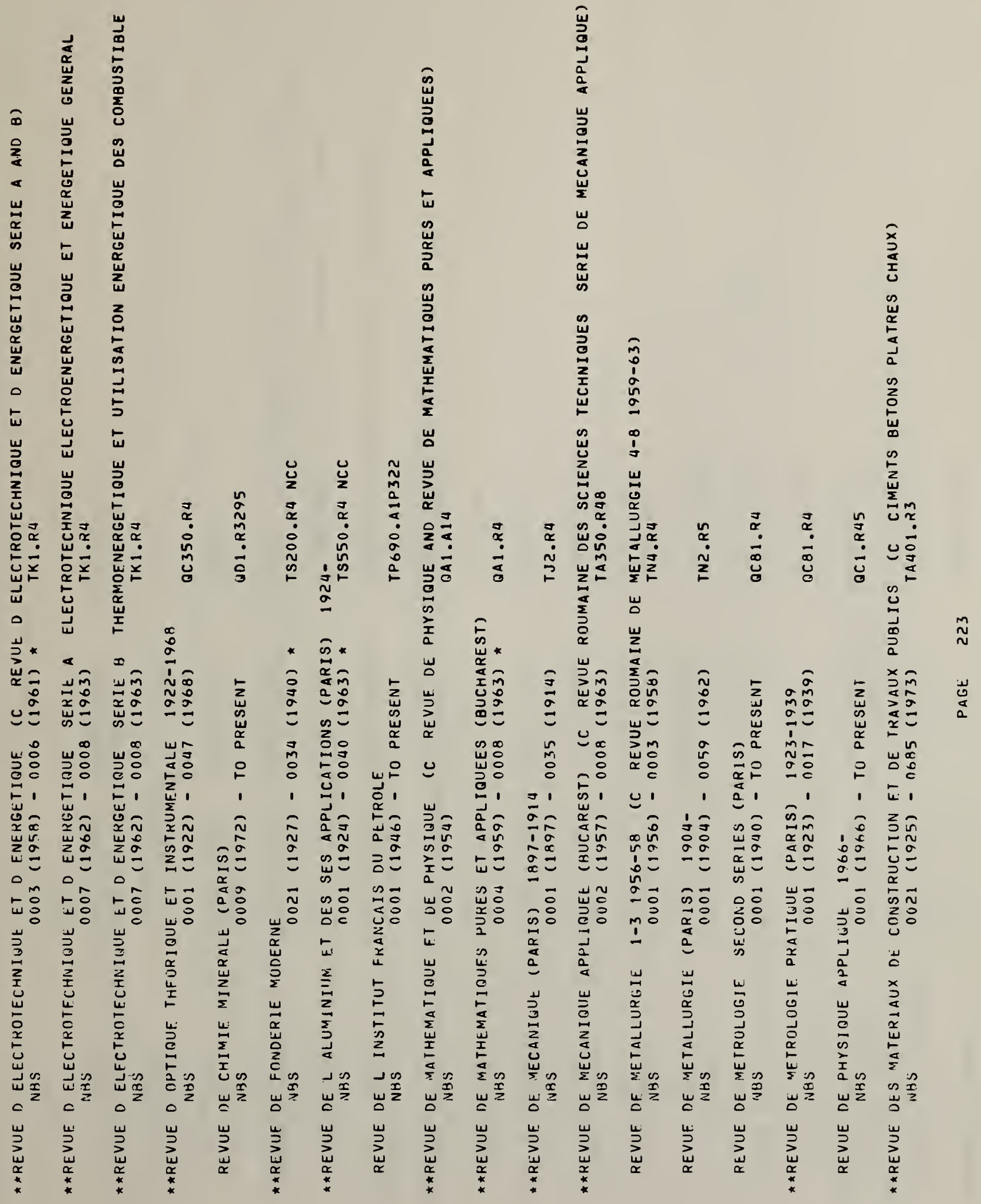




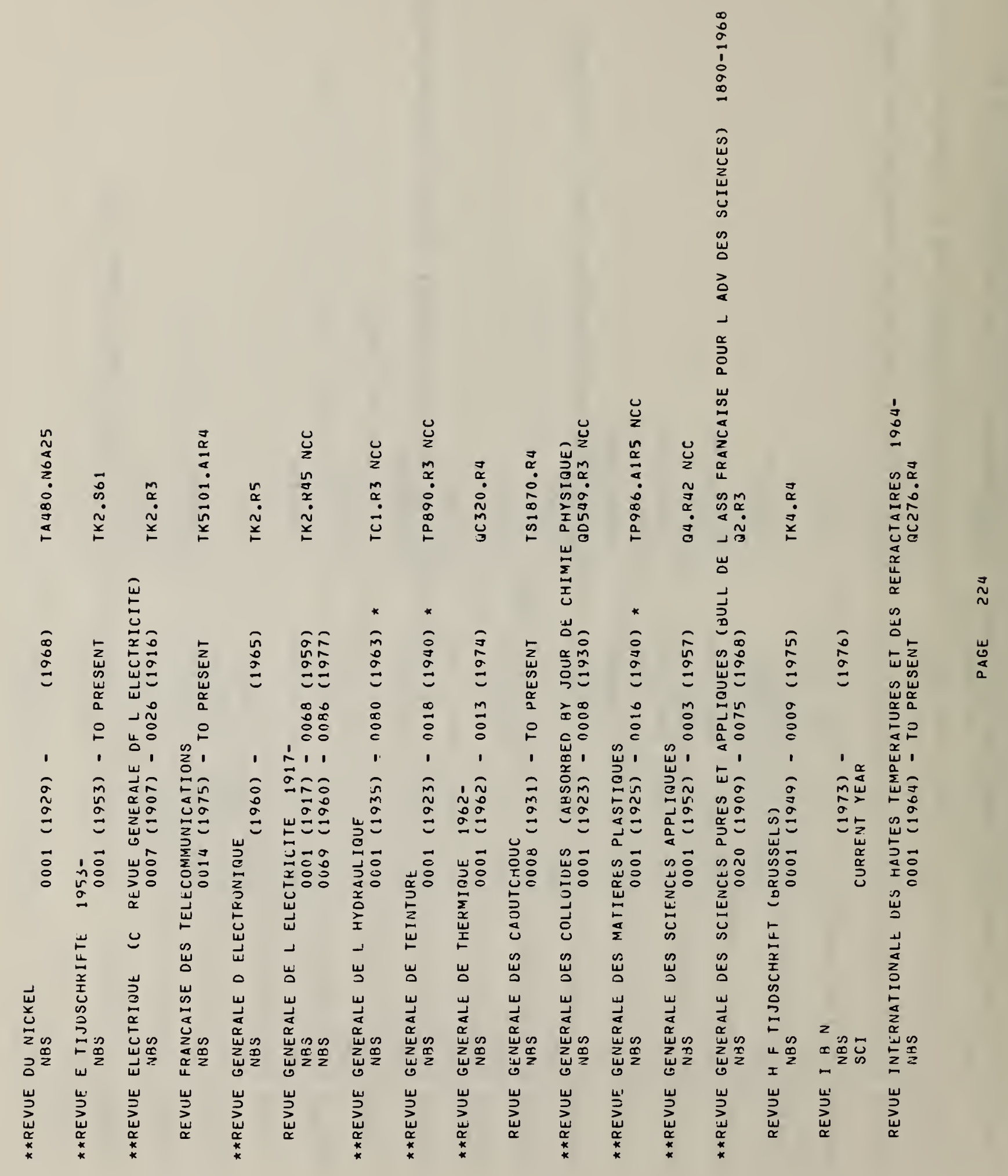




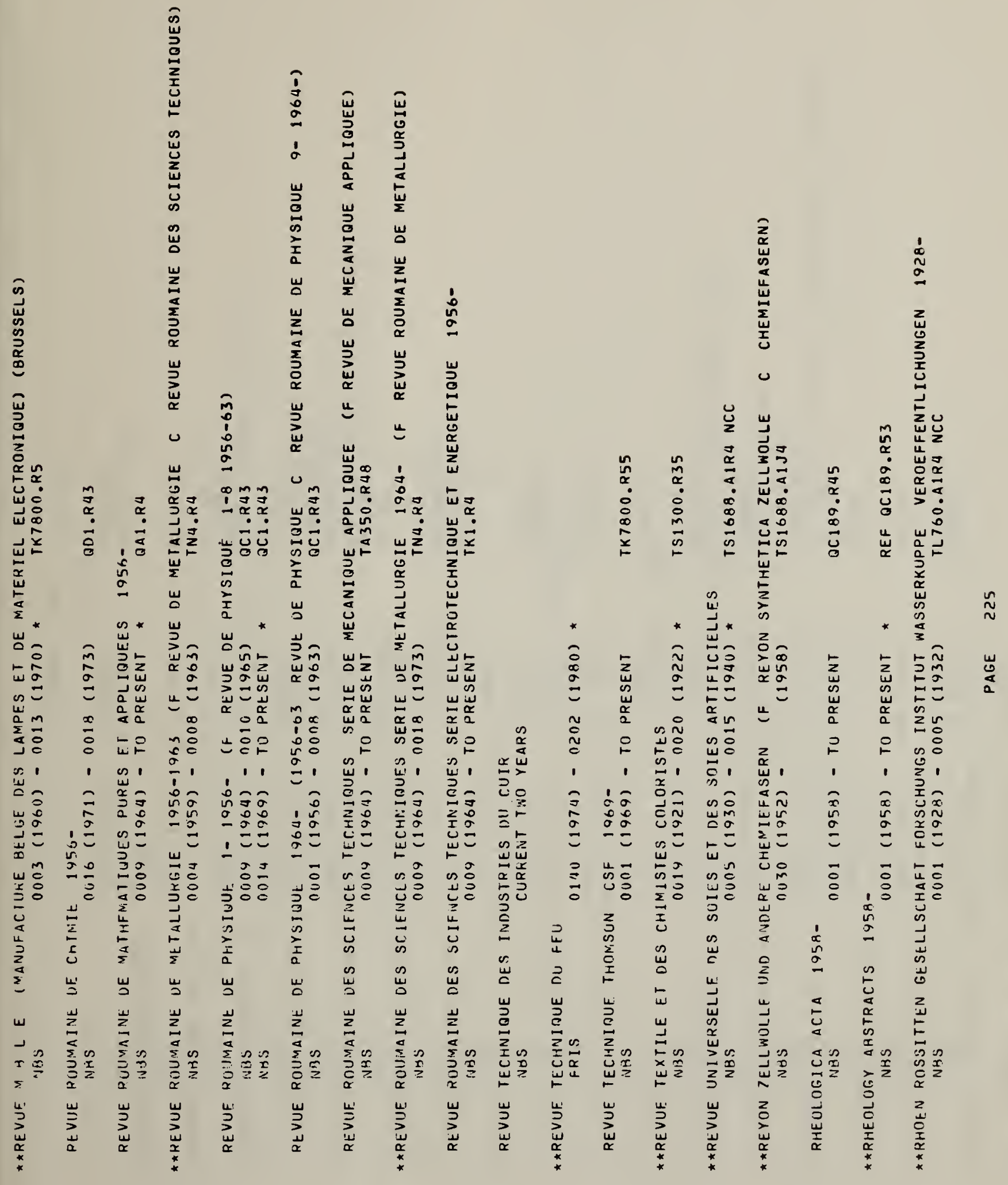




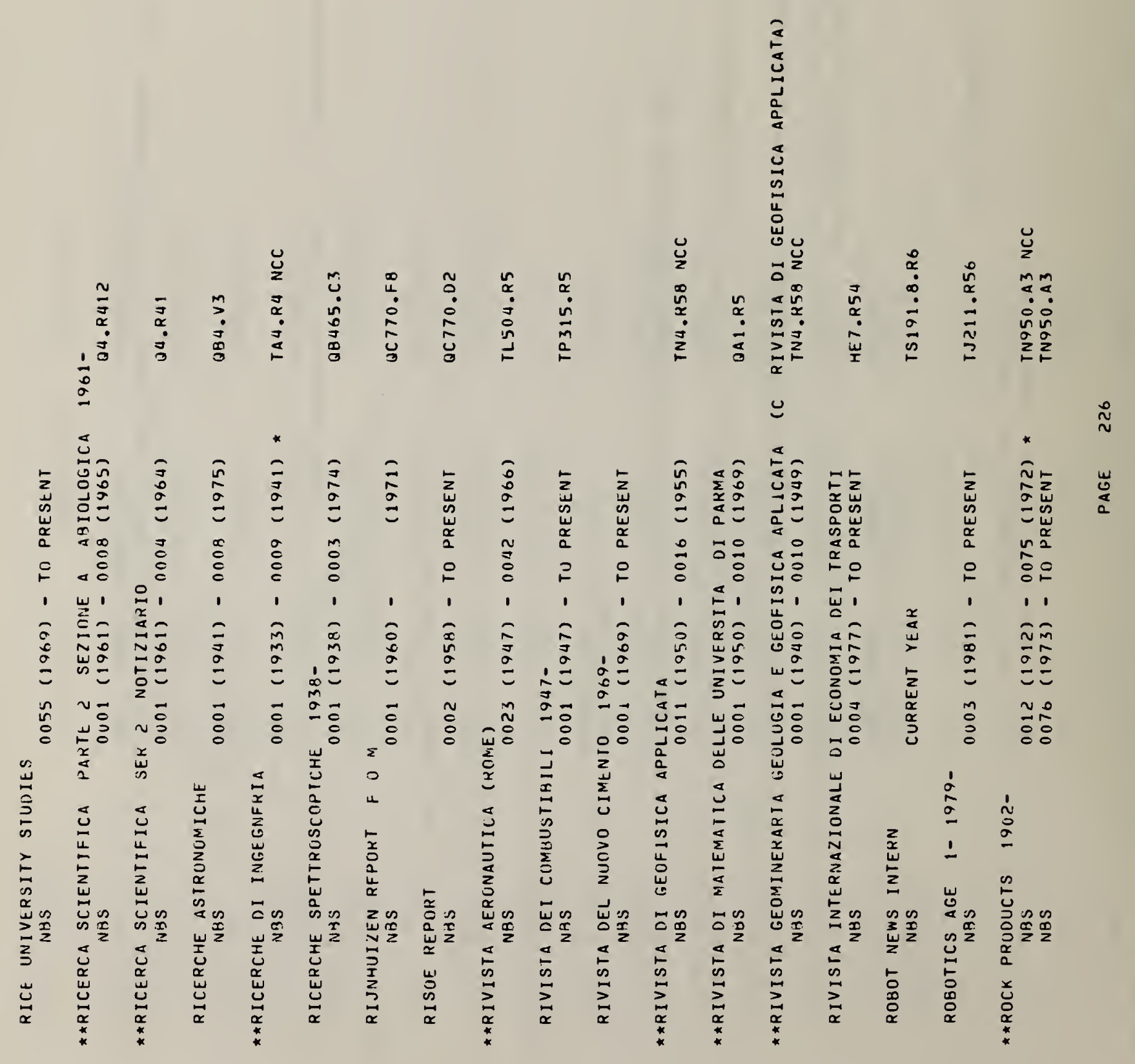




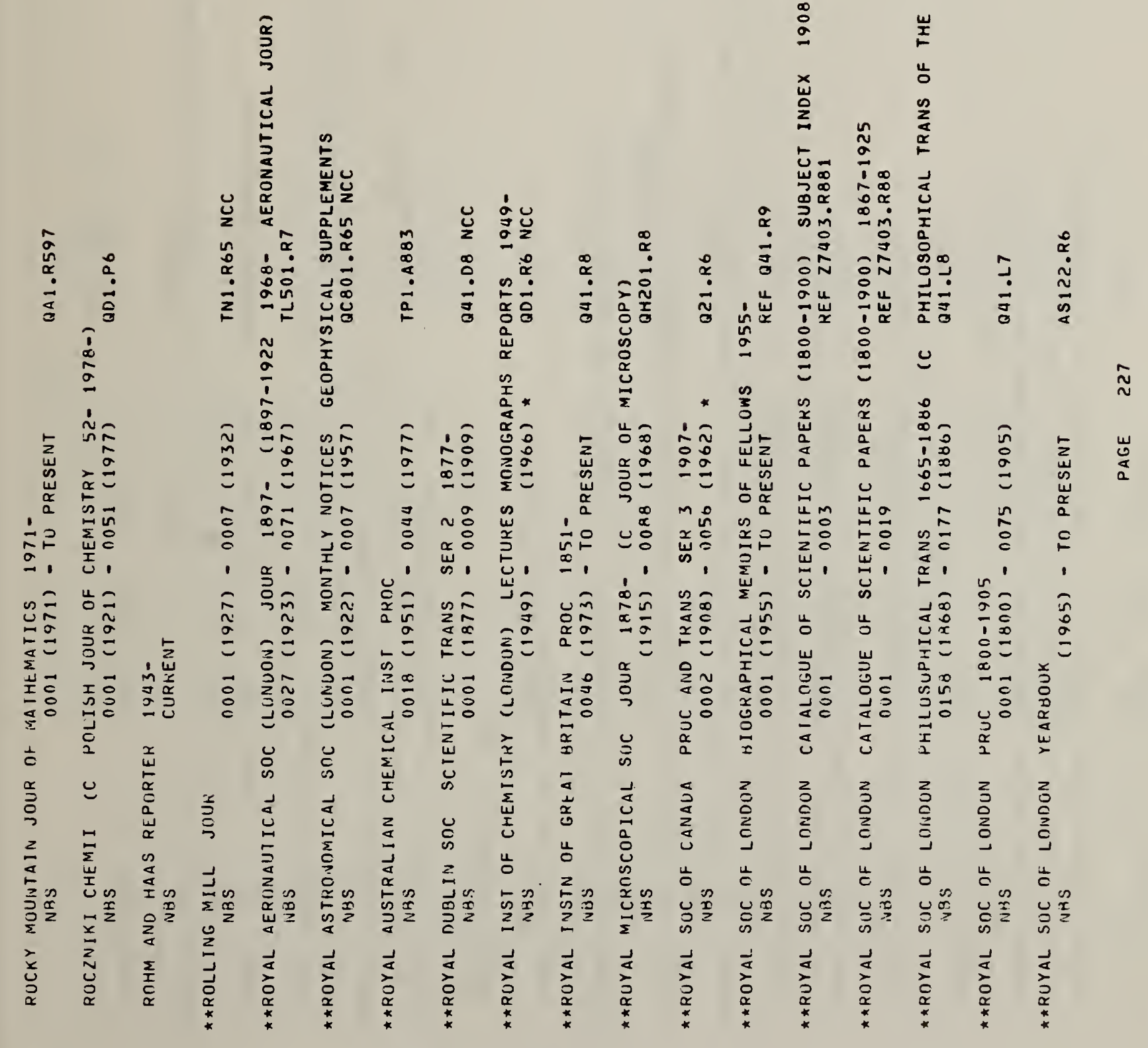




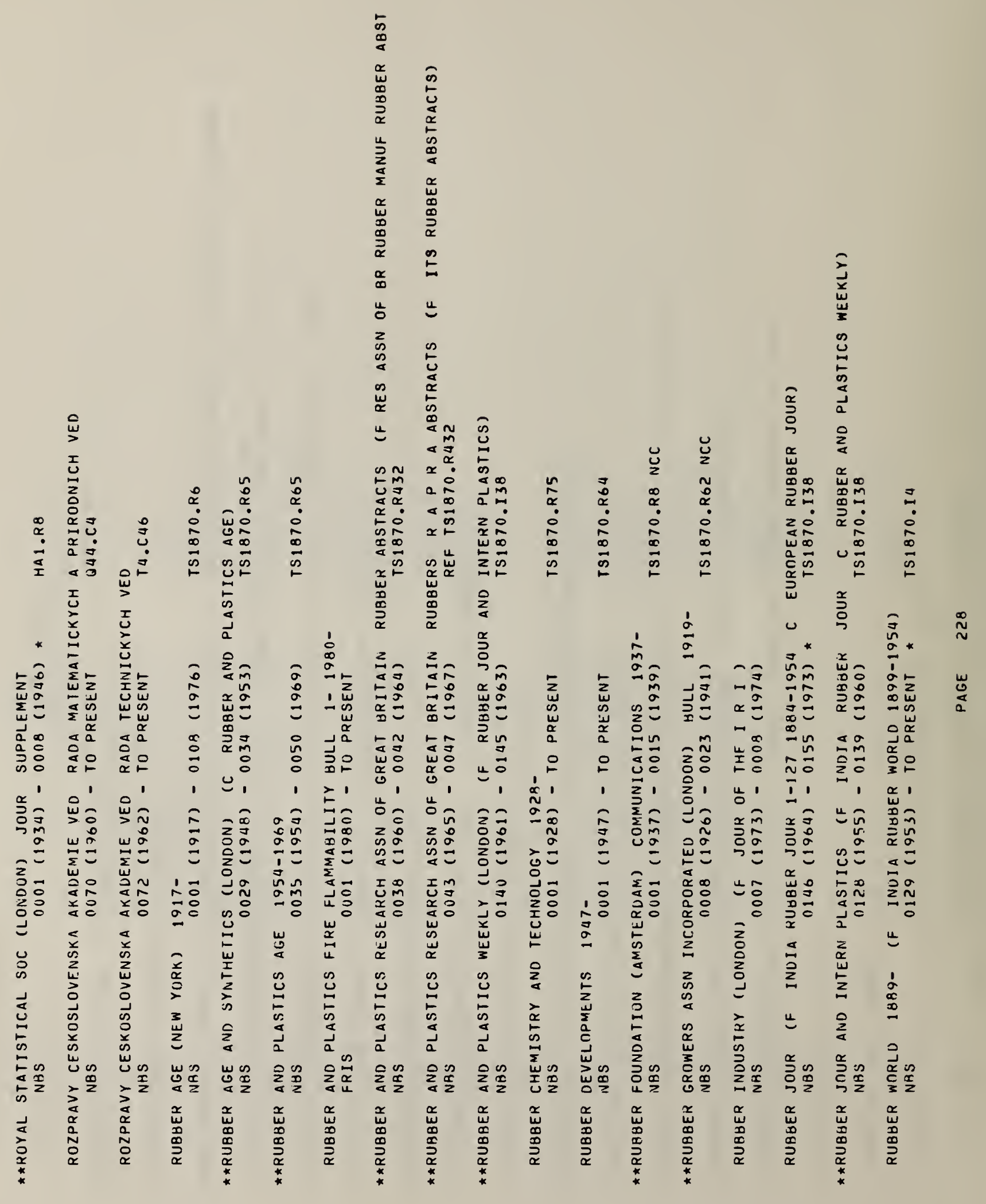




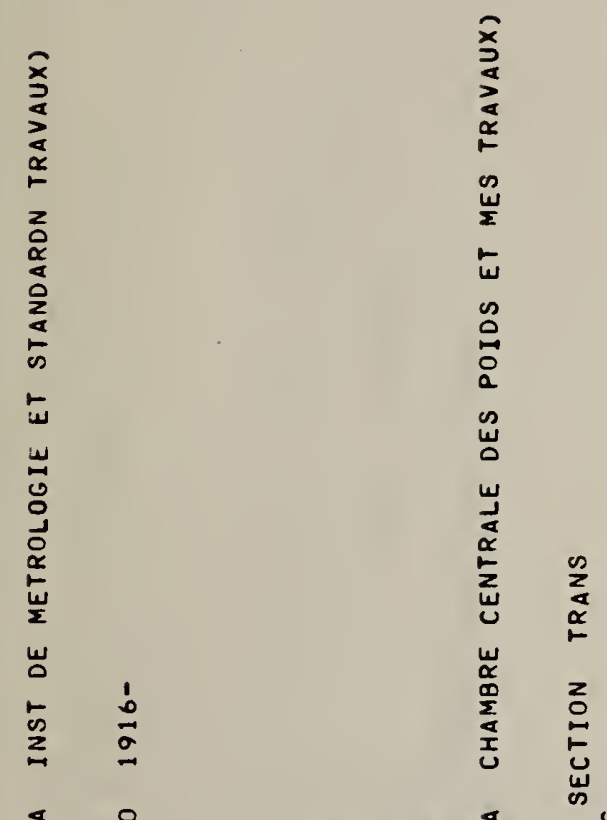

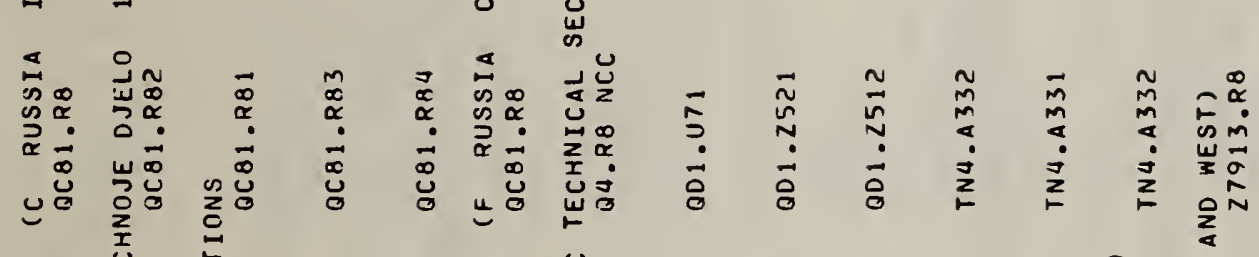

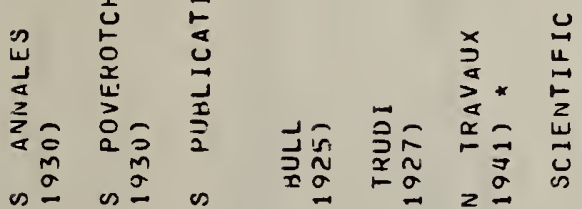

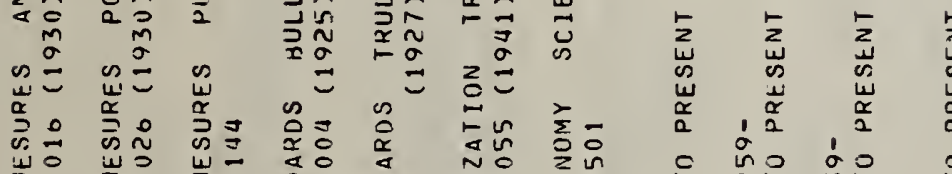

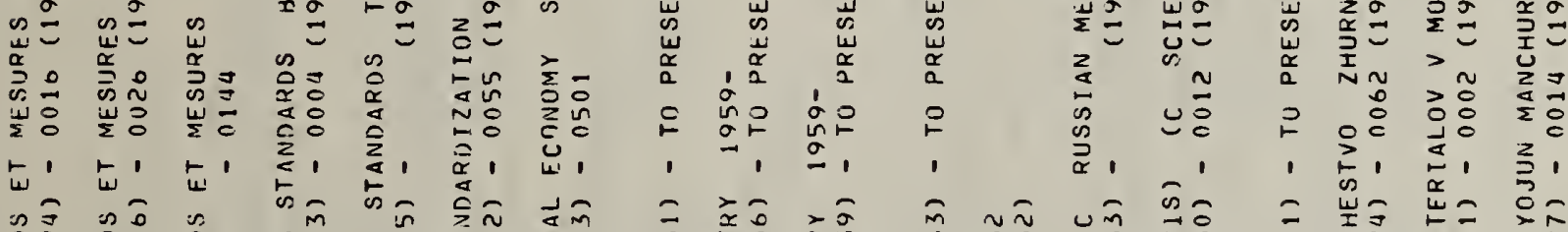

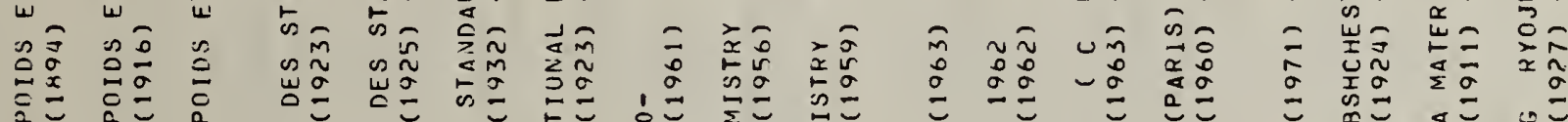

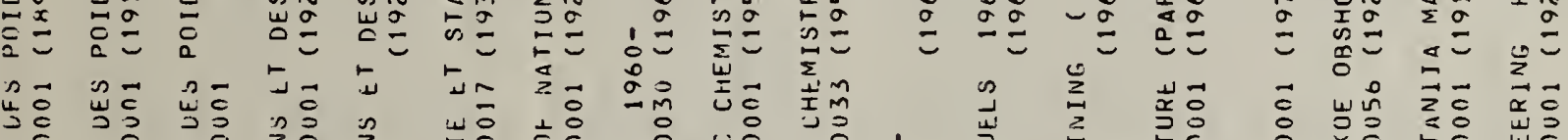

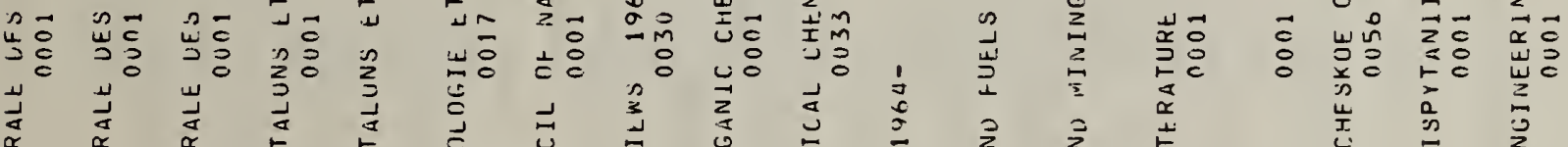

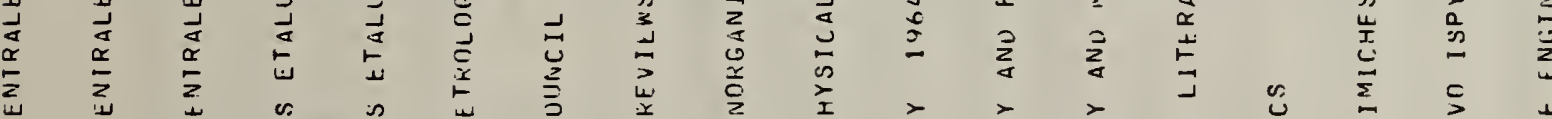

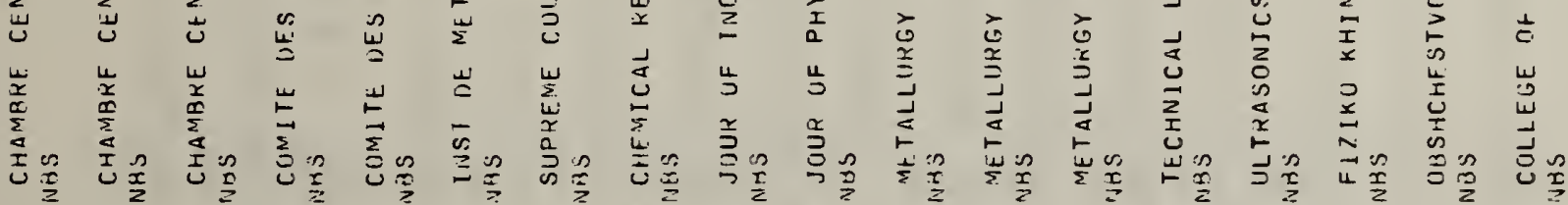

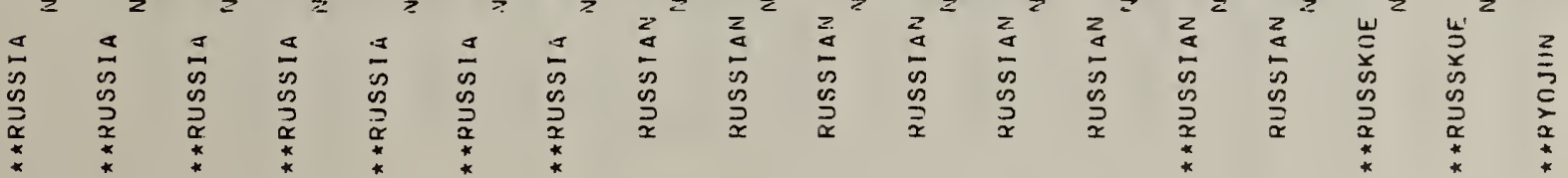




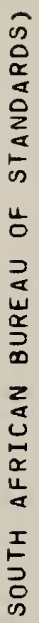

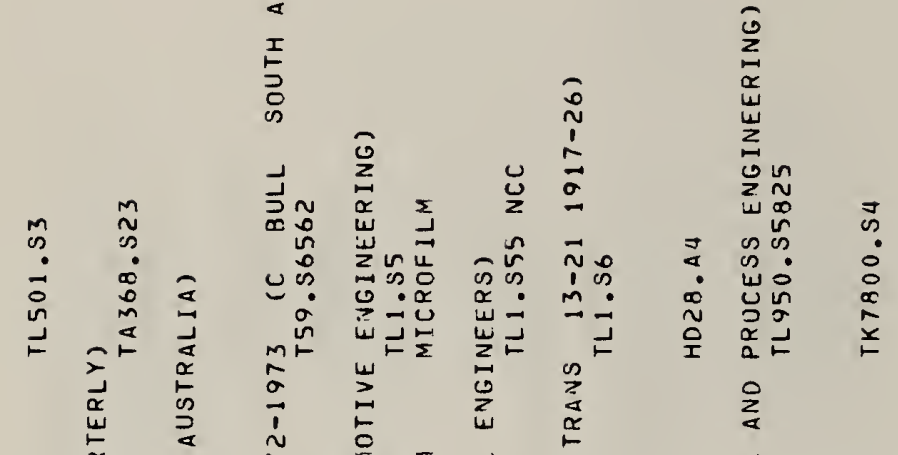

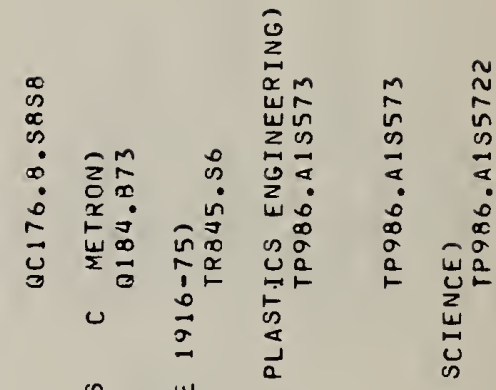

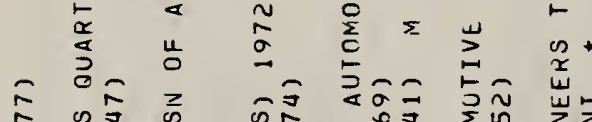

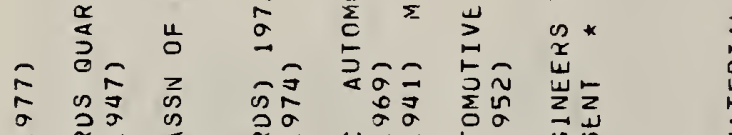

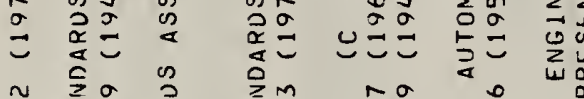

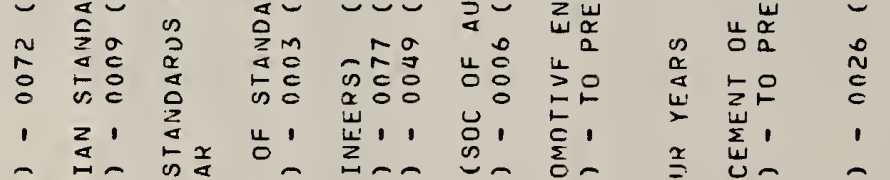

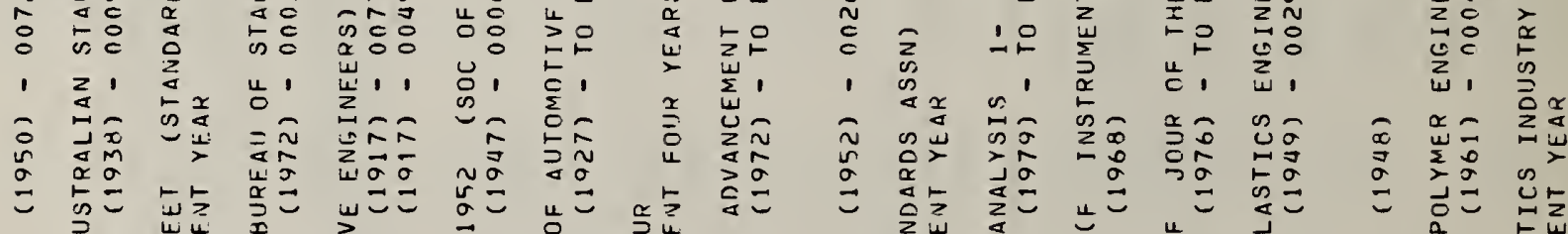

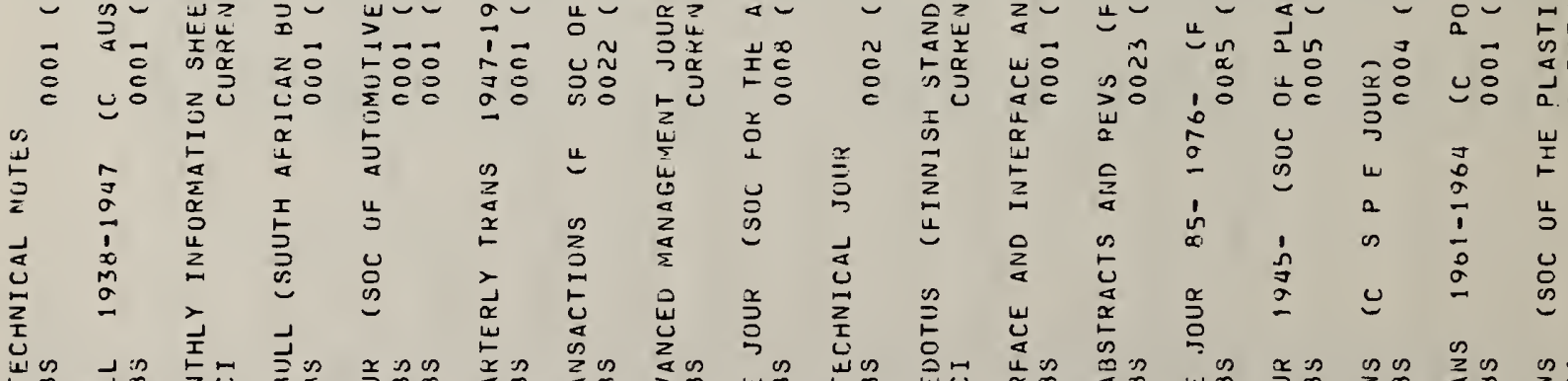

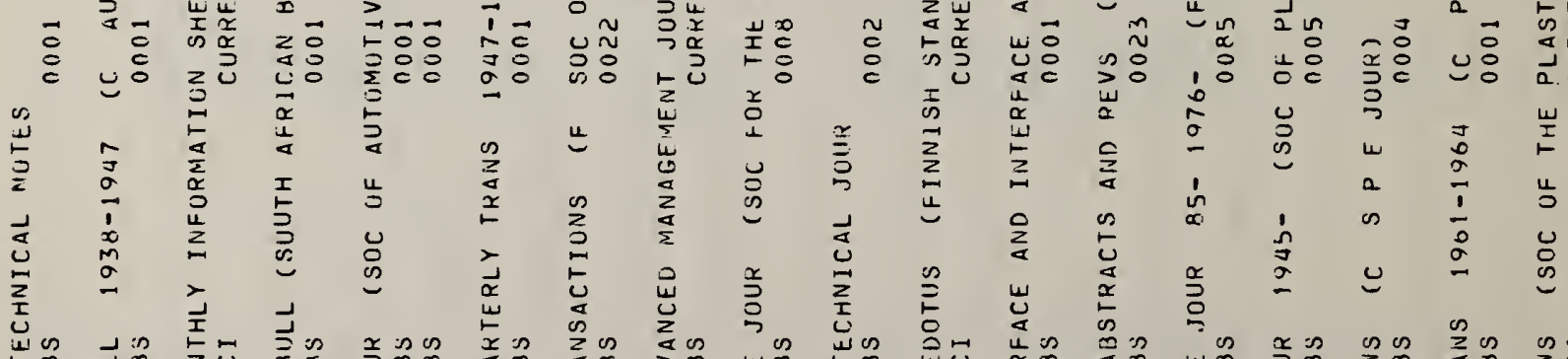

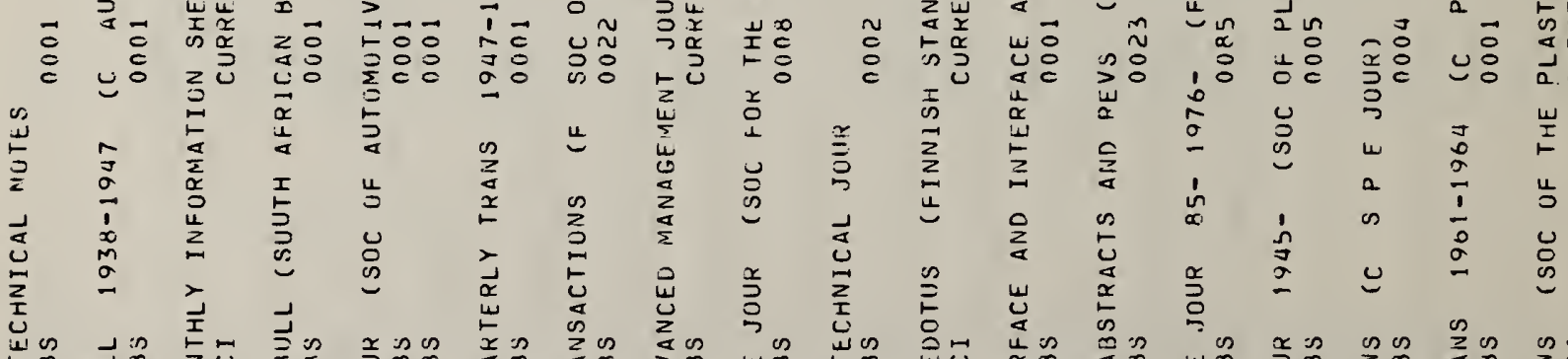

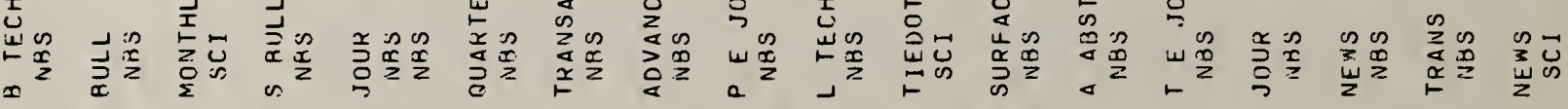

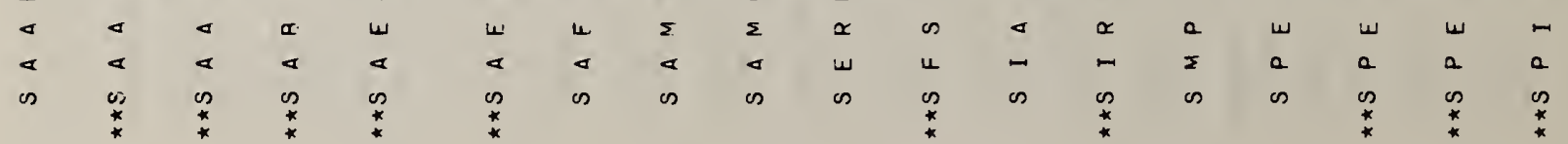




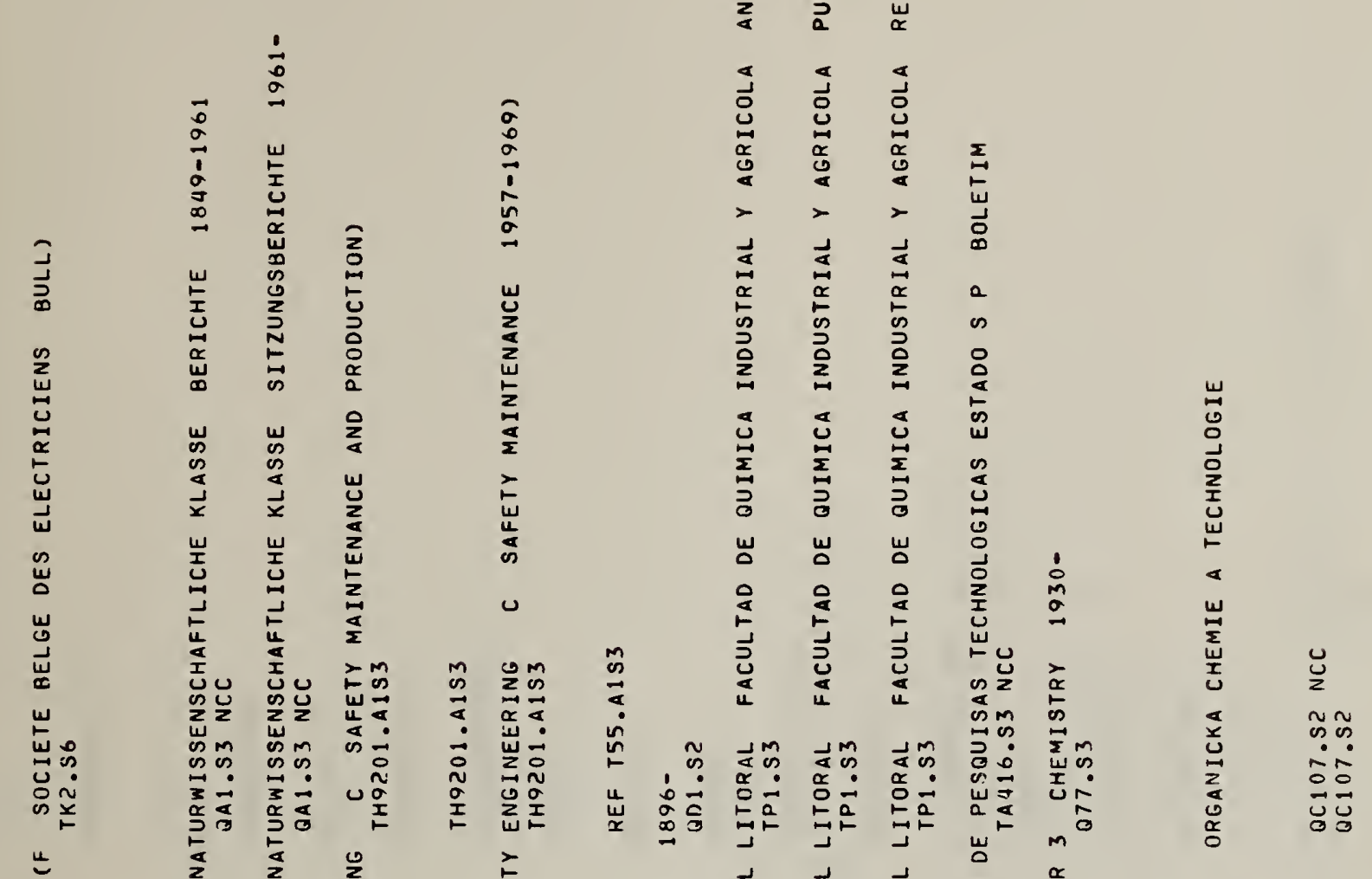

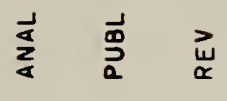

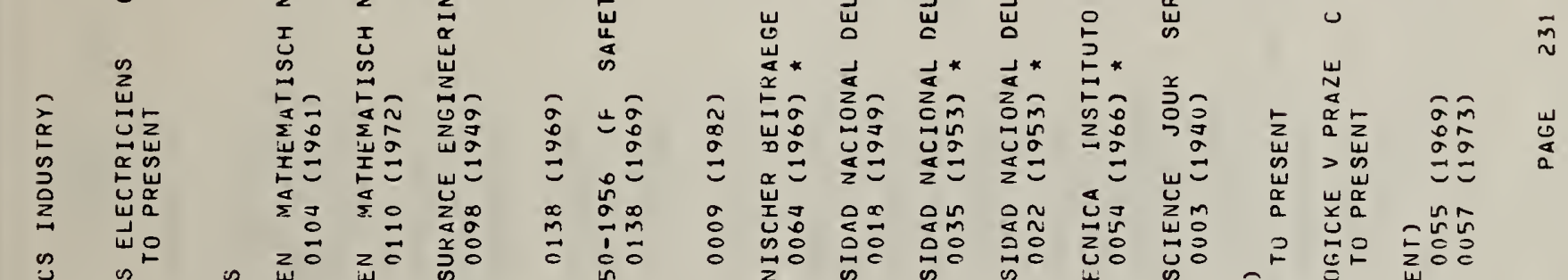

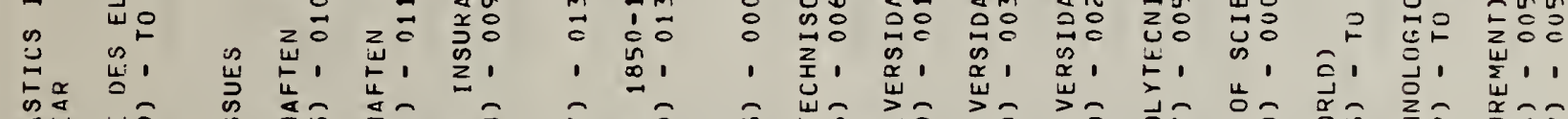

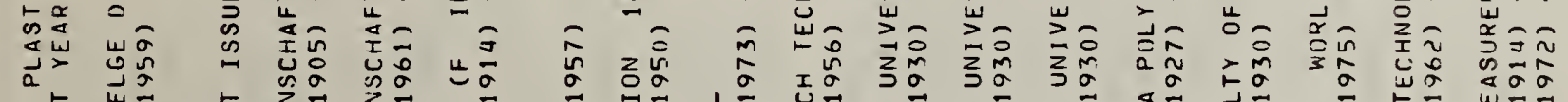

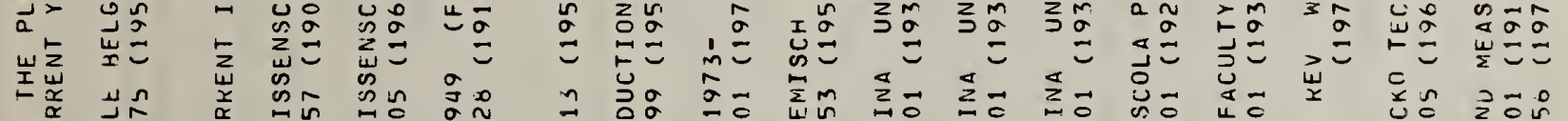

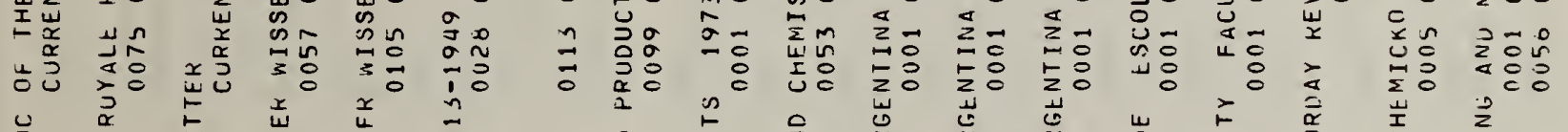

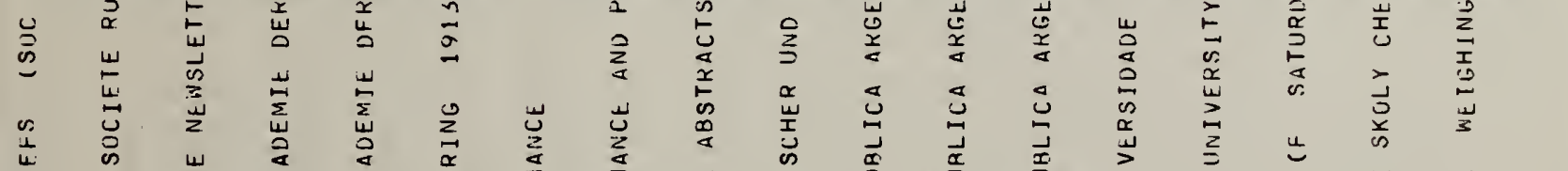

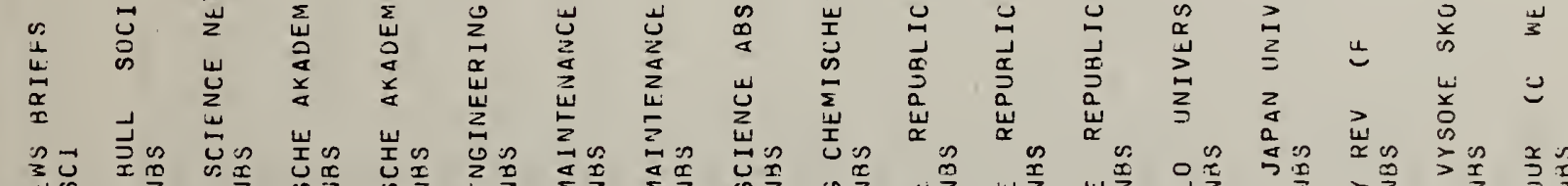

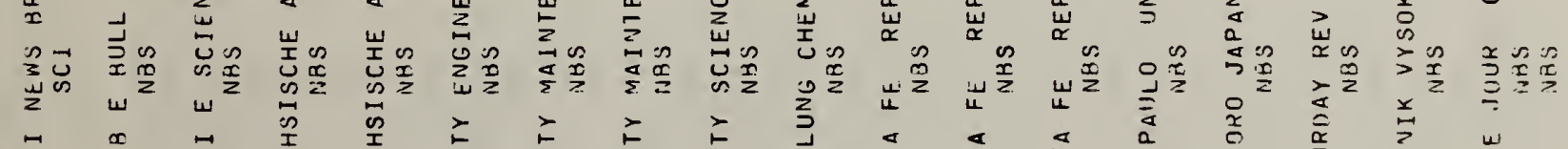




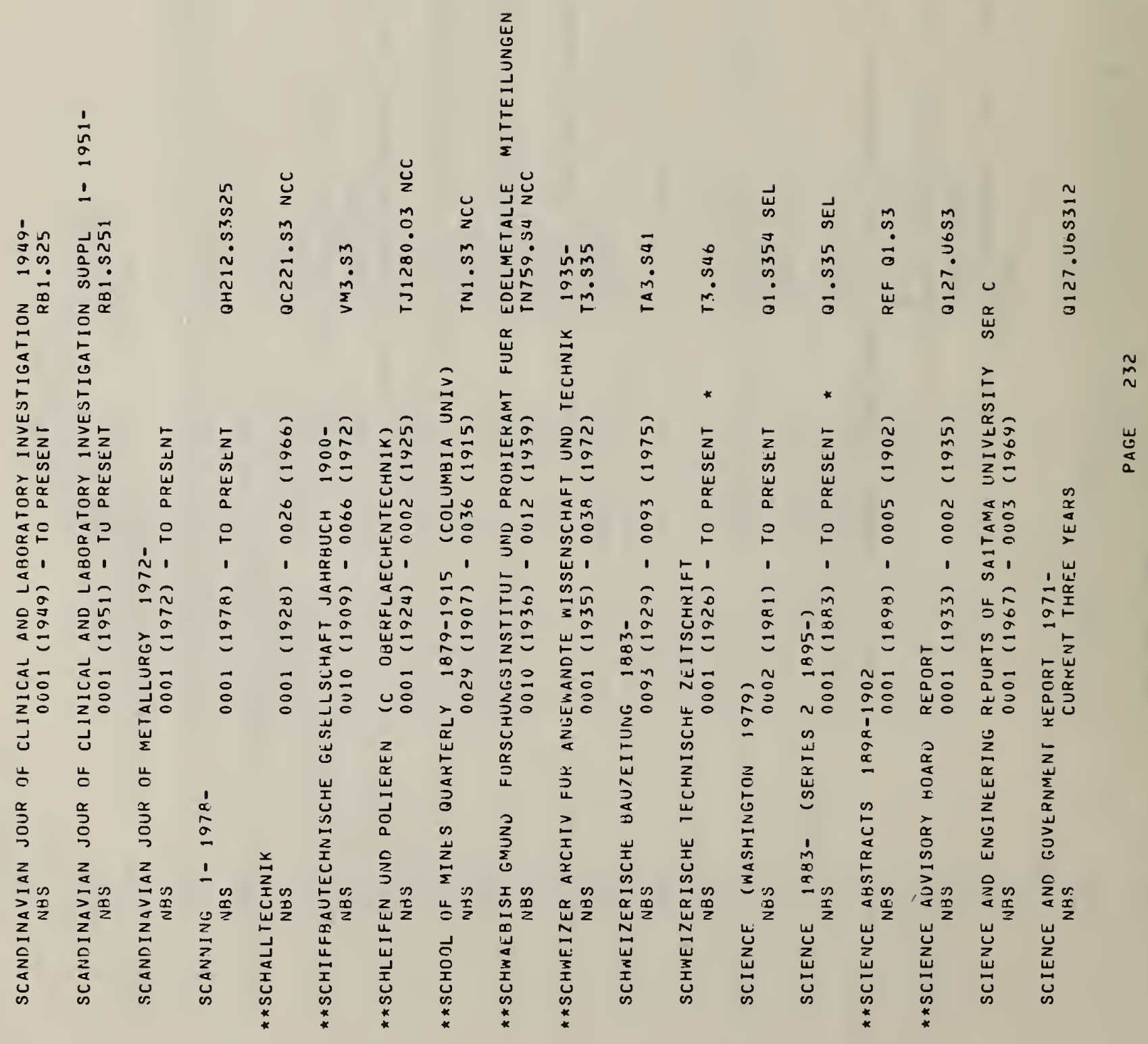




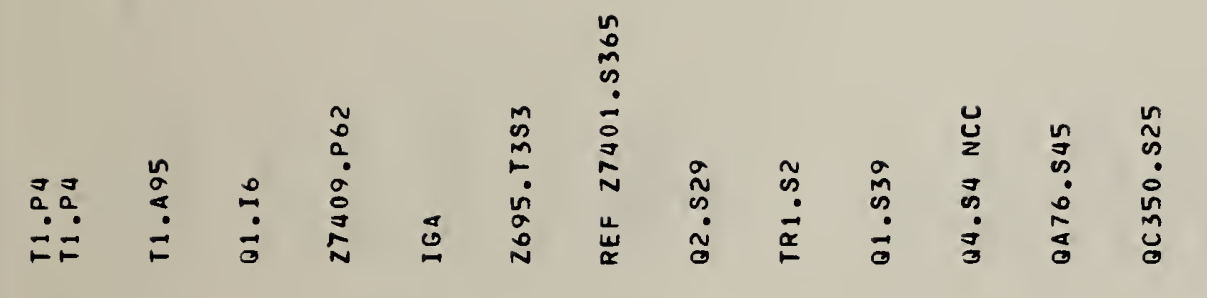

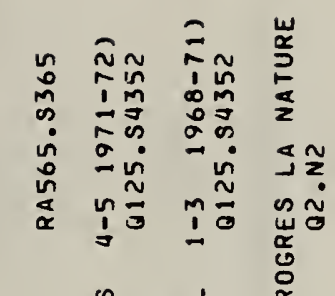
釆 J

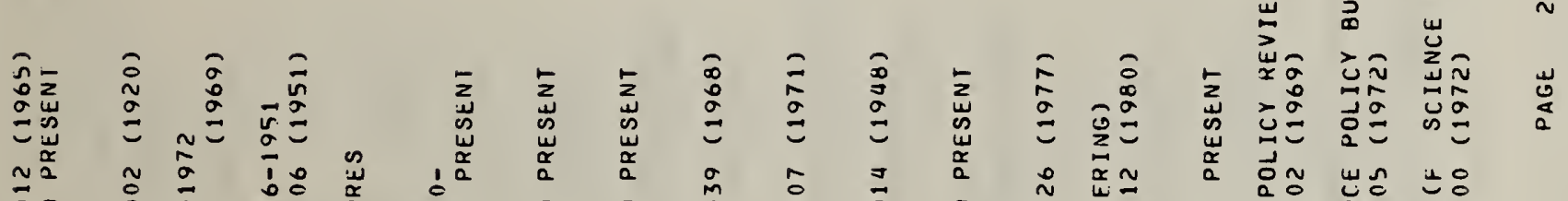

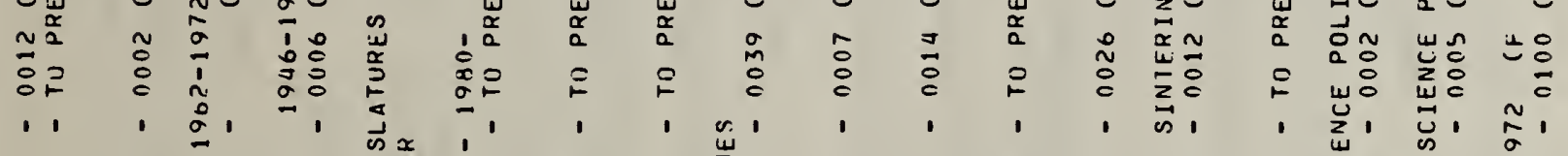
元

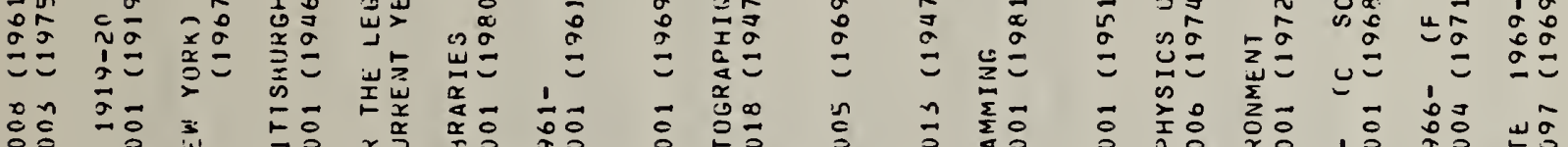

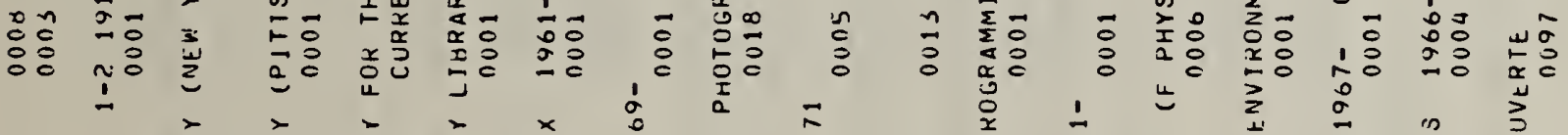

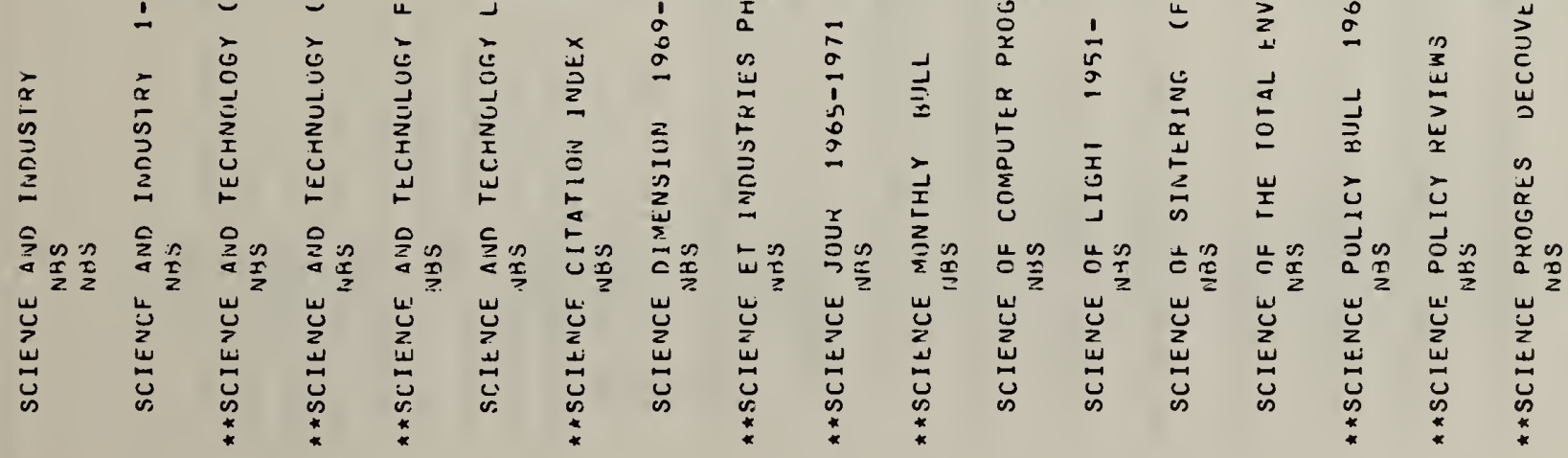




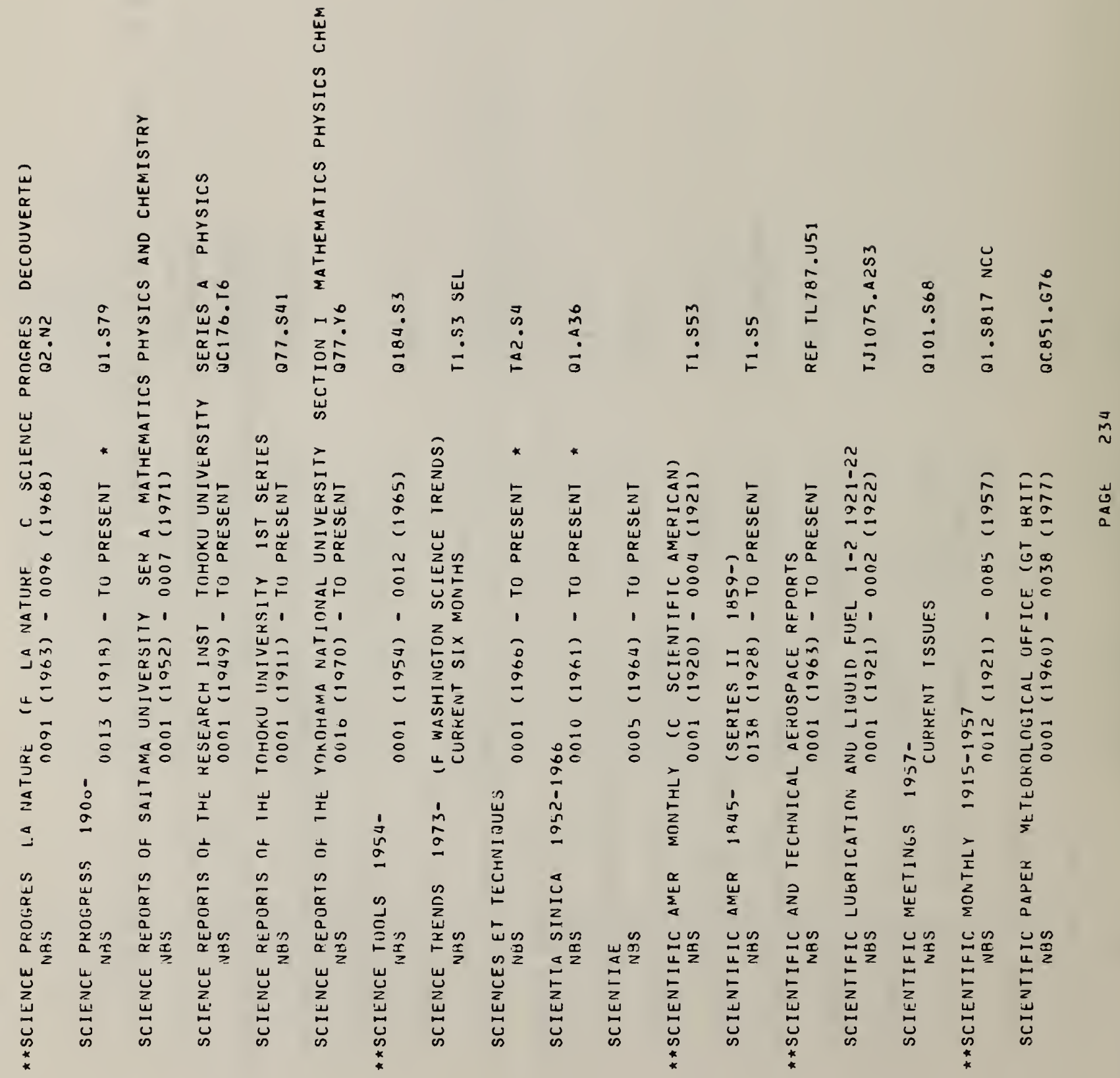


$\underset{\mathfrak{N}}{\mathfrak{m}}$

is

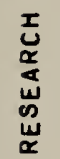

$\sum_{\substack{u \\:}}^{u}$

岌

㟔

$\stackrel{\infty}{3}$

2

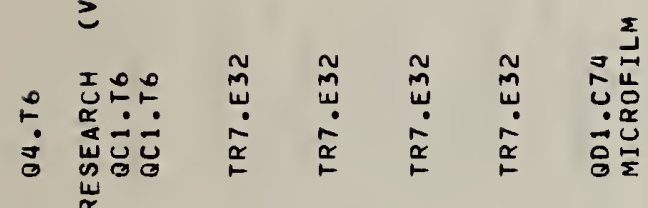

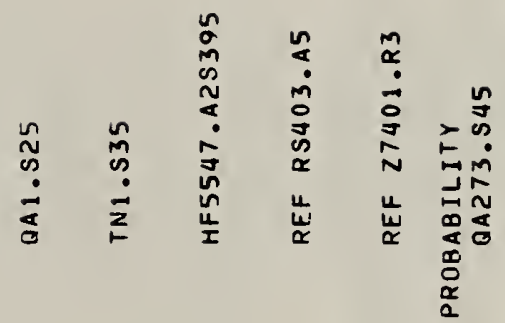

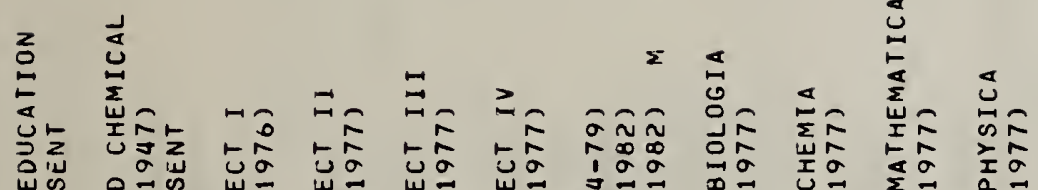

w

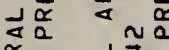

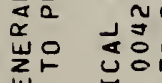

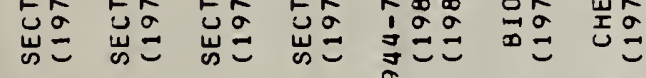

का

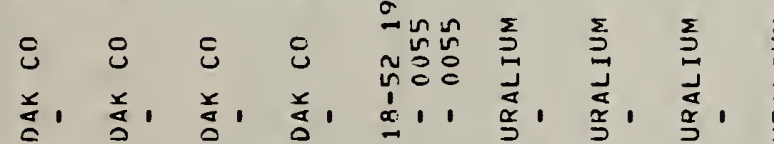

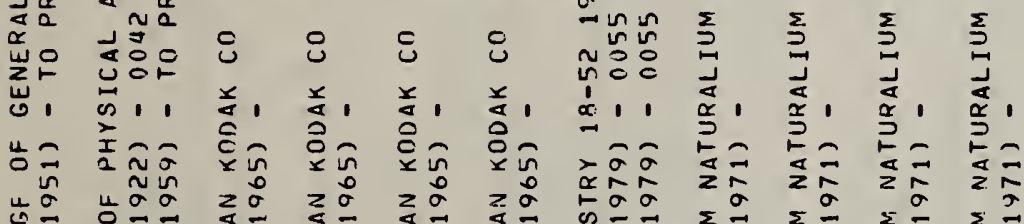

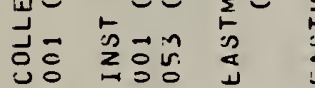

.

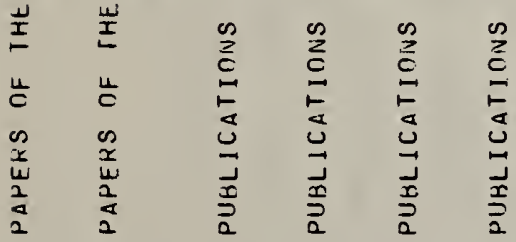

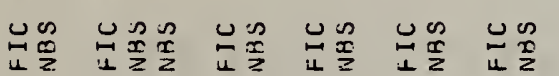

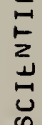

$\frac{1}{5}$

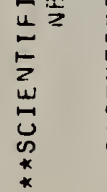

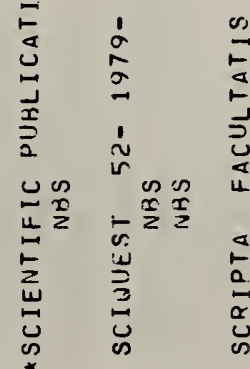

$\frac{1}{2}$

这市

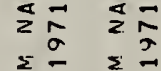

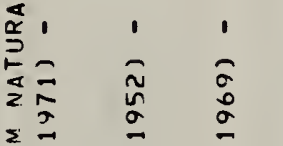


1
$\infty$
$\infty$

ज क ल

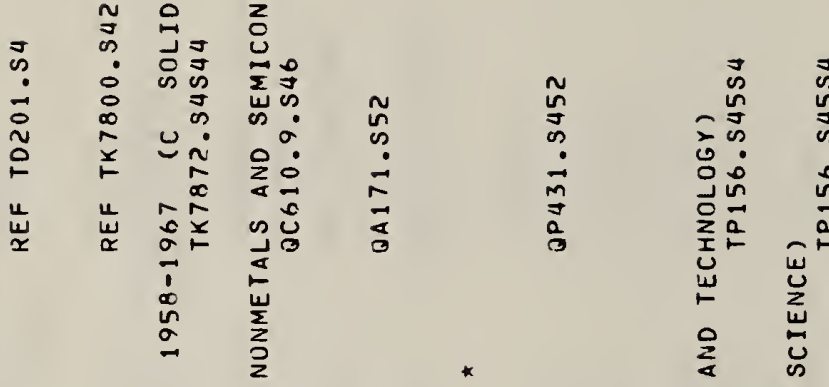

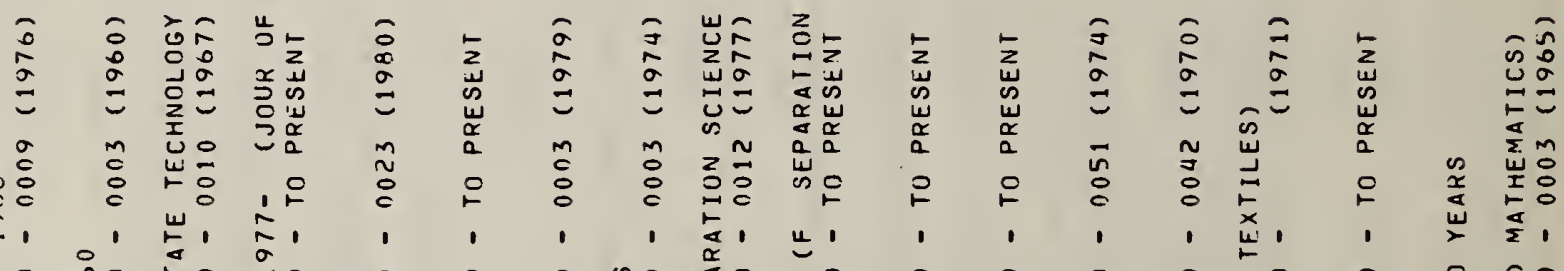

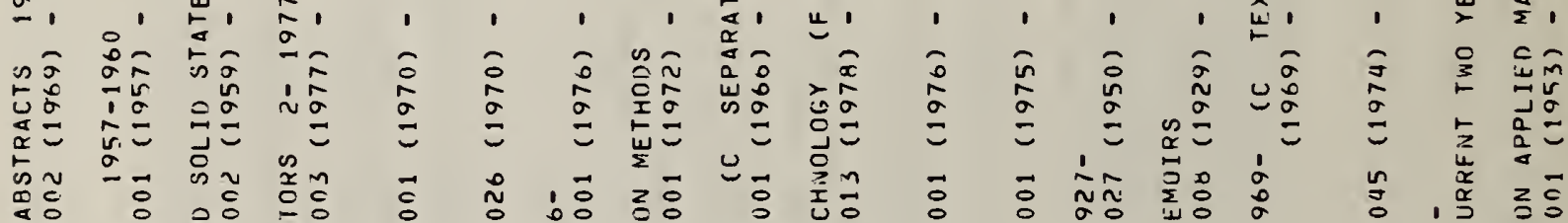

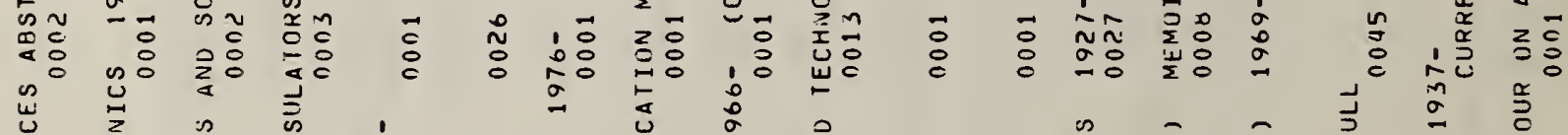

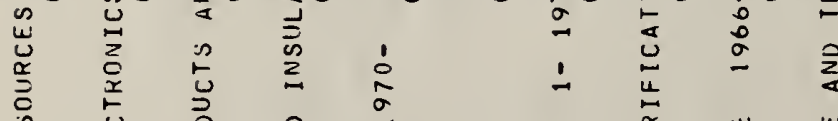

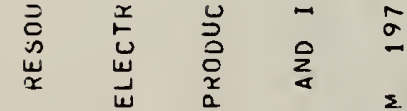

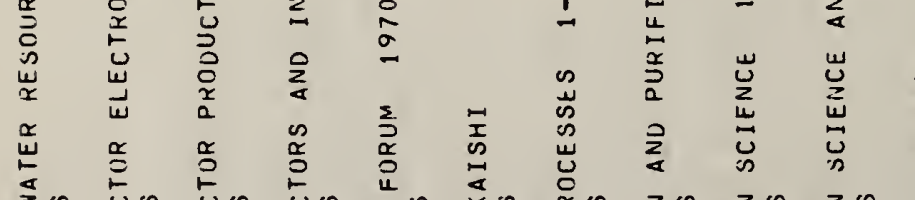

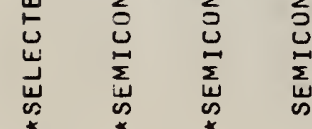




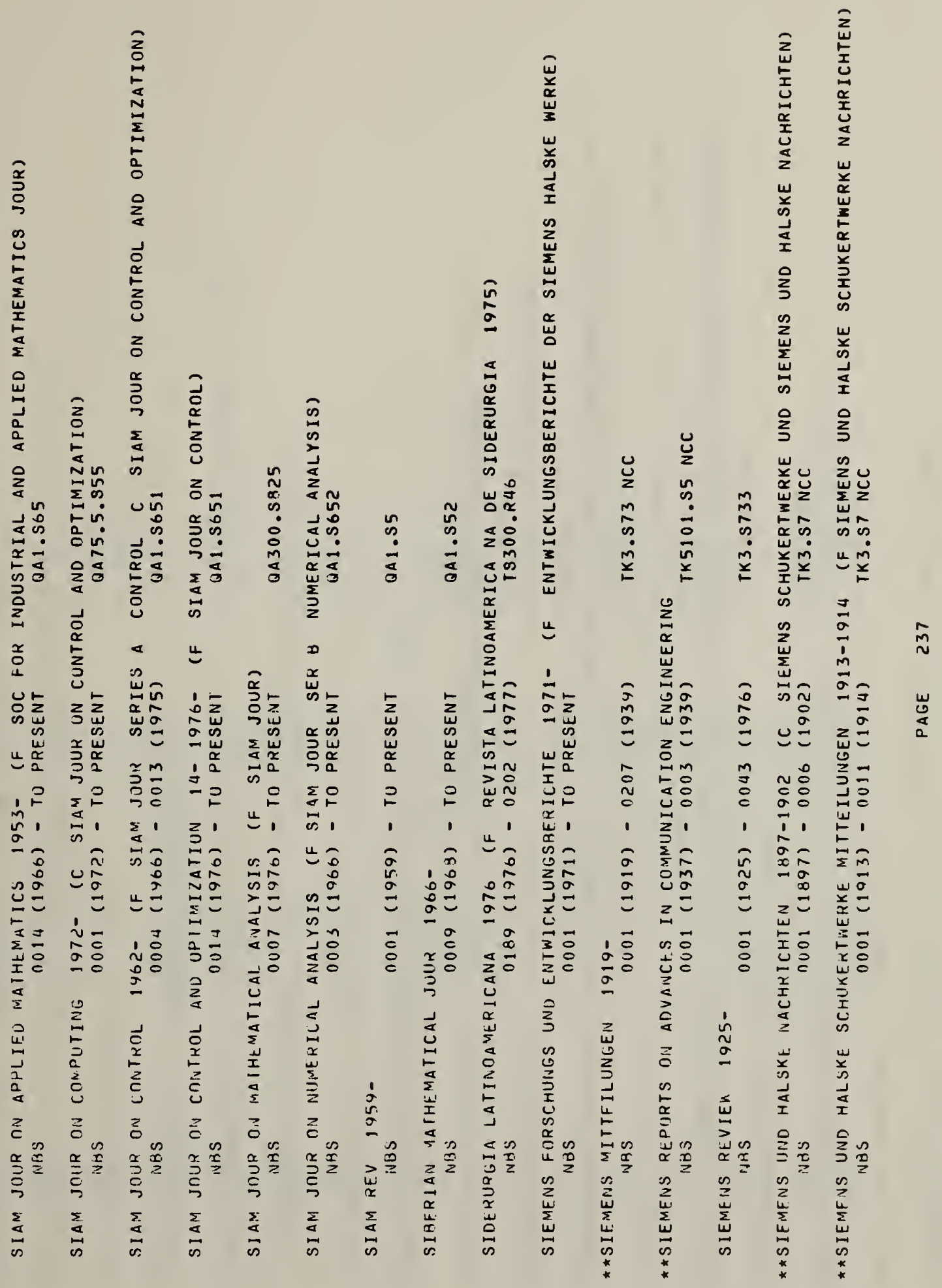




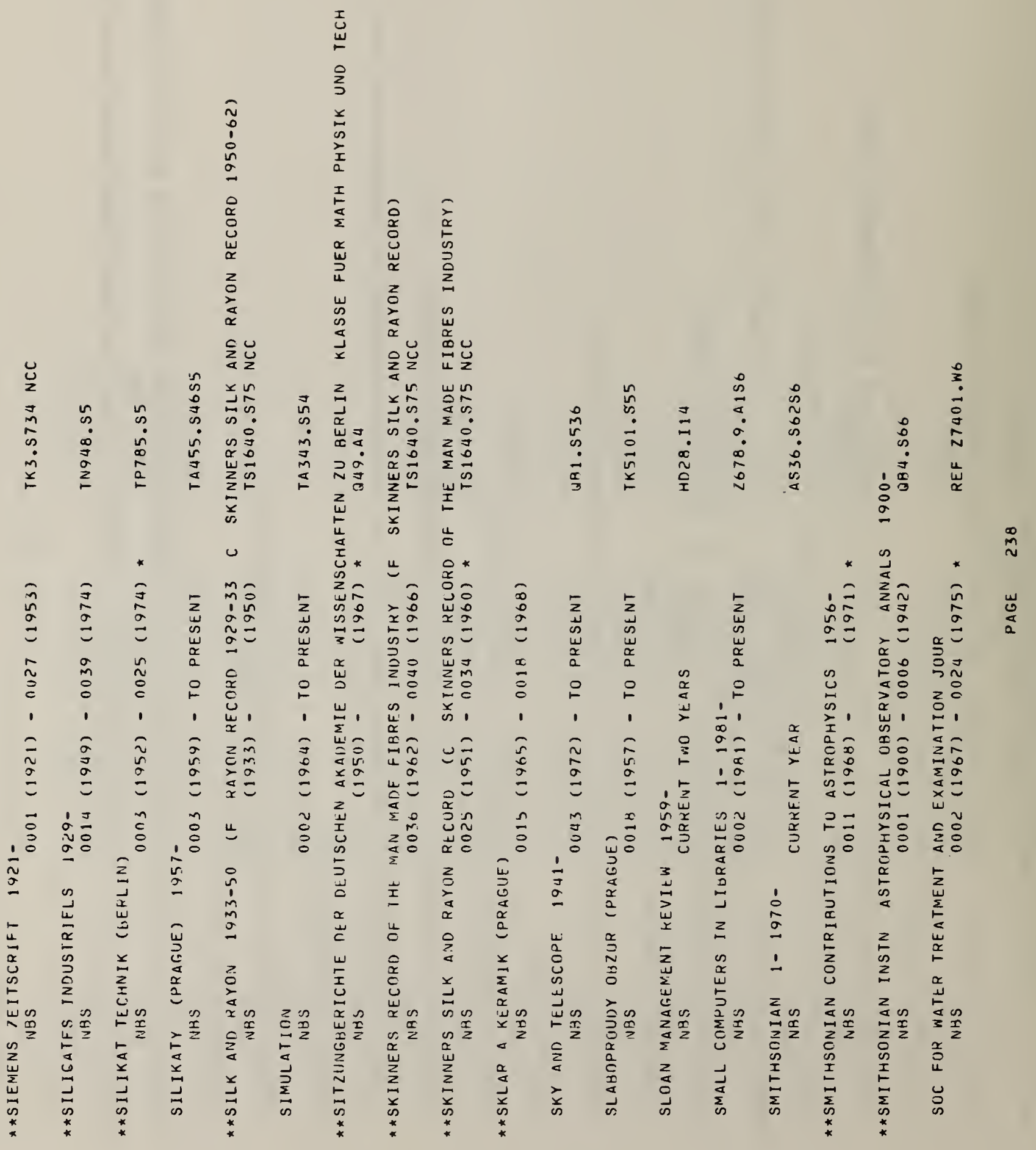




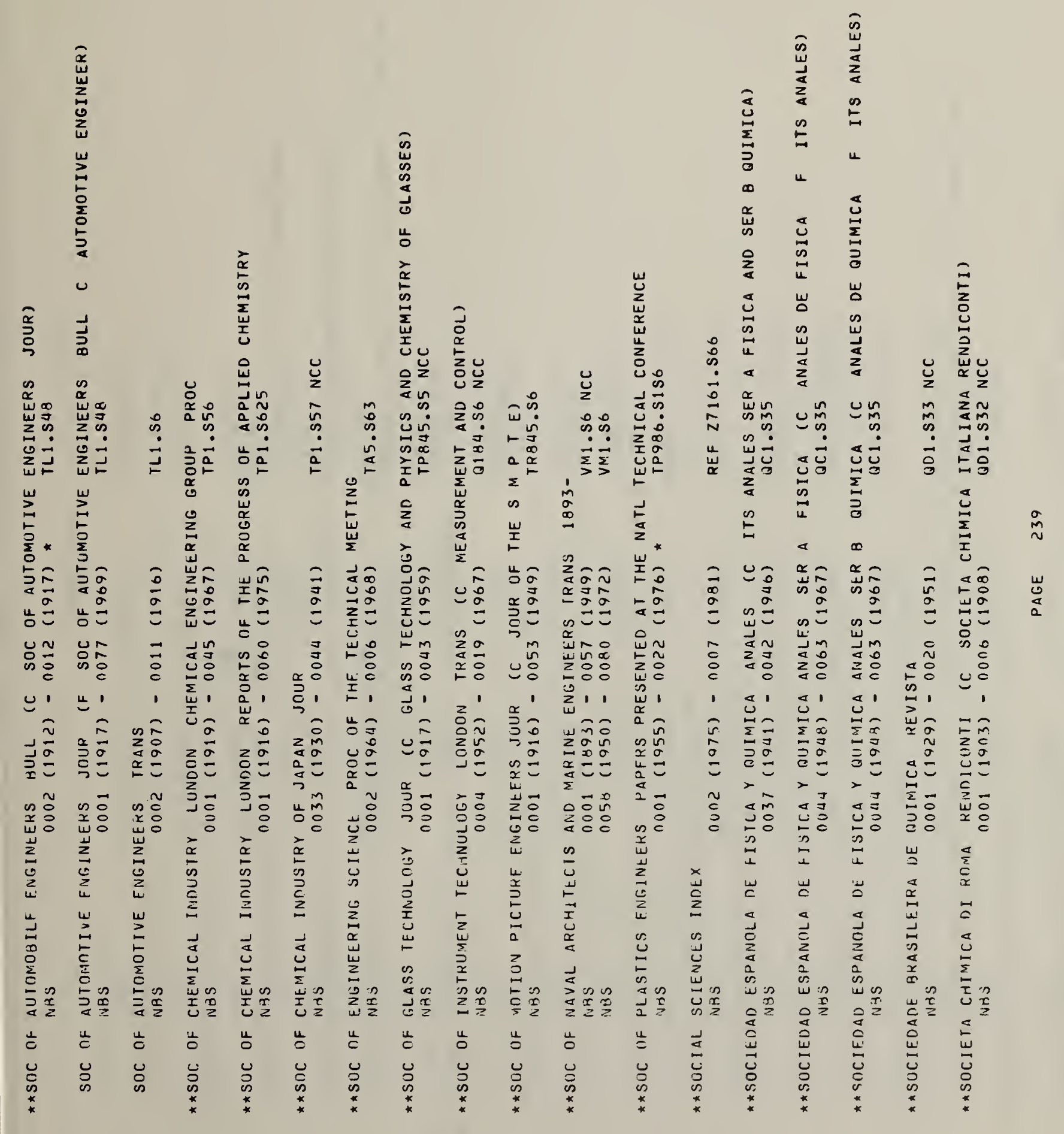




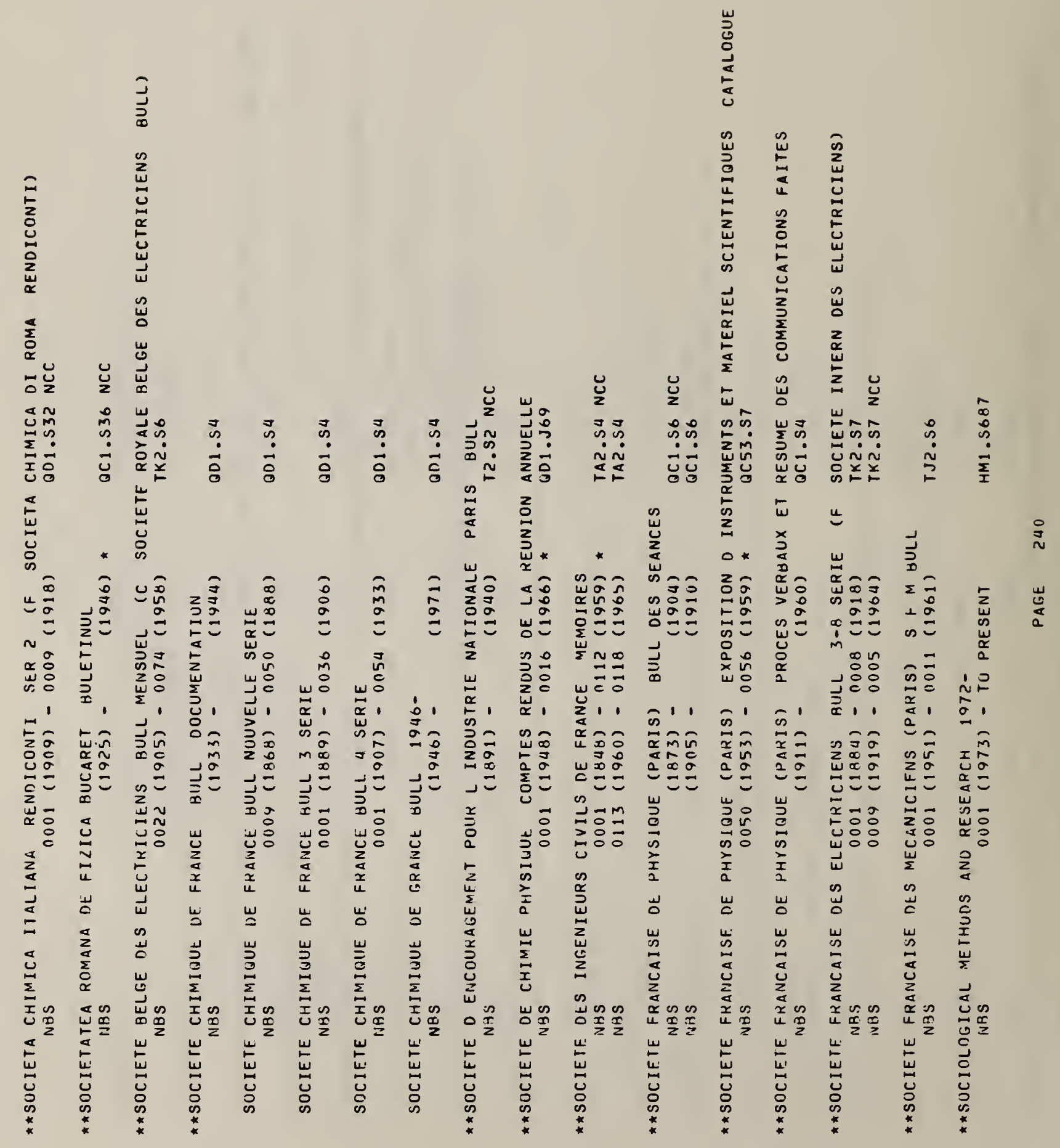




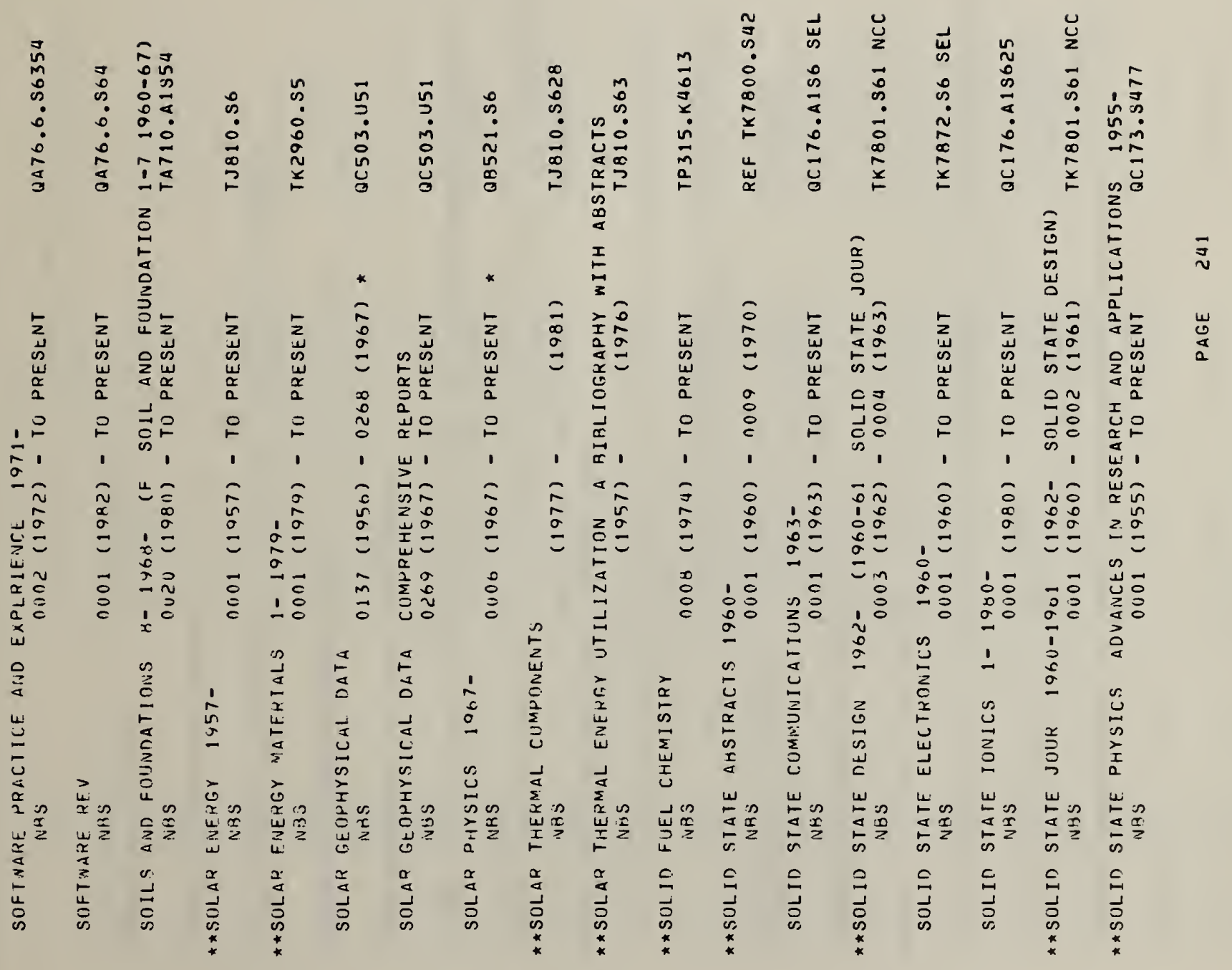




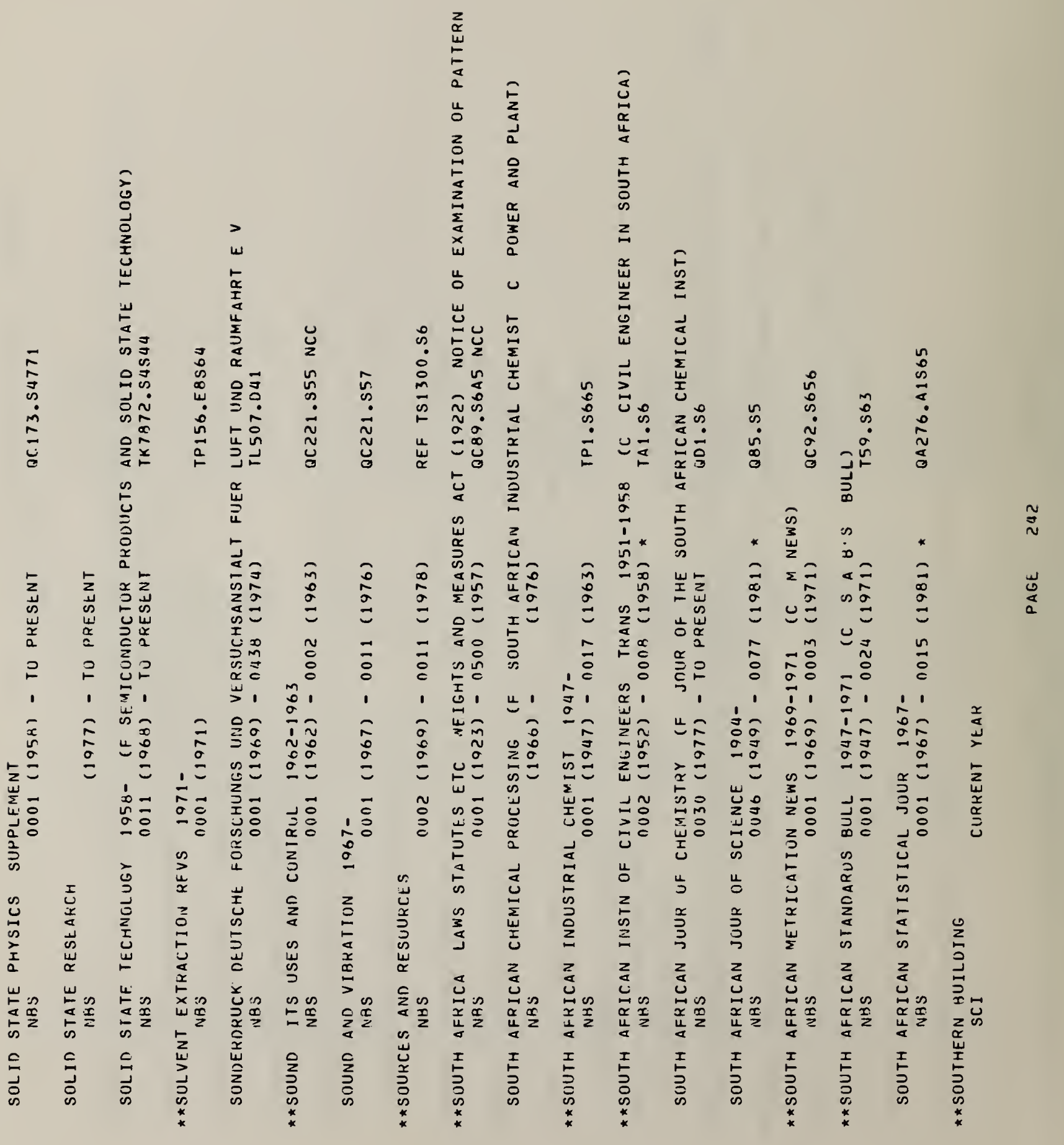




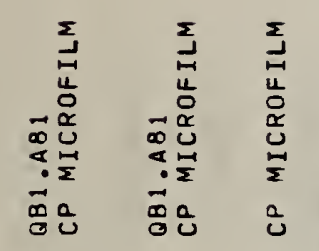

I

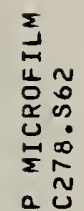

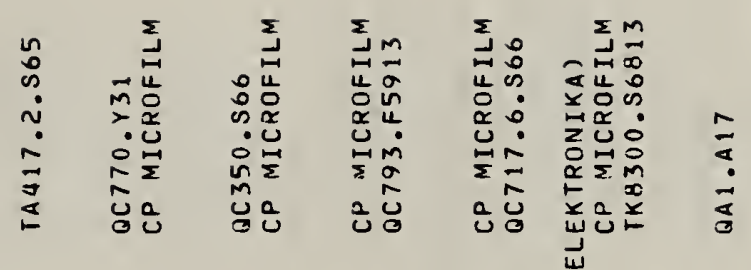
产

(1)

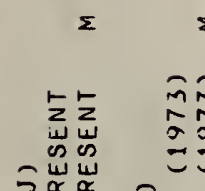

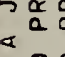

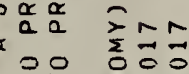

西,

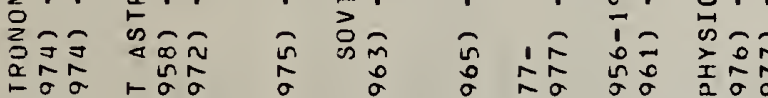

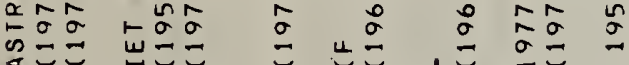

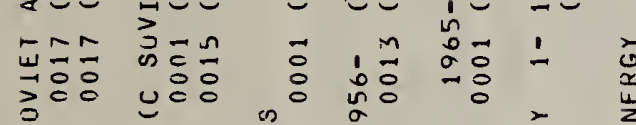

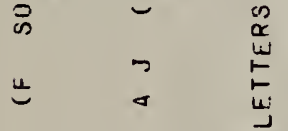

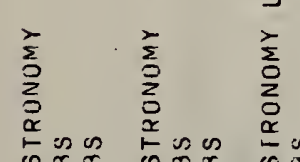

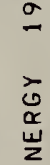

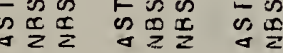

言

言紊章

言

言

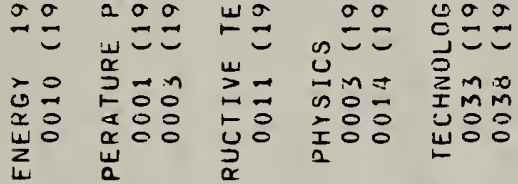

4 这

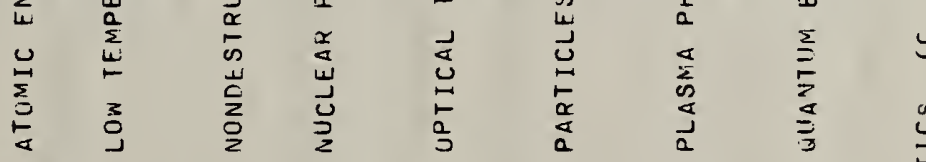

㟔 岂岂范

㟔 嵅岂㟔

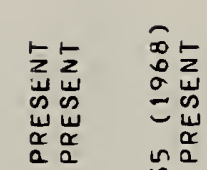

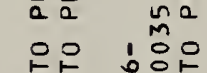

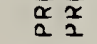

은으

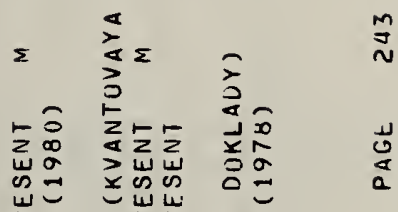

a d

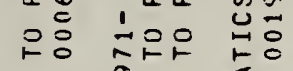

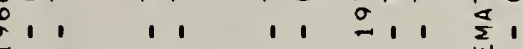

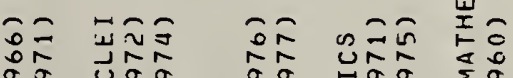

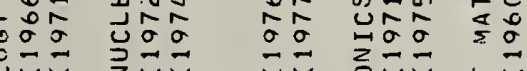

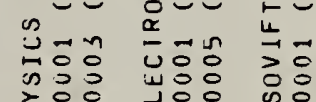

गु०० is:

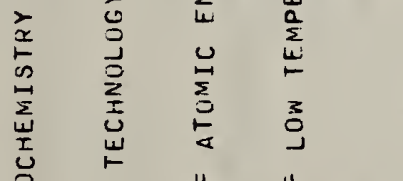

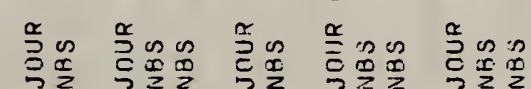

a d a

岂

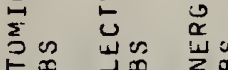

山我

(

产言

言

言

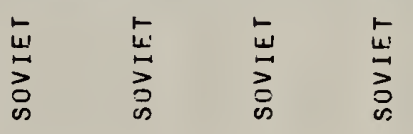




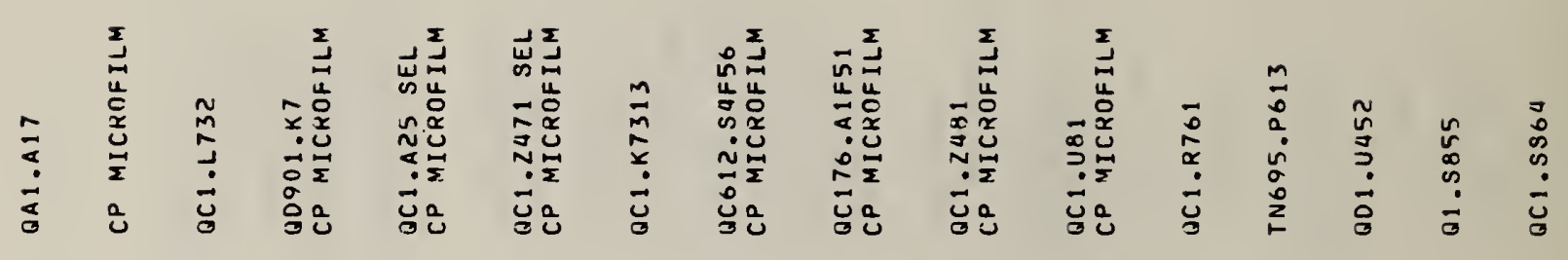

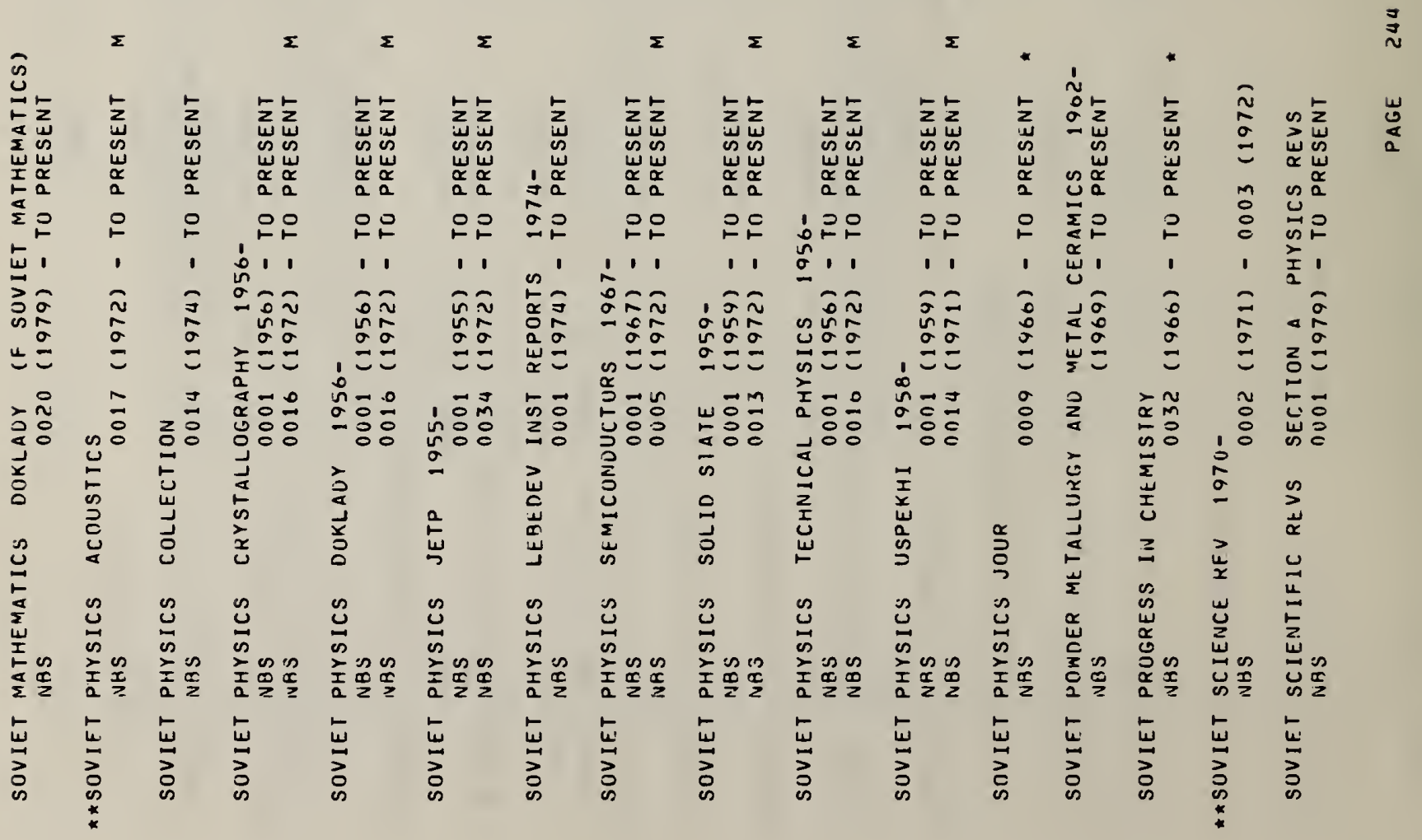




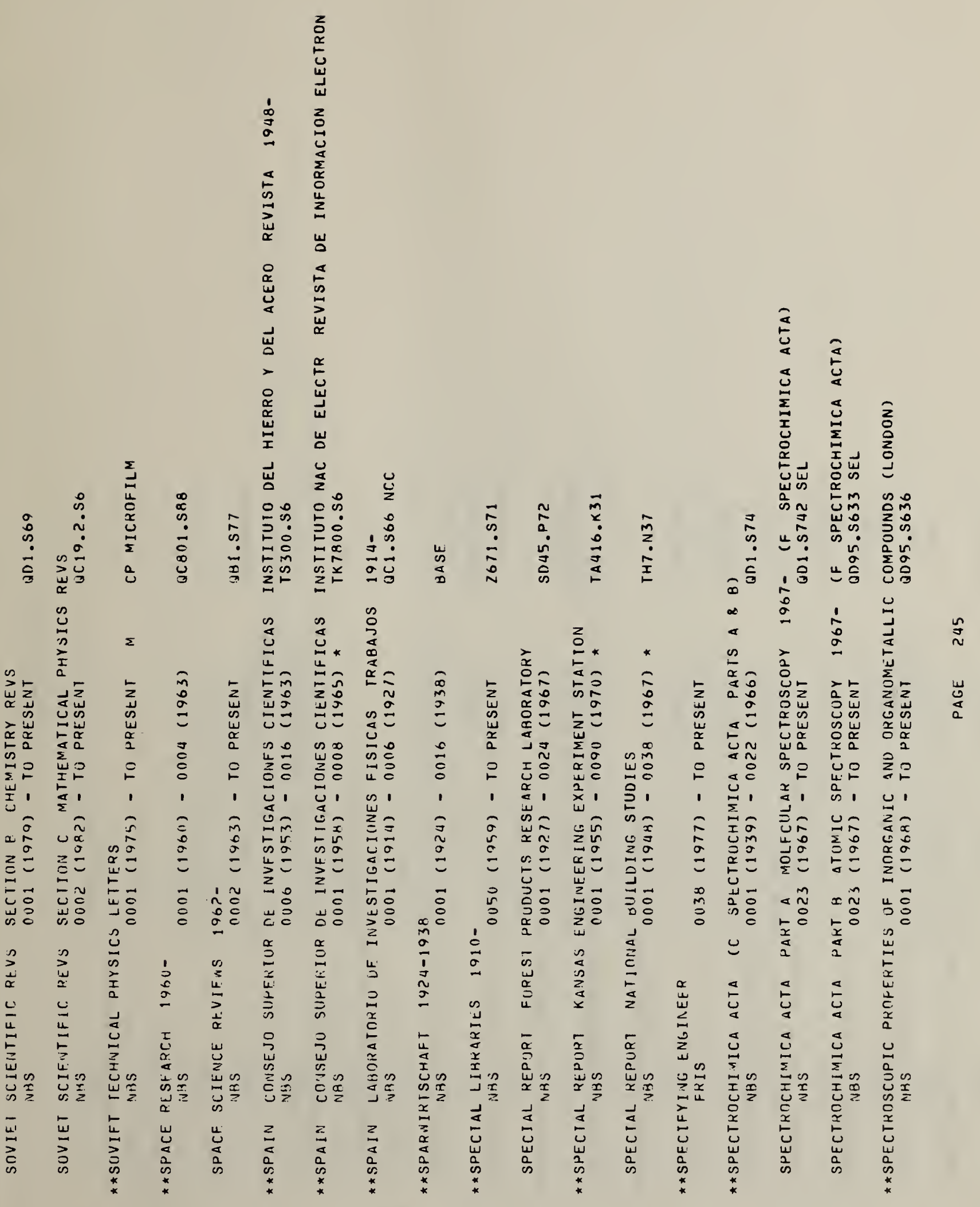




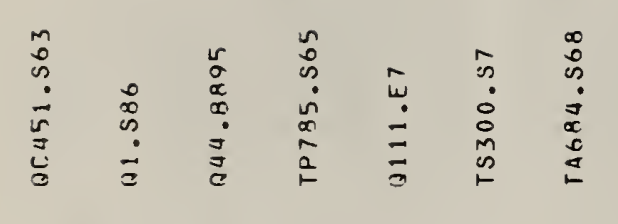

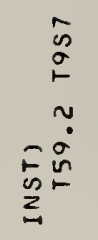

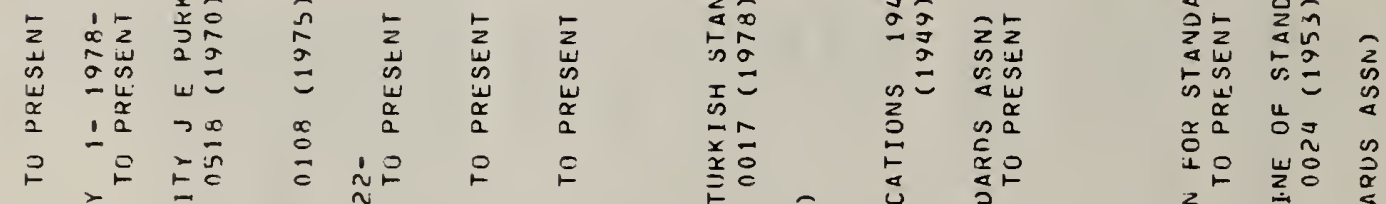

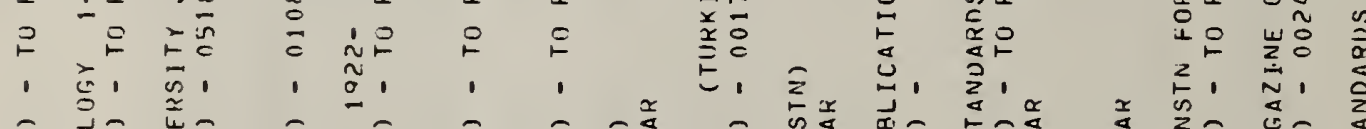

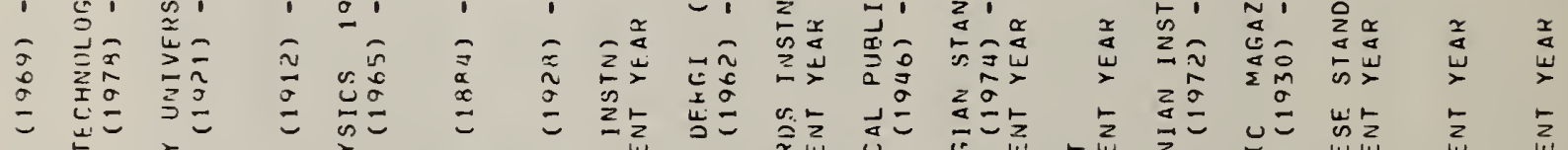

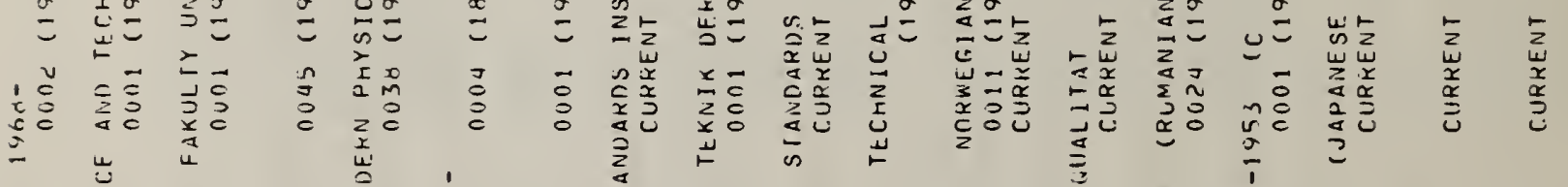

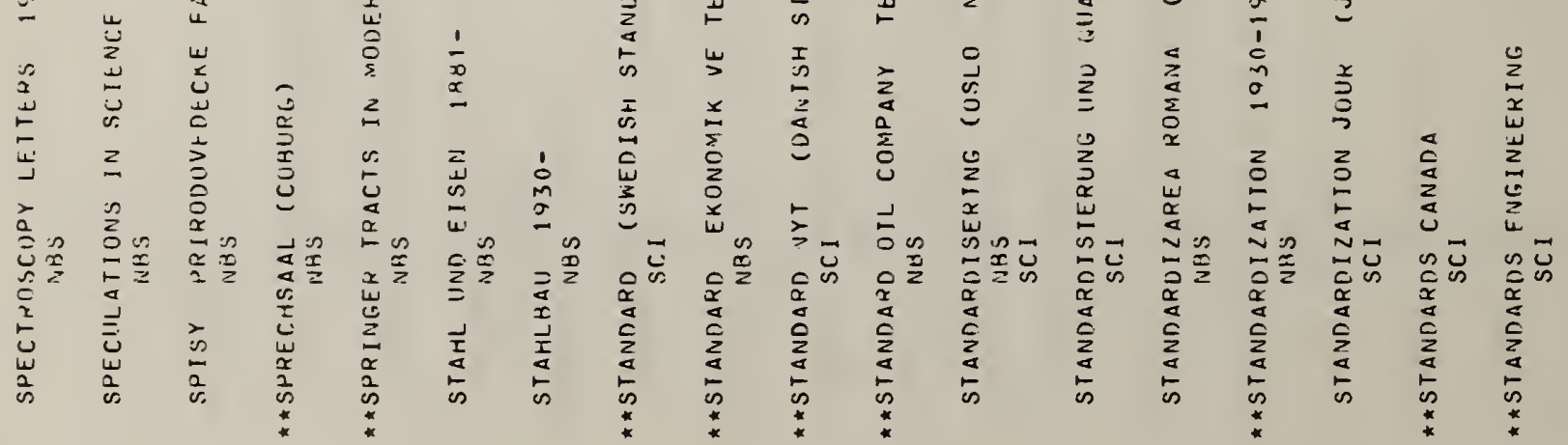


$\stackrel{\dot{\sim}}{\tilde{\alpha}}$

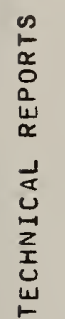

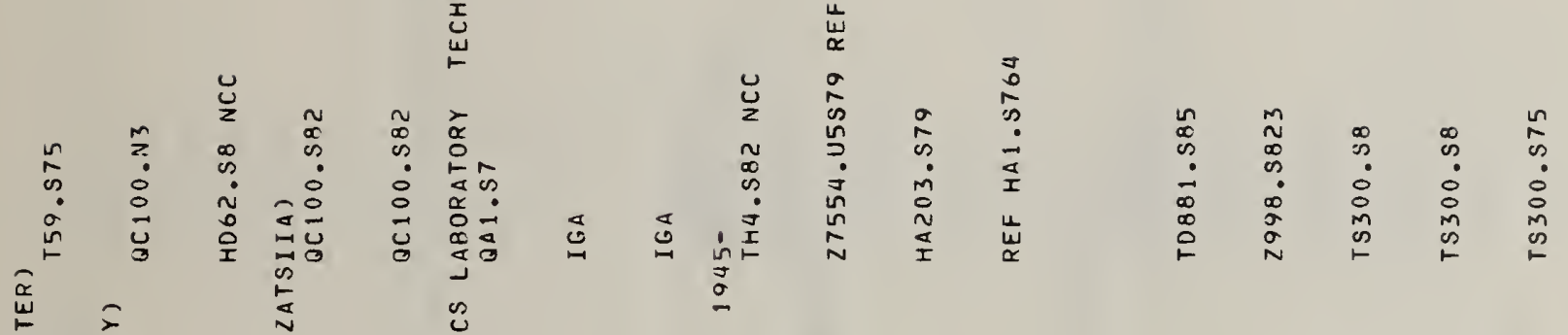

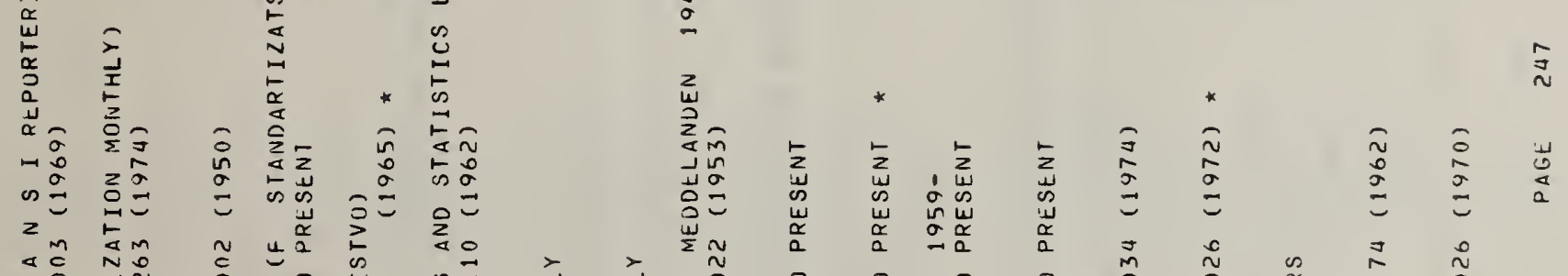

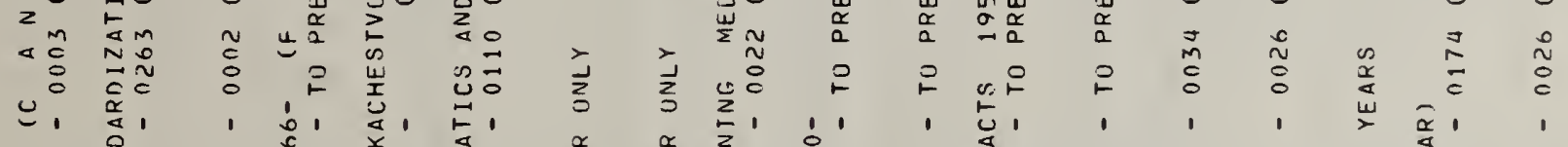

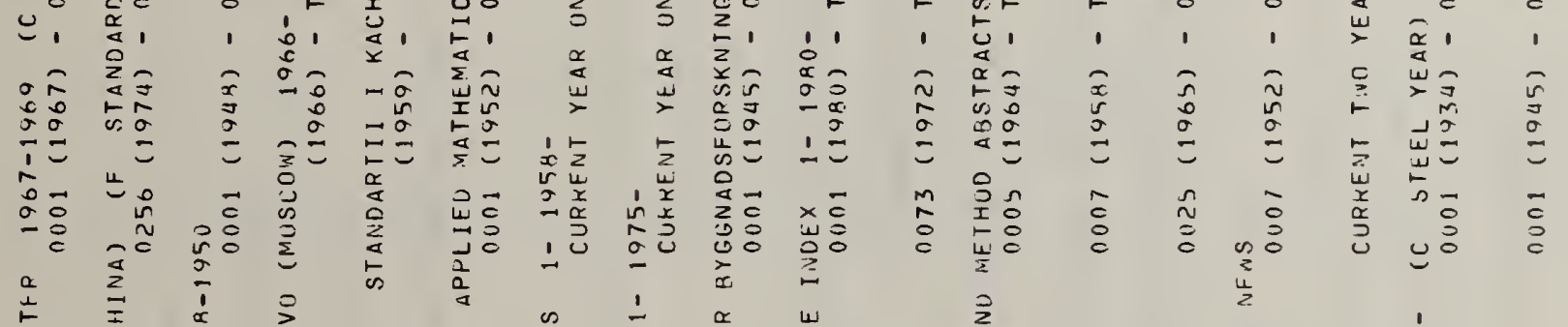

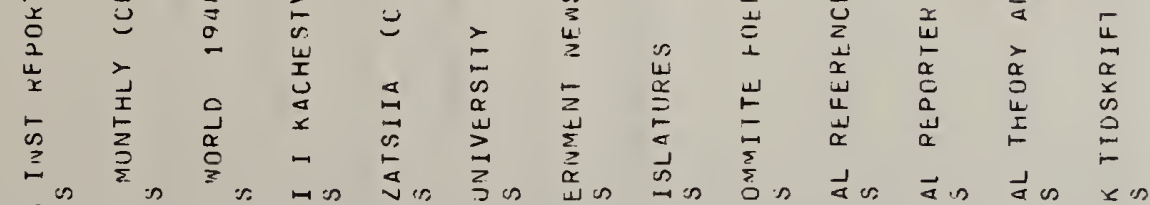

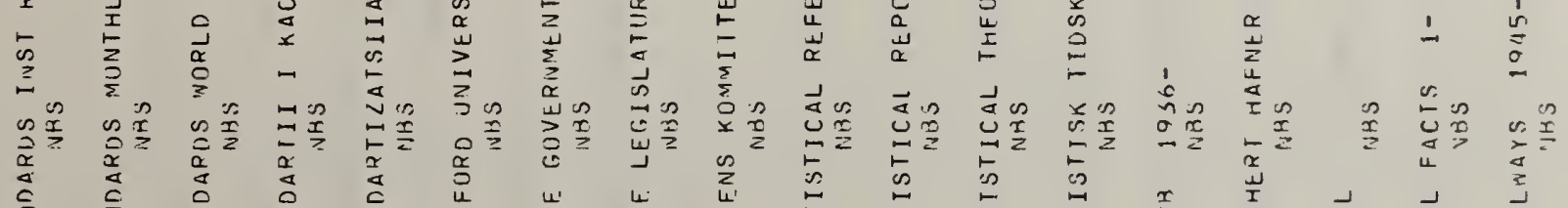
站

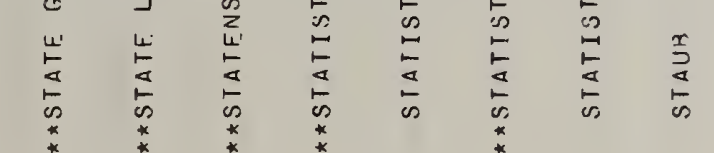


$\hat{x}$
$\infty$
$a$
0
$\frac{\alpha}{a}$
0
0
0

$\stackrel{\dot{a}}{\stackrel{\vec{\sigma}}{\sigma}}$

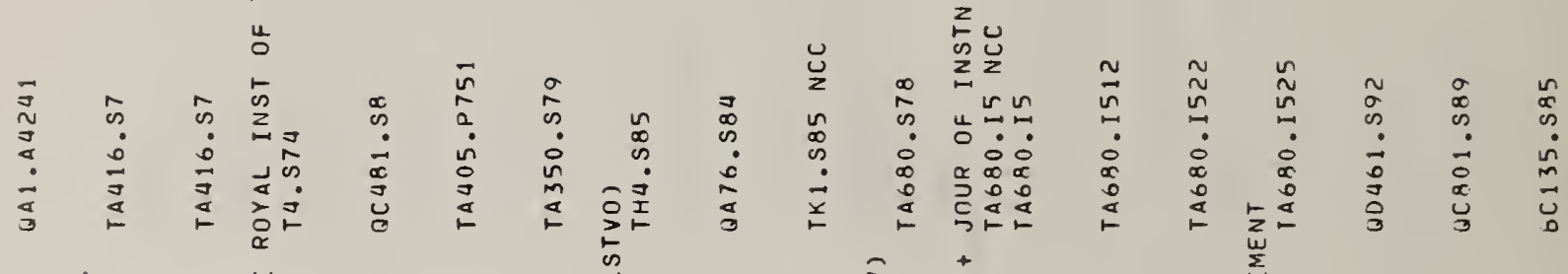

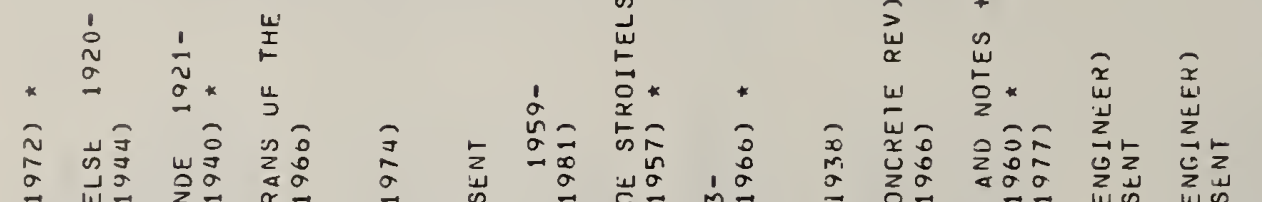

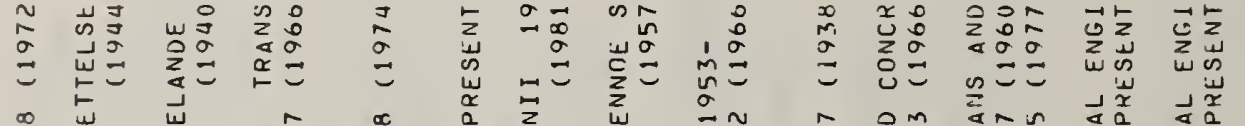

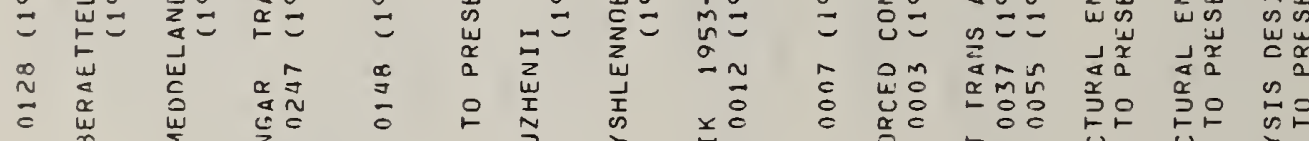

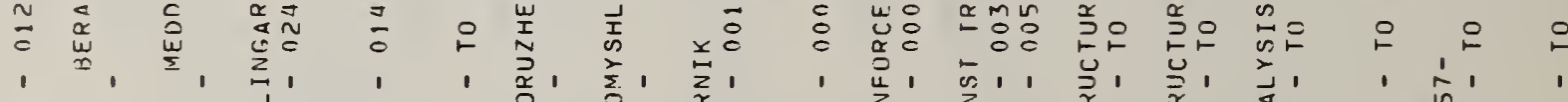

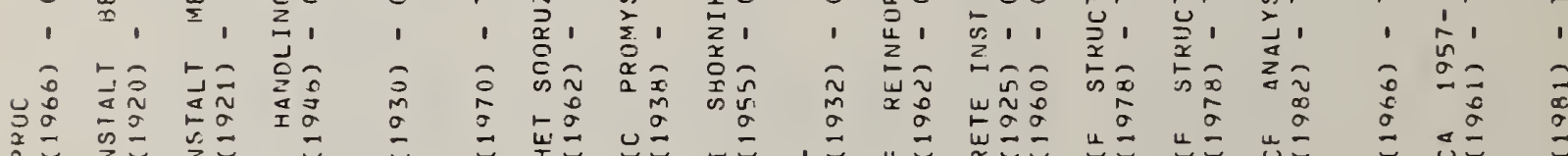

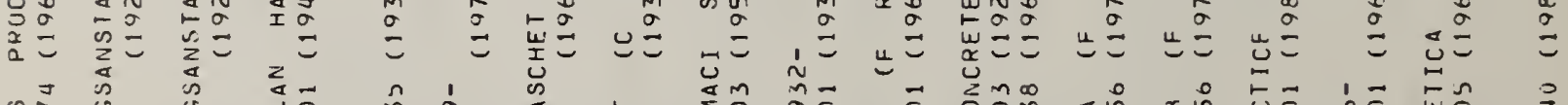

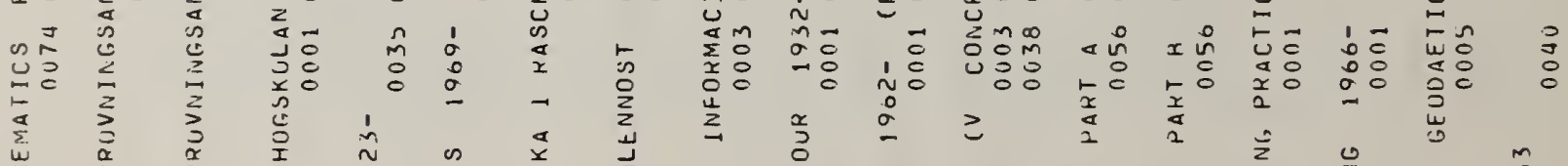

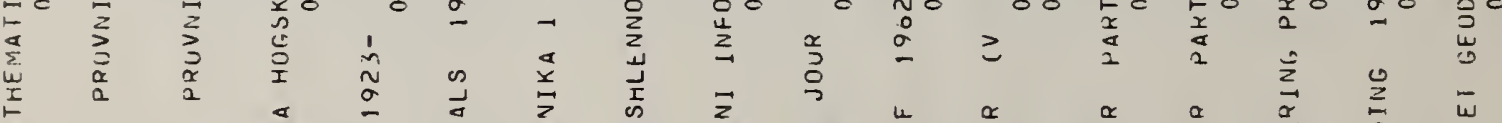

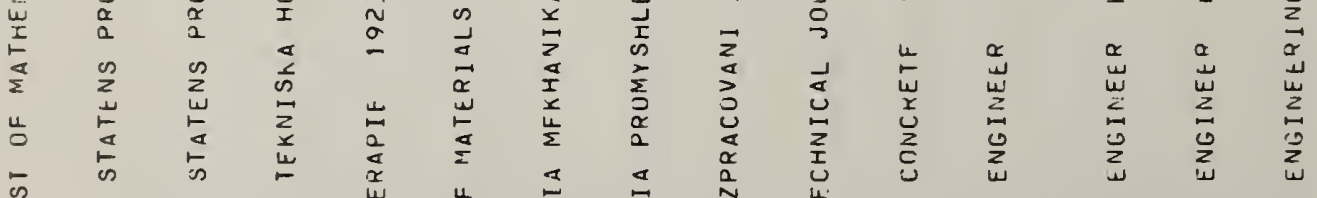

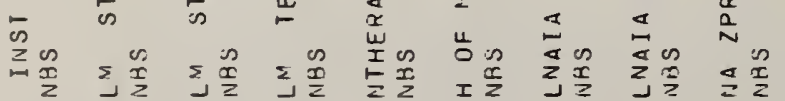

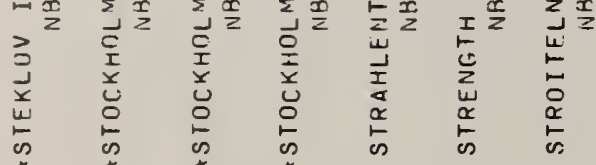

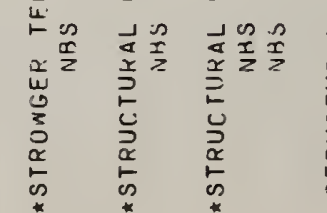

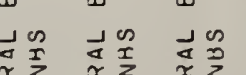

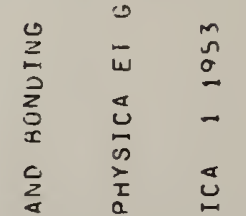

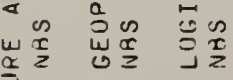

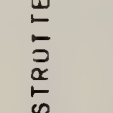

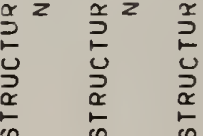

空 

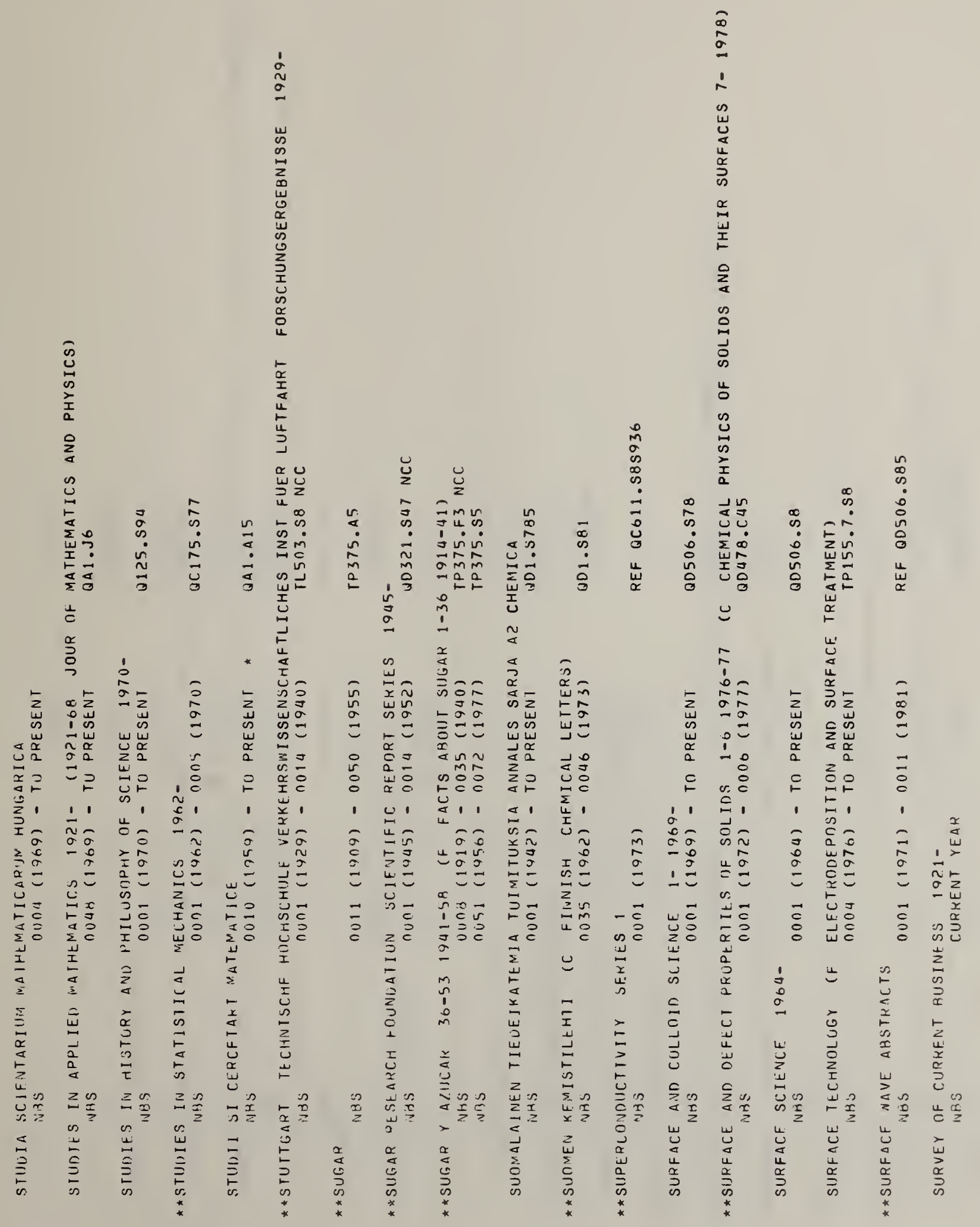


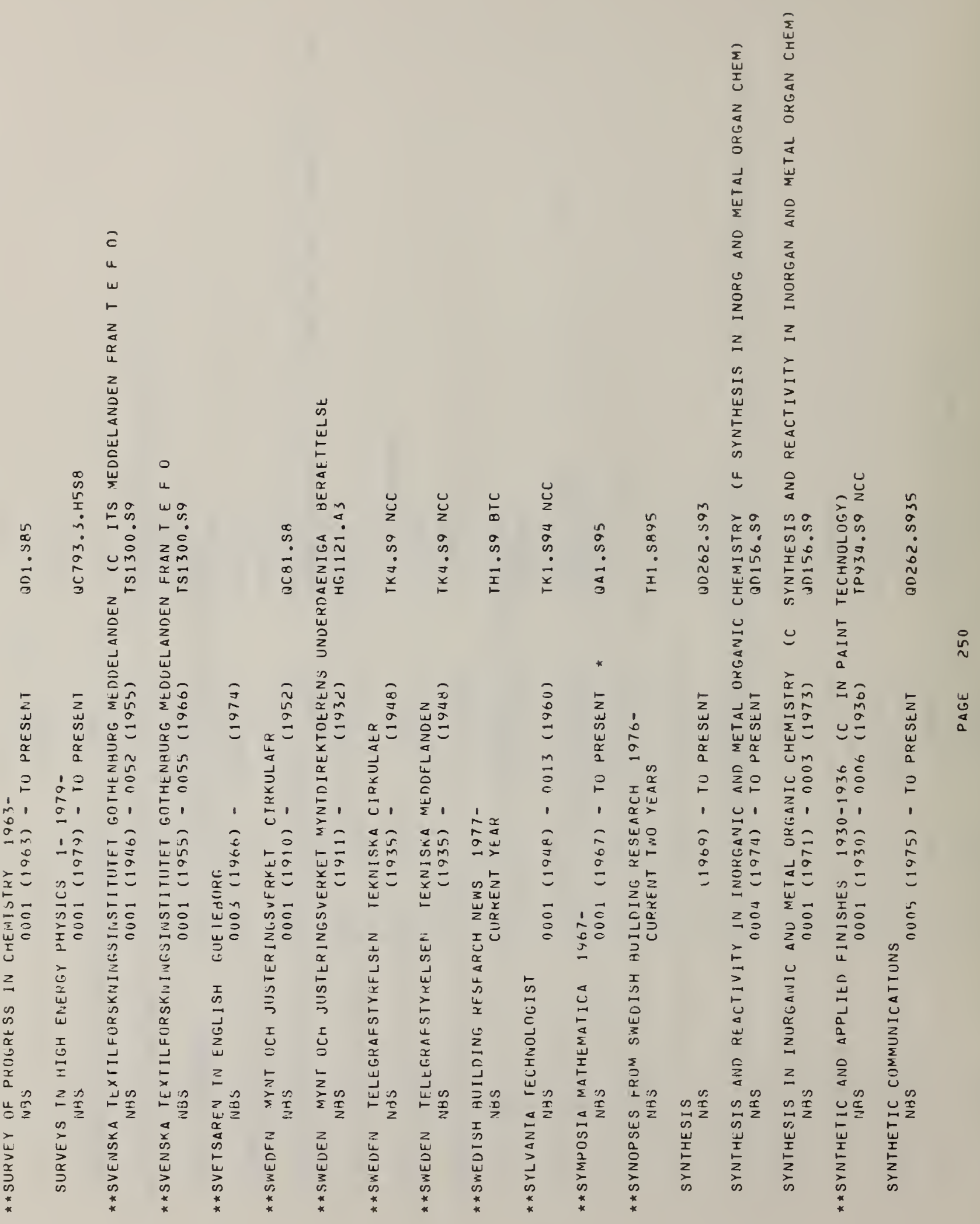




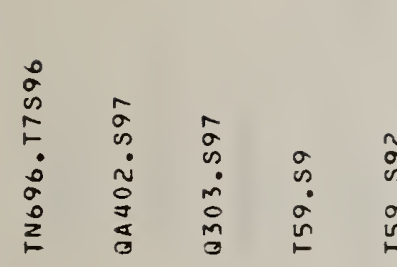

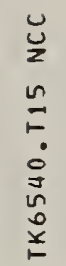
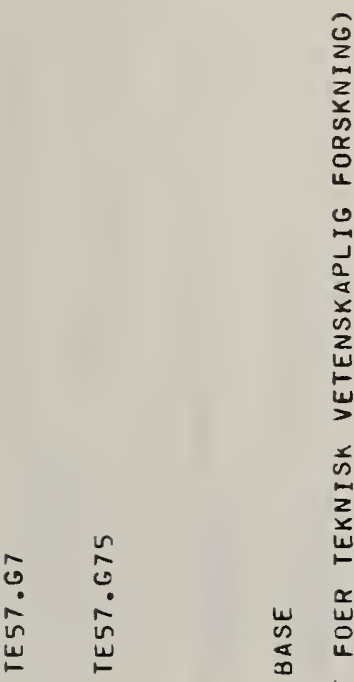

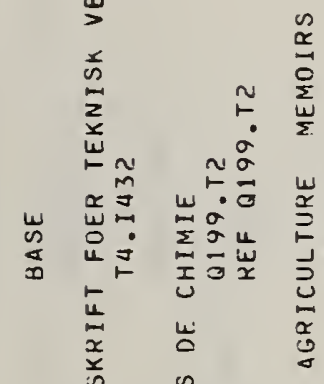

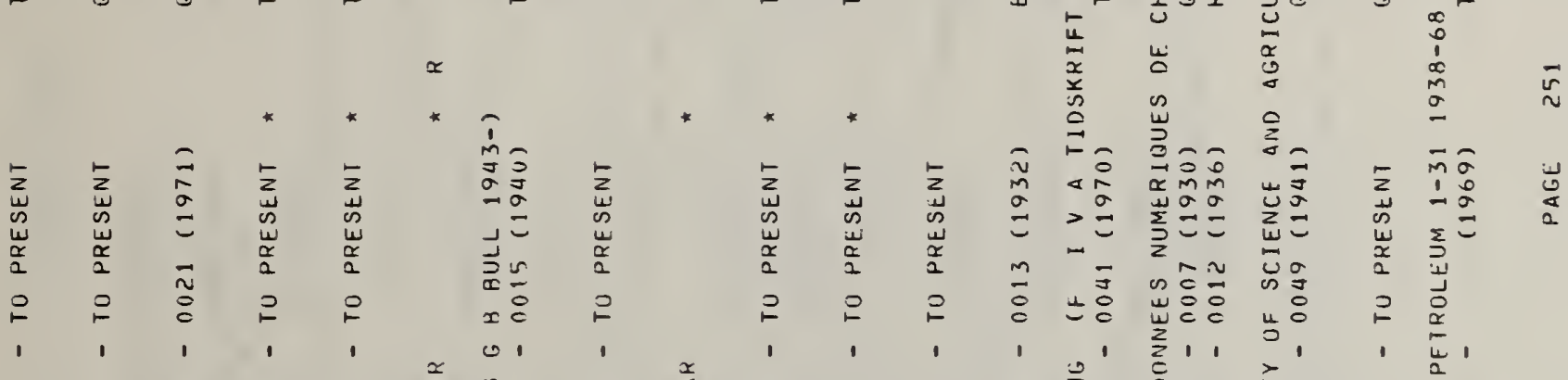

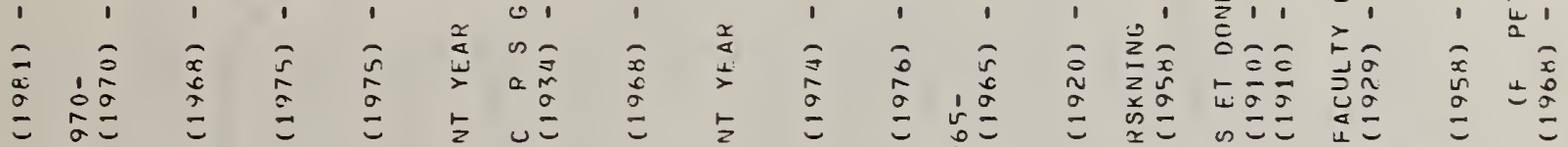

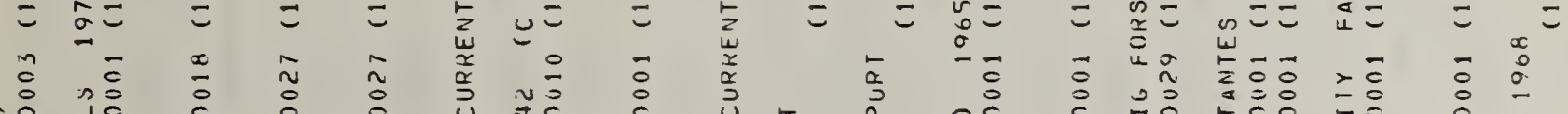

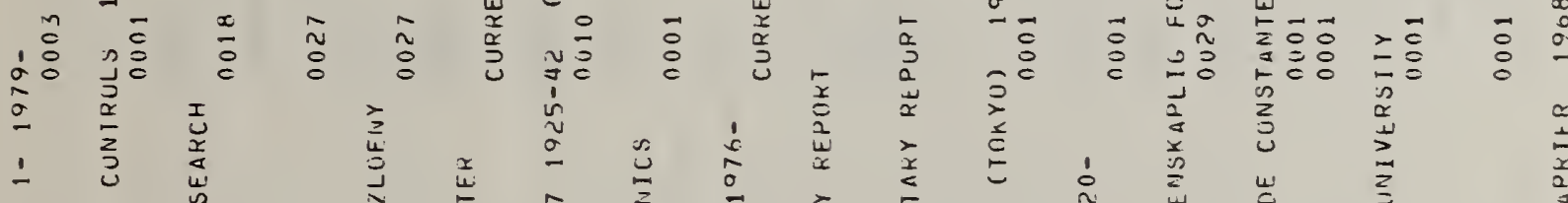

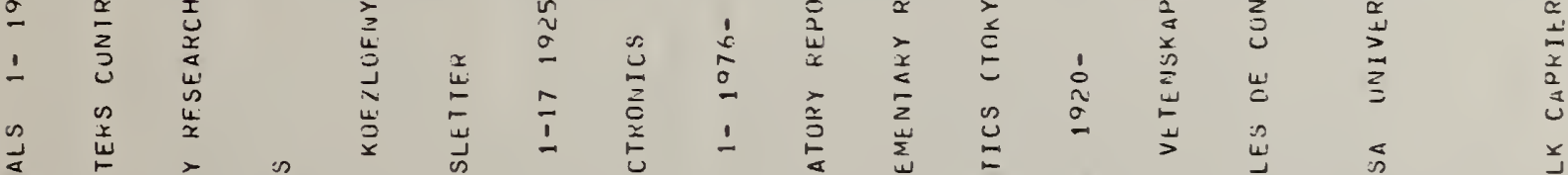

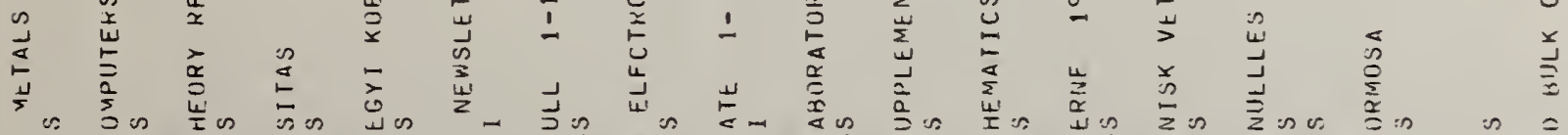

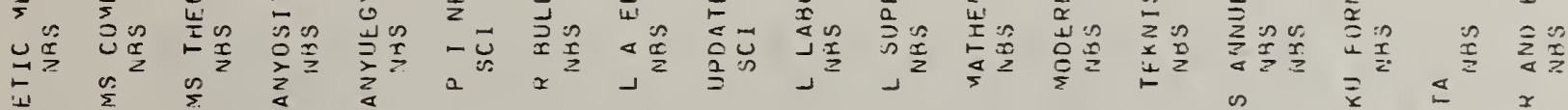

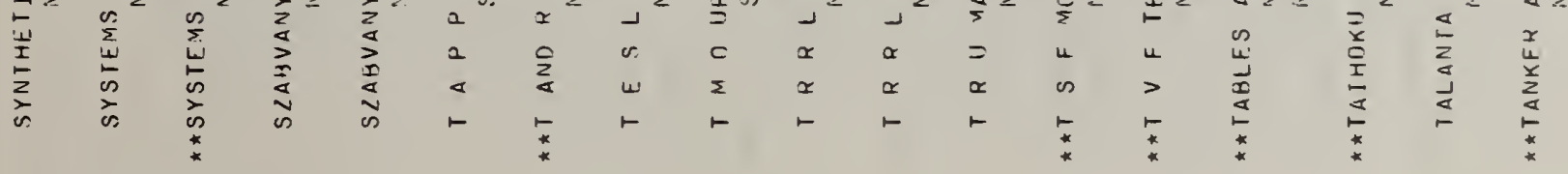




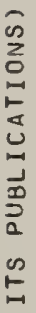

$\underset{\frac{a}{a}}{a}$

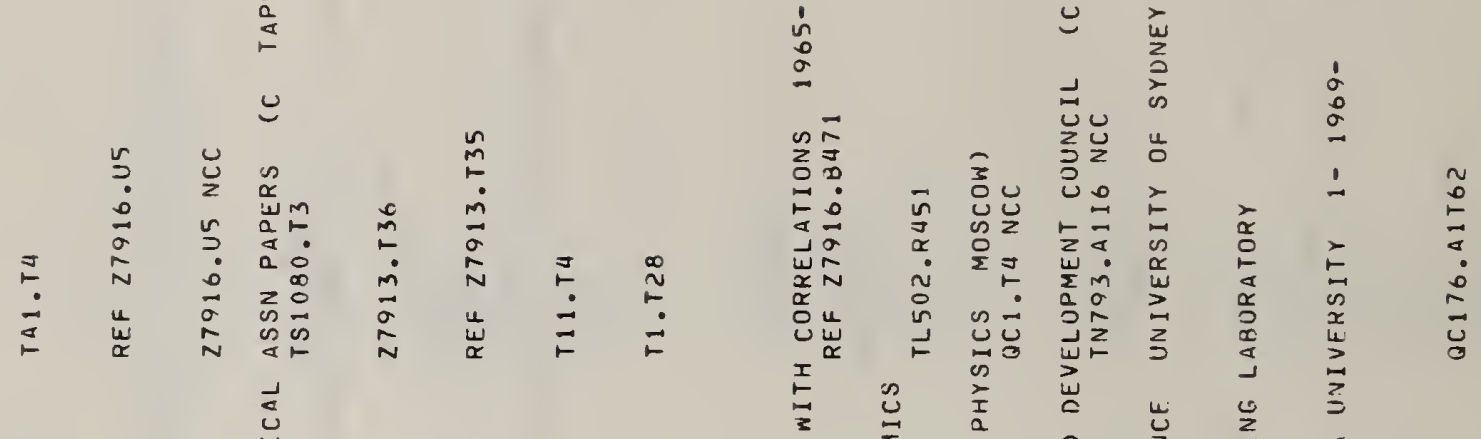

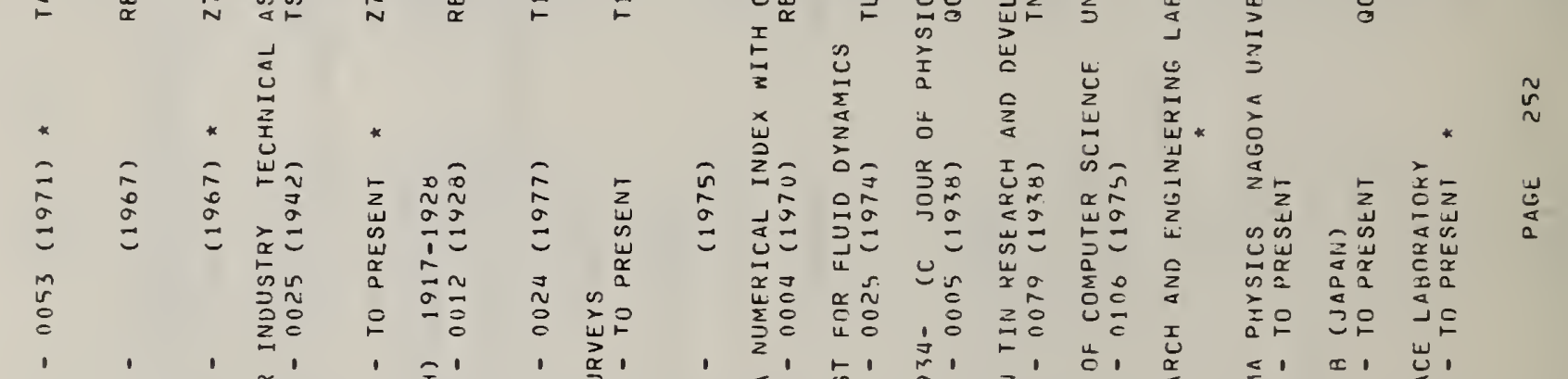

(

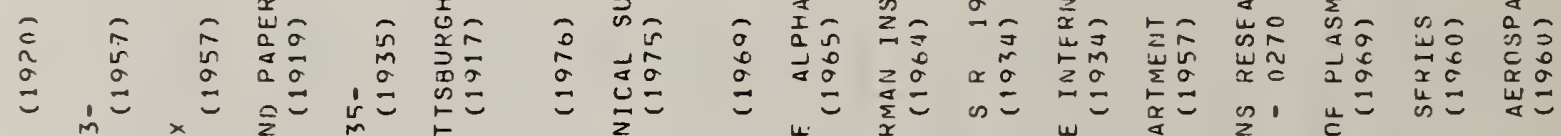

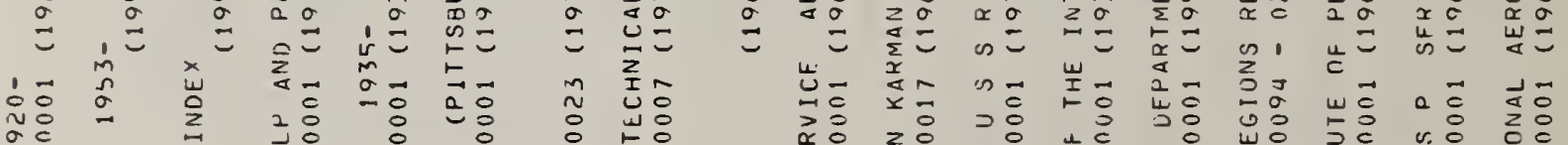

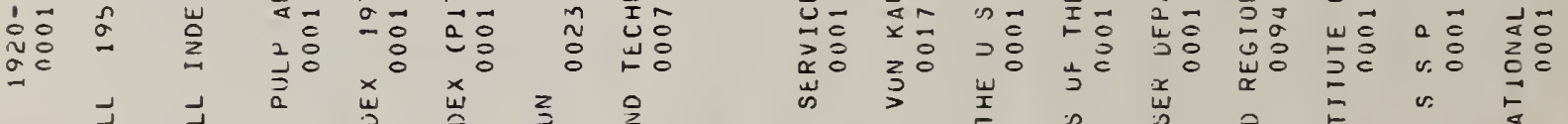

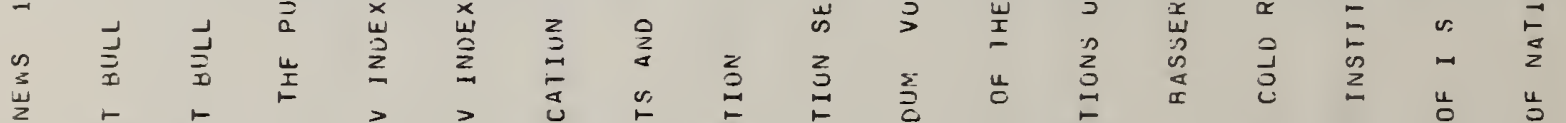

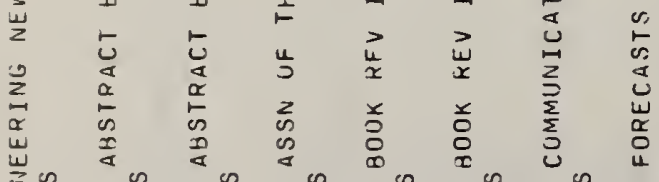

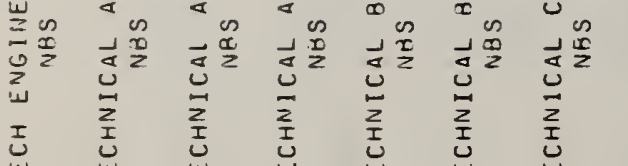

忈

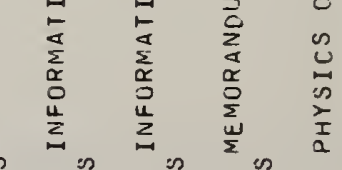

离

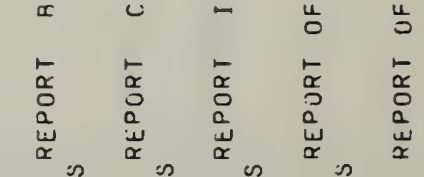

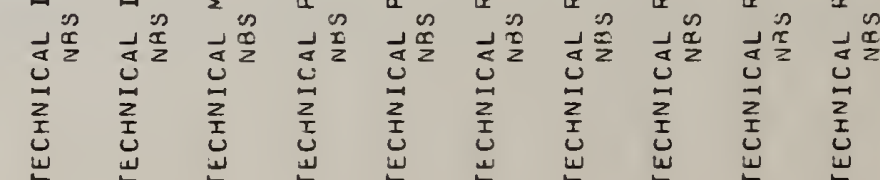




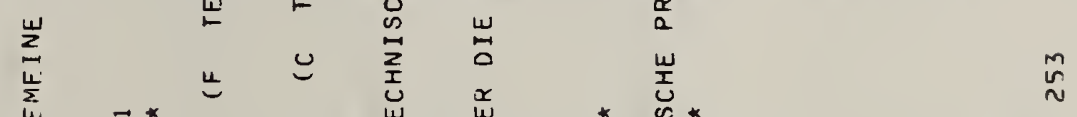

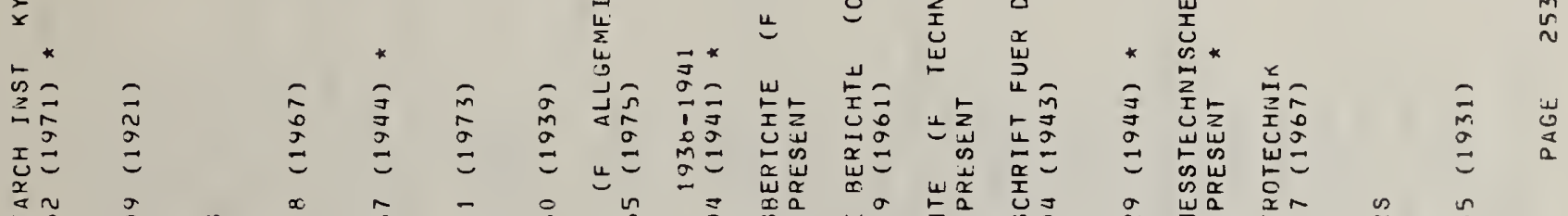

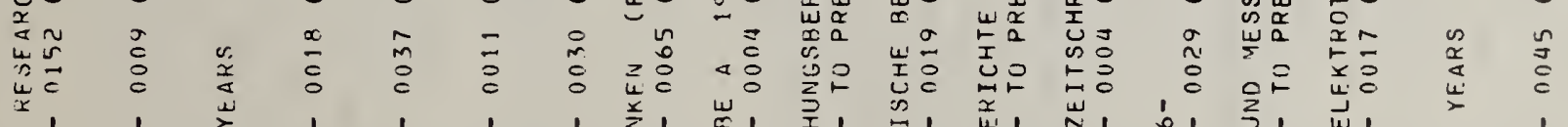

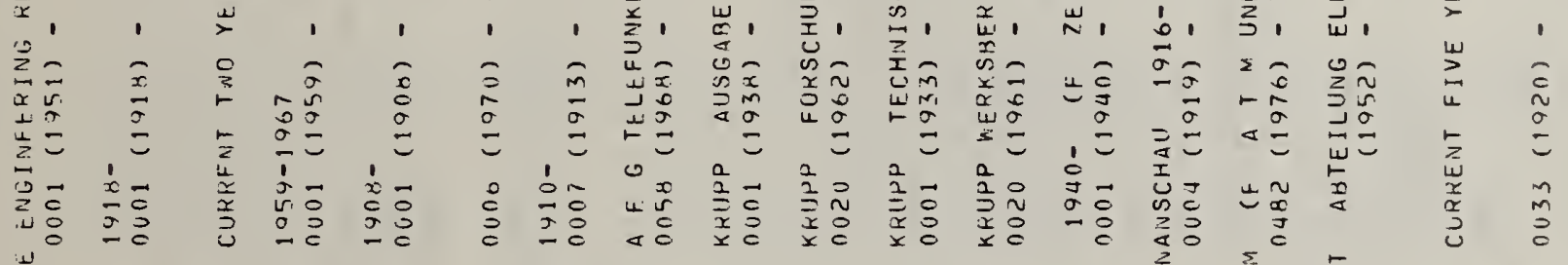

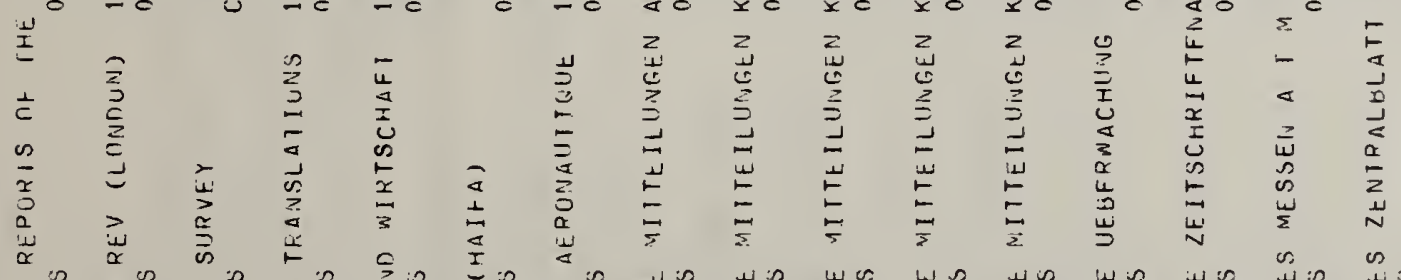

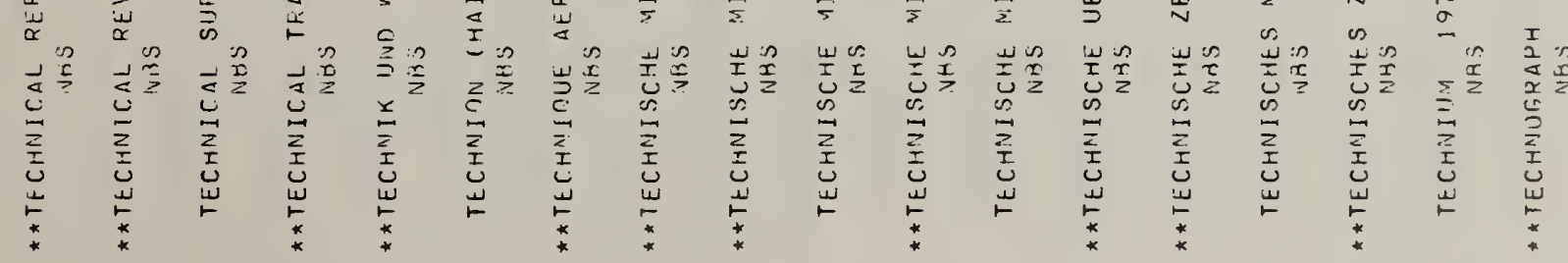




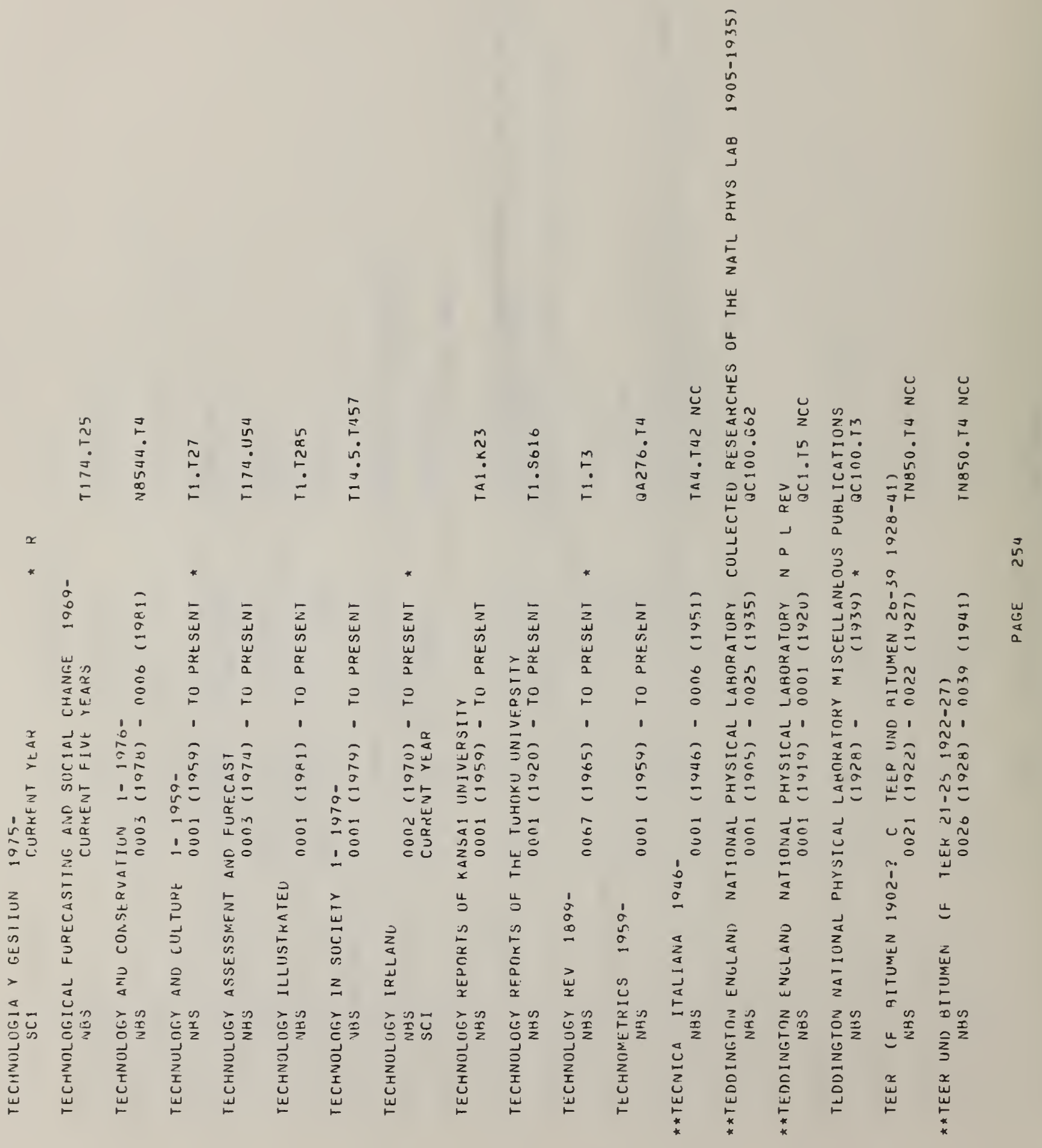




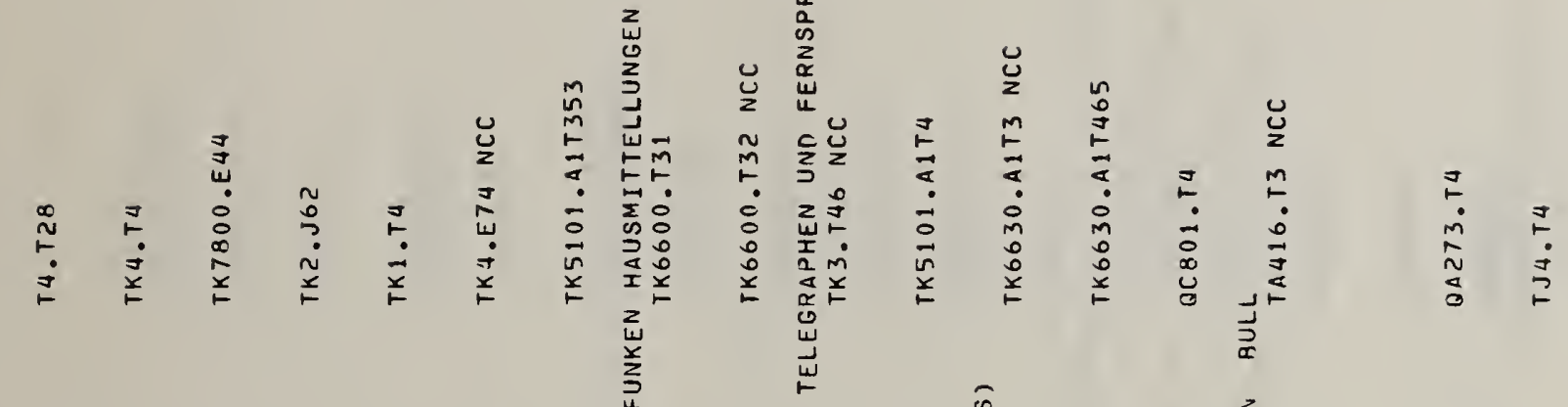

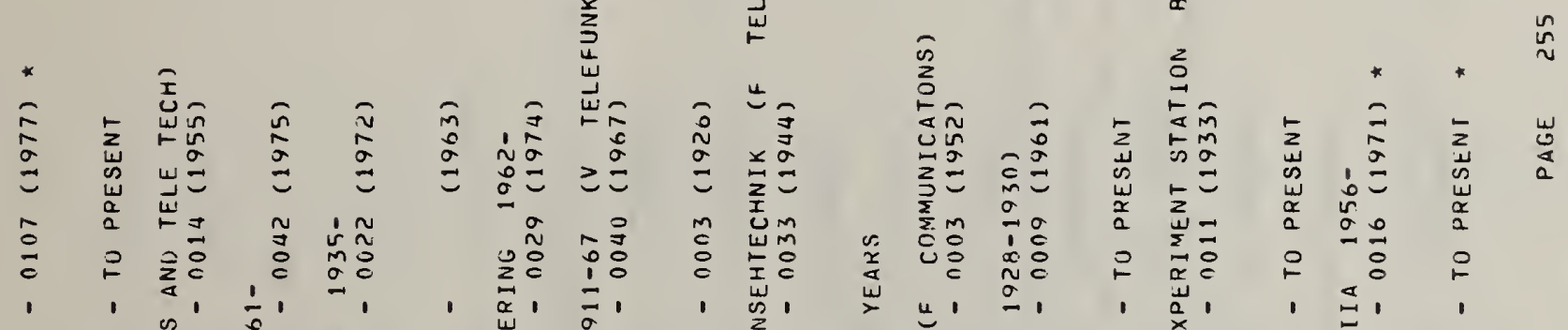

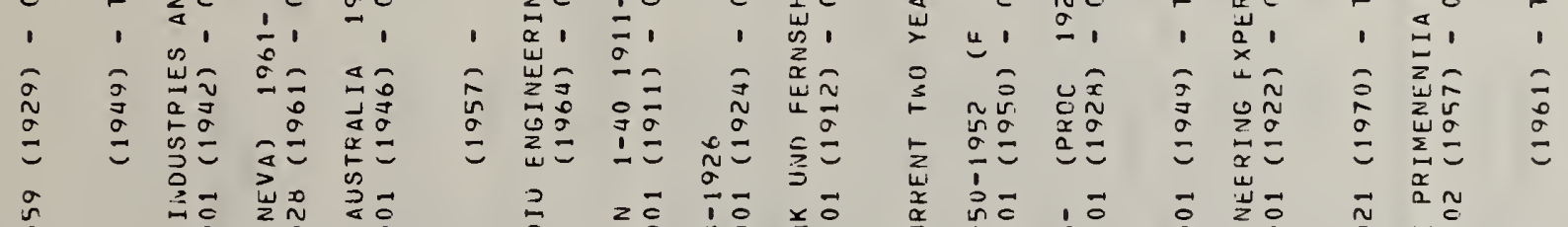

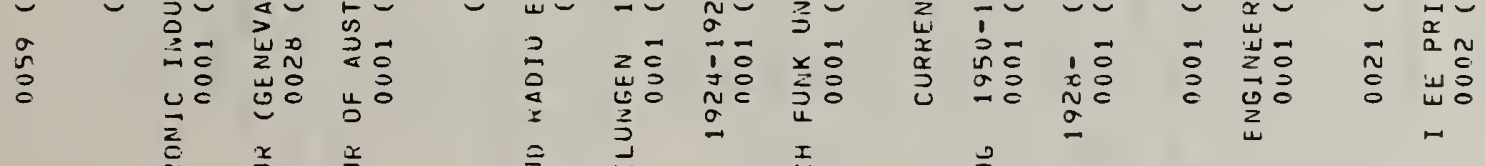




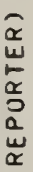

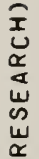

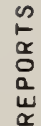

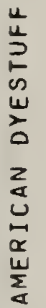

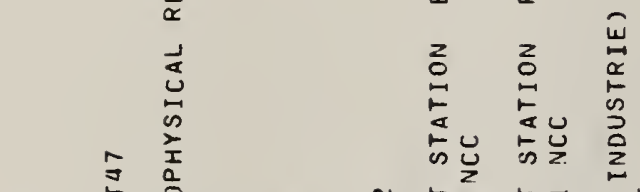

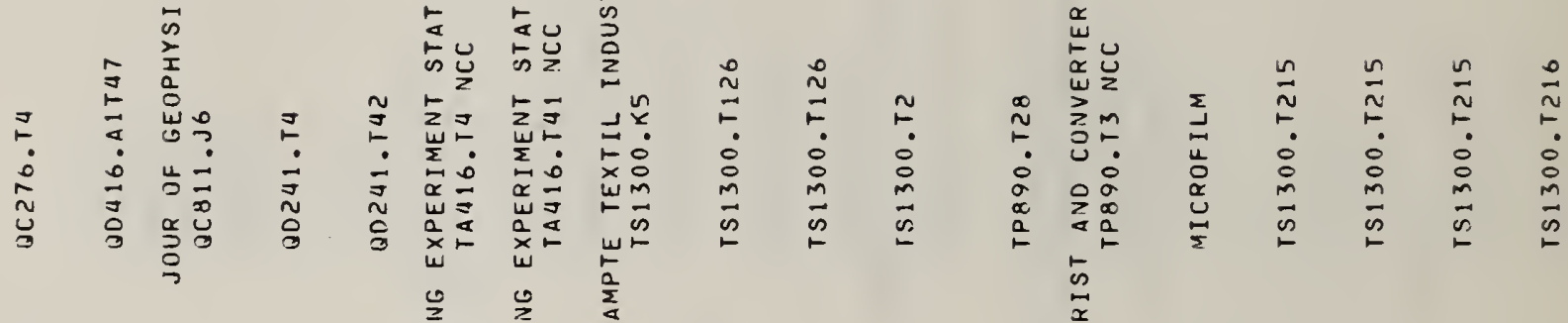

* 0 究

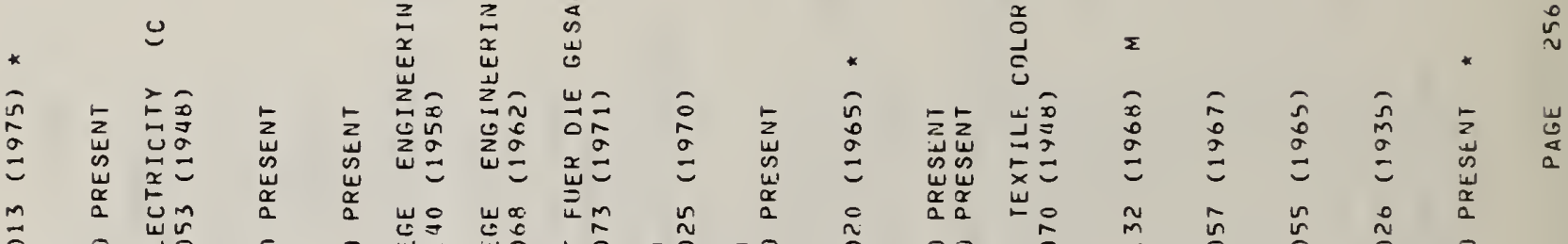

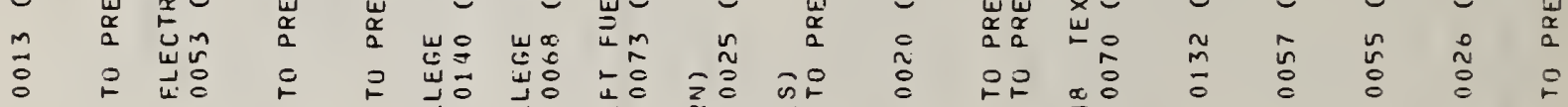

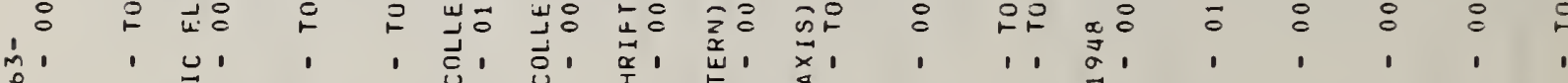

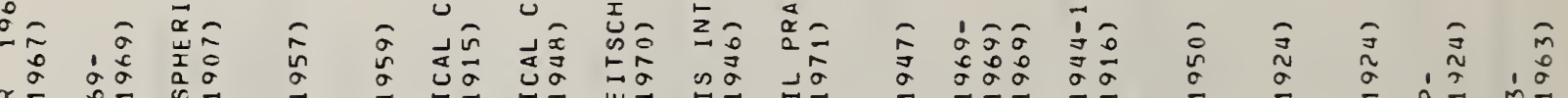

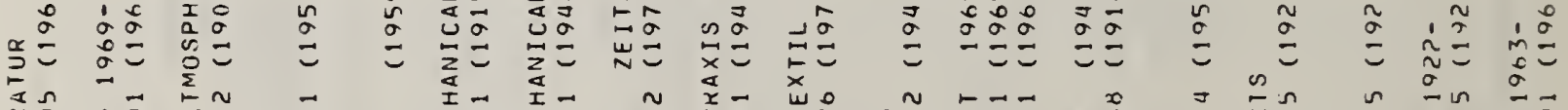

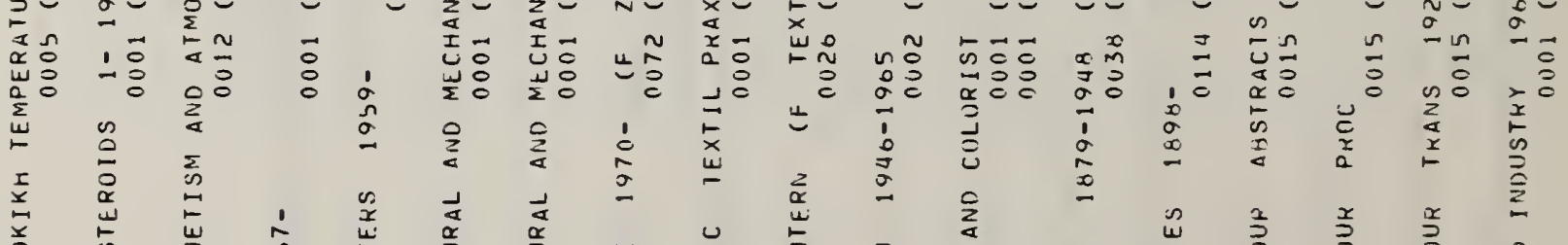

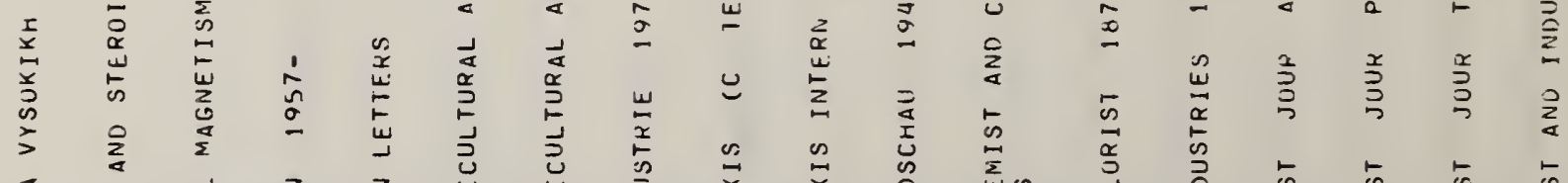

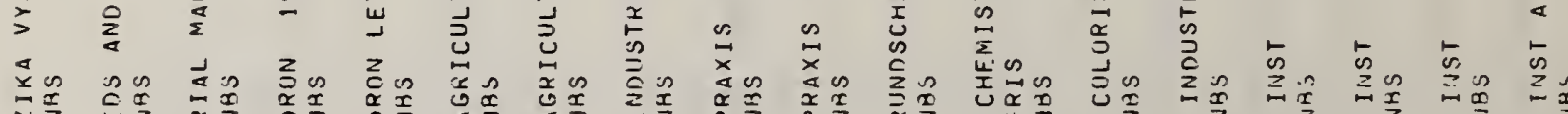

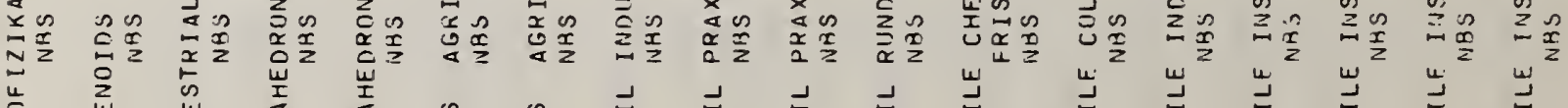

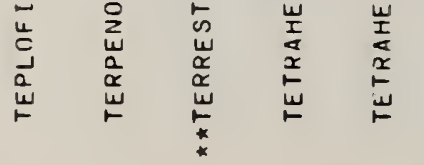

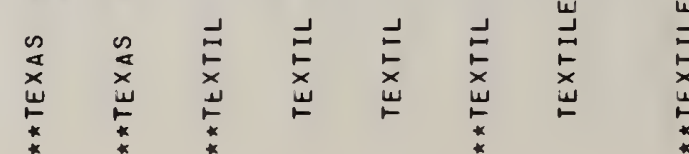




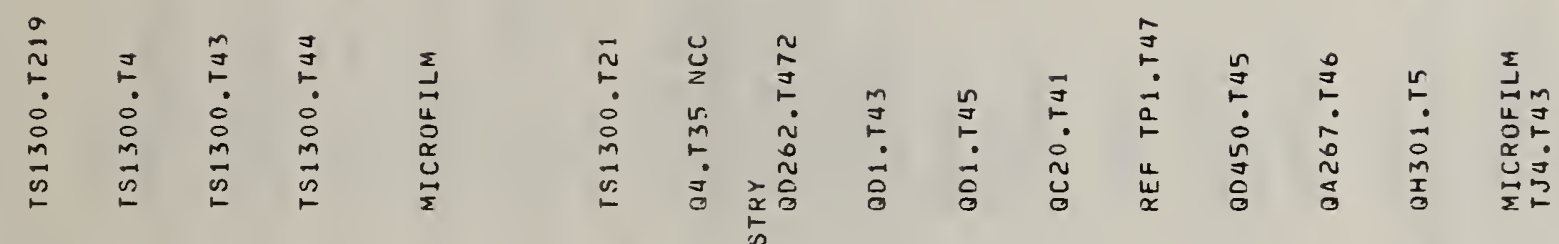

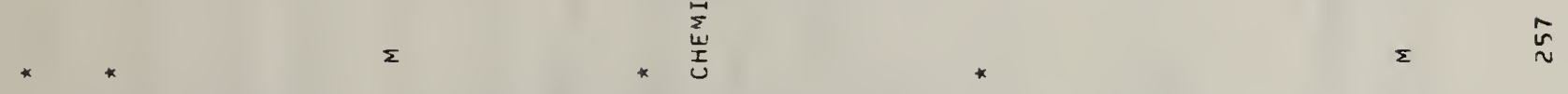

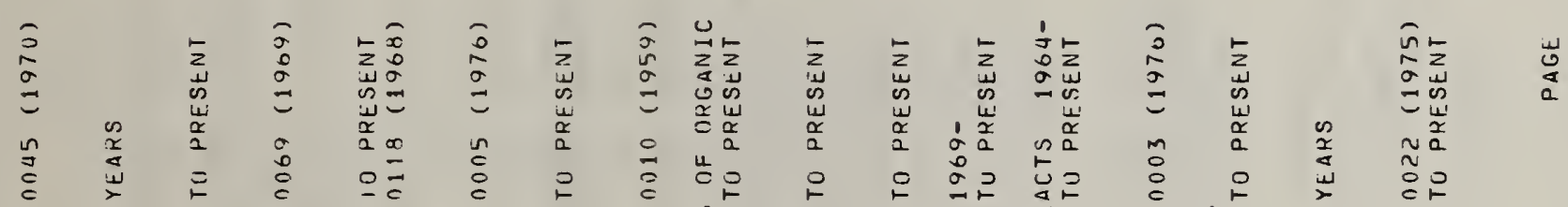

1

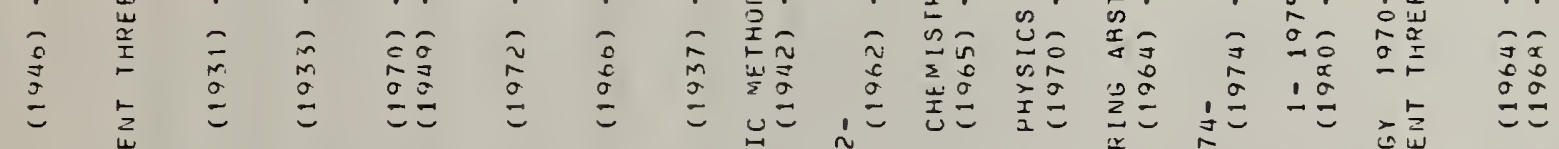

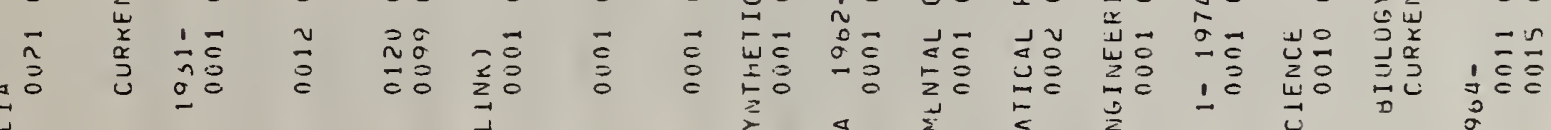

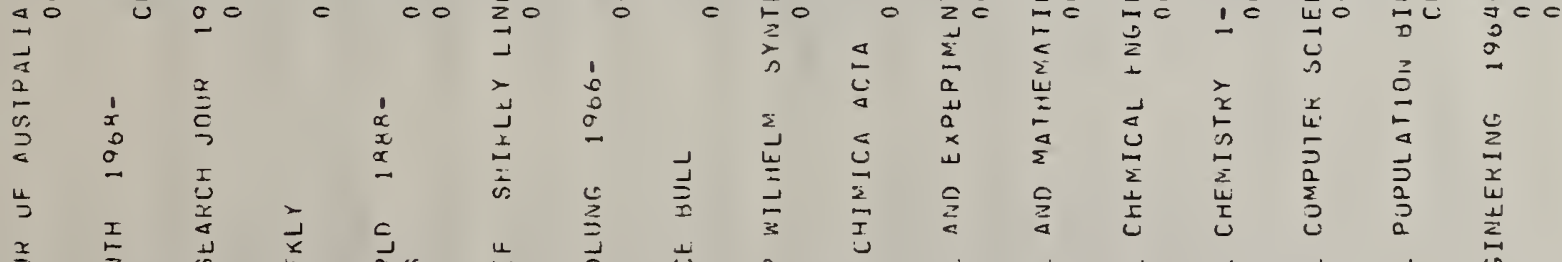

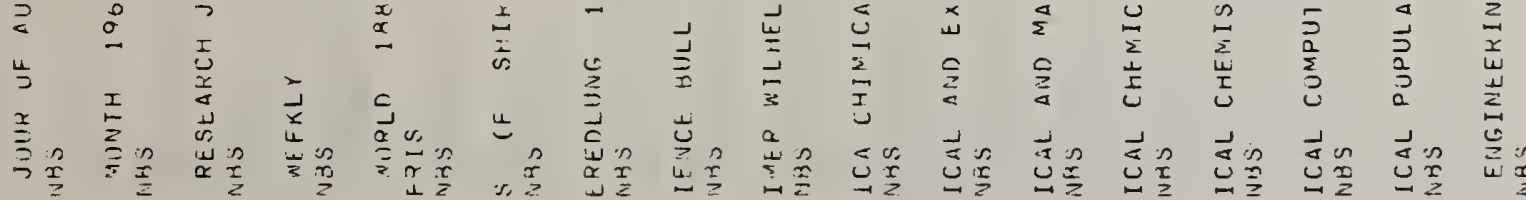

(i.

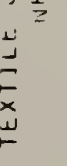

年

岌

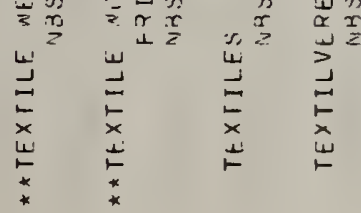

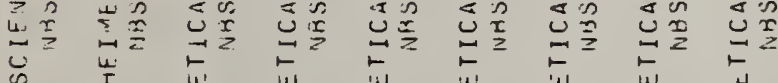

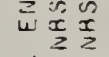




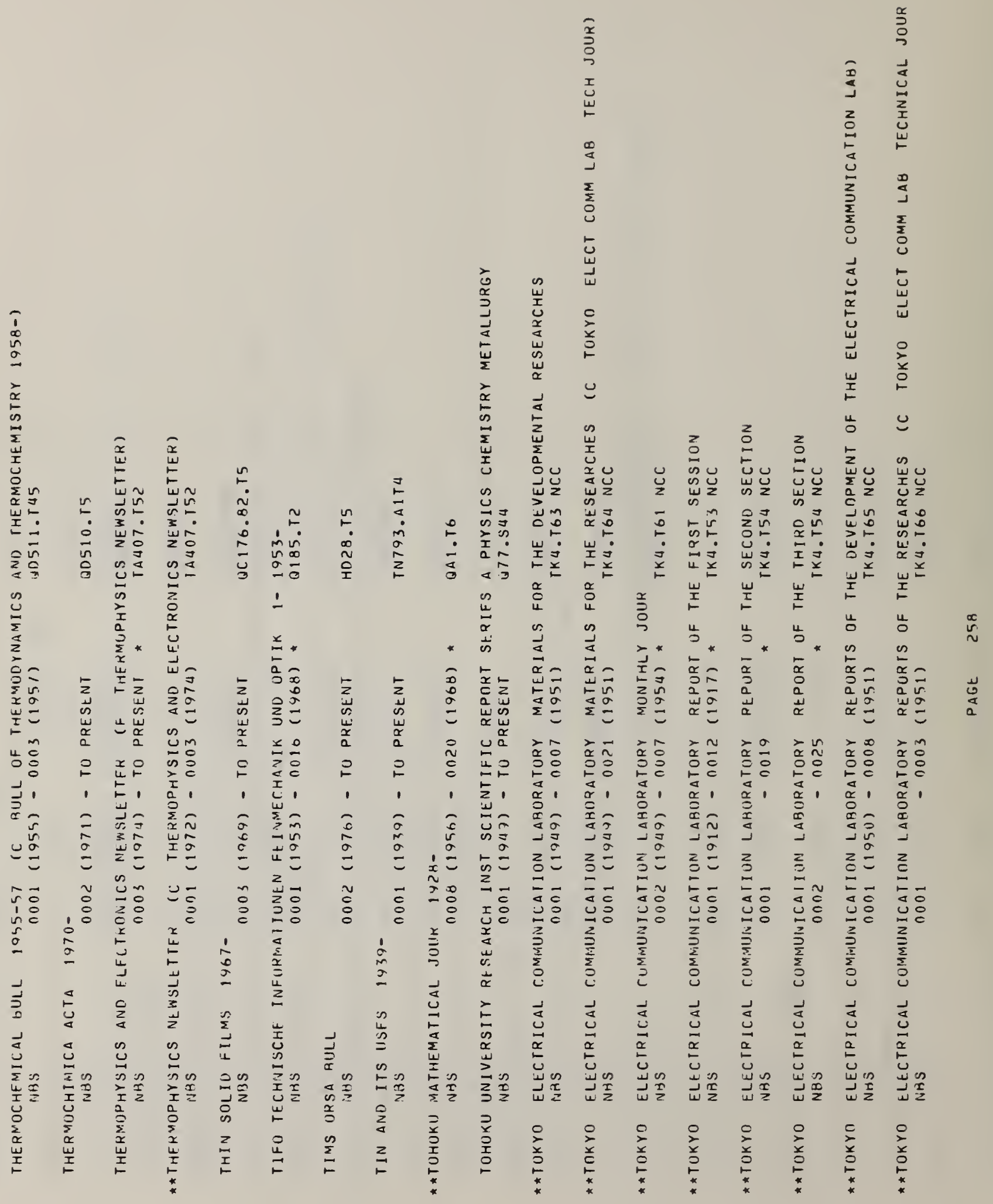




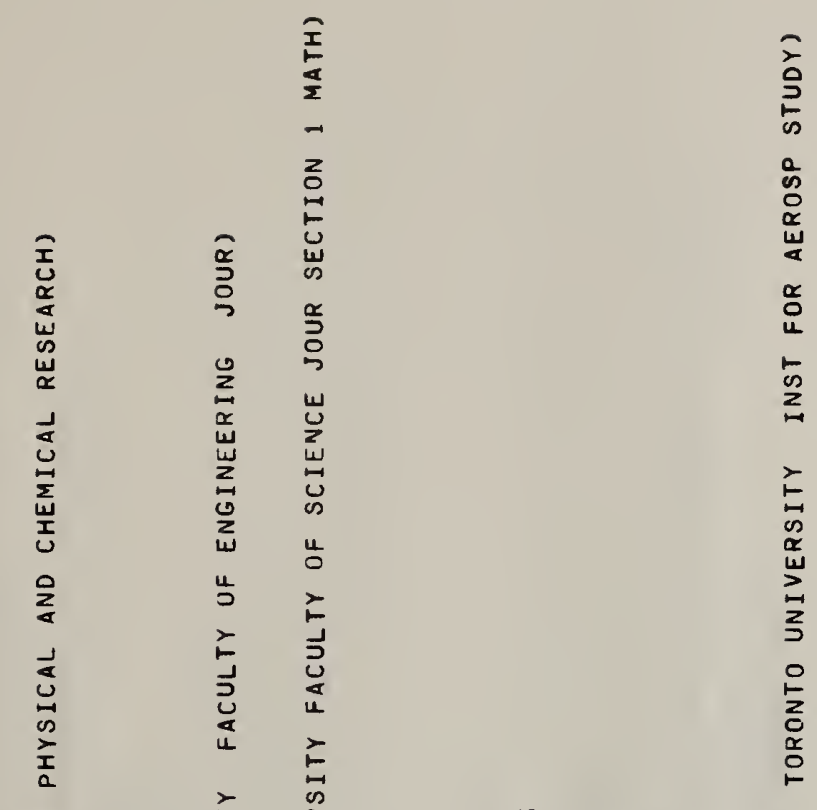

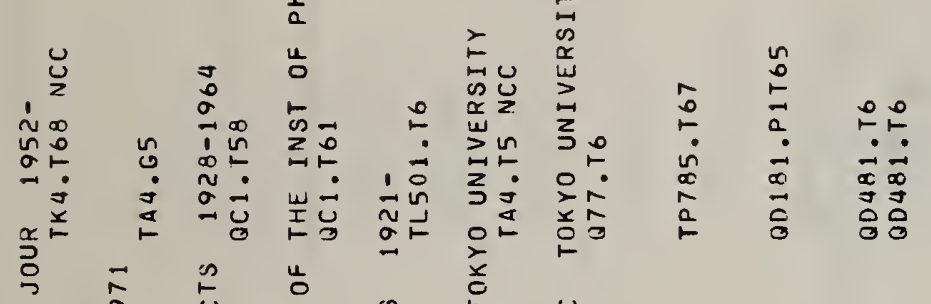

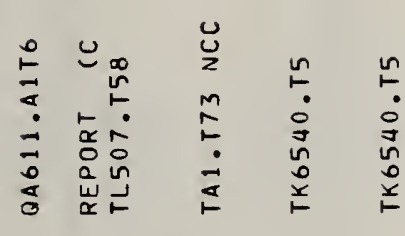

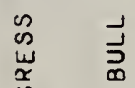

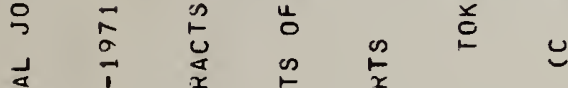

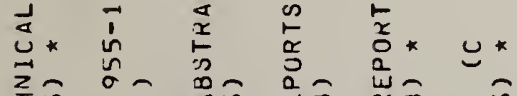

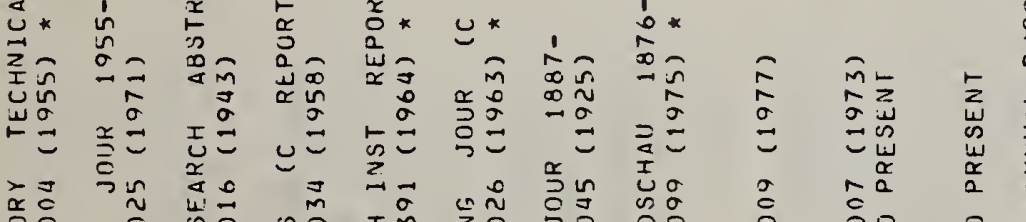

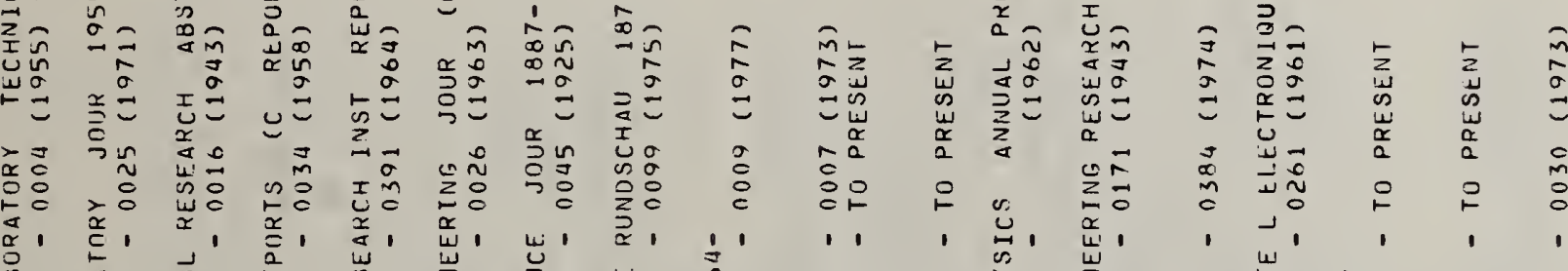

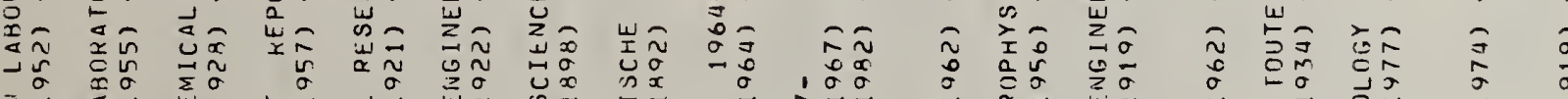

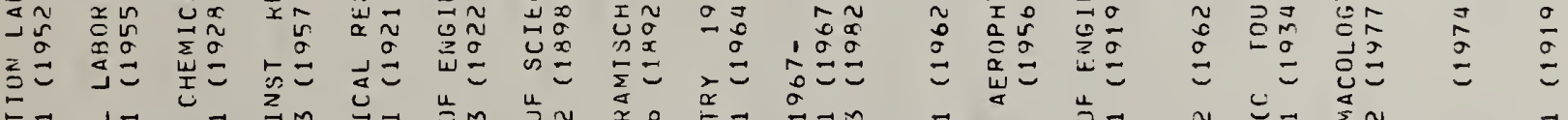

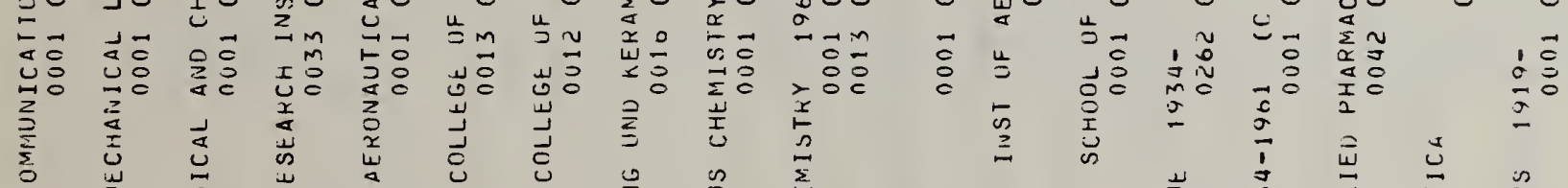

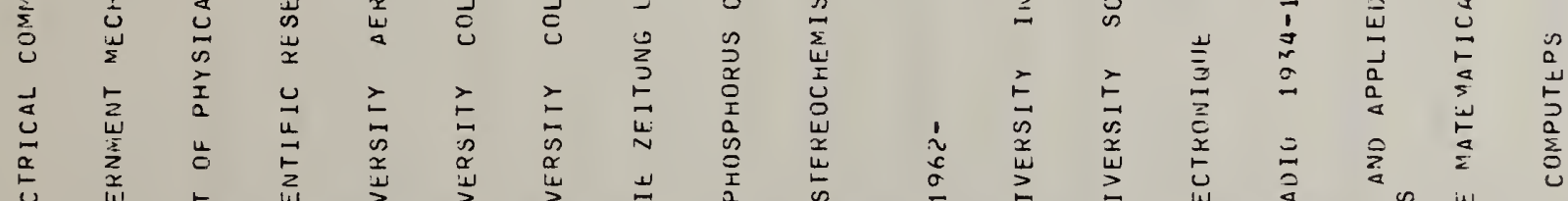

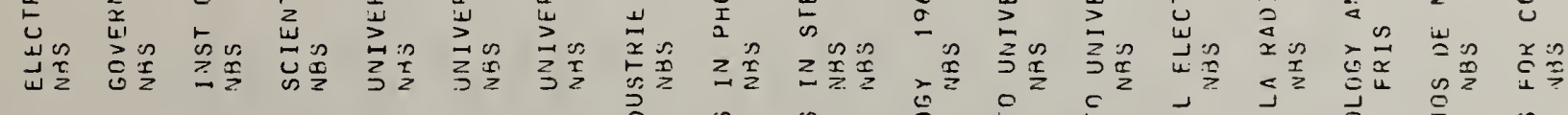

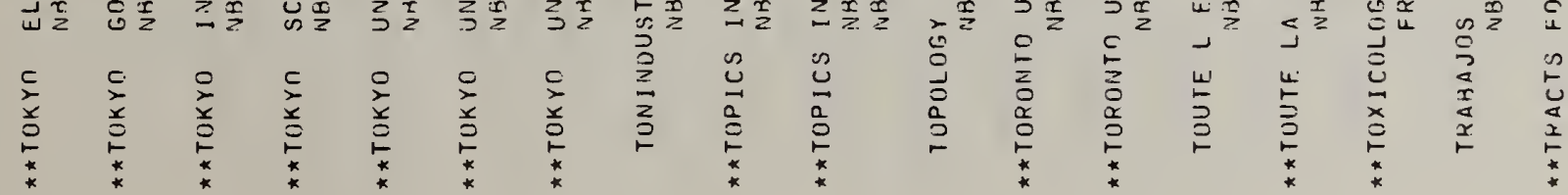




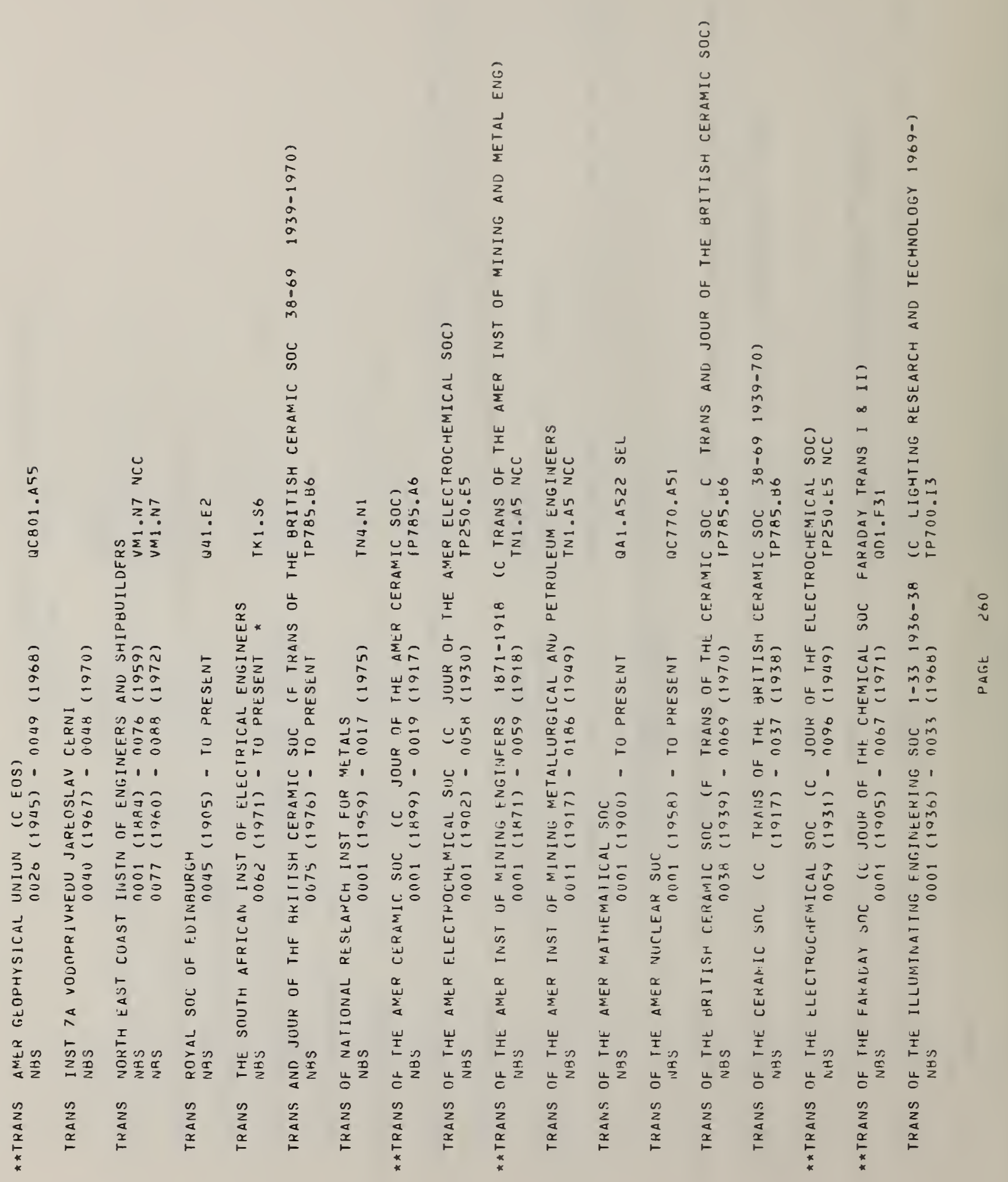




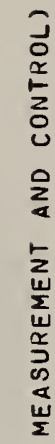

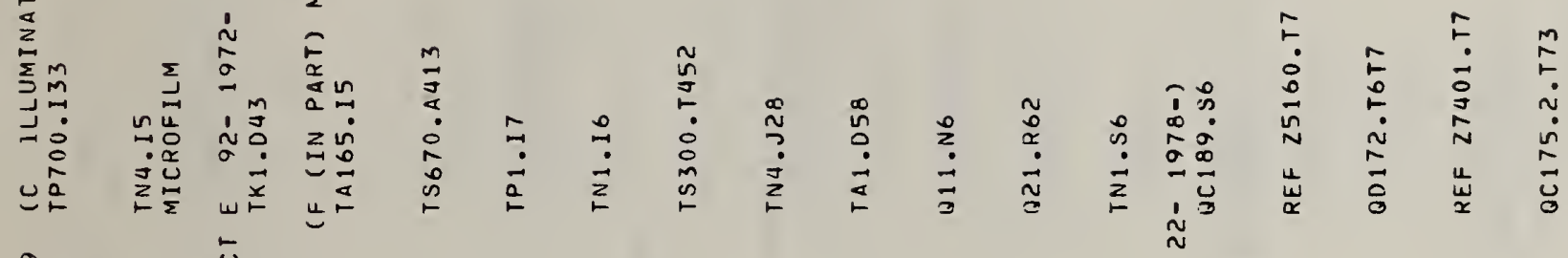
$\begin{array}{lllll} & \\ 0\end{array}$ 


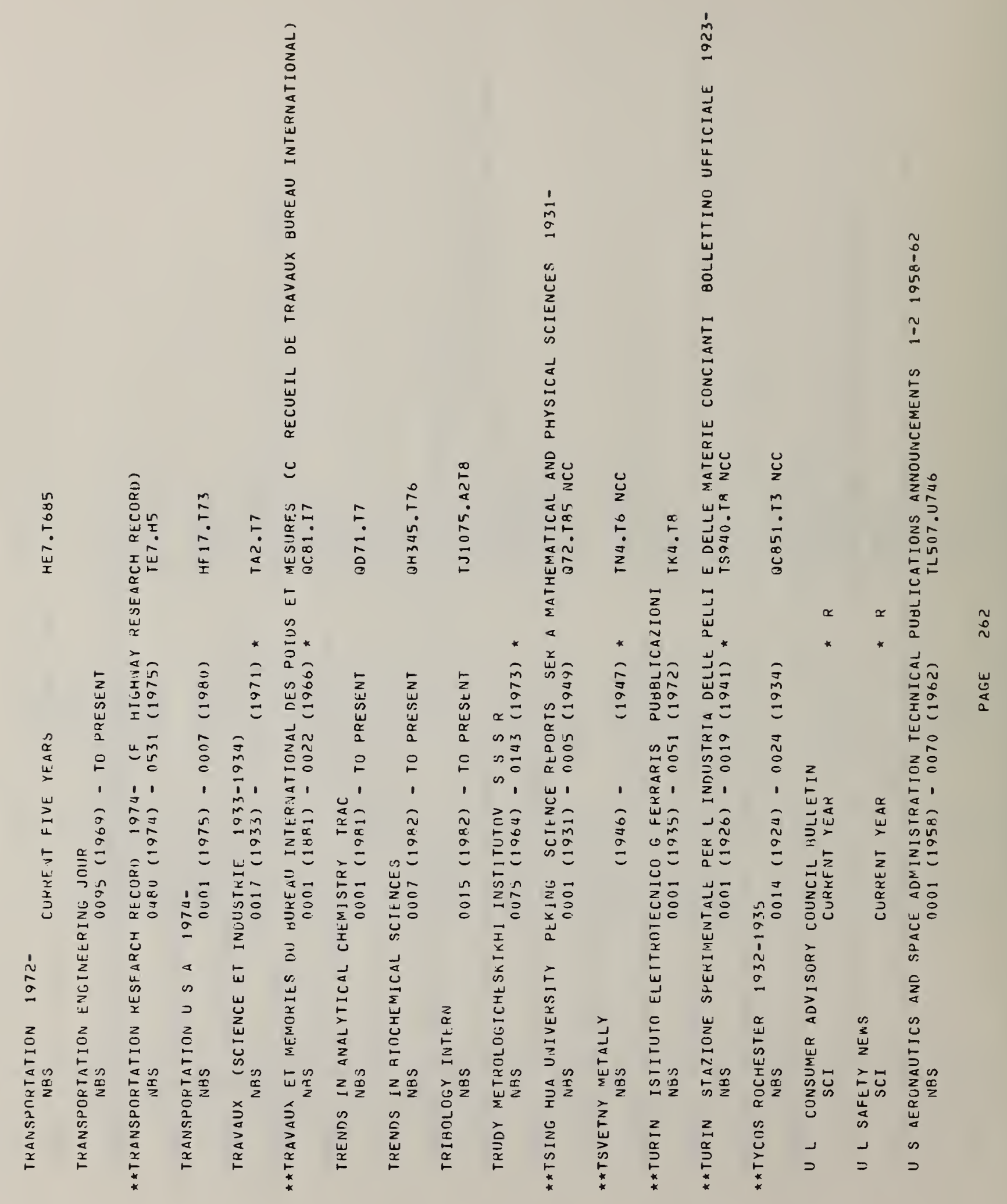




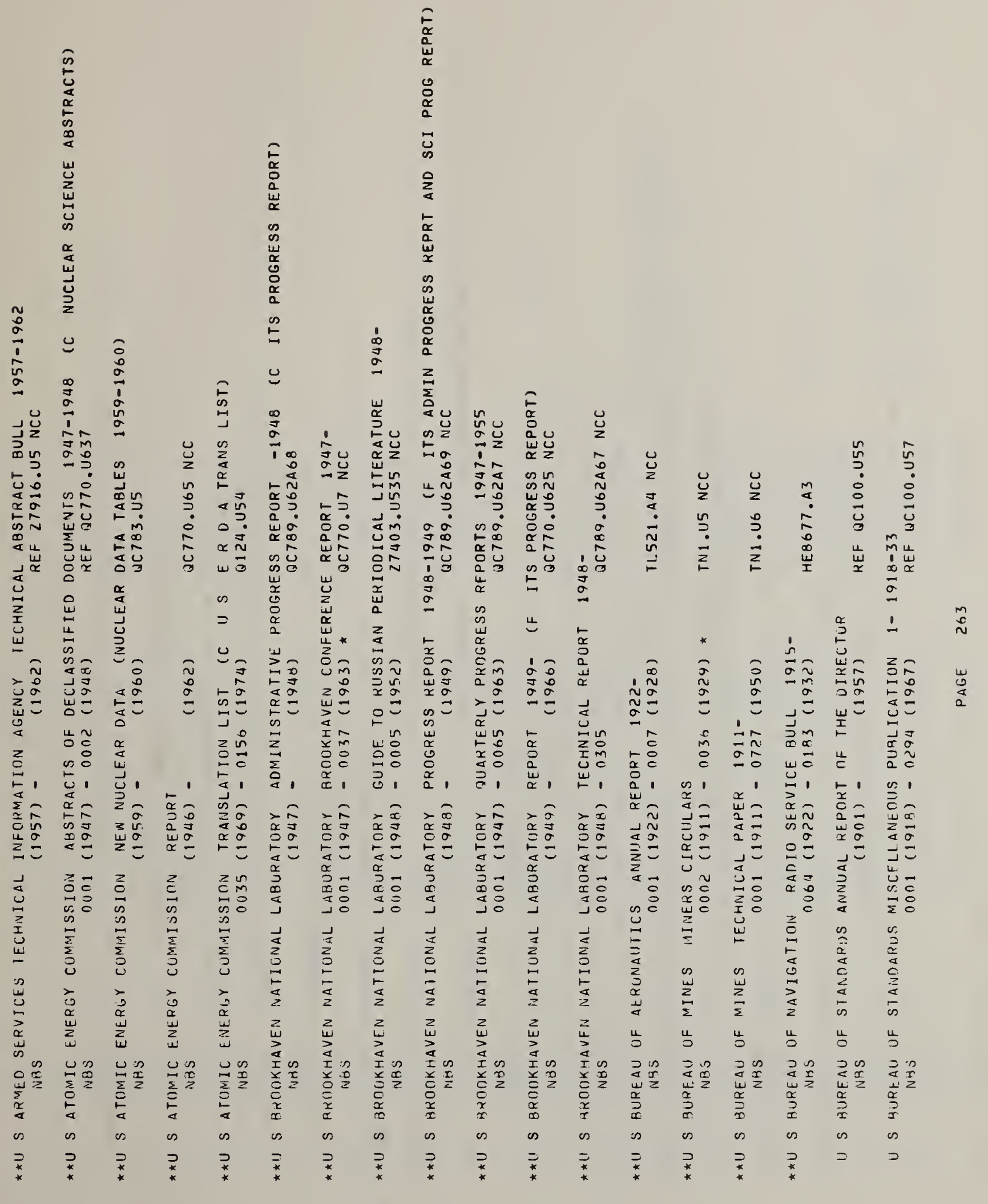



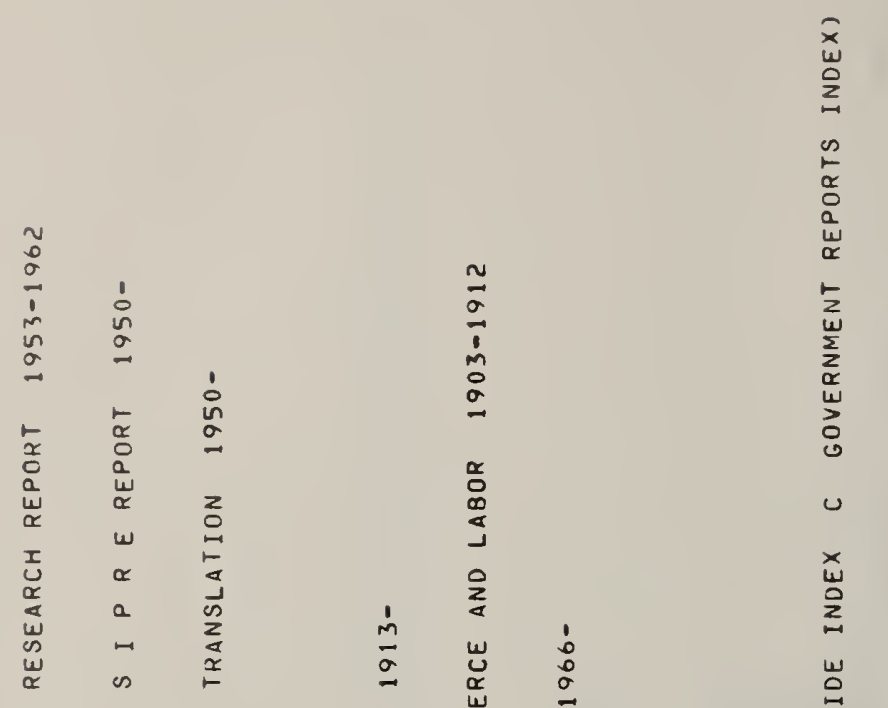

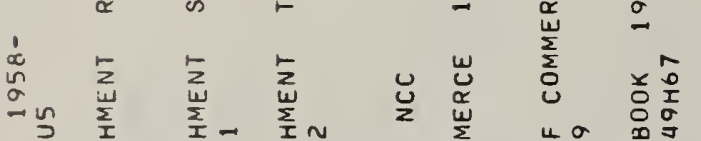

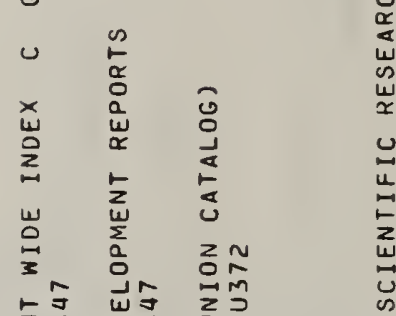

$\frac{1}{\circ}$

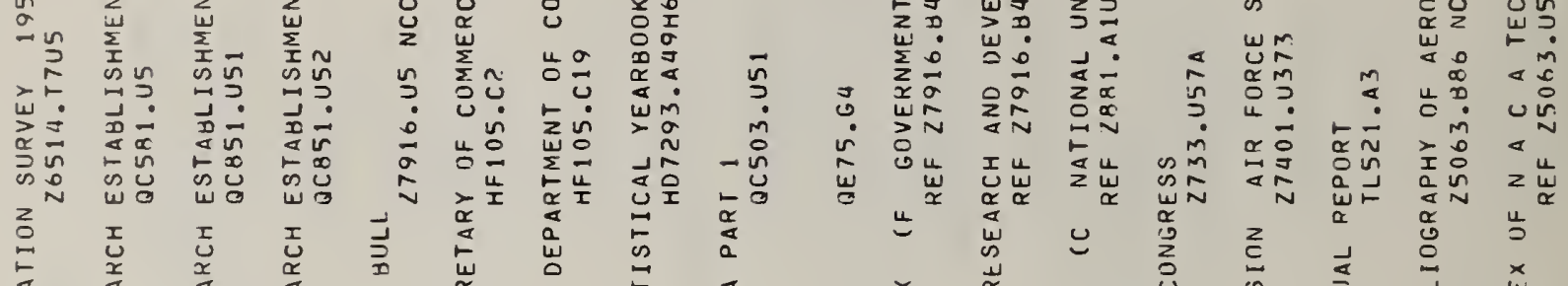

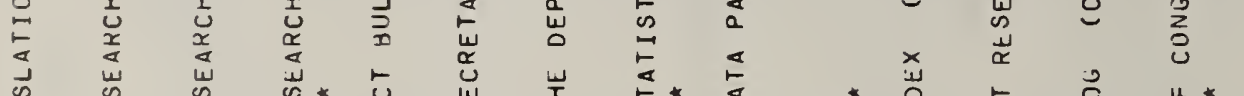

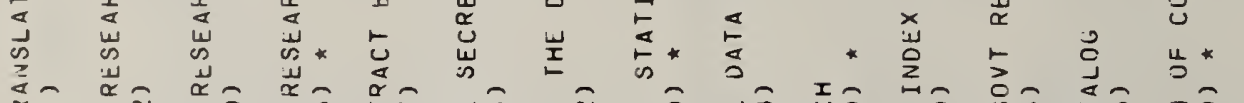

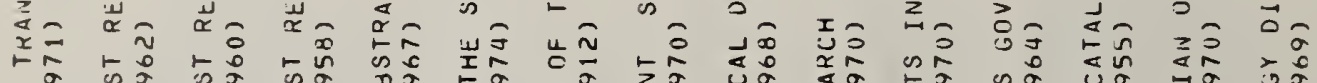

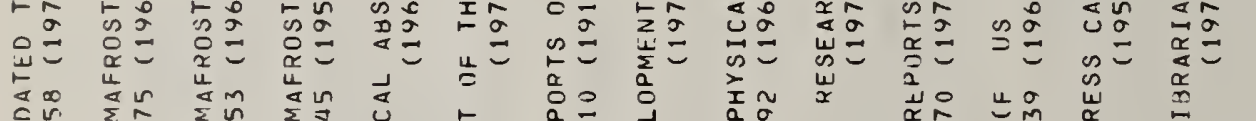

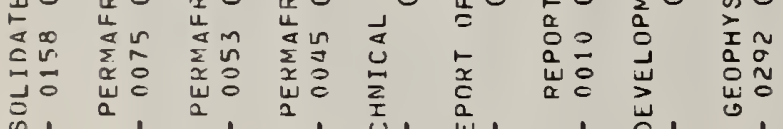

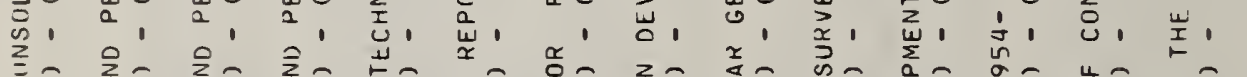

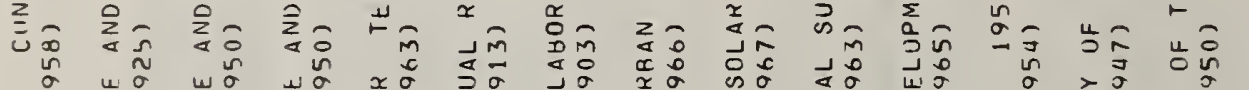

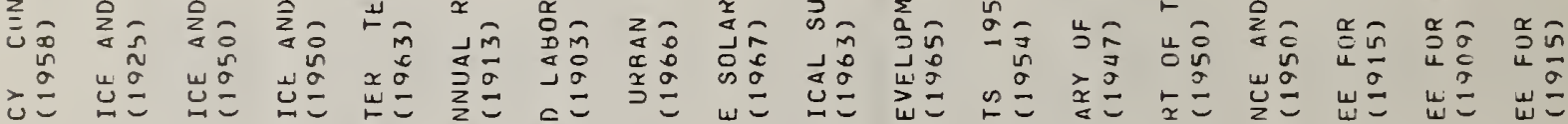

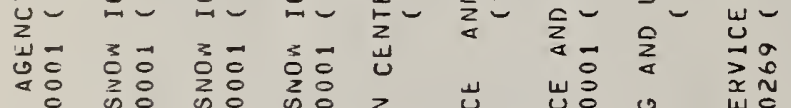

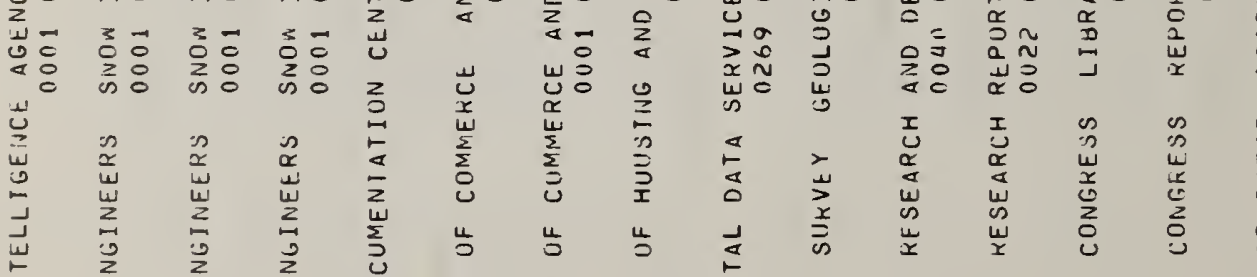

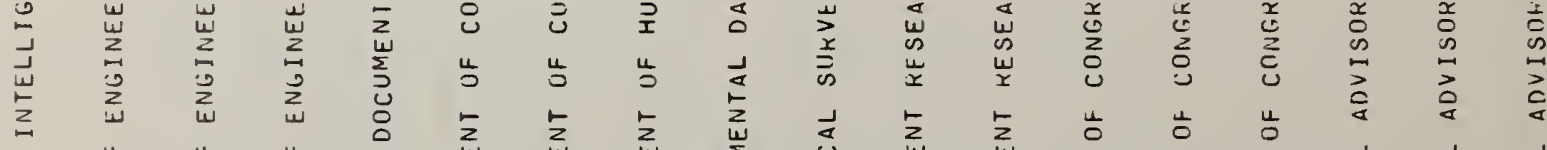

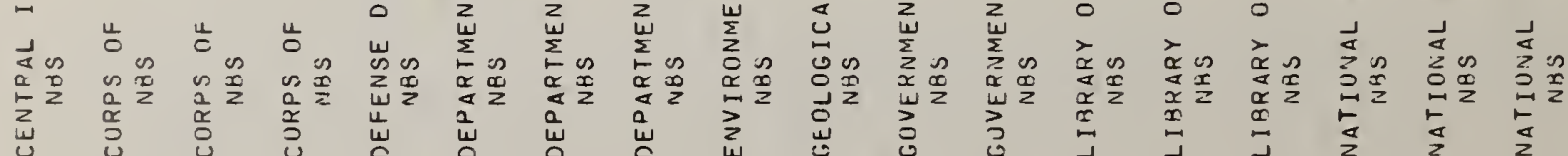

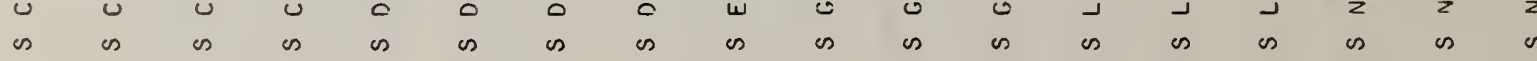

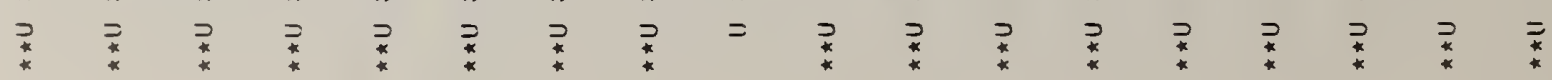




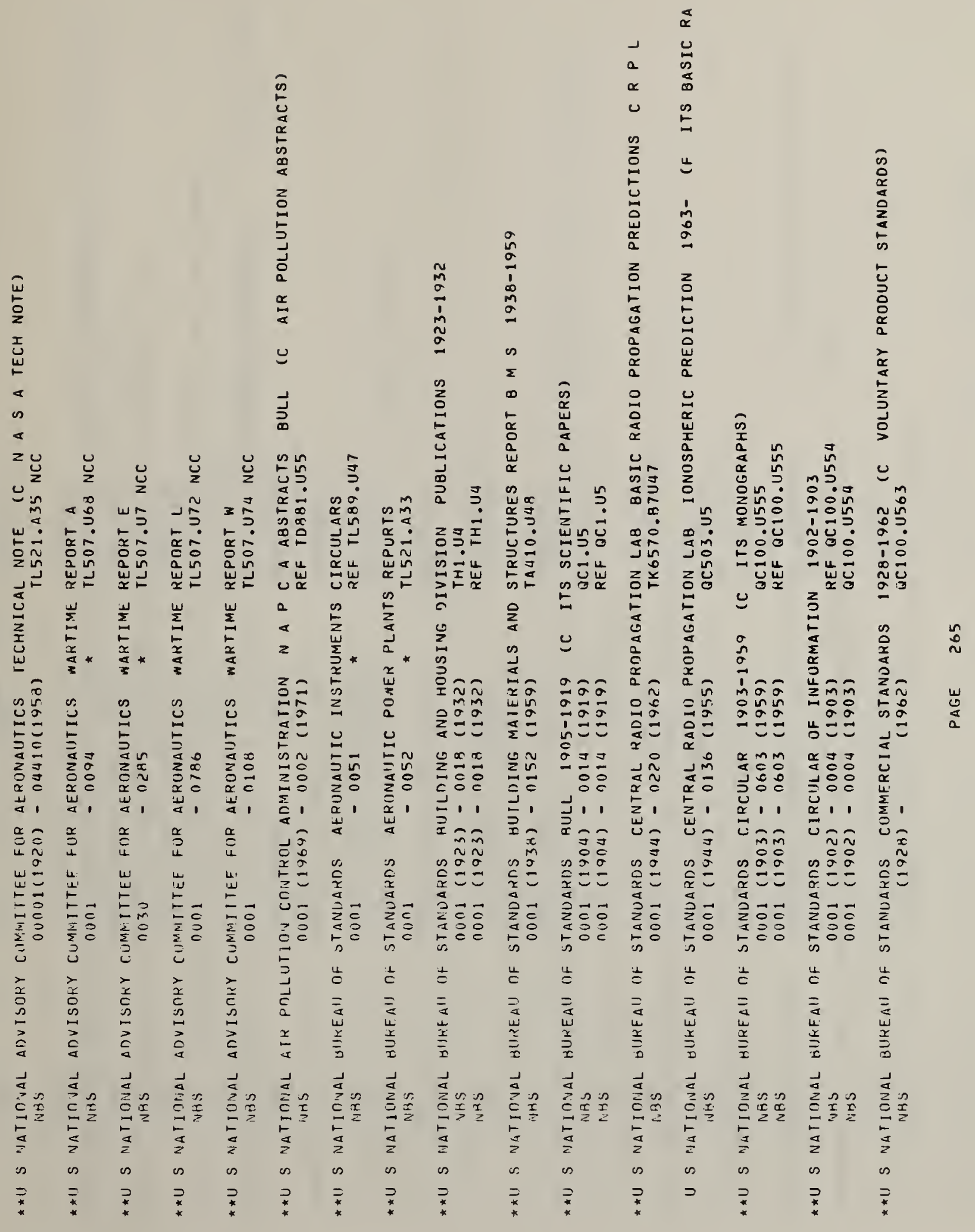




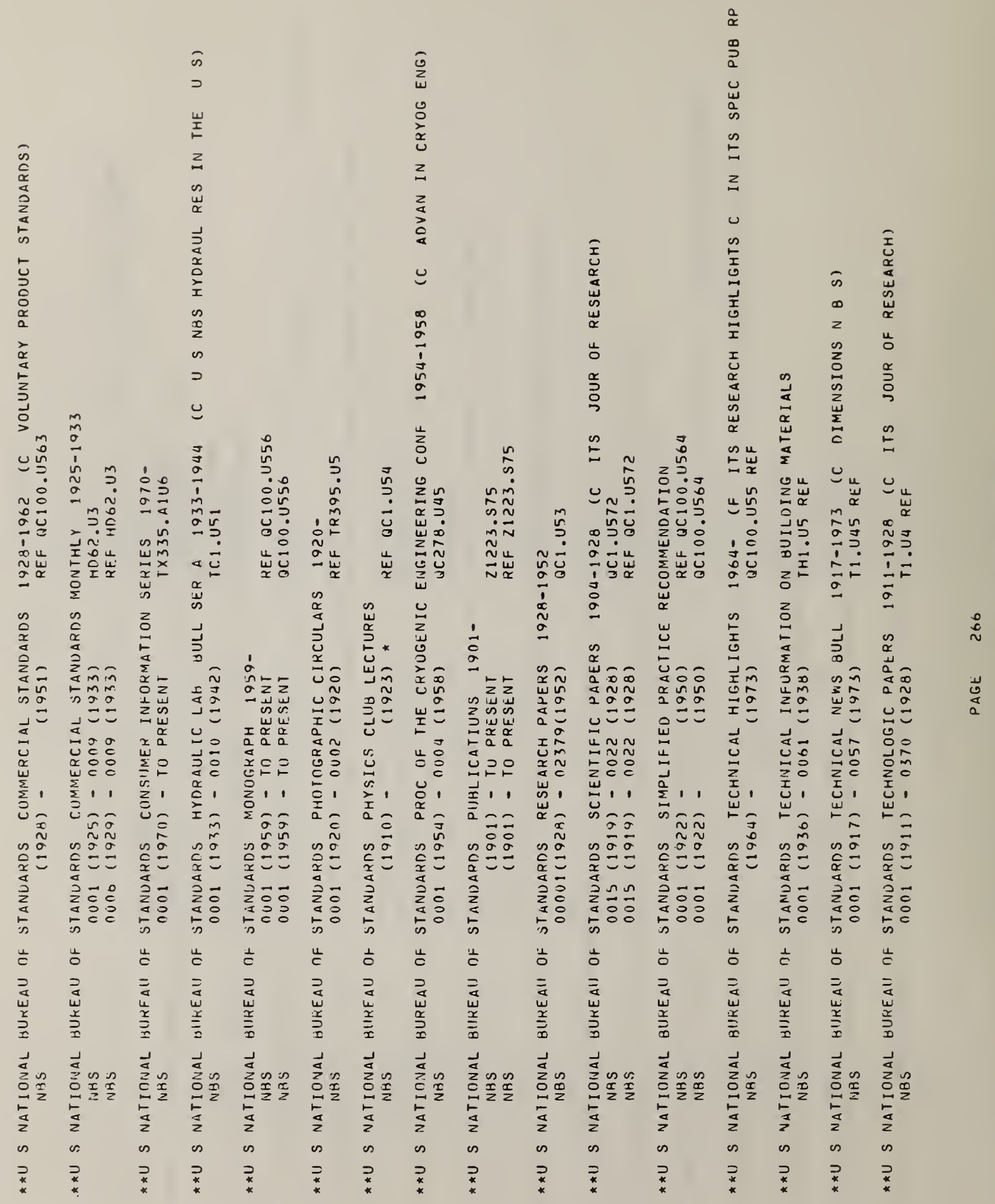




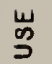

占

3

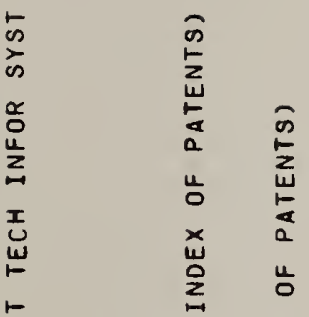

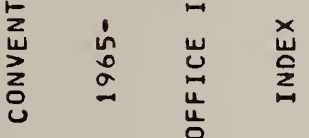

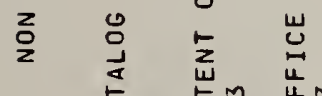

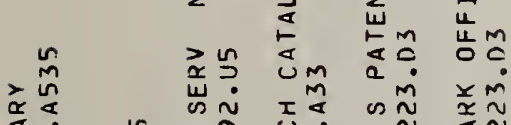

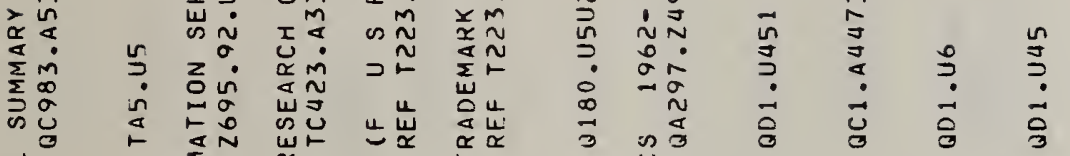

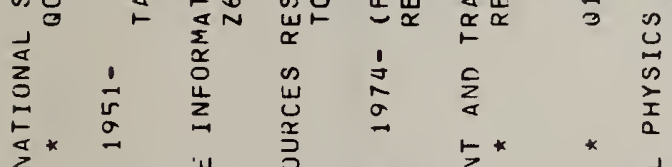

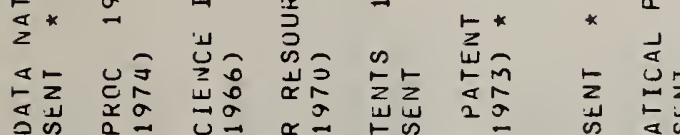

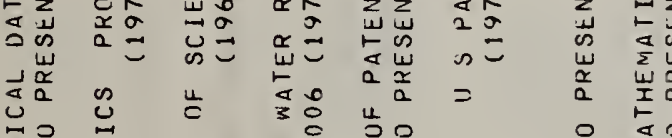

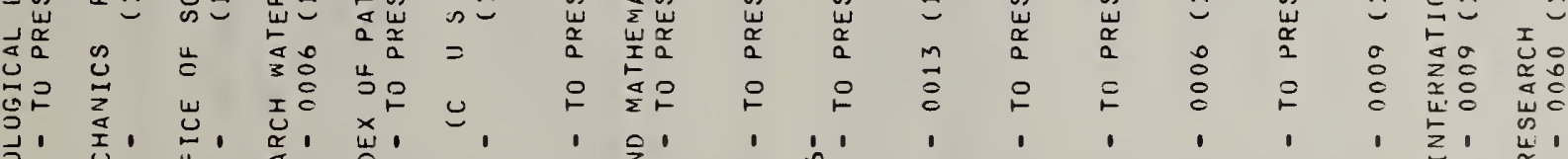

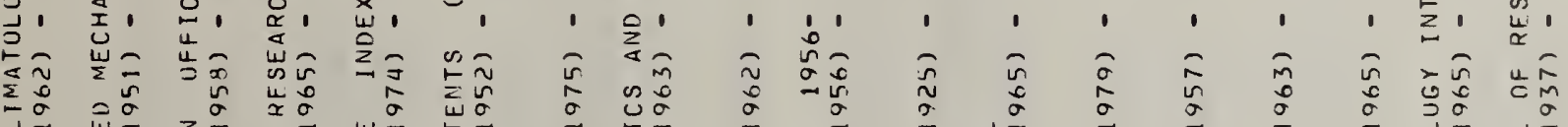

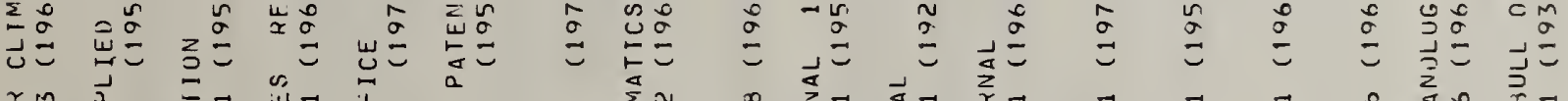

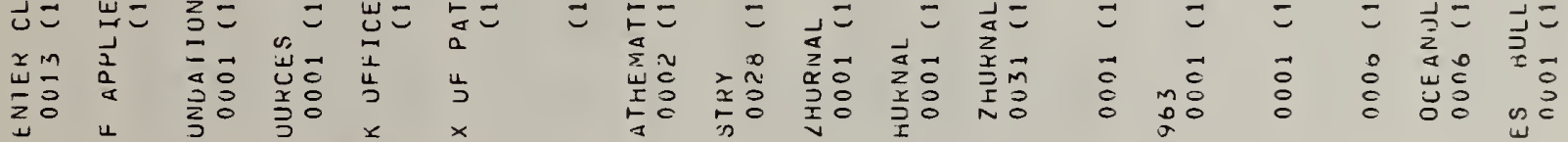

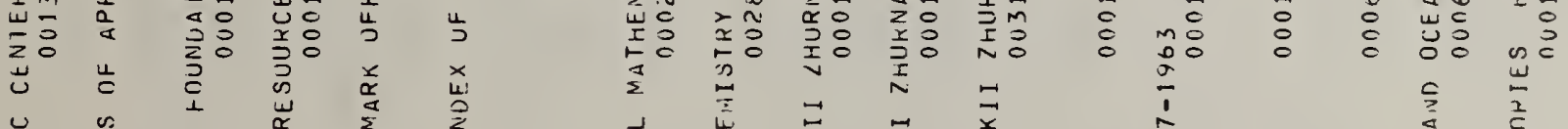

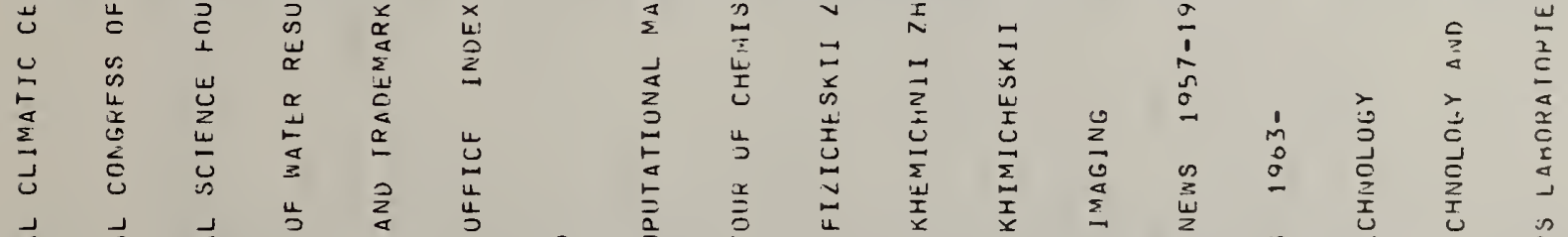

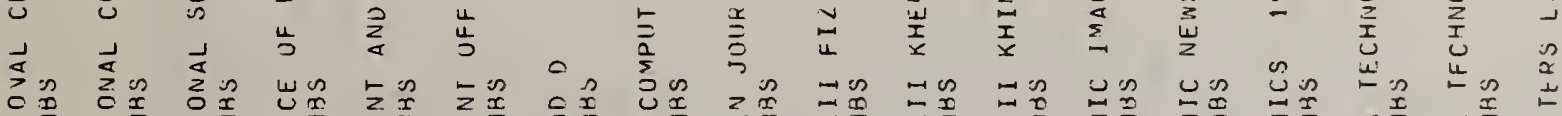

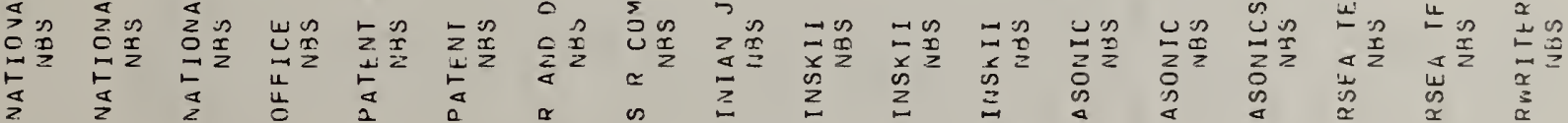

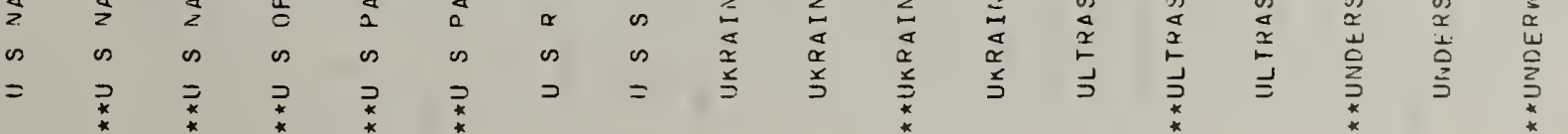




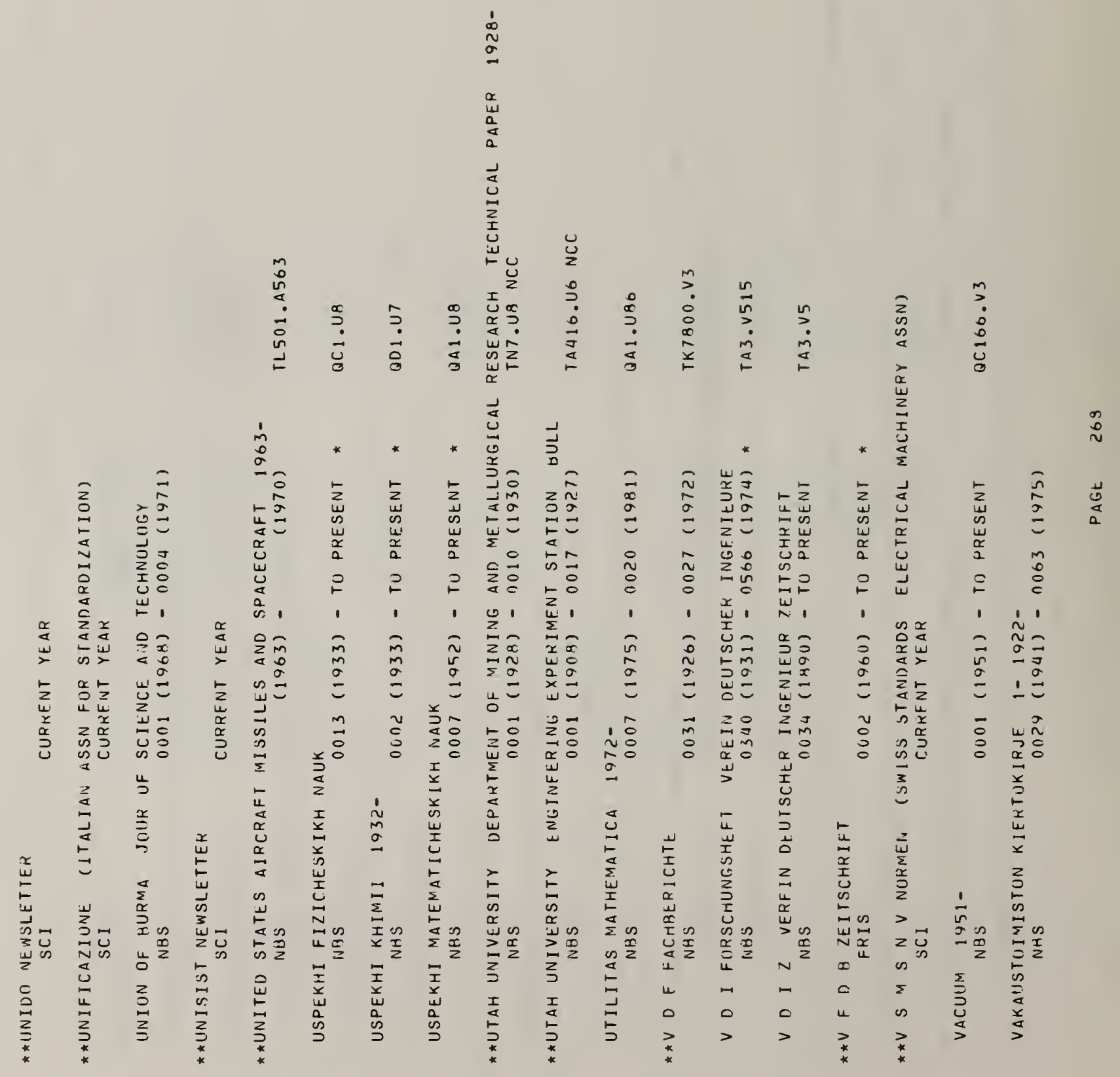




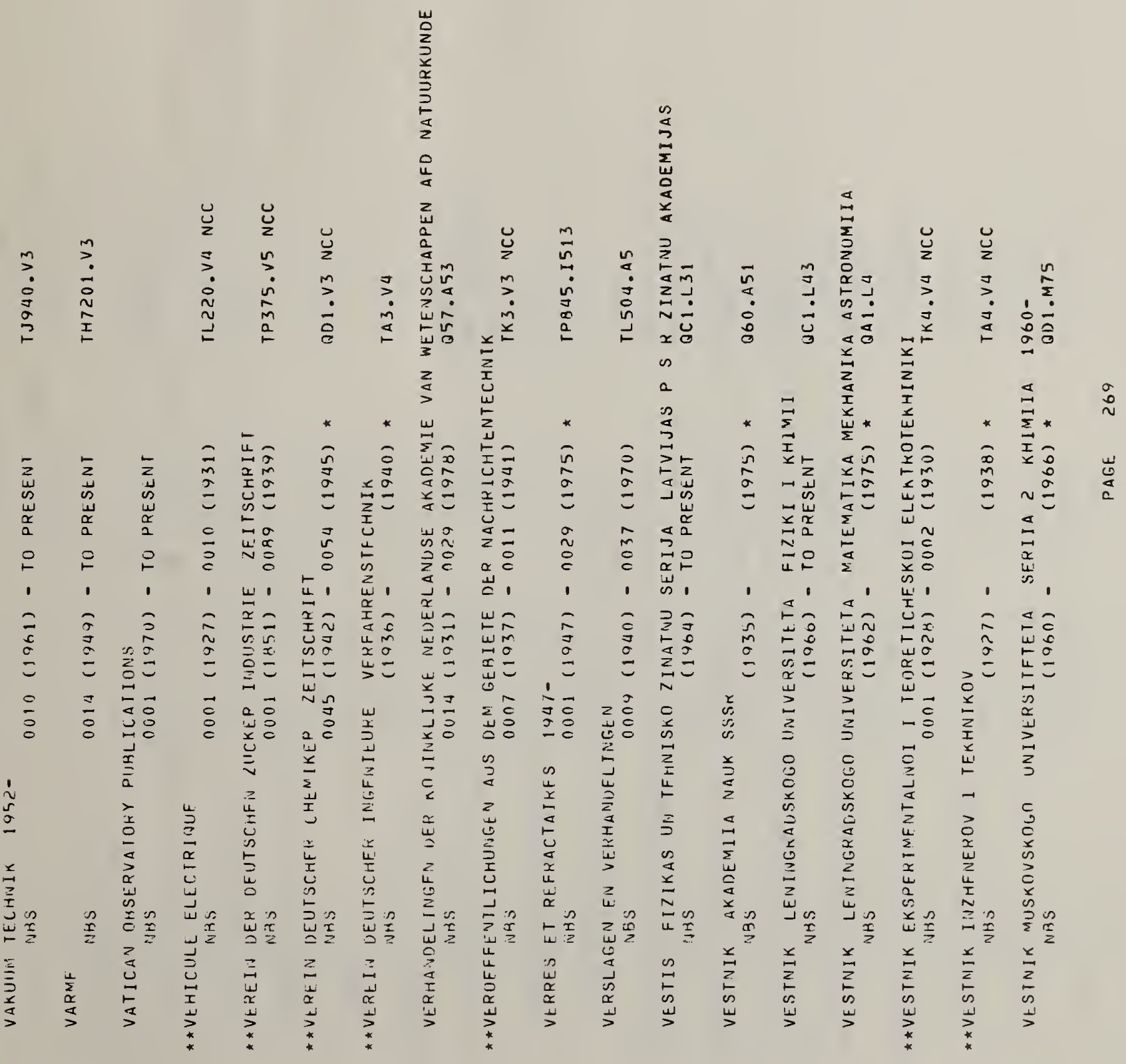




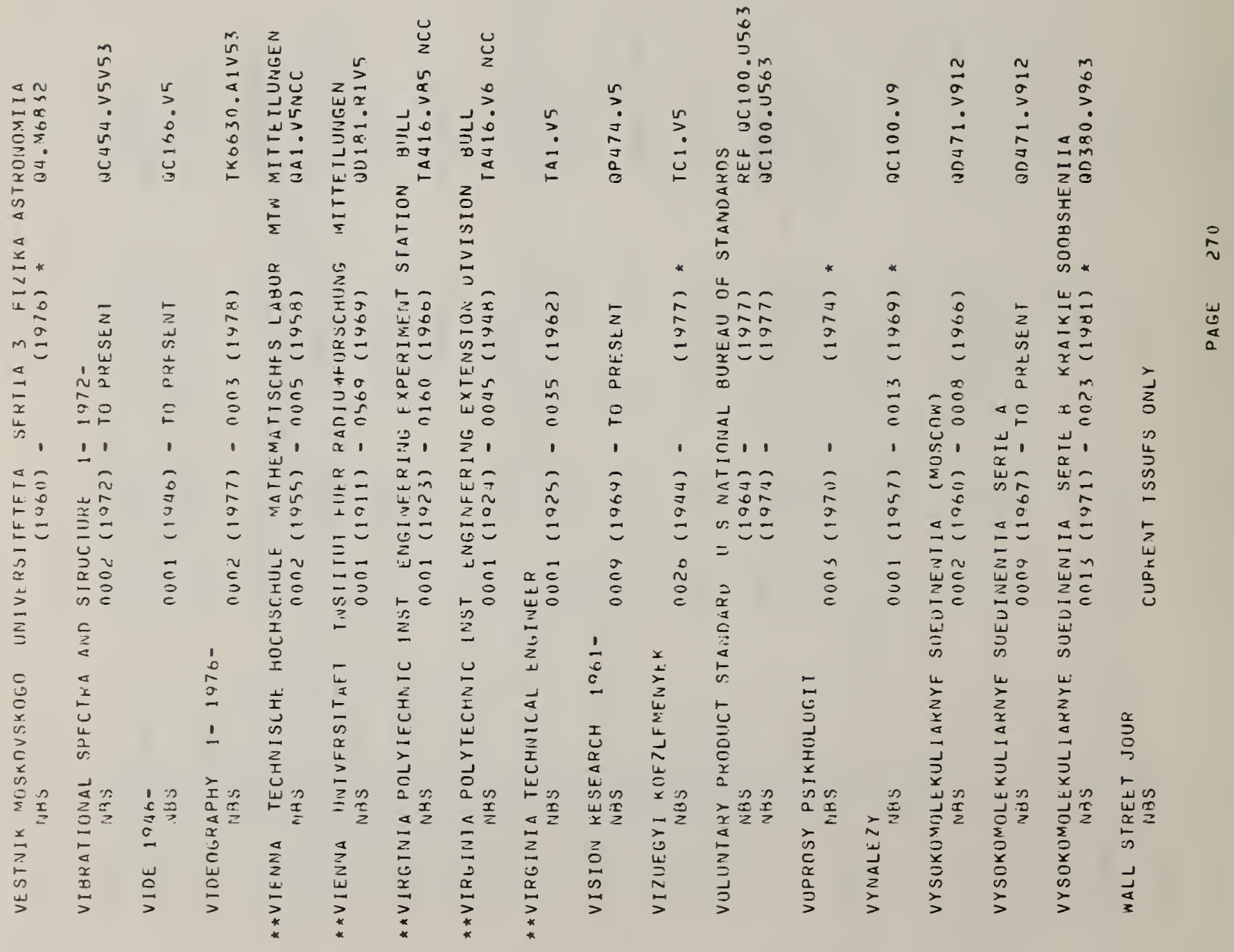




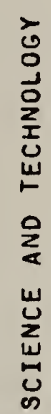

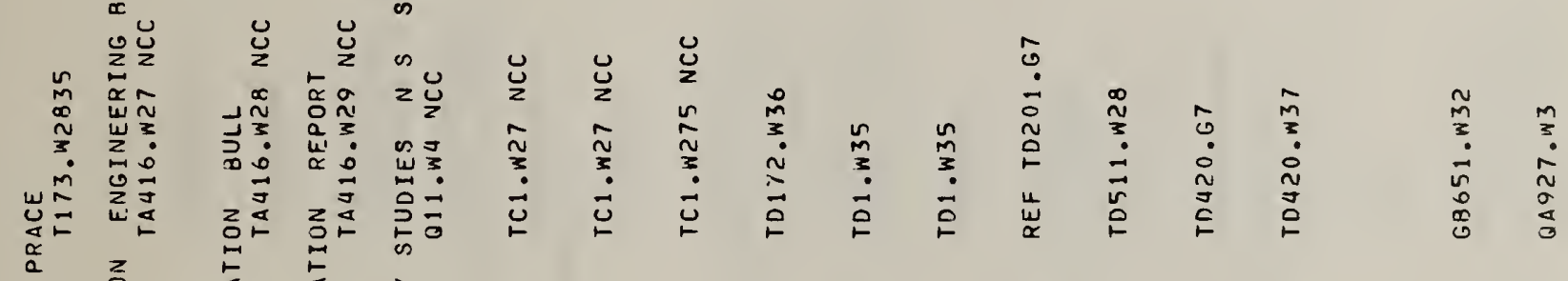

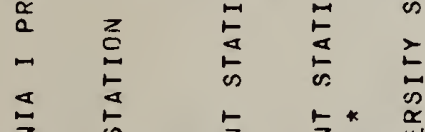

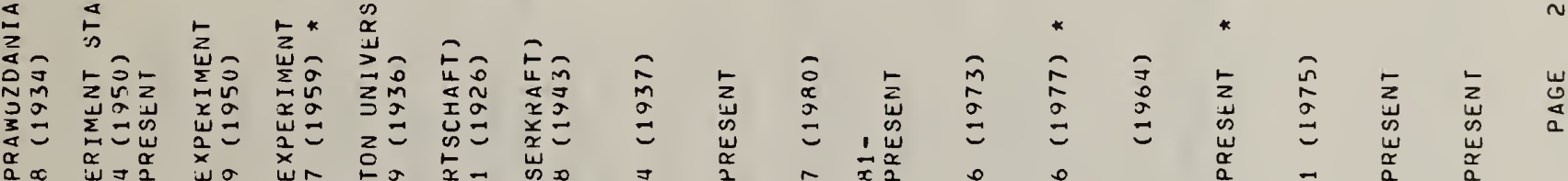

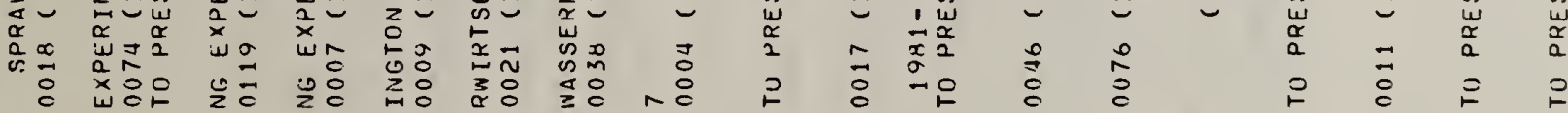

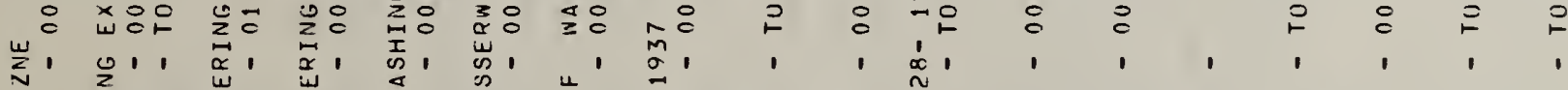

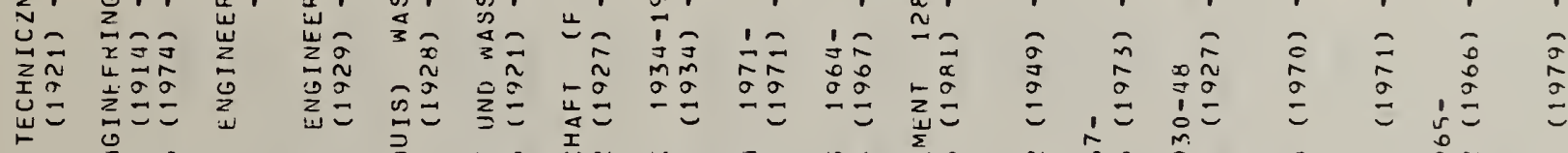

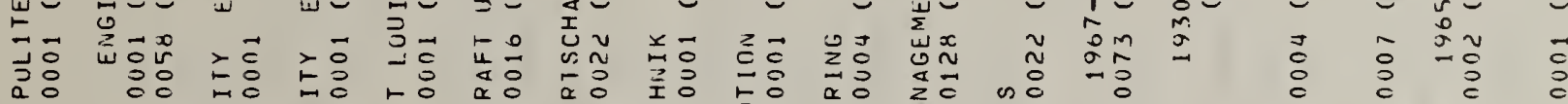

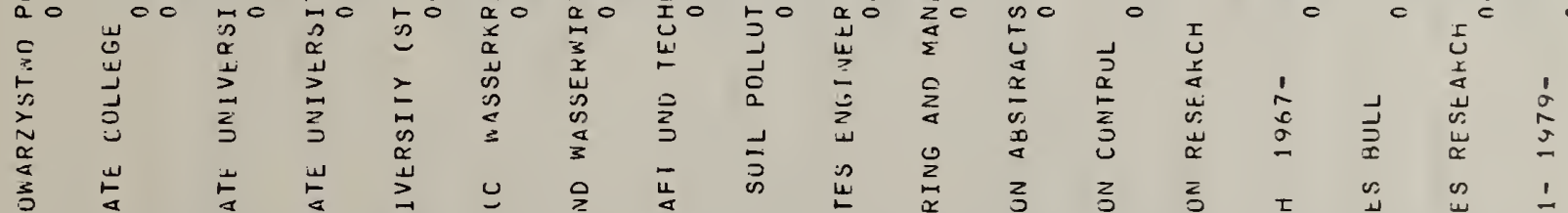

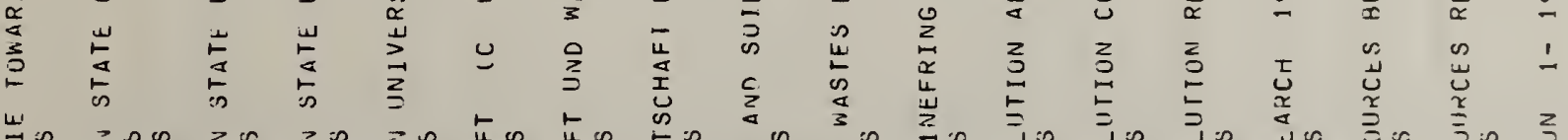

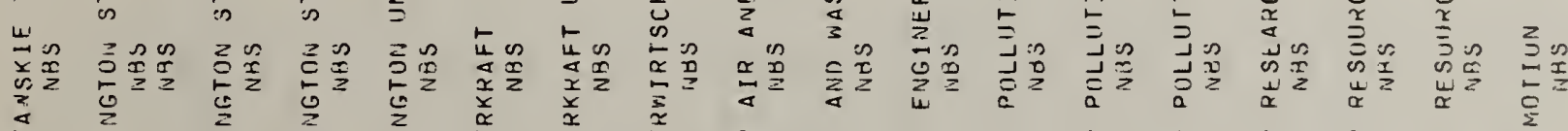

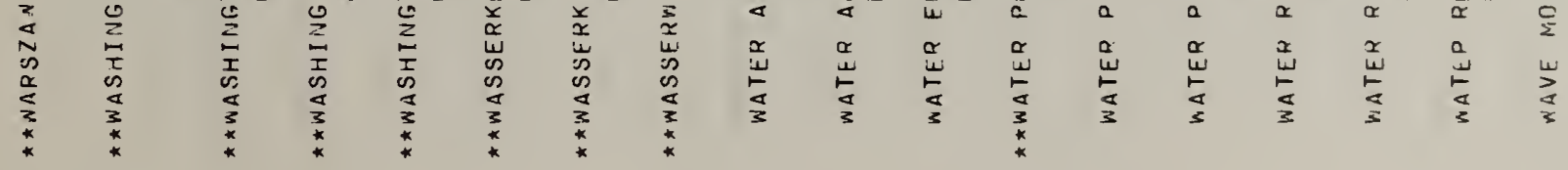




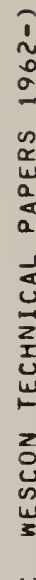

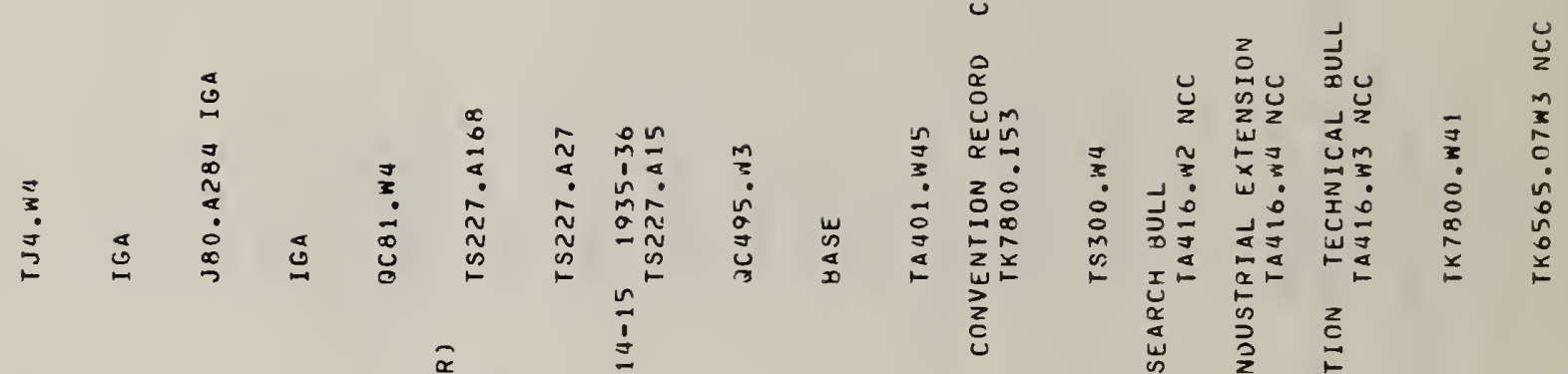

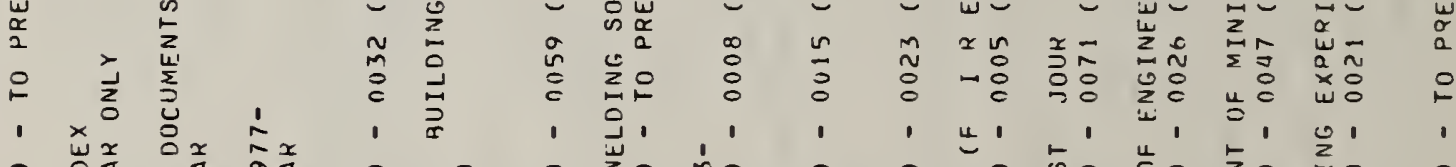

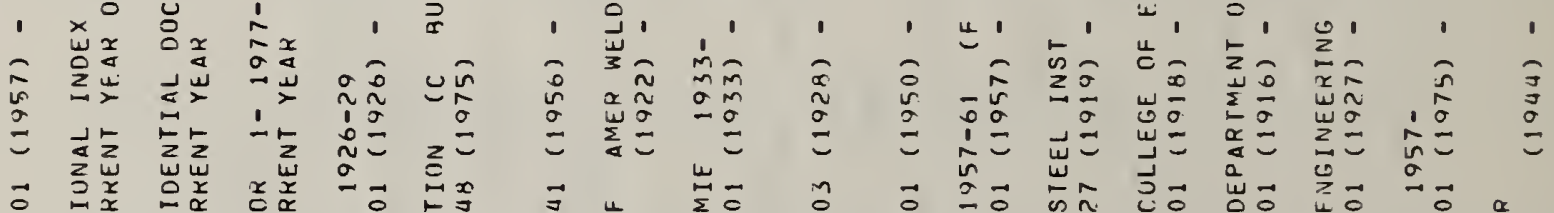

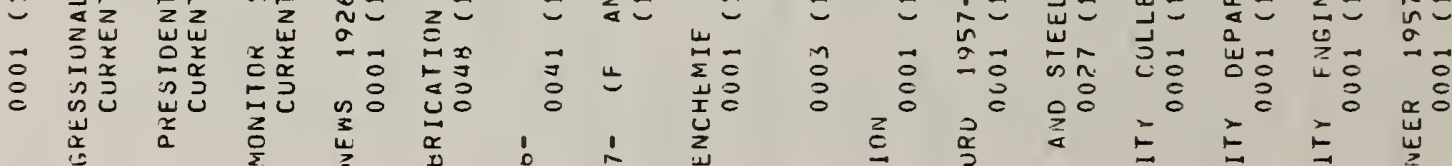

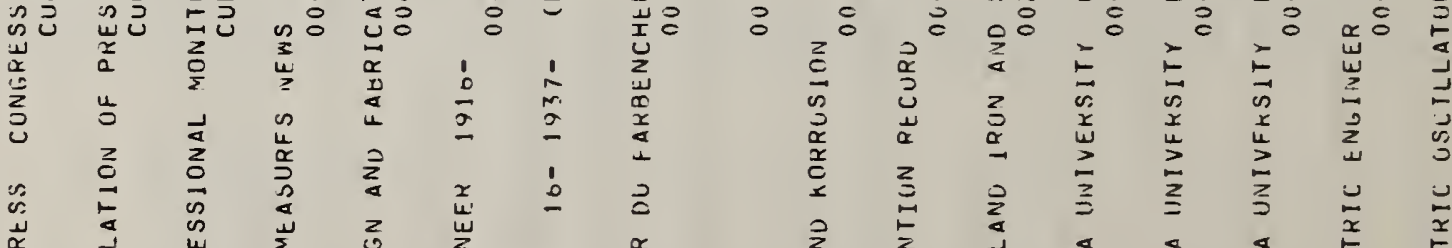

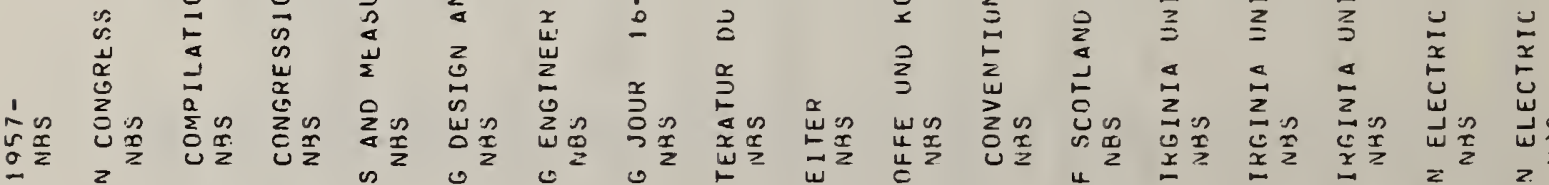

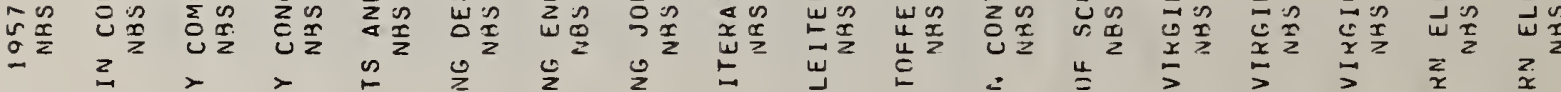

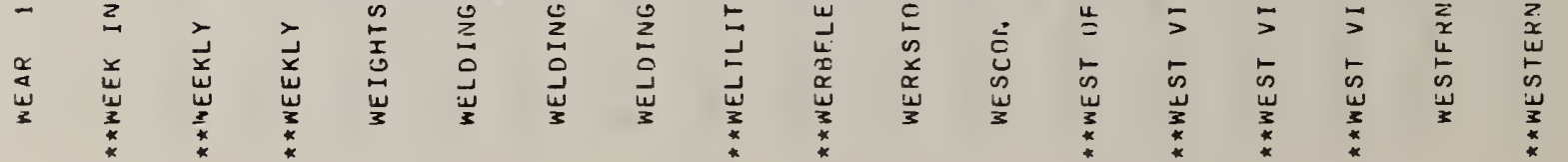




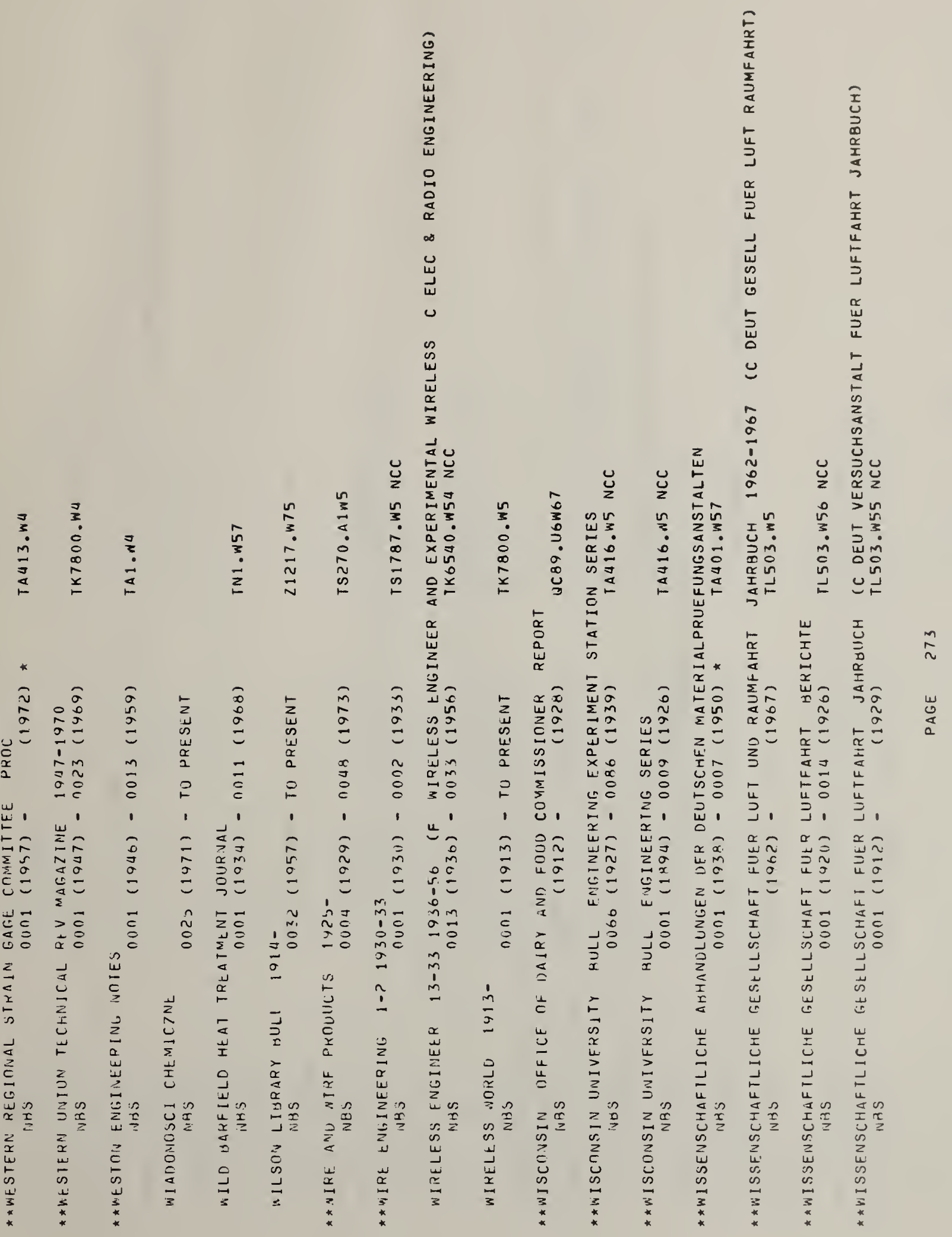




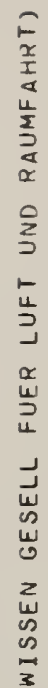

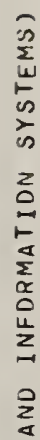

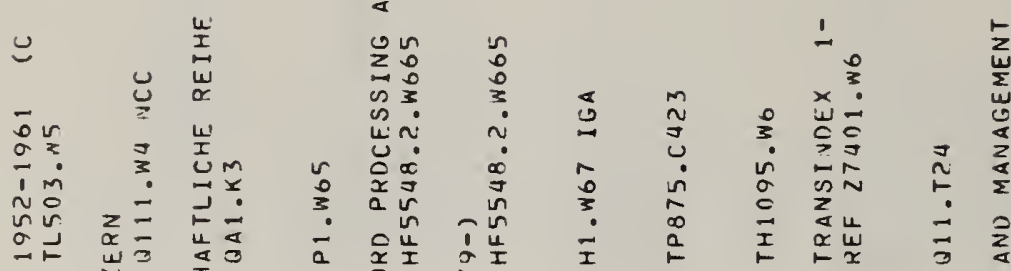

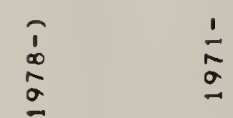

$\underset{\substack{w \\ \sim}}{\stackrel{w}{z}}$

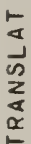

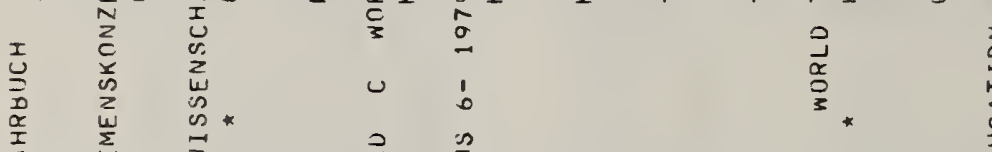

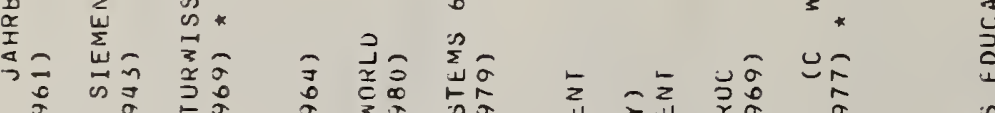

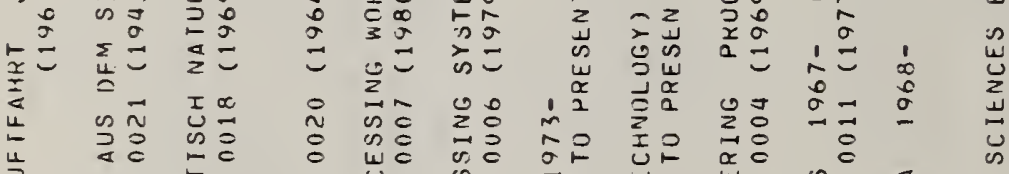

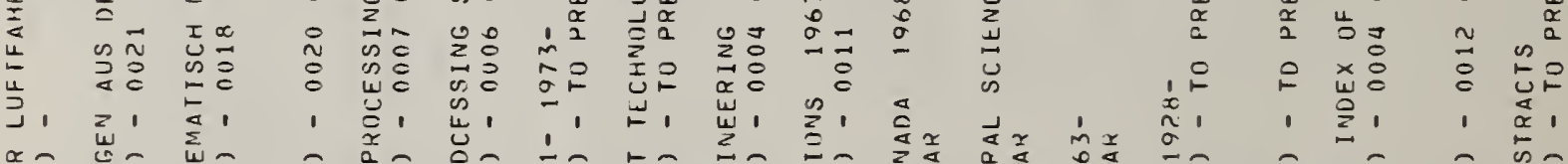

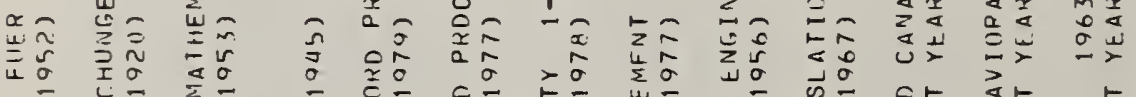

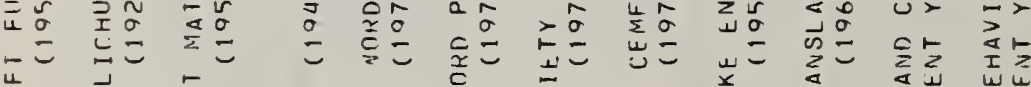

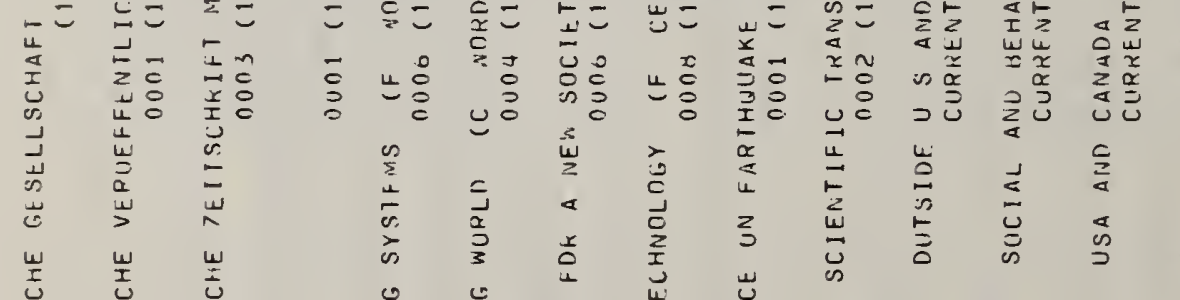

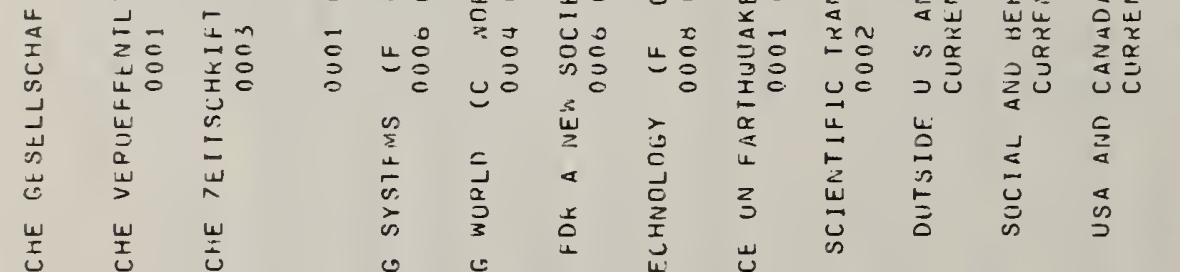

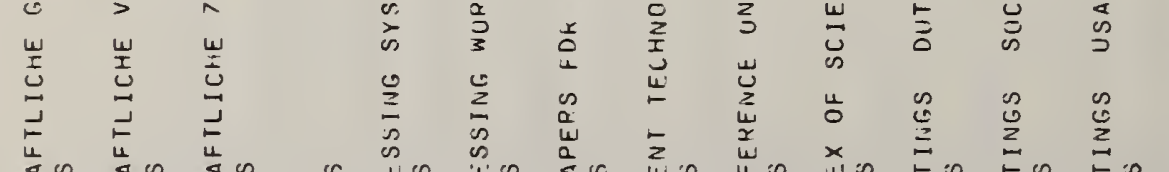

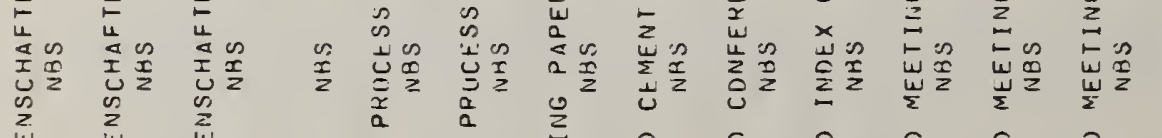

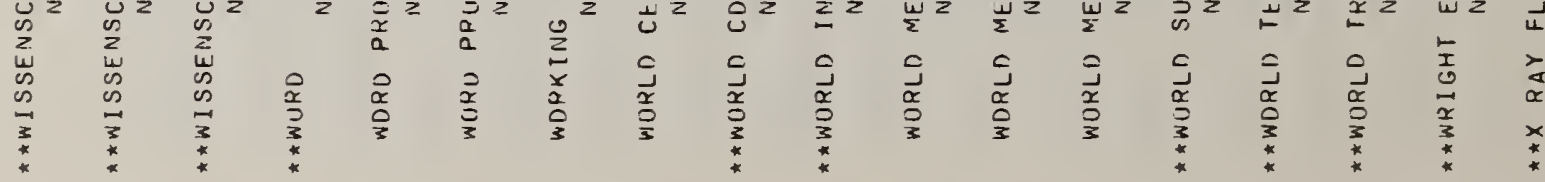


$\stackrel{i}{\stackrel{i}{\circ}}$

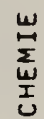

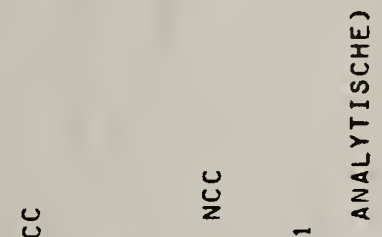

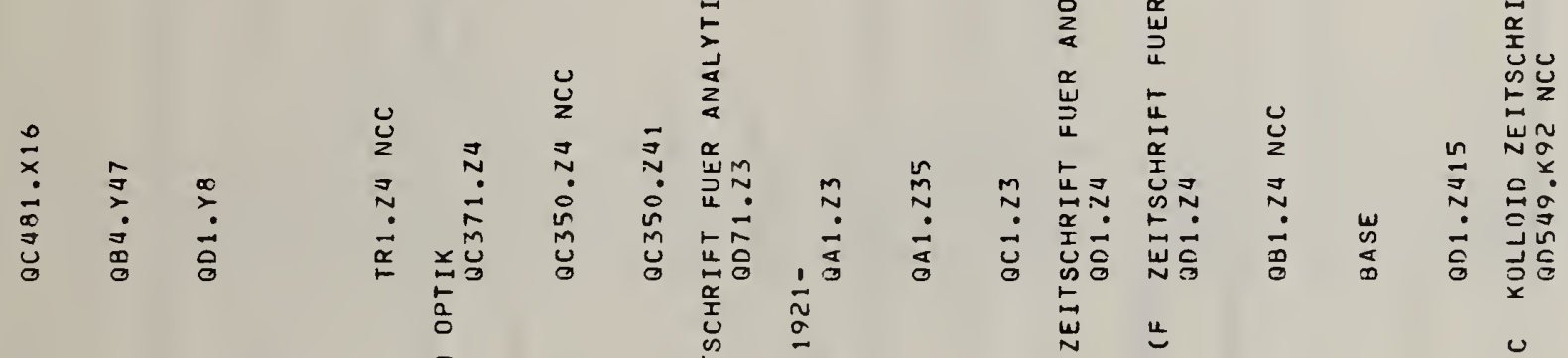

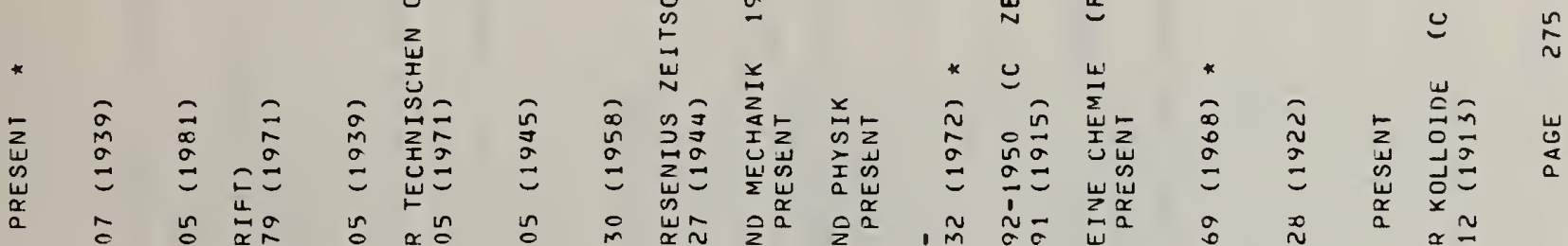

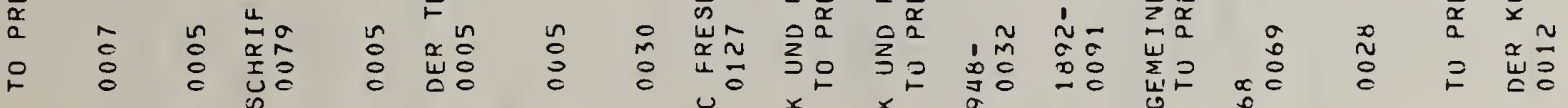

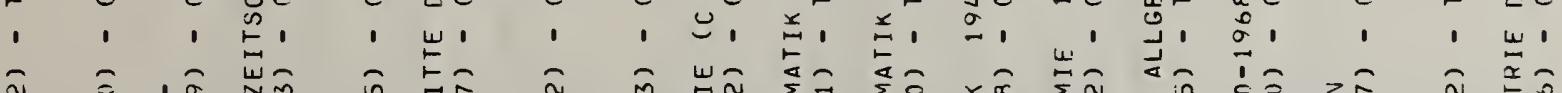

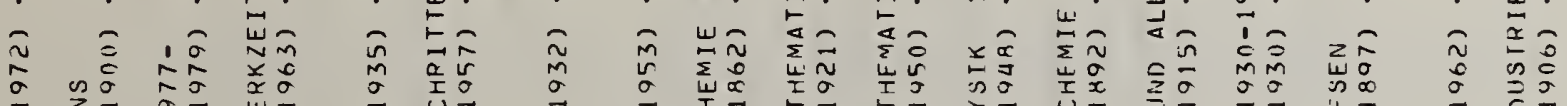

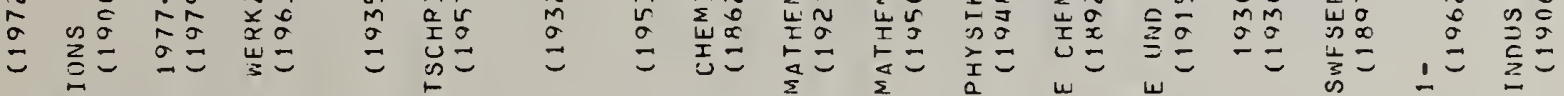

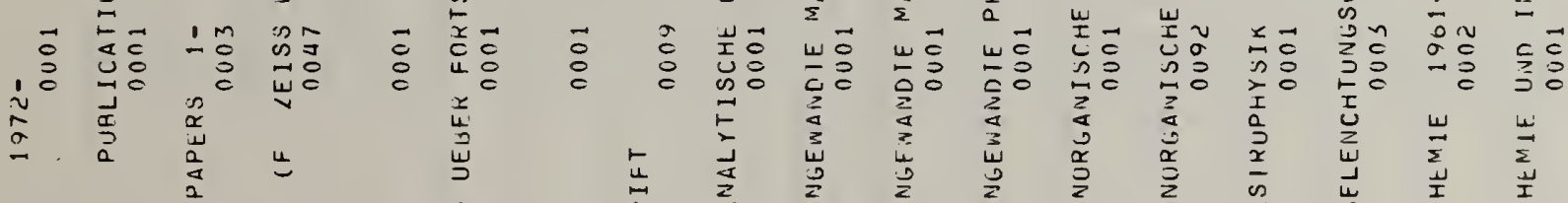

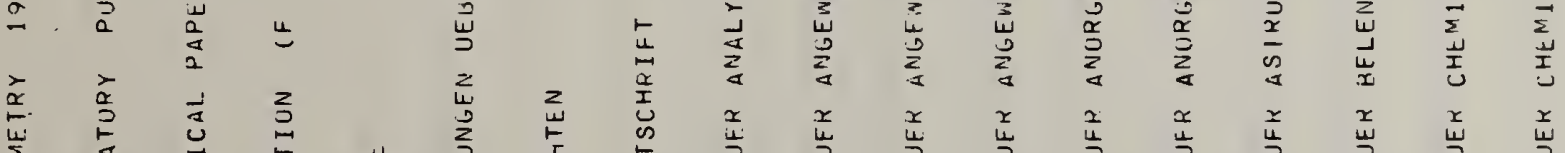

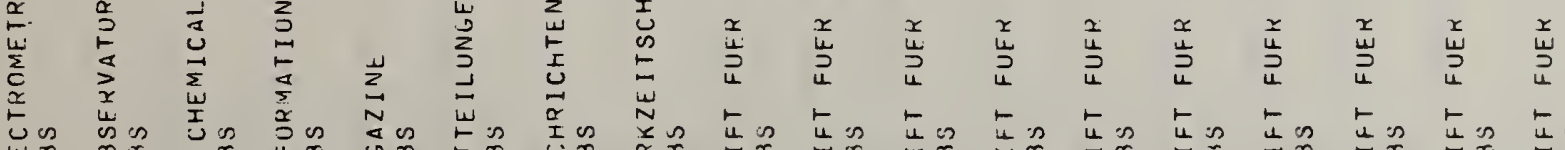

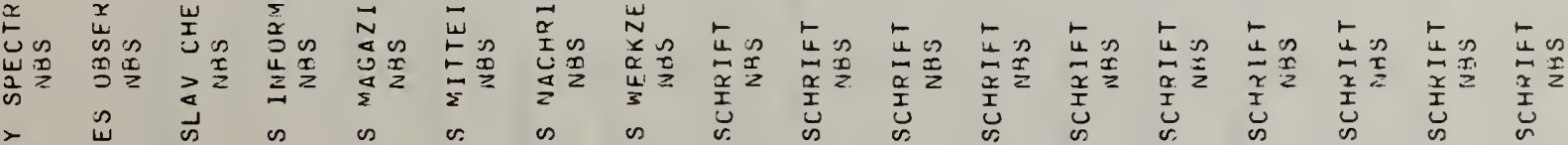

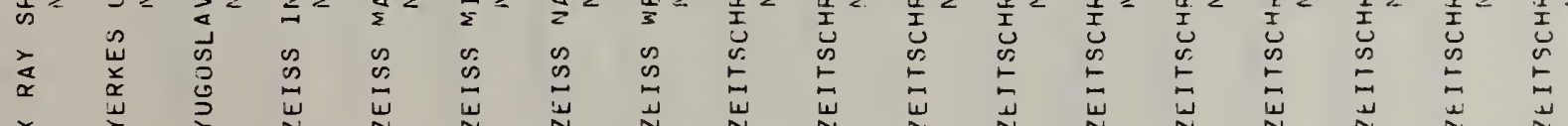

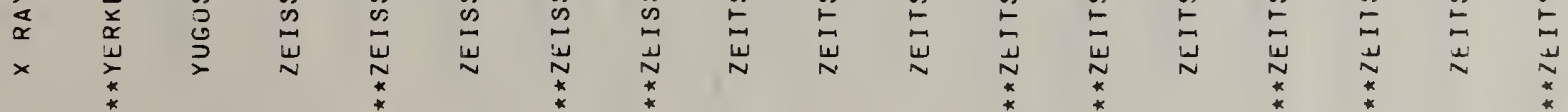




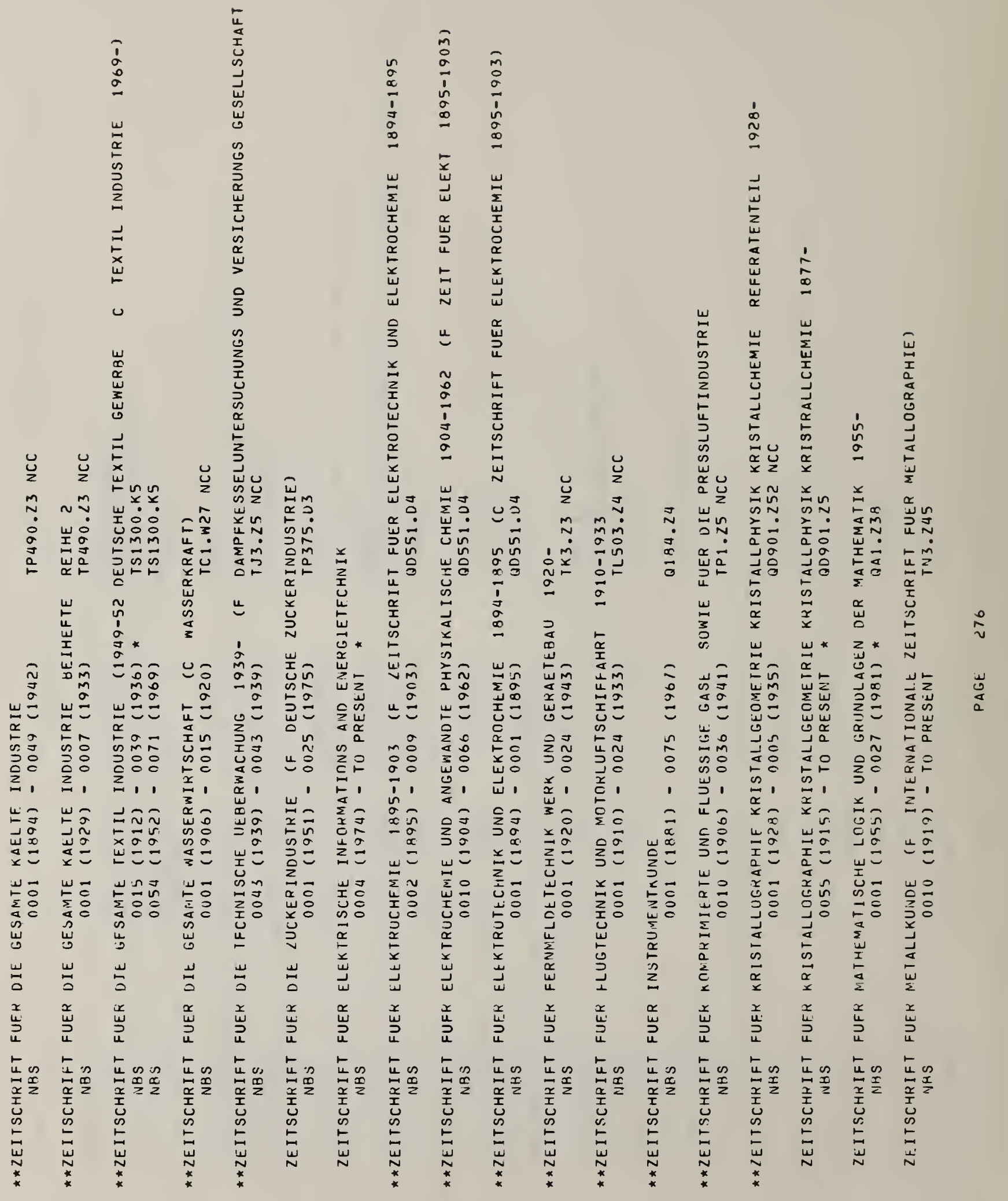




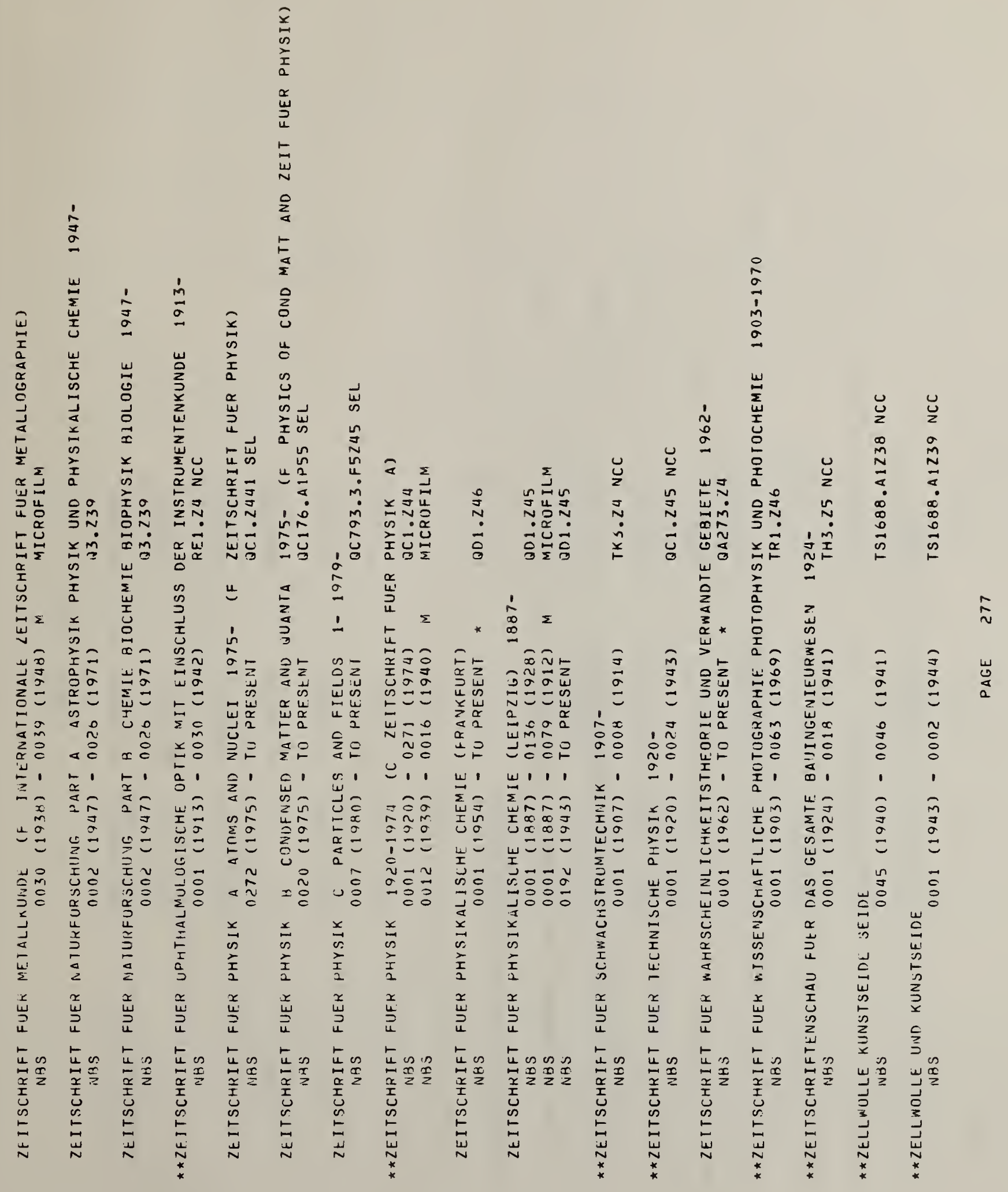




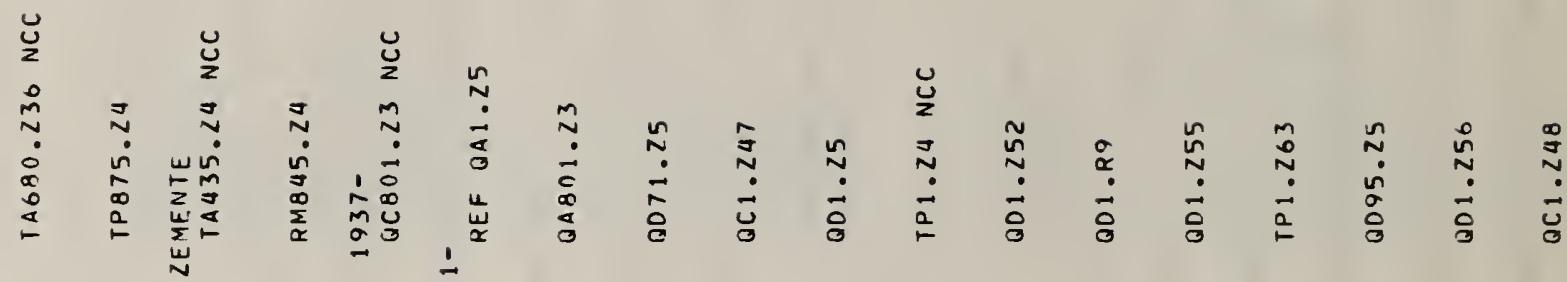

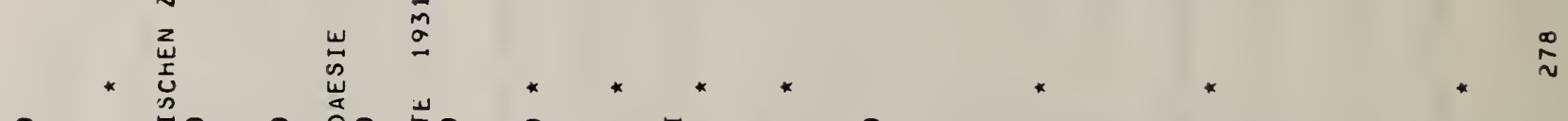

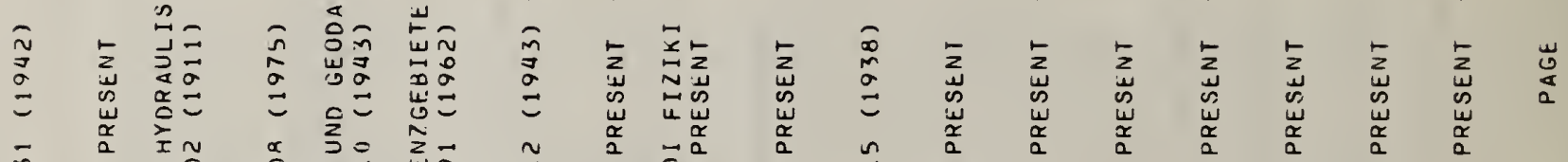

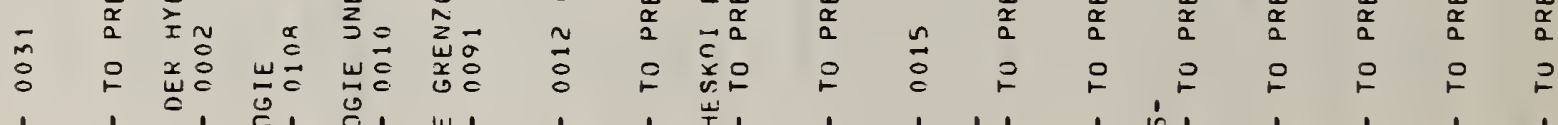

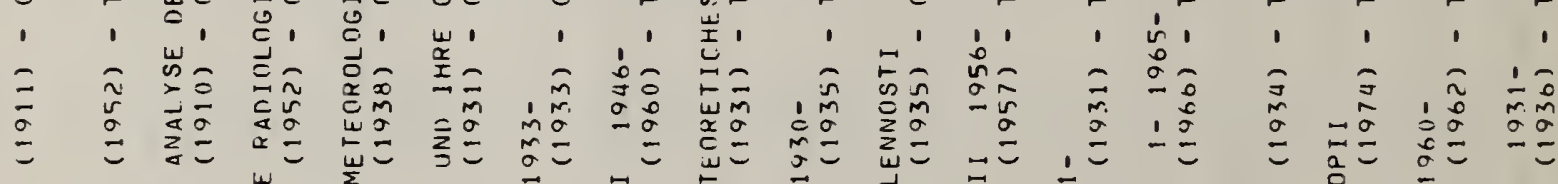

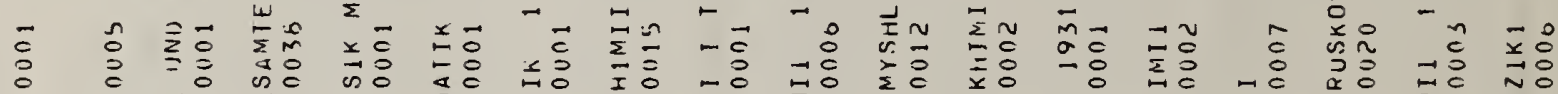

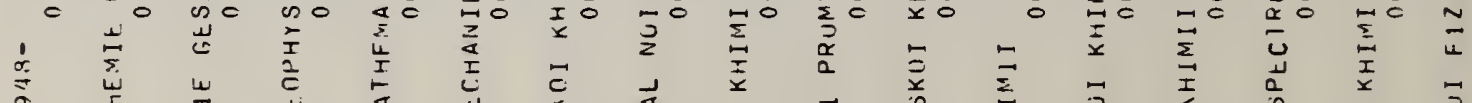

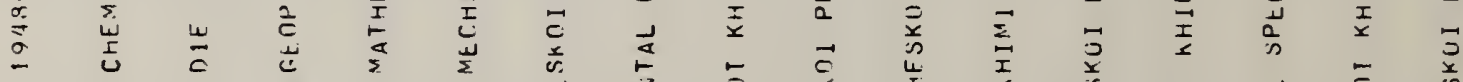

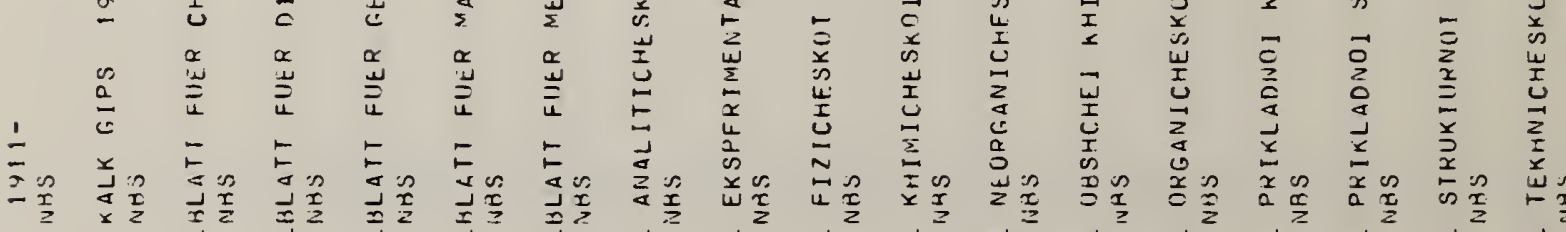

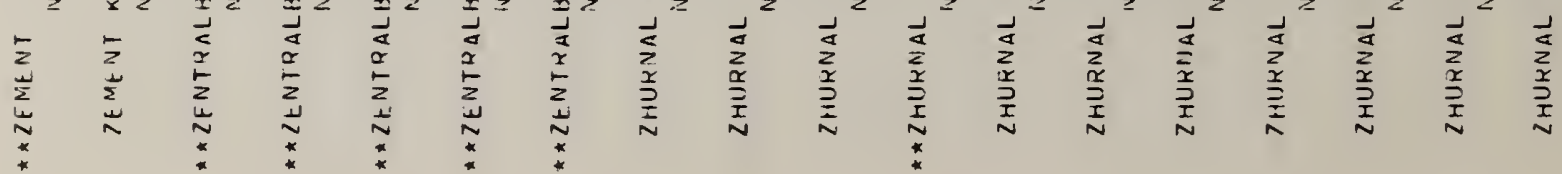




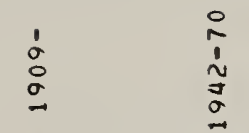

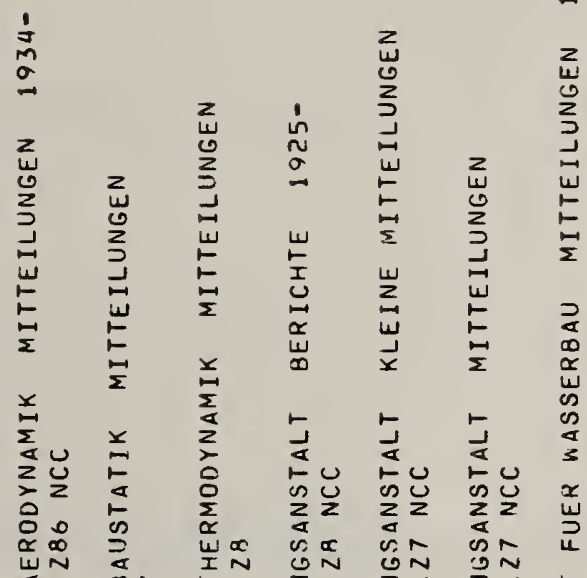

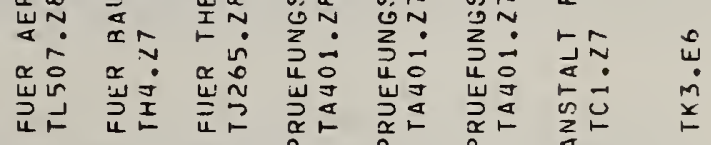

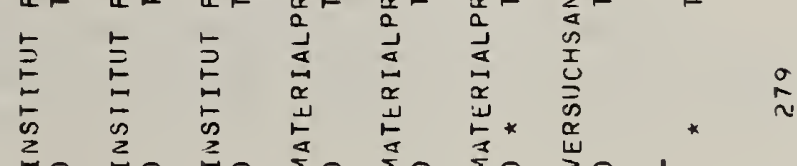

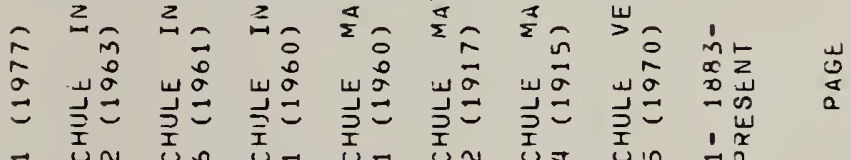

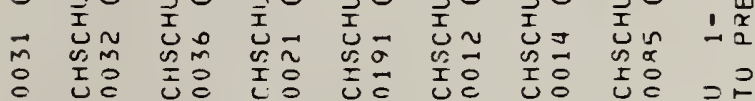

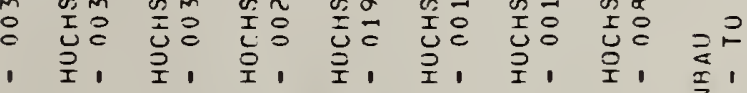

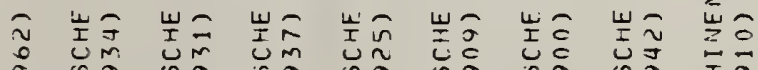

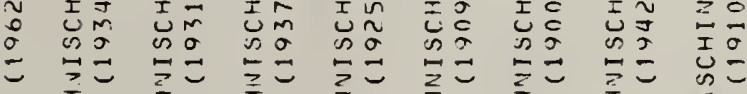

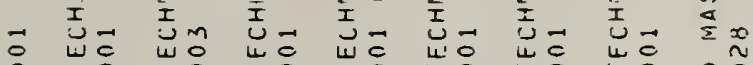

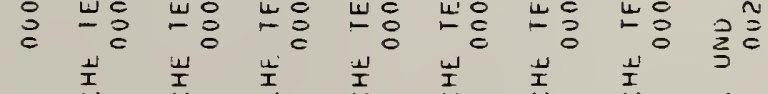

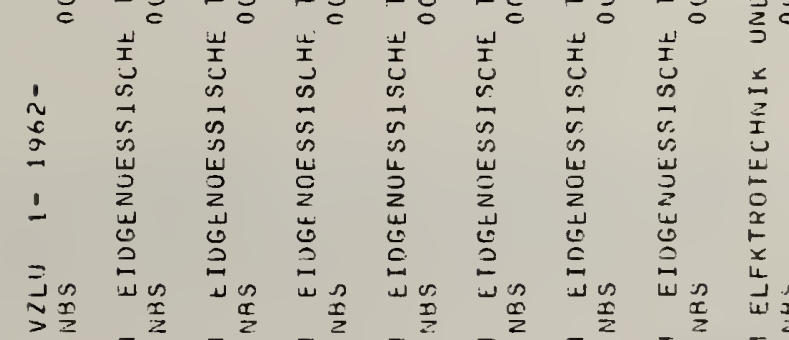

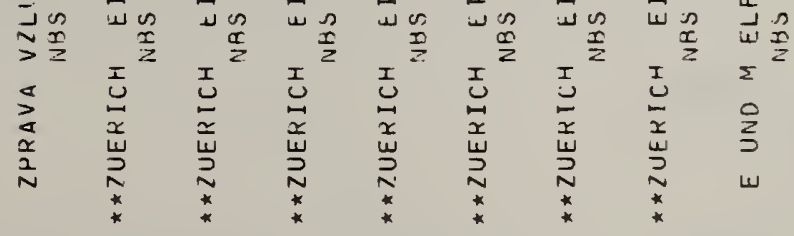



NBS-114A (REV. 2-8C)

U.S. DEPT. OF COMM.

BIBLIOGRAPHIC DATA

SHEET (See instructions)
1. PUBLICATION OR REPORT NO.

NBSIR $82-2575$
2. Performing Organ. Report No. 3. Publication Date

September 1982

4. TITLE AND SUBTITLE

NBS Serial Holdings 1982

5. $\operatorname{AUTHOR}(S)$

Mary Lynn Kingston, Editor

6. PERFORMING ORGANIZATION (If joint or other than NBS, see instructions)

7. Contract/Grant No.

NATIONAL BUREAU OF STANDARDS

DEPARTMENT OF COMMERCE

WASHINGTON, D.C. 20234

8. Type of Report \& Period Covered

9. SPONSORING ORGANIZATION NAMY ANO COMPLETE ADDRESS (STTEL, City, StOTE, ZIP)

National Bureau of Standards

Library

Admin. E106

Washington, D.C. 20234

10. SUPPLEMENTARY NOTES

Supersedes 1981 edition

[ Document describes a computer program; SF-185, FIPS Software Summary, is attached,

11. ABSTRACT (A 200-word or less factual summary of most significant information. If document includes a significant bibliography or literature survey, mention it here)

This publication contains holdings information for approximately 4600 titles representing current and noncurrent journals, periodicals, annuals, memoirs, proceedings, and transactions. The holdings of the NBS Library and 3 collections specializing in fire research, standards, and diffusion in metals are represented.

12. KEY WORDS (Six to twelve entries; alphabetical order; capitalize only proper names; and separate key words by semicolons) Annual reports; journals; library holdings, NBS Library; NBS periodicals; periodicals; proceedings; serials; transactions; fire; diffusion in metals; standards.

\section{AVAILABILITY}

X] Unlimited

[. For Official Distribution. Do Not Release to NTIS

[ Order From Superintendent of Documents, U.S. Government Printing Office, Washington, D.C. 20402.

X Order From National Technical Information Service (NTIS), Springfield, VA. 22161
14. NO. OF

PRINTED PAGES

\section{8}

15. Price 




